Elizângela de Jesus Oliveira Suelânia Cristina Gonzaga de Figueiredo Rafael Alves Pedrosa Wanderson da Silva Damiāo Rute Holanda Lopes (Organizadores)

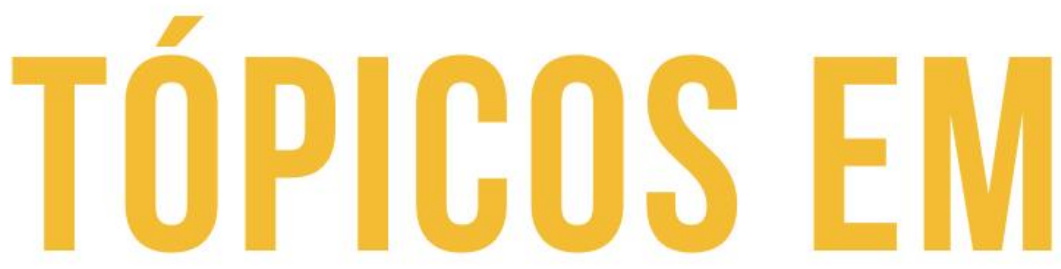

ADMINSTAGÃO

\title{
Volume 32
}


Elizângela de Jesus Oliveira

Suelânia Cristina Gonzaga de Figueiredo

Rafael Alves Pedrosa

Wanderson da Silva Damião

Rute Holanda Lopes

(Organizadores)

\section{Tópicos em Administração Volume 32}

1a Edição

Belo Horizonte

Poisson

2020 


\section{Editor Chefe: Dr. Darly Fernando Andrade}

\section{Conselho Editorial}

Dr. Antônio Artur de Souza - Universidade Federal de Minas Gerais

Ms. Davilson Eduardo Andrade

Dra. Elizângela de Jesus Oliveira - Universidade Federal do Amazonas

Msc. Fabiane dos Santos

Dr. José Eduardo Ferreira Lopes - Universidade Federal de Uberlândia

Dr. Otaviano Francisco Neves - Pontifícia Universidade Católica de Minas Gerais

Dr. Luiz Cláudio de Lima - Universidade FUMEC

Dr. Nelson Ferreira Filho - Faculdades Kennedy

Ms. Valdiney Alves de Oliveira - Universidade Federal de Uberlândia

Dados Internacionais de Catalogação na Publicação (CIP)

T674
Tópicos em Administração - Volume 32/
Organização Elizâgela de Jesus
Oliveira, Suelânia Cristina Gonzaga de
Figueiredo, Rafael Alves Pedrosa,
Wanderson da Silva Damião, Rute Holanda
Lopes - Belo Horizonte - MG: Poisson,
2020
Formato: PDF
ISBN: 978-65-86127-94-2
DOI: 10.36229/978-65-86127-94-2
Modo de acesso: World Wide Web
Inclui bibliografia
1. Administração 2. Gestão. 3. Produção
I. OLIVEIRA, Elizângela de Jesus II.
FIGUEIREDO, Suelânia Cristina Gonzaga de
III. PEDROSA, Rafael Alves IV. DAMIÃo,
Wanderson da Silva V. LOPES, Rute Holanda
VI. Título

O conteúdo dos artigos e seus dados em sua forma, correção e confiabilidade são de responsabilidade exclusiva dos seus respectivos autores.

www.poisson.com.br contato@poisson.com.br 


\section{SUMÁRIO}

Capítulo 1: Soluções fiscais eletrônicas para o varejo: Nova fronteira de modernização e controle fiscal de operações com mercadorias 07

Marcelo Luiz Alves Fernandez, Eduardo Mário Dias

DOI: 10.36229/978-65-86127-94-2.CAP.01

Capítulo 2: A importância da Controladoria no processo de tomada de decisões: Estudo de caso na Companhia de Água e Esgoto do Ceará (CAGECE). 17

Maricoeli Gonçalves Tavares, Anna Karine Monteiro de Sousa, Sheila Raquel de Moraes Lima, Andson de Freitas Viana, Neurisangelo Cavalcante de Freitas

DOI: $10.36229 / 978-65-86127-94-2 . C A P .02$

Capítulo 3: Método de construção de carteira de investimento a partir do coeficiente de variação: Um estudo empírico no mercado de ações brasileiro. 30

Marcio Pereira Basílio, Ricardo Bordeaux Rego

DOI: 10.36229/978-65-86127-94-2.CAP.03

Capítulo 4: Custo de implantação e viabilidade econômica do cultivo de uva niagara no município de Jales-SP. 44

Christian Turato Bolognezi, João Vitor Ferrari, Edy Carlos Santos de Lima

DOI: 10.36229/978-65-86127-94-2.CAP.04

Capítulo 5: Conflitos na gestão de pessoas na construção civil. 51 Aureliano Tavares, Orlando Longo, Robson Sueth

DOI: 10.36229/978-65-86127-94-2.CAP.05

Capítulo 6: Fatores de conflito e produção em uma unidade hospitalar pública. 65

Francisco de Assis Coelho

DOI: 10.36229/978-65-86127-94-2.CAP.06

Capítulo 7: A inclusão da pessoa com deficiência no mercado de trabalho: Estudo de caso em um hospital particular de Juiz de Fora - MG 73

Clara Aguiar Reis, Eduarda Barbosa Velloso, Giovana Tassi de Paula, Joyce Gonçalves Altaf

DOI: 10.36229/978-65-86127-94-2.CAP.07 


\section{SUMÁRIO}

Capítulo 8: 0 processo de socialização em segurança do trabalho em uma indústria alimentícia.

Adriela de Marchi, Aretuza Balardin Sainz, Diulnéia Granja Pereira, Eleandra Maria Prigol Meneghini, Larisa Hemkemeier Webber de Mello

DOI: 10.36229/978-65-86127-94-2.CAP.08

Capítulo 9: A empreendedora afro-brasileira: Desafios e perspectivas 100

Marcia Ferreira da Silva, Maria Crauviceia dos Santos Vieira, Francisco Carlos Ribeiro, Marcileide Muniz Cavalcante, Alexandre Santos

DOI: 10.36229/978-65-86127-94-2.CAP.09

Capítulo 10: A audiência pública como ferramenta para a gestão municipal: A participação popular como fundamento para as decisões administrativas e sua vinculação. 109

Diego Santos Rebelo

DoI: 10.36229/978-65-86127-94-2.CAP.10

Capítulo 11: Análise de riscos em não cumprimento de prazo de obras através da rede PERT/CPM - Um estudo de caso de uma obra pública no município de Belém.. 124

Alexandra Algélia da Silva França, Amanda Cremilda Lima Batista, André Augusto Azevedo Montenegro Duarte, Luíz Maurício Furtado Maués

DOI: 10.36229/978-65-86127-94-2.CAP.11

Capítulo 12: Gerenciamento de risco no transporte rodoviário de cargas 135

Sergio Henrique Ribeiro Costa, Daniel Martins da Silva, Eliene Rodrigues Sousa

DOI: 10.36229/978-65-86127-94-2.CAP.12

Capítulo 13: 0 gerenciamento de riscos aplicado às organizações: Integrando os silos do GRC 147

Sérgio Luiz Hoeflich, Elenilson Oliveira Pinheiro, Marcelo D’Alessandro, Helios Malebranche

DoI: 10.36229/978-65-86127-94-2.CAP.13

Capítulo 14: Aplicações da filosofia lean manufacturing na recepção da cana-de-açúcar 157

Manoel Gonçales Filho, Reinaldo Gomes da Silva, Clóvis Delboni, Sílvio Roberto Ignácio Pires

DOI: $10.36229 / 978-65-86127-94-2 . C A P .14$ 


\section{SUMÁRIO}

Capítulo 15: Utilização do Controle Estatístico do Processo (CEP) para o monitoramento do teor de umidade dos grãos de soja armazenada no Silo Agro Verde. 168

Claudilaine Caldas de Oliveira, Adriana de Souza Ferreira de Oliveira, Leandro Flora, Antônio Renato Pereira Moro

DOI: $10.36229 / 978-65-86127-94-2 . C A P .15$

Capítulo 16: Utilização de abordagem sistêmica para proposta de solução de problemas construtivos em reservatório de água elevado em edifício residencial

Carla Vitor Paim, White José dos Santos, Antônio Cleber Gonçalves Tibiriçá

DOI: $10.36229 / 978-65-86127-94-2 . C A P .16$

Capítulo 17: Plano de otimização da comunicação e estoque de um supermercado: Um estudo de caso 189

Ana Angélica Batista Diniz Pereira, Raquel Ferreira de Souza, Paulo Marcelo Villani

DOI: $10.36229 / 978-65-86127-94-2 . C A P .17$

Capítulo 18: Planejamento de logística e transportes: Um estudo dos planos de infraestrutura brasileiros 198

Camila Avosani Zago, Helios Malebranche

DOI: 10.36229/978-65-86127-94-2.CAP.18

Capítulo 19: Relato técnico: 0 uso de biodigestor em pequenas propriedades da agricultura familiar no Município de Marechal Cândido Rondon - PR.

Elisiane Salzer, Elenice da Silva Carvalho, Djeimi Angela Leonhardt Neske, Thayse Ana Ferreira

DOI: 10.36229/978-65-86127-94-2.CAP.19

Autores: 


\section{Capítulo 1}

Soluções fiscais eletrônicas para o varejo: Nova fronteira de modernização e controle fiscal de operações com mercadorias

\section{Marcelo Luiz Alves Fernandez}

\section{Eduardo Mário Dias}

Resumo: Com o advento de projetos fiscais de documentos eletrônicos, como a Nota Fiscal eletrônica (para a indústria e o comércio atacadista) e o Conhecimento de Transporte eletrônico (para o setor de transporte de mercadorias), é chegada a hora de completar a cadeia produtiva e expandir os benefícios desse tipo de projeto ao comércio varejista. Dois projetos destacam-se no Estado de São Paulo: uma solução em Hardware (SAT - Sistema Autenticador e Transmissor) e outra apenas com Software (NFC-e - Nota Fiscal de Consumidor eletrônica). Ambos são projetos ganha-ganha, e permitem, com segurança, a modernização desse importante setor econômico. 0 objetivo desse trabalho é descrever e comparar os dois projetos, de modo a trazer informações ao mercado e aos consumidores.

Palavras-Chave: SAT, NFC-e, Documentos Fiscais Eletrônicos, Varejo, Emissor de Cupom Fiscal - ECF. 


\section{INTRODUÇÃO}

Com os projetos de documentação fiscal denominados Nota Fiscal eletrônica (NF-e) e Conhecimento de Transporte eletrônico de Cargas (CT-e), implantados em 2005 e 2009, respectivamente, os fiscos estaduais criaram soluções eletrônicas que modernizaram a emissão dos documentos fiscais [1], [2], [5], [7], [10], [11]. Estes projetos permitiram aprimoramento do controle fiscal, redução de custos e simplificação de obrigações acessórias aos contribuintes. Novos passos foram dados também com a implantação da Escrituração Fiscal Digital (EFD) - projeto no âmbito do Sistema Público de Escrituração Digital - SPED (Decreto federal 6.022/2007), que moderniza, agiliza, reduz custos e melhora a qualidade da entrega da escrita fiscal pelas empresas.

Como consequência natural, a implantação de documentos fiscais eletrônicos passou a incluir o varejo. Dado seu tamanho, a fiscalização presencial de todo o setor é inviável, tornando imprescindível a implantação de soluções modernas.

Dois projetos surgiram como solução de modernização do varejo paulista: uma solução em hardware e outra puramente em software. [14]

Este trabalho tem o objetivo de trazer as reflexões teóricas realizadas em 2015 sobre tais projetos, apresentadas no XII CONTECSI [13], detalhando seus modelos e propostas, avaliando e comparando suas vantagens e desvantagens e, por fim, destacando os benefícios que os contribuintes e o fisco paulista têm com sua adoção.

A metodologia ora adotada envolve basicamente a explicação e comparação dos dois projetos. Do ponto de vista do mercado varejista, esse trabalho traz mais elementos para que cada varejista opte pela melhor solução ao seu negócio.

\section{MOTIVAÇÕES PARA A BUSCA DE ALTERNATIVAS PARA O VAREJO}

Podemos destacar três principais motivos para a busca de soluções fiscais eletrônicas para o varejo:

\section{a. $\quad$ Limitações da solução atual (ECF) [14] [15]}

Até 2015 as operações de circulação de mercadorias dos maiores contribuintes do setor varejista tributadas pelo ICMS eram documentadas pelo Cupom Fiscal, documento em papel emitido pelo equipamento Emissor de Cupom Fiscal - ECF. O ECF apresenta características que limitam a modernização do controle fiscal do varejo tais como:

$\checkmark$ Custo de aquisição: à época variando entre $R \$ 1.500,00$ e $R$ \$ 2.600,00; a legislação nacional exige a obrigatoriedade de seu uso para contribuintes com receita bruta anual superior a $R \$ 120.000,00$, o que resultava na presença dessa solução em apenas $20 \%$ dos contribuintes varejistas no Estado de São Paulo. Aqueles contribuintes não obrigados ao ECF devem emitir a Nota Fiscal de Venda a Consumidor (NFVC), a partir de talonário em papel.

$\checkmark$ Custos de intervenção técnica: toda manutenção em ECF é realizada por empresa interventora técnica, podendo gerar custos periódicos ao contribuinte.

$\checkmark$ Complexidade de relatórios: para controle das operações do ECF e escrituração fiscal, são gerados diversos relatórios (redução Z, leitura X, mapa resumo), cuja geração e guarda são obrigatórias ao contribuinte.

\section{b. $\quad$ Transmissão de informações para o programa Nota Fiscal Paulista (NFP) [14], [15]}

A implantação do programa de Estímulo à Cidadania Fiscal do Estado de São Paulo, denominado Nota Fiscal Paulista, obrigou que os contribuintes enviassem à Secretaria da Fazenda do Estado de São Paulo (Sefaz/SP) um arquivo digital denominado Registro Eletrônico de Documentos Fiscais (REDF), contendo informações dos documentos emitidos no mês anterior.

A despeito dos benefícios do programa Nota Fiscal Paulista, a obrigação de envio do REDF agregou alguns custos e certa complexidade à operação do contribuinte, e problemas ao fisco e consumidor: 
$\checkmark$ Para geração do REDF o contribuinte deve extrair dados do ECF, ou dos talonários em papel, sujeitando-o a erros e omissões de informações; ressalte-se que a falta de registro de um documento sujeita o contribuinte a penalidades no âmbito do direito do consumidor e tributário;

$\checkmark \quad$ Os REDF gerados não possuem assinatura digital, sujeitando-os a contestações de autoria;

$\checkmark \quad 0$ prazo para envio do REDF à Secretaria da Fazenda é longo, variando de 40 a 90 dias após a operação, o que poderia desestimular o consumidor a acompanhar suas compras pela internet.

\section{c. Controle de toda a cadeia produtiva [12]}

A Nota Fiscal eletrônica (NF-e) e o Conhecimento de Transporte eletrônico (CT-e) são documentos que registram, de forma eletrônica, as operações com mercadorias e a correspondente prestação de serviço de transporte, visando, principalmente, a questão tributária e, mais especificamente, o Imposto sobre Circulação de Mercadorias e Serviços de Transportes Intermunicipais e Interestaduais, o ICMS. Há ainda o Manifesto Eletrônico de Documentos Fiscais (MDF-e), cuja principal função é registrar as informações logísticas do transporte da mercadoria, vinculando unidade de transporte (caminhão) aos documentos fiscais emitidos. [4], [6]

0 controle efetivo da cadeia produtiva requer que todo o ciclo comercial esteja registrado eletronicamente. Se parte dos elos da cadeia foge a essa regra, será mais difícil identificar eventuais desvios, uma vez que a base de dados não estará completa.

Sendo assim, e considerando que toda a indústria, comércio atacadista, comércio interestadual, comércio exterior, bem como o transporte de cargas e mercadorias já estão obrigados à utilização da NF-e e do CT-e, o passo natural é a extensão de soluções eletrônicas ao varejo.

De certa forma, o varejo já era obrigado a prestar, no Estado de São Paulo, periodicamente, informações eletrônicas para fins do programa "Nota Fiscal Paulista", como já citado. O REDF não é, contudo, um arquivo nos padrões da NF-e e do CT-e, e não precisa ser assinado digitalmente, justificando, portanto, sua modernização. [14] [15]

\section{OBJETIVOS DOS NOVOS PROJETOS DE DOCUMENTOS FISCAIS PARA O VAREJO}

A implantação de novos projetos busca atingir os seguintes objetivos: [14]

$\checkmark$ Simplificar e reduzir custos com obrigações acessórias do contribuinte (exemplo: eliminação de relatórios das leituras do ECF e da intervenção técnica);

$\checkmark$ Permitir ampliação da base de contribuintes monitorados;

$\checkmark$ Melhorar o acompanhamento das operações por parte do fisco (abrangência e qualidade das informações) e, portanto, o combate à sonegação e concorrência desleal;

$\checkmark$ Garantir que o documento emitido seja o efetivamente armazenado na base de dados da Secretaria da Fazenda;

$\checkmark$ Simplificar a transmissão de informações das operações ao fisco, eliminando a necessidade de Registro Eletrônico de Documentos Fiscais (REDF) e, consequentemente, reduzindo erros, omissões e autuações do contribuinte;

$\checkmark$ Permitir ao consumidor acompanhar suas compras em prazo muito menor do que o atual, propiciando maior transparência e maior exercício da cidadania;

$\checkmark$ Garantir que o documento fiscal emitido seja não apenas transmitido à Secretaria da Fazenda, mas também que seja transmitido sem nenhum tipo de adulteração das suas informações. Note que sempre haverá o risco (comum a qualquer solução fiscal no varejo, eletrônica ou não), de o documento fiscal não vir a ser emitido, o que deve ser combatido com ações de fiscalização e apurações de denúncia do consumidor no programa Nota Fiscal Paulista. 


\section{SOLUÇÕES FISCAIS ELETRÔNICAS PARA O VAREJO: PROJETOS EM IMPLANTAÇÃO EM SÃO PAULO}

Para atender aos objetivos propostos, destacamos dois projetos de documentos fiscais eletrônicos: o SATCF-e (Sistema Autenticador e Transmissor de Cupons Fiscais eletrônicos) e a NFC-e (Nota Fiscal de Consumidor eletrônica). O SAT é um projeto paulista, idealizado e implantado pela Secretaria da Fazenda do Estado de São Paulo; o segundo é um projeto nacional, coordenado pelo Encontro Nacional de Coordenadores e Administradores Tributários (ENCAT) [9] elaborado a partir de conceitos trazidos pela NF-e e pelo próprio SAT-CF-e.

A documentação, legislação e informações técnicas dos projetos, que foram sinteticamente mencionadas a seguir, podem ser consultadas nos sites https://portal.fazenda.sp.gov.br/servicos/sat/Paginas/Sobre.aspx [16], [19] e http://www.nfce.fazenda.sp.gov.br/NFCePortal/. [3], [17], [18]

\subsection{SAT-CF-e - SISTEMA AUTENTICADOR E TRANSMISSOR DE CUPONS FISCAIS ELETRÔNICOS [14], [16], [19]}

Para superar as limitações do ECF, o projeto SAT conta com os seguintes produtos:

$\checkmark$ Cupom Fiscal Eletrônico-SAT (CF-e-SAT): Novo modelo de documento fiscal eletrônico, aderente ao modelo da NF-e, emitido em substituição ao Cupom Fiscal e à Nota Fiscal de venda a consumidor final, ambos em papel.

$\checkmark$ Equipamento SAT: Novo padrão de equipamento de custo menor que gera, autentica e transmite automaticamente, quando conectado à internet Banda Larga, os Cupons Fiscais Eletrônicos emitidos pelos estabelecimentos, com validade jurídica.

$\checkmark$ a. Breve descrição do funcionamento do SAT

$\checkmark \quad$ O SAT gera o CF-e-SAT, a partir dos dados da venda enviados pelo software Aplicativo Comercial (AC);

$\checkmark$ Garantindo sua validade jurídica, o CF-e-SAT possui assinatura digital, gerada a partir de Certificado Digital contido no equipamento SAT - Certificado fornecido pela Secretaria da Fazenda sem ônus ao contribuinte;

$\checkmark$ Durante as vendas o SAT pode funcionar off-line, pois os documentos eletrônicos emitidos são armazenados temporariamente para que o equipamento os transmita assim que conectado, posteriormente, à internet. Isso significa que o estabelecimento não precisa arcar com custos para dispor de internet no ambiente de frente de caixa durante todo o período de funcionamento. A transmissão pode ocorrer, por exemplo, no final do expediente, a partir da internet existente em escritório administrativo do estabelecimento;

$\checkmark$ Independente da transmissão, o SAT envia cópia do CF-e-SAT ao Aplicativo Comercial para que este imprima o extrato, registro das compras para entrega ao consumidor;

$\checkmark \quad 0$ extrato poderá ser impresso em impressora comum, e conterá QRCode (espécie de código de barras) para que o consumidor possa checar sua validade por meio de aplicativo em smartphone, mesmo antes da transmissão do CF-e à Secretaria da Fazenda. A legislação poderá prever outras formas de disponibilização do extrato ao consumidor;

$\checkmark \quad 0$ consumidor poderá checar as compras no sistema da Nota Fiscal Paulista ou em consulta pública, assim que recebido o CF-e-SAT pela Sefaz, dispensando o envio do REDF pelo contribuinte;

$\checkmark$ Um mesmo equipamento SAT e uma mesma impressora podem ser compartilhados por mais de um caixa, bastando que haja controle por rede interna de dados no estabelecimento. 


\section{b - Principais vantagens e benefícios}

\section{$\checkmark \quad$ Para o contribuinte:}

- O SAT não necessita de manutenção ou intervenção técnica, que o atual ECF demanda;

- Não é necessário dispor de conexão à internet no ponto de venda durante o período de funcionamento (vendas);

- Os meios de transmissão e impressão podem ser compartilhados, ou seja, pode haver uma impressora servindo mais de um equipamento SAT, assim como a existência de conexão à internet pode ser compartilhada por todos os equipamentos;

- Não há necessidade de um equipamento SAT para cada ponto de venda. A legislação do SAT permite que o estabelecimento comercial monte sua rede interna de informações, de modo que um equipamento SAT atenda a vários caixas e permitindo que o estabelecimento varie a quantidade de pontos de venda sem a necessidade de aquisição de outros equipamentos SAT. Esta flexibilidade no ajuste da quantidade de pontos de venda não era permitida com o ECF; por força de legislação exige-se um ECF para cada ponto de venda;

- $\quad$ uso do SAT poderá ser expandido a contribuintes de menor porte que hoje não utilizam o $\mathrm{ECF}$, mas emitem notas fiscais em papel;

- O contribuinte não necessitará mais extrair as informações da máquina, formatá-las e transmiti-las para o sistema da Nota Fiscal Paulista, pois o próprio SAT fará isso automaticamente.

\section{Para o consumidor e sociedade:}

- O consumidor encontrará dados de suas compras na internet em questão de horas ou, no máximo, de alguns dias;

- Isso reforçará, à sociedade, a noção de que a emissão do documento fiscal junto ao estabelecimento comercial está sendo controlada pelo fisco, e que o consumidor continuará recebendo seus créditos e participando dos sorteios junto ao programa Nota Fiscal Paulista.

\section{Para o fisco:}

○ $\quad 0$ fisco terá os dados das operações do varejo de forma mais rápida e segura, o que permitirá maior controle e planejamento fiscal. A segurança consiste na transmissão compulsória dos cupons que foram emitidos pelo SAT diretamente à Secretaria da Fazenda, sem que as informações possam ser adulteradas.

\subsection{NFC-E - NOTA FISCAL DE CONSUMIDOR ELETRÔNICA [3], [14], [17], [18]}

O modelo operacional da NFC-e segue o mesmo modelo consolidado da NF-e.

De maneira simplificada, o estabelecimento emitente de NFC-e gera um arquivo eletrônico contendo as informações fiscais da operação comercial de venda ao consumidor final. 0 arquivo deverá ser assinado digitalmente, no padrão ICP-Brasil, de maneira a garantir a integridade dos dados e a autoria do emissor.

Este arquivo eletrônico será então transmitido pela internet para a Secretaria da Fazenda, que fará uma pré-validação do arquivo e devolverá, em tempo real, um protocolo de recebimento (autorização de uso), sem o qual a venda não poderá ser concluída.

Após o recebimento da NFC-e, a Secretaria da Fazenda disponibilizará consulta na internet para que o consumidor possa verificar sua autorização e conteúdo.

Autorizada a NFC-e, deverá ser impressa uma representação gráfica simplificada da Nota Fiscal de Consumidor eletrônica, intitulado DANFE-NFC-e (Documento Auxiliar da NFC-e), em papel comum e via única. Da mesma forma como no projeto SAT, o consumidor poderá optar por receber o extrato completo (com todos os dados de sua compra) ou simplificado (ou seja, sem o detalhamento da 
compra), lembrando que a legislação poderá prever outras formas de disponibilização do DANFE NFCe ao consumidor.

O DANFE-NFC-e conterá, assim como no projeto SAT, um QRCode a partir do qual o consumidor poderá consultar os dados completos de sua compra que já foram transmitidos pela internet à Sefaz/SP, em um smartphone. Note que, nesse caso, o QRCode depende da transmissão do documento a base de dados da Secretaria da Fazenda, diferentemente do modelo do SAT.

A NFC-e foi implantada em praticamente todas as unidades da federação, em substituição ao ECF. Em São Paulo, a legislação vigente (Portaria CAT-147/2012) prevê a substituição do ECF pelo SAT, sendo que a NFC-e será alternativa posta à disposição do contribuinte, que poderá emiti-la em lugar do CF-e-SAT.

\subsubsection{MODELO NACIONAL DE CONTINGÊNCIA DA NFC-E [3]}

Para contornar o problema da disponibilidade de internet, o projeto nacional da NFC-e prevê que, em caso de problemas técnicos que impeçam sua autorização on-line, a NFC-e possa ser emitida off-line. Superado o problema técnico, o arquivo digital da NFC-e deve ser enviado para autorização pela Sefaz, em prazo estipulado em legislação estadual, contado a partir de sua emissão off-line. Vide Cláusula décima primeira, I do Ajuste Sinief 19/2016 [3].

O DANFE-NFC-e da NFC-e emitida off-line deve conter a informação desta emissão em contingência.

0 controle das informações das NFC-e emitidas na contingência off-line e o posterior encaminhamento para autorização são de responsabilidade do contribuinte. Em consequência, há a possibilidade de que:

$\checkmark$ As NFC-e emitidas em contingência e posteriormente encaminhadas para autorização possam vir a ser rejeitadas pela Sefaz, gerando retrabalho e pendências junto ao contribuinte; nesta situação, a retirada da mercadoria pelo consumidor já ocorreu, e a operação não foi acobertada por documento fiscal válido;

$\checkmark \quad 0$ contribuinte assuma o risco de perda das informações da NFC-e emitidas em contingência, e não conseguir transmiti-las posteriormente;

$\checkmark$ O contribuinte mal organizado possa não transmitir as NFC-e emitidas em contingência, especialmente quando o consumidor final não se identificou por meio de seu CPF/CNPJ, ou, ainda, transmitir a NFC-e com informações adulteradas;

$\checkmark$ As NFC-e emitidas off-line somente estejam disponíveis para consulta no site da Sefaz, ou mesmo via consulta do QRCode, após a transmissão e autorização, podendo gerar reclamações ou denúncias dos consumidores.

\section{COMPARATIVO ENTRE O SAT-CF-e E A NFC-e}

\subsection{SEMELHANÇAS}

Inúmeras são as semelhanças entre os dois projetos, até porque ambos foram baseados no leiaute e padrões da NF-e (como assinatura digital, padrões abertos, consulta pública).

Semelhanças que podem ser destacadas:

$\checkmark$ Quanto à geração do documento fiscal:

- Tanto o CF-e gerado pelo SAT como a NFC-e são documentos eletrônicos desde a sua geração, ambos no formato XML;

- Ambos são transmitidos ao fisco por meio de WebServices e uso de internet;

- A guarda de ambos, pelo prazo decadencial, cabe ao contribuinte. 
$\checkmark \quad$ Quanto à necessidade de infraestrutura:

- A impressão do Extrato do CF-e ou do DANFE-NFC-e pode ser feita a partir de uma impressora não fiscal, que pode ser compartilhada entre os diversos pontos de venda do estabelecimento;

- Tanto o SAT como a NFC-e requer um suporte físico (exemplo computador ou dispositivo móvel), que não necessariamente precisa estar disponível ou exposto no ponto de venda;

- Tanto o SAT como a NFC-e necessitam de um Aplicativo Comercial para capturar as informações da venda e, posteriormente, gerar o documento fiscal eletrônico (CF-e ou NFC-e);

- Tanto o SAT como a NFC-e permitem emissões centralizadas, deslocadas do ponto de venda.

\section{Quanto ao extrato entregue ao consumidor:}

- à semelhança do extrato do CF-e-SAT, o projeto NFC-e prevê a emissão, pelo contribuinte, de um documento impresso de registro das compras efetuadas pelo consumidor, o DANFE NFCe. Tal documento, assim como o extrato, relaciona os itens comprados; possui QRCode que permite, via aplicativo em smartphone, consultar a NFC-e autorizada junto à Sefaz. A legislação poderá prever, em ambos os casos, formas alternativas de tratamento do extrato e do DANFE NFC-e.

Quanto às obrigações tributárias acessórias:

- Tanto o SAT como a NFC-e dispensam a transmissão adicional de informações à Secretaria da Fazenda para fins do programa Nota Fiscal Paulista;

- Eliminação de emissão de documentos auxiliares que eram exigidos pelo ECF, tais como leitura X, redução Z e Mapa resumo;

- Escrituração simplificada na Escrituração Fiscal Digital (EFD) do CF-e e da NFC-e, a partir de suas chaves de acesso e totalizadores.

\subsection{DIFERENÇAS}

A NFC-e é documento fiscal eletrônico (modelo 65), com mesmo leiaute da NF-e adaptado às peculiaridades do varejo. Entretanto, por adotar as mesmas diretrizes da NF-e, sua implantação e operacionalização pelo contribuinte apresentam diferenças em relação ao SAT:

Tabela 1 - Diferenças entre modelos operacionais NFC-e e SAT

\begin{tabular}{|c|c|c|}
\hline & NFC-e & SAT \\
\hline $\begin{array}{l}\text { Meio de emissão do } \\
\text { documento eletrônico }\end{array}$ & $\begin{array}{l}\text { Programa emissor de mercado - } \\
\text { Software }\end{array}$ & Equipamento SAT - Hardware \\
\hline $\begin{array}{l}\text { Certificado Digital para } \\
\text { assinatura do documento }\end{array}$ & $\begin{array}{l}\text { Certificado digital ICP-Brasil do } \\
\text { contribuinte (e-CNPJ), com aquisição } \\
\text { e renovação por conta deste }\end{array}$ & $\begin{array}{l}\text { Certificado digital do equipamento } \\
\text { SAT, vinculado ao contribuinte, } \\
\text { fornecido sem ônus pela Sefaz/SP (1) }\end{array}$ \\
\hline $\begin{array}{l}\text { Disponibilidade de internet } \\
\text { para emissão (geração) do } \\
\text { documento }\end{array}$ & $\begin{array}{l}\text { Full-time: } \\
\text { Necessária autorização de uso da } \\
\text { Sefaz, previamente à conclusão da } \\
\text { transação comercial }\end{array}$ & $\begin{array}{l}\text { Desnecessária: } \\
\text { SAT pode operar off-line na emissão } \\
\text { do CF-e-SAT, que será transmitido } \\
\text { quando conectar-se à internet }\end{array}$ \\
\hline $\begin{array}{l}\text { Disponibilidade de internet } \\
\text { para transmissão } \\
\text { documento à Secretaria do } \\
\text { Fazenda }\end{array}$ & $\begin{array}{l}\text { Full-time: } \\
\text { Conforme dito acima, é necessária } \\
\text { autorização de uso da Sefaz, } \\
\text { previamente à conclusão da } \\
\text { transação comercial }\end{array}$ & $\begin{array}{l}\text { Periódica: } \\
\text { O CF-e-SAT é emitido off-line e } \\
\text { armazenado no equipamento. } \\
\text { Somente serão transmitidos quando } \\
\text { o SAT conectar-se à internet (ou seja, } \\
\text { a transmissão pode ser posterior à } \\
\text { venda) }\end{array}$ \\
\hline
\end{tabular}

(1) Conforme MP 2200-2, art.10, § 2º, [8] alternativamente, o contribuinte poderá optar por utilizar Certificado Digital, próprio para equipamentos e emitido na cadeia ICP-Brasil, correndo os custos de aquisição e manutenção por sua conta. 
Conforme visto, a disponibilidade de internet de boa qualidade é fator crítico para a eficiente operacionalização da NFC-e. Em não havendo tal disponibilidade, ficaria o contribuinte impedido de autorizar as NFC-e e, portanto, de concretizar as operações de venda, restando a adoção de contingências. Não apenas a falta de sinal da internet, mas também a demora na resposta da autorização pela Secretaria da Fazenda pode ocasionar demora na finalização da operação. Em se tratando de comércio varejista, tais situações podem impactar negativamente as vendas. Ressalte-se que vários fatores podem ocasionar falta ou baixa qualidade da disponibilidade da internet: infraestrutura interna do estabelecimento, o provedor de internet, ou mesmo a própria Secretaria da Fazenda pode, eventualmente, sofrer indisponibilidade de seus serviços.

\subsubsection{MODELO DE CONTINGÊNCIA DA NFC-E PREVISTO EM SÃO PAULO [17], [18]}

Conforme legislação vigente, em caso de problemas técnicos, o contribuinte deverá utilizar o SAT (vide artigo 10 da Portaria CAT 12/2015) [17]

\section{Argumentos:}

- A emissão de documentos fiscais sempre foi acompanhada de certa rastreabilidade. Para os documentos em papel há a Autorização de Impressão de Documentos Fiscais (AIDF); na Nota Fiscal eletrônica (e no Conhecimento de Transporte eletrônico - CT-e), a emissão do documento é prévia ao fato gerador, sendo que na contingência o contribuinte deve: (i) emitir o documento em ambiente de contingência, antes do fato gerador; (ii) usar formulário de segurança controlado; (iii) transmitir resumo da operação comercial antes do fato gerador (Declaração ou Evento Prévio de Emissão de Contingência - DPEC ou EPEC), ou seja, sempre há alguma rastreabilidade. Adotar um modelo off-line significa que não haverá nenhuma rastreabilidade nos documentos sem identificação do consumidor, quebrando o paradigma de controle pelo fisco (uso de contingência como regra; não envio de documentos sem identificação do consumidor; adulteração de informações da operação comercial);

- Mesmo no caso de documentos com identificação do consumidor, a participação da população na "fiscalização" da emissão do documento fiscal no varejo deve ser considerada com ressalvas, pois nem todo consumidor irá acompanhar suas compras ou registrar algum tipo de reclamação;

- Combate à concorrência desleal, dificultando a possibilidade de não emissão de documentos fiscais em algum elo da cadeia produtiva;

- Considerando o programa Nota Fiscal Paulista, a adoção da contingência off-line da NFC-e traz os mesmos problemas da solução atual com o ECF que se quer reduzir / eliminar, ou seja, o consumidor sai com um documento em papel (o Cupom Fiscal ou o DANFE-NFC-e), e o estabelecimento, que bastaria transmitir a informação correspondente por meio de um arquivo que deve ser montado para tanto (REDF ou XML), por alguma razão ou problema técnico, não o faz.

\subsubsection{COMPARAÇÃO DA ADOÇÃo DO SAT COMO CONTINGÊNCIA DA NFC-e X MODELO OFF-LINE}

Tabela 2 - Contingência NFC-e: uso do SAT vs. modelo off-line

$$
\text { Pontos a favor }
$$

\begin{tabular}{|c|c|}
\hline SAT & NFC-e - Modelo off-line \\
\hline $\begin{array}{l}\text { Mais seguro. Evita risco de o contribuinte perder arquivo do CF-e e não } \\
\text { conseguir enviá-lo à Sefaz, pois a transmissão é feita automaticamente pelo SAT } \\
\text { quando conectado à internet; } \\
\text { " Teoricamente elimina risco do CF-e não ser autorizado pela Sefaz, pois foi } \\
\text { consistido pelo SAT antes da emissão; } \\
\text { - Reduz a autuação no âmbito da NFP por não envio do documento fiscal à } \\
\text { Sefaz/SP; } \\
\text { Validação do QRCode independe de transmissão do CF-e-SAT. }\end{array}$ & 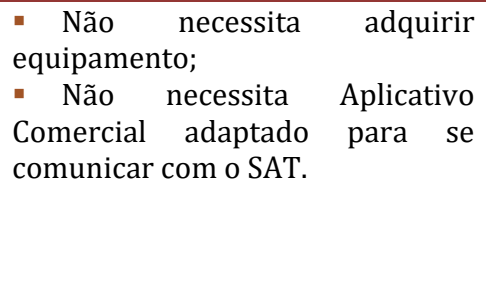 \\
\hline
\end{tabular}




\begin{tabular}{|c|c|}
\hline SAT & NFC-e - Modelo off-line \\
\hline $\begin{array}{l}\text { É necessário adquirir } \\
\text { equipamento; } \\
\text { Necessário } \\
\text { Comercial adaptado para se } \\
\text { comunicar com o SAT. }\end{array}$ & $\begin{array}{l}\text { " Não propiciará redução acentuada de autuação no âmbito do programa NFP } \\
\text { referente ao não envio do documento; } \\
\text { - Permite, na prática, que o contribuinte opere o tempo todo em contingência; } \\
\text { - Aplicativo Comercial ou sistema do contribuinte deve controlar as NFC-e } \\
\text { geradas em contingência, para posterior envio para autorização pela Sefaz, com } \\
\text { os seguintes riscos: } \\
\text {. Risco de a NFC-e emitida off-line não ser autorizada pela Sefaz (e o consumidor } \\
\text { já retirou a mercadoria); } \\
\text {. Risco de o contribuinte perder o arquivo da NFC-e, e não conseguir enviá-lo } \\
\text { posteriormente para autorização na Sefaz (e o consumidor já retirou a } \\
\text { mercadoria). } \\
\text { - Frequentes instabilidades e demora na resposta da autorização on-line } \\
\text { causam uso frequente da contingência off-line, potencializando os riscos acima; } \\
\text { - Mesmo emitindo somente um tipo de documento (NFC-e), adaptações são } \\
\text { necessárias: } \\
\text { - O arquivo da NFC-e deve ser modificado para conter informações específicas } \\
\text { indicando emissão em contingência; } \\
\text {. O DANFE NFC-e deve conter indicação que foi emitido em contingência; } \\
\text { - Não é possível validar o QRCode sem a transmissão da NFC-e à Sefaz }\end{array}$ \\
\hline
\end{tabular}

\section{CONCLUSÕES}

A implantação dos documentos fiscais eletrônicos para documentação de operações com mercadoria avançou para sua próxima etapa: os contribuintes varejistas.

Existem dois projetos implantados, nascidos a partir dos mesmos conceitos de sucesso da NF-e, que surgem para suprir essa necessidade. Como visto acima, há mais semelhanças do que diferenças, cada qual com suas vantagens e desvantagens. A principal diferença diz respeito ao suporte de emissão dos documentos eletrônicos: o SAT pressupõe a adoção de um hardware homologado, enquanto a NFC-e trabalha apenas com software, sem a existência de um suporte físico homologado pelo fisco.

Os pontos chaves de escolha por um ou outro são (i) a disponibilidade e confiabilidade de internet no ponto de venda (obrigatórias no caso da NFC-e, dispensáveis no caso do SAT); e (ii) custo (do hardware, multiplicado pela quantidade necessária para atender os pontos de venda - medida que cada contribuinte deverá avaliar - versus custo de certificado digital e de manutenção do Software emissor de NFC-e).

Conforme já exposto, a escolha caberá ao contribuinte, alertando-se apenas para o caso de contingência na NFC-e prevista em São Paulo.

Analisando ambas as soluções, temos que elas atendem e cumprem os objetivos listados no item 3, principalmente no que diz respeito à simplificação e redução de custos aos contribuintes em relação às soluções atuais em papel.

Sendo assim, trarão benefícios a todos os envolvidos na compra no varejo: o contribuinte terá menos burocracia e menor custo para cumprimento de suas obrigações acessórias, ao menos no médio e longo prazo; o fisco terá segurança na informação que receberá, para fins de controle e planejamento fiscal; o consumidor e a sociedade encontrarão um mercado mais controlado, e poderão acompanhar melhor seus créditos e bilhetes de sorteio no âmbito do programa Nota Fiscal Paulista.

São projetos em que todos saem ganhando.

\section{REFERÊNCIA}

[1] BRASIL. CONFAZ. Ajuste SINIEF 07, de 30 de setembro de 2005 . Disponível em https://www.confaz.fazenda.gov.br/legislacao/ajustes/2005/aj_007_05. Acesso em 02/07/2020.

[2] Brasil. CONFAZ. Ajuste SINIEF 09, de 25 de outubro de 2007. Disponível em: https://www.confaz.fazenda.gov.br/legislacao/ajustes/2007/aj_009_07. Acesso em 02/07/2020.

[3] BRASIL. CONFAZ. Ajuste SINIEF 19, de 9 de dezembro de 2016 . Disponível em https://www.confaz.fazenda.gov.br/legislacao/ajustes/2016/AJ_019_16. Acesso em 02/07/2020. 
[4] BRASIL. CONFAZ. Ajuste SINIEF 21, de 10 de dezembro de 2010. Disponível em https://www.confaz.fazenda.gov.br/legislacao/ajustes/2010/aj_021_10. Acesso em 02/07/2020.

[5] BRASIL. Documentos Fiscais Eletrônicos. Portal do Projeto CT-e. MOC versão 3.00. Disponível em <http://www.cte.fazenda.gov.br/portal/>. Acesso em 02/07/2020.

[6] BRASIL. Documentos Fiscais Eletrônicos. Portal do Projeto MDF-e. MOC versão 3.00. Disponível em $<$ https://dfe-portal.svrs.rs.gov.br/Mdfe/Documentos>. Acesso em 02/07/2020.

[7] BRASIL. Documentos Fiscais Eletrônicos. Portal do Projeto NF-e. MOC versão 6.00. Disponível em <http://www.nfe.fazenda.gov.br>. Acesso em 02/07/2020.

[8] Brasil. Medida provisória N. 2.200-2, De 24 De Agosto De 2001. Disponível em: http://www.planalto.gov.br/ccivil_03/MPV/Antigas_2001/2200-2.htm. Acesso em 02/07/2020.

[9] Brasil. Site do ENCAT. Disponível em www.encat.org. Acesso em 02/07/2020.

[10] Brasil. Site Nacional da NF-e. Disponível em www.nfe.fazenda.gov.br. Acesso em 02/07/2020.

[11] Brasil. Site Nacional do CT-e. Disponível em www.cte.fazenda.gov.br. Acesso em 02/07/2020.

[12] FERNANDEZ, M.L.A. Avaliação da utilização de documentos fiscais eletrônicos na rastreabilidade de cargas. Dissertação (mestrado) - Escola Politécnica da Universidade de São Paulo - USP. 2012.

[13] FERnANDEZ, M. L. A. ; DIAS, E. M. . Soluções Fiscais Eletrônicas para o Varejo Nova Fronteira de Modernização e Controle Fiscal de Operações com Mercadorias. In: 12 CONTECSI Congresso Internacional de Gestão da Tecnologia e Sistemas de Informação, 2015, São Paulo. Anais do 12o CONTECSI. São Paulo, 2015.

[14] FERNANDEZ, M.L.A.. Capítulo 9 - Documentos Fiscais Eletrônicos. In: SPED E SISTEMAS DE INFORMAÇÃO. São Paulo: FISCOSOFT EDITORA LTDA, 2013 (Selo títulos contábeis). Vários autores. ISBN 978-85-87365-79-8.

[15] MEllo, N. O. ; FERnANDEZ, M. L. A. ; MELO, V. A. Z. C. ; DIAS, E. M. ; FOnTANA, Caio Fernando . New Technologies for Nota Fiscal Paulista (São Paulo tax Invoice): Automation of the Tax Documents Issue Process in the Retail of the State of São Paulo - Brasil. In: 8tht WSEAS International Conference on System Science and Simulation in Engeneering (ICOSSSE 09), 2009, Genova. Anais do 8th WSEAS International Conference on System Science and Simulation in Engeneering. Genova: WSEAS Press, 2009. p. 251-258.

[16] SÃo PAUlO (Estado). Portaria CAT no 147, de 05 de novembro de 2012 (SAT). Disponível em https://portal.fazenda.sp.gov.br/servicos/sat/Paginas/Legislacao.aspx. Acesso em 02/07/2020.

[17] SÃo PAULO (Estado). Portaria CAT no 12, de 02 de maio de 2015 (NFC-e). Disponível em http://www.nfce.fazenda.sp.gov.br/NFCePortal/Paginas/LegislacaoEmVigor.aspx. Acesso em 02/07/2020.

[18] SÃO PAULO (Estado). Site oficial do projeto NFC-e. Disponível em http://www.nfce.fazenda.sp.gov.br/NFCePortal/Default.aspx. Acesso em 02/07/2020.

[19] SÃO PAULO (Estado). Site oficial do projeto SAT. Disponível em www.fazenda.sp.gov.br/sat. Acesso em $02 / 07 / 2020$. 


\section{Capítulo 2}

A importância da Controladoria no processo de tomada de decisões: Estudo de caso na Companhia de Água e Esgoto do Ceará (CAGECE)

\section{Maricoeli Gonçalves Tavares \\ Anna Karine Monteiro de Sousa \\ Sheila Raquel de Moraes Lima \\ Andson de Freitas Viana \\ Neurisangelo Cavalcante de Freitas}

Resumo: Com o cenário de mudanças, as empresas passaram a institucionalizar a controladoria como um instrumento para auxiliar os gestores em suas tomadas de decisões. Essa pesquisa buscou resposta para a seguinte pergunta: Qual o papel da Controladoria na Companhia de Saneamento Básico no Ceará? tem-se como hipótese que a Companhia de Água e Esgoto do Ceará (CAGECE), por meio de sua Gerência de Estudos Estratégicos e Orçamentos (GESOR), que as informações adequadas são garantidas aos usuários para os processos decisórios imprescindíveis para a continuidade da entidade. O objetivo geral é apresentar a importância das informações da controladoria na tomada de decisão da companhia no que se refere ao controle para assegurar a continuidade da missão e a ampliação de investimentos na CAGECE. 0 paradigma epistemológico utilizado foi o Interpretativismo. Metodologicamente, trata-se de uma pesquisa qualitativa, bibliográfica, descritiva, exploratória, com estudo de caso na CAGECE. 0 resultado confirmou a hipótese.

Palavras Chave: Controladoria, Saneamento, CAGECE 


\section{INTRODUÇÃO}

O processo de globalização ampliou de forma significativa a economia brasileira, com isso as empresas brasileiras vêm sendo forçadas a se adaptarem a essa realidade. Algumas empresas públicas foram privatizadas, porém algumas empresas ainda ficaram sob a responsabilidade do poder público, podemos citar como exemplo a Companhia de Água e Esgoto do Ceará (CAGECE). A partir de então, foram criadas as agências reguladoras, e essas empresas passaram a ser fiscalizadas com mais rigor. Diante deste cenário de mudanças, as empresas sentiram a necessidade de controlar melhor a gestão de seus negócios, passando então a institucionalizar a controladoria, como um instrumento para auxiliar os gestores em suas tomadas de decisões. 0 presente estudo aborda a controladoria explicando sua importância no contexto de uma empresa de economia mista do setor de saneamento básico localizada no Ceará.

No início do corrente ano, novas alterações na Lei de criação da Cagece foram discutidas e em 23 de abril de 2013 ocorreram alterações na Lei 9.499/71 - Lei de Criação da CAGECE - aprovada pela Assembléia Legislativa do Ceará. As alterações da Lei trazem como principais benefícios a ampliação da atuação econômica e geográfica da CAGECE - que poderá explorar toda a cadeia produtiva do saneamento (água, esgoto, drenagem e resíduos sólidos), além da atuação em atividades de geração e comercialização de energia, em todo o Estado do Ceará, em outros Estados da federeção brasileira e no exterior.

Com o cenário atual de crescimento da Companhia e visando a realização de sua missão, de seus objetivos estratégicos e de sua estrutura organizacional essa pesquisa pretende responder a seguinte questão: Qual o papel da Controladoria na Companhia de Saneamento Básico no Ceará? Tem-se como hipótese que a Companhia de Água e Esgoto do Ceará (CAGECE), por meio de sua Gerência de Estudos Estratégicos e Orçamentos (GESOR), que as informações adequadas são garantidas aos usuários para os processos decisórios imprescindíveis para a continuidade da entidade. 0 objetivo geral é apresentar a importância das informações da controladoria na tomada de decisão da companhia no que se refere ao controle para assegurar a continuidade da missão e a ampliação de investimentos na CAGECE. Os objetivos específicos são: (I) identificar como as informações da Controladoria são úteis para auxiliar os administradores nas tomadas de decisões na Cagece, (II) analisar a posição da controladoria no organograma da Companhia. Metodologicamente, trata-se de uma pesquisa qualitativa, descritiva, com estudo de caso na Companhia de Água e Esgoto do Ceará (CAGECE).

Assim, estudar a controladoria em uma organização ligada à administração pública indireta após uma mudança organizacional atende a interesses não apenas acadêmicos e profissionais, mas acima de tudo, sociais, pois a eficiência das Companhias ligadas às esferas do Estado contribui para o desenvolvimento do País. Para atender aos objetivos propostos, a pesquisa está estruturada em duas seções relativas ao referencial teórico compostas da seguinte forma: a primeira trata dos conceitos de controladoria, suas funções e o do controller, a segunda aborda a tomada de decisão, os conceitos de staff, os subsistemas do sistema de informação e a mudança organizacional; metodologia de pesquisa; estudo de caso contendo resultados e discussões; e; conclusão.

\section{CONTROLADORIA}

A Controladoria é abordada nesse trabalho quanto ao significado para a gestão das entidades e sua importância para a tomada de decisão nas organizações. Os estudos relacionados à Controladoria demonstram uma forma de progresso dos níveis de como indicadores podem ser melhorados, tanto em nível de planejamento, transparência, controle e responsabilização dos gestores, tudo isso aliado, principalmente, as informações produzidas pela contabilidade.

\subsection{CONCEITOS}

De acordo com Catelli (2001, p.344), "A Controladoria é uma evolução natural da contabilidade tradicional". A Controladoria surgiu mediante a necessidade de um sistema contábil mais adequado para ter um controle gerencial mais efetivo nas empresas. Ela foi criada para proporcionar uma melhor compreensão e organização das demonstrações para auxiliar os gestores nas tomadas de decisões. Para que a controladoria consiga desempenhar suas funções, ela precisa se abastecer de informações, que são originadas por diversas áreas da empresa. De acordo com Mosimann e Fisch (1999), a Controladoria tem como finalidade garantir informações adequadas ao processo decisório, colaborar com os gestores em seus esforços de obtenção da eficácia de suas áreas quanto aos aspectos econômicos, e assegurar a eficácia empresarial, também sob aspectos econômicos, por meio da coordenação dos esforços dos gestores das áreas. 
A Controladoria tem a finalidade de dá suporte, para as tomadas de decisões dentro de uma empresa, ele utiliza as demonstrações feitas pela contabilidade, faz as análises dos dados ligados ao orçamento e ao planejamento empresarial para depois dar o seu parecer. Ela também pode utilizar-se de quaisquer outras ferramentas de informação, pode se apoiar nas informações geradas pela administração da produção, da estrutura organizacional e também da administração financeiro. Catelli (2001) menciona que, a Controladoria não pode ser vista como um processo, voltado ao como fazer. Devemos cindi-la em dois vértices: o primeiro como ramo do conhecimento responsável pela instituição de toda a base conceitual, e o segundo como função administrativa, respondendo pela divulgação do conhecimento, modelagem e implantação de sistemas de informações. A Controladoria é utilizada para dar suporte aos administradores das empresas, não importando em que área as informações serão utilizadas, o controller agirá como um tradutor das demonstrações contábeis.

Segundo Padoveze (2010), a controladoria é responsável pelo sistema de informações contábil gerencial da empresa, e tem como missão assegurar o resultado da companhia. Por tanto ela deve, atuar fortemente em todas as etapas do processo de gestão da empresa. E além das funções gerenciais, deve assumir as funções regulatórias, normalmente vinculadas aos aspectos contábeis societários e de legislação fiscal. De acordo com Koliver (2005), a Controladoria consiste em um corpo de princípios e conhecimentos referentes a gestão econômica. Pode ser considerada sob dois enfoques: (1) Como instrumento administrativo com uma missão, função e princípios norteadores eterminados no modelo de gestão do sistema da empresa; e (2) como um campo de conhecimento humano com fundamentos, conceitos, princípios e métodos originados de outras ciências. Para Oliveira et. al (2011), a função da Controladoria é auxiliar as diversas gestões da empresa, abastecendo mensuração das escolhas econômicas e, por meio da visão sistêmica, unificar informações e reportá-las para facilitar o processo decisório. Perante essa informação, pode-se afirmar que o controller exerce influencia na organização à medida que orienta os gestores para que conservem sua eficácia e da organização.

As responsabilidades e as atividades básicas da Controladoria incluem planejamento, controle e avaliação de desempenho, elaboração e interpretação das informações, a contabilidade em geral e outras atividades que implicam no desempenho empresarial. Para Catelli (2001) a Controladoria enquanto ramo de conhecimento, apoiada na Teoria da Contabilidade e numa visão multidisciplinar, é responsável pelo estabelecimento das bases teóricas e conceituais necessárias para a modelagem, construção e manutenção de sistema de informação e Modelos de Gestão Econômico, que supram adequadamente as necessidades informativas dos Gestores e os induzem durante o processo de gestão, quando requerido, a tomarem decisões ótimas. A Controladoria é um segmento que pode ser exercido em várias áreas e principalmente pela contabilidade, tudo dependerá da visão dos tomadores de decisões, e do enfoque dado pelos gestores e responsáveis pelo suprimento das informações. De acordo com Figueredo e Caggiano (2008), a Controladoria pode ser conceituada como o conjunto de princípios, procedimentos e métodos oriundos das ciências de Administração, Economia, Psicologia, Estatística e principalmente da Contabilidade, que se ocupam da gestão Econômica das empresas, com o fim de orientá-las para eficácia.

Segundo Oliveira et. al (2011), entende-se por Controladoria como o setor responsável pelo projeto, preparação, implementação e sustentação do sistema integrado de informações operacionais, financeiras e contábeis de determinada entidade, com ou sem finalidades lucrativas, sendo avaliada por muitos autores o atual estágio evolutivo da Contabilidade. Quando se fala em sistema integrado de informações não podemos nos distanciar de um sistema de informações bem estruturado, de forma que seja capaz de responder sobre receitas, despesas, sobre o patrimônio econômico, financeiro, social e outros. Catelli (2001), afirma que a Controladoria vista como unidade administrativa é responsável pela coordenação e disseminação da tecnologia da gestão (teoria, conceitos, sistemas de informações) e também como órgão que reúne esforços dos demais gestores para conduzirem à otimização do resultado global da organização.

De acordo com Nascimento e Reginato (2010), a constituição do controle organizacional está vinculada à capacidade da alta administração da empresa de reunir suas áreas e os gerentes em volta de um único objetivo, com o intuito de facilitar a gestão da empresa a partir do monitoramento e acompanhamento dos desempenhos desses profissionais, investigando e diagnosticando as razões para que os eventuais desvios ocorram entre os resultados e perspectivas esperadas. Garcia (2010) apresenta: a Controladoria como o setor responsável pela preparação e excursão de um sistema integrado de informações operacionais e financeiras para, a partir das demonstrações contábeis e baseadas em uma estrutura adequada de controles internos, suprir os gestores com instrumentos de análise e controle gerencial, permitindo o alcance das metas organizacionais impostas pela administração. Segundo Catelli (2001), a Controladoria é uma área coordenadora das informações sobre gestão econômica; entretanto ela não substitui a responsabilidade dos gestores por seus resultados obtidos, mas busca aconselha-los à otimização do 
resultado econômico.

Entende-se que a Controladoria coordena o processo de planejamento das diversas áreas e atividades organizacionais, através de um sistema de informações que apoia todas as fases do processo decisório, para facilitar a ação dos gestores em suas rotinas de tomada de decisões. Oliveira et. al (2011) considera que a Controladoria pode ser compreendida como o departamento responsável, pelo projeto elaboração, excursão e manutenção do sistema integrado das informações operacionais, contábeis e financeiras de certa entidade, com ou sem finalidades lucrativas, sendo considerada por muitos autores como o atual estágio evolutivo da Contabilidade. Ademais Catelli (2001, p.348) reforça que "É Responsabilidade da Controladoria ser a indutora dos gestores, para à melhora das decisões, pois a atuação envolve implementar um conjunto de ações cujos produtos materializam-se em instrumentos disponibilizados aos gestores". Por fim, Garcia (2010) refroça que a Controladoria não necessita somente das informações contábeis, mas também das informações geradas pelos diversos gestores da empresa, tornando assim a contabilidade totalmente condicionada às ações dos profissionais que ocupam outras gerencias da empresa.

Diante dos posicionamentos dos autores pode-se compreender que as empresas são compostas por dados inter-relacionados, que trabalham unidos, com objetivos determinados, formando assim um sistema de informação. Desta forma, não se considera um sistema de informação, onde as partes trabalham separadas, pois é a simples agregação de suas partes, as conecções e interações entre os seus elementos que o competem.

\subsection{FUNÇ̃̃ES DA CONTROLADORIA}

De acordo com Nascimento e Reginato (2010), podemos justificar que a Controladoria tem como função primordial o controle, o planejamento e o orçamento, o seu principal papel, é por meio de informações, assessorar, orientar investigar e diagnosticar as razões para as ocorrências de eventuais desvios entre os resultados alcançados e os esperados, indicando as correções quando necessário, apontando as melhores opções para as tomadas de decisões nos diversos segmentos e departamentos de uma instituição, contribuindo para o fortalecimento dos controles internos dos custos, otimização de recursos e ampliação de sua capacidade de investimento e principalmente colocar em prática o princípio contábil da continuidade, assegurando bons resultados para a empresa.

De acordo com Coronado (2006, p.24), "É tarefa da Controladoria desenvolver procedimentos de conciliação para efeito de utilização pelos usuários, tais como: planos de contas, normas e procedimentos, critérios de rateios, etc". Dessa maneira, Figueredo e Caggiano (2008) fundamentam que o papel da Controladoria como órgão administrativo é zelar pelo bom desempenho da empresa, administrando as sinergias existentes entre as áreas em busca de maior grau de eficácia empresarial - ou seja, "A controladoria tem por finalidade garantir informações adequadas ao processo decisório, colaborando com os gestores na busca da eficácia gerencial" (FIGUEREDO; CAGGIANO, 2008, p.11).

A função da Controladoria é promover a conexão entre as áreas da empresa, por meio do fornecimento de dados que facilitam a otimização da gestão e a eficácia dos recursos. De acordo com Oliveira et. al (2011) a Controladoria assume o papel de observar e controlar a cúlupa administrativa, preocupando-se constantemente com a avaliação de eficácia e eficiência dos vários departamentos no exercício de suas atividades. Portanto, ela acaba por fornecer os dados e as informações planejadas e pesquisadas, buscando sempre mostrar a essa mesma cúpula os pontos de estrangulamento presentes e futuros que põem em perigo ou reduzem a rentabilidade da empresa.

Catelli (2001) enfatiza que: na Controladoria suas funções estão ligadas a um conjunto de objetivos decorrentes da missão e, quando desempenhadas, viabilizam o processo de gestão econômica. As funções desempenhadas são: (a) subsidiar o processo de gestão, (ajudar na adequação do processo à realidade da empresa, monitorando o processo de elaboração do orçamento, e respectiva consolidação, nas diversas áreas de responsabilidade da empresa). (b) apoiar a avaliação de desempenho, (elaborando a análise econômica das áreas, a análise de desempenho dos gestores, análise de desempenho econômico da empresa, avaliar o desempenho da própria área). (c) apoiar a avaliação de resultado, (elaborando a análise de resultado econômico dos produtos e serviços, monitorando e orientando o processo de estabelecimento de padrões, avaliando o resultado de seus serviços). (d) gerir os sistemas de informações, (definindo a base de dados que permita a organização da informação necessária a gestão, elaborando modelos de decisão para os diversos eventos econômicos, padronizando e harmonizando o conjunto de informações econômicas. (e) atender aos agentes do mercado, (analisando e mensurando o impacto das 
legislações no resultado econômico da empresa).

A Controladoria afeta tudo o que é essencial para uma organização ou unidades de negócio, para cultivar sua capacidade competitiva e aumentar suas vantagens em relação aos concorrentes. A Controladoria tem como foco os resultados empresariais e avalia a eficácia da empresa através dos resultados periódicos obtidos. Garcia (2010) sugere que os resultados obtidos reflitam as decisões de investimento tomadas, e, consequentemente, a controladoria assume o papel de avaliar o desempenho das decisões tomadas. Dessa maneira, entende-se, principalmente, que o objeto da Controladoria é o estudo e a prática das funções de planejamento, controle, registro e divulgação dos fenômenos da administração econômica financeira das empresas em geral (OLIVEIRA et al., 2011). Portanto, cabe a Controladoria otimizar os resultados econômicos da empresa, por meio da definição de um modelo de informações baseado na estrutura organizacional e no modelo de gestão definido pela empresa, assessorando, fornecendo mensurações sobre as alternativas do negócio utilizando para isso dados confiáveis com o objetivo de subsidiar as tomadas de decisões geradas com visão sistêmica e integradora.

\subsection{CONTROLLER}

O "Controller" é um profissional que analisa os números, informações contábeis e operacionais reunindo todas as informações quantitativas necessárias, como, rentabilidade, taxas, investimentos, resgates, despesas, captação, empréstimos, riscos, etc. Ele tem pleno conhecimento da vida financeira da empresa. De uma forma geral, a função do controller é de orientar as diversas áreas no sentido de que todos se comprometam com os resultados e com os objetivos da organização. 0 controller é o chefe da contabilidade, aquele que supervisiona e mantém os arquivos financeiros formais da empresa, embora suas funções não tenham que restringir apenas as funções contábeis e o que mais se espera é que ele amplie sua atuação ao desenvolvimento da contabilidade em aplicações gerenciais. (FIGUEREDO; CAGGIANO, 2008).

De acordo com Figueredo e Caggiano (2008), o Controller é o Gestor encarregado do departamento de Controladoria; seu papel é, por meio do gerenciamento de um eficiente sistema de informações, zelar pela continuidade da empresa, viabilizando as sinergias existentes, fazendo com que as atividades desenvolvidas conjuntamente alcancem resultados superiores aos que alcançariam se trabalhassem independentemente. Ainda de acordo com Figueredo e Caggiano (2008), o profissional da Controladoria precisa ter algumas habilidades para conseguir exercer a profissão, podemos citar o conhecimento profundo ao ramo de atividade da empresa; habilidades para analisar os dados contábeis e estatísticos, ter facilidade para se expressar bem, tanto oralmente como por escrito e profundo conhecimento dos princípios contábeis e das implicações fiscais que afetam o resultado empresarial. 0 controller tem papel preponderante no auxílio aos gestores da empresa na implantação das melhores práticas de controle, até mesmo porque ele tem interesse que tais controles sejam exercidos da melhor maneira possível, para garantir as informações com integridade, que por sua vez, alimentarão a contabilidade. (GARCIA, 2010). Já para Oliveira et. al (2011), o moderno controller deve ter uma visão proativa, capacidade de prever os problemas que poderão surgir, ser mantenedor das informações necessárias para as tomadas de decisões, fornecer as informações específicas a cada usuário e prepará-las na linguagem do executivo que as recebe, elaborar relatórios da forma mais rápida possível, gerando informações atualizadas e confiáveis e ser imparcial e justo em suas críticas e comentários. 
Diante dessas afirmações podemos discorrer que o Controller exerce influência à organização à medida que norteia os gestores para que mantenham sua eficácia e a da organização. Garcia (2010) enfatiza alguns requisitos, que o mercado de trabalho exige para um controller: (a) elaboração do planejamento financeiro; (b) confecção de relatórios gerenciais visando dar suporte à diretoria para a tomada de decisões; (c) revisão e implementação de processo de controles; (d) controle, análise e consolidação dos relatórios financeiros mensais; (e) coordenação do planejamento estratégico, construção de cenários econômicos e análise competitiva; e (f) análise de viabilidade econômica de projetos e investimentos. Ainda de acordo com Garcia (2010), mesmo com a aptidão de expressar claramente à administração com informações benéficas e que adicionem valor aos negócios da companhia, através de relatórios gerenciais objetivos e sucintos, o controller deverá ter o poder de influenciar os demais gestores sobre os benefícios, riscos, e as restrições na decisão de se praticarem controles internos, bem como na maneira como esses controles devem ser realizados. Diante das afirmações expostas, podemos perceber a necessidade que um controller apresenta em ser um profissional com ampla formação e de comportamento adequado para lidar com várias situações que a função lhe exige. De acordo com Padoveze (2010, p.36): “O papel do controller é o de monitoramento do plano de ação da empresa, fazendo a avaliação coordenada da atuação de todos os gestores, sempre com o foco no desempenho e nos resultados, global e setorial". 0 controller atua como um influenciador junto aos gestores, para ajuda-los nas tomadas de decisões, ele monitora o planejamento no sentido de procurar alcançar as metas da empresa. Após explicação identificamos que a Controladoria é a área que implanta e acompanha, regula os sistemas de controle proporcionando ao usuário da informação contábil a transparência das informações para a tomada de decisões.

\subsection{TOMADA DE DECISÃO}

De acordo com Caravantes et. al (2010), o processo de tomada de decisões vincula-se mais estreitamente ao planejamento, uma vez que todo planejamento envolve tomar decisões. Na realidade só se planeja com um objetivo: aprimorar o processo decisório. Podemos assegurar então, que tomada de decisão é uma escolha que temos que fazer quando nos defrontamos com múltiplas alternativas, ou diversas opções num curso de ação. Segundo Robbins (1999) a Tomada de Decisão ocorre como uma reação a um problema. Isto é, existe uma discrepância entre alguns estados de coisas atuais e algum estado desejado, demandando considerações de cursos alternativos de ação. Para Caravantes et. al (2010), tomar decisões é o método de indicar uma alternativa entre várias. Logo, quando gerentes tomam decisões, eles adaptam uma série de escolhas potencialmente viáveis e sugerem aquela que esperam ser a melhor em particular para a circunstância. Tomada de decisão e resolução de problemas são métodos rapidamente distintos, mas mesmo assim estão inter-relacionados. A tomada de decisão fundamenta o trabalho de um administrador. De fato, administrar toma muitas decisões sobre os mais diversos assuntos, diariamente, e a qualidade dessas decisões tem impacto muito significativo no desempenho da organização. Ante o exposto, a tomada de decisão não é um processo trivial e fácil já que cada alternativa de decisão está diretamente associada à incerteza de suas consequências e impactos. (SOBRAL, 2008).

Guimarães e Évora (2004) apontam, a tomada de decisão é analisada como a função que caracteriza a atuação da gerência. Independentemente do aspecto da decisão, este modo deve ser produto de um processo sistematizado, que abrange o estudo do problema a partir de um levantamento de dados, produção de informação, estabelecimento de propostas de soluções, escolha da decisão, viabilização e implementação da decisão e análise dos resultados obtidos. Para que o processo de tomada de decisão seja utilizado da melhor forma, com mais aproveitamento e resultado é necessário determinar metas, os objetivos a serem alcançados e depois as ações relevantes para quem tomará a decisão. Para Guimarães e Évora (2004), nos vários modelos de decisão estudados é possível reconhecer que a decisão nem sempre é resultado de um processo sequencial, estruturado e dirigido para uma única solução. Mas é possível afirmar que a informação é um recurso primordial para a tomada de decisão e que, quanto mais estruturado for este processo, como no caso dos modelos racionais e de processo, mais indicado se faz o uso de sistemas de informação que possam responder às demandas e necessidades informacionais do decisor.

As decisões a serem tomadas dentro de uma empresa são importantes, e são tomadas dentro de um conjunto de fatores internos e externos da empresa, para identificar várias alternativas para solucionar as dúvidas existentes. Por isso os tomadores de decisões precisam utilizar de todas as informações possíveis e cabíveis dentro da empresa, para traçar estratégias de desempenho em resistência às restrições, diminuindo a vulnerabilidade das atividades de sua equipe de trabalho. De acordo com Figueredo e Caggiano (2008), a informação é o componente básico das decisões, e a Contabilidade é um sistema de informações especializado, de base financeira, que possibilita aos usuários alocações mais eficientes dos 
recursos sob sua responsabilidade. A contabilidade, não é, pois, um sistema que encontra finalidade em si mesmo, existe para os tomadores de decisões a utilizarem. 0 ponto fundamental que se destaca aqui é que as atividades contábeis (coleta, processamento e comunicação da informação) devem estar voltadas aos interesses do usuário e de suas decisões. Para tanto, Angeloni (2002) afirma que não há uma fórmula certa para a tomada de decisões corretas na empresa. Na organização tradicional, as decisões são tomadas por um grupo que se perpetuam no poder através de um amplo processo de alianças, provocando distanciamento do macro objetivo e perda de informação. Um elemento essencial para este processo de tomada de decisões é a expectativa de um comportamento individual maduro, tanto social quanto moral. Com efeito Oliveira et. al (2011, p.10) destacam que "O processo decisório é influenciado pela atuação da controladoria por meio das informações de planejamento e controle". É importante que o processo de tomada de decisão esteja em perfeita harmonia com o processo de gestão, que os resultados esperados de uma tomada de decisão estejam de acordo com os resultados planejados pela empresa.

\subsection{CONCEITOS DE STAFF}

Staff são órgãos de assessoria e ligam-se indiretamente aos objetivos básicos da organização através dos setores de linha e sua autoridade é apenas funcional. Conforme Fayol (2000), os órgãos de staff não possuem autoridade de cargo conferido pela estrutura organizacional. Mas para entender o que é staff precisamos entender o que é setor de linha, que também segundo Fayol são os órgãos responsáveis pelo alcance dos objetivos básicos da organização, possuindo autoridade pela posição ocupada na estrutura organizacional. 0 setor de staff não possui autoridade de comando em relação aos setores de linha. Sua autoridade, chamada autoridade de staff, é autoridade de especialista e não autoridade de comando. Autoridade de staff é a forma de autoridade atribuída aos especialistas de staff em suas áreas de atuação e de prestação de serviços. A autoridade de staff é mais estreita e inclui o direito de aconselhar, recomendar e orientar. A autoridade de staff é uma relação de comunicação. Os especialistas de staff aconselham os gerentes em suas áreas de especialidade.

\subsection{OS SUBSISTEMAS DO SISTEMA DE INFORMAÇÃO CONTÁBIL}

Para que a controladoria tenha um bom desempenho se faz essencial um eficaz sistema de informação. "O Sistema de Informação Contábil, é o meio que o contador gerencial ou controller utilizarão para efetivar a Contabilidade e a informação contábil dentro da organização, para que a Contabilidade seja utilizada em toda a sua plenitude". (PADOVEZE, 2010). A Controladoria trabalha basicamente com informações, e para que se tenham esses subsídios com precisão, ela necessita de se aliar a um sistema de informações, para que possam unir e integrar todos os subsistemas componentes dos sistemas operacionais da empresa. A base para elaboração de um sistema de informações contábil é necessariamente focada nos conhecimentos contábeis, e todas essas informações devem ser Úteis à administração, para que possam dar suporte aos tomadores de decisões.

\subsection{MUDANÇA ORGANIZACIONAL}

Atualmente a Companhia de Água e Esgoto do Ceará, transcorre por uma mudança organizacional, em que a Controladoria está inserida nesse processo de mudança. De acordo com Rodrigues et. al (2010, p.8), “0 processo de mudança organizacional pode incidir sobre vários aspectos, nomeadamente sobre a estrutura, as tarefas, a tecnologia, a reengenharia, os comportamentos, a cultura e os produtos ou serviços.".

Podemos dizer que a mudança organizacional, não é originada por um único fator, ou seja, ela pode ser ocasionada por diversos fatores, de acordo com a visão a qual se pretende mudar, pode ser levado em consideração, até os fatores externos da organização. Segundo Kisil (2002, p.15), "No processo de Mudança Organizacional cada membro da organização deve obrigatoriamente ser envolvido. Gerentes, supervisores ou chefes de equipe são chamados para liderar e conduzir algum aspecto do processo". A mudança organizacional abrange toda a organização, geralmente ocorrem às mudanças pela necessidade que a empresa "sente" em criar um diferencial, na procura de maximizar a qualidade de seus produtos ou serviços. Com a visão de maximizar seus serviços a CAGECE, mudou toda a sua composição organizacional, que pode ser evidenciada no estudo de caso a seguir descrito. 


\section{METODOLOGIA}

O paradigma epistemológico utilizado foi o Interpretativismo, devido à pesquisa ter buscado dados na realidade estudada, ter analisado e interpretado esses, validando ou rejeitando a hipótese levantada.

Para a classificação desse estudo, toma-se, inicialmente, como base a taxionomia de Vergara (2007), que classifica a pesquisa em relação a dois aspectos: quantos aos fins e quanto aos meios. Quanto aos fins, a pesquisa é exploratória e descritiva. Exploratória, porque investiga de forma incipiente aspectos relacionados à importância da Controladoria no contexto de uma empresa de economia mista, no contexto específico da Companhia de Água e Esgoto do Ceará. Descritiva, porque visa identificar como as informações da Controladoria são úteis para auxiliar os administradores nas tomadas de decisões, descrevendo a posição da Controladoria no organograma da Companhia e explorando aspectos ressaltados como críticos, tais como as correções de possíveis deficiências nas informaç̧ões colhidas.

Quanto aos meios, a pesquisa é bibliográfica, uma vez que se apóia no levantamento da literatura pertinente junto a livros, dissertações, periódicos e anais de eventos, tendo sido realizada por meio de estudo de caso. É, também, documental, dado que se fundamenta, parcialmente, em dados obtidos no Relatório Anual (2012), em atas de reuniões do Conselho de Administração (2012-2013), etc. É, em especial, uma pesquisa telematizada, pois utiliza prioritariamente, dados e informações coletados diretamente da intranet e do website oficial da empresa.

Ressalta-se que, adicionalmente, foi realizada uma visita técnica à empresa, ocasião em que se fez entrevistas, não estruturada, com seus gestores seniores, abordando-se questões relativas à gestão e a tomada de decisão, temas que constituem, em grande parte, o foco desse trabalho. Quanto à natureza dos dados, a pesquisa configura-se como qualitativa. A escolha de uma pesquisa qualitativa implica estabelecer, a priori, que o resultado final não se volta para a generalização, mas para a compreensão de uma dada realidade, sob uma determinada perspectiva.

A relevância deste estudo está na aplicação da controladoria na gestão das organizações e na identificação de sua importância para a tomada de decisões, observadas por meio do estudo de caso na Cagece, uma empresa de economia mista com atuação em 149 municípios dos 184 que compõem o Estado do Ceará.

\subsection{ESTUDO DE CASO: A COMPANHIA DE ÁGUA E ESGOTO DO CEARÁ (CAGECE)}

A CAGECE é uma sociedade de economia mista, criada pela Lei № 9.499, de 20 de julho de 1971, vinculada diretamente à Secretaria das Cidades, e faz parte da administração indireta do Governo do Estado do Ceará, ela tem como finalidade a prestação dos serviços de abastecimento de água e esgotamento sanitário em todo o Estado. Ficando delegada a companhia as atividades de planejar, projetar, executar, ampliar, manter e explorar industrialmente os sistemas de água e esgoto. Fixar e arrecadar tarifas, proveniente dos serviços prestados, promovendo reajustamentos periódicos de modo que atenda à cobertura da amortização dos investimentos, custo de operação e manutenção e acumulo de reservas para expansão dos sistemas. Realizar outras atividades que, direta ou indiretamente, explicita ou explicitamente, digam com os seus objetivos.

A Lei № 9.499, de 20 de julho de 1971, que trata da criação da CAGECE, foi reformulada no dia 02 de maio de 2013, por meio da Lei $n^{\circ} 15.348$, seu novo texto aborda a autorização para geração e comercialização de energia, para si ou para terceiros, derivada ou não do aproveitamento de subprodutos dos processos relacionados aos serviços de saneamento. Também foi autorizada a realização, mediante pregão ou concorrência, no que couber, chamamento público para a seleção de interessados na constituição de parcerias e empreendimentos no âmbito do seu objeto social, por meio da constituição de Sociedade de propósito específica ou outra forma jurídica, para o cumprimento desses objetivos. 
Ainda de acordo com a Lei № 9.499, fica o Estado do Ceará autorizado a firmar Convênios de Cooperação com outros entes públicos, para a gestão associada de serviços públicos de saneamento básico, independentemente de estarem tais entes em microrregiões, aglomerados urbanos ou regiões metropolitanas instituídas no âmbito do Estado do Ceará, ficando a Companhia de Água e Esgoto do Ceará incumbido da execução dos serviços delegados por meio de Contrato de Programa. A transferência de encargos, serviços, pessoal e bens necessários à prestação dos serviços, bem como os aspectos econômicos e técnicos da delegação, serão disciplinados no próprio Convênio de Cooperação e Contrato de Programa, respeitada a legislação respectiva. Embasada na reformulação dessa lei, a Companhia acrescentou seus serviços, passando agora a operar, além de água e esgoto, os serviços de drenagem e resíduos sólidos.

Diante das alterações perpetradas a lei de criação da CAGECE, a alta administração da companhia determinou o acréscimo nos seus serviços, antes do dia 02 de maio de 2013, a companhia só prestava serviços de água e esgoto, sendo que de agora em diante a empresa passará a trabalhar também com drenagem e resíduos sólidos. A Companhia tem como missão contribuir para a melhoria da saúde e qualidade de vida, provendo soluções em saneamento básico, com sustentabilidade econômica, social e ambiental. Sua visão é estar entre as três melhores empresas no seu setor de atuação, com gestão focada no cliente e na contínua transformação para sustentabilidade e competitividade. 0 objetivo do seu negócio é o desenvolvimento de soluções em saneamento básico. Os clientes direcionados são pessoas físicas, entidades comerciais e industriais, organizações não governamentais e órgãos públicos. Os Valores expressam os princípios e convicções que orientam o relacionamento da CAGECE com seus clientes, fornecedores, funcionários, acionista, parceiros, concorrentes, governo e sociedade. E por fim tem como estratégia o desenvolvimento e crescimento de mercado com sustentabilidade econômico-financeiro e excelência operacional.

\subsection{A CONTROLADORIA NA CAGECE}

Por ser uma sociedade de economia mista e sendo o governo do estado controlador com um percentual de 85,65\% de suas ações, a alta administração da companhia pode vir passar por mudanças, essas geralmente acontecem no intervalo de tempo de quatro anos. Observou-se que no inicio do ano de 2013 houve mudanças consideráveis na estrutura organizacional da empresa, em consequência a essas mudanças o organograma da companhia sofreu modificações, aconteceu então uma diminuição na quantidade de gerencias e a criação de coordenações. Essas mudanças refletiram diretamente na Controladoria da Companhia. Segundo Nascimento e Reginato, (2010) abrange como construção do controle organizacional a conexão ligada à capacidade da alta administração da empresa de agrupar suas áreas e os gerentes em volta de um único objetivo, com o intuito de promover a gestão da empresa a partir do monitoramento e acompanhamento das atuações desses profissionais, averiguando e diagnosticando as razões para os eventuais desvios ocorram entre os resultados e perspectivas esperadas. No modelo anterior a Controladoria da empresa estava alocada na Gerência de controladoria da CAGECE (GCONT), a qual tinha como missão planejar, controlar e organizar as atividades contábeis, econômicas, orçamentárias, operacionais e patrimoniais, visando disponibilizar informações que possibilitem aos gestores e órgãos fiscalizadores a avaliação sistemática do desempenho da CAGECE, suas atribuições eram organizar e reportar dados e informações contábeis, gerenciais e estratégicas para os tomadores de decisão; Manter monitoramento permanente sobre os controles internos, no âmbito contábil, econômico, orçamentário, gerencial e fiscal das diversas atividades da organização; Assegurar a otimização do resultado econômico da organização; Controlar e elaborar demonstrativos financeiros de todos os registros contábeis; Elaborar e monitorar o planejamento fiscal e tributário, apurar e calcular tributos; Treinar as áreas de negócios da Companhia quanto às análises gerenciais e estratégicas.

A gerência mantinha relação direta com a diretoria da presidência, conselho fiscal, conselho de administração e todas as unidades organizacionais da CAGECE, cabia a GCONT dá suporte e mantê-las informadas. A gerencia de controladoria também tinha por obrigação repassar informações para alguns órgão, como por exemplo: Comissão de Valores Mobiliários (CVM) Governo do Estado; Prefeitura Municipal; Junta Comercial do Estado do Ceará (JUCEC) Secretaria de Controladoria (SECON); Agências Reguladoras do Estado do Ceará; Associação das Empresas de Saneamento Básico Estadual (AESBE) Demais instituições envolvidas nos assuntos pertinentes em seu campo de atuação. 
E dá suporte aos auditores Independentes. A GCONT se dividia em três supervisões: Supervisão de Informações Gerenciais; Supervisão de análise e controles contábeis; Supervisão de Controles Fiscais e Tributários. Cada supervisão tinha uma área contábil de atuação, ficando a primeira com atriobuições ligadas à área de controladoria e as demais com atribuições contábeis e ficais.

\subsection{SUPERVISÃO DE INFORMAÇÕES GERENCIAIS}

A controladoria da CAGECE de fato era realizada nessa supervisão, o fornecimento de todas as informações demandadas pelos órgãos externos e internos da Companhia, as informações para subsidiar os gestores da CAGECE nas tomadas de decisões, eram fornecidas pela supervisão de informações gerenciais. A qual tinha como principais atribuições: Mensalmente, a Companhia realizava um encontro dos coordenadores das unidades de negócios da CAGECE, a supervisão tinha como atribuições orientar os gestores das unidades de negócios e serviços quanto à correta análise dos indicadores econômicos financeiros, sempre com a maior integridade e transparência e tomando como base as informações disponibilizadas no módulo de contabilidade gerencial do ERP e na DRE gerencial regulatória do sistema empresarial de informações (SEI); Também mensalmente, a supervisão de informações gerenciais tinha a obrigação de analisar o resultado corporativo e por unidade de negócio e unidade de serviço para emissão de relatórios de críticas e sugestões e fazia comparativos do realizado com o orçamento; Com base nas análises realizadas mensalmente era elaborado o comentário de desempenho, era nesse comentário onde eram abordados os dados financeiros de cada unidade da companhia. Cabia a GCONT quando julgasse necessário propor melhorias nos modelos de análises das informações contábeis e estratégicas e na integração dos demais sistemas com o sistema contábil; Sempre que requisitada a supervisão devia fornecer subsídios de análises contábeis e estratégicas aos gestores para elaboração do planejamento do demonstrativo de resultado da companhia; Era elaborado o Relatório de Desempenho de Gestão que tinha como objetivo demonstrar a aplicação dos recursos utilizados e os resultados obtidos, dentro da conformidade das leis, regulamentos e normas emanadas das autoridades administrativas competentes. No relatório continha as seguintes informações: desempenho operacional; recursos orçamentário e financeiro; recursos patrimoniais; recursos humanos; tecnologia de informações; recursos materiais, infraestrutura de veículos; relacionamento com os clientes e mercado; diretrizes, politicas e plano de governo; expansão dos serviços, avaliação do desempenho da execução do programa de governo; indicadores de gestão.

A supervisão tinha por obrigação diariamente planejar, elaborar, controlar e monitorar a realização da projeção do demonstrativo de resultado da companhia; ainda era atividades da supervisão, acompanhar e monitorar as análises comparativas dos principais desvios das receitas, dos custos e das despesas em relação ao projetado e ao histórico e emitir recomendações preventivas para evitar distorções nos resultados da companhia; A mais complexa atribuição da supervisão era disponibilizar relatórios de acompanhamento da execução do demonstrativo de resultado projetado para subsidiar as decisões dos gestores, esses relatórios pode-se dizer que eram a unificação de todas as informações da gerência; acompanhava os indicadores de desempenho negociados com os órgãos financiadores, bem como elaborava outros relatórios solicitados pelos mesmos; Elaborava as demonstrações financeiras (DF's), anualmente e trimestralmente (ITR) informações trimestrais que é abordava toda a posição financeira da empresa, nela continha o planejamento estratégico, como se encontrava no mercado, era abordado um comparativo da clientela; o faturamento; o desempenho operacional; o fornecimento da matéria prima no caso a água; receita bruta; gestão de pessoas; os projetos e programas de responsabilidade social; o balanço patrimonial; a demonstração do resultado; demonstração das mutações do patrimônio liquido; demonstração do fluxo de caixa; demonstração do valor adicionado; e as notas explicativas. Essas informações eram exibidas na intranet e no portal da CAGECE, a cada trimestre, eram disponibilizados os ITR's e ao final de cada ano era elaborado as demonstrações financeiras; sempre que eram disponibilizadas novas informações, a supervisão de informações gerenciais precisava atualizar da página da GCONT na intranet e na internet; ainda era responsabilidade da supervisão, diariamente monitorar a importação dos dados gerados nos demais sistemas da companhia para o sistema contábil e analisá-los através da DRE gerencial regulatória no sistema empresarial de informações (SEI).

A supervisão atualizava mensalmente os Boletins de Informações, o Boletim de Informações Mensais (BIM), nele contém os dados físicos, os dados financeiros os indicadores, e as informações contábeis, o Boletim de Informações Gerenciais (BIG) nesse boletim eram repassadas as informações econômicas, financeiras e informações gerais; E com base nos dados dos BIM's e BIG's, anualmente era atualizado o boletim de informações anual, que continham as informações físicas e financeiras; Sempre que aconteciam modificações no sistema ou nos modos como fazer nas análises, cabia à supervisão treinar as 
unidades de negócio e unidades de serviço quanto às análises gerenciais e estratégicas; também era atribuição da supervisão de informações gerenciais, enviar anualmente informações relevantes para entidades externas, entre essas entidades destacam-se, informações para associações, revistas e premiações, entre elas podemos citar: Associação das Empresas de Saneamento Básico (AESB) são elaborados relatórios, e nesses são requisitadas informações econômico-financeiro; Revista Dinheiro era coletada informações nas áreas de sustentabilidade financeira, recursos humanos, inovação e qualidade, responsabilidade social e meio ambiente, governança corporativa, essas informações eram repassadas para a obtenção de ranking em cada indicador e no setor de atuação; Revista Melhores e Maiores, as informações, para essa revista eram disponibilizados dados sobre o número de empregados, receita líquida (mercado interno e mercado externo), salários mais encargos sociais; Prêmio Delmiro Gouveia é uma premiação que é oferecida as empresas cearenses, nos setores econômico e social. Também anualmente era elaborado o relatório da administração, esse documento era organizado para apresentar aos clientes e acionistas uma visão geral dos resultados alcançados, abrangendo demonstrações financeiras, com respectivos pareceres de auditores, conselho fiscal e administrativo, além de temas relacionados aos gerenciamentos estratégicos corporativo, operacionais, econômico-financeiros e voltados à responsabilidade sócia ambiental. Preenchimento do formulário de referência, esse era feito anualmente. O Formulário de Referência era o principal e mais completo informe de comunicação e de prestação de contas da companhia a todos os públicos alvos, uma vez que nele estavam reunidas informações relevantes para a compreensão e avaliação da companhia e dos valores mobiliários por ela emitidos, tais como, atividades desenvolvidas, estrutura de controle, fatores de risco, dados econômicofinanceiros, comentários dos administradores sobre o desempenho, políticas e práticas de governança corporativa e descrição da composição e da remuneração de sua administração. Preenchimento do Sistema Nacional de Informações sobre Saneamento (SNIS). Esse formulário também preenchido anualmente é de bastante importância para a Companhia, pois é com base nessas informações em que a CAGECE tem acesso a recursos de investimento em Programas do Ministério das Cidades. A realização desse trabalho demandava bastante tempo, pois as informações são solicitadas a diversas áreas que por sua vez consolidavam as informações conforme descrições enviadas pela GCONT. Essas informações ainda eram trabalhadas para atender a especificações técnicas de preenchimento no programa.

Tendo em vista que a Controladoria é realizada basicamente de informações, e que ela necessita se coligar a um bom sistema de informações para a Gerência, buscando o aperfeiçoamento implantou dois fundamentais bancos de dados que são as suas principais ferramentas de trabalho. A Cagece utiliza o Enterprise Resource Planning (ERP), onde são geradas todos as informações, tanto o que se refere ao contábil, quanto os lançamentos fiscais e o Sistema Empresarial de Informações (SEI), que é basicamente a conexão de todas as informações, é no SEI onde estão disponibilizadas as Demonstração do Resultado (DR's). Com base nessas informações eram feitas todas as análises, os preenchimentos de formulários, os relatórios, enfim todas as atividades da supervisão de informações gerenciais de acordo como já foi citado nesse trabalho. Podemos então a mencionar que a GCONT, atuou de acordo com os ensinamentos de Padoveze (2010) onde ele menciona que "O Sistema de Informação Contábil, é o meio que o contador gerencial ou controller utilizarão para efetivar a Contabilidade e a informação contábil dentro da organização, para que a Contabilidade seja utilizada em toda a sua plenitude".

Recentemente a Companhia de Água e Esgoto do Ceará passou por uma mudança organizacional e todo o seu organograma foi mudado, foram criadas coordenações e extintas gerências. Essa mudança se deu de acordo com a resolução 027/13, a partir do dia 06 de maio de 2013, a estrutura organizacional na CAGECE mudou, a controladoria passou a ter um novo posicionamento, anteriormente, a controladoria estava ligada à Diretoria de Gestão Empresarial (DGE), na posição de supervisdão, depois da mudança a controladoria passou a fazer parte da Diretoria de Planejamento e Controle (DPC), em uma coordenação denominada Coordenação de Gestão de Informações subordinada à Gerência de Estudos Estratégicos e Orçamento (GESOR), centralizando todas as informações a serem remetidas para os órgãos de controle e demais entidades de acordo com o banco de dados da Companhia, evitando com isso distorções na leitura dos dados publicados pela Companhia, isso demonstra que o controle e o tratamento dos dados são realizados por uma equipe de profissionais qualificados e atualidos com as exigências do mercado. De acordo com as mudanças enfatizadas podemos mencionar Rodrigues et. al $(2010$, p.08) que ressalta "O processo de mudança organizacional pode incidir sobre vários aspectos, nomeadamente sobre a estrutura, as tarefas, a tecnologia, a reengenharia, os comportamentos, a cultura e os produtos ou serviços". 0 novo organograma, demonstra com detalhes as mudanças ocorridas, a partir de então a controladoria vai ser realizada dentro de uma nova gerência a GESOR. Na reestruração ocorrida, a Cagece fortificou a controladoria contemplando-a numa posição mais elevada que a anteriormente era exercida, ou seja, houve a migração da Supervisão de Informações Gerenciais para a Coordenação de Gestão de Informações, 
embora sua posição atual seja divergente com a literatura a qual recomendada por Fayol que trata a controladoria com a posição de Staff. De acordo com Fayol (2000), a autoridade de staff é mais estreita e inclui o direito de aconselhar, recomendar e orientar. A autoridade de staff é uma relação de comunicação. Os especialistas de staff aconselham os gerentes em suas áreas de especialidade. Independente do seu posicionamento, a Coordenação de Gestão de Informações da CAGECE exerce esse papel em suas atividades, subsidiando a Diretoria e as diversas áreas da Companhia com relatórios e informações capazes de promover solidez na tomada de decisão. 0 propósito das mudanças organizacionais ocorridas no ano vigente é o aprimoramento dos seus serviços e como em toda e qualquer empresa seguir o principio da continuidade. Segundo Sá (2007, p.88), "Tal princípio baseia-se na premissa de que as demonstrações contábeis devem identificar o estado especial pelo qual a empresa passa e, não o fazendo, é de supor-se que a atividade continua normalmente e não tem intenção de paralisar". De acordo com os estudos realizados no presente trabalho houve a confirmação da hipótese: A Companhia de Água e Esgoto do Ceará (CAGECE), por meio de sua Gerência de Estudos Estratégicos e Orçamentos (GESOR), garante as informações adequadas aos processos decisórios imprescindíveis para a continuidade da entidade.

\section{CONCLUSÃO}

A Controladoria dispõe de diversos meios para realizar a sua função, e ajudar os gestores nas tomadas de decisões, um desses meios é bastante notório neste trabalho que são os sistemas de informações. Os profissionais atuantes nessa área são os Controlles, eles são, geralmente, profissionais formandos em ciências contábeis e áreas afins e estão capacitados para assumir de forma eficiente e eficaz a gestão. Esses profissionais se utilizam da tecnologia da informação produzidas por meio de relatórios, demonstrações contábeis e entre outros. Eles avaliam, planejam, implantam e acompanham as práticas que devem ser adotadas para o cumprimento das normas e da boa gestão na Companhia. Neste trabalho levantou-se o problema a respeito de como é desempenhado o papel da Controladoria na Companhia de Saneamento Básico no Ceará (CAGECE). A Controladoria na entidade pesquisada era realizada na gerência de controladoria, mais precisamente, na supervisão de informações gerenciais, de acordo com a resolução 027/13, a partir do dia 06 de maio de 2013, a estrutura organizacional na CAGECE mudou, a controladoria passou a ter um novo posicionamento, no organograma anterior a controladoria estava ligada a Diretoria de Gestão Empresarial (DGE)e após a implantação da nova resolução a controladoria passou para um novo posicionamento na empresa, ficando ligada diretamente à Diretoria de Planejamento e Controle (DPC), a nomenclatura passou de Supervisão de Informações Gerenciais para uma Coordenação de Gestão de Informação subordinada a Gerência de Estudos Estratégicos e Orçamento (GESOR), foi observado que houve um deslocamento hierárquico da controladoria passando de supervisão para Coordenação.

Os objetivos deste trabalho foram alcançados quando se apresentam os conceitos, de controladoria e a forma como ela é inserida na companhia, conceituamos também a tomada de decisão, para entendermos como realmente ela está colocada no contexto desse trabalho, ainda pesquisamos os conceitos de staff, os subsistemas do sistema de informação contábil, mudança organizacional, os quais servirão de base para entendermos como a controladoria inserida na companhia de água e esgoto do Ceará. Podemos observar que a controladoria na entidade é uma peça fundamental, pois é onde são reunidas todas as informações, para a composição dos relatórios, e são esses documentos, que embasam a alta administração na tomada de decisão. Outro fator preponderante são as análises, que são feitas com o intuito de investigar as informações exibidas, e se por acaso for detectado algum erro nos lançamentos, a gerência busca encontrar a causa. Foi demonstrado que embora a Controladoria da Cagece não esteja na função de staff que a literatura afirma ser o ponto estratégico para a localizaçãodessa área, a Controladoria da Companhia é de extrema importância nas tomadas de decisões. Também foi demonstrado que uma nova visão gerencial por meio de uma mudança organizacional pode fortificar ou enfraquecer áreas, no caso da Controladoria da Cagece, essa passou para uma posição hierárquica mais elevada, ocorrendo com isso maior grau de "poder" na Companhia. A hipótese foi confirmada, pois, é realmente, por meio de sua Gerência de Estudos Estratégicos e Orçamentos (GESOR), que as informações adequadas são garantidas aos usuários para os processos decisórios imprescindíveis para a continuidade da entidade.

\section{REFERÊNCIAS}

[1] ANGELONI, Maria Terezinha. Elementos intervenientes na tomada de decisão. 2002, Disponível em: < http://www.scielo.br/pdf/ci/v32n1/15969.pdf.>. Acesso em: 22 abr. 2013.

[2] BRASIL. Constituição da República Federativa do Brasil: Texto constitucional promulgado em 5 de outubro de 1988, com alterações adotadas pelas Emendas Constitucionais $n^{\circ}$ s $1 / 92$ a 53/2006 e pelas Emendas 
Constitucionais de Revisão ns 1 a 6/9. - Brasília: Senado Federal, Subsecretaria de Edições Técnicas, 2007.

a. LEI № 13.548, DE 20 DE DEZEMBRO DE 2004. Altera dispositivo da Lei no 9.499, de 20 de julho de 1971, que dispõe sobre a criação da Companhia de Água e Esgoto do Ceará - CAGECE, e dá outras providências. Fortaleza, 27 de dezembro de 2004.

[3] LEI № 15.348, de 02 maio de 2013. Alteram dispositivos da lei no 9.499, de 20 de julho de 1971, que dispõe sobre a criação da companhia de água e esgoto do ceará - CAGECE, e dá outras providências. Fortaleza, 02 maio de 2013.

[4] CARAVANTES, Geraldo R; CARAVANTES, Claudia B; KLOECKNER, Mônica C. Administração: teorias e práticas. São Paulo: Pearson, 2010.

[5] CATELLI, A. (Coordenador) - Controladoria: uma Abordagem de Gestão Econômica. São Paulo: Atlas, 2001. CORONADO, Osmar. Contabilidade Gerencial Básica. São Paulo: Atlas, 2006.

[6] FAYOL, Henri. A teoria Clássica da Administração. Disponível em: <

www.ftm.edu.br/aula_a./administracao/Teoria-Classica-Adm-Fayol.ppt:>. Acesso em: 20 fev. 2013.

[7] FIGUEREDO, Sandra ; CAGGIANO, Paulo Cesar. Controladoria - Teoria e Prática. São Paulo: Atlas, 2008.

[8] GARCIA, Alexandre Sanches. Introdução à controladoria: instrumento básico de controle de gestão das empresas. São Paulo: Atlas, 2010.

[9] GUIMARÃES, Eliane M. Palhano; ÉVORA, Yolanda D. Martins. Sistema de informação: instrumento para tomada de decisão no exercício da gerência. 2004. Disponível: < http://www.scielo.br/pdf/ci/v33n1/v33n1a09>. Acesso em: 22 abr. 2013

[10] KISIL, Marcos. Gestão da Mudança Organizacional. São Paulo: Fundação Peirópolis, 2002.

[11] KOLIVER, Olivio. A Contabilidade e a Controladoria, Tema Atual e a alta relevância para a profissão contábil. Porto Alegre Conselho de Contabilidade do Rio Grande do Sul, 2005. no 198, ano 2012, edição especial.

[12] MOSIMANN, Clara Pellegrinello; FISCH, Sílvio. Controladoria seu papel na administração de empresas. São Paulo: Atlas, 1999.

[13] NASCIMENTO, Auster Moreira; REgINATO Luciane. Controladoria - Instrumento de apoio ao processo decisório. São Paulo: Atlas, 2010.

[14] OLIVEIRA, Luis Martins de, PEREZ JR., José Hernandez, SILVA, Carlos Alberto dos Santos. Controladoria Estratégica. Atlas, 2011.

[15] PADOVEZE, Clóvis Luís. Contabilidade gerencial: Um enfoque em sistema de informação contábil. 5. ed. São Paulo: Atlas, 2008.

[16] RODRIGUES, Jorge Nascimento; VIEIRA Leandro; COSTA Silvia Generali da. Gestão da Mudança: explorando o comportamento organizacional. São Paulo: Atlas, 2010.

[17] SÁ, Antonio Lopes de. Princípios Fundamentais de Contabilidade. 4. ed. São Paulo: Atlas, 2007

[18] SILVA, Antônio Carlos Ribeiro. Metodologia Da Pesquisa Aplicada à Contabilidade. 2. ed. São Paulo: Atlas, 2006.

[19] CAGECE. Disponível em: < http://www.cagece.com.br/>. Acesso em: 06/05/2013.

[20] SOBRAL, Filipe; PECI, Alketa. Administração: Teoria e Prática no Contexto Brasileiro. São Paulo: Pearson Prentice-Hall, 2008.

[21] TAM, B.C.Y.: TEO,H.H.; WEI,K.K. Promoting consensus insmall decision making groups. Information \& Management, v.28, p.251-259, 1995.

[22] VERGARA, Sylvia Constant. Projeto e relatórios de pesquisa em administração. São Paulo: Atlas, 2007. 


\section{Capítulo 3}

Método de construção de carteira de investimento a partir do coeficiente de variação: Um estudo empírico no mercado de ações brasileiro

\section{Marcio Pereira Basílio}

Ricardo Bordeaux Rego

Resumo: A pesquisa objetivou testar um método alternativo de construção de carteiras de investimento. Quanto aos fins a pesquisa pode ser classificada como metodológica e quanto aos meios ex post facto. A amostra foi coletada no site da BOVESPA. Foram selecionadas informações dos ativos negociados no mercado a vista, que tiveram 100\% de participação nos 246 pregões realizados em 2015 e que possuíam número médio negócios/dia maior ou igual a 1000. 0 resultado da estratificação resultou na seleção de 115 ativos. Foram construídos três tipos de carteiras de investimentos. Após a construção das carteiras realizou-se uma simulação resultando em uma comparação na qual se constatou que em $75 \%$ dos cenários as carteiras formadas a partir do coeficiente de variação apresentaram retornos positivos em relação as demais e que em $100 \%$ dos cenários os retornos destas carteiras foram superiores ao do IBOVESPA para as condições que vigoraram em 2015.

Palavras-chave: Diversificação; coeficiente de variação; carteiras de ações; mercado de ações. 


\section{INTRODUÇÃO}

0 tema sobre diversificação de carteiras de investimento tem sido objeto de estudo a décadas, em virtude da necessidade humana de encontrar um espaço que, a priori, produza a percepção de segurança e gere na pessoa, que procura alavancar sua riqueza, um sentimento motivador a por parte ou a totalidade de seus recursos em algum tipo de investimento. É sabido que não existe investimento sem risco. 0 risco afeta tanto as pessoas quanto as empresas. Um conceito relacionado é o da incerteza, que segundo Bodie \& Merton (2002) existe sempre que não se sabe ao certo o que vai ocorrer no futuro. 0 risco é a incerteza que importa, pois afeta o bem-estar das pessoas.

Existem três métodos de transferência do risco que são: hedging, seguro e diversificação. Diversificar significa portar quantidades similares de ativos de múltiplo risco em vez de concentrar todos os investimentos em um só. Segundo Bodie \& Merton (2002:267) "a diversificação, portanto, limita sua exposição ao risco de qualquer ativo individual.

A presente pesquisa objetivou encontrar um método alternativo aos tradicionais, que com uma base computacional comum, pudesse fornecer ao pequeno investidor um caminho para construção de uma carteira de investimento baseada em ações negociadas em bolsa de valores, que lhe permitisse escolher "os melhores ovos" que comporiam sua cesta, sem ficar detido ao que o mercado lhe impulsiona. Quanto aos fins a pesquisa pode ser classificada como metodológica e quanto aos meios ex post facto. A amostra foi coletada por meio do arquivo COTAHIST.2015.xlsx obtido no site da BOVESPA. A partir dos registros neste arquivo foram selecionadas informações dos ativos negociados no mercado a vista, que tiveram 100\% de participação nos 246 pregões realizados em 2015 e que possuíam número médio negócios/dia maior ou igual a 1000. 0 resultado da estratificação resultou na seleção de 115 ativos, os quais foram estudados e utilizados na construção de três tipos de carteiras de investimentos: a primeira com inclusão aleatória de ativos na base da carteira; a segunda com a inclusão tão somente dos pares de ativos fortemente correlacionados negativamente e a terceira formada a partir da inclusão dos ativos com menor coeficiente de variação na base da carteira. Após a construção das carteiras realizou-se uma simulação com os dados da cotação de fechamento diário dos ativos no ano de 2015, resultando em uma comparação na qual se constatou que em $75 \%$ dos cenários as carteiras formadas a partir do coeficiente de variação apresentaram retornos positivos em relação as demais e que em $100 \%$ dos cenários os retornos destas carteiras foram superiores ao do IBOVESPA para as condições que vigoraram em 2015.

\section{REVISÃO DA LITERATURA}

Abordar o tema sobre o efeito da diversificação de carteira de investimento é tratar implicitamente de risco. 0 que se pretende ao agregar vários ativos e formar uma carteira é a redução dos riscos individuais dos ativos. Segundo Ehrhardt \& Brigham (2012) o risco unitário de um ativo é o que um investidor fica exposto quando possuem em sua carteira um único ativo. É importante compreender o risco individual de um ativo para entender como ocorre o risco em carteira.

Campbel et al (2001) em sua pesquisa abordou de forma empírica o comportamento do mercado americano no período de julho de 1962 a 1997, em relação a volatilidade e correlação das ações negociadas na NYSE, AMEX e Nasdaq. Um de seus achados foi a observação do declínio da correlação entre os retornos dos ativos estudados. As correlações com base em cinco anos de dados mensais declinaram de 0,28 em 1960 para 0,08 em 1997, e as correlações com base em dados anuais declinou de 0,12 em 1960 para entre 0,02 e 0,04 na década de 1990.

Bergin \& Pyun (2016) pesquisou o comportamento da covariância entre carteiras multinacionais, constatando-se o risco envolvido não depende tão somente das covariâncias individuais dos ativos, mas da covariância global, indicando que este tipo de diversificação é uma vantagem para redução de riscos individuais.

Alekneviciene et al (2012) em pesquisa realizada no mercado de ações Lituano, assevera que a pesquisa sobre a diversificação de carteiras de investimento tem ao longo do tempo despertado o interesse da comunidade acadêmica no sentido estudar o modelo que melhor reduz o risco sistêmico dos ativos. Os pesquisadores buscam o entendimento sobre a formação das carteiras naive, diferentemente ponderadas, internacionalização ou regionalização. Recentemente os pesquisadores tem desviado o foco das pesquisas da estratégia do risco-retorno e concentrado os estudos na estratégia da mínima vitalidade. Segundo o autor o resultado das pesquisas tem encontrado similaridade. 
Tang (2004) em seu estudo afirma que a diversificação de uma carteira de naive é uma maneira simples, mas poderosa para reduzir eficazmente o risco da carteira, sem sacrificar a taxa de retorno esperada. Os seus resultados de investigação mostraram que, para uma população infinita de ativos, um tamanho de carteira que comporte 20 ativos seria suficiente para eliminar 95\% do risco não sistêmico.

A estimativa do efeito de diversificação de carteiras de ações construída de forma diferentemente ponderadas continua a ser um problema. Woerheide \& Persson (1993) criticaram estudos anteriores pela razão de que o montante dos ativos reflete o grau de diversificação da carteira somente quando os pesos ativos são iguais. Eles tentaram encontrar o indicador que seria adequado para carteiras de ações de forma diferente ponderadas. Um deles é o índice Herfindahl.

Quando os mercados de ações são enormes, um dos problemas é selecionar as ações apropriadas para a carteira. Quando os mercados de ações são pequenas carteiras podem consistir de todas as suas ações. Em qualquer caso, há muitas combinações de carteiras. Por esta razão, é necessária uma metodologia de seleção de ativos em carteiras. Ele deve permitir medir o efeito de diversificação tanto das carteiras de naive e carteiras de ações de forma diferentemente ponderadas.

Statman (1987) mostrou que "uma carteira bem diversificada de ações escolhidas aleatoriamente deve incluir pelo menos 30 ações. Isto contradiz a noção amplamente aceita de que os benefícios da diversificação estão praticamente esgotados quando um portfólio contém cerca de 10 ações. Newbould \& Poon (1993) pesquisou uma série de livros de investimento dos EUA e estudos acadêmicos, e descobriu que a visão consensual é que as carteiras compostas de 8 a 20 unidades populacionais são geralmente considerados bem diversificada. Enquanto Newbould \& Poon não fornecem um número específico de ações que constituiria uma carteira bem diversificada, eles sugerem que o número seria muito maior do que 20. Sharpe et al., (1997) sugerem que 30 ações é o número "mágico".

A diversificação para redução do risco individual dos ativos está intimamente relacionada com o comportamento investidor em relação ao risco. Goetzmann \& Kumar (2008) pesquisaram o mercado dos E.U.A, durante um período de seis anos entre 1991 e 1996, as carteiras de 60.000 investidores e chegou a conclusão de que as carteiras mais diversificadas estavam relacionadas com investidores mais experientes, com maiores idades e ricos e com um nível de investimento alto, e que a maioria dos pequenos investidores acompanham as oscilações do mercado, ou se dedicam a algum tipo de ativo ligada a alguma indústria especifica, com isso suas carteiras são sub diversificadas.

Nieuwerburgh \& Veldkamp (2010) pesquisaram a formação de carteiras a partir da obtenção de informações específicas sobre os ativos antes da formação de uma carteira de investimento, este método diferencia o método padrão de construção de carteiras. Na ótica dos autores, a suposição na maioria dos modelos de carteira que os investidores não podem adquirir informações antes de investir não é inócua. Quando o investidor pode escolher aprender sobre os retornos de ativos, a previsão mais básica da teoria da carteira, que os investidores devem diversificar, é derrubada. Em sua pesquisa Nieuwerburgh \& Veldkamp (2010) mostram como resolver em conjunto para a aquisição de informações ideal e alocação de carteira. A mensagem principal percebida seria que, quando os investidores podem escolher quais informações para adquirir antes de investir, eles podem investir em carteiras que seriam sub-ótima para um investidor que não tenha tal conhecimento. Do ponto de vista da teoria da carteira padrão, essas carteiras podem ser consideradas anômala ou irracional.

Tu \& Zhou (2011) basearam sua pesquisa na ideia de combinar estratégias de carteira, mais precisamente na combinação da regra 1 / N com as regras Markowitz. Como resultado, forneceram novas estratégias de carteira baseadas em teorias que são as combinações da regra 1 / $\mathrm{N}$ com as estratégias baseadas na teoria sofisticada. Concluíram que as regras de combinação são substancialmente melhor do que os seus homólogos, em geral, mesmo quando o tamanho da amostra é pequeno. No geral, o estudo de TU e ZHOU (2011) reafirmam a utilidade da teoria de investimento e mostra que a combinação de regras de carteira pode potencialmente adicionar um valor significativo na gestão de carteiras em relação aos erros de estimativa.

\section{METODOLOGIA}

Na presente pesquisa foi empregada uma metodologia própria, em virtude de ter observado que em cada um dos trabalhos pesquisados havia inúmeras divergências de métodos, e que para atingir o objetivo proposto deveria construir um caminho que conduzisse a um conjunto de resultados esperados. Desta forma, foram adotados os seguintes passos: 
a) Definiu-se que o período de pesquisa, que corresponde a uma instância do problema, que vai permitir inferir para o restante do conjunto de dados, no caso em questão corresponderá ao exercício de 2015;

b) A amostra foi retirada no conjunto de ações negociadas na BOVESPA, e coletada no site http://www.bmfbovespa.com.br/pt_br/servicos/market-data/historico/mercado-a-vista/serieshistoricas/, e que atendiam as seguintes restrições:

i Que, em relação ao tipo de mercado, pertencessem ao mercado a vista, identificado no arquivo de nome COTAHIST.2015.TXT, pela coluna TPMERC, sob o código no 010 , conforme Tabela 1 ;

\begin{tabular}{|c|l|}
\hline \multicolumn{1}{|c|}{ Código Tipo de Mercado da bovesp } \\
\hline 010 & A Vista \\
\hline 012 & Exercício de opções de compra \\
\hline 013 & Exercício de opções de venda \\
\hline 017 & Leilão \\
\hline 020 & Fracionário \\
\hline 030 & Termo \\
\hline 050 & Futuro com retenção de ganho \\
\hline 060 & Futuro com movimentação contínua \\
\hline 070 & Opções de compra \\
\hline 080 & Opções de venda \\
\hline
\end{tabular}

Fonte: Elaborada pelos Autores

2015;

ii - Que o número médio de negócios/dia fosse igual ou maior a 1000;

iii - Que os ativos tivessem participação em 100\% dos pregões realizados em

Após a aplicação destes filtros ao arquivo COTAHIST.2015.xlsx, oriundo da conversão do arquivo COTAHIST.2015.TXT para o Excel, resultou em um total de 115 ativos que atendiam as restrições i, ii e iii. Inicialmente foram ordenados pelo número médio de negócios/dia "NUNNEG", conforme apresentado na Tabela 2.

c) Após a seleção dos ativos que atenderam aos critérios b1 e b2, construiu-se as seguintes carteiras:

a. Uma carteira aleatória, construída a partir da inclusão de ativos dentro dos 115 selecionados, sem critérios específicos de aderência;

b. Uma carteira construída a partir de uma amostra com os coeficientes de correlação menor ou igual a -0,8 e maior ou igual a $-1,0$;

c. Uma carteira construída a partir dos ativos selecionados no item b) sendo que ordenados pelos coeficientes de variação de cada ativo. 
Tabela 2: Ativos selecionados para amostra

\begin{tabular}{|c|c|c|c|c|c|c|c|c|c|c|c|c|c|c|c|}
\hline ATIVO & EG & $\sigma$ & V & 0 & NEG & $\sigma$ & CV & 0 & NEG & $\sigma$ & CV & TO & NEG & $\sigma$ & CV \\
\hline ALSC 3 & 1 & 427 & 302 & ETR4 & 6639 & 7660 & 1,379 & & 810 & 2544 & & STC3 & 8561 & 4735 & 1,553 \\
\hline & 041 & 494 & & & & & 79 & & & 357 & & & 612 & 2559 & \\
\hline ABEV3 & 599 & .07 & 14 & LM3 & 381 & 503 & 384 & QTL3 & 407 & \begin{tabular}{|l|}
2385 \\
\end{tabular} & 441 & GLU3 & 1912 & 1075 & 562 \\
\hline $\mathrm{PA3}$ & 543 & 997 & & 13 & 572 & 163 & 8 & & 4 & 578 & & E3 & 481 & 3084 & \\
\hline GGBR4 & 5695 & 5023 & & $\mathrm{R} 3$ & 5111 & 10 & 89 & & 30 & 3819 & & & 97 & 36 & 567 \\
\hline LAME4 & 89 & 69 & & JBSS3 & 563 & 517 & 0,389 & GRND3 & 1347 & 596 & & S3 & 1557 & 907 & 83 \\
\hline CIEL3 & 4147 & 4624 & & CTIP3 & 069 & 753 & 0,389 & LE3 & 4091 & 1816 & & ET3 & 4994 & 2932 & 587 \\
\hline TBLE3 & 4133 & 1358 & 29 & VALE3 & 16182 & 6338 & 0,392 & ISIM5 & 8918 & \begin{tabular}{|l|}
3993 \\
\end{tabular} & 448 & IBR4 & 6621 & 3980 & 0,601 \\
\hline s. & 7797 & & & R3 & & & 2 & & & 180 & & & 45 & 1349 & \\
\hline ENBR3 & 7217 & 2 & & BBDC4 & 244 & 96 & 0,394 & TAEE11 & 7 & 1453 & 5 & AGB33 & 1245 & 799 & 0,642 \\
\hline CPLE6 & 509 & & & CSNA3 & 52 & 01 & 0,396 & BTOW3 & 92 & 799 & & $\mathrm{CX} 3$ & 3765 & 2428 & 645 \\
\hline QUAL3 & 8548 & 2871 & & BVMF3 & 20951 & 8361 & 0,399 & BBDC3 & 6083 & \begin{tabular}{|l|}
2926 \\
\end{tabular} & 31 & R11 & \begin{tabular}{|l|}
2561 \\
\end{tabular} & 1659 & 0,648 \\
\hline PSSA3 & 86 & 43 & & HYPE3 & 26 & 3 & & FSA3 & 4484 & 2186 & & N3 & 5687 & 3766 &, 662 \\
\hline CPFE3 & 5998 & 36 & & SULA11 & 3 & 572 & 0 & PL4 & 9 & 942 & & & 1551 & 1044 & 673 \\
\hline ITUB 4 & 31660 & 10750 & & ITSA4 & 29827 & 12026 & 0,403 & T6 & 4326 & 2146 & & RK3 & 1144 & 831 & 0,727 \\
\hline CCRO3 & 15346 & & & GT3 & 24 & 58 & 0,404 & MYPK3 & 9 & 1067 & 96 & 111 & 9135 & 7229 & 0,791 \\
\hline SBSP3 & 5204 & 1788 & 43 & LAME3 & 1732 & & 0,41 & ANIM3 & 2602 & 1300 & & R3 & 2492 & 1980 & 0,795 \\
\hline KLBN11 & & & & LID3 & & & - & IRFG3 & 374 & \begin{tabular}{|l|}
3197 \\
\end{tabular} & 0,002 & DG3 & 2012 & 1621 & 805 \\
\hline DTEX3 & 5075 & 1 & $\underline{0}$ & BRFS3 & 0354 & 55 & 0,411 & BRAP4 & 7493 & 3776 & 4 & D3 & 1510 & 1234 & 818 \\
\hline BBSE3 & 4594 & & 9 & TIMP3 & & 37 & 0,413 & RAPT 4 & 2588 & 1306 & & ML3 & 1131 & 956 &, 845 \\
\hline PCAR4 & 6029 & 2174 & 0,361 & BRKM5 & 8392 & 3475 & 0,414 & ELPL4 & 2788 & 1430 & 0,513 & RIN3 & 1011 & 892 & 0,882 \\
\hline MULT3 & & & 51 & TOTS3 & & 13 & 0,417 & CMIG4 & 11429 & 5870 & 14 & CG11 & 2083 & 2154 & 1,034 \\
\hline MRVE3 & 8078 & 2937 & 364 & CVCB3 & 238 & & 0,418 & POMO4 & 5632 & 2982 & 0,529 & RTR3 & 1155 & 1452 & 1,258 \\
\hline RENT3 & 4798 & 175 & & GETI4 & & 12 & 0,42 & QGEP3 & 0 & 1546 & & GR3 & 3014 & 4909 & 629 \\
\hline FIBR3 & 1511 & & 65 & SMTO3 & 1240 & & & TCSA3 & 1729 & 922 & 0,533 & CR11 & 1018 & 1741 & 1,71 \\
\hline ODPV3 & 4545 & 1669 & 0,367 & MPLU3 & 2033 & 857 & 0,421 & SANB11 & 3788 & 2035 & & & & & \\
\hline SUZB5 & 14874 & 5480 & 0,368 & CSMG3 & 1192 & & 0,433 & BRPR3 & 343 & 1812 &, 542 & & & & \\
\hline EZTC3 & 2647 & & & CYRE3 & 034 & 53 & 0,434 & GOAU4 & 9013 & \begin{tabular}{|l|l|}
4927 \\
\end{tabular} & & & & & \\
\hline NATU3 & 4803 & 1800 & & KROT3 & 22440 & 55 & 0,435 & 13 & 1101 & 604 & 9 & & & & \\
\hline $\mathrm{Cr}$ & 28 & 1589 & 76 & L3 3 & 38 & 2594 & 437 & R3 & 640 & 05 & 2 & & & & \\
\hline
\end{tabular}

Fonte: Elaborada pelos Autores

Para as análises estatísticas foram utilizados o Excel e o software SPSS statistics 22 da IBM. Sendo utilizado as seguintes variáveis e fórmulas:

Para se obter preço médio anual da cotação de fechamento de um ativo A, utilizou-se a seguinte expressão:

$$
\bar{X}=\sum_{i=1}^{n} \frac{X_{i}}{n}
$$

Sendo, Xi o valor de cotação de fechamento de um ativo em um determinado pregão; $\bar{X}$ o valor médio anual da cotação de fechamento do Ativo A; n o número de pregões realizados em um determinado ano. No presente experimento, $n=246$, correspondente ao número de pregões realizados na BOVESPA em 2015.

Para se obter o coeficiente de correlação de uma determinada carteira, utilizou-se a seguinte formulação:

$$
\rho \text { estimado }=R=\frac{\sum_{t=1}^{n}\left(X_{i, t}-\overline{X_{l}}\right)\left(X_{j, t}-\overline{X_{J}}\right)}{\sqrt{\left\{\sum_{t=1}^{n}\left(X_{i, t}-\overline{X_{l}}\right)^{2}\right\}}\left\{\sum_{t=1}^{n}\left(X_{j, t}-\overline{X_{J}}\right)^{2}\right\}}
$$


A estimativa de correlação com base em uma amostra de dados históricos é denominada "R". Esta fórmula é utilizada para estimar a correlação entre as ações i e j.

Para se obter o Coeficiente de Variação (CV) de uma ativo A, utilizou-se a seguinte formulação:

$$
\text { Coeficiente de variação }=C V_{A}=\frac{\sigma}{\bar{X}_{A}}
$$

Para obter o peso (Wi) de investimento de cada ativo, utilizou-se a seguinte fórmula:

$$
W_{A}=\frac{\sigma_{B}\left(\sigma_{B}-P_{A B} \sigma_{A}\right)}{\sigma_{A}^{2}+\sigma_{B}^{2}-2 \rho_{A B} \sigma_{A} \sigma_{B}}
$$

Variáveis:

$$
\begin{aligned}
& W_{A}=\text { percentual do investimento a ser feito no ativo A; } \\
& \sigma_{A}=\text { desvio padrão do ativo A; } \\
& \sigma_{B}=\text { desvio padrão do ativo B; } \\
& \sigma_{A}^{2}=\text { variância do ativo A; } \\
& \sigma_{B}^{2}=\text { variância do ativo B } \\
& P_{A B}=\text { Coeficiente de correlação entre os ativos A e B. }
\end{aligned}
$$

\subsection{CONSTRUÇÃO DA CARTEIRA DE FORMA ALEATÓRIA}

Construiu-se a carteira com inclusão aleatória de ativos, sem levar em consideração desvio padrão, coeficiente de correlação, coeficiente de variação, ou o nível de negociação na bolsa de valores. Este experimento será comparado na simulação com as outras carteiras construídas com base em critérios objetivos. Os ativos desta carteira foram os 115 ativos selecionados na primeira amostra e que estão ilustrados na Tabela 2.

Após os resultados obtidos utilizando-se as formulações de 1 a 3, obteve-se os preções médios da cotação de fechamento das carteiras no período n, os desvios padrões e os coeficientes de variação (CV), igual procedimento foi utilizado para o cálculo das mesmas variáveis dos ativos separadamente. As Figuras 1 e 2 representam graficamente a variação dos desvios padrões e dos coeficientes de variação da carteira com um único ativo até a carteira com 115 ativos. O que pode observar é que a distribuição não ocorre de forma decrescente como afirma os especialistas na literatura. Em relação ao desvio padrão a C2 apresenta $\rho=0,7835$, o menor entre as 115 carteiras. A C8 apresenta $\rho=2,3866$, o pico mais elevado do experimento. Já a C115 apresenta um $\rho=1,3148$. Como pode-se inferir que investir na C2 possui um risco menor do que a C115. 0 que contraria a literatura consagrada. No que se refere ao coeficiente de variação pode-se observar que da mesma forma que o desvio padrão sua distribuição ocorre de forma irregular. A C49 possui o $\mathrm{CV}=0,03397$, sendo o menor dentre as 115 carteiras construídas de forma aleatória. A C8 obteve o maior coeficiente, com CV=2,3866, a C115 com um CV=1,3148. Contudo, nas Figuras 3 e 4 foram comparados os desvios padrões e os coeficientes de variação das carteiras com os ativos isoladamente, e pode-se afirmar que mesmo a distribuição irregular, as carteiras apresentam risco menor que os ativos isoladamente. A aglutinação dos ativos em carteira reduz o risco individual dos ativos. 
Figura 1: Evolução dos desvios padrões nas carteiras aleatórias.

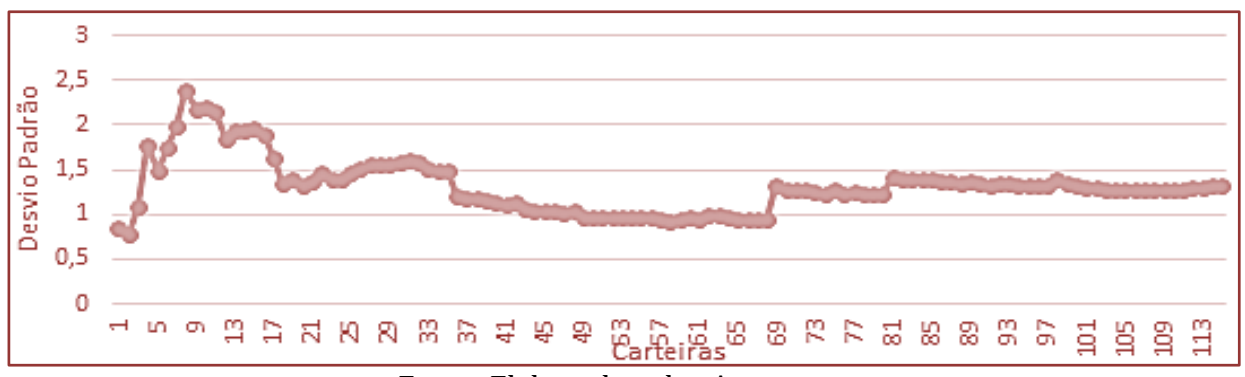

Fonte: Elaborada pelos Autores

Figura 2: Evolução dos coeficientes de variação das carteiras aleatórias.

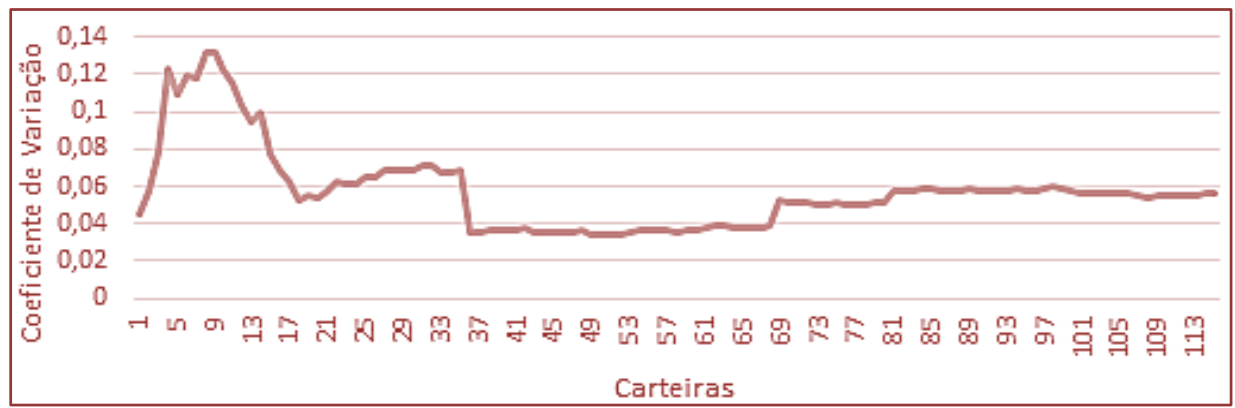

Fonte: Elaborada pelos Autores

Figura 3: Comparação entre os coeficientes de variação da carteira aleatória e os ativos que a compõe

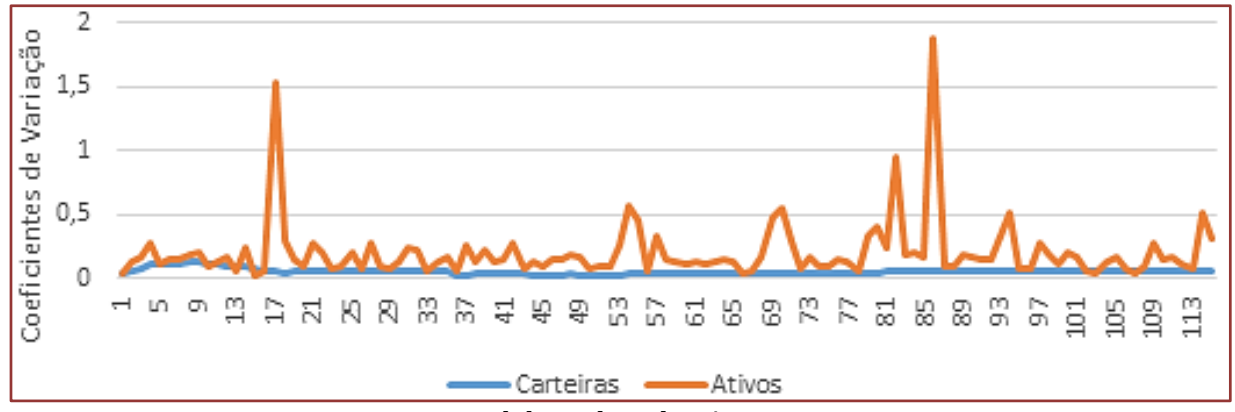

Fonte: Elaborada pelos Autores

Figura 4: Comparação entre os desvios padrões da carteira aleatória e os ativos que a compõe

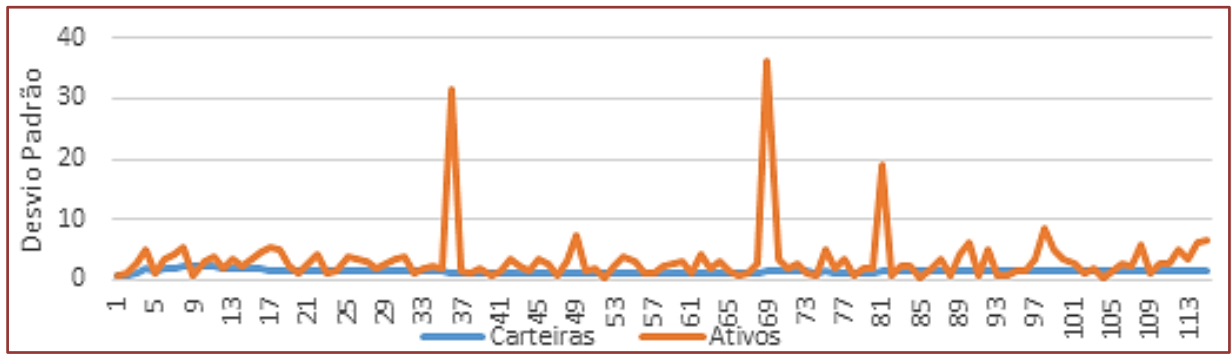

Fonte: Elaborada pelos Autores

\subsection{CONSTRUÇÃO DE CARTEIRA ORDENADA POR COEFICIENTE DE CORRELAÇÃO}

A amostra inicial selecionada dentro de todos os ativos negociados na BOVESPA em 2015, que que atenderam as premissas postas na metodologia, resultou na seleção de 115 ativos. Para construir a carteira a partir da ordenação pelos pares com os coeficientes de correlação próximos de -1 , resultou em nova seleção dentro do conjunto de 115 ativos selecionados. A variável utilizada para o teste de 
correlação foi a cotação de fechamento do ativo em cada pregão realizado em 2015. Inicialmente, foi estabelecido um limite inferior de corte de -0,6. Aplicou-se o SPSS statistics 22, e foram produzidos 13.225 pares de ativos correlacionados. A partir do limite inferior foi selecionado 561 pares com coeficientes de correlação <=-0,6. Após análise preliminar, redimensionou-se o limite inferior para o patamar de $-0,85$, resultando em uma amostra com 88 pares, com 43 ativos distintos, que compõem a Tabela 3.

Tabela 3: Ativos com coeficiente de correlação <- 0,85

\begin{tabular}{|c|c|c|c|c|c|c|c|}
\hline $\mathrm{N}$ & ATIVO (A) & ATIVO (B) & $\mathrm{R}$ & $\mathrm{N}$ & ATIVO (A) & ATIVO (B) & $\mathrm{R}$ \\
\hline 1 & KLBN11 & GOLL4 & $-0,953$ & 45 & WEGE3 & ENBR3 & \begin{tabular}{|l|l|}
$-0,878$ \\
\end{tabular} \\
\hline 2 & GOLL4 & FIBR3 & $-0,941$ & 46 & SULA11 & BBRK3 & \begin{tabular}{|l|l|}
$-0,877$ \\
\end{tabular} \\
\hline 3 & SUZB5 & GOLL4 & \begin{tabular}{|l|}
$-0,938$ \\
\end{tabular} & 47 & BRLM3 & BEEF3 & $-0,875$ \\
\hline 4 & KLBN11 & ECOR3 & \begin{tabular}{|l|}
$-0,937$ \\
\end{tabular} & 48 & RAPT4 & KLBN11 & $-0,875$ \\
\hline 5 & SUZB5 & ECOR3 & \begin{tabular}{|l|}
$-0,929$ \\
\end{tabular} & 49 & KLBN11 & BRAP4 & \begin{tabular}{|l|l|}
$-0,874$ \\
\end{tabular} \\
\hline 6 & RADL3 & HBOR3 & $-0,925$ & 50 & VIVT4 & BEEF3 & \begin{tabular}{|l|l|}
$-0,873$ \\
\end{tabular} \\
\hline 7 & TIMP3 & KLBN11 & $\mid-0,921$ & 51 & HBOR3 & EQTL3 & $-0,873$ \\
\hline 8 & BEEF3 & ALSC3 & \begin{tabular}{|l|}
$-0,919$ \\
\end{tabular} & 52 & SULA11 & RLOG3 & $-0,873$ \\
\hline 9 & SULA11 & BRSR6 & \begin{tabular}{|l|}
$-0,918$ \\
\end{tabular} & 53 & TIMP3 & SULA11 & \begin{tabular}{|l|l|}
$-0,873$ \\
\end{tabular} \\
\hline 10 & VVAR11 & SULA11 & $\mid-0,914$ & 54 & VVAR11 & BEEF3 & $\mid-0,872$ \\
\hline 11 & KLBN11 & BRSR6 & \begin{tabular}{|l|}
$-0,913$ \\
\end{tabular} & 55 & SULA11 & OIBR3 & \begin{tabular}{|l|l|}
$-0,872$ \\
\end{tabular} \\
\hline 12 & SULA11 & BRAP4 & \begin{tabular}{|l|}
$-0,908$ \\
\end{tabular} & 56 & GGBR4 & BEEF3 & \begin{tabular}{|l|l|}
$-0,871$ \\
\end{tabular} \\
\hline 13 & SUZB5 & BBDC4 & \begin{tabular}{|l|}
$-0,907$ \\
\end{tabular} & 57 & RADL3 & ECOR3 & $\mid-0,871$ \\
\hline 14 & SULA11 & OIBR4 & \begin{tabular}{|l|}
$-0,907$ \\
\end{tabular} & 58 & MRFG3 & DTEX3 & $-0,87$ \\
\hline 15 & PCAR4 & BEEF3 & \begin{tabular}{|l|}
$-0,905$ \\
\end{tabular} & 59 & VVAR11 & MRFG3 & $-0,87$ \\
\hline 16 & KLBN11 & BBDC4 & \begin{tabular}{|l|}
$-0,904$ \\
\end{tabular} & 60 & RENT3 & BEEF3 & $-0,869$ \\
\hline 17 & FIBR3 & BRSR6 & $-0,904$ & 61 & WEGE3 & EQTL3 & $-0,869$ \\
\hline 18 & MRFG3 & CMIG4 & $-0,904$ & 62 & VVAR11 & KLBN11 & \begin{tabular}{|l|l|}
$-0,868$ \\
\end{tabular} \\
\hline 19 & QUAL3 & FIBR3 & \begin{tabular}{|l|}
$-0,903$ \\
\end{tabular} & 63 & SUZB5 & RAPT4 & \begin{tabular}{|l|l|}
$-0,868$ \\
\end{tabular} \\
\hline 20 & MRFG3 & ALSC3 & \begin{tabular}{|l|}
$-0,899$ \\
\end{tabular} & 64 & EZTC3 & BEEF3 & $-0,866$ \\
\hline 21 & BEEF3 & BBRK3 & $\mid-0,899$ & 65 & SUZB5 & CESP6 & $-0,866$ \\
\hline 22 & SUZB5 & BRSR6 & \begin{tabular}{|l|}
$-0,899$ \\
\end{tabular} & 66 & KLBN11 & BBDC3 & \begin{tabular}{|l|l|}
$-0,864$ \\
\end{tabular} \\
\hline 23 & FIBR3 & BBDC4 & \begin{tabular}{|l|}
$-0,897$ \\
\end{tabular} & 67 & TIMP3 & FIBR3 & $-0,864$ \\
\hline 24 & ITSA4 & BEEF3 & \begin{tabular}{|l|}
$-0,897$ \\
\end{tabular} & 68 & RADL3 & GOAU4 & $-0,862$ \\
\hline 25 & MRFG3 & IGTA3 & $-0,896$ & 69 & MRFG3 & ITUB4 & \begin{tabular}{|l|l|}
$-0,861$ \\
\end{tabular} \\
\hline 26 & GOAU4 & BEEF3 & $\mid-0,895$ & 70 & CCRO3 & BEEF3 & $-0,86$ \\
\hline 27 & SUZB5 & BBDC3 & \begin{tabular}{|l|}
$-0,893$ \\
\end{tabular} & 71 & RADL3 & BBDC3 & $-0,859$ \\
\hline 28 & SULA11 & QUAL3 & \begin{tabular}{|l|}
$-0,892$ \\
\end{tabular} & 72 & MRFG3 & BBRK3 & $-0,859$ \\
\hline 29 & SUZB5 & QUAL3 & \begin{tabular}{|l|}
$-0,892$ \\
\end{tabular} & 73 & CESP6 & BEEF3 & $-0,859$ \\
\hline 30 & TIMP3 & SUZB5 & \begin{tabular}{|l|}
$-0,892$ \\
\end{tabular} & 74 & VVAR11 & FIBR3 & $-0,859$ \\
\hline 31 & SULA11 & BBDC4 & \begin{tabular}{|l|}
$-0,891$ \\
\end{tabular} & 75 & KLBN11 & GOAU4 & $-0,859$ \\
\hline 32 & SULA11 & PCAR4 & \begin{tabular}{|l|}
$-0,891$ \\
\end{tabular} & 76 & SUZB5 & RSID3 & $-0,859$ \\
\hline 33 & FIBR3 & ECOR3 & $-0,89$ & 77 & VIVT4 & SUZB5 & $-0,859$ \\
\hline 34 & QUAL3 & KLBN11 & \begin{tabular}{|l|}
$-0,889$ \\
\end{tabular} & 78 & BEEF3 & BBDC4 & $-0,857$ \\
\hline 35 & RSID3 & RADL3 & \begin{tabular}{|l|}
$-0,888$ \\
\end{tabular} & 79 & VIVT4 & KLBN11 & $-0,857$ \\
\hline 36 & MYPK3 & ALSC3 & \begin{tabular}{|l|}
$-0,887$ \\
\end{tabular} & 80 & MYPK3 & BBRK3 & $-0,856$ \\
\hline 37 & SULA11 & GOAU4 & \begin{tabular}{|l|}
$-0,887$ \\
\end{tabular} & 81 & RENT3 & MRFG3 & $-0,855$ \\
\hline 38 & SULA11 & ECOR3 & \begin{tabular}{|l|}
$-0,885$ \\
\end{tabular} & 82 & ENBR3 & ECOR3 & $-0,853$ \\
\hline 39 & SULA11 & GOLL4 & \begin{tabular}{|l|}
$-0,885$ \\
\end{tabular} & 83 & MULT3 & BEEF3 & $-0,852$ \\
\hline 40 & SUZB5 & HBOR3 & \begin{tabular}{|l|}
$-0,881$ \\
\end{tabular} & 84 & QUAL3 & BEEF3 & $-0,852$ \\
\hline 41 & PCAR4 & MRFG3 & $-0,88$ & 85 & HBOR3 & BEEF3 & $-0,85$ \\
\hline 42 & BRSR6 & BEEF3 & $-0,878$ & 86 & EQTL3 & ECOR3 & $-0,85$ \\
\hline 43 & RSID3 & BEEF3 & \begin{tabular}{|l|} 
\\
\end{tabular} & 87 & RAPT4 & FIBR3 & $-0,85$ \\
\hline 44 & SULA11 & CESP6 & $-0,878$ & 88 & MRFG3 & ITSA4 & $-0,85$ \\
\hline
\end{tabular}

Fonte: Elaborada pelos Autores.

Após a seleção da amostra de pares correlacionados iniciou-se a construção da carteira, com adição dos ativos selecionados de forma ordenada considerando os pares mais fortemente correlacionados negativamente. 0 primeiro ativo a ser incluso foi o KLBN11, com um valor de cotação média de fechamento anual de $R \$ 19,50$, com um desvio padrão de 2,9535 e coeficiente de variação de 0,1514 . A 
Tabela 4, apresenta o resultado da inclusão de cada até o limite de 43. As Figuras 3 e 4 ilustram o comportamento evolutivo do desvio padrão e o coeficiente de variação de cada carteira. 0 que se pode inferir que ambas variáveis apresentam comportamento similar, contudo a redução tanto do desvio padrão quanto do CV não ocorre de forma uniforme com o acréscimo de ativos a carteira.

Tabela 4: Construção da carteira ordenada por coeficiente de correlação $>-1$ e $<-0,85$

\begin{tabular}{|c|c|c|c|c|c|c|c|c|c|}
\hline $\mathrm{N}$ & ATIVOS & $\bar{X}$ & $\mathrm{R}$ & CV & $\mathrm{N}$ & ATIVOS & $\bar{X}$ & $\mathrm{R}$ & $\mathrm{CV}$ \\
\hline 1 & KLBN11 & 19,50 & 2,953568 & 0,151459 & 23 & 22 +IGTA3 & 17,13 & 1,556636 & 0,090874 \\
\hline 2 & $1+$ GOLL4 & 13,21 & 0,479016 & 0,036252 & 24 & $23+\mathrm{GOAU} 4$ & 16,69 & 1,634243 & 0,097936 \\
\hline 3 & $2+$ FIBR3 & 23,83 & 2,396334 & 0,10054 & 25 & $24+\mathrm{BBDC} 3$ & 17,16 & 1,715328 & 0,099955 \\
\hline 4 & $3+$ ECOR3 & 19,83 & 1,426637 & 0,071959 & 26 & 25 +RSID3 & 16,56 & 1,677501 & 0,101287 \\
\hline 5 & 4 +SUZB5 & 18,99 & 1,615322 & 0,085047 & 27 & $26+$ MYPK3 & 16,43 & 1,557962 & 0,094826 \\
\hline 6 & 5 +RADL3 & 21,79 & 2,216607 & 0,101742 & 28 & $27+$ CESP6 & 16,54 & 1,632582 & 0,098716 \\
\hline 7 & $6+$ HBOR3 & 19,07 & 1,782702 & 0,093494 & 29 & $28+$ WEGE3 & 16,68 & 1,718322 & 0,103044 \\
\hline 8 & 7 +TIMP3 & 17,88 & 1,386361 & 0,077526 & 30 & $29+$ ENBR3 & 16,49 & 1,628812 & 0,098796 \\
\hline 9 & 8 +BEEF3 & 17,06 & 1,399905 & 0,082065 & 31 & 30 +BRLM3 & 16,41 & 1,641936 & 0,100049 \\
\hline 10 & $9+$ ALSC3 & 16,76 & 1,067522 & 0,06369 & 32 & $31+$ RAPT4 & 16,00 & 1,604953 & 0,100281 \\
\hline 11 & $10+$ SULA11 & 16,69 & 1,226027 & 0,073477 & 33 & $32+$ VIVT4 & 16,85 & 1,698647 & 0,100792 \\
\hline 12 & $11+$ BRSR6 & 16,07 & 0,93997 & 0,05851 & 34 & 33 +EQTL3 & 17,32 & 1,579277 & 0,091184 \\
\hline 13 & $12+$ VVAR11 & 15,72 & 0,573088 & 0,036467 & 35 & 34 +RLOG3 & 16,88 & 1,552408 & 0,091948 \\
\hline 14 & 13 +BRAP4 & 15,32 & 0,492186 & 0,032126 & 36 & $35+0 I B R 3$ & 16,55 & 1,552348 & 0,093783 \\
\hline 15 & $14+$ BBDC4 & 16,17 & 0,502291 & 0,031064 & 37 & $36+$ GGBR4 & 16,31 & 1,56261 & 0,095783 \\
\hline 16 & $15+$ OIBR4 & 15,45 & 0,54815 & 0,035486 & 38 & 37 +DTEX3 & 16,08 & 1,542632 & 0,095956 \\
\hline 17 & $16+$ PCAR4 & 18,96 & 1,531924 & 0,080805 & 39 & $38+$ RENT3 & 16,44 & 1,617196 & 0,098377 \\
\hline 18 & 17 +MRFG3 & 18,20 & 1,401763 & 0,077002 & 40 & 39 +EZTC3 & 16,42 & 1,641486 & 0,099982 \\
\hline 19 & 18 +CMIG4 & 17,80 & 1,474201 & 0,08282 & 41 & 40 +ITUB4 & 16,79 & 1,692992 & 0,100806 \\
\hline 20 & 19 +QUAL3 & 17,94 & 1,582974 & 0,088219 & 42 & $41+$ CCRO3 & 16,74 & 1,683076 & 0,100519 \\
\hline 21 & $20+\mathrm{BBRK} 3$ & 17,19 & 1,527965 & 0,088865 & 43 & $42+$ BBAS3 & 16,84 & 1,715523 & 0,101859 \\
\hline 22 & 21 +ITSA4 & 16,81 & 1,506291 & 0,089626 & & & & & \\
\hline
\end{tabular}

Fonte: Elaborada pelos Autores

Figura 5: Evolução dos desvios padrões das carteiras formadas pelo coeficiente de correlação

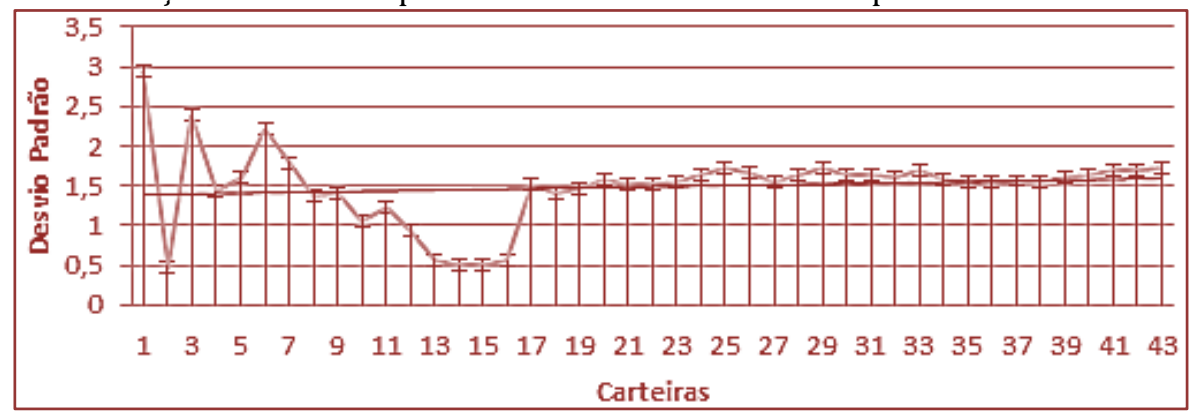

Fonte: Elaborada pelos Autores

Figura 6: Evolução dos coeficientes de variação das carteiras formadas pelo coeficiente

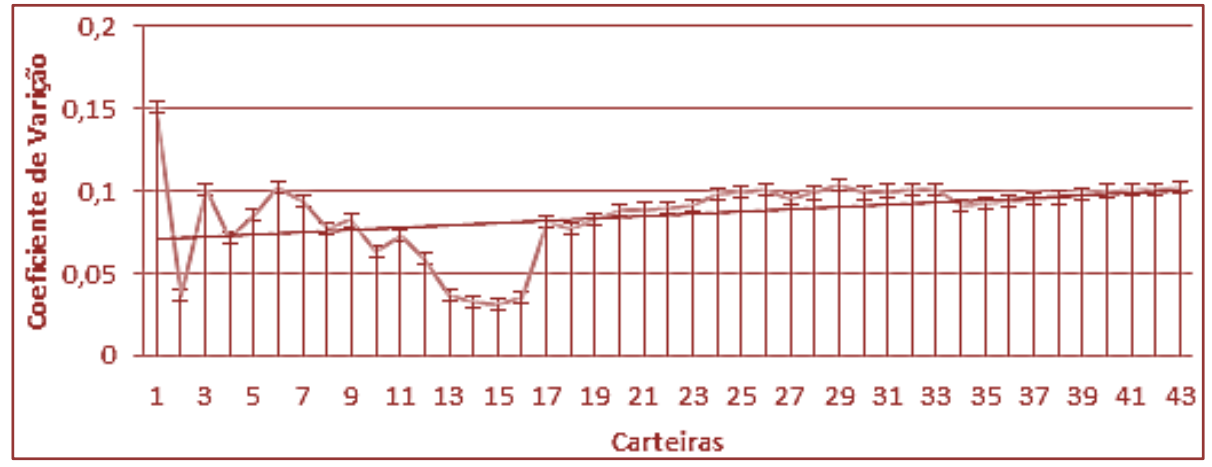

Fonte: Elaborada pelos Autores 


\subsection{CONSTRUÇÃO DE CARTEIRA ORDENADA PELO COEFICIENTE DE VARIAÇÃO}

De Igual modo como foi construída a carteira ordenada pelo coeficiente de correlação, a estratégia de construção da carteira nesta seção será pelo coeficiente de variação - CV dos ativos negativamente correlacionados, selecionados dentro os 115 da primeira amostra. Para obter-se o Coeficiente de Variação de cada ativo utilizou-se a seguinte fórmula:

Após a aplicação das fórmulas 1 a 4, com a utilização do EXCEL, construiu-se 87 carteiras, com a inclusão dos ativos baseando-se no valor dos coeficientes de variação de cada ativo. A inclusão deu-se de forma crescente, do menor para o maior coeficiente. A Tabela 5 apresenta o resultado extraído a partir de cada carteira.

Tabela 5: Carteira ordenadas pelo coeficiente da variação - CV

\begin{tabular}{|c|c|c|c|c|c|c|c|c|c|}
\hline $\mathrm{N}$ & ATIVOS & & $\mathrm{R}$ & CV & $\mathrm{N}$ & ATIVOS & & $\mathrm{R}$ & $\mathrm{CV}$ \\
\hline 1 & DAGB33 & 449,61 & 31,71 & 0,07052 & 45 & 44+TIMP3 & 31,63 & 1,18 & 0,03734 \\
\hline 2 & $1 \div$ ODPV3 & 230,03 & 15,84 & 0,06884 & 46 & $45 \div$ RADL3 & 31,72 & 1,2 & 0,03775 \\
\hline 3 & $2 \div$ GRND3 & 159 & 10,8 & 0,06793 & 47 & $46 \div \mathrm{POMO} 4$ & 31,09 & 1,17 & 0,03771 \\
\hline 4 & 3 +BOVA11 & 131,34 & 8 & 0,06093 & 48 & $47+$ CYRE 3 & 30,65 & 1,16 & 0,03787 \\
\hline 5 & $4 \div$ VLID3 & 114,12 & 6,85 & 0,06003 & 49 & $48+B E E F 3$ & 30,24 & 1,13 & 0,03753 \\
\hline 6 & $5+$ CPLE 6 & 100,51 & 5,73 & 0,05705 & 50 & $49+A L S C 3$ & 29,92 & 1,12 & 0,03753 \\
\hline 9 & $8 \div$ BVMF3 & 75,52 & 3,93 & 0,05205 & 53 & $52 \div$ SMLE3 & 29,47 & 1,13 & 0,03834 \\
\hline 10 & $9+$ UGPA3 & 74,38 & 4,03 & 0,05419 & 54 & $53 \div$ QUAL3 & 29,31 & 1,12 & 0,03831 \\
\hline 11 & $10+\mathrm{CCRO} 3$ & 68,95 & 3,62 & 0,05246 & 55 & $54 \div$ BBDC4 & 29,29 & 1,12 & 0,03826 \\
\hline 12 & 11 + MULT3 & 67,18 & 3,26 & 0,0485 & 56 & $55+$ CESP 6 & 29,11 & 1,13 & 0,03871 \\
\hline 13 & $12 \div$ BBSE 3 & 64,38 & 3,07 & 0,04772 & 57 & 56+SULA11 & 28,88 & 1,09 & 0,03785 \\
\hline 17 & $16+\mathrm{EQTL} 3$ & 53,3 & 2,54 & 0,04757 & 61 & $60 \div E C O R 3$ & 27,63 & 1,1 & 0,03984 \\
\hline 18 & $17+$ VIVT 4 & 52,78 & 2,31 & 0,04383 & 62 & 61+BRAP4 & 27,35 & 1,1 & 0,04014 \\
\hline 19 & $18 \div$ IGTA 3 & 51,28 & 2,22 & 0,04329 & 63 & $62 \div$ CSMG3 & 27,16 & 1,09 & 0,04026 \\
\hline 20 & 19 + ITUB 4 & 50,31 & 2,13 & 0,04235 & 64 & $63+$ PCAR 4 & 27,91 & 1,28 & 0,04575 \\
\hline 21 & $20 \div$ SMTO3 & 49,72 & 2,06 & 0,04137 & 65 & 64+GGBR4 & 27,6 & 1,28 & 0,04632 \\
\hline 22 & $21+$ ENBR3 & 47,96 & 2 & 0,04173 & 66 & $65 \div$ DIRR3 & 27,26 & 1,2 & 0,04661 \\
\hline 23 & $22+$ DTEX3 & 46,2 & 1,92 & 0,04167 & 67 & $66+$ BRSR 6 & 26,99 & 1,27 & 0,04722 \\
\hline 24 & $23+$ NATU3 & 45,36 & 1,83 & 0,04033 & 68 & $67+$ USIM5 & 26,65 & 1,27 & 0,04766 \\
\hline 25 & $24+$ ITSA 4 & 43,89 & 1,76 & 0,04018 & 69 & $68+$ CMIG 4 & 26,42 & 1,29 & 0,0488 \\
\hline 26 & $25+J B S S 3$ & 42,76 & 1,75 & 0,04097 & 70 & 69+SEER3 & 26,21 & 1,3 & 0,04946 \\
\hline 27 & $26+$ ALPA 4 & 41,49 & 1,71 & 0,04126 & 71 & $70+$ ANIM3 & 26,08 & 1,32 & 0,05051 \\
\hline 35 & $34+$ HGTX3 & 35,19 & 1,36 & 0,03878 & 79 & $78 \div 0 I B R 4$ & 24,31 & 1,24 & 0,05108 \\
\hline 36 & $35+B B D C 3$ & 35 & 1,31 & 0,03733 & 80 & $79+$ GOLL4 & 24,09 & 1,25 & 0,05179 \\
\hline 37 & 36+RAPT 4 & 34,15 & 1,27 & 0,0372 & 81 & $80 \div$ LREN3 & 24,72 & 1,58 & 0,06376 \\
\hline 38 & $37+$ BRLM3 & 33,62 & 1,25 & 0,03731 & 82 & $81+$ RSID3 & 24,44 & 1,56 & 0,06396 \\
\hline 39 & $38+$ RENT3 & 33,53 & 1,26 & 0,03756 & 83 & $82 \div$ VVAR11 & 24,28 & 1,6 & 0,06599 \\
\hline 40 & $39+$ ELET 6 & 32,91 & 1,23 & 0,03752 & 84 & $83+$ MGLU3 & 24,07 & 1,56 & 0,06489 \\
\hline 41 & $40 \div$ BBAS3 & 32,62 & 1,25 & 0,03831 & 85 & $84 \div \mathrm{GOAU} 4$ & 23,86 & 1,58 & 0,06604 \\
\hline 42 & $41+$ SUZB5 & 32,21 & 1,23 & 0,03815 & 86 & $85 \div$ PDGR3 & 23,59 & 1,55 & 0,06584 \\
\hline 43 & $42+$ FIBR 3 & 32,51 & 1,23 & 0,0379 & 87 & $86 \div$ BRIN3 & 23,36 & 1,51 & 0,06456 \\
\hline 44 & 43+VALE5 & 32,13 & 1,21 & 0,0377 & & & & & \\
\hline
\end{tabular}

Fonte: Elaborada pelos Autores

Na figura 7 pode-se observar que a aglutinação dos ativos a partir do menor coeficiente de variação individual, proporciona uma redução regular dos desvios padrões das carteiras. Neste experimento podese observar que a C1 possuía o mais alto $\rho=31,71$ e que a C87 possui um $\rho=1,51$. Esta estratégia de 
combinação de ativos foi a que mais se aproximou da literatura. A Figura 9 ilustra a distribuição do coeficiente de variação. 0 que se pode observar é que a combinação dos ativos nesta estratégia, inicia-se com a $\mathrm{C} 1$ com um $\mathrm{CV}=0,07052$ descarecendo até o $\mathrm{C} 52$ com $\mathrm{CV}=0,03711$, e a partir deste ponto adotando um comportamento ascendente até o C87 que possui um CV=0,06456. Na Figura 8, conforme observado nas carteiras aleatórias, o risco em carteira neste experimento continua sendo menor que o risco individual da maioria dos ativos que compõem a amostra. A Figura 10 ilustra que o coeficiente de variação dos ativos individuais é maior que os das carteiras. Desta forma, pode-se afirmar que a diversificação das carteiras conduz a uma redução do risco individual dos ativos.

Figura 7: Evolução dos desvios padrão das carteiras formadas a partir dos CV

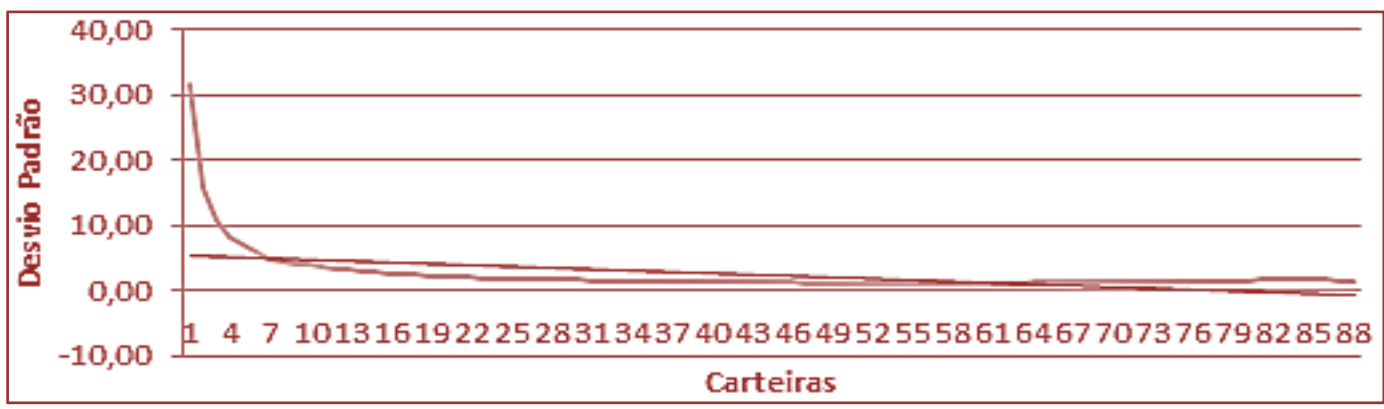

Fonte: Elaborada pelos Autores

Figura 8: Comparação entre os desvios padrão dos ativos individuais e a carteira CV

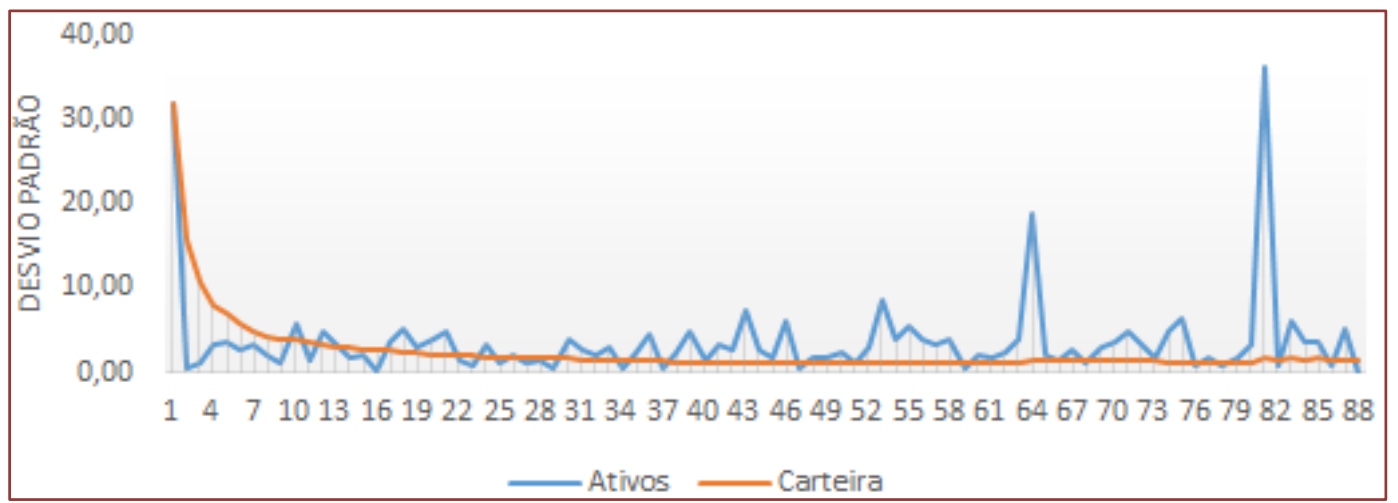

Fonte: Elaborada pelos Autores

Figura 9: Evolução dos coeficientes de variação das carteiras formadas pelos CV

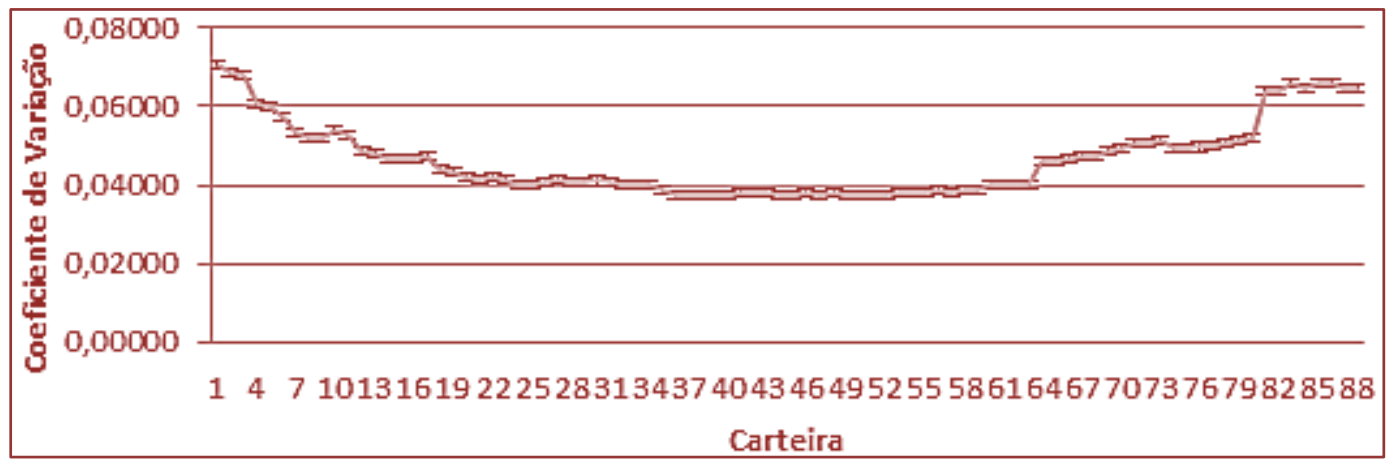

Fonte: Elaborada pelos Autores 
Figura 10: Comparação entre os coeficientes de variação dos ativos individuais e as carteiras CV

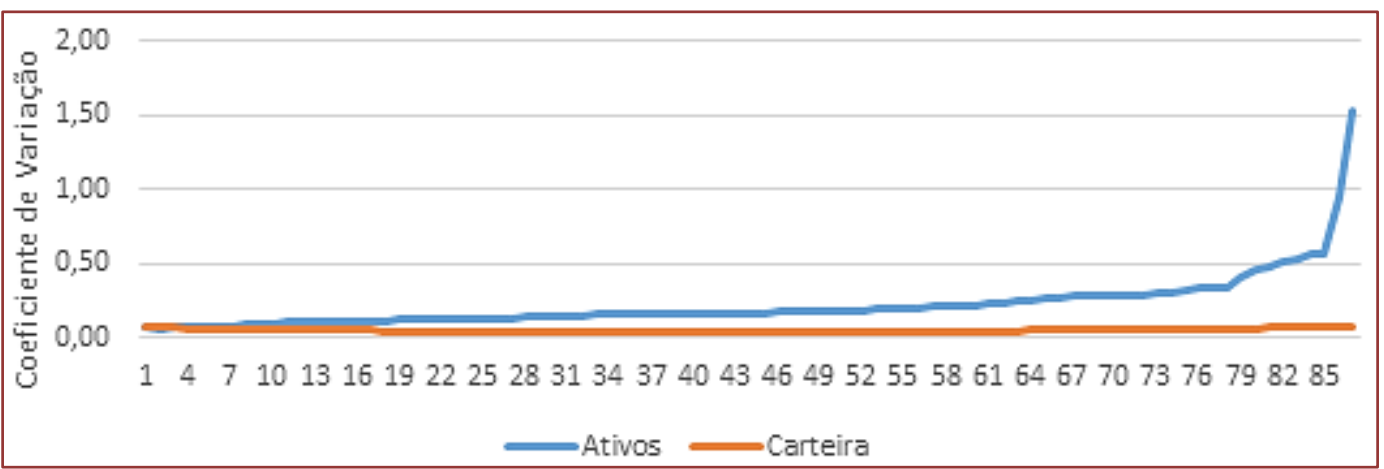

Fonte: Elaborada pelos Autores

\subsection{SIMULAÇÃO E COMPARAÇÃO DOS RENDIMENTOS EXPO FACTO ENTRE AS CARTEIRAS}

Para ilustrar o efeito da diversificação das carteiras no mercado de ações brasileiro, tendo como referência os pregões realizados na BOVESPA no ano de 2015. Realizou-se uma simulação com base nos valores das cotações de fechamento dos ativos relacionados no estudo, que está demonstrado na Tabela 6 e na Figura 11.

\section{Exemplo:}

"Um professor de biologia de uma Universidade Federal do estado de Minas Gerais, de sobrenome Ferreira, recebeu em 03 de dezembro de 2014 uma herança de seu tio avô, num montante de R \$ 5.000.000,00. E decidiu investir $1 / 5$ da herança no mercado de ações. Após realizar várias consultas técnicas com especialistas do setor, decidiu via o home Broker do seu banco iniciar por conta própria sua carteira de investimento. Como ele deveria começar a formar sua carteira? Partindo da premissa que o investidor pretende adquirir os ativos selecionados no primeiro pregão de 2015 e somente pretende utilizar tais em recursos a partir de 2020."

Dados:

Investimento inicial $=\mathrm{R} \$ 1.000 .000,00$.

Carteira Aleatória $=\mathrm{M}$; Carteira Correlação $=\mathrm{P} ;$ Carteira CV =B

$\mathrm{CN}=$ Número de ativos da carteira $=\{\mathrm{C} 10, \mathrm{C} 20, \mathrm{C} 30, \mathrm{C} 40\}$

Após a simulação dos dados utilizando o EXCEL, foram geradas a Tabela 6 e a Figura 11. Com base em tais informações pode-se inferir que as carteiras do tipo $\mathrm{M}$, em $100 \%$ dos cenários apresentaram retorno negativo, sendo a menor perda de investimento de $(8,42 \%)$ e a maior de $(34,06 \%)$; as carteiras do tipo P, em $75 \%$ dos cenários apresentaram perdas de investimento variando suas taxas entre $(27,63 \%)$ a (28,65\%), em apenas $25 \%$ dos cenários apresentou retorno positivo de $10,34 \%$; as carteiras do tipo B, apresentaram em $75 \%$ dos cenários retorno positivo variando entre 0,60 a 9,85\%, apresentando apenas em $25 \%$ dos cenários retorno negativo de $(2,15 \%)$, sendo dentro dos cenários com retorno negativo o melhor índice. Em relação a estratégia de construção de carteiras, os dados apresentados permitem afirmar, que a ordenação de entrada dos ativos, dentro de uma cesta de ativos selecionados, apresenta melhor resultado quando a inclusão é realizada em ordem crescente do coeficiente de variação - CV. 
Tabela 6:Resultado da simulação de investimento com as carteiras tipo M, P e B

\begin{tabular}{|c|c|c|c|c|c|}
\hline Tipo Carteira & $\mathrm{CN}$ & $\begin{array}{l}\text { Investimento } \\
(02.01 .2015)\end{array}$ & $\begin{array}{c}\text { Valor da } \\
\text { Carteira } \\
(31.12 .2015)\end{array}$ & Retorno & OBS \\
\hline \multirow{4}{*}{ M } & $\mathrm{C} 10$ & \multirow{14}{*}{$1.000 .000,00$} & 659.359 & $-34,06$ & \multirow{4}{*}{$\begin{array}{c}100 \% \text { de } \\
\text { retorno } \\
\text { negativo }\end{array}$} \\
\hline & $\mathrm{C} 20$ & & 821.331 & $-17,87$ & \\
\hline & C30 & & 790.834 & $-20,92$ & \\
\hline & $\mathrm{C} 40$ & & 915.781 & $-8,42$ & \\
\hline \multirow{4}{*}{$\mathrm{P}$} & $\mathrm{C} 10$ & & 1.103 .396 & 10,34 & \multirow{4}{*}{$\begin{array}{l}25 \% \text { de } \\
\text { retorno } \\
\text { positivo }\end{array}$} \\
\hline & $\mathrm{C} 20$ & & 723.733 & $-27,63$ & \\
\hline & $\mathrm{C} 30$ & & 701.276 & $-29,87$ & \\
\hline & $\mathrm{C} 40$ & & 713.500 & $-28,65$ & \\
\hline \multirow{4}{*}{ B } & $\mathrm{C} 10$ & & 1.098 .511 & 9,85 & \multirow{4}{*}{$\begin{array}{l}75 \% \text { de } \\
\text { retorno } \\
\text { positivo }\end{array}$} \\
\hline & $\mathrm{C} 20$ & & 1.026 .857 & 2,69 & \\
\hline & $\mathrm{C} 30$ & & 1.006 .015 & 0,60 & \\
\hline & $\mathrm{C} 40$ & & 978.452 & $-2,15$ & \\
\hline \multicolumn{2}{|c|}{ IBOVESPA } & & 866.858 & $-13,31$ & \\
\hline \multicolumn{2}{|c|}{ DOLAR } & & 1.475 .998 & 47,49 & \\
\hline
\end{tabular}

Fonte: Elaborada pelos Autores

Figura 11: Resultado da simulação do investimento nos três tipos de carteiras

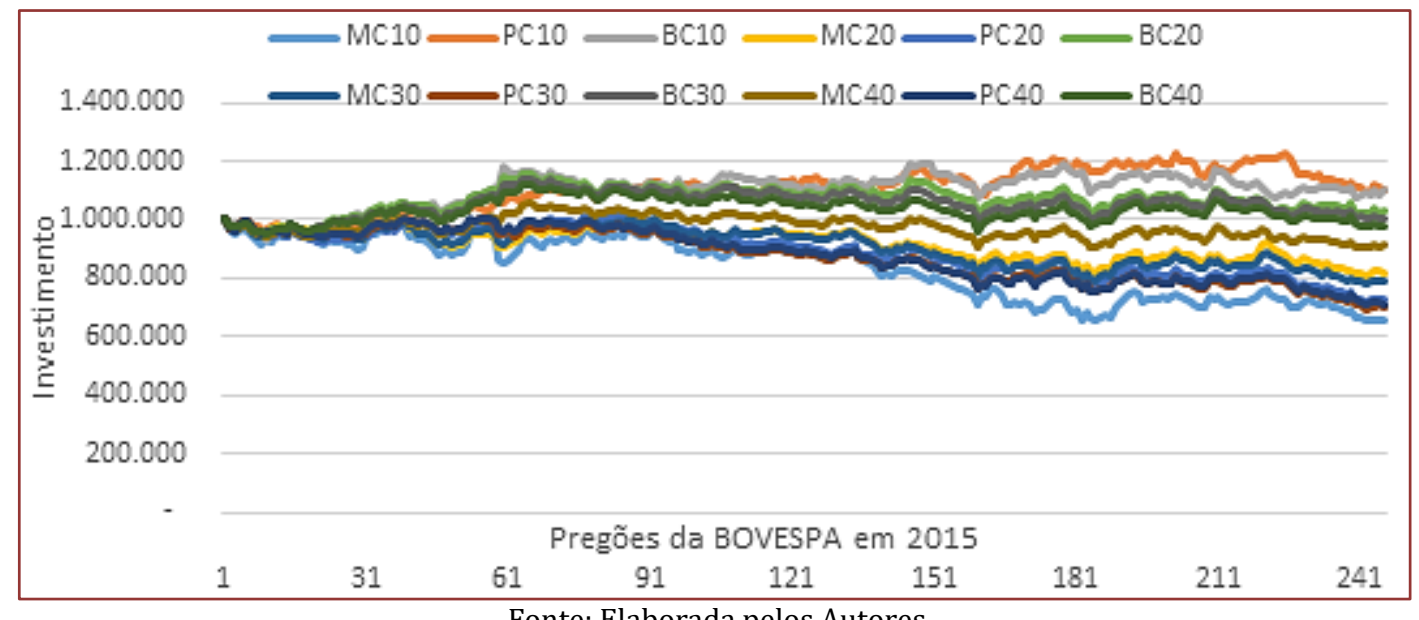

Fonte: Elaborada pelos Autores

\section{CONSIDERAÇõES}

A diversificação de carteiras de investimento busca em seu âmago a redução de risco individual dos ativos. A busca pela redução do risco está intimamente relacionada ao perfil do investidor. Investidores são mais ou menos avessos ao risco. 0 estudo sistemático sobre a diversificação das carteiras de investimentos procura identificar e testar métodos de construção de carteiras que reduzam os riscos individuais dos ativos e produzam retornos esperados.

A presente pesquisa buscou testar uma metodologia própria a partir de premissas básicas e construir três tipos de carteiras: a primeira de agregação de ativos de forma aleatória, sem levar em consideração os coeficientes de correlação, desvios padrões individuais dos ativos e os coeficientes de variação. A princípio este tipo de carteira simula o comportamento de um investidor sem experiência e ou informações de mercado. 0 segundo tipo foi extraído da primeira amostra de 115 ativos um subconjunto com 43 ativos fortemente correlacionados negativamente. A terceira carteira foi construída utilizando-se o coeficiente de variação dos ativos individuais. A análise dos experimentos revelou que tanto as carteiras aleatórias como as construídas com base na correlação apresentaram uma distribuição dos desvios padrões assintomáticos, enquanto a carteira construída a partir do coeficiente de variação apresentou uma distribuição próxima a descrita na literatura, com redução sintomática dos desvios padrões à medida que novos ativos foram sendo inclusos. Um ponto comum entre as três carteiras é que os desvios padrões das carteiras são em sua maioria menores que os ativos individuais. 
O estudo buscou simular os três tipos de carteiras com dados reais coletados nos 246 pregões da bolsa de valores de São Paulo - BOVESPA no ano de 2015. Utilizou-se o IBOVESPA e a taxa cambial do Dólar como investimento de controle para efeitos de comparação. Os resultados obtidos ilustrados na Tabela 6, revelam que as carteiras construídas aleatoriamente em 100\% dos cenários testados apresentaram retornos negativos; as carteiras construídas com base nos coeficientes de correlação apresentaram 25\% de retorno positivo, enquanto que com as carteiras formadas pelo critério do coeficiente de variação os resultados indicam que em $75 \%$ dos cenários os retornos obtidos foram positivos. Ao comparar os resultados das simulações das carteiras com o IBOVESPA e com o DOLAR, pode-se afirmar que para as condições de negócios da BOVESPA em 2015, os resultados dos três tipos de carteiras foram inferiores aos resultados simulados com a aquisição do DOLAR. Todavia, comparando os resultados das carteiras com o IBOVESPA, em 25\% dos cenários tanto as carteiras aleatórias quanto as formadas pelos coeficientes de correlação foram superiores ao IBOVESPA, enquanto que as carteiras construídas a partir dos coeficientes de variação superaram o IBOVESPA em 100\% dos cenários simulados.

\section{REFERÊNCIA}

[1] ALEKNEVICIENE, V., ALEKNEVICIUTE, E., \& RINKEVICIENE, R. 2012. Portfolio size and diversification effect in lithuanian stock exchange Market. Inzinerine Ekonomika-Engineering Economics, 23(4), 338-347.

[2] BERGIN, P. R., \& PYUN, J. H. 2016. International portfolio diversification and Multilateral effects of correlations. Journal of International Money and Finance 62, 52-71.

[3] BODIE, Z., \& MERTON, R. C. 2000. Finance. Prentice-Hall, Inc.

[4] BRUNER, R. F., LI, W., KRITZMAN, M., MYRGREN, S., \& PAGE, S., 2008. Market integration in developed and emerging markets: evidence from the CAPM. Emerging Markets Review 9, 89-103.

[5] CAMPBELL, J. Y., LETTAU, M., MALKIEL, B. G., \& XU, Y. 2001. Have individual stocks become more volatile? An empirical exploration of idiosyncratic risk. The Journal of Finance, Vol. 56, No. 1. (Feb), pp. 1-43.

[6] EHRHARDT, M. C., \& BRIGHAM, E. F. 2012. Administração financeira: teoria e prática. São Paulo: Cengage Learning.

[7] FAMA, E. F., \& FRENCH, K. R. 1993. Common risk factors in the returns on stocks and bonds. North-Holland: Journal of Financial Economics no 33, pp. 3-56.

[8] GOETZMANN, W. N.; \& KUMAR, A. 2008. Equity Portfolio Diversification. Review of Finance.12: 433-463.

[9] HYUNG, N., \& VRIES, C. G. 2005. Portfolio diversification effects of downside risk. Journal of Financial Econometrics, Vol. 3, No. 1, 107-125.

[10] NEWBOULD, G. D., \& POON, P. S. 1993. The Minimum Number of Stocks Needed for Diversification. Financial Practice and Education, 3, 85-87.

[11] NIEUWERBURGH, S. V., \& VELDKAMP, L. 2010. Information Acquisition and Under-Diversification. Review of Economic Studies 77, 779-805.

[12] SHARPE, W. F., ALEXANDER, G. J., BAILEY, J. V., \& FOWLER, D. J. 1997. Investments. Second Canadian Edition, Scarborough, Ontario, Prentice Hall Canada Incorporated.

[13] STATMAN, M. 1987. How Many Stocks Make a Diversified Portfolio? Journal of Financial and Quantitative Analysis, 22, 353-363.

[14] WOERHEIDE, W., \& PERSSON, D. 1993. An Index of Portfolio Diversification. Financial Services Review, 2(2), 73-85.

[15] TANG, G. Y. N. 2004. How Efficient is Naive Portfolio Diversification? An Educational Note. The International Journal of Management Science, 32, 155-160.

[16] TU, J., \& ZHOU, G. 2011. Markowitz meets Talmud: A combination of sophisticated and naive diversification strategies. Journal of Financial Economics 99 204-215. 


\section{Capítulo 4}

Custo de implantação e viabilidade econômica do cultivo de uva niagara no município de Jales-SP

Christian Turato Bolognezi

João Vitor Ferrari

Edy Carlos Santos de Lima

Resumo: A uva é um dos produtos mais consumidos no mundo, seja processada ou in natura, dando origem a inúmeros produtos derivados. Na região noroeste paulista há um grande cultivo de uvas, destacando a região de Jales-SP. 0 trabalho teve como objetivo analisar o custo de implantação e viabilidade econômica do cultivo da uva niagara no município de Jales- SP. Para tanto, visitaram-se propriedades típicas na produção de uva niagara no referido município para o levantamento dos dados técnicos desta atividade e seus indicadores de lucratividade.

Palavras Chave: Lucratividade; Viabilidade; Uva Niagara; Custo de Implantação. 


\section{INTRODUÇÃO}

A viticultura no Brasil vem ganhando cada vez mais expressão no contexto agrícola e um dos motivos é a capacidade do país em exportar frutas "in natura" para outros países como os Estados Unidos e a Europa, quando estes estão na entressafra. Novas áreas estão sendo utilizadas para o plantio da uva e a região do semiárido vem se mostrando uma região apta para a produção de frutas com qualidade para a exportação. 0 consumo brasileiro de uva tem crescido na última década; passando de, $4 \mathrm{~kg} \mathrm{hab}^{-1} \mathrm{ano}^{-1}$ na década de 80 para $2,5 \mathrm{~kg} \mathrm{hab}^{-1} \mathrm{ano}^{-1}$ no ano de 1999 (Araújo, 2000).

Nas regiões leste e sudoeste do Estado de São Paulo, os Escritórios de Desenvolvimento Rural (EDRs), de Campinas (municípios de Jundiaí e Louveira) e de Sorocaba e Itapetininga respondem, respectivamente, por $67 \%, 14 \%$ e $10 \%$ da produção de Niagara Rosada. Na região noroeste do Estado, o EDR de Jales que responde por $2 \%$ da produção tem registrado um aumento expressivo no cultivo dessa variedade (BANCOIEA, 2007).

No estado de São Paulo os principais cultivares de uvas rusticas utilizadas são: a Niagara Branca, Niagara Rosada, Isabel e a Concord. Atualmente as regiões mais abrangentes em áreas plantadas com videira rusticas concentram-se nos estados da Bahia, Minas Gerais, Pernambuco, Paraná, Santa Catarina e São Paulo (MELLO, 2011).

Na região de Jales, a produção da uva exige muito conhecimento técnico de irrigação, reguladores vegetais e sistemas de podas fundamentais para a produção de uvas de qualidade e fora da época de produção, (COSTA, 2011).

É importante ressaltar que a uva de mesa possui um mercado internacional altamente competitivo, tanto em preço e qualidade, situação que obriga os produtores a executar suas atividade de produção, com alta eficiência técnica e econômica, com risco de perder espaço de mercado e perder lucro consequentemente.

E esses custos que interferem significativamente na exploração e exigem que o viticultor passe a gerenciar com mais profissionalismo sua unidade produtiva, a fim de obter uma alta produtividade física, e uma alta produtividade econômica.

E por ser em nossa região uma cultura tradicional e muito importante tanto para o município quanto para os produtores e até para quem pensa investir no ramo, torna-se necessário que os produtores ou investidores tenham um conhecimento dos custos e receitas de suas explorações agrícolas, se quiserem determinar a sua real viabilidade. Este projeto, que teve como objetivo determinar os custos de implantação e rentabilidade da uva niagara produzida ra região de Jales - SP.

\section{REFERENCIAL TEÓRICO}

Na literatura estão presentes vários artigos que em projetos foram utilizadas ferramentas para análises e também metodologias de custos de produção foram utilizadas para tomadas de decisão de investimentos relacionados à agricultura, principalmente à fruticultura. Fett, et al (2000).

Para obter um levantamento de custo de produção agrícola outra forma usada é pela metodologia denominada painel (GUIDUCCI et al., 2012). Isso consiste em uma reunião com pesquisadores, produtores e responsáveis técnicos para elaboração de uma planilha de custo de produção da propriedade mais como, ou "típica", na região alvo (PLAXICO; TWEETEN, 1963; WHITE, 2008; FERREIRA FILHO et al.,2009; PAGLIUCA, 2014).

Portanto, as informações necessárias para a discussão no painel são principalmente: produtividade média, área da propriedade em produção e em implantação estrutura mais comum de condução na região, manejo adotado, adensamento, preço praticado na comercialização, entre outras informações. Através desse método é possível obter os dados necessários à estrutura convencional de um propriedade considerada "típica" na região, com ferramentas utilizadas, equipamentos, máquinas e determinar os tratos culturais além de produtividade média e modo de captação de recursos para implantação das videiras ou safra: participação de capital próprio e capital de terceiros. (CAPPELLO, 2014).

Segundo o CRC-SP (1992, p. 16), a contabilidade de custos deve atender a três objetivos básicos, que são: 1- Determinação do lucro utilizando os dados dos registros convencionais de contabilidade; 2- Controle das operações do estoque, estabelecimento de padrões e orçamentos entre o custo real e o orçado e, ainda, previsões; 3 - Tomada de decisões, formação de preços, quantidade a ser produzida, que produto produzir, corte de produtos, comprar ou fabricar. 
Santos (2005, p. 23) afirma que o coração está para a vida do corpo, assim como o controle do custo para a vida da empresa.

A gestão nas propriedades rurais enfrenta aspectos específicos que são incontroláveis como, variações climáticas, perecibilidade dos produtos, pragas, doenças e como consequência desses aspectos a produção se torna sazonal, dificultando ainda mais o controle gerencial (BATALHA, 2013).

Afonso (2000), complementa que é importante se conhecer os processos de execução para se conseguir reduzir custos, sem comprometer a qualidade dos serviços prestados.

\section{PROCEDIMENTOS METODOLÓGICOS}

Primeiramente para o levantamento dos dados foi, feita uma revisão na literatura sobre viticultura de forma geral. As unidades agrícolas de análise desse projeto (plano de negócio) são produtoras de uva niagara na região de Jales - SP e para a obtenção dos dados a serem coletados foram utilizado os seguintes procedimentos: 1- Entrevistas com técnicos e engenheiros agrônomos da área de produção das empresas que prestam assistência técnica e até mesmo com o produtor rural, para se identificar as atividades e quantificar as atividades executadas pelos mesmos para a produção da uva, e também a estrutura das propriedades produtoras de uva; 2- 0 levantamento dos insumos foi realizada nas próprias empresas que comercializam em Jales - SP; 3- Os preços de venda da uva foram obtidos com os próprios produtores entrevistados.

E foram feitos usos de pesquisas bibliográfica, onde se buscou o embasamento teórico através de revista e artigos publicados na internet por instituições e autores.

Para a análise dos custos de implantação da cultura e de sua viabilidade já que a videira é uma cultura perene, com vida útil prevista para 20 anos foi desenvolvido um projeto (plano de negócio) de implantação da cultura da uva niagara.

\section{RESULTADOS}

Tabela 1. Custo de implantação e manutenção de 02 (dois) hectares de uva niagara na região de jales - SP, ano I (um). 2017.

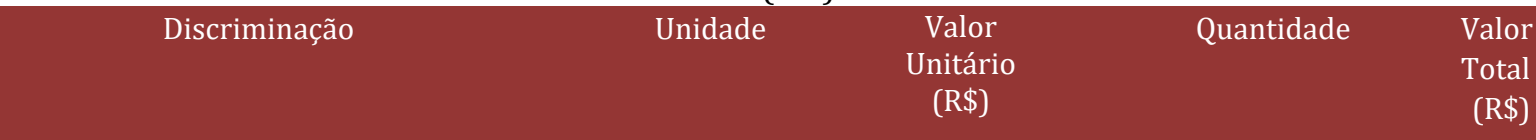

Estruturação do Terreno e Preparo do solo

\begin{tabular}{|l|c|c|c|c|}
\hline Gradagem pesada & $\mathrm{Hm}$ & 140,00 & 1 & 140,00 \\
\hline Gradagem Pesada & $\mathrm{Hm}$ & 40,00 & 1 & 40,00 \\
\hline Gradagem niveladora & $\mathrm{Hm}$ & 110,00 & 2 & 220,00 \\
\hline Calagem Subtotal & $\mathrm{Hm}$ & 110,00 & 1,20 & 132,00 \\
\hline \multicolumn{2}{|c|}{} & & & $\mathbf{5 3 2 , 0 0}$ \\
\hline Plantio & & 2000 & $4.000,00$ \\
\hline Estacas Porta Enxertos & Unidade & 2,00 & 4000 & $1.600,00$ \\
\hline Borbulha & Unidade & 0,40 & 16 & 272,00 \\
\hline Plantio e Replantio & $\mathrm{Dh}$ & 17,00 & $\mathbf{5 . 8 7 2 , 0 0}$ \\
\hline \multicolumn{1}{|c|}{ Subtotal } & & & & \\
\hline
\end{tabular}


continuação...

Tabela 1. Custo de implantação e manutenção de 02 (dois) hectares de uva niagara na região de jales - SP, ano I (um). 2017

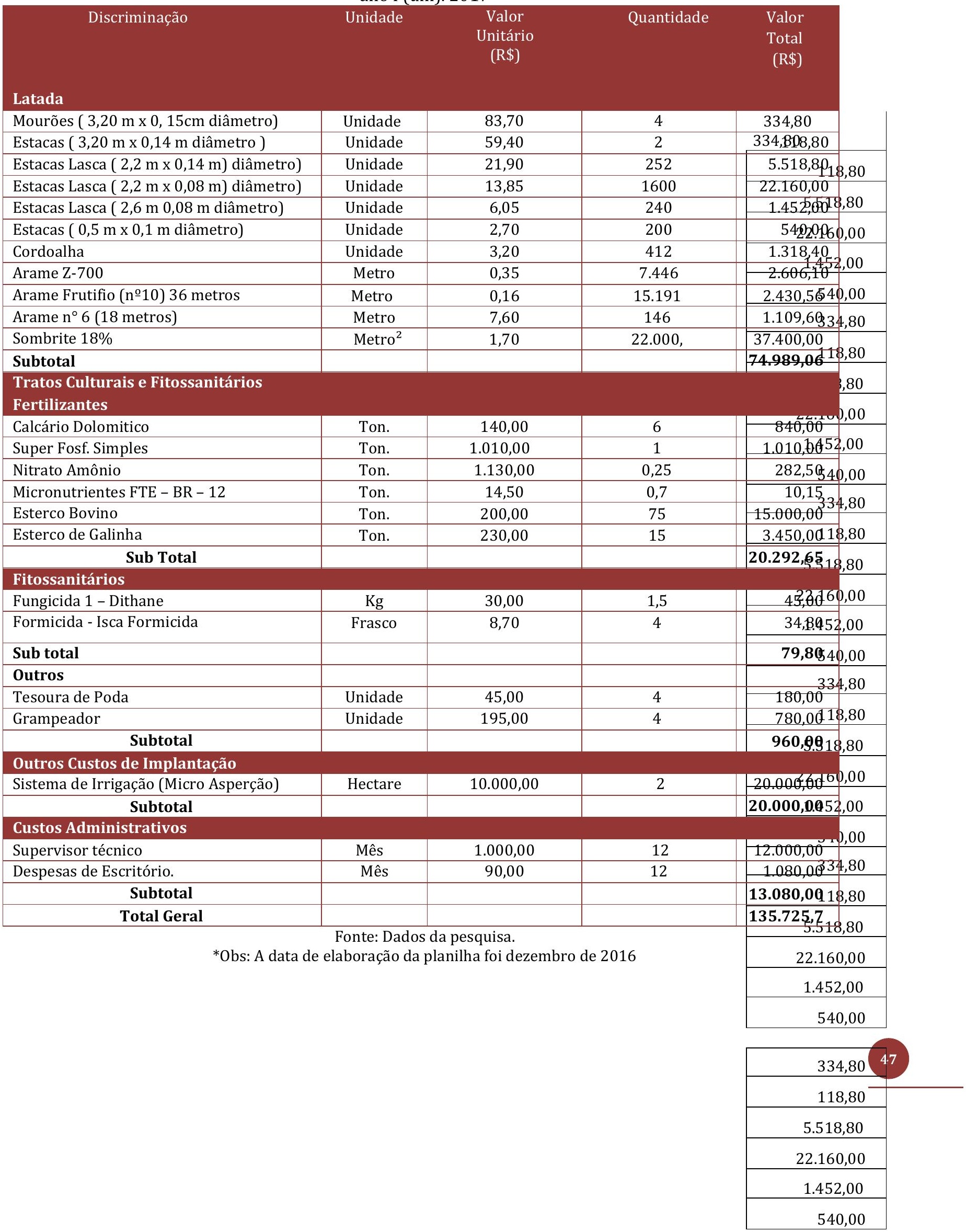


Tabela 2 - custo de implantação e manutenção de 02 (dois) hectares de uva niagara na região de jales - SP, anos II (dois) e III (três).

\begin{tabular}{|c|c|c|c|c|c|c|}
\hline & & & An & & & \\
\hline Discriminação & $\begin{array}{l}\text { Unida- } \\
\text { de }\end{array}$ & $\begin{array}{c}\text { Valor } \\
\text { Unit. (R\$) }\end{array}$ & $\begin{array}{c}\text { Quantida - } \\
\text { de }\end{array}$ & $\begin{array}{l}\text { Valor } \\
\text { Total } \\
(\mathrm{R} \$)\end{array}$ & $\begin{array}{l}\text { Quantida- } \\
\text { de }\end{array}$ & $\begin{array}{l}\text { Valor } \\
\text { Total } \\
(\mathrm{R} \$)\end{array}$ \\
\hline Tratos Culturais e Fertilizantes & Ton. & 140,00 & 1,5 & 210,00 & 1 & 140,00 \\
\hline Super Fosfato Simples & Ton. & $1.010,00$ & 1,07 & $1.080,70$ & 0,53 & 535,30 \\
\hline Cloreto de Potassio & Ton. & $1.820,00$ & 0,2 & 364,00 & 0,13 & 236,60 \\
\hline Fórmula $19-10-19$ & Ton. & $1.650,00$ & 0,8 & $1.320,00$ & 0,8 & $1.320,00$ \\
\hline Micronutrientes FTE - BR - 12 & Ton. & 14,50 & 0,04 & 0,58 & 0,04 & 0,58 \\
\hline Adubo Foliar & Litro & 12,00 & 3,58 & 42,96 & 3,58 & 42,96 \\
\hline Esterco Bovino & Ton. & 200,00 & 10,6 & $2.120,00$ & 6,7 & $1.340,00$ \\
\hline Esterco de Galinha & Ton. & 230,00 & 2,7 & 621,00 & 4 & 920,00 \\
\hline Sub total & & & & $5.759,24$ & & $4.535,44$ \\
\hline Fitossanitarios & & & & & & \\
\hline Ethephon $720 \mathrm{~g} / \mathrm{l}$ & Litro & 150,00 & 3,5 & 525,00 & 3 & 450,00 \\
\hline Cinamida Hidrogenada & Litro & 105,00 & 9 & 945,00 & 8 & 840,00 \\
\hline Regulador Vegetal - Giberelin & Grama & 7,40 & 14 & 103,60 & 14 & 103,60 \\
\hline Fungicida 1- Dithane & $\mathrm{Kg}$ & 30,00 & 25,76 & 772,80 & 25,76 & 772,80 \\
\hline Fungicida 2- Cerconil & $\mathrm{Kg}$ & 39,00 & 0,34 & 13,26 & 0,21 & 8,19 \\
\hline Controle Alternária - Folicur & Litro & 99,00 & 1,3 & 128,70 & 0,92 & 91,08 \\
\hline Inseticida - Karate & Litro & 58,00 & 0,7 & 40,60 & 0,46 & 26,68 \\
\hline Formicida - Isca Formicida & Frasco & 8,70 & 1,5 & 13,05 & 1 & 8,70 \\
\hline Fita & Pacote & 8,75 & 54 & 472,50 & 22 & 192,50 \\
\hline Grampo & Caixa & 3,00 & 46 & 138,00 & 19,00 & 57,00 \\
\hline Subtotal & & & & $3.152,51$ & & $2.550,55$ \\
\hline Custos Administrativos & & & & & & \\
\hline Supervisor técnico & Mês & $1.000,00$ & 12 & $12.000,00$ & 12 & $12.000,00$ \\
\hline Despesas de Escritório. & Mês & 90,00 & 12 & $1.080,00$ & 12 & $1.080,00$ \\
\hline Subtotal & & & & $13.080,00$ & & $13.080,00$ \\
\hline Total & & & & $21.961,75$ & & $20.165,99$ \\
\hline
\end{tabular}

Fonte: Dados da pesquisa.

*Obs: A data de elaboração da planilha foi dezembro de 2016

A partir do terceiro ano de produção até decimo catorze os custos com insumos, matérias se mantem iguais.

Tabela 3 - Demonstrativo de resultados de 02 (dois) hectares de uva niagara em Jales - SP

\begin{tabular}{|c|c|c|c|c|c|c|}
\hline \multirow[b]{2}{*}{ Descrição } & \multicolumn{2}{|c|}{ Ano 1 (Produção) } & \multicolumn{2}{|c|}{ Ano 2 (Produção) } & \multicolumn{2}{|c|}{ Ano 3 ao 14(Prod.) } \\
\hline & $(\mathrm{R} \$)$ Anual & $(\%)$ & $(\mathrm{R} \$)$ Anual & $(\%)$ & $(\mathrm{R} \$)$ Anual & $(\%)$ \\
\hline 1. Receita com Total de Vendas & $\mathrm{R} \$ 240.370,00$ & $100 \%$ & $\mathrm{R} \$ 240.370,00$ & $100 \%$ & $\mathrm{R} \$ 2.644 .070,00$ & $100 \%$ \\
\hline 2. Custo Variáveis Totais & $\mathrm{R} \$ 48.393,11$ & $20,13 \%$ & $\mathrm{R} \$ 6.666,75$ & $2,77 \%$ & $\mathrm{R} \$ 57.859,89$ & $2,19 \%$ \\
\hline $\begin{array}{l}2.1 \text { (-) Custos com Materiais } \\
\text { diretos e/ou CMV }\left(^{*}\right)\end{array}$ & - & - & - & - & 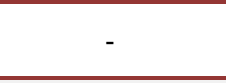 & - \\
\hline $2.2(-)$ Impostos sobre Vendas & $\mathrm{R} \$ 31.130,15$ & $12,95 \%$ & $\$ 31.130,15$ & $12,95 \%$ & $\mathrm{R} \$ 342.431,69$ & $12,95 \%$ \\
\hline 2.3 (-) Gastos com Vendas & $\mathrm{R} \$ 0,00$ & $\mathrm{R} \$ 0,00$ & $\mathrm{R} \$ 0,00$ & $0,00 \%$ & $\mathrm{R} \$ 0,00$ & $0,00 \%$ \\
\hline Total de Custos Variáveis & $\mathrm{R} \$ 79.523,26$ & $33,08 \%$ & $\mathrm{R} \$ 37.796,90$ & $15,72 \%$ & $\mathrm{R} \$ 400.291,58$ & $15,14 \%$ \\
\hline 3. Margem de Contribuição & $76 \%$ & $0,00 \%$ & $76 \%$ & $0,00 \%$ & $479 \%$ & $0,00 \%$ \\
\hline $4(-)$ Custos Fixos Totais & $\mathrm{R} \$ 56.699,88$ & $23,59 \%$ & $\mathrm{R} \$ 56.699,88$ & $23,59 \%$ & $\mathrm{R} \$ 56.699,88$ & $2,14 \%$ \\
\hline Resultado Operacional: & $\mathrm{R} \$ 104.146,86$ & $43,33 \%$ & $\mathrm{R} \$ 145.873,22$ & $60,69 \%$ & $\mathrm{R} \$ 2.187 .078,54$ & $82,72 \%$ \\
\hline
\end{tabular}
Fonte: Dados da pesquisa.

*Obs: 0 ano 1 é referente ao ano de produção, e do ano 3 ao 14 como a produção se estabiliza e fica igual entre eles, foi feita uma multiplicação x (vezes) 11 anos que é o total do 3 ao 14. 
Tabela 4 - Indicadores de viabilidade de 02 (dois) hectares de uva niagara em Jales - SP

\begin{tabular}{|c|c|c|c|c|c|}
\hline Indicadores & Ano 1 & Ano 2 & Ano 3 & Ano 4 & Media \\
\hline $\begin{array}{l}\text { Ponto de Equilíbrio Financeiro } \\
\text { (em unidades produzidas) }\end{array}$ & $\mathrm{R} \$$ & 18738 & 11336 & 11084 & 13719,35 \\
\hline $\begin{array}{l}\text { Ponto de Equilíbrio Econômico } \\
\text { (em unidades produzidas) }\end{array}$ & $\mathrm{R} \$$ & 39452 & 30139 & 133894 & 67828,41 \\
\hline Lucratividade (em \%) & $\mathrm{R} \$$ & $6,31 \%$ & $79,43 \%$ & $94,16 \%$ & $59,97 \%$ \\
\hline Rentabilidade (em \%) & $\mathrm{R} \$$ & $14,90 \%$ & $187,37 \%$ & $222,11 \%$ & $141,46 \%$ \\
\hline Prazo de retorno (em anos) & $\mathrm{R} \$ \quad-$ & 17,2 & 1,4 & 0,1 & 6,23 \\
\hline
\end{tabular}

*Obs: Retorno esperado para cálculo do ponto de equilíbrio econômico no 2 ano 50\% e do 3 ao 14 ano $60 \%$.

\section{DISCUSSÃo}

\subsection{CARACTERIZAÇÃO DOS CUSTOS}

Antes de entrar nas análises dos custos, é interessante comentar, que alguns fatores têm contribuído para essa expansão da uva niagara como: maior rusticidade, menor custo de produção, maior facilidade no momento da venda e melhores preços. De acordo com os produtores entrevistados e um especialista, essa cultivar requer menos mão-de-obra nos tratos culturais, um menor uso de defensivos por ser mais rústica a doenças e a colheita mais simplificada por ser uma variedade rústica.

Na Tabela 1, são apresentados os custos de instalação e de manutenção do primeiro ano de exploração de dois hectares de uva de niagara, no pólo de produção de Jales - SP. O sistema típico de cultivo da uva niagara apresenta um espaçamento médio de 1,50 m (Entre plantas) x 2,50m (Entre ruas) ocupando um espaço de $3,75 \mathrm{~m}^{2}$ por pé de uva, com irrigação por micro aspersão, sendo que, já no primeiro ano, alcança uma produtividade média de $21 \mathrm{t} / \mathrm{ha}$.

Neste projeto (plano de negócio) se buscou mostrar sistema típico de cultivo de uva niagara no sistema de cultivo latada. Constata-se, nesta análise, que os gastos com a confecção da latada, respondem por cerca de $55,25 \%$ do custo total e com o gasto mais expressivo tem o sombrite no primeiro ano de cultivo da uva. Já os gastos referentes ao preparo do solo são responsáveis por menos de $0,5 \%$ deste mesmo custo, enquanto os tratos culturais e fitossanitários, a compra de adubos representa o gasto mais elevado (Tabela 1).

No segundo ano (Tabela 2), os tratos culturais e fitossanitários correspondem a 40,57\% do custo total, em um vinhedo típico. Neste segmento, o gasto mais representativo entre os insumos é a aquisição dos adubos e alguns fungicidas.

No terceiro ano de cultivo (Tabela 3), quando a uva niagara alcança a produtividade plena, da ordem de 21 t/ha, e se estabiliza constata-se que os gastos correspondentes ao segmento dos tratos culturais e fitossanitários passam a ser inferiores aos contabilizados no primeiro e segundo ano de produção.

A análise apresentada na Tabela 3 apresenta os demonstrativo de resultados do primeiro ano ao último ano de produção de uma videira adulta. Entretanto, por se tratar de uma cultura perene com vida útil prevista para 20 anos, más em nossa região é feita a renovação com 14 anos. E para o cálculo dos indicadores de rentabilidade da produção da uva niagara na região de Jales - SP considerou-se preço de venda de $\mathrm{R} \$ 5,59 / \mathrm{kg}$.

No projeto (plano de negócio) da uva niagara, observa-se que a partir do 2.․ ano de implantação que começa a produzir, e a lucratividade já poderá ser positivo. Portanto, a recuperação do investimento acontecerá entre o quarto e o quinto ano, como pode ser observado na Tabela 4.

Dentre os custos levantados, até a viabilidade do projeto (plano de negócio) é muito importante saber todos esses custos discriminados e de forma coerente para a obtenção dos melhores resultados possíveis e consistentes com a região a ser estudada.

E pra isso deve-se observar as características da região, como quais espécie mais plantada, os tratos culturais utilizados, qual o valor de venda da uva, e até mesmo se as propriedades visitadas são parecidas em nível tecnológico, tratos culturais e assim buscar pro propriedades que não se diferenciem da propriedade tradicional. Como disse Guiducci et al., (2012) para obter um levantamento de custo de produção agrícola outra forma usada é pela metodologia denominada painel. 


\section{CONSIDERAÇÕES FINAIS}

O estudo revela que a exploração da uva niagara na região de Jales - SP é uma atividade altamente rentável, visto que, nas diversas análises de desempenho financeiro e econômicos estudadas os resultados foram bastantes positivos. E diante desses dados podemos observar que os custos de implantação de um parreira de uva são altos só para confecção da latada, é cerca de 55,25\% do custo total do primeiro ano.

E mesmo com todos esses gastos elevados ainda compensa investir na área, desta forma conclui-se que a viabilidade da produção de uva niagara no município de Jales - SP se mantem favorável ao produtor, foi estimado um retorno em um curto prazo de 4 anos, além de o demonstrativo ter apresentando um ótimo resultado operacional.

E com a apresentação desses dados para agricultores que pensam em sair do ramo da viticultura por não dar lucro, iram consegui perceber que o problema está na administração da propriedade e isso o ajudará a localizar o erro e a ajuda-lo a voltar a ter lucro, e o projeto (plano de negócio) também ajudará aqueles que ainda tem dúvida se investem ou não na área da viticultura em Jales - SP. Entretanto, tem a existência do risco climático, já que a ação de agentes da natureza é uma variável que interfere na produtividade dos vinhedos não podendo ser controlada.

\section{REFERÊNCIAS}

[1] AFONSO, Roberto Alexandre E. O direcionamento dos recursos públicos para as atividades fins do Estado. Brasil. Ministério da Fazenda. Secretaria do Tesouro Nacional. IV Prêmio da STN de Monografias. Brasília: ESAF, 2000.

[2] BANCOIEA. Previsões e estimativas das safras agrícolas no estado de São Paulo. 2007. Disponível em: http://www.iea.sp.gov.br.

[3] BATALHA, Mário Otávio; Gestão Agroindustrial: GEPAI - Grupo de estudos e pesquisas agroindustriais; 3. ed.; Atlas; São Paulo, 2013

[4] CAPPELLO, F, P. Análise comparativa do custo de produção e rentabilidade da uva 'Niágara Rosada' cultivada em diferentes regiões do Estado de São Paulo. 2014. 105 f. Dissertação (Mestrado em Ciências) - Universidade de São Paulo, Piracaba, 2014.

[5] COSTA, T. V.; Avaliação Técnica e Socioeconômica da Cultura da Uva para Mesa em Pequenas Propriedades Rurais da Região de Jales (SP). Disponível em: http://repositorio.unesp.br/handle/11449/98724 acesso em: $15 / 04 / 2017$.

[6] COSTA, T. V.; TARSiTANO, M. A. A.; CONCEIÇÃO, M. A. F. Caracterização Social e Tecnológica da Produção de Uvas para Mesa em Pequenas Propriedades Rurais da Região de Jales-SP. Disponível em: http://www.scielo.br/scielo.php?script=sci_arttext\&pid=S0100-29452012000300016. Acesso em: 21/05/2017.

[7] CRC - SP. Curso sobre Contabilidade de Custos. 5. ed. São Paulo: Atlas, 1992.

[8] GUIDUCCI, R.C.N.; ALVES, E.R.A.; MOTA, M.M. Aspectos metodológicos da análise de viabilidade econômica de sistemas de produção. In: GUIDUCCI, R.C.N.; LIMA FILHO, J.R.;

[9] MELLO, L. M. R; Agência Embrapa de informação e tecnologia: Mercado Brasileiro de Uvas e Vinhos, Panorama 2011. Disponível em

[10] http://www.agencia.cnptia.embrapa.br/gestor/uva_para_processamento/arvore/CONT000g56 mkakt02wx5ok0dkla0saajvx4x.html. Acesso em 18/06/2016.

[11] PLAXICO, J.S.; TWEETEN, L.G. Representative farms for policy and projection research. Journal of Farm Economics, Ithaca, v. 45, n. 5, p. 1458-1465, Dec. 1963. Disponível em: <http://chla.library.cornell.edu/cgi/t/text>. Acesso em: 05/06/17

[12] SANTOS, Joel J. Análise de custos: Sistema de custeio marginal, relatórios e estudos de casos. 4. ed. São Paulo: Atlas, 2005. 


\section{Capítulo 5}

\section{Conflitos na gestão de pessoas na construção civil}

\section{Aureliano Tavares}

\section{Orlando Longo}

Robson Sueth

Resumo: Este estudo teve como principal objetivo discutir os tipos de conflito que se manifestam no relacionamento profissional entre o engenheiro civil e seus colaboradores, por ocasião da prática de gestão de pessoas no canteiro de obras em contexto de construção civil. Evidencia as condições em que foram ou puderam ter sido gerados e também analisa seus respectivos efeitos na execução e fiscalização do projeto de construção civil. Com vistas no alcance dos objetivos, desenvolveu-se um estudo descritivo com base na bibliografia pertinente e também apoiado num ensaio de campo que envolveu a participação de 51 engenheiros civis, atuando diretamente na construção civil em empresas de construção civil prestando serviços na cidade do Rio de Janeiro, Brasil. Depois de identificados, analisadas a variáveis que lhes deram origem, bem como discutidos seus efeitos produzidos no contexto de atuação dos engenheiros civis, recomendações foram oferecidas visando estratégias fundamentais que orientem a gestão de conflitos no ambiente de trabalho na construção civil.

Palavras-Chave: Conflitos; Gestão de Pessoas; Conflitos na Construção Civil; Engenharia Civil 


\section{INTRODUÇÃO}

Por influência do desenvolvimento tecnológico, é possível concordar que há notória diminuição dos integrantes da cadeia hierárquica com visível incremento da produtividade nas empresas, atualmente. Da mesma forma que se observa profissionais com conhecimento técnico específico ao negócio institucional, como exemplo, farmacêuticos que antes somente se incumbiam das atividades relacionadas aos medicamentos e orientação de clientes, nos dias de hoje acumulam o papel de gestores nas Drogarias Pacheco, Rio de Janeiro, também o engenheiro civil encarrega-se, além de suas atribuições convencionais, do gerenciamento da obra. Parece uma prática adotada pelas empresas construtoras para enxugar seu quadro de colaboradores, reduzir custos e possibilitar a comunicação direta àquele que vai executar o planejamento da construção contratada.

A gestão, de acordo com Bergue (2010), pode assumir a conotação de administração. Segundo esse autor, administrar trata-se de executar de forma contínua e virtuosa o processo administrativo. No processo administrativo há interação entre, pelo menos, quatro eventos considerados indispensáveis ao ato de administrar. São eles o planejamento, organização, direção e controle, configurando-se num ciclo interdependente. Esses eventos ou fases podem receber diversos desdobramentos por alguns autores, mas têm origem na definição original dos princípios da administração de Taylor (1987).

Logo, não se caracteriza erro entender a gestão como um segmento do processo administrativo, ao se considerar, segundo Fayol (1981), que o gestor é identificado pelas atividades desempenhadas na empresa. Ou seja, é aquele que vai executar o planejamento estratégico e operacional de maneira a obter os melhores resultados que, para isso, considerando a estrutura institucional, cria regras, desenvolve políticas e sugere, com sua liderança e supervisão, ações que vão permitir a consecução dos resultados pretendidos.

Pelos conhecimentos adquiridos e demais atividades desenvolvidas no processo de sua formação, o engenheiro civil se habilita a análise, planejamento e execução de projetos voltados para a promoção da qualidade de vida das pessoas, bem como a preservação ambiental. Especificando suas atribuições técnicas, vai atuar nas áreas de projeto, estruturas, construção civil, saneamento e recursos naturais. Também obtém conhecimentos das ciências administrativas e econômicas.

Por tudo isso, o engenheiro civil se capacita para o estudo, avaliação, fiscalização, elaboração de projetos de construção civil, rodovias, ferrovias, projetos de captação e abastecimento de água, drenagem e irrigação, para atuar em portos, aeroportos, saneamento urbano e rural; em indústrias, empresas comerciais e de serviços, escritórios de elaboração de projetos e consultorias, na construção civil; em instituições de pesquisa e de ensino, de natureza pública e privada. Considerando na sua formação as atribuições de direção, execução e fiscalização de obra e serviço técnico, o engenheiro civil desenvolve perfil de gestor.

Além das atribuições técnicas do engenheiro civil numa obra, é também sua função a gestão dos profissionais diretamente responsáveis pela execução das inúmeras etapas de sua concretização. Nesse contexto, surge uma realidade profissional que precisa ser bem conhecida pelo engenheiro civil. Trata-se da gestão de pessoas. Chiavenato (2005, p.9), define gestão de pessoas como o conjunto de decisões integradas sobre as relações de emprego que influenciam a eficácia dos funcionários e das organizações.

No comando de pessoas, um dos problemas que pode desencadear-se é o conflito. Um tipo de reação regularmente evidenciada nas diversas formas do relacionamento humano. Certamente não escapará o engenheiro civil desse tipo de comportamento em seu ambiente de trabalho. Interpreta-se, portanto, que o conflito sempre existirá em ambiente formado por indivíduos que buscam os mesmos propósitos e possuem interesses comuns, além das condições individuais. Esse tipo de evento, próprio da condição humana, nas empresas pode se deslocar em, pelo menos, dois sentidos: (1) oferecendo discussões proveitosas com troca de conhecimento profissional e pessoal e, por isso, proporcionando maior entrosamento entre os trabalhadores e melhorando o clima organizacional; e (2) desenvolvendo disputas hostis e a antipatia, comprometendo, sobremaneira, o ambiente produtivo e as relações sociais no trabalho. Assim, o engenheiro civil deve considerar seus colaboradores, além das atividades de produção técnica, elementos que têm de receber tratamento que os entenda também como patrimônio institucional. Deles resultarão o cumprimento dos prazos contratuais estabelecidos e a qualidade dos serviços prestados.

0 estudo sobre conflito no ambiente de trabalho não pode se restringir apenas à sua identificação. Deve deslocarse, também, para os possíveis desdobramentos que interferem nas condições satisfatórias e de desenvolvimento harmônico entre integrantes de um grupo de profissionais. 
A busca pela eliminação das barreiras na cadeia produtiva e o estímulo para se estabelecer um ambiente de cooperação são propósitos que se configuram como indispensáveis nessa tarefa. Comunga-se com o entendimento de que o conflito precisa ser tratado numa dimensão dialética, que considere o ambiente de trabalho longe dos efeitos pessoais danosos que pode se desenvolver, prejudicando o processo produtivo. É preciso empregar flexibilidade no tratamento do conflito por se levar em conta seus riscos na execução das atividades profissionais. Um estudo comprometido com essas preocupações se reveste de necessidade, relevância e oportunidade.

Este estudo teve por objetivo geral discutir os tipos de conflito que podem estar se manifestando no relacionamento profissional entre o engenheiro civil e seus colaboradores, por ocasião da prática de gestão de pessoas no canteiro de obras em contexto de construção civil. Como desdobramento, foram identificadas situações conflitivas que se estabelecem por conseqüência da direção de tarefas e/ou orientação técnica do engenheiro civil aos seus subordinados na cadeia hierárquica, durante a execução de projetos de construção civil; evidenciadas condições em que são geradas essas situações de conflito em busca das variáveis responsáveis por sua manifestação; analisados respectivos efeitos das situações de conflitos apuradas, para a direção, execução e fiscalização do projeto de construção civil, objeto do presente estudo; e por fim propostas estratégias fundamentais que orientem a gestão de conflitos no ambiente de trabalho na construção civil, com base no estudo realizado.

A presente investigação caracteriza-se com um estudo descritivo exploratório. De acordo com Vergara (2011), descritivo porque analisa as contribuições fornecidas pela literatura pertinente e por dados extraídos do relacionamento entre o engenheiro civil e seus colaboradores subordinados, e exploratório levando-se em conta que não se possui noções prévias concretas e bem fundamentadas sobre o tema pesquisado. Inicialmente, a pesquisa bibliográfica se constituiu da identificação e posterior consulta em livros, artigos, dissertações, teses e sites pertinentes ao assunto. Questionários com perguntas fechadas foram aplicados aos engenheiros civis que tiveram por finalidade conhecer, de forma direta, os tipos de conflitos que vêm enfrentando no exercício da gestão de seus colaboradores e na execução de seus projetos.

No trabalho de campo o levantamento foi realizado por meio de um questionário composto por perguntas com base no desdobramento das variáveis identificadas como aquelas que pudessem se manifestar nos conflitos ou fossem responsáveis por sua ocorrência, que buscou respostas de 51 engenheiros civis, atuando diretamente na construção civil em empresas de construção civil prestando serviços na cidade do Rio de Janeiro, Brasil, selecionados por amostragem não probabilística acidental, acessando-se aqueles que se encontravam disponíveis e dispostos a responder o respectivo instrumento de coleta de dados, em seus respectivos locais de trabalho, nos dias e horários em que foram efetivamente visitados.

Os dados sofreram tratamento estatístico descritivo por meio da tabulação dos resultados com cálculos de frequência e percentual, com o propósito de facilitar o entendimento do texto pelo uso da representação dos dados numéricos obtidos da análise dos questionários aplicados que teve por finalidade a identificação dos conflitos manifestados, sua caracterização teórica, a classificação das variáveis motivadoras, a argumentação sobre os prováveis desdobramentos profissionais e as iniciais orientações sobre soluções pertinentes.

\section{A GESTÃO E O ENGENHEIRO CIVIL GESTOR}

Reconhecendo os esforços direcionados para conceituar-se o termo gestão, pode-se aceitar com relativo consenso que a gestão seja constituída de uma quantidade de atividades voltadas para o emprego dos recursos disponibilizados pela instituição, visando o alcance de cada objetivo da organização, a contemplar a sua principal missão. Isso atribui à gestão a responsabilidade de conduzir o funcionamento da empresa de forma otimizada com decisões objetivas e sustentadas contribuindo, assim, com o pleno desenvolvimento de seus processos, satisfazendo expectativas internas de proprietários e colaboradores, como também os vários interesses de grupos envolvidos, clientes diretos e da sociedade como um todo.

Pode-se, então, admitir, de maneira mais simples, que a gestão seja uma forma de participação ativa, do profissional encarregado, intervindo diretamente no funcionamento de segmentos específicos em uma organização. $\mathrm{O}$ gestor é um profissional contratado para realizar atividades condizentes à gestão. Para Fayol (1981), o gestor é identificado por aquilo que realiza na empresa. Trata-se daquele que vai interpretar os objetivos organizacionais e atuar por meio de um planejamento, segundo os princípios e cultura da empresa, com vistas no alcance desses objetivos. 
Fugindo-se das características de redundância, os engenheiros civis também realizam estudos, em sua formação profissional, sobre os conteúdos da área de Administração relacionados à gestão, de acordo com a programação dos cursos de engenharia civil oferecidos pelas instituições de ensino superior consultada neste estudo.

Por essa fundamentação, a atividade do engenheiro civil também se apoia na realidade profissional da gestão. Como gestor de logística, função na qual tem de decidir sobre os diversos materiais que precisa adquirir e empregar nas obras, e gestor de pessoas visando o cumprimento do cronograma previsto no projeto de construção acompanhando cada etapa programada e supervisionando as condições de sua execução preservando, dessa forma, os padrões de qualidade e garantindo a segurança no trabalho.

\subsection{A GESTÃO DE PESSOAS NA CONSTRUÇÃO CIVIL}

É constatável a dificuldade de encontrar textos científicos para a devida sustentação de posições sobre a gestão de pessoas na construção civil. Gomez (2009) reforça essa constatação ao realizar sua busca bibliográfica para fundamentar seu texto apresentado no IX Simpósio de Excelência em Gestão e Tecnologia - SEGeT, da Associação Educacional Dom Bosco, ao afirmar que uma pesquisa bibliográfica constata a inexistência de textos metodologicamente construídos para apoiar os gestores e estudiosos de pessoas voltados para empresas de pequeno e médio porte na indústria da construção.

Com base nesse evento, pesquisando sobre os textos aprovados nos últimos cinco anos, foi possível identificar três trabalhos apresentados em 2007, 2008 e 2009. Respectivamente, o artigo intitulado Educação corporativa: principais influências na gestão de pessoas na construção civil, produzido por Fausto de Bessa Braga e Carlos José Guimarães Cova em 2007, tratando-se de:

uma pesquisa bibliográfica com base na literatura brasileira e que visa conhecer as principais influências da educação corporativa como ferramenta estratégica na construção civil brasileira. No mercado competitivo as empresas têm buscado níveis de excelência não dependentes apenas de práticas mecânicas. É neste panorama que entra a educação corporativa; um sistema de desenvolvimento de pessoas que faz progredir as competências ligadas a estratégias de negócios, pois empresas com tecnologia similar estão obtendo mais lucros e vantagens em relação à concorrência investindo na formação e na educação de seus colaboradores. (BRAGA; COVA, 2007, Resumo)

Em 2008 foi encontrado o estudo Práticas Inovadoras na Gestão de Pessoas: Pesquisa realizada em empresas representativas da Indústria da Construção Civil, elaborado por Marcos Muniz Moreira, Carlos Alberto Pereira Soares e Carlos Roberto Jóia Hozumi. Esse trabalho

aborda a gestão de pessoas em empreendimentos da Indústria da Construção Civil. A partir de estudos sobre comportamento organizacional, peculiaridades do setor e sistemas gerenciais, é proposto um modelo de Sistema de Gestão de Pessoas, composto pelas seguintes dimensões: Planejamento Estratégico, Liderança, Atividades Básicas de Recursos Humanos, Sistemas de Informação, Qualidade de Vida, Ética e Responsabilidade Socioambiental, e Resultados. Para levantamento das práticas gerenciais correspondentes àquelas dimensões, foi desenvolvida pesquisa de campo junto a empresas representativas do setor. Como resultado, este trabalho apresenta um conjunto de práticas para a gestão de pessoas de empreendimentos da Construção Civil, que se propõe a contribuir de forma inovadora para a qualidade de vida dos trabalhadores e a lucratividade das empresas. (MOREIRA; SOARES; HOZUMI, 2008, Resumo)

E em 2009 o estudo de José Luiz Portela Gomez, com o título de Gestão de Pessoas na Indústria da Construção Civil Base para a Construção Sustentável - Um Estudo de caso. Esse autor concorda que as chances de sucesso das organizações estão dependentes de uma efetiva gestão de finanças, estratégias, processos de tecnologia e de informações, ambiente, segurança, saúde ocupacional e de outros fatores críticos. Para ele a gestão de pessoas, torna-se imprescindível quando se decide impor excelência na gestão, que vai resultar na sustentabilidade institucional. Nesse artigo,

avalia-se o modelo atual de gestão de pessoas na construção civil, especificamente no setor de obras comerciais. Por meio de algumas abordagens dos processos de gestão de pessoas e das ferramentas existentes para manter as pessoas motivadas 
nas empresas, faz-se um diagnóstico da gestão de pessoas nesse segmento do mercado. Com base na utilização da ferramenta de análise S.W.O.T., sugere-se a implantação de novo modelo de gestão na construção civil, com a aplicação dos conceitos de estratégia empresarial. Como pesquisa de campo, o artigo apresenta um estudo de caso referente a uma empresa de pequeno porte de construção e instalação de Terminais e Bases de Distribuição de Combustíveis e Postos de Serviços e Abastecimento. (GOMEZ, 2009, Resumo)

Apesar da insuficiente literatura sobre esse tema, é possível afirmar que a realidade de convivência profissional entre trabalhadores passa necessariamente pelo grau de atendimento às suas necessidades ao se considerar esse ambiente como um sistema de trocas de valor que acaba por tornar-se uma variável fundamental responsável por instituir uma esfera de harmonização entre os integrantes da empresa e contribuindo com o estabelecimento de um clima de estabilidade organizacional. Pode-se concordar que o progresso institucional por meio da gestão de pessoas precisa ir além dos protocolos das relações interpessoais e criar mecanismos de perceber as necessidades dos trabalhadores e com mais naturalidade contornar as conturbações próprias decorrentes do cotidiano profissional.

Uma variável parece se destacar com mais frequência se referindo à dimensão administrativa apontando para as condições de emprego adequado das ferramentas de gestão. 0 caráter centralizador predominante no processo administrativo das micro e pequenas empresas é notado nos resultados de estudos já conhecidos e acaba por prejudicar mais a partir do crescimento dessas empresas.

Buscando uma análise nas empresas de construção civil, essa situação parece não ser diferente. De acordo com Farah (1996) a utilização intensiva de mão-de-obra e o ritmo sempre acelerado da construção, acabam por indicar problemas com relação à gestão de pessoas e a qualidade das relações entre capital e trabalho. Uma premissa pode ser aceita ao se considerar que a gestão de pessoas nas empresas de construção civil, com a prática constatável de considerar seus trabalhadores como fatores de competitividade, lançam sobre eles o estigma de indústria de resultados, levando dessa forma ao alcance das metas pretendidas e consequente crescimento da empresa.

É possível, pelo menos empiricamente, perceber a distância entre as formas adequadas de gestão de pessoas na construção civil. Tradicionalmente o trabalhador da Construção civil possui uma margem reduzida de opções no mercado de trabalho que para tal não lhe é exigida alta escolaridade. Têm-se notícias, por meio de diversos documentários produzidos pelas emissoras de televisão brasileiras, que a maioria desses trabalhadores constitui-se de migrantes de várias cidades ou da zona rural na busca de um emprego. Em geral suas atividades não lhes exigem capacidade mental que por isso favorece uma forma de acomodação em que aceitam atuar por longo tempo como ajudantes na construção.

Observando com mais atenção, percebe-se que muitos deles se esforçam aprendendo atividades afins para a obtenção de melhores salários como ladrilheiros, por exemplo, e, com isso, tornando sua jornada de trabalho mais motivada. É constatável o consumo de álcool muito provavelmente para suportar as condições pesadas da atividade que desempenha.

Essas características podem dificultar o entendimento sobre o empreendimento no qual é importante integrante e a formação de uma consciência profissional que faz dele um elemento corresponsável pela obra e pela manutenção da empresa. Nessa situação deve-se pensar numa peculiar política de gestão de pessoas que possa estimular a motivação acompanhada de um programa de benefícios como fator desencadeador de produtividade. Pode ser que com essa conduta de gestão diminua os desperdícios de toda natureza, elimine a alta rotatividade entre os trabalhadores e desenvolva um espírito coletivo de comprometimento por parte dos trabalhadores, que provavelmente fazem o que fazem sem o necessário compromisso.

Desde 1999, segundo dados do Instituto Mc Kinsey, acredita-se que a construção civil continua sendo uma das forças da economia no Brasil, correspondendo a 8\% do PIB. Considerando a distribuição percentual de assalariados brasileiros, em 2000, de acordo com o IBGE representava 3,7\% de assalariados. Importante refletir sobre a gestão de pessoas na construção civil com vistas em encontrar uma posição fundamentada para transformar o pensamento que se tem sobre operários apenas, e passar a entender os trabalhadores como capital humano da empresa a fim de mantê-los estimulados a desenvolver capacidades e competências que podem favorecer a obtenção de vantagens competitivas, de acordo com formas planejadas de gestão de pessoas sustentada em estratégias. 


\subsection{PRINCIPAIS CONFLITOS NA GESTÃO DE PESSOAS NA CONSTRUÇÃO CIVIL}

A grande maioria dos engenheiros respondentes $(94,12 \%)$ concorda que já enfrentou algum tipo de resistência por parte de colaboradores no canteiro de obras. Isso pode ser interpretado como possibilidade de conflito que inicialmente tenha sido contornado ou que após a manifestação resistente o problema tenha sido resolvido sem se caracterizar em um clássico tipo de conflito com o pronto entendimento da comunicação que gerou a resistência. Mas, por outro lado os mesmos $94,12 \%$ dos respondentes admitem que esse tipo de resistência pode ser considerado como um conflito de comunicação entre o engenheiro civil e seus colaboradores.

0 dado deve ser considerado com preocupação tendo em vista o elemento motivador da resistência. Se tiver sido provocado por questões técnicas entre o engenheiro e algum funcionário graduado ou com conhecimento prático profissional, a resistência pode ser entendida como um tipo de contestação gerado pela dúvida daquele que resistiu a determinação, o que provavelmente tenha sido sanado sem se constituir em conflito.

Se a resistência teve conotação pessoal, uma análise sobre o relacionamento interpessoal deve ser feita para se descobrir suas razões e imediatamente propor uma solução para o problema, visando-se além da instabilidade da cadeia hierárquica com possibilidade de indisciplina, também os benefícios que a desconstrução daquilo que pode estar impedindo o bom relacionamento pode trazer para a empresa, sem prejudicar suas atividades e seu clima organizacional.

Considerando os dados obtidos com relação a ter conhecimento sobre algum conflito que o respondente já tenha enfrentado no processo de gestão de pessoas, $94.12 \%$ também têm conhecimento de outros conflitos enfrentados por colegas engenheiros. Esse dado se confirma entre os respondentes e oferece constatação da ocorrência do evento entre a totalidade dos $94,12 \%$ dos respondentes. Isso se explica por existir a concordância em ter passado por episódios de conflitos e terem presenciado conflitos ocorridos com os outros respondentes. Ou seja, $94,12 \%$ dos engenheiros passaram por situações conflitivas e os mesmos engenheiros presenciaram essas situações ocorrerem entre outros colegas de profissão ou entre eles mesmos.

Outra interpretação que se pode obter, certamente reduziria o percentual obtido pelo levantamento. Trata-se do entendimento sobre o evento conflitivo observado ter sido o mesmo conflito constatado por todos ou parte dos respondentes. Mas, mesmo assim, não se pode concordar com a falta de mobilização com vistas na tomada de decisão que possibilite formas de controle sobre a manifestação do conflito ou que o converta como evento positivo que elimine as variáveis responsáveis pela sua motivação em prol de um relacionamento profissional mais adequado, aproximação pessoal entre os envolvidos e da adequada manutenção do clima organizacional.

\subsection{CONFLITOS DE COMUNICAÇÃO}

Quando a intenção tratou-se de identificar os tipos de conflito enfrentados pelos engenheiros no canteiro de obras, foi possível conhecer a ocorrência dos conflitos de comunicação. Os engenheiros informaram a existência desse tipo de conflito com percentual de $94,10 \%$. Considerando os diversos tipos de conflito identificados na comunicação, faz-se imprescindível tomar as medidas apropriadas para se evitar que se transforme numa situação grave e incontrolável, principalmente se uma das partes envolvidas não concordar com a negociação por meio do diálogo. Reações pessoais podem se manifestar e se tornar um problema para toda a empresa.

Não se configura objeto do presente estudo, mas pode ocorrer um conflito que se configure como uma situação de disputa entre os envolvidos. É necessário que haja concordância na busca de solução entre eles com adequado processo de negociação.

Imprevisíveis podem ser as motivações dos conflitos de comunicação. Uma preocupação que se deve ter nesse tipo de conflito refere-se ao momento da emissão da mensagem e a quem deve ser dirigida. 0 estresse ou outras formas de desgastes físicos ou emocionais podem influenciar a recepção da mensagem e torná-la distorcida ou mal compreendida. Considerando a hierarquia, já se sabe que os conflitos de comunicação podem ocorrer do nível superior para o inferior ou o seu contrário, entre departamentos e funções, e ainda, entre os demais níveis da hierarquia.

Tubbs e Moss (2008) descrevem quatro tipos de conflitos na comunicação: (1) o conflito intrapessoal no qual se manifesta uma inconsistência nas ideias, atitudes, emoções ou valores em uma pessoa; (2) o conflito interpessoal que se caracteriza por acontecer entre pessoas que mantêm algum tipo de relacionamento diante de uma discordância; (3) o conflito intragrupo identificado em um pequeno grupo no qual surgem interesses individuais diferentes que interferem nas pessoas de todo o grupo; e (4) o 
conflito intergrupo que acontece entre grupos diferentes de pessoas mobilizando seus integrantes e que pode ter longa duração.

Considerando os dados apurados na pesquisa, o tipo de conflito de comunicação que parece ter se manifestado foi o interpessoal, muito provavelmente decorrente de posições contrárias a respeito de alguma discordância sobre certo procedimento profissional, uma ordem num momento inadequado ignorando o direito do trabalhador, como, por exemplo, além do horário de trabalho ou, ainda, pela forma desrespeitosa como a ordem tenha sido emitida ou direcionada.

Qualquer que tenha sido o motivo desse tipo de conflito, ele deve ser evitado para que a jornada de trabalho se transcorra de maneira harmoniosa, respeitosa e principalmente profissional. Do resultado do trabalho do operário depende todo o contingente profissional de hierarquia ascendente, porque, em tese, todos são responsáveis pela qualidade da execução da obra.

\subsection{CONFLITOS DE RELACIONAMENTO}

Outro tipo de conflito apontado foi o de relacionamento do engenheiro com o funcionário. Afirmam isso $88,24 \%$ dos engenheiros pesquisados. Pelo que se sabe, segundo Robbins; Judge; Sobral (2010), os conflitos de relacionamento tem sido aqueles mais responsáveis por comprometer a produção e a qualidade nas organizações. Isso pode ser entendido em função das atuais orientações da gestão de pessoas no ambiente de trabalho em situações que empregam e valorizam a atuação participativa do trabalhador, estimulam o comprometimento por meio da cooperação, proporcionando, dessa forma, uma maior interação e aproximação dos funcionários.

Acredita-se que os conflitos de relacionamento podem se desenvolver em decorrência das variáveis individuais, diferenciando-se quanto às características de personalidade, às expectativas pessoais, aos valores internalizados, à cultura, às diferentes formas de estímulos e motivação, às condições de controle sobre as reações dos indivíduos, e às peculiaridades de visão profissional ou pessoal futuras. Pode-se aceitar que a essas variáveis acrescentam-se outras que dizem respeito ao espírito competitivo, à autovalorização, aos hábitos, ao senso de liberdade, à assertividade, às expectativas de crescimento na organização ou seu inverso ligado à frustração, às formas de lidar com a autoridade, como também as características pessoais de se comunicar com liberdade de expressão.

O trabalhador da construção civil, considerando seu perfil que já é de domínio público, geralmente deslocam-se de suas cidades do interior do Brasil para buscar melhores oportunidades de emprego e de qualidade de vida. Por isso, trata-se de indivíduos sem escolarização ou com ela somente iniciada, solitário, sem residência, enfim, trabalhando muito longe de casa.

Parece que uma forma de lidar com esse tipo de conflito ou evitá-lo, poderia ser o emprego de uma atitude que priorizasse o aprofundamento sobre as características dos funcionários considerando sua dimensão humana, com vistas na sua forma de agir, levando-se em conta as variáveis pertinentes ao seu comportamento pessoal e profissional, seus traços de personalidade, suas expectativas de trabalho, suas necessidades e seu esforço para se relacionar com seus companheiros de trabalho. Dessa forma, acreditase serão encontradas condições mais adequadas de interpretar o comportamento dos funcionários e conduzir mais adequadamente o processo de gestão de pessoas.

Outras fortes variáveis que contribuem com o surgimento do conflito de relacionamento entre funcionários podem ser a insatisfação com o salário, benefícios e as condições de trabalho, e quem sabe a existência de um plano de carreira. E a respeito das empresas e dos engenheiros gestores as formas de lidar com os regulamentos, orientação sobre as atividades profissionais, a maneira de comunicar ordens e a definição objetiva em delegar autoridade e outras atribuições, com preocupação em evitar as condições nas quais surgem as contraordens ou duplicidade de ordens simultâneas.

Ainda no contexto gerencial, a antiga frase faz o que mando e não o que faço pode trazer implicações no relacionamento. Os comportamentos dos gestores não devem contrariar o comportamento exigido dos funcionários. Provavelmente um estilo de gestão admitindo mais liberdade como os modelos democráticos de gestão reduziriam os conflitos de relacionamento.

\subsection{CONFLITO RELACIONADO AO CONHECIMENTO TÉCNICO}

Novamente com alto percentual $(90,20 \%)$, os engenheiros civis apontam já ter enfrentado conflitos de conhecimento técnico na construção civil enquanto gestores de pessoas. Entende-se que todo o conteúdo 
estudado na formação profissional na academia não pode prescindir do conhecimento técnico. Assim, a atividade técnica distingue os contextos profissionais empíricos e científicos.

A atividade profissional do engenheiro civil é orientada pelo conhecimento técnico e científico que pode contrastar com um tipo de conhecimento considerado também técnico obtido com a prática profissional dos demais atuantes do canteiro de obras. Mesmo não se tratando do domínio sobre a tecnologia da engenharia civil, o mestre de obras, por exemplo, é capaz de discordar de uma orientação profissional ou determinação recebida de um engenheiro. Nesse sentido consegue-se entender o surgimento de conflitos no contexto do conhecimento técnico.

Ao mestre de obras, com toda a experiência que possa comprovar, cabe o conhecimento sobre qual procedimento profissional deve executar em determinado momento da obra e como realizá-lo, mas não consegue planejar esse tipo de procedimento na medida adequada segundo os cálculos de tempo, economia e resistência do material, segurança e qualidade, como também outras informações pertinentes ao contexto da atividade profissional do engenheiro, orientada pelo conhecimento técnico e científico.

Dessa forma, no contexto da gestão de pessoas, todos os funcionários, desde o engenheiro chefe até o trabalhador responsável pelo portão de entrada do canteiro de obras, devem ser preparados, recebendo treinamento e informações específicas sobre suas atribuições, com vistas em evitar os conflitos relacionados à área técnica de outros integrantes de seu ambiente comum de trabalho. É inconcebível que por incipiência profissional ou despreparo o engenheiro emita ordens ou proponha tarefas inadequadas aos seus colaboradores. Isso elimina o conflito e mantem o devido respeito profissional que merece em decorrência de sua formação técnica e científica.

\subsection{CONFLITOS COMPORTAMENTAIS}

Outro tipo de conflito confirmado por $88,30 \%$ dos respondentes foi o comportamental, entendido neste estudo como um trabalhador ou grupo praticando uma atitude não admitida pelo engenheiro civil na condução do processo de gestão de pessoas no canteiro de obras. São aqueles geralmente explícitos identificados por ações e reações, bem como a verbalização dos envolvidos no conflito. Normalmente podem ter a intenção de prejudicar alguém, ter o tom de ameaça, colocar em dúvida determinada ordem em conotação de desafio, podendo ter sido por mal entendimentos e até chegar a algum tipo de agressão. São conflitos danosos ao relacionamento profissional que precisam de tratamento imediato em benefício da ordem e disciplina, num contexto de cooperação de trabalho em equipe. Imprescindível a identificação de suas causas para contornar seus desdobramentos sendo possível chegar ao extremo da dispensa de um ou mais envolvido.

A distância que pode ser percebida, pelas diferenças culturais e de forma de vida, entre o trabalhador e o engenheiro é suficiente para agravar uma desavença entre eles. A falta de atividades integradoras entre chefes e subalternos também é uma variável a se considerar nesse contexto. Acredita-se que quanto maior for essa distância mais possibilidade de se manifestar o conflito comportamental. Não deve haver tratamento discriminatório na relação hierárquica, por mais flagrante que seja a distância profissional entre o chefe e seu subordinado. Acredita-se que atividades de lazer e reuniões para esclarecer decisões importantes no ambiente de trabalho, estimulam situações compreensivas entre os integrantes da empresa. É possível que o conflito comportamental seja uma consequência do tratamento autoritário praticado na cadeia hierárquica. Valorizar a contribuição profissional dos trabalhadores e empregar um modelo democrático de gestão tende a afastar a ocorrência desse tipo de conflito.

\subsection{CONFLITOS CULTURAIS}

Outro tipo de conflito constatado por $82,30 \%$ dos respondentes foi o cultural, no presente estudo concebido como o choque das realidades do engenheiro e dos trabalhadores impedindo a aceitação de ordens. Apesar de já ter sido considerada na análise e discussão dos conflitos de comunicação, a dificuldade de interpretação ou decodificação da mensagem em consequência da insuficiente ou inexistente escolarização do trabalhador foi aceita como mais uma causa dos conflitos culturais.

O conflito cultural ao se referir às disputas de poder que pode ocorrer entre diferentes gerações envolve valores diversos que podem caracterizar formas distintas de conceber determinadas situações sociais pessoais e profissionais. 0 conhecimento adquirido pelos mais experientes em confronto com o conhecimento técnico científico das gerações jovens, por meio do uso das ferramentas disponíveis pelas tecnologias é um exemplo disso. Nesse contexto, a desobediência ou resistência velada (não contestar, mas 
também não realizar) ao cumprir determinações profissionais conduzem aos tipos de conflitos culturais concebidos neste estudo, impedindo o desenvolvimento pleno das atividades programadas.

Trabalhadores podem se sentir inseguros diante da pouca idade e experiência do jovem engenheiro gestor, mas com o tempo, acredita-se, isso vai se minimizando e o engenheiro vai sendo acatado pelas ordens adequadas, ausência de erros, firmeza nas decisões e maturidade profissional. Mesmo assim, é preciso combater esses conflitos para que haja um convívio harmônico, produtivo, responsável e respeitoso entre engenheiros civis gestores e trabalhadores no canteiro de obras das empresas de construção civil.

\subsection{CONFLITOS HORIZONTAIS}

Para 78,50\% dos respondentes, profissionais de outras áreas tais como administradores, contadores e psicólogos, por exemplo, desempenhando suas funções no mesmo ambiente de trabalho têm gerado conflito horizontal.

Os conflitos horizontais são entendidos como desavenças entre integrantes de um mesmo nível hierárquico, por exemplo. Os conflitos, de modo geral, também são considerados importantes para o desenvolvimento e melhoria do funcionamento de uma empresa. Esses conflitos, por vezes difíceis de ser evitados, podem desenvolver resultados negativos. Se não tratados, como qualquer outro tipo de conflito e nesse caso específico entre profissionais do staff da administração superior da empresa, podem provocar situações de estresse, competitividade nociva e clima de hostilidade. Por se manifestar, geralmente, pelo desencontro de expectativas e propósitos entre indivíduos, os conflitos de natureza horizontal precisam ser combatidos imediatamente, caso contrário é certo seu agravamento tornando-se um conflito de proporções maiores. Um plano de cargos e funções deve estabelecer as atribuições de cada profissional para que não haja invasão de um profissional na área do outro e seja estabelecida uma cultura de responsabilização sobre as atitudes demonstradas e decisões tomadas por cada encarregado dos setores da empresa.

\subsection{CONFLITOS GERADOS PELA FALTA DE ESTUDOS DA ÁREA DE GESTÃO DE PESSOAS}

Como desdobramento natural de sua atividade profissional, o engenheiro civil vem ultimamente ocupando cargos de gestão na estrutura hierárquica das organizações. Aos respondentes foi indagado se essa atribuição poderia se constituir em mais um motivo dos conflitos na gestão de pessoas, por falta de formação específica para exercer mais essa tarefa.

Segundo os dados obtidos, esses profissionais, na sua grande maioria $(80,40 \%)$, concordaram que o desconhecimento de conteúdos específicos técnicos e profissionais sobre gestão de pessoas são também causas dos conflitos enfrentados por eles no canteiro de obras. Tais conteúdos focalizam, com aprofundamento, informações técnicas e atividades relacionadas às características de liderança, gerenciamento de conflitos no ambiente de trabalho e formas de negociação de conflitos. Nesse contexto, acredita-se, contribuiria sobremaneira com a atividade de gestor do engenheiro civil.

\subsection{DESDOBRAMENTOS DOS CONFLITOS NA CONSTRUÇÃO CIVIL}

Com vistas na confirmação da posição de que fazem falta informações técnicas na área de gestão de pessoas, $94,20 \%$ dos engenheiros pesquisados concordam que uma política de treinamento e desenvolvimento (T\&D), por meio de cursos específicos à função de gestor exercida pelo Engenheiro Civil, pode tratar-se de uma conveniente ferramenta que vai contribuir para a correção ou eliminação dos possíveis conflitos de gestão numa obra.

Por treinamento entende-se um conjunto de procedimentos que tem o propósito de instrumentalizar pessoas para o exercício de atividades profissionais num ambiente de trabalho. De acordo com Chiavenato (2008), treinamento é um processo educacional de curto prazo, aplicado de maneira sistemática e organizada, através do qual as pessoas aprendem conhecimentos, habilidades e atitudes em função de objetivos definidos.

Tachizawa, Ferreira e Fortuna (2004), afirmam que o treinamento: (a) tem como objetivo a preparação das pessoas para a execução imediata das diversas tarefas peculiares à organização; (b) proporciona chances para o permanente desenvolvimento pessoal, seja na atual função que desempenha ou em outras que o indivíduo vier a exercer; e (c) modifica as atitudes das pessoas, visando estimular um clima mais satisfatório entre elas, aumentando-lhes a motivação e tornando-as mais receptivas às técnicas de supervisão e gestão. 
Dentre os quatro tipos de treinamento descritos por esses autores, destacamos o treinamento técnicooperacional cuja finalidade é a capacitação de profissionais para realizar determinadas atividades específicas; o treinamento gerencial, com o qual são desenvolvidas, num profissional, condições para lidar segundo as exigências técnicas, administrativas e comportamentais; e o treinamento comportamental que é utilizado para contornar ou resolver situações inadequadas de relacionamento entre pessoas no ambiente de trabalho. (TACHIZAWA; FERREIRA; FORTUNA, 2004)

Com propósito mais abrangente, o desenvolvimento é concebido como um caminho planejado ou circunstancial por meio do qual uma pessoa empenha-se em busca de seu crescimento profissional que acaba por agregar valores ao crescimento pessoal. Para Chiavenato (2008) desenvolvimento é um processo contínuo que aprimora as capacidades e motivações do colaborador que faz com que o mesmo se torne um bem valioso da empresa.

Assim, o T\&D direciona a pessoa ao aprimoramento de suas condições pela apropriação de conteúdos exclusivos, aparato técnico adequado, comportamento profissional direcionado e estudo mais específico a respeito das funções que já realiza como também outras que tiver que desenvolver. As informações obtidas no processo de T\&D podem se referir às normas, objetivos, informações a respeito de atribuições profissionais ou outros documentos institucionais, inserção aprofundada no mercado em que atua, conhecendo seus clientes, fornecedores e concorrentes. E no caso específico de gestão de pessoa na construção civil, o engenheiro terá a oportunidade de conhecer e exercitar estratégias para melhor lidar com seus subordinados. Com essa intenção, certamente, com empenho direcionado, a missão da organização tem fortes chances de ser contemplada com satisfatório comprometimento.

Buscando-se apurar a opinião sobre os modelos de gestão centralizado e descentralizado como o melhor a ser adotado na gestão de uma obra, pode-se ter três entendimentos segundo os dados obtidos: (1) que os engenheiros confundiram as características desses modelos; (2) que admitem os dois modelos, igualmente, como os melhores para a gestão de uma obra; ou (3) se confundiram no momento de responder o questionário. Os dados ficaram no mesmo patamar, evidenciando o mesmo entendimento aprovando os dois modelos de gestão. Foram respectivamente $78,40 \%$ concordando com o modelo centralizado e 78,50\% concordando com o modelo descentralizado. Ao se considerar apenas o terceiro entendimento (confusão no preenchimento do questionário) sobre os dados dos dois gráficos como válidos, os outros dois entendimentos (confusão sobre as características dos modelos de gestão e a admissão de que os dois modelos são os melhores para a gestão) só reforçam a interpretação de que, por meio dessa amostra de engenheiros civis, por indução, esses profissionais carecem de treinamento para cumprir sua função de gestor de pessoas.

Os modelos possuem características técnicas diferentes e quase inversas um do outro. No ambiente profissional da gestão, já se aceita que os conflitos têm mais chances de acontecer em realidades organizacionais que empregam o modelo centralizador e autoritário de gestão de pessoas. Por outro lado, o modelo descentralizado é orientado pelos valores democráticos e de liberdade, o que vem garantindo um tipo de relacionamento profissional quase sem conflitos. Isso demonstra que os engenheiros não conhecem satisfatoriamente esses importantes conteúdos do contexto técnico e profissional da gestão. (CHIAVENATO, 1994)

Acredita-se que solucionar ou reduzir os conflitos também passa pela decisão do modelo de gestão a ser empregado pela empresa. Gestores precisam ficar atentos quanto ao desenvolvimento de potenciais atitudes que derivam de adequadas relações humanas e sociais no ambiente de trabalho. 0 emprego dessa estratégia de gestão deve priorizar a solução dos problemas por consenso ao invés das decisões geradas somente no nível gerencial. Tem-se a crença que essas atitudes melhoram o relacionamento pessoal entre gestores e funcionário e também entre os funcionários, tornando o clima organizacional sob a égide da satisfação e da paz.

Entende-se que o maior e mais preocupante resultado dos conflitos que ocorrem entre o engenheiro civil e seus colaboradores refere-se ao atraso no cumprimento do cronograma da obra. Com vistas nisso, duas perguntas do questionário foram elaboradas para se conhecer a posição dos respondentes sobre essa forte variável. Sobre o cumprimento do cronograma das obras ser influenciado por problemas na comunicação do engenheiro civil aos seus colaboradores do canteiro de obras, visando à realização das tarefas dos trabalhadores, 98,04\% aceitam essa possibilidade.

Outra variável pesquisada foi sobre a possibilidade dos conflitos comprometerem a gestão do engenheiro civil na condução de seu projeto. Nessa pergunta o resultado não ficou muito distante do evidenciado. Os respondentes confirmaram essa variável em 96,08\%. Ao se pensar sobre os tipos de conflito que ocorrem no ambiente de trabalho, imediatamente é possível lembrar daqueles que dizem respeito ao relacionamento entre funcionários. Na atualidade, circula nos sites e blogs dedicados à área de gestão de pessoas que os conflitos que mais vem se manifestando nas empresas, referem-se ao conflito de tarefas, 
caracterizado pelos problemas que decorrem dos resultados de uma atividade realizada, mas que não se conecta com as características pessoais do executor da atividade, como seu caráter, por exemplo. Robbins; Judge; Sobral (2010) muito bem elucidam esse tipo de conflito.

Mas o conflito de relacionamento é pessoal e pelo tom que pode receber na sua identificação e tratamento, pode ser danoso alterando o espírito do trabalho em equipe, comprometendo o relacionamento pessoal e interferindo negativamente no seu tratamento ou eliminação, e, ainda prejudicando o clima organizacional.

A ideia de Pelled (1996) sobre o conflito de Tarefas, pela data de sua publicação observa-se que não se trata de uma preocupação recente. Mas está retornando às discussões atuais. Há uma interpretação sobre os efeitos negativos sobre o conflito de relacionamento, por apresentar o poder de influência no processo produtivo e nas condições pessoais do trabalhador ao realizar suas atividades profissionais. Dessa forma, pode converter o modelo de gestão para ações antidemocráticas e autoritárias por parte dos gestores. No caso de se trabalhar na tarefa se ganha mais pela produtividade e economia de tempo para a solução do conflito. Assim, o conflito de tarefas pode proporcionar condições mais efetivas, auxiliando o processo de tomada de decisão pelos gestores e contribuindo com mais benefícios para a solução de problemas. Também podem evidenciar situações veladas e estimular a compreensão sobre posições controvertidas e a reflexão sobre posições pessoais, como também oferecer mais variáveis para análise durante o processo de decisão. Pode sugerir uma injeção de ânimo nos trabalhadores impulsionando-os em direção à realização de suas atividades com mais qualidade.

\section{CONCLUSÕES}

Fato comprovado pelo ensaio de campo foi a existência de conflitos na realidade profissional da construção civil. As situações conflitivas que se estabelecem por consequência da direção de tarefas e/ou orientação técnica do engenheiro civil aos seus subordinados na cadeia hierárquica, durante a execução de projetos de construção civil, com percentuais muito altos obtidos das respostas dos engenheiros foram os conflitos de comunicação, de relacionamento, relacionados ao conhecimento técnico, comportamentais, culturais, horizontais e aqueles gerados por falta de estudos na área de gestão de pessoas. Este último ocorre em função do desconhecimento de técnicas que auxiliem na prevenção, solução ou eliminação dos conflitos.

Como acontecem nos demais ambientes de trabalho, os conflitos identificados têm certas peculiaridades próprias do contexto da construção civil e outras comuns às empresas de um modo geral. Com o propósito de melhor caracterizar as variáveis motivadoras desses conflitos, apresentam-se separadamente, a seguir, os tipos de conflito e suas respectivas prováveis causas. 0 uso da expressão "prováveis causas" está sendo usado nestas conclusões porque não houve condições de um estudo classificatório mais específico das variáveis que motivam os tipos de conflitos que se manifestam na construção civil, pela falta de comprovação científica por parte dos engenheiros que pouco sabem lidar tecnicamente com esses eventos. A dificuldade de sustentação dessas variáveis impediu o emprego de matrizes de avaliação e parametrização dos conflitos.

Os conflitos de comunicação podem encontrar motivação em questões técnicas entre o engenheiro e algum funcionário graduado ou com conhecimento prático profissional, interpretado como um tipo de contestação pela dúvida daquele que resistiu a determinação. Podendo ser por inadequado uso da voz de comando, pelo desconhecimento de maneiras mais respeitosas e isentas de emoção, próprias das recomendações do contexto da gestão de Pessoas. Também pode ter se constituído por um tipo de resistência de conotação pessoal. 0 que remete a um estudo para se descobrir suas razões e imediatamente propor uma solução para o problema. Isso poderá desfazer a instabilidade da cadeia hierárquica e corrigir o ato de indisciplina. A desconstrução daquilo que impede o bom relacionamento traz benefícios às atividades profissionais e ao clima organizacional da empresa.

Os conflitos de relacionamento, considerados como os que mais comprometem a produção e a qualidade nas organizações, normalmente decorrem de variáveis individuais como características de personalidade, expectativas pessoais, valores internalizados, cultura, diferentes formas de estímulos e motivação, condições de controle sobre as reações dos indivíduos, e peculiaridades de visão profissional ou pessoal futuras. Da mesma forma, o espírito competitivo, à autovalorização, os hábitos, o senso de liberdade, a assertividade, as expectativas de crescimento na organização ou seu inverso ligado à frustração, as formas de lidar com a autoridade, e as características pessoais de se comunicar com liberdade de expressão.

Os trabalhadores da construção civil possuem perfil já conhecido. São oriundos de cidades do interior do Brasil em busca de melhores oportunidades de emprego e de qualidade de vida, analfabetos ou com escolarização interrompida, solitários, sem residência e trabalhando muito longe de casa. Essas variáveis 
já servem para justificar tensões, intolerâncias diversas, impaciência e desânimo, o que certamente poderá resultar em conflito de relacionamento. Questões ligadas aos salários, benefícios, as condições de trabalho, a forma de lidar com as normas da empresa, o jeito de orientar atividades profissionais, a maneira de comunicar ordens e a forma como é exercida a autoridade, além do comportamento do engenheiro contrariando suas exigências, podem suscitar conflitos de relacionamento.

Os conflitos relacionados ao conhecimento técnico podem surgir da controvérsia entre a determinação de um procedimento ou orientação do engenheiro e, por exemplo, um tipo de conhecimento considerado técnico obtido com a prática profissional dos demais atuantes do canteiro de obras. Identificar o que fazer e como fazêlo, vai divergir do aparato técnico que sustenta o planejamento, cálculos pertinentes e demais variáveis científicas utilizadas pelo engenheiro. Ou, na esfera profissional dos engenheiros, discordâncias técnicas entre esses profissionais com base em metodologias apropriadas a um tipo de construção em dado momento da obra. Nesse contexto, a inexperiência ou despreparo do engenheiro ao emitir ordens ou propor tarefas inadequadas aos seus colaboradores pode ser outra provável causa desse tipo de conflito.

Os conflitos comportamentais podem se manifestar levando-se em conta a distância entre o engenheiro e seu colaborador referente às diferenças culturais e de forma de vida. A falta de atividades integradoras entre chefes e subalternos também é uma variável a se considerar nesse contexto. Quanto mais distância houver entre esses personagens mais chance de ocorrer terá o conflito comportamental. Outra causa pode ser o tratamento discriminatório e autoritário na relação hierárquica.

Os conflitos culturais concebidos como o choque das realidades do engenheiro e dos trabalhadores, podem impedir a aceitação de ordens. A dificuldade de interpretação ou decodificação da mensagem em consequência da insuficiente ou inexistente escolarização do trabalhador também foi aceita como mais uma causa dos conflitos culturais. As disputas de poder ocorridas entre diferentes gerações envolvendo valores diferentes podem caracterizar formas distintas de conceber determinadas situações sociais pessoais e profissionais; o conhecimento dos mais experientes em confronto com o conhecimento técnico científico das gerações jovens, com o emprego das tecnologias; a insegurança frente a pouca idade e experiência do jovem engenheiro gestor, com ordens inadequadas, erros, falta de firmeza nas decisões e pouca maturidade profissional são indicadores dos conflitos culturais.

Os conflitos horizontais se manifestam pelas desavenças e desencontros de expectativas e propósitos que podem ocorrer entre integrantes de um mesmo nível hierárquico e no caso da Construção civil entre os demais envolvidos no canteiro de obras. A falta de informações contidas num plano de cargos e funções definindo atribuições de cada profissional, e por isso, invasão de um profissional na área do outro estabelecem um terreno fértil para os conflitos horizontais. Considerando a atividade de gestão exercida pelo engenheiro na estrutura hierárquica das organizações, o desconhecimento sobre os conteúdos específicos técnicos e profissionais sobre gestão de pessoas são, também, causas dos conflitos enfrentados por eles no canteiro de obras.

A falta de informações técnicas e específicas na área de gestão de pessoas pode ser corrigida pela implantação de uma política de treinamento e desenvolvimento (T\&D), disponibilizando aos engenheiros civis cursos direcionados à função de gestor, como conveniente ferramenta para contribuir com a correção ou eliminação dos possíveis conflitos de gestão numa obra.

Esse ideal justifica-se pela análise dos dados obtidos da pesquisa de campo, no qual os engenheiros demonstram desconhecimento sobre modelos de gestão centralizado e descentralizado, ao concordarem, na quase totalidade deles, que os dois modelos de gestão são adequados para a gestão de pessoas na construção civil. Os efeitos apurados das situações de conflitos, para a direção, execução e fiscalização do projeto de construção civil, foram confirmados como negativos. 0 cumprimento do cronograma das obras é influenciado por conflitos entre o engenheiro civil e seus colaboradores do canteiro de obras, principalmente considerando as tarefas realizadas pelos trabalhadores. Da mesma forma os conflitos comprometem a gestão do engenheiro civil e prejudicam a condução de seu projeto de construção.

\section{RECOMENDAÇÕES}

Visando propor estratégias fundamentais que orientem a gestão de conflitos no ambiente de trabalho na construção civil, com base no estudo realizado, têm-se as seguintes recomendações:

1- Empreender uma política de treinamento e desenvolvimento (T\&D) com vistas na preparação técnica dos engenheiros gestores para conhecimento de conteúdos específicos das Relações Humanas e maior domínio dos procedimentos aplicáveis de negociação de conflitos; 
2- No processo inicial de preparação dos novos colaboradores, incluir a socialização de conhecimentos sobre relações humanas e sociais no ambiente de trabalho;

3- Visando o incremento permanente da qualidade das atividades realizadas pelos trabalhadores, instituir o programa de avaliação de desempenho por competências;

4- Desenvolver atividades intencionais de aproximação entre engenheiros civis e trabalhadores, que possam desencadear melhor relacionamento entre eles, por meio de reuniões que abordem simuladas situações de conflito no ambiente de trabalho ou outras situações que necessitem de decisão compartilhada, como também a prática democrática de lazer;

5- Manter preocupação contínua com a emissão de informações de toda natureza e com os canais internos de comunicação;

6- Considerando o emprego de modelos de gestão democrática e participativa, instituir uma política de compartilhamento de informações e decisões de diversos níveis com os integrantes da empresa, de forma clara e objetiva;

7- Caracterizar os conflitos dentre os tipos existentes, identificar os envolvidos e buscar solução por meio de uma mediação que priorize a manutenção do colaborador, pelo reestabelecimento do convívio harmonioso, de respeito mútuo, mantendo o desejado clima organizacional;

8- Manter acompanhamento direto e discreto sobre os trabalhadores que se envolveram nos conflitos, visando o cumprimento dos acordos firmados no processo da negociação; e

9- Disciplinar tarefas com objetivos comuns, em mesmas metas de desempenho, numa ambiência democrática, visando a transformação de grupos em equipes, de acordo com o entendimento de Katzembach e Smith (1994).

\section{REFERÊNCIAS}

[1] BERGUE, Sandro Trescastro. Gestão de pessoas em organização pública. 3ª Ed. rev. e atual. RS: Educs, 2010.

[2] BRAGA, Fausto de Bessa; COVA, Carlos J. Guimarães. Educação corporativa: principais influências na gestão de pessoas na construção civil. SEGeT - Simpósio de Excelência em Gestão e Tecnologia. Associação Educacional Dom Bosco. Resende, RJ, 2007.

[3] CHIAVENATO, Idalberto. Gestão de pessoas. 2ª ed. RJ: Elsevier, 2005

[4] CHIAVENATO, Idalberto. Gestão de pessoas. 3aㅡ ed. RJ: Elsevier - Campus, 2008.

[5] CHIAVENATO, Idalberto. Treinamento e Desenvolvimento de Recursos Humanos. Como incrementar talentos na empresa. 7a Edição. SP: Manole Editora, 2008.

[6] CHIAVENATO, Idalberto, Administração de empresas: uma abordagem contingencial. 3. a edição. São Paulo: Makron Books, 1994.

[7] FAYOL, Henri. Administração Industrial e geral. SP: Atlas. 1981.

[8] FARAH, M. F. S.; Processo de trabalho na construção habitacional: tradição e mudança. SP: Annablume, 1996.

[9] FERREIRA, Aurélio Buarque de Holanda. Novo Dicionário da Língua Portuguesa. RJ: Pioneira, 2010.

[10] GOMEZ, Jose Luiz Portela. Gestão de Pessoas na Industria da Construção Civil - Base para a Construção Sustentável - Um Estudo de caso. SEGeT - Simpósio de Excelência em Gestão e Tecnologia. Associação Educacional Dom Bosco. Resende, RJ, 2009.

[11] INSTITUTO MC. KINSEY. A produtividade no Brasil: a chave do desenvolvimento acelerado. RJ: Atlas, 1999.

[12] IBGE (2002), Estatísticas do Cadastro Central de Empresas 2000. Rio de Janeiro, Disponível em http://biblioteca.ibge.gov.br/ visualizacao/monografias/GEBIS\%20-\%20RJ/estatcadcentralempr/cempre2000.pdf . Acesso em 10/01/2012.

[13] KATZENBACH, John e SMITH, Douglas. A Força e o Poder das Equipes. SP: Makron Books, 1994.

[14] MOREIRA, Marcos Muniz; SOARES, Carlos Alberto Pereira; HOZOMI, Carlos Roberto Jóia. Práticas Inovadoras na Gestão de Pessoas: Pesquisa realizada em empresas representativas da Indústria da Construção Civil. SEGeT Simpósio de Excelência em Gestão e Tecnologia. Associação Educacional Dom Bosco. Resende, RJ, 2008. 
[15] PELLED, L. H. Demographic diversity, conflict, and work group outcomes: an intervening process theory. Organization Science, Hanover, MD, v. 7, n. 6, p. 615-631, 1996.

[16] ROBBINS, S.; JUDGE, T.; SOBRAL, F. Comportamento Organizacional: teoria e prática no contexto brasileiro. 14를 ed. São Paulo: Pearson Prentice Hall, 2010.

[17] TACHIZAWA, Takeshy; FERREIRA, Victor Cláudio Paradela; FORTUNA, Antônio Alfredo Melo. Gestão com pessoas. Uma abordagem aplicada às estratégias de negócios. 3. ed. RJ: FGV, 2004.

[18] TAYLOR, Frederick W. Princípios da administração científica. SP: Atlas, 1987.

[19] TUBBS, Stewart L.; Moss, Sylvia. Human Communication: Principles and Contexts. 11a Ed. SP: MacGraw Hill, 2008.

[20] VERGARA, Sylvia Constant. Projetos e relatórios de pesquisa em administração. 8aa ed. SP: Atlas, 2011. 


\section{Capítulo 6}

\section{Fatores de conflito e produção em uma unidade hospitalar pública}

\section{Francisco de Assis Coelho}

Resumo: A qualidade da assistência à saúde é prejudicada, diante do possível conflito entre o corpo clínico e o corpo administrativo dos hospitais. 0 objetivo deste estudo foi identificar alguns dos fatores que interferem na relação de trabalho entre corpo clínicomédicos e corpo administrativo-gestores de unidades hospitalares. Como método foi aplicado um estudo transversal, realizado em Hospitais do município de Taubaté, vale do Paraíba, estado de São Paulo, Brasil, no período de maio a agosto de 2013, por intermédio da aplicação de questionários aos chefes de clinicas e aos gestores de dois hospitais do município. Os dados foram analisados, dividindo-se em dois grupos, corpo clínico e corpo administrativo. 0 resultado aponta diversas relações de conflitos entre os dois grupos, com destaque para o grau de importância e atenção que cada um deve dispensar no atendimento aos pacientes, na utilização dos recursos e na diversidade de procedimentos realizados nas unidades hospitalares.

Palavras chave: Conflito de Interesses, Estudos Transversais, Gestão Hospitalar. 


\section{INTRODUÇÃO}

Os avanços tecnológicos vêm provocando mudanças relevantes no processo de produção em todas as áreas, principalmente na saúde, surgindo ferramentas de gestão, máquinas e ferramentas de diagnose e execução de procedimentos de saúde, medicamentos e materiais que facilitam e contribuem para o conforto e cura dos pacientes. Tais avanços fazem com que a população acredite na melhoria da qualidade de vida e na erradicação de doenças antes tidas como incuráveis.

A inovação é provocada nas diversas indústrias como processo de evolução pela criatividade, vontade de produzir melhorias para o ser humano. Na indústria da saúde esse processo é chamado de necessidade de busca de soluções para enfermidades, tanto de cura quanto de prevenção.

A evolução tecnológica e econômica impõe adaptações à organização da produção, e há crescente necessidade de controle dos gestores sobre o pessoal operacional-produção. Nesse contexto, encontramse as instituições de saúde, com destaque para os hospitais, onde o principal produto é a prestação de cuidados e assistência à saúde das pessoas. Sua área de produção é liderada por médicos, profissão que exige alto grau de especialização e relacionamento com os pacientes-clientes, o que dificulta o controle pelos gestores.

As instituições hospitalares são consideradas ambientes complexos, devido à multidisciplinaridade dos profissionais que nelas atuam e também devido à divergência de objetivos. Entre esses grupos estão os médicos (corpo clínico) e a direção (gestores). Os médicos responsáveis pelo operacional-produção buscam prover a melhor assistência possível, independentemente do custo a ela relacionado. Já os gestores buscam obter o equilíbrio econômico-financeiro a partir da recuperação dos custos e da maximização do resultado (BEUREN e SCHLINDWEIN, 2008).

A fim de atender aos objetivos da instituição com eficiência, Farias e Vaitsman (2002) dividem o trabalho, observando a articulação entre indivíduos e grupos. Embora funcionalmente esses grupos devam responder às necessidades operativas da organização, eles tendem a desenvolver interesses específicos, os quais podem dificultar a realização das atividades operacionais e dos interesses organizacionais.

Essa divergência de interesses profissionais gera conflitos entre esses grupos, uma vez que o médico se preocupa com o conforto e cura do paciente, fator de geração de custos, sem se preocupar com a intensidade dos gastos. Do outro lado, o gestor tem como principal função exatamente o inverso, quanto à intensidade dos gastos. Sua função é disponibilizar os recursos para o trabalho do corpo clínico. Esses recursos, materiais ou humanos, resumem-se em recursos financeiros, e sua otimização foge ao controle do gestor, pois a utilização é feita pelo corpo clínico. Com isso, há um desequilíbrio na produção e nas finanças da instituição.

Apesar da evolução das organizações hospitalares, elas ainda estão sujeitas ao poder do corpo clínico e ao controle dos administradores hospitalares. 0 objetivo deste estudo foi identificar os fatores que interferem na relação de trabalho do corpo clinico e dos gestores de unidades hospitalares, buscando o entendimento sobre as relações de poder que se estabelecem entre eles, bem como os possíveis conflitos.

\section{REVISÃO BIBLIOGRÁFICA}

\subsection{PODER E CONFLITOS ENTRE CATEGORIAS DE PROFISSIONAIS}

0 poder refere-se à produção de efeitos intencionais, dependendo, para isso, da relação entre as pessoas. Poder também é definido como capacidade de influenciar outros indivíduos, numa situação em que um sujeito ou grupo impõe sua vontade sobre outro, sendo o processo de influência social intrínseco ao exercício de poder. É a partir desse exercício que uma pessoa induz a outra a modificar seu comportamento (COSTA e MARTINS, 2011).

Ao analisar o exercício do poder individual, Costa e Martins (2011) depararam com o conceito de bases de poder, que são recursos utilizados por um indivíduo para se tornar capaz de influenciar outra pessoa, possibilitando-lhe atingir seus objetivos. A base de poder é composta por seis tipos, a partir da percepção daquele que é alvo do exercício do poder: poder de recompensa, poder de coerção, poder legítimo, poder de referência, poder de perícia e poder de informação. 
Considerando o ambiente hospitalar, há uma série de fatores que geram conflitos aos profissionais que nele atuam. Os profissionais do corpo clínico talvez sejam os mais atingidos nesse ambiente. Alguns dos componentes causadores de conflitos são: desproporcionalidade entre o número reduzido de profissionais, excesso de atividades a serem executadas, dificuldade de delimitação dos papéis entre aqueles que formam a equipe técnica e questões relacionadas ao achatamento salarial, que impõem aos profissionais a necessidade de ter mais de um vínculo de trabalho, o que resulta em carga horária longa e desgastante.

Estudos de Costa e Martins (2011) afirmam que existe conflito entre categorias profissionais em organizações hospitalares públicas brasileiras, e apontam que conflito intragrupal e poder estão estreitamente relacionados, quando se consideram as relações de trabalho entre os profissionais da área da saúde. Existem indícios de que esses dois fatores geram consequências negativas para os relacionamentos interpessoais e para o desempenho no trabalho.

O hospital é uma instituição importante nos sistemas de saúde, representando a institucionalização dos conhecimentos médicos especializados e o poder social da profissão médica. Nele ocorrem tensões de natureza grupal e profissional, pois ali alguns médicos têm dificuldade em repartir seu poder, aceitar normas de disciplina coletiva, ouvir sugestões ou recomendações. É necessário mudanças nas relações de poder entre corpo diretivo, clínico e técnico administrativo, para melhorar a assistência à população (FERREIRA et al., 2010).

Para Matos (2006), os conflitos podem ser comparados às dores no organismo humano. As dores funcionam como um sinal de alerta, indicando a existência de disfunções orgânicas que, se não forem tratadas, poderá levar o doente à falência dos órgãos. Assim são os conflitos, pois indicam a existência de disfunções operacionais na organização e, do mesmo modo que a dor podem ser aliviados por ação terapêutica adequada. Existem no campo da psicologia e da gestão organizacional várias modalidades de soluções para os conflitos, e, se aplicadas eficazmente, poderão reduzir e até eliminar a situação conflitante. Dessa forma, constata-se que o conflito pode ter um papel de sensor, apontando que há problemas no desempenho funcional de uma organização, motivando as pessoas e grupos envolvidos a resolverem os problemas revelados. Caso contrário, tal como ocorre com a dor, o conflito é passível de apresentar agravamento e exigir procedimento mais radical, para que não ocorra a falência da organização.

Segundo Matos (2006), o bom gestor deve observar e planejar os conflitos, aplicar uma das modalidades de resolução de conflito mais adequada e tirar o máximo de proveito da situação conflitante em benefício dos objetivos da instituição, sem influenciar negativamente nos objetivos do seu oponente.

\subsection{CULTURA ORGANIZACIONAL NAS UNIDADES HOSPITALARES}

Segundo Bowden e Smits (2012), as culturas organizacionais desenvolvem dentro das instituições uma função de liderança, com impactos sobre dimensões importantes, como a performance e a mudança de gestão. Elas funcionam como o sistema imunológico, quando uma decisão é tomada e implementada, se for percebida como risco aos aspectos básicos e a valorização do organismo, o sistema entra em modo de proteção, provocando uma rejeição à alteração de conduta, o que chamamos de conflito nas organizações.

Buttigieg e West (2013) fizeram uma análise do efeito da qualidade da liderança dos gestores da administração superior, quanto ao apoio social e à relação do trabalho estressante, causadores de tensões em ambiente de hospitais no Reino Unido. Aplicaram um questionário e obtiveram 65.412 respostas. Concluíram que há evidências de que a liderança, a alta administração, faz a diferença para o desempenho das equipes e que os grupos de profissionais têm seus comportamentos influenciados.

Os autores acima definem o apoio social como as relações pessoais que interagem nos grupos de funcionários, para expandir suas capacidades de eliminar o estresse, por aumentar o grau de percepção quanto ao valor de suas contribuições e preocupação com o seu bem-estar. Identificam o ambiente hospitalar como ambiente hostil. A grande sobrecarga de trabalho e esse ambiente hostil são os principais causadores de tensão, que influenciam negativamente os grupos.

Saame et al. (2011) afirmam que a cultura organizacional é muito utilizada nas organizações modernas, para analisar os valores, atitudes e crenças externadas pelo comportamento das pessoas em seus ambientes de trabalho. Ela reflete as opiniões dos membros da organização sobre seus produtos e ou serviços. Tem suas raízes na história e implicitamente influencia na compreensão da organização. Vários estudos têm demonstrado que as organizações de saúde tendem a ser orientadas internamente, 
valorizando regras e determinações formais, embora a cultura organizacional seja diferente, de acordo com o tipo de hospital. Nos hospitais privados constata-se uma cultura mais de cooperação, já o hospital público é dominado por certo grau de tensão entre os grupos de profissionais.

\subsection{CONFLITOS NA GESTÃO DE HOSPITAIS}

Para Vendemiatti et al. (2010), as inovações dos processos gerenciais nas instituições hospitalares constituem uma necessidade, tanto do ponto de vista da eficiência, quanto do ponto de vista da competitividade na administração de conflitos derivados do processo de profissionalização dos hospitais. Nesse tipo de organização existe uma dualidade no processo de gestão, orientada por direcionadores que, em alguns momentos, se colocam em posições opostas.

De um lado, é encontrada a liderança do corpo clínico, composta por médicos, enfermeiros, fisioterapeutas, psicólogos, e outros profissionais da saúde, que são tomadores de decisões que envolvem a dimensão do uso de recursos. Essas lideranças tendem a orientar-se pela lógica de sua formação profissional, e são detentoras de poder, tanto em função de seu conhecimento específico, quanto em função do ambiente de urgência e risco. Por outro lado, há os gestores, deslocados das rotinas dos médicos, que ocupam funções que envolvem processos de fornecimento e controle do uso dos recursos utilizados e direcionamento das atividades diárias dos hospitais. Nesse sentido, a estrutura organizacional dos hospitais abriga subculturas com peculiaridades que demarcam campos de poder que se constituem em desafios para o processo de gestão (VENDEMIATTI et al., 2010).

Entre os diversos conceitos e autores citados por Cecílio (2005), o conflito é sempre consciente, considerando-se que a eclosão e o desenvolvimento do conflito podem ser explicados a partir das funções ocupadas nas estruturas ou das intencionalidades opostas dos decisores que ocupam essas funções, por serem os únicos que podem decidir por um ambiente de cooperação ou por manter o conflito num confronto real. Há conflito, no sentido estrito, quando um ou mais decisores fazem uma apreciação situacional divergente de outro ou de outros decisores engajados na ação.

A tomada de decisão é sempre antes da ação, das atividades diárias, podendo-se afirmar que é composta por intencionalidades. Isso significa que no cotidiano das organizações há uma constante diferença entre o modo de pensar dos distintos decisores, e a sua racionalidade depende da posição que ocupam na organização, do contexto e do grau de acesso às informações pertinentes a cada decisão. Quanto à disposição para a cooperação ou para o conflito, isso depende da formação como individuo e profissional de cada decisor, do grau de relacionamento interpessoal e socialização entre os colaboradores institucionais, da aceitação da cultura organizacional e do respeito pelos agentes potenciais formadores dessa cultura interna da organização.

As decisões nas unidades hospitalares, quanto ao grau de intensidade do atendimento aos pacientes e do uso e qualidade dos recursos, na visão dos gestores (direção administrativa) não tem a mesma importância que lhes atribui o Corpo Clínico (médicos), visto que os primeiros têm a função de suprir os recursos necessários para a produção dos serviços de cuidados aos pacientes, que são avaliados pelo resultado econômico-financeiro da unidade. Já o Corpo Clínico tem a função de confortar e curar o paciente, o que é de difícil mensuração. É avaliado pela satisfação do paciente, independentemente de resultado econômico-financeiro. Essa diferença é um do principais responsáveis pelo conflito entre esses dois grupos de profissionais, causando tensões nas tomadas de decisões, dificuldades nas atividades diárias e perda de eficiência operacional, o que não beneficia a todos, principalmente a instituição.

Vaghetti et al. (2011) citam que, nos Estados Unidos da América, a reflexão "Hospital medical staff culture clash: is it inevitable or preventable?" aponta que também existem tensões históricas entre os médicos e os administradores. Ambos os grupos de profissionais estão unidos pelo desejo de oferecer aos pacientes um ótimo atendimento, mas essa intenção é obstaculizada por conflitos decorrentes de uma série de diferentes posições, que estão vinculadas a profundas divisões culturais, quanto à autonomia dos médicos e ao controle efetuado pelos administradores.

A administração dos hospitais públicos e os profissionais mais técnicos, especialmente os da área da saúde, têm visões distintas sobre a condução dessas organizações. Uma delas é voltada às questões gerenciais, e a outra, aos problemas estritamente assistenciais. Essas visões geram certa disputa. Os significados dessa disputa traduzem uma cultura de distanciamento entre os trabalhadores, condicionada pelos diferentes entendimentos sobre a finalidade e o produto final do trabalho nos hospitais, ocasionando sérias rupturas nos processos de trabalho, mesmo que todos almejem a otimização do atendimento hospitalar (VAGHETTI et al., 2011). 
A gestão de serviços de saúde é uma prática administrativa complexa, em decorrência da amplitude desse campo e da necessidade de conciliar interesses individuais, corporativos e coletivos nem sempre convergentes.

Gestão envolve a melhoria do funcionamento das organizações. Para isso, ela tem que encontrar a melhor combinação possível dos recursos disponíveis, para atingir os seus objetivos. Encontrada essa combinação, ela é institucionalizada por meio da formalização de estruturas, processos, rotinas, fluxos e procedimentos. Toda essa construção é concebida visando obter um funcionamento otimizado em um contexto complexo, que exige tomada de decisões para dar respostas às situações, a fim de manter o funcionamento ou melhorar os níveis de eficiência e eficácia dos serviços (TANAKA e TAMAKI, 2012).

\section{MÉTODO}

0 presente estudo tem abordagem qualitativa. Trata-se de pesquisa descritiva, quanto aos fins, e Survey, quanto aos meios. 0 instrumento de investigação foi a entrevista com questões estruturadas (MIGUEL, 2007).

O universo de pesquisa foi constituído pelos Administradores Hospitalares, pelo lado dos Gestores, já o corpo clínico foi composto pelos Diretores da área médica e Chefes de clínicas dos Hospitais, no município, que prestam serviços para o SUS: um Hospital Regional integrado ao Hospital Universitário, que atendem a região metropolitana do vale do Paraíba, interior do estado de São Paulo, Brasil.

A amostra envolveu onze profissionais das organizações, sendo seis médicos - Corpo Clínico - e cinco gestores administrativos - Corpo Administrativo. Os sujeitos foram escolhidos por acessibilidade, de forma estratificada, procurando contemplar as funções estratégicas, que englobam a gestão administrativa de pessoas, de controladoria e financeira, e as funções operacionais, que envolvem a gestão técnica das Clínicas, departamentos em unidades hospitalares, geridas por profissionais médicos especializados.

0 instrumento de pesquisa aborda questões relacionadas ao grau de importância que os profissionais devem dispensar em determinadas atividades que podem aumentar a quantidade de atendimento aos pacientes e melhorar o resultado econômico-financeiro. Isso sem prejudicar a qualidade dos serviços ou comprometer a responsabilidade do profissional de saúde, na identificação de possíveis conflitos entre o processo decisório e liderança.

Nas entrevistas não foram identificados os respondentes, apenas sua área de atuação, tomando-se o cuidado de respeitar a individualidade. Foram realizadas em momento e ambientes discretos, sem a participação ou conhecimento de outras pessoas. Foram utilizadas escalas ordinais de zero a dez, estruturadas com opções de intervalos de dois, segundo o grau de importância que o profissional deve dispensar ao desempenhar suas funções. 0 grau zero significa que aquela afirmação (pergunta) não tem qualquer importância para o profissional, ou seja, não precisa dispensar qualquer atenção naquele sentido. Já o grau dez significa que aquela afirmação (pergunta) é de muita importância ao profissional, que deve dispensar atenção ao executar suas tarefas diárias.

\section{RESULTADO E DISCUSSÃO}

A Tabela 1 mostra os resultados estatísticos da pesquisa, possibilitando extrair importantes conclusões das afirmações dos grupos de profissionais, cuja maioria absoluta aponta para um alto grau de oposição na dispensa de atenção durante a execução de suas atividades, e, consonância com os objetivos profissionais de cada grupo.

De forma geral os resultados obtidos na pesquisa apontam para uma confirmação das publicações citadas no referencial teórico sobre o tema, quanto aos objetivos de cada grupo profissional e a forma como os trabalhos são conduzidos institucionalmente, o que gera tensões internas e reflete negativamente no desempenho das funções e, por consequência, no atendimento aos pacientes e nos resultados econômicofinanceiros das unidades hospitalares. 
Tabela 1. Resultado do questionário aplicado pelos autores

\begin{tabular}{|c|c|c|c|c|c|c|c|c|}
\hline \multirow{2}{*}{ Afirmação } & \multicolumn{2}{|c|}{ Mediana } & \multicolumn{2}{|c|}{ Média } & \multicolumn{2}{|c|}{ Moda } & \multicolumn{2}{|c|}{ Desvio Padrão } \\
\hline & $\mathrm{CC}$ & CA & $\mathrm{CC}$ & $\mathrm{CA}$ & $\mathrm{CC}$ & CA & $\mathrm{CC}$ & $\mathrm{CA}$ \\
\hline $\mathrm{A} 1$ & 10 & 4 & 8,8 & 4 & 10 & 6 & 1,789 & 2,309 \\
\hline $\mathrm{A} 2$ & 10 & 7 & 8,4 & 7,5 & 10 & 10 & 2,191 & 1,915 \\
\hline A3 & 10 & 9 & 8 & 8,5 & 10 & 8 & 4,472 & 1,915 \\
\hline $\mathrm{A} 4$ & 2 & 2 & 3,6 & 3 & 0 & 0 & 4,336 & 3,830 \\
\hline A5 & 0 & 1 & 2 & 2 & 0 & 0 & 2,828 & 2,828 \\
\hline A6 & 10 & 4 & 8 & 5 & 10 & 2 & 2,828 & 3,830 \\
\hline A7 & 2 & 5 & 2,8 & 4,5 & 0 & 8 & 3,033 & 4,123 \\
\hline A8 & 8 & 10 & 8 & 9,333 & 10 & 10 & 2,449 & 4,761 \\
\hline A9 & 10 & 6 & 10 & 6 & 10 & 6 & 0,000 & 1,633 \\
\hline A10 & 2 & 6 & 3,2 & 5,5 & 0 & 6 & 3,633 & 2,517 \\
\hline A11 & 8 & 3 & 8 & 4 & 4 & 2 & 2,449 & 2,828 \\
\hline A12 & 10 & 2 & 9,6 & 1,5 & 10 & 2 & 0,894 & 1,000 \\
\hline A13 & 4 & 7 & 4 & 7 & 4 & 6 & 3,742 & 2,582 \\
\hline A14 & 6 & 7 & 4,4 & 7,5 & 6 & 6 & 3,286 & 1,915 \\
\hline A15 & 2 & 5 & 4 & 5,5 & 2 & 2 & 4,690 & 3,416 \\
\hline A16 & 8 & 4 & 7,6 & 4,5 & 8 & 4 & 3,286 & 1,000 \\
\hline A17 & 0 & 6 & 3,6 & 6,5 & 0 & 6 & 4,980 & 1,000 \\
\hline A18 & 4 & 6 & 5,6 & 7,333 & 2 & 6 & 4,099 & 4,123 \\
\hline A19 & 4 & 4 & 4 & 5 & 8 & 4 & 3,162 & 3,464 \\
\hline A20 & 8 & 10 & 8,4 & 9,5 & 8 & 10 & 1,673 & 1,000 \\
\hline A21 & 4 & 4 & 4,8 & 4 & 4 & 4 & 3,633 & 1,633 \\
\hline
\end{tabular}

Conforme a Figura 1, as afirmações A1, A6, A9, A11, A12 e A16 destacam-se pela alta importância dada pelo corpo clínico. Numa escala de zero a dez, está entre 7,6 e 10,0. A média dessas afirmações ficou em 8,67. Em comparação, o corpo administrativo apresenta baixa importância, entre 1,5 e 6,0, e a média foi de 4,17. Essas afirmações são referentes ao número de atendimentos mínimo, ou seja, o profissional deve dispensar a máxima atenção aos pacientes (A1). Questões as prescrições, se devem indicar o medicamento específico ou a composição química necessária para a cura ao paciente (A6), determinam que a qualidade deve ser o critério para decidir as comprar de medicamentos e materiais médicos (A9). 0 número de atendimentos é o objetivo principal em unidades hospitalares (A11); quanto maior a diversidade de procedimentos, melhor (A12). A cultura organizacional de unidades hospitalares é positiva e tem como ator o corpo clinico (A16).

Por outro lado, as afirmações de A10, A13, A14 e A17 destacam-se pela alta importância dada ao corpo administrativo, entre 5,5 e 7,5, e a média, em 6,62. Em comparação, o corpo clínico apresenta baixa importância, entre 3,2 e 4,4, e média de 3,8. Essas afirmações correspondem aos seguintes fatores: o custo deve ser o critério para decidir compras de medicamentos e matérias médicos (A10); a direção administrativa apoia o corpo clínico a encontrar soluções criativas, a criar grupos de estudos internos para melhorar e facilitar o fluxo de atendimento aos pacientes e se envolve positivamente na gestão e dificuldades do corpo clínico (A13, A14 e A17).

A afirmação de que o corpo clínico deve dispensar atenção para a taxa de permanência do paciente (A3) teve pontuação de grau de importância muito próxima, com média 8,0 para o corpo clínico e 8,5 para o corpo administrativo. Isso representa uma novidade, pois, enquanto diversas afirmações são opostas, nesta afirmação os dois grupos entendem que o corpo clínico deve dispensar muita atenção para o tempo de permanência dos pacientes nas unidades hospitalares. Embora o motivo não tenha sido objeto da pesquisa, foi colocado pelos profissionais da área de saúde que o médico deve acompanhar o paciente e preocupar-se com sua estada no hospital, devido ao alto grau de risco de contaminação . Já o corpo administrativo afirma que se trata de função específica de profissionais de saúde, e que o médico é o especialista responsável. Isso pode resultar em menor taxa de permanência do paciente e, por consequência, em maior giro, resultando em ganho de escala, devido ao sistema de reembolso do SUS e aos gastos fixos.

Embora das vinte e uma afirmações, vinte tenham apontado situações opostas, entre os dois grupos, em maior ou menor grau de importância, a afirmação de que a intensidade dos cuidados aos pacientes depende do reembolso (A5) teve a mesma pontuação para ambos os grupos, grau de importância 2,0. 
Isso significa que os dois grupos interpretam que não devem dispensar atenção para a intensidade dos cuidados aos pacientes considerando o valor do reembolso, o que não seria novidade na resposta do corpo clínico. No entanto, contraria outras afirmações, principalmente a afirmação A1 e a justificativa para as respostas da afirmação $\mathrm{A} 3$, mencionada acima.

Figura 1. Comparação gráfica das afirmações dos profissionais.

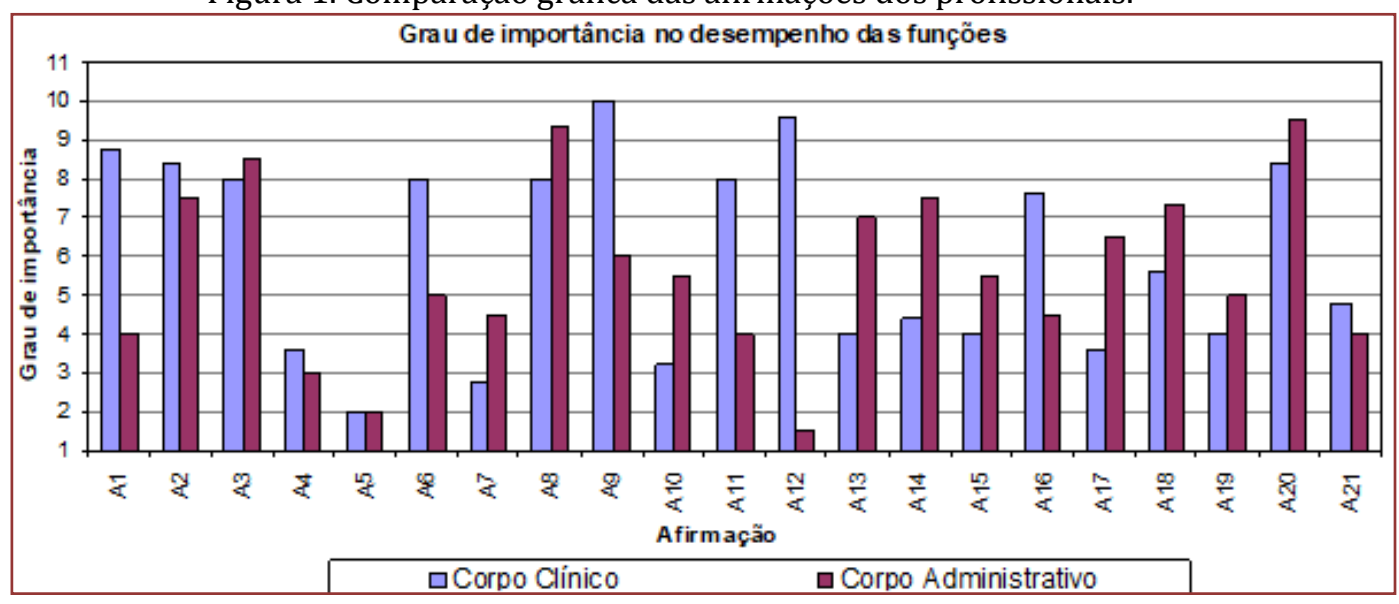

Fonte: Autor.

\section{CONSIDERAÇÕES FINAIS}

Embora as instituições estudadas neste artigo sejam do mesmo tipo, elas têm singularidades ambientais que as diferem umas das outras. A pesquisa procurou explorar pontos que tendem a ser comuns às unidades hospitalares públicas, tendo clareza de que os problemas discutidos apresentam diferentes graus de intensidade em cada instituição específica.

As afirmações analisadas com base nos dados obtidos mostram as opiniões e percepções sobre as relações de responsabilidades e dever de dispensar maior ou menor atenção nos assuntos de produção institucional. Há divergência de critérios de tomada de decisão quanto ao desempenho das funções no que tange ao grau de uso dos recursos e intensidade de cuidados aos pacientes, causando certo conflito, que diminui ou elimina a sinergia entre os grupos de profissionais e, por consequência, os resultados econômico-financeiros das unidades hospitalares.

O corpo administrativo tem a responsabilidade de estabelecer e acompanhar os processos de controle que necessitam responder à eficiência das atividades; mas, ao mesmo tempo, devem ser adequados e compatíveis com os objetivos do corpo clínico, que só adota os procedimentos que considera compatíveis com o exercício de sua profissão. Esses fatores compõem uma base suficiente para originar conflitos relativos ao controle da gestão, divergência de interesses e desigualdade de tratamento entre os membros dos grupos.

Destaca-se que foram encontrados alguns fatores de conflito no ambiente de trabalho, entre o corpo clinico e gestores, com destaque para o grau de atendimento, de atenção aos pacientes e diversidade de procedimentos, que evidenciaram a existência de conflitos.

\section{REFERÊNCIAS}

[1] BEUREN, I. M.; SCHLINDWEIN, N. F. Uso do custeio por absorção e do sistema RKW para gerar informações gerenciais: um estudo de caso em Hospital. Revista ABCustos Associação Brasileira de Custos, 3(2): 24-47. 2008

[2] BOWDEN, D. E.; SMITS, S. J. VIEWPOINT Managing in the context of healthcare's escalating technology and evolving culture. Journal of Health Organization and Management, 26(2): 149-157. 2012.

[3] BUTTIGIEG, S. C.; WEST, M. A. Senior management leadership, social support, job design and stressor-tostrain relationships in hospital practice. Journal of Health Organization and Management, 27(2): 171-192. 2013.

[4] CECÍLIO, L. C. O. É possível trabalhar o conflito como matéria-prima da gestão em saúde? Caderno Saúde Pública, Rio de Janeiro, 21(2): 508-516. 2005. 
[5] COSTA, D. T.; MARTINS, M. C. F. Estresse em profissionais de enfermagem: impacto do conflito no grupo e do poder do médico. Revista da Escola de Enfermagem - USP, 45(5):1191-1198. 2011.

[6] FARIAS, L. O.; VAITSMAN, J. Interação e conflito entre categorias profissionais em organizações hospitalares públicas. Caderno Saúde Pública, Rio de Janeiro, 18(5): 1229-1241. 2002.

[7] FERREIRA, L. C. M.; GARCIA, F. C.; VIEIRA, A. Relações de poder e decisão: conflitos entre médicos e administradores hospitalares. RAM, Revista Administração Mackenzie, 11(6): 31-54. 2010.

[8] MATOS, M. A. Negociação e conflitos. Palhoça-SC: UnisulVirtual, www.virtual.unisul.br, acesso 23 de agosto de 2013.

[9] MIGUEL, P. A. C. Estudo de caso na engenharia de produção: estruturação e recomendações para sua condução. Revista Produção, 17(1): 216-229. 2007.

[10] SAAME, L.; REINO, A.; VADI, M. Organizational culture based on the example of an Estonian hospital. Journal of Health Organization and Management, 25(5): 526-548. 2011.

[11] TANAKA, O. Y.; TAMAKI, E. M. O papel da avaliação para a tomada de decisão na gestão de serviços de saúde. Revista Ciência \& Saúde Coletiva, 17(4): 821-828. 2012.

[12] VAGHETTI, H. H.; PADILHA, M. I. C. S.; LUNARDI FILHO, W. D.; LUNARDI, V. L.; COSTA, C. F. S. Significados das hierarquias no trabalho em hospitais públicos brasileiros a partir de estudos empíricos. Revista Acta Paulista de Enfermagem, 24(1): 87-93. 2011.

[13] VENDEMIATTI, M.; SIQUEIRA, E. S.; FILARDI, F.; BINOTTO, E.; SIMIONI, F. J. Conflito na gestão hospitalar: o papel da liderança. Revista Ciência \& Saúde Coletiva, 15(1): 1301-1314. 2010. 


\section{Capítulo 7}

A inclusão da pessoa com deficiência no mercado de trabalho: Estudo de caso em um hospital particular de Juiz de Fora - MG

Clara Aguiar Reis

Eduarda Barbosa Velloso

Giovana Tassi de Paula

Joyce Gonçalves Altaf

Resumo: A inclusão de pessoas com deficiência (PcDs) no mercado de trabalho tem sido uma prática complexa, onde ao mesmo tempo em que essa parcela da população tem ocupado cada vez mais postos formais de trabalho, ocorre a desvalorização profissional e pessoal dos mesmos graças a uma estagnação das atividades. Sendo assim, o principal objetivo deste trabalho é identificar qual a percepção da inclusão da pessoa com deficiência em uma organização. De maneira complementar, este trabalho busca ainda compreender o cenário de inclusão de pessoas com deficiência no mercado de trabalho, identificando as principais dificuldades e barreiras inclusivas. Trata-se de uma pesquisa qualitativa bibliográfica e um estudo de caso realizado em um hospital particular da cidade de Juiz de Fora - MG. Foram utilizados formulários aplicados junto a 15 colaboradores, sendo 10 pessoas com deficiência e 5 líderes de equipe, buscando captar a percepção dos mesmos em relação a inclusão no mercado de trabalho. A pesquisa abordou no referencial teórico questões como a inclusão e a responsabilidade social, historicamente marcadas pelo preconceito, além da análise sobre a inclusão de PcDs no mercado de trabalho, que ocorreu em quatro fases distintas sendo elas a de exclusão, a segregação, a integração e a atual fase que é representada pela busca da efetiva inclusão. Foram tratados também aspectos conceituais da política assistencial à PcDs como o Benefício de Prestação Continuada (BPC) e a Lei de Cotas, que apesar de serem consideradas iniciativas concretas na busca pela inclusão, ainda não são capazes de prover reais condições de inclusão de PcDs no mercado de trabalho. Os resultados obtidos através do estudo de caso demonstraram-se inconclusivos já que a realidade vivenciada na empresa requer uma análise constante. Porém foi possível compreender que na empresa analisada há práticas inclusivas importantes que permitem a pessoa com deficiência se sentir incluída e respeitada. Os líderes apresentam uma visão realista sobre seu papel dentro da empresa e em relação à pessoa com deficiência os mesmos possuem a compreensão da necessidade do tratamento igualitário e reconhecimento dos PcDs, assim como os demais colaboradores.

Palavras-Chave: Inclusão; Liderança; PcD; Mercado. 


\section{INTRODUÇÃO}

Este trabalho aborda a inclusão de pessoas que seja em caráter temporário, intermitente, ou permanente, possuem algum tipo de deficiência resultante de sua condição dessemelhante e que, por este motivo enfrentam barreiras para a inclusão no mercado de trabalho.

A palavra inclusão é marcada historicamente por lutas contínuas de minorias, buscando garantir direitos perante uma sociedade excludente e desigual. No contexto do mercado de trabalho, as pessoas com algum tipo de deficiência tinham maiores dificuldades em serem contratadas pelas empresas, porém, com a evolução de leis trabalhistas, surgiram estratégias de integração e busca pela inclusão da pessoa com deficiência no mercado de trabalho (FONSECA, 2006).

Em contrapartida, a realidade vivenciada nos dias atuais ainda aponta a existência de barreiras à efetiva inclusão da pessoa com deficiência no mercado de trabalho, onde mesmo sendo contratadas, acabam sendo desvalorizadas, seja pela desqualificação profissional, seja pelo preconceito (MACIEL, 2000).

A justificativa para a escolha deste tema surgiu a partir de motivações pessoais, com base em experiências vivenciadas por uma das pesquisadoras. Além disso, o tema se apresenta atual e de relevante discussão uma vez que a representatividade de pessoas com deficiência inseridas no mercado nacional e mundial é crescente.

De acordo com o último censo demográfico realizado pelo Instituto Brasileiro de Geografia e Estatística (IBGE, 2010), no Brasil, cerca de 45 milhões de pessoas possuem algum tipo de deficiência, representando quase $24 \%$ da população total. Em relação à inserção desta parcela da população no mercado formal, o Ministério do Trabalho alega que em 2017, um total de 441.339 pessoas com algum tipo de deficiência já atuavam no mercado formal (MINISTÉRIO DO TRABALHO, 2017).

A estratégia metodológica utilizada baseou-se na pesquisa qualitativa de revisão bibliográfica sobre o tema. Apresenta um estudo de caso em um hospital particular renomado da cidade de Juiz de Fora - MG. Foram realizadas entrevistas em profundidade junto à alguns colaboradores da instituição, buscando captar a percepção dos mesmos em relação à pessoa com deficiência no ambiente de trabalho.

A questão problema que se buscou responder foi como a organização objeto deste estudo de caso pode promover a inclusão de pessoas com deficiência dentro do ambiente de trabalho, indo além da necessidade de contratação pelo cumprimento de cotas?

Com base no exposto até o momento, o objetivo principal do trabalho é identificar qual a percepção da inclusão da pessoa com deficiência em uma organização. De maneira complementar, este trabalho busca ainda compreender o cenário de inclusão de pessoas com deficiência no mercado de trabalho, identificando as principais dificuldades e barreiras inclusivas.

0 trabalho foi estruturado da seguinte forma. Após a introdução sobre a temática e a delimitação dos objetivos a serem alcançados com a pesquisa, o segundo tópico trouxe o referencial teórico abordando temas como a responsabilidade social, a inclusão de pessoas com deficiência no mercado de trabalho, a Lei de Cotas e o Benefício de Prestação Continuada (BPC) e a acessibilidade nas empresas consideradas inclusivas. Já o terceiro traz a descrição da metodologia utilizada, descrevendo o percurso da pesquisa e contextualizando a empresa analisada pelo método de estudo de caso. 0 quarto consiste na análise dos resultados alcançados com este trabalho, seguido da conclusão e da apresentação das referências bibliográficas utilizadas.

\section{FUNDAMENTAÇÃO TEÓRICA}

\subsection{ASPECTOS HISTÓRICOS SOBRE INCLUSÃO E RESPONSABILIDADE SOCIAL}

A inclusão tem sido tema constante de discussões e por isso tem passado por um período de mudanças no intuito de favorecer a efetividade da mesma principalmente no mercado de trabalho. Para Freire (2008) a inclusão está relacionada muitas vezes, às oportunidades de inserção de indivíduos com deficiência no ambiente de trabalho, de modo que compreender as dificuldades encontradas por estas pessoas é primordial para analisar a efetividade do processo inclusivo.

O significado de inclusão vai além da integração de pessoas com deficiência, estando diretamente relacionado a aspectos jurídicos, sociais e econômicos, dando origem a definições de inclusão associadas à inclusão social, profissional, educacional, dentre outras. 
No aspecto social, a inclusão pode ser entendida como um processo de adaptação vivenciado pela sociedade, no intuito de incluir pessoas com necessidades especiais no sistema geral (CHICON, SOARES, 2009). 0 objetivo da inclusão é equilibrar a relação entre a sociedade e as pessoas denominadas excluídas, gerando um cenário de equiparação de oportunidades e direitos.

No aspecto histórico, a inclusão sempre foi tratada como uma política complexa, que envolve principalmente o direcionamento de ações em prol das pessoas com algum tipo de deficiência, seja ela intelectual ou física. Desde os primórdios da humanidade, os nascidos com alguma característica diferente eram condenados à morte (FREIRE, 2008).

No período pré-histórico, estima-se que não havia perspectiva para a sobrevivência de nascidos com deficiência, visto que a estrutura social baseava-se no ser nômade, itinerante e exposto às intempéries. Somente a partir da organização social em locais fixos foi que se pôde contemplar condições mínimas para a sobrevivência de indivíduos com deficiência (CHICON, SOARES, 2009).

Na idade antiga, a deficiência passou a ser considerada como uma monstruosidade passível de punição como a morte, sendo assim vista de forma peculiar. Na Europa, os deficientes eram tratados a partir de uma perspectiva simbólica e religiosa, sendo ora associada ao céu, ora vista como algo ruim. Associando a deficiência a aspectos sobrenaturais, a sociedade não aceitava membros com qualquer tipo de mutação, sendo o aspecto físico altamente valorizado nesta época (FROEDE, 2013).

Na Grécia o indivíduo com deficiência era considerado fraco e incompleto e só aquele que detinha o controle de seu sustento ou era auxiliado por alguém não sofria discriminação severa. A perfeição física também era primordial em Esparta onde crianças com algum tipo de deficiência eram condenadas a serem arremessadas de um penhasco com mais de 2000 metros de altura (FREIRE, 2008).

Já em Roma, existiam leis que garantiam os direitos dos recém-nascidos, e crianças com mutações ou deficiência não eram assistidas por esta legislação. A Lei das Doze Tábuas é um destes exemplos, onde qualquer recém nascido com sinais do que eles designavam monstruosidade ou deformação poderiam ser mortas imediatamente após seu parto. Apesar de assegurar a prática do infanticídio, na Roma antiga às crianças com deficiência eram deixadas em cestas para que escravos ou para algum fim como prostituição ou para pedir esmolas (TESSARO et al., 2005).

No Egito antigo, a deficiência era concebida de forma diferente daquela da Europa antiga. As principais deficiências encontradas nesta região eram casos associados a problemas oculares (catarata, glaucoma) e casos de nanismo, o que, na percepção do povo egípcio, era uma dádiva associada aos deuses. Esta concepção acerca da deficiência fez com que o Egito antigo contemplasse a deficiência a partir de uma visão respeitosa e moralmente ética (FREIRE, 2008).

A visão do Cristianismo para a deficiência contribuiu para que o indivíduo passasse a ser reconhecido como ser dotado de alma perante o entendimento da sociedade, em contrapartida, as mutações ou deficiências encontradas no ser humano era tido como castigo divino (AZEVEDO, 2012).

Na Idade Média eram excessivos os casos em que os deficientes eram negligenciados e tratados de forma desumana, sendo que somente após muitas discussões no cenário político e social é que atitudes de cunho humanitário passaram a vislumbrar ações para a assistência aos indivíduos com necessidades especiais (TESSARO et al., 2005).

$\mathrm{O}$ Renascimento, período que compreende o século XVI, trouxe à tona uma visão científica sobre a deficiência, tratando os indivíduos como doentes e que requerem atendimento específico para que possam ser inseridos na sociedade. Nos séculos posteriores, houve um avanço na concepção social sobre os deficientes, principalmente junto aqueles com alguma necessidade mental, ampliando a visão humanitária no tratamento desses indivíduos (AZEVEDO, 2012).

Porém, ainda é possível observar o preconceito acentuado junto aos deficientes em todo mundo, agravado pela falta de acesso, políticas públicas ineficientes, dificuldades de inclusão e minimização de direitos.

No contexto de análise da inserção de pessoas com deficiência no mercado, surge a necessidade de abordar a questão da responsabilidade social, em especial a responsabilidade social corporativa, aquela praticada pelas empresas. De acordo com Perlin et al. (2016), entende-se por responsabilidade social corporativa, o conjunto de obrigações, leis e compromissos firmados pelas organizações capazes de impactar tanto o ambiente interno da empresa quanto o externo, como a sociedade. 0 objetivo da responsabilidade social corporativa é promover condições de trabalho saudáveis, respeitando aspectos como a qualidade de vida, a sustentabilidade e o desenvolvimento social. Sendo assim, a inclusão insere-se neste contexto, sendo um dos parâmetros a serem trabalhados e praticados pelas empresas. 
Ao serem consideradas como integrantes do meio social em que se instalam, as empresas tem o dever de praticar ações que permitam a ela se beneficiar, mas que também busquem beneficiar toda a comunidade. A inclusão, especialmente a inclusão de pessoas com deficiência, mostra-se como uma das inúmeras ações que devem ser contempladas pelas empresas no contexto da responsabilidade social corporativa (KEELER, 2002).

A partir da contextualização histórica, pode-se abordar de maneira mais específica a situação vivenciada pela pessoa com deficiência frente a legislação trabalhista, em especial sobre o sistema de cotas.

\subsection{INCLUSÃO DE PESSOAS COM DEFICIÊNCIA NO MERCADO}

No contexto da inclusão sob a ótica social e do trabalho, a primeira fase de transformação foi a de exclusão. Era considerada uma crueldade que pessoas com deficiência trabalhassem e empregá-las era visto como exploração que deveria ser condenada por lei e a imagem de pessoa com deficiência era alvo de caridade (SASSAKI, 2010)

Já na fase de segregação, as empresas começaram a oferecer trabalho (não emprego) às pessoas com deficiência, vendo uma forma de lucro fácil e mão de obra barata e sem vínculos empregatícios. Para Sassaki (2010), partir de então, essas pessoas começavam a se livrar da eliminação dos movimentos de integração e houve a possibilidade de (re) integração. Embora houvesse um avanço em relação à realidade, as pessoas com deficiência ainda eram vistas como cidadãos de segunda classe (NASCIMENTO; BAHIA; CUNHA; 2008)

$\mathrm{Na}$ realidade cotidiana dessas pessoas ainda predomina a dependência econômica (uma vez que a grande maioria não possui renda própria), o subemprego e a estagnação profissional - fatores que contribuem para que se mantenham à margem da vida nacional, sem chances de participação social e estigmatizadas. (SASSAKI, 2010, p. 59)

Para Amaral (1993), na fase de integração, pessoas com deficiência são contratadas em órgãos públicos e empresas privadas, contando que tenham qualificação profissional e não sejam necessárias adaptações, ou, sejam necessárias apenas pequenas adaptações no ambiente de trabalho. Essas pessoas são colocadas em áreas exclusivas, de preferência com pouco contato com o público.

Muitas pessoas com deficiência estão cercadas por outras pessoas que não reconhecem o que fazem como trabalho. Em um mundo no qual o emprego remunerado para todos nem sempre é possível, é importante que a contribuição das pessoas com deficiência seja reconhecida. (WESTMACOTT, 1996, p.4)

A fase da inclusão se diferencia da integração e das outras fases anteriores, por defender o direito de todas as pessoas, sem distinção, tendo como seu principal objetivo o desenvolvimento humano e harmonia social, buscando garantir a aceitação da diversidade e a inclusão efetiva de todos os membros da sociedade (NASCIMENTO; BAHIA; CUNHA; 2008).

Para que a inclusão seja implementada de fato, a sociedade precisa passar por transformações e se adaptar as especificidades do indivíduo e não o contrário. Para Nascimento, Bahia e Cunha (2008), o paradigma da inclusão incentiva não somente a convivência, mas também a interação entre os diferentes.

\subsection{LEI DE COTAS E BENEFÍCIO DA PRESTAÇÃO CONTINUADA (BPC)}

As políticas de inclusão social certificam de que grupos minoritários visivelmente em desvantagem na sociedade sejam favorecidos na inserção no espaço social, baseando-se na percepção da ausência de ações da própria sociedade em promover essa inserção. A definição de cotas é um dos mecanismos que reserva vagas para pessoas com deficiência no mercado de trabalho (RIBEIRO; CARNEIRO, 2009).

Segundo Fonseca (2006), a Organização das Nações Unidas (ONU) é responsável pela Declaração dos Direitos das Pessoas Portadoras de Deficiência aprovada em 1975 que afirma que as pessoas com deficiência possuem os mesmos direitos civis e políticos, econômicos, sociais e culturais que os demais membros da sociedade. 
A Organização Mundial do Trabalho (OIT) declarou em 1983 a necessidade de adotar medidas capazes de possibilitar e incentivar o acesso dos portadores de deficiência a ocupação produtiva, conforme os princípios normativos da resolução da ONU. Desde que a declaração entrou em vigor, em 1985, o acordo da OIT já foi sancionado em 70 países principalmente em países com maior nível de desenvolvimento socioeconômico (UNICEF, 2018).

A implantação da Política Nacional de Cotas Empregatícias para pessoas com deficiência, e demais políticas assistenciais como a lei sobre Planos de Benefícios da Previdência Social por meio da Lei 8.213 de julho de 1991, não foi imediata. A necessidade de padronização de aspectos impediu sua aplicação por quase uma década, até que em dezembro de 1999 foi promulgado o Decreto no 3.298 que determina e certifica a operacionalidade da norma legal (BRASIL, 1991).

A Lei 8.213 determina que qualquer empresa, com mais de 100 empregados, tenha em suas ocupações ou cargos a reserva de vagas de trabalho destinadas a pessoas com deficiência, habilitadas ou reabilitadas para desempenharem a função. A cota destinada a essas pessoas é proporcional ao número de empregados formalmente contratados, variando entre $2 \%$ a $5 \%$ do total de funcionários.

Figura 1 - Cota para pessoas com deficiência

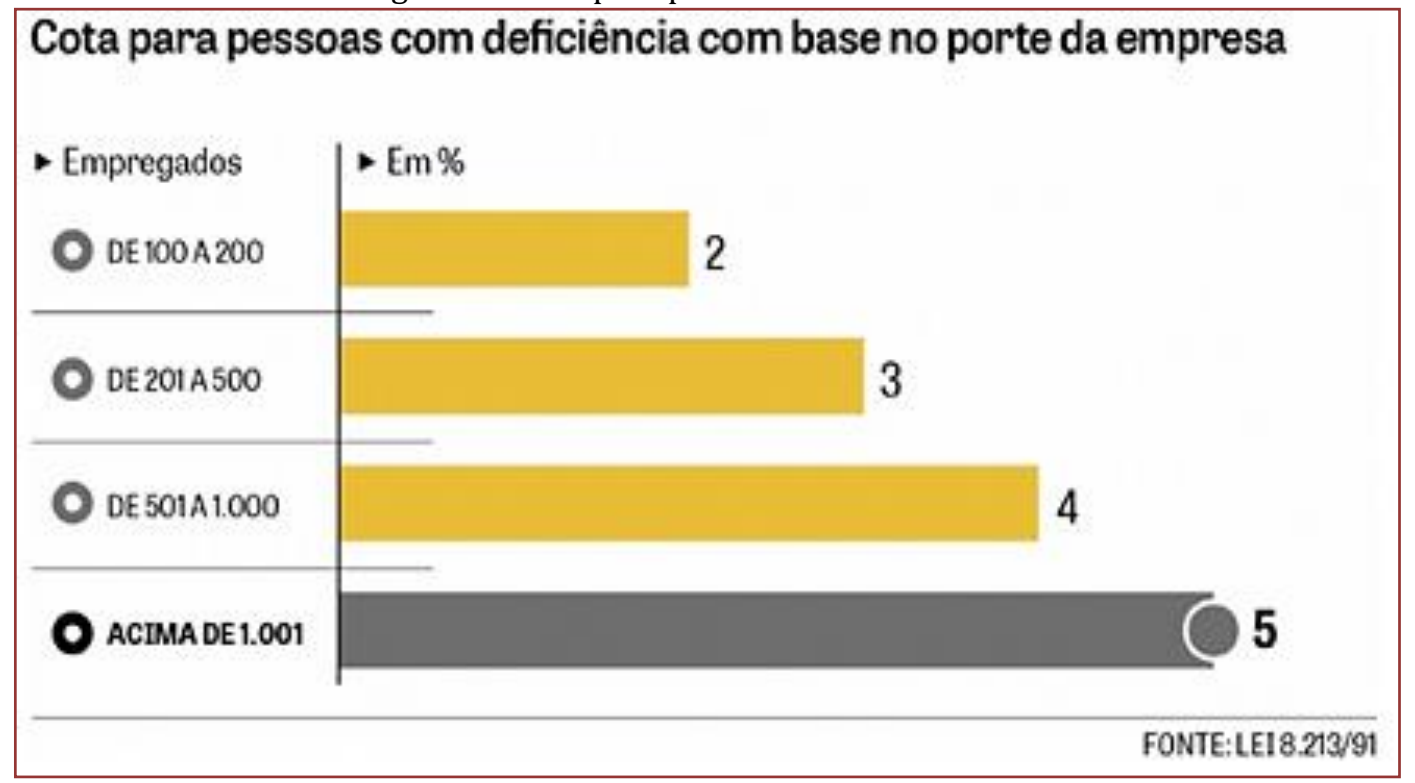

Fonte: Brasil (1991)

Sobre a distribuição da pessoa com deficiência dentro da empresa, segundo a Cartilha da Lei de Cotas, não há exigência para que as pessoas sejam distribuídas de forma proporcional, embora seja recomendado para que haja a integração social com os demais funcionários da empresa. 0 não cumprimento dessa lei é considerado prática discriminatória, que vai contra a Constituição Federal de 1988 (BRASIL, 1988).

Ressalta-se ainda, que a dispensa de um trabalhador que faça parte da reserva de vagas, só pode ocorrer mediante a contratação de um substituto em situação do enquadramento.

Fica sobre a responsabilidade do Ministério Público do Trabalho (MPT), em conjunto com o Ministério do Trabalho e do Emprego (MTE), composto por diversas Delegacias Regionais do Trabalho (DRT), a efetivação e monitoração das empresas quanto ao cumprimento da reserva de vagas.

As empresas que obrigatoriamente devem cumprir as cotas, pesquisadas no banco de dados do MTE, são notificadas para participar de reuniões com o propósito averiguar o cumprimento ou descumprimento da Lei. Caso estejam em descumprimento da Lei, a DRT acorda um prazo de 120 dias, ou mais, para regularização da situação. Com o problema persistindo após o prazo estipulado, a empresa é multada e a DRT notifica a empresa com um auto de infração, encaminhando ao MPT uma instauração de procedimentos especiais para o cumprimento da cota diante a Justiça do Trabalho (MINISTÉRIO DO TRABALHO, 2018).

Ainda assim, a aplicação da lei de cotas vem mostrando resultados pouco significativos, que evidencia as dificuldades que sobrepõe o objetivo das políticas de inclusão da pessoa com deficiência no mercado de 
trabalho. Para Lopes (2005), há uma baixa aceitação da norma legal as empresas que estão no processo, sendo que diante da institucionalidade precária, são tomadas por parte das empresas, medidas resistentes às normas legais que contrariam seus interesses.

Algumas dessas medidas resistentes às normas legais são as denominadas fraudes. De acordo com Sassaki (2010) uma dessas formas de fraude é empregar pessoas com deficiência por meio da terceirização da mão de obra. Um exemplo, esse tipo de fraude pode ser dado pela análise feita em um inquérito conduzido pela Procuradoria Regional do Trabalho da 22 2 a Região onde foi constatado que em uma empresa pública, trabalhadores eram contratados sem o cumprimento legal da realização de concurso público, onde recebiam um salário mínimo, rendimento que representa um valor abaixo do que os demais servidores da empresa recebiam.

Outro tipo de fraude encontrada na Cartilha da Lei de Cotas, ocorre quando as exigências para a seleção de uma pessoa com deficiência não estão adequadas particularidades que caracterizam essas pessoas, inviabilizando a contratação.

Segundo a Relação Anual de Informações Sociais (RAIS), do Ministério do Trabalho e Emprego (MTE), 93,48\% dos profissionais contratados com alguma deficiência conseguiram a inserção no ambiente organizacional devido à obrigação legal. "Isso demonstra que, infelizmente, sem política afirmativa de reserva de vagas não há mercado de trabalho para as pessoas com deficiência” (CAVALCANTI, 2018, p.1).

Apesar dos problemas e disparidades existentes em relação a Lei de Cotas, a mesma representa uma tentativa de inserção da pessoa com deficiência no mercado, sendo essencial porém, que a mesma esteja acompanhada de uma campanha constante de conscientização da sociedade frente a importância da inclusão e não somente vislumbrando o cumprimento de uma exigência legal.

Outra estratégia política associada à pessoa com deficiência é o Benefício de Prestação Continuada (BPC). 0 Benefício da Prestação Continuada (BPC) é um benefício assistencial, instituído pela Constituição Federal de 1988 e regulamentada pela Lei Orgânica da Assistência Social - LOAS (Lei no 8.742/93) que garante um salário mínimo mensal a pessoa com deficiência e ao idoso que comprovar não possuir meios para manter-se e nem ser mantido pela sua família (BRASIL, 2002).

A renda familiar per capita deve ser inferior a um quarto do salário mínimo e a cada dois anos peritos do BPC reavaliam a situação social quanto à condição de deficiência, para verificar se as condições do beneficiário continuam as mesmas. (BRASIL, 2002). Segundo Medeiros, Diniz e Squinca (2006, p.12)

0 benefício é individual e não pode ser cumulativo com outra transferência de renda, salvo em casos que a pessoa com deficiência esteja em contrato de aprendizagem, por até dois anos, conforme autoriza o parágrafo $2^{\circ}$ do artigo 21 da Lei no 8.742/93 e em casos que o beneficiário receba pensão especial indenizatória e assistência médica, conforme o parágrafo $4^{\circ}$ do art. 20 da Lei 8.742/93.

O BPC é pago pelo Ministério de Desenvolvimento Social e Combate a Fome - MDS, garantido pelo Fundo Nacional de Assistência Social - FNAS, sendo prescindível a contribuição na Previdência Social para ter direito ao benefício (MDS, 2015).

Nos casos de falecimento do titular, o benefício não será transferido para os dependentes e quando a pessoa passa a contribuir com a Previdência, por estar trabalhando de carteira assinada, o benefício será suspenso. “O BPC não paga 13ํㅗำ salário, férias e outros benefícios como plano de saúde e ticket alimentação" (CARVALHO; ANTUNES, 2016, p.3).

As ações em prol das pessoas com deficiência passaram a ser abordadas como política pública de inclusão social para garantir a cidadania através do reconhecimento social, valorização da pessoa e acessibilidade. O BPC gera impactos relevantes na diminuição da pobreza no País (CARVALHO; ANTUNES, 2016).

Numa análise mais apurada da legislação, para Nascimento, Bahia e Cunha, (2008, p.8), "a integração da pessoa com deficiência com o BPC é parcial e condicional, aqueles que se adaptam à sociedade, cabendo aos que "não se adaptam" somente o suprimento de suas necessidades básicas".

Conclui-se que, embora o amparo legal existente no Brasil para contratação de pessoa com deficiência seja considerado avançado em relação ao de muitos países, as leis vigentes garantem apenas a obrigatoriedade da contratação, sem, entretanto, prover reais condições para que a inclusão social da pessoa com deficiência seja efetivamente realizada (BAHIA, 2006). 
Embora haja o amparo legal da Lei de Cotas, que assegura a reserva de vagas para as pessoas com deficiência, essa Lei não garante e não assegura a entrada e permanência no mercado de trabalho, explicitando a necessidade de formação adequada, acessibilidade e infra-estrutura (CARVALHO; ANTUNES, 2016).

Ao ingressar no mercado de trabalho, a pessoa com deficiência tem o BPC suspenso, isto é, ao deixar o trabalho, receberá o benefício novamente requerendo ao INSS. Isso proporciona a essas pessoas a segurança e tranquilidade de, caso a experiência do trabalho não der certo, não ficarão descobertos de assistência. (BRASIL, 1991). Embora o BPC seja um benefício financeiro importante para as pessoas com deficiência e seus familiares, também podem ser considerados como uma barreira para a inserção de profissionais com deficiência no mercado formal de trabalho (CARVALHO; ANTUNES, 2016).

Essa barreira é mais perceptível para as pessoas com deficiência que possuem baixa qualificação profissional, cujo trabalho formal pode significar remuneração equivalente ou semelhante ao valor do benefício assistencial, não compensando o risco de trocar líquido certo e vitalício (BPC) pelo duvidoso (ser trabalhador assalariado - sem estabilidade) (NASCIMENTO; BAHIA; CUNHA, 2008).

Nesta perspectiva, conclui-se que são fundamentais ações políticas que possibilitem a autonomia, e a superação do assistencialismo, que vençam os obstáculos, como preconceito, escolaridade qualificação profissional, acessibilidade e viabilizem a inclusão efetiva do deficiente (CARVALHO; ANTUNES, 2016).

\section{CARACTERIZAÇÃO DA EMPRESA}

A empresa escolhida como base para o estudo de caso é uma instituição de saúde de grande porte presente no mercado de Juiz de Fora há mais de 20 anos, sendo considerado um hospital de excelência na Zona da Mata Mineira. Sinônimo de pioneirismo médico-científico e gestão de qualidade, o hospital busca ser referência nacional em assistência hospitalar com ênfase em alta complexidade. Incrementando recursos, valores da hospitalidade e qualificação do corpo assistencial, o hospital já é referência para uma região pólo da saúde com mais de 2 milhões de pessoas e trabalha seus processos para ser referência nacional. Possui ainda o maior centro de medicina diagnóstica da região, associado ao pioneirismo baseado na alta especialização do corpo clínico. A empresa possui um total de 1061 funcionários sendo 42 pessoas com deficiência.

Para a realização do trabalho de pesquisa no local, foram aplicados formulários semi estruturados com alguns dos líderes e com as pessoas com deficiência. A abordagem com os líderes foi realizada com o intuito de correlacionar a percepção da liderança com a participação da pessoa com deficiência no ambiente organizacional. A pesquisa com a pessoa com deficiência mostra a percepção dela sobre o líder e sobre o sentimento de sua inclusão.

\section{METODOLOGIA}

A metodologia é a etapa do projeto responsável pelo estudo e aplicação das técnicas a serem observadas para a elaboração do conhecimento, bem como demonstrar sua veracidade no meio acadêmico.

A metodologia, em um nível aplicado, examina, descreve e avalia métodos e técnicas de pesquisa que possibilitam a coleta e o processamento de informações, visando ao encaminhamento e à resolução de problemas e/ou questões de investigação (PRODANOV, 2013, p. 14)

Para Yin (2005), a pesquisa acadêmica pode ainda ser classificada como telematizada, quando há o predomínio de dados coletados pela internet.

Neste contexto, a metodologia utilizada por este trabalho baseia-se em uma pesquisa qualitativa, telematizada, adotando o método de revisão bibliográfica associado ao estudo de caso, realizando entrevistas semi-estruturadas com uso de formulários. 0 conceito apresentado por Marconi e Lakatos (2011, p.43) defende que a revisão bibliográfica é o "levantamento de toda a bibliografia já publicada em forma de livros, revistas, publicações avulsas e imprensa escrita. Sua finalidade é colocar o pesquisador em contato direto com tudo aquilo que foi escrito sobre determinado assunto [...]". Para Yin (2005), o estudo de caso e recomendado para situações onde o pesquisador não tenha o controle de um determinado fenômeno, não havendo a possibilidade de manipulação do mesmo. Além disso, o estudo de caso é utilizado para averiguar um fenômeno ainda pouco explorado ou que seja caracterizado como contemporâneo. 
A partir desta concepção, este estudo consultou livros, artigos científicos e demais publicações contidas na base de dados Scientific Electronic Library Online (SCIELO), Biblioteca Virtual de Saúde (BVS), Scientific Periodicals Electronic Library (Spell) e em sites de instituições de ensino sobre a temática.

De maneira complementar foi utilizado o método de estudo de caso que para Freitas e Jabbour (2011) é uma estratégia metodológica utilizada para compreender determinado fenômeno ou situação a partir da observação e contextualização de sua inserção na realidade e utiliza como base de sustentação a pesquisa bibliográfica. Neste contexto, utilizou-se como base para a aplicação do estudo de caso, em um hospital particular situado na cidade de Juiz de Fora, MG, aplicando 15 questionários abertos junto a colaboradores e lideranças do local. 0 roteiro da entrevista pode ser observado no apêndice deste trabalho.

Entre os meses de Setembro e Outubro de 2018, foram realizadas entrevistas semi estruturadas junto a 15 colaboradores de um hospital particular da cidade de Juiz de Fora, MG, abordando a percepção destes sobre a inclusão de pessoas com deficiência no mercado de trabalho, tendo como base, a realidade vivenciada na empresa estudada.

0 roteiro utilizado (apêndices A e B) abordou questões sobre o processo de inclusão na empresa estudada sendo aplicado pelas pesquisadoras. A análise dos dados foi feita com base nos procedimentos básicos orientados por Malhotra (2012) onde deve-se escolher os aspectos a serem analisados, interpretas as falas dos entrevistados e verificar as implicações das mesmas para a análise geral da pesquisa.

\section{ANÁLISE DOS RESULTADOS}

A pesquisa se deu a partir da aplicação de questionários semi estruturados junto a 15 colaboradores através de entrevistas onde era deixado o questionário com o colaborador e o mesmo respondia e devolvia ao pesquisador.

Foram entrevistados líderes e pessoas com deficiência de diversas áreas da empresa, dos diferentes turnos, porém, houve predominância de entrevistados dos turnos da manhã e da tarde. Vale ressaltar que foram elaborados dois questionários distintos, apresentados no apêndice, um direcionado para a análise da percepção de inclusão pelo PcD e outro direcionado para a captação da visão do líder e seu papel frente à inclusão na empresa em que atua.

O perfil dos participantes evidencia que todos são residentes da cidade de Juiz de Fora, com faixa etária entre 25 e 40 anos. Observa-se que $50 \%$ das pessoas entrevistadas apresentam deficiência física. As demais sendo $20 \%$ auditivo e $30 \%$ mental. No que se refere à escolaridade dos entrevistados, $60 \%$ das pessoas com deficiência (PcD) possuem nível médio, seguido de $40 \%$ das pessoas com nível superior em andamento, seguido pelos líderes com nível superior completo, demonstrando que as PcDs possuem nível razoável de escolaridade, sendo possível a busca pelo aperfeiçoamento profissional e a melhor colocação dentro da empresa.

Após traçar o perfil dos participantes, pode-se realizar a análise das questões abertas abordadas nas entrevistas, com o objetivo de identificar a percepção do PcD do processo de inclusão na empresa, satisfação e valorização, fatores positivos da inclusão, dificuldades existentes no processo de inclusão e pontos a serem melhorados. No caso do questionário direcionado ao líder, as perguntas buscaram captar a visão do mesmo quanto a importância da atuação da liderança e a mudança e melhoria possível ao PcD com a intervenção da mesma.

\subsection{PERCEPÇÃO DA PESSOA COM DEFICIÊNCIA}

Para tornar a análise mais didática, inicialmente serão avaliadas as falas apresentadas pelas 10 pessoas com deficiência entrevistadas. 0 questionário (vide apêndice A) contou com 15 perguntas e as respostas foram agrupadas em 4 blocos temáticos, sendo eles, liderança, realização profissional, dificuldades e pontos positivos do local de trabalho.

Quando questionados sobre a relação com o líder e com os colegas de trabalho, os entrevistados alegaram que possuem uma relação harmoniosa com os líderes e com os colegas de trabalho, alegando que possuem liberdade para a troca de experiências, além de se sentirem respeitados. 0 Quadro 1 demonstra algumas falas apresentadas pelos participantes, sendo que cada entrevistado foi identificado a partir de uma sigla (P1, P2, P3, P4, P5, P6, P7, P8, P9, P10). 
Quadro 1 - Percepção quanto à liderança e o ambiente

\begin{tabular}{|c|c|}
\hline \multicolumn{2}{|r|}{ Percepção quanto à liderança e o ambiente } \\
\hline Entrevistado & Trechos \\
\hline P1 & $\begin{array}{l}\text { "Minha relação é de bom convívio, com liberdade para troca de opiniões em prol da empresa. } 0 \\
\text { ambiente é bastante bom, de cooperação e certa amizade, com respeito ao espaço do outro }\end{array}$ \\
\hline P3 & $\begin{array}{l}\text { "Minha relação com minha líder é tranquila. A relação com meus colegas é bem harmoniosa, com } \\
\text { o tempo a gente aprende a lidar com cada um de forma legal" }\end{array}$ \\
\hline P6 & $\begin{array}{l}\text { "A relação com meu líder é boa, sou tratada de forma respeitosa e ele apresenta a todo momento } \\
\text { preocupação com a minha permanência no hospital, o que me gera uma dúvida se realmente meu } \\
\text { trabalho é necessário ou se estou apenas cumprindo a cota. Tenho uma boa relação profissional, } \\
\text { porém por ter entrado temporariamente, a minha impressão e que tomei a vaga da cota que ela } \\
\text { pertencia. }\end{array}$ \\
\hline P9 & "Tenho bom convívio com meu líder e também com a equipe em geral" \\
\hline P10 & $\begin{array}{l}\text { "O convívio é ótimo, tem respeito, bom convívio, não me sinto excluída. Os espaços são a } \\
\text { e me sinto confortável em lidar com os colegas" }\end{array}$ \\
\hline
\end{tabular}

Fonte: as autoras (2018)

Através da fala de 5 dos 10 participantes, pode-se observar que o ambiente de trabalho do hospital busca efetivar a inclusão, envolvendo as pessoas com deficiência no processo de trabalho, de modo que não haja preconceito ou exclusão. Esta tarefa deve ser implementada pela empresa, mas cabe também ao líder criar um ambiente favorável ao desenvolvimento e ao trabalho da pessoa com deficiência.

Esta constatação é reafirmada por Serrano e Brunstein (2011) ao alegarem que ao receber uma pessoa com deficiência em sua equipe, o gestor é responsável por desenvolver competências que assegurem a inclusão e desenvolvam plenamente os seus talentos e potencialidades.

Ao compreender que a pessoa com deficiência necessita de se sentir parte da equipe sem distinção ou tratamento diferenciado, a liderança passa a ter uma postura mais ativa e inclusiva dentro da organização, favorecendo a criação de um relacionamento interpessoal com a equipe baseado na confiança, no respeito e no comprometimento da pessoa com deficiência (ANDRADE et al., 2008).

O líder deve estar atento a qualquer tipo de mudança de comportamento ou tratamento para com a pessoa com deficiência, no intuito de coibir qualquer atitude preconceituosa e não inclusiva.

A liderança deve orientar ações na identificação das habilidades dos colaboradores, sendo que esta atitude deve também ser colocada em prática no caso de pessoas com deficiência, onde ao invés de considerar o que este tipo de colaborador pode ou não fazer, é preciso influenciá-lo a desenvolver suas habilidades e utilizá-las em prol do alcance dos objetivos da equipe e da instituição (ANDRADE et al., 2018)

Conforme a relação entre grupos diferentes seja mais constante no ambiente organizacional, maior deve ser a percepção do gestor quanto à comunicação e negociação diante de possíveis conflitos e discordâncias (DAVEL, VERGARA, 2001).

Neste contexto tem-se ainda os aspectos associados a realização profissional dos indivíduos, onde, ao serem questionados sobre questões como motivação, sentimento de realização profissional, oportunidade de crescimento e favorecimento do desenvolvimento profissional, os participantes apresentaram percepções que favorecem a construção de um cenário profissional onde há a dúvida acerca da capacidade profissional das pessoas com deficiência. 
Quadro 2 - Percepção quanto à realização profissional Realização profissional e oportunidade de crescimento

Entrevistado

\begin{tabular}{|c|l|}
\hline P2 & $\begin{array}{l}\text { "Eu sou realizada profissionalmente, mas desejo chegar mais longe. Já tenho melhorado muito, } \\
\text { mas procuro melhorar a cada dia mais, mas não vejo diferenciação por ser PcD. Acredito que } \\
\text { posso ter oportunidade de crescimento, só depende da gente fazer o nosso trabalho ser } \\
\text { reconhecido, pois a empresa oferece condições para que venha ter crescimento dentro dela sim" }\end{array}$ \\
\hline P4 & $\begin{array}{l}\text { "Meu trabalho não me dá sensação de realização profissional, pois tenho algumas divergências } \\
\text { de ideias em relação a algumas coisas. Mas nada que impeça que eu faça minha função com } \\
\text { qualidade. Não vejo oportunidade de crescimento mas depende do que a pessoa chama de } \\
\text { desenvolvimento profissional" }\end{array}$ \\
\hline P5 & $\begin{array}{l}\text { "Não me sinto satisfeita pois tenho dúvida se meu trabalho é realmente necessário ou se estou } \\
\text { cumprindo a cota. Não acredito nem na oportunidade de crescimento pois a rotatividade dentro } \\
\text { do setor na empresa entre os PCDs não acontece por que o hospital tem a preocupação de } \\
\text { cumprir cota pelo setor que a pessoa ocupa. Porém, me sinto apta a exercer um cargo com maior } \\
\text { responsabilidade, acredito que sou capaz e dependendo da função estou apta para exercê-las" }\end{array}$ \\
\hline P7 & $\begin{array}{l}\text { "A empresa me propicia um ambiente favorável de trabalho, vejo oportunidades, porém ainda } \\
\text { muito pequenas de crescimento. Me sinto satisfeita trabalhando aqui, mas sim pelo ambiente de } \\
\text { trabalho que é muito bom. Acho que com o tempo serão dadas maiores oportunidades para os } \\
\text { PcDs". }\end{array}$ \\
\hline P8 & $\begin{array}{l}\text { "Estou satisfeita, mas tenho receio de que não consiga ocupar outro cargo dentro da empresa } \\
\text { pois entrei para cumprir uma cota. Apesar disso, vejo que a empresa tem cuidado e busca } \\
\text { melhorar sempre. Acho que terei oportunidade no futuro e acredito até na possibilidade de } \\
\text { investirem em nós, dando cursos essas coisas" }\end{array}$ \\
\hline
\end{tabular}

Fonte: as autoras (2018)

As falas dos participantes observadas no Quadro 2, evidenciam um sentimento de dúvida. Ao mesmo tempo em que eles se sentem acolhidos no ambiente de trabalho, os mesmos não observam, na maioria dos casos, oportunidades de crescimento profissional, muitas vezes estando este fato associado a necessidade do cumprimento de cotas. Este tipo de sentimento acaba colocando em risco a inclusão efetiva de PcDs. Para Serrano e Brunstein (2011), a falta de preparo das organizações para receber este profissional e fazê-lo desenvolver na empresa caracterizam a segregação e o não reconhecimento de sua capacidade em desempenhar funções referentes à sua ocupação profissional.

Outra questão analisada pelo questionário foram às dificuldades encontradas pela pessoa com deficiência durante a realização de suas tarefas ou relacionado ao convívio, ambiente ou forma de tratamento.

Quadro 3 - Percepção quanto às dificuldades

\begin{tabular}{|c|c|}
\hline \multicolumn{2}{|r|}{ Percepção quanto às dificuldades } \\
\hline Entrevistado & Trechos \\
\hline P2 & $\begin{array}{l}\text { "Eles respeitam minhas limitações até mais do que eu mesma. Porém, já houve casos em que fui } \\
\text { tratada de forma diferente, não por ser PcD, mas por uma funcionária de mesmo cargo. Mas } \\
\text { como tenho um pouco de conhecimento contornei a situação" }\end{array}$ \\
\hline P3 & $\begin{array}{l}\text { "Em relação as minhas limitações vejo que não tenho problemas. Tive dificuldades só no início, } \\
\text { mas por questão de adaptação ao local de trabalho, mas isso foi superado" }\end{array}$ \\
\hline P8 & $\begin{array}{l}\text { "Acontece até um excesso de cuidado. Mas tem algumas coisas que precisavam modificadas. o } \\
\text { hospital possui acessibilidade para alguns tipos de deficiência, mas não todas. Como exemplo, } \\
\text { podemos citar os deficientes visuais, não há faixas no piso, cores diferenciadas para facilitar a } \\
\text { identificação para os que possuem baixa visão e falta de signos Braille. Os banheiros não são } \\
\text { adaptados para cadeirantes, pois há falhas de infraestrutura como o espaço das cabines. Não há } \\
\text { pessoas que possam recepcionar deficientes auditivos, pois não há conhecimento da linguagem } \\
\text { de sinais entre os colaboradores" }\end{array}$ \\
\hline P9 & $\begin{array}{l}\text { "Sei que tem lugares que o trabalho do PcD passa por muita dificuldade, mas aqui é bem } \\
\text { tranquilo. Já trabalhei em locais onde tive muito problema, como preconceito, exclusão e etc., } \\
\text { mas aqui não" }\end{array}$ \\
\hline
\end{tabular}

Fonte: as autoras (2018)

A análise do Quadro 3 evidencia um total respeito as limitações das pessoas com deficiência pela empresa estudada. Porém, foram identificadas dificuldades quanto ao uso das instalações pelos pacientes ou visitantes com algum tipo de deficiência, sendo primordial a adequação desses quesitos para a efetiva inclusão no local. 
Por fim, o último item analisado foi referente aos pontos positivos e as mudanças necessárias para a realização do trabalho e para a prática da inclusão, como demonstra o Quadro 4.

\begin{tabular}{|c|c|}
\hline \multicolumn{2}{|r|}{ Percepção quanto aos pontos positivos e mudanças } \\
\hline Entrevistado & Trechos \\
\hline P1 & $\begin{array}{l}\text { "Os pontos positivos aqui da empresa são muitos, mas principalmente o fato de eu nunca ter } \\
\text { sido tratada com diferença. No meu caso não necessita ser feito nenhuma mudança" }\end{array}$ \\
\hline $\mathrm{P} 2$ & $\begin{array}{l}\text { "A empresa é ótima e possui respeito e inclusão, permitindo que eu exerça minha função } \\
\text { perfeitamente. No meu caso nenhuma mudança precisa ser feita e a única que solicitei foi } \\
\text { prontamente atendida. Na época pedi a mudança do telefone convencional para headset, } \\
\text { pois devido a angulação limitada do cotovelo direito, era necessário que eu utilizasse muito } \\
\text { o braço. Com a troca deixei de ter dor por esforço repetitivo neste braço" }\end{array}$ \\
\hline P6 & $\begin{array}{l}\text { "Muitos pontos positivos, como respeito, atenção as nossas necessidades, coleguismo, não } \\
\text { vejo preconceito nem nada disso. Só precisa mesmo mudar a questão das oportunidades, } \\
\text { melhorar pra nós. Tirando isso tá ótimo }\end{array}$ \\
\hline P10 & $\begin{array}{l}\text { "Uma das empresas que melhor me recebeu até hoje em todos os anos de trabalho. Tem } \\
\text { ponto pra melhorar sim, como todas, mas são coisas que não atrapalham o compromisso } \\
\text { com os trabalhadores. Poderia só haver maior oportunidade, mas só isso" }\end{array}$ \\
\hline
\end{tabular}

Fonte: as autoras (2018)

A empresa apresenta muitos pontos positivos pela percepção das pessoas com deficiência que trabalham no local, como respeito, coleguismo e tratamento igualitário. Porém, é enfatizada a questão da necessidade de oportunizar melhorias de trabalho para os PcDs, visto que não seja apenas uma forma de preenchimento de cotas. A segunda etapa de análise vislumbrou a percepção dos líderes da empresa.

\subsection{PERCEPÇÃO DOS LÍDERES}

A gestão inclusiva exige além de normas e procedimentos: exige mudanças culturais, e o gestor, como representante e responsável por manter a cultura do ambiente organizacional, precisa desenvolver competências para lidar com desafios e oportunidades que a diversidade apresentar (SERRANO, BRUNSTEIN, 2011).

Sendo assim, a análise se dividiu em três etapas, contemplando as respostas dos 5 líderes entrevistados (P11, P12, P13, P14, P15).

A primeira questão analisada através das respostas do questionário foi a percepção do líder o conceito e representatividade do mesmo em uma empresa

Quadro 5 - Percepção quanto ao conceito de liderança

\begin{tabular}{|c|l|}
\hline Entrevistado & \multicolumn{1}{|c|}{$\begin{array}{l}\text { Percepção quanto ao conceito de liderança } \\
\text { Trechos }\end{array}$} \\
\hline P11 & $\begin{array}{l}\text { "Trabalho junto com minha equipe e não apenas ordeno a execução das atividades. Tenho } \\
\text { uma boa relação com todos da equipes e pra mim um líder precisa saber incentivar, } \\
\text { trabalhar junto e descentralizar funções, fazendo acreditar que a responsabilidade é de } \\
\text { todos, e não apenas de um." }\end{array}$ \\
\hline P13 & $\begin{array}{l}\text { "O líder precisa estar próximo da equipe, ajudar também no operacional quando preciso, } \\
\text { acredito que consigo bem me diferenciar da opção de ser chefe. Os líderes são pessoas que } \\
\text { exercem uma atividade de extrema responsabilidade, pois cuidam do lado financeiro da } \\
\text { instituição. Tenho uma relação excelente com minha equipe, pois me considero mais amigo } \\
\text { do que líder e assim temos conquistado ótimos resultados juntos" }\end{array}$ \\
\hline P15 & $\begin{array}{l}\text { "Minha relação com a equipe é muito boa, pois sei a hora certa de estar sempre por perto em } \\
\text { qualquer dificuldade quando houver. Para ser um líder é necessário vários fatores: ser } \\
\text { responsável, dar exemplo, recompensar por desempenho, saber ouvir, trazer segurança para } \\
\text { a equipe, fazer perguntas, pedir conselhos, resolver problemas, é estar sempre ao lado da } \\
\text { equipe, diferente de chefe que é aquele que trabalha impondo ordens. }\end{array}$ \\
\hline
\end{tabular}


A percepção dos líderes sobre o conceito e papel da liderança envolve o respeito, o trabalho em equipe, a segurança e o bom relacionamento interpessoal com os liderados. Essa definição é dada por diversos autores na literatura que contemplam essas e muitas outras características da liderança.

Para Pestana et al (2003), na formação de um líder considera-se como competências essenciais possuir a mente aberta para o novo e para mudanças, conhecimento técnico, flexibilidade, sensibilidade, capacidade de julgamento, reflexão, competitividade, saber gerir situações complexas, adaptabilidade, saber lidar com diferentes perfis e habilidades, capacidade de agregar informações e experiências e principalmente, estar preparado para atuar em climas de incerteza.

Outro aspecto que merece destaque é a confiança que, segundo Santiago (2007), envolve intimidade e transforma o líder em uma pessoa aberta ao diálogo e opiniões dos demais. Para que a mesma não se torne um problema, a confiança dada pelo líder deve ser medida de maneira correta, evitando que pessoas se aproveitem da situação.

De acordo com Santiago (2007), deve-se agregar à formação de líderes, a inteligência emocional, formada por cinco componentes, sendo eles, a autoconsciência, o autogerenciamento, a automotivação, a empatia e as habilidades sociais.

No contexto psicológico, cita-se a inteligência emocional como característica de destaque, sendo ela capaz de agregar valor ao desempenho do líder. Associa-se a este fato a psicologia, atuando por meio de programas de acompanhamento identificando pontos a serem trabalhados como: a ansiedade, o estresse e a percepção dos colaboradores (SANTIAGO, 2007).

Deve-se priorizar ainda, a ética, fator primordial no estabelecimento de estratégias e na forma de comunicação e relacionamento interpessoal (FERNANDES, 2006).

No caso de pessoas com deficiência, o perfil do líder também pode influenciar o trabalho destes colaboradores na organização. Para Andrade et al. (2008, p.7), as características do líder exigem que o mesmo tenha paciência, gentileza, humildade, respeito, altruísmo, perdão, honestidade e compromisso. Todas essas características inerentes a um líder corroboram a percepção dos líderes do hospital analisado, permitindo compreender que os líderes possuem uma noção, mesmo que simplificada sobre o papel do líder e as habilidades que formam um líder.

A segunda etapa de análise observou a influência que a liderança exerce sob os entrevistados, buscando informações sobre as vantagens de ser um líder, situações em que os mesmos fizeram a diferença na organização, situações onde foi necessária a intermediação de conflitos e a importância do líder.

A importância de um líder foi analisada com base na sistematização de algumas das falas dos participantes entrevistados como pode ser observado no Quadro 6.

Quadro 6 - Percepção quanto à importância de um líder

\begin{tabular}{|c|c|}
\hline \multicolumn{2}{|r|}{ Percepção quanto à importância de um líder } \\
\hline Entrevistado & Trechos \\
\hline $\mathrm{P} 12$ & $\begin{array}{l}\text { "Independente de ser ou não ser líder, precisamos respeitar as diferenças e habilidades de cada } \\
\text { funcionário, mas o principal você tem que gostar do que faz. A desvantagem é que mesmo } \\
\text { dividindo a responsabilidade, no final é você quem responde por tudo. Não sou muito de } \\
\text { mandar o funcionário fazer, prefiro mostrar para o mesmo a importância do que estou } \\
\text { solicitando e as consequências que pode gerar caso a tarefa não seja executada. Me sinto um } \\
\text { líder quando pego nas tarefas que são deles para ajudar." }\end{array}$ \\
\hline P13 & $\begin{array}{l}\text { "A maior vantagem de ser líder é a confiança da equipe e a desvantagem é que quando na falha } \\
\text { tende a decepcionar um maior número de pessoas. Quando uma tarefa não é cumprida, busco } \\
\text { ouvir os motivos que levam a desobediência e a partir daí traçar um plano de ação. Com } \\
\text { frequencia eu desempenho atividades de nível técnico apoiando-os em horários de pico e } \\
\text { turbulências. Gosto de fazer reuniões com a equipe e ouvi-los, dar feedback e compartilhar } \\
\text { resultados" }\end{array}$ \\
\hline P14 & $\begin{array}{l}\text { "Ser um líder já é uma vantagem pois demonstra sua capacidade, comprometimento e } \\
\text { reconhecimento. Quando há desobediência de um pedido pergunto ao colaborador o motivo } \\
\text { pelo qual não realizou a tarefa aí analiso se houve má vontade ou impossibilidade de realização } \\
\text { da atividade. Uma situação que fez a diferença foi quando intervi em um relacionamento } \\
\text { interpessoal entre dois funcionários, que não é permitido pela empresa, culminando na } \\
\text { dispensa de ambos" }\end{array}$ \\
\hline
\end{tabular}


A participação dos líderes é bem compreendida pelos entrevistados, que vislumbram a cooperação, o diálogo e a busca pela colaboração e confiança dos liderados para construir um ambiente propício ao trabalho. A comunicação se mostrou uma importante ferramenta entre líder e equipe, quando o líder primeiro procura saber do motivo de algum problema junto ao colaborador, para depois realizar intervenções.

Para D’Souza (1996 p.153) “todo líder deve considerar a comunicação como uma responsabilidade importante e permanente. Seu sucesso ou fracasso depende diretamente de sua capacidade de comunicarse com os subordinados". De acordo com o autor a má comunicação pode destruir líderes promissores e mesmo reconhecendo tal importância, os profissionais não recebem treinamento ou orientação devida para este assunto.

Para Murray (2012), um líder precisa estar a todo o momento repassando informações a seus colaboradores e mantendo o foco dos mesmos nessas informações. Proporcionar aos membros da equipe confiança também está relacionado ao sucesso do processo de comunicação. 0 respeito também precisa ser priorizado na comunicação dentro do ambiente organizacional. Respeitar as opiniões e informações a serem trazidas pelos colaboradores faz com que os mesmo se sintam a vontade para falar e opinar.

0 último item analisado foi a percepção do líder sobre os colaboradores com deficiência. As falas analisadas podem ser observadas no Quadro 7.

Quadro 7 - Percepção do líder quanto ao PcD

\begin{tabular}{|c|l|} 
Entrevistado & \multicolumn{1}{c}{$\begin{array}{c}\text { Percepção do líder quanto a PCD } \\
\text { Trechos }\end{array}$} \\
\hline P11 & $\begin{array}{l}\text { "Não podemos de forma alguma discriminar uma pessoa por suas limitações, no setor são todos } \\
\text { tratados iguais. Agimos de forma natural até mesmo para que esta pessoa não se sinta discriminada. } \\
\text { No nosso setor a pessoa consegue desenvolver todas as tarefas e não houve necessidade de } \\
\text { adaptação, pois o PCD consegue acompanhar o ritmo tranquilo junto com os demais" }\end{array}$ \\
\hline P12 & $\begin{array}{l}\text { "Os PcDs do meu setor são tão eficientes e competentes quanto qualquer outro funcionário sem } \\
\text { nenhum limitação. Claro que muito disso se passa pelo processo de seleção, que viabiliza o perfil do } \\
\text { PcD, com o perfil da vaga. Acredito que isso seja fundamental para a adaptação do mesmo ao } \\
\text { trabalho e integração com os demais. Além das práticas de desenvolvimento técnico, buscamos } \\
\text { também integrar o funcionário e fazê-lo entender e sentir-se muito a vontade, para conversar e } \\
\text { expor dificuldades. No setor que trabalho não percebo necessidade de mudanças pois o PcD está } \\
\text { muito integrado ao setor" }\end{array}$ \\
\hline P15 & $\begin{array}{l}\text { "São funcionários igual a qualquer outro são tratados da mesma forma. Na minha opinião uma das } \\
\text { políticas que devem ser tomadas é o tratamento igualitário com todos, pois a partir daí eles irão } \\
\text { perceber que o fato de serem diferentes não são capazes de realizar qualquer atividade. Bom eu } \\
\text { acho que na empresa que eu trabalho já são feitas mudanças para garantir a plena participação do } \\
\text { PcD. Não houve nenhuma necessidade de mudança" }\end{array}$ \\
\hline
\end{tabular}

Fonte: as autoras (2018)

As falas dos líderes evidenciam o reconhecimento da necessidade de praticar uma gestão cada vez mais inclusiva. Essa concepção também é dada por Appelbaum, Shapiro e Elbaz (1998) que alegam que para gerenciar a diversidade e promover a inclusão, os gestores devem ter consciência das diferenças, sempre as respeitando, para que isso inspire e mobilize pessoas. Amaral (1995) complementa ao alegar que incluir exige aprender a lidar com as diferenças e dar um novo significado a deficiência, descartando o significado pejorativo que o acompanha durante todos esses anos.

\section{CONCLUSÃO}

O trabalho abordou a percepção de líderes e pessoas com deficiência (PcDs) frente a inclusão no mercado de trabalho, tendo como base um estudo de caso realizado em um hospital particular situado na cidade de Juiz de Fora/MG.

O objetivo proposto pela pesquisa que foi identificar qual a visão da inclusão da pessoa com deficiência em uma organização, foi alcançado permitindo captar a percepção dos participantes frente à importância da inclusão de PcDs no mercado de trabalho, devendo ser reconhecidos pela capacidade profissional, adotando um olhar além da deficiência. 
Foi possível compreender que assim como exposto no referencial teórico, o momento vivenciado pelo contexto da inclusão de PcDs ainda é o de busca pela efetiva inclusão. As políticas públicas direcionadas ao assistencialismo dessa parcela da população se mostram pouco eficientes na promoção de reais condições de ocupação formal e oportunidade de trabalho aos PcDs, fato que pode ser observado também na empresa analisada, onde a contratação de PcDs se dá somente pela obrigatoriedade do cumprimento da Lei de Cotas.

De maneira geral, o ambiente de trabalho analisado apresenta-se receptivo a pessoa com deficiência, tratando-a de forma igualitária, respeitosa e capaz. Tanto os colaboradores, quanto os líderes, possuem uma visão positiva da inclusão na empresa, reconhecendo a importância do líder em praticar constantemente a inclusão no ambiente, não realizando distinção entre os colaboradores, por exemplo.

As atividades já são adaptadas desde o processo de recrutamento onde só são contratados os que estão aptos para a vaga.

Em contrapartida alguns pontos merecem atenção. A pesquisa constatou que os colaboradores entrevistados alegam que o crescimento profissional é difícil na empresa, alguns afirmam não haver relação com o fato de serem $\mathrm{PcD}$, porém, outros afirmam que só estão contratados para o cumprimento da cota exigida pela lei. Portanto, alguns apresentam certo nível de preocupação quanto a estagnação na função.

Neste aspecto, tem-se a questão problema que se pretendeu responder foi como as organizações podem promover a inclusão de pessoas com deficiência dentro do ambiente de trabalho, indo além da necessidade de contratação pelo cumprimento de cotas?

Uma das respostas para esta questão está na atuação do líder que ao reconhecer seu papel e importância frente à equipe, tem a possibilidade de criar estratégias para promover a cultura de inclusão dentro da organização, indo além do cumprimento de políticas públicas, investindo em qualificação para as pessoas com deficiência, favorecendo o aproveitamento destes profissionais em cargos de maior responsabilidade e confiança, como os de chefia.

Este tipo de mudança de paradigma deve ser praticado em uma escala que vai do local para o global, iniciando com uma iniciativa interna até alcançar outras organizações.

A principal fragilidade que esta pesquisa encontrou foi a dificuldade em entrevistar pessoas de outros turnos, por questões de impossibilidade de ter acesso a pessoas de outros horários de trabalho. Porém, a pesquisa demonstrou a importância da gestão inclusiva dentro de um hospital privado, que além de ser referência técnica e médica, pode torna-se uma referencia social, ao investir cada dia mais no tratamento igualitário e na inclusão efetiva das pessoas com deficiência.

\section{REFERÊNCIAS}

[1] ANDRADE, Elaine Cristina Rocha; et al. O papel do líder na inclusão de pessoas com necessidades especiais na empresa. Revista Científica Eletrônica de Administração, a.8, n.14, jun. 2008. Disponível em: <http://faef.revista.inf.br/imagens_arquivos/arquivos_destaque/DwRPnle4DUopTR1_2013-4-30-12-25-22.pdf>. Acesso em: 15 nov. 2018.

[2] AZEVEDO, Aline Cristian Guimarães. In/Exclusão de alunos com necessidades educacionais especiais. Revista Eletrônica Pro-Docência UEL, v.1, n.1, jan/jun. $2012 . \quad$ Disponível em: <http://www.uel.br/revistas/prodocenciafope/pages/arquivos/NOVOS\%20TEXTOS\%2006\%20a\%2014/ALINE\%20 AZEVEDO\%20\%20C.SOCIAIS.pdf>. Acesso em: 06 nov. 2018.

[3] BAHIA, M.S. Responsabilidade social e diversidade nas organizações: contratando pessoas com deficiência. Rio de Janeiro: Qualitymark, 2006.

[4] BRASIL. Ministério da Educação. Declaração dos Direitos dos Deficientes. 1975. Disponível em: <http://portal.mec.gov.br/seesp/arquivos/pdf/dec_def.pdf> Acesso em: 4 fev. 2015.

[5] BRASIL. Constituição da República Federativa do Brasil de 1988. Diário Oficial da República Federativa do Brasil, Poder Executivo, Brasília, DF, 05 out. 1988. Disponível em < http://www.planalto.gov.br/ccivil_03/Constituicao/Constituiçao.htm>. Acesso em: 12 Nov. 2018.

[6] BRASIL. Lei n ${ }^{\circ} 8.213$ de 24 de Julho de 1991. Dispõe sobre os Planos de Benefícios da Previdência Social e dá outras providências. Disponível em: <http://www.planalto.gov.br/ccivil_03/LEIS/L8213cons.htm>. Acesso em: 29 Out. 2018. 
[7] BRASIL. Ministério do Trabalho e Emprego. Características do Emprego Formal - RAIS 2014 - Principais

Brasília/DF, 2014

Disponível

em:<http://acesso.mte.gov.br/data/files/FF8080814F4D225D014FE173A06371C7/Apresenta\%C3

A7\%C3\%A3o\%20RAIS\%202014\%20-\%20divulga\%C3\%A7\%C3\%A3o.pdf>. Acesso em: 4 nov. 2018.

[8] CARTILHA LEI DE COTAS. A lei de cotas em perguntas e respostas. Disponível em: <http://www.pcdlegal.com.br/leidecotas/wpcontent/themes/leidecotas/downloads/Leidecotas_Cartilha.pdf>. Acesso em: 23 out. 2018

[9] CARVALHO, Elaine Samora; ANTUNES, França. Estudo comparativo entre pessoas com deficiência com benefícios de prestação continuada - BPC e aqueles que optaram pela suspensão do benefício. 2016. Disponível em: <http://www.inscricoes.fmb.unesp.br/upload/trabalhos/2016513225910.docx>. Acesso em: 23 Nov. 2018.

[10] CAVALCANTE, Fernanda Maria Pessoa. PCDs e o mercado de trabalho. 2018. Disponível em: <https://abrhsp.org.br/geral/noticias/pcds-e-o-mercado-de-trabalho-2/>. Acesso em: 28 Out. 2018

[11] CHICON, José Francisco; SOARES, Jane Alves. Compreendendo os Conceitos de Integração e Inclusão. 2009. Disponível em: <http://www.todosnos.unicamp.br:8080/lab/links-uteis/acessibilidade-einclusao/textos/compreendendo-os-conceitos-de-integracao-e-inclusao/>. Acesso em: 11 Set. 2018.

[12] D’SOUZA, Anthony. Torne-se um líder: estratégias para uma liderança efetiva. São Paulo: Loyola, 1996.

[13] FERNANDES, Karina Ribeiro; ZANELLI, José Carlos. O processo de construção e reconstrução das identidades dos indivíduos nas organizações. Rev. adm. contemp. [online]. 2006, vol.10, n.1, pp. 55-72. Disponível em: <http://dx.doi.org/10.1590/S1415-65552006000100004>. Acesso em: 22 out. 2018

[14] FONSECA, Ricardo Tadeu Marques. O trabalho da pessoa com deficiência e a lapidação dos direitos humanos: o direito do trabalho, uma ação afirmativa. São Paulo: LTr, 2006

[15] FREIRE, Sofia. Um olhar sobre a inclusão. Revista da Educação, v. 16, n.1, p.5-20, 2008. Disponível em: < http://repositorio.ul.pt/bitstream/10451/5299/1/Um\%20olhar\%20sobre\%20a\%20Inclus\%C3\%A3o.pdf>. Acesso em: 12 Set. 2018.

[16] FREITAS, Wesley R. S.; JABBOUR, Charbel J. C. Utilizando estudo de caso(s) como estratégia de pesquisa qualitativa: boas práticas e sugestões. Estudo \& Debate, Lajeado, v. 18, n. 2, p. 07-22, 2011. Disponível em: <http://www.univates.br/revistas/index.php/estudoedebate/article/view/560/550>. Acesso em: 25 Nov. 2018.

[17] FROEDE, Cristina G. Martins. Ações afirmativas e acessibilidade como instrumentos de efetivação do princípio da igualdade para as pessoas com deficiência. Dissertação (Mestrado em Direito). Universidade FUMEC FCH, Programa de Pós-Graduação Stricto Sensu em Direito. Belo Horizonte: FUMEC - FCH, 2013.

[18] KEELER, D. Responsabilidade social corporativa - RSC. Já não é mais um caso fundamentado em instinto. Trata-se de uma exigência do negócio. Relações com Investidores, São Paulo, n. 53, p. 17-20, jul. 2002.

[19] LOPES, Gláucia Gomes Vergar. A inserção do portador de deficiência no mercado de trabalho: a efetividade das leis brasileiras. São Paulo: LTr, 2005.

[20] MALHOTRA, N. K. Pesquisa de marketing: uma orientação aplicada. 6.ed. Porto Alegre: Bookman, 2012.

[21] MARCONI, Marina de Andrade; LAKATOS, Eva Maria. Metodologia do trabalho científico: procedimentos básicos, pesquisa bibliográfica, projeto e relatório, publicações e trabalhos científicos. 7. ed. 6.reimpr.São Paulo: Atlas, 2011.

[22] MEDEIROS, Marcelo; DINIZ, Débora; SQUINCA, Flávia. Transferência de renda para a população com deficiência no Brasil: uma análise do Benefício de Prestação Continuada. IPEA, Brasília, agosto de 2006.

[23] MDS. Benefício assistencial ao idoso e à pessoa com deficiência (BPC). 2015. Disponível em: <http://mds.gov.br/assuntos/assistencia-social/beneficios-assistenciais/bpc>. Acesso em: 20 nov. 2018.

[24] MINISTÉRIO DO TRABALHO E EMPREGO. Relação Anual de Informações Sociais (Rais). 2016. Disponível em: < http://pdet.mte.gov.br/rais?view=default>. Acesso em: 23 out. 2018.

[25] MURRAY, Kevin. A linguagem dos líderes: como os principais CEO's, se comunicam para inspirar, influenciar e obter resultados. São Paulo: Clio Editora, 2012.

[26] NASCIMENTO, Paulo A. Meyer M; BAHIA, Melissa Santos; CUNHA, Mateus Almeida. O Benefício de Prestação Continuada como Entrave à Inclusão da Pessoa com Deficiência no Mercado Formal de Trabalho: uma Proposta de Modificação da Lei n. 8.742/93 (LOAS). VI CONFERENCIA REGIONAL DE ISTR PARA AMÉRICA LATINA Y EL CARIBE. 8 al 11 novembro de 2007, Salvador de Bahia, Brasil.

[27] PERLIN, Ana Paula. Inclusão de Pessoas com Deficiência no Mercado de Trabalho Um Estudo em uma Empresa do Setor Cerâmico. Revista Desenvolvimento em Questão, a.14, n. 34, abr./jun. 2016. 
[28] PESTANA, Maria Cláudia; et al. Desafios da sociedade do conhecimento e gestão de pessoas em sistemas de informação. Ciência e Informação, Brasília, v. 32, n. 2, p. 77-84, maio/ago. 2003. Disponível em: <http://www.scielo.br/pdf/ci/v32n2/17036.pdf>. Acesso em: 23 out. 2016.

[29] PRODANOV, Cleber Cristiano; FREITAS, Ernani César de. Metodologia do trabalho científico: métodos e técnicas de pesquisa e do trabalho academico. 2.ed. Novo Hamburgo: Feevale, 2013.

[30] RIBEIRO, Marco Antônio; CARNEIRO, Ricardo. A inclusão indesejada: as empresas brasileiras face á lei de cotas para pessoas com deficiência no mercado de trabalho. O\&S, Salvador, v.16 - n.50, p. 545-564 - Julho/Setembro 2009 .

[31] SANTIAGO, Flávio Zola. Liderança, características e habilidades: um estudo em organizações prestadoras de serviços e consultoria em seguros no estado de Minas Gerais. Dissertação. Universidade FUMEC, Belo Horizonte, 2007. Disponível

em: <http://www.fumec.br/anexos/cursos/mestrado/dissertacoes/completa/flavio_zola_santiago_zelia.pdf>. Acesso em: 13 nov. 2018.

[32] SASSAKI, Romeu Kazumi. Inclusão: construindo uma sociedade para todos. Rio de Janeiro: WVA, 1999.

[33] TESSARO, Nilza Sanches; et al. Inclusão escolar: Visão de alunos sem necessidades educativas especiais. Psicologia Escolar e Educacional, Paraná, v. 9, n. 1, p.105-115, 2005. Disponível em: <http://www.redalyc.org/pdf/2823/282321815010.pdf>. Acesso em: 09 Set. 2018.

[34] UNICEF. Convenção sobre os Direitos das Pessoas com Deficiência. 2018. Disponível em: <https://www.unicef.org/brazil/pt/resources_27812.htm>. Acesso em: 25 Out. 2018.

[35] YIN. R. K. Estudo de caso: planejamento e métodos. 3 ed., Porto Alegre: Bookman, 2005. 


\section{Capítulo 8}

O processo de socialização em segurança do trabalho em uma indústria alimentícia

\section{Adriela de Marchi}

Aretuza Balardin Sainz

Diulnéia Granja Pereira

Eleandra Maria Prigol Meneghini

Larisa Hemkemeier Webber de Mello

Resumo: Este estudo teve como objetivo analisar como ocorre o processo de socialização organizacional em segurança do trabalho em uma indústria do ramo alimentício, localizada na cidade de São José, estado de Santa Catarina. Realizou-se uma pesquisa qualitativa descritiva, onde os dados foram obtidos por meio de entrevistas semiestruturadas com os três responsáveis pela área de Segurança do Trabalho na empresa: Engenheiro de Segurança do Trabalho e dois Técnicos de Segurança do Trabalho. Para análise dos dados coletados empregou-se a técnica de análise de conteúdo. Como resultados evidenciou-se que o fato de uma empresa possuir diversos programas e ações focados em segurança, não garante que ela possua uma eficaz estratégia de socialização, nem mesmo uma cultura de segurança forte. Conforme relatos nas entrevistas, o número de acidentes com afastamento na empresa é significativo. Logo, destacam-se as colocações de Van Maanen (1996) que dependendo da forma como o novo funcionário é socializado, o controle do comportamento pode não ser eficaz.

Palavras-Chave: Socialização Organizacional; Cultura de Segurança; Segurança do Trabalho; Estratégia de Socialização. 


\section{INTRODUÇÃO}

Os acidentes e as doenças provocadas pelo trabalho vem ocasionando um grande problema para a sociedade como um todo, tanto que esta temática tornou-se um motivo de preocupação, não só para as organizações como também para a academia, isto em decorrência dos dispêndios não só financeiros, mas também de lesão, doenças e até mesmo fatalidades que assombram tanto as instituições como a sociedade, famílias e as próprias vítimas (VASSEN, et. al., 2017).

As consequências dos acidentes de trabalho são grandes, tanto para a economia quanto para a produtividade de uma nação, além de causar um enorme sofrimento à sociedade e as famílias dos vitimados, no entanto, os acidentes de trabalho podem ser evitados (SANTANA, et. al., 2006), visto que eles manifestam total negligência e injustiça social (DORMAN, 2000).

Muitos dos casos de acidentes com vítimas fatais, especialmente na indústria da construção civil refletem, segundo, Nascimento Mangas, Minayo Gómez e Fonseca Thedim-Costa (2008), além de outras práticas, a inexistência de uma política de segurança efetiva nas empresas, fato este que colabora com a exposição dos trabalhadores à condições de trabalho precárias e a desproteção social.

Dados como esses reforçam a necessidade de se enfatizar alguns fatores organizacionais, tais como, a cultura de segurança, a prevenção e os processos de capacitação, incluindo a socialização. Sousa-Uva e Serranheira (2013) defendem a necessidade de um maior investimento na capacitação dos trabalhadores, no sentido de estimular a prevenção dos riscos profissionais e a promoção da sua saúde, visto que a segurança dos trabalhadores está atrelada aos fatores de riscos físicos, químicos, biológicos, mecânicos e ergonômicos presentes nos processos de trabalho e também é condicionada por fatores culturais, sociais, econômicos, tecnológicos e organizacionais (GONÇALVES FILHO, 2010).

Goulart, Ituassu e Mattos (2018) defendem que um funcionário ao iniciar em uma organização deverá aprender sobre a sua cultura e seus valores, para a partir desses conhecimentos ir se identificando com o jeito de ser da empresa. Em contrapartida, a empresa precisa informar e conscientizar este novo funcionário sobre o seu papel na organização. Neste sentido, a socialização organizacional deve ser evidenciada, visto que a mesma estabelece o processo que tornará o novo funcionário um membro efetivo da organização, edificando suas atitudes, comportamentos e conhecimentos (GRIFFIN, COLELLA \& GOPARAJU, 2000).

Diante destas evidências este estudo buscou responder a seguinte questão de pesquisa: como ocorre o processo de socialização de segurança do trabalho em uma indústria alimentícia? Para isto, realizou-se um estudo de caso único e descritivo em uma indústria alimentícia, localizada no estado de Santa Catarina. Optou-se por investigar este tema, nessa empresa pelo fato de a mesma possuir várias ações e programas voltados à segurança do trabalho, o que leva a crer que estes contribuem para a promoção de uma cultura de segurança, podendo refletir na redução do número de acidentes de trabalho.

O objetivo geral deste estudo foi analisar como ocorre o processo de socialização em segurança do trabalho em uma indústria alimentícia. E como objetivos específicos estabeleceu-se: a) descrever o processo de socialização em segurança do trabalho realizado na empresa; b) verificar a estratégia de socialização praticada pela área de segurança do trabalho, segundo tipologia de Van Mannen (1996); e c) verificar se o processo de socialização promove uma cultura de segurança, contribuindo para a redução no número de acidentes.

\section{FUNDAMENTAÇÃO TEÓRICA}

\subsection{CULTURA DE SEGURANÇA NO TRABALHO}

O termo "cultura de segurança" foi mencionado oficialmente pela primeira vez, na década de 1980 no relatório técnico sobre o acidente nuclear de Chernobyl na Ucrânia. Este relatório teve como objetivo apresentar os erros organizacionais e violações operacionais que estabeleceram as condições para o desastre. Segundo Glendon e Stanton (2000), a causa do acidente foi atribuída a uma falha na cultura de segurança, e desde que o conceito de cultura de segurança foi apresentado neste relatório, o tema tornouse primordial para a segurança nas organizações (NAEVESTAD, 2009).

Segundo Silva (2003, p. 34) o conceito apresentado para cultura de segurança relaciona-se a um [...] conjunto de características e atitudes das organizações e dos indivíduos, que garante que a segurança de uma planta nuclear, pela sua importância, terá a maior prioridade [...]. 
O termo cultura de segurança é muito utilizado, no entanto, não existe uma concordância precisa sobre o seu significado e nem mesmo como ela pode ser mensurada (Reason, 2016). No Quadro 1 apresenta-se algumas definições de Cultura de Segurança surgidas ao longo dos anos.

É importante destacar que embora os conceitos de cultura apresentados no Quadro 1 sejam diferentes de um autor para o outro, há de considerar que a maioria deles faz menção as questões comportamentais dos indivíduos ou grupos nas organizações. Na visão de Reason (2016), uma organização que possui uma cultura de segurança positiva compreende as seguintes características inter-relacionadas: a) cultura de reporte; é aquela onde os trabalhadores imediatamente indicam falhas, problemas e situações de quaseacidente; b) cultura justa; é aquela em que os trabalhadores são envolvidos por um clima de confiança, que faz com que eles se sintam à vontade para reportar informações relevantes e sabem o que significa comportamentos aceitáveis ou não; c) cultura flexível; é a que permite aos trabalhadores se adaptarem as mudanças ou novas exigências, sem perder o foco na segurança e saúde do trabalho e; d) cultura de aprendizagem é aquela onde os trabalhadores de forma individual ou grupal apresentam interesse em melhorar a segurança e saúde do trabalho, e manifestam isto por meio do seu próprio comportamento.

Quadro 1. Definições de cultura de segurança

\begin{tabular}{|l|l|}
\hline \multicolumn{2}{|c|}{ Autor/ano } \\
\hline Cooper $(1998,2018)$ & $\begin{array}{l}\text { É o resultado da interação entre: as percepções e atitudes; o comportamento e ações; e o } \\
\text { Sistema de Gestão da Segurança do Trabalho (SGST). }\end{array}$ \\
\hline $\begin{array}{l}\text { Glendon e Stanton } \\
(2000)\end{array}$ & $\begin{array}{l}\text { Conjunto de crenças, valores e normas compartilhados pelos membros de uma } \\
\text { organização, que representam os requisitos básicos para a segurança do trabalho. }\end{array}$ \\
\hline Luz (2003) & $\begin{array}{l}\text { É o reflexo da cultura organizacional em termos de atitudes e comportamentos dos } \\
\text { indivíduos e dos grupos dentro das organizações com relação à segurança do trabalho. }\end{array}$ \\
\hline Richter e Koch (2004) & $\begin{array}{l}\text { São as experiências vividas, interpretadas e manifestadas de forma simbólica pelos } \\
\text { membros de uma organização, que servem como ações para os trabalhadores frente aos } \\
\text { riscos, acidentes e prevenção. }\end{array}$ \\
\hline
\end{tabular}

Fonte: Elaborado pelas autoras (2018) com base em Gonçalves Filho, Andrade e Marinho (2011).

Autores como Parker, Lawrie e Hudson (2006) veem a cultura de segurança como uma hierarquia em fase de desenvolvimento nas organizações, já Reason (2016), acredita que a cultura de segurança é uma condição que as organizações desejam atingir. No entanto, autores como Glendon e Stanton (2000) colocam que a cultura de segurança é como uma propriedade da cultura organizacional, ou seja, só existe cultura de segurança em uma organização, quando a cultura organizacional prioriza este tema.

\subsection{SOCIALIZAÇÃO ORGANIZACIONAL}

0 tema socialização tem sua base de estudos apoiados na área da sociologia, psicologia e psicologia social e a transposição desta temática para o campo organizacional, mais especificamente da gestão ocorreu de forma natural, visto que as organizações são constituídas por grupos de indivíduos que estão em constante integração (DIAS, 2014).

Berger e Luckmann (2007) esclarecem que há dois tipos de socialização; a primária, que ocorre durante a infância do indivíduo, caracterizando-se pela sua inserção como membro de uma sociedade, mediante as relações estabelecidas com a família e com a escola primordialmente; a secundária é aquela que ocorre no local de trabalho dos indivíduos e caracteriza-se pela interiorização de saberes específicos e de papéis.

Neste estudo, nosso foco se concentrou na socialização secundária, ou seja, aquela que ocorre em uma determinada organização. Para Van Maanen e Schein (1979), a socialização organizacional constitui-se em um processo onde se transmite para um indivíduo as normas, regras, valores e comportamentos vividos naquele ambiente organizacional, os quais serão necessários para que este indivíduo possa participar como membro da organização. Os referidos autores ressaltam que este processo é contínuo e ocorre durante toda a carreira do indivíduo na organização.

O setor de Segurança do Trabalho juntamente com o setor de Recursos Humanos deve garantir a transmissão aos membros mais experientes da organização, assim como os recém-chegados, as normas, valores e conhecimentos pré-existentes na organização e também relacionados à segurança do trabalhador. 0 programa de integração é a principal ferramenta destinada a transmitir aos recémchegados estes aspectos, além da cultura organizacional. 
A finalidade de um programa de integração é fazer com que todos novos funcionários incorporem em suas práticas cotidianas, todos os aspectos da organização (MOTTA, 1979).

Pinto e Mortari (2008) defendem que o desempenho eficaz de uma atividade está relacionado ao conhecimento técnico da execução que o indivíduo possui, com relação àquela atividade. Logo, os autores deduzem que a falta de conhecimento da execução da atividade, por parte do indivíduo pode ocasionar em erros, omissões e até o risco de acidentes de trabalho. Portanto prover o conhecimento por meio de treinamentos ou momentos de socialização é fundamental.

\subsection{ESTRATÉGIAS DE SOCIALIZAÇÃO ORGANIZACIONAL}

A socialização organizacional tem sido desenvolvida mais profundamente a partir das publicações de Schein $(1965,1988)$ na área de psicologia organizacional e geraram influência nas pesquisas posteriores. Podemos conceituar socialização organizacional como "o processo pelo qual um novo membro aprende o sistema de valores, as normas e os padrões de comportamento exigidos da sociedade, organização ou grupo que ele está entrando" (Schein, 1988, p. 2).

Já o processo de socialização segundo Van Maanen (1996), não ocorre apenas durante o período de integração de um novo funcionário em uma organização, mas sim durante toda a sua carreira na organização, visto que este é um processo contribui para a mudança de comportamentos por parte dos indivíduos. De acordo com Van Maanen (1996) existem sete estratégias de socialização organizacional utilizadas pelas organizações, estas não são mutuamente exclusivas e na prática podem ser combinadas de diversas formas. Estas estratégias são apresentadas no Quadro 2.

\section{Quadro 2. Estratégias de socialização}

\begin{tabular}{|c|c|}
\hline Estratégia & Significado da Estratégia \\
\hline $\begin{array}{l}\text { Estratégias formais e } \\
\text { informais de } \\
\text { socialização. }\end{array}$ & $\begin{array}{l}\text { A estratégia formal de socialização atua exclusivamente na preparação do novato para ocupar } \\
\text { um cargo específico. Quanto mais formal for esta preparação mais específico é o papel do } \\
\text { novato, o que causará maior tensão e maior influência sobre as atitudes e valores dos recém- } \\
\text { chegados. Já a estratégia de socialização informal não define com precisão o papel do novo } \\
\text { funcionário, ocorrendo principalmente por meio da aprendizagem das novas tarefas, ou seja, } \\
\text { da experiência. Assim, o processo formal de socialização acaba por ser apenas a primeira } \\
\text { etapa da socialização, sendo que a segunda ocorre quando o novato é destinado a posição } \\
\text { organizacional aprendendo informalmente as tarefas e as práticas específicas de sua função e } \\
\text { seu setor. }\end{array}$ \\
\hline $\begin{array}{l}\text { Estratégias coletivas } \\
\text { e individuais de } \\
\text { socialização }\end{array}$ & $\begin{array}{l}\text { Considera-se uma estratégia coletiva de socialização quando um grupo de novatos passa pelo } \\
\text { mesmo processo de socialização organizacional. Dessa forma, o grupo tem a tendência de } \\
\text { criar pensamentos, comportamentos e atitudes similares. Como barreira da socialização } \\
\text { coletiva, destaca-se que as pessoas podem desenvolver determinada consciência coletiva, fato } \\
\text { que pode gerar incompatibilidade entre os objetivos organizacionais e os objetivos do grupo. } \\
\text { Na estratégia de socialização individual, a visão adotada pelo novo membro da empresa } \\
\text { depende da visão que o agente possui da organização. }\end{array}$ \\
\hline $\begin{array}{l}\text { Estratégias } \\
\text { sequenciais e não } \\
\text { sequenciais de } \\
\text { socialização }\end{array}$ & $\begin{array}{l}\text { Estratégias de socialização sequenciais referem-se a processos transitórios, por meio das } \\
\text { quais o indivíduo deve passar para ocupar uma posição ou um papel na organização. É } \\
\text { importante salientar que cada etapa depende da etapa anterior, por este motivo é necessário } \\
\text { um programa sequencial para que o processo de aprendizagem seja facilitado. As estratégias } \\
\text { não sequenciais são realizadas provisoriamente com etapas independentes. }\end{array}$ \\
\hline $\begin{array}{l}\text { Estratégias fixas e } \\
\text { variáveis de } \\
\text { socialização }\end{array}$ & $\begin{array}{l}\text { A estratégia fixa de socialização refere-se a um processo com tempo determinado de } \\
\text { socialização, ou seja, o novo funcionário sabe quanto tempo ele terá para completar } \\
\text { determinada etapa. A estratégia variável é exatamente o contrário, ou seja, quando o processo } \\
\text { não oferece ao novo membro um aviso sobre o seu período de transição. }\end{array}$ \\
\hline $\begin{array}{l}\text { Estratégias de } \\
\text { socialização por } \\
\text { competição ou por } \\
\text { concurso }\end{array}$ & $\begin{array}{l}\text { A base da socialização competitiva é a prática de separar os novos funcionários em diferentes } \\
\text { processos de socialização, baseados em habilidades, ambição ou antecedência. Em } \\
\text { contrapartida, os processos de socialização por concurso permitem uma participação e uma } \\
\text { cooperação maior entre os indivíduos que pertencem ao mesmo grupo de avaliação. }\end{array}$ \\
\hline
\end{tabular}


(Continuação)

\section{Quadro 2. Estratégias de socialização}

\begin{tabular}{|c|c|}
\hline Estratégia & Significado da estratégia \\
\hline $\begin{array}{l}\text { Estratégias de } \\
\text { socialização em série } \\
\text { e isoladas }\end{array}$ & $\begin{array}{l}\text { No processo de socialização em série, o novo funcionário é socializado para uma série de } \\
\text { papéis organizacionais similares, normalmente é treinado por funcionários já integrados a } \\
\text { organização. Nas estratégias isoladas de socialização, o indivíduo é socializado ao longo de } \\
\text { suas ações e não por uma regra determinada pela organização. Essa estratégia apresenta } \\
\text { um elevado risco, visto que o novo integrante poderá ficar confuso e se perder durante o } \\
\text { processo de socialização. }\end{array}$ \\
\hline $\begin{array}{l}\text { Estratégias de } \\
\text { socialização por } \\
\text { meio da investidura } \\
\text { e do despojamento }\end{array}$ & $\begin{array}{l}\text { A estratégia de socialização por meio da investidura ocorre quando a empresa quer utilizar } \\
\text { as características do novo funcionário, ao contrário do que acontece na estratégia do } \\
\text { despojamento, em que a organização insere as suas características no novo funcionário. Em } \\
\text { outras palavras são tipos de estratégias que visam confirmar ou destruir a identidade de } \\
\text { um novato na organização. No processo de investidura, o novato é bem-vindo da maneira } \\
\text { como ele é; e no processo de despojamento procura-se destruir certas crenças e valores do } \\
\text { recém-chegado à organização. }\end{array}$ \\
\hline
\end{tabular}

Fonte: Elaborado pelas autoras (2018) com base em Van Maanen (1996).

Estas estratégias têm o intuito de controlar e dirigir o comportamento de seus membros em uma organização, no entanto, dependendo da forma como o novo funcionário é socializado, o controle do comportamento pode não ser eficaz (Van Maanen, 1996). Dessa forma torna-se fundamental verificar a eficácia de cada ação. Além disso monitorar os indicadores da área, a fim de evidenciar se as ações realizadas estão trazendo reflexos positivos em termos de uma cultura positiva de segurança.

\section{MÉTODO DE PESQUISA}

O presente estudo configura-se como uma pesquisa de abordagem qualitativa do tipo descritiva. A pesquisa qualitativa para Denzin e Lincoln (2006) possui um caráter interpretativo, "[...] o que significa que seus pesquisadores estudam as coisas em seus cenários naturais, tentando entender ou interpretar os fenômenos em termos dos significados que as pessoas a eles conferem" (DENZIN \& LINCOLN, 2006, p. 17). O carácter descritivo está relacionado aos objetivos da pesquisa, o que quer dizer, segundo Triviños (1987) descrever os fatos e fenômenos da realidade pesquisada, visando responder aos objetivos do estudo.

Como estratégia de pesquisa utilizou-se o estudo de caso, que de acordo com Yin (2015), refere-se a uma pesquisa investigativa que se baseia em fatos reais dentro do seu contexto, cujos limites não são claramente definidos. Yin (2015) acrescenta que este tipo de pesquisa abrange o planejamento, a coleta de dados e a análise dos dados coletados.

Para a coleta de dados utilizou-se a entrevista semiestruturada que para Triviños (1987), caracteriza-se por roteiros de perguntas, com base em teorias que tenham relevância para a pesquisa, onde, a partir das respostas do informante podem surgir novas hipóteses. Os entrevistados foram três funcionários da área de Segurança da empresa que possuem os seguintes cargos: Engenheiro de Segurança do Trabalho e dois Técnicos de Segurança do Trabalho. A escolha por estes funcionários foi pelo fato deles estarem diretamente envolvidos nos processos da área de Segurança do Trabalho na empresa.

As entrevistas foram realizadas no mês de abril de 2018 nas dependências da empresa e tiveram duração média de 45 minutos cada. As três entrevistas foram gravadas e posteriormente transcritas na integra em um documento de Word para posterior análise. A empresa trata-se de uma indústria do ramo alimentício, localizada na cidade de São José, Santa Catarina, a mesma autorizou a realização das entrevistas e o acesso à todas as informações necessárias, porém, não autorizou a divulgação do seu nome neste estudo, isto em função da sua posição no mercado e da atual concorrência. Para identificar os entrevistados, estes serão chamados de: Engenheiro de Segurança do Trabalho, Técnico de Segurança do Trabalho I e Técnico de Segurança do Trabalho II. Por fim, analisou-se os dados coletados a partir da técnica de análise de conteúdo de Bardin (1977) que é um conjunto de técnicas onde se busca descrever o conteúdo emitido no processo de comunicação, seja ele por meio de falas ou de textos. 


\section{ANÁLISE DOS RESULTADOS}

\subsection{O PROCESSO DE SOCIALIZAÇÃO REALIZADO NA EMPRESA}

Com a finalidade de verificar como ocorre o processo de socialização na empresa pesquisada, realizaramse as entrevistas com os três profissionais da área de Segurança do Trabalho, buscando entender como os novos funcionários são integrados nas normas de segurança do trabalho na empresa; se os novos funcionários recebem materiais em meio físico sobre as normas relacionadas à segurança do trabalho; e se os novos funcionários participam de outros programas de treinamento voltados à segurança do trabalho.

Conforme pode ser constatado nos trechos que seguem, a resposta com relação ao programa de integração foi unânime para os três entrevistados, ou seja, os novos funcionários participam de um programa de uma integração de dois dias na empresa. Esta integração aborda questões relacionadas às áreas de Recursos Humanos, Qualidade e quatro horas são voltadas para a Segurança no Trabalho. "[...] a empresa tem uma integração tá, tipo a pessoa, partir do momento que ela é selecionada depois de passar por todo o processo seletivo que ela é selecionada é reservado dois dias de integração" (ENGENHEIRO DE SEGURANÇA DO TRABALHO, 2018).

A gente faz uma integração, né [...]. Dentro dessa integração contém tudo o que eles precisam saber de normas da empresa e o que eles precisam lá dentro da fábrica. A integração ela é feita tanto por parte de segurança, de RH, qualidade, área médica, então envolve todas as áreas de apoio (TÉCNICO DE SEGURANÇA DO TRABALHO I, 2018).

O Técnico de Segurança II abordou inclusive, os tópicos que são tratados na integração em Segurança do trabalho.

A gente tem integração aqui começa às 6 horas da manhã aí geralmente começa com a segurança, nós temos todo um conteúdo que a gente entrega a gente entrega manual que é o manual 714, a gente relata tudo que um funcionário precisa ter e fazer como direitos e obrigações e nós temos uma apresentação. Daí nessa apresentação que que a gente aborda? Todos os tipos de leis, de deveres, de potenciais de risco, tudo para evitar que eles entrem na indústria sem ter informação necessária para evitar acidentes. A gente fala sobre acidente de trabalho, sobre máquinas e equipamentos (TÉCNICO DE SEGURANÇA DO TRABALHO II, 2018).

Com relação a entrega de materiais em meio físico contendo as normas de segurança na empresa, os entrevistados colocaram que os funcionários recebem tanto o manual da integração impresso, como materiais referentes a operação de máquinas. “[...] sim eles recebem. Recebem a parte de integração que aí é uma apostila, tá é uma apostila com todo o material que eles viram na integração recebem a ordem de serviço e além da ordem de serviço tem um manual técnico [...]" (ENGENHEIRO DE SEGURANÇA DO TRABALHO, 2018). "Nós temos um manual técnico que são para os novos colaboradores, aí no momento que a gente faz integração com eles a gente entrega esse manualzinho técnico e dentro dele tem as normas" (TÉCNICO DE SEGURANÇA DO TRABALHO I, 2018).

O Técnico de Segurança II salientou que além dos novos funcionários, os terceiros e visitantes também recebem o manual com as normas da Segurança. "Quem é visitante tem informativo na portaria. Terceiro também. E quem é integração de novos funcionários recebe manual e terceiro também recebe manual" (TÉCNICO DE SEGURANÇA DO TRABALHO I, 2018).

Com relação a outros programas de capacitação referente à segurança, os entrevistados citaram: programa específico nas trinta e seis NR - Normas Regulamentadoras, o programa "escolinha de segurança" que é uma reciclagem, como uma reintegração, treinamento de produtos químicos, direcionado os funcionários que trabalham com produtos químicos, treinamento com os operadores de máquinas de bloqueio e sinalização.

Segundo o Engenheiro de Segurança do Trabalho, os programas de segurança na empresa são bem robustos e inclusive eles são auditados pelo corporativo (matriz) quanto ao atendimento destes programas.

[...] a gente tem todo o nosso acompanhamento mensal de comprimento desse programa e somos auditados também por esse programa por auditoria interna e cruzada tá, então pode acontecer por exemplo: mês que vem vir aqui três Engenheiros e ficarem uma semana me auditando toda a parte documental $e$ 
campo de como tá sendo realizado. Então tem um programa bem robusto bem, bem forte mesmo com relação a segurança (ENGENHEIRO DE SEGURANÇA DO TRABALHO, 2018).

Além de socializar os novos funcionários, a área de segurança da empresa também mantém programas e ações com objetivo de trabalhar a conscientização dos funcionários, assim como as questões comportamentais que contribuem para a redução dos acidentes. Para isto, realizam em conjunto com as lideranças de cada setor o DDS - Diálogo Diário de Segurança, onde todos os dias os Supervisores param a linha de produção ou as áreas administrativas por cinco minutos para falarem sobre um assunto envolvendo à segurança. Além do DDS as lideranças realizam semanalmente, a auditoria comportamental que tem por finalidade avaliar comportamentos seguros no trabalho e em caso de desvios realizar as ações corretivas.

Enfim, essas são algumas das ferramentas. Além dessas, tem as rotas dos técnicos de segurança, tem os DSS dos técnicos de segurança que também fazem junto, tem da equipe da CIPA mas enfim é, diariamente qualquer setor que você entrar você vai ouvir que ah, hoje ao discutir segurança, hoje alguém falou segurança hoje alguém visualizou segurança no setor (ENGENHEIRO DE SEGURANÇA DO TRABALHO, 2018).

As ações e programas realizados pelos responsáveis pela área de Segurança do Trabalho juntamente com as lideranças na empresa condizem com as colocações dos autores Van Maanen e Schein (1979) que conceituam a socialização como um processo em que se transmite para os funcionários normas, regras, valores e comportamentos da organização.

\subsection{ESTRATÉGIA DE SOCIALIZAÇÃO PRATICADA PELA EMPRESA}

Outro aspecto que se verificou neste estudo foi se, as estratégias de socialização praticadas pela área de segurança do trabalho na empresa possuíam relação com a estratégias descritas por Van Mannen (1996). Percebeu-se que sim, a empresa pratica muitas destas estratégias, tais como, integração com novos funcionários, onde as normas de segurança do trabalho são repassadas; o momento do diálogo diário de segurança (DSS); procedimento para troca de funções; realização de treinamentos respeitando as NR's Normas Regulamentadoras; atuação da CIPA e treinamento em local de trabalho. No Quadro 3 são apresentadas estas ações ou estratégias realizadas na empresa.

Quadro 3. Estratégias de socialização realizadas na empresa

\begin{tabular}{|c|c|}
\hline $\begin{array}{l}\text { Estrat } \\
\text { Van }\end{array}$ & Estratégias de socialização na empresa \\
\hline $\begin{array}{l}\text { Estratégias } \\
\text { formais e } \\
\text { informais de } \\
\text { socialização }\end{array}$ & $\begin{array}{l}\text { Uma das estratégias formais é a própria Integração de Novos Funcionários, onde por quatro horas } \\
\text { os novatos são colocados em uma sala de treinamento e lá recebem todas as orientações sobre as } \\
\text { normas de segurança. "Dentro dessa integração contém tudo o que eles precisam saber de normas } \\
\text { da empresa e o que eles precisam lá dentro da fábrica [...]" (TÉCNICO DE SEGURANÇA DO } \\
\text { TRABALHO I, 2018). } \\
\text { Além das orientações transmitidas verbalmente, os novatos ainda recebem em meio físico, por meio } \\
\text { de um manual, tudo que foi abordado na integração, deixando claro para cada novo funcionário qual } \\
\text { o seu papel frente à segurança no ambiente de trabalho. Recebem a parte de integração que aí é uma } \\
\text { apostila, tá é uma apostila com todo o material que eles viram na integração recebem a ordem de } \\
\text { serviço e além da ordem de serviço tem um manual técnico [...] (ENGENHEIRO DE SEGURANÇA DO } \\
\text { TRABALHO, 2018). } \\
\text { Momentos de socialização mais formal e relacionado a questões específica estão relacionados a } \\
\text { operadores que farão manuseio de produtos químicos ou operação em máquinas. Para isto há } \\
\text { treinamento de produtos químicos e treinamento com os operadores de máquinas de bloqueio e } \\
\text { sinalização. Estes são exemplos de socialização que requerem uma maior atitude dos recém- } \\
\text { chegados, visto o risco existente. } \\
\text { Com relação as estratégias informais, os novatos vão aprendendo no dia a dia com apoio das } \\
\text { lideranças e colegas mais experientes. Além disso, há rotinas que contribuem com estes } \\
\text { aprendizados, tais como o DDS - Diálogo Diário de Segurança e a auditoria comportamental, que tem } \\
\text { por finalidade avaliar comportamentos seguros no trabalho. }\end{array}$ \\
\hline
\end{tabular}




\section{(Continuação)}

Quadro 3. Estratégias de socialização realizadas na empresa

\begin{tabular}{|c|c|}
\hline \multicolumn{2}{|c|}{$\begin{array}{l}\text { Estratégias de Van } \\
\text { Mannen }\end{array}$} \\
\hline $\begin{array}{c}\text { Estratégias } \\
\text { coletivas e } \\
\text { individuais de } \\
\text { socialização }\end{array}$ & $\begin{array}{l}\text { Como estratégias coletivas de socialização podemos citar novamente a Integração de Novos } \\
\text { Funcionários e o momento do DDS - Diálogo Diário de Segurança. } \\
\text { Como estratégias individuais temos como exemplo a socialização dos funcionários para uma nova } \\
\text { função, onde segundo entrevistados existe todo um fluxo para esta rotina, onde o funcionário que } \\
\text { troca de função. } \\
\text { [...] vai para área médica para ver se a pessoa está apta a fazer essa mudança de risco, vamos dizer, } \\
\text { se ela está apta a ir para o frio, se está apta a ir para o calor, se está apta a fazer essa alteração. Eles } \\
\text { fazem o ASO dessa pessoa, que é o Atestado de Saúde Ocupacional. Depois de fazer isso, vai para a } \\
\text { segurança para gente treinar a pessoa nesse risco que ela vai ser exposta e entregar os EPIs } \\
\text { adequados para ela também. [...] Recebe treinamento, recebe toda documentação, depois que a } \\
\text { gente valida tudo (TÉCNICO DE SEGURANÇA DO TRABALHO II, 2018). }\end{array}$ \\
\hline $\begin{array}{c}\text { Estratégias } \\
\text { sequenciais e } \\
\text { não } \\
\text { sequenciais de } \\
\text { socialização }\end{array}$ & $\begin{array}{l}\text { Neste caso temos claramente o exemplo da troca de função, pois como descrito na estratégia } \\
\text { anterior (Estratégia individual), existe na empresa toda uma rotina de socialização, ou seja, uma } \\
\text { sequência de ações, que deve ser cumprida para se efetivar uma troca de função de um funcionário. } \\
\text { [...] A pessoa vai para área de saúde para parte de medicina. Então ela passa pela troca de função } \\
\text { para verificar se ela tem capacitação, também para se ela tem capacidade, na verdade, para aquele } \\
\text { cargo. Depois que ela fez dessa parte da medicina ocupacional se aprovado daí ela vai para a parte } \\
\text { de segurança. Ela é treinada na nova atividade dela em todo o procedimento tudo aquilo que a gente } \\
\text { falou lá no primeiro. Então toda ordem de serviço, procedimento é se precisar estágio } \\
\text { acompanhado, se precisar algum procedimento operacional específico. Então ela passa por tudo } \\
\text { isso, depois que fechou tudo isso, aí ela está liberada para ir pra atividade dela. Esse é um } \\
\text { procedimento, procedimento para troca de função interno da empresa. E caso ela reprove em } \\
\text { qualquer um desses ela não vai para a atividade nova, é reaberto desde o início o processo daí } \\
\text { (ENGENHEIRO DE SEGURANÇA DO TRABALHO,2018). }\end{array}$ \\
\hline $\begin{array}{l}\text { Estratégias } \\
\text { fixas e } \\
\text { variáveis de } \\
\text { socialização }\end{array}$ & $\begin{array}{l}\text { Por se tratar de uma área que segue normas de Segurança como as NR's - Normas } \\
\text { Regulamentadoras, por exemplo, existe sim estratégias de socialização que são fixas. [...] a gente } \\
\text { segue as normas regulamentadoras de saúde e segurança, conforme as periodicidades: Tem } \\
\text { treinamento que é anual, tem treinamento que é semestral, tem treinamento que é mensal e tem } \\
\text { treinamento que é bianual. A gente tem um cronograma com todos os treinamentos que devem ser } \\
\text { feitos e também tem um planejamento anual da empresa de treinamentos também pra gente poder } \\
\text { encaixar tanto custo, encaixar também quem vai fazer atividade, quem vai dar o treinamento e a } \\
\text { quantidade de pessoas que a gente tem [...] (ENGENHEIRO DE SEGURANÇA DO TRABALHO, 2018). }\end{array}$ \\
\hline $\begin{array}{l}\text { Estratégias de } \\
\text { socialização } \\
\text { por } \\
\text { competição ou } \\
\text { por concurso }\end{array}$ & $\begin{array}{l}\text { No caso da socialização por competição, onde a prática é separar os novos funcionários em } \\
\text { diferentes processos de socialização os entrevistados veem como exemplo disso, os Cipeiros. [...] } \\
\text { Tem um Cipeiro ele tem que ter um comprometimento né? Então eles não se elegem só por conta da } \\
\text { estabilidade. Ele tem que ajudar a área de segurança fazendo DDS eles fazem comunique, eles fazem } \\
\text { vistoria dos EPIs, como a gente. Tudo que a gente faz eles fazem e todo mês tem a reunião da CIPA } \\
\text { né que é programada conforme a NR e o Cipeiro excelência é aquele que se destaca por ter entregue } \\
\text { tudo, por estar ajudando, ele ganha uma vez por mês uma premiação bem legal (TÉCNICO DE } \\
\text { SEGURANÇA DO TRABALHO I, 2018). } \\
\text { Então a gente tem Cipeiro excelência, o que mais participa, que mais é ativo, que mais traz situações } \\
\text { é premiado [...] (TÉCNICO DE SEGURANÇA DO TRABALHO II, 2018). } \\
\text { Em termos de estratégias por concurso o Engenheiro de Segurança do Trabalho menciona uma } \\
\text { premiação por setores que atingem no ano o maior número de dias sem acidentes de trabalho. [...] } \\
\text { premiação existe por setores existe, é mais focada assim, por exemplo, o setor ou a unidade atingiu X } \\
\text { tempo sem acidente de trabalho faz uma premiação ou almoço pro pessoal às vezes ou rola um café } \\
\text { com eles mas existe sim (ENGENHEIRO DE SEGURANÇA DO TRABALHO, 2018). }\end{array}$ \\
\hline $\begin{array}{l}\text { Estratégias de } \\
\text { socialização } \\
\text { em série e } \\
\text { isoladas }\end{array}$ & $\begin{array}{l}\text { Este tipo de estratégia em função dos riscos existentes na operação não é praticado, somente } \\
\text { quando vai haver a troca de função ou o próprio treinamento on the job (treinamento no posto de } \\
\text { trabalho). } \\
\text { Faz primeiro o teórico e depois do teórico vai pra dentro para mostrar por exemplo, como que faz o } \\
\text { bloqueio e etiquetagem de uma máquina ele entra dentro para mostrar onde que é uma } \\
\text { seccionadora onde que é um botão de emergência o que que ele tem que fazer caso acontecer esse } \\
\text { tipo de falha então tem de máquina, de trabalho em altura, onde ele faz } 4 \text { horas em sala aí vai as } \\
\text { outras quatro horas pro ambiente de trabalho dele para usar o cinto dele na linha de vida dele } \\
\text { (ENGENHEIRO DE SEGURANÇA DO TRABALHO, 2018). }\end{array}$ \\
\hline
\end{tabular}


(Continuação)

Quadro 3. Estratégias de socialização realizadas na empresa

\begin{tabular}{|c|c|}
\hline \multicolumn{2}{|c|}{$\begin{array}{l}\text { Estratégias de Van } \\
\text { Mannen }\end{array}$} \\
\hline $\begin{array}{l}\text { Estratégias de } \\
\text { socialização } \\
\text { através da } \\
\text { investidura e } \\
\text { do } \\
\text { despojamento }\end{array}$ & $\begin{array}{l}\text { No caso das estratégias de investidura verificou-se que a empresa procura inclusive enaltecer } \\
\text { funcionários com comportamentos positivos com relação a segurança do trabalho. } \\
\text { [...] tem lá seu José com } 20 \text { anos de empresa nunca se acidentou então é reconhecido dentro desse } \\
\text { evento. A gente tem, tem bastante funcionários que nunca se acidentaram, são bem exemplares com } \\
\text { relação à segurança do trabalho então é feito junto com o evento geral (ENGENHEIRO DE } \\
\text { SEGURANÇA DO TRABALHO, 2018). Já no caso do despojamento, são utilizadas algumas } \\
\text { ferramentas visando acabar com certas crenças e valores do recém-chegado à organização. [...] Tem } \\
\text { auditoria comportamental que é uma ferramenta que a gente implantou. A gente vai no setor de } \\
\text { trabalho do supervisor da área e ele observa a pessoa a trabalhar, pontual, não é sempre a mesma } \\
\text { pessoa, e ele fica de longe por um período do dia observando tudo que ela fez, não só em segurança, } \\
\text { tudo né! E depois de fazer a observação, ele vai chamar ela e vai fazer uma crítica construtiva. Vai } \\
\text { parabenizar tudo que a pessoa fez certo e vai ensinar a fazer tudo que foi feito errado e depois de } \\
\text { fazer isso, ele firma um compromisso com ela e todos os dias ele vai reforçando para ver se está } \\
\text { dando certo. Essa ferramenta é bem legal e são os supervisores que fazem (TÉCNICO DE } \\
\text { SEGURANÇA DO TRABALHO II, 2018). }\end{array}$ \\
\hline
\end{tabular}

Fonte: elaborado pelas autoras com base na análise dos dados coletados (2018).

Em uma área como a Segurança do Trabalho, onde as atitudes e aspectos comportamentais, além da capacitação são fundamentais para se evitar acidentes ou riscos à saúde e integridade das pessoas, as estratégias descritas por Van Maanen (1996) tornam-se fundamentais, visto que segundo o próprio autor, elas servem para controlar e dirigir o comportamento dos funcionários. Van Maanen (1996) enfatiza ainda, que a forma que uma pessoa é socializada resulta, em grande parte, na maneira como esta pessoa se comportará no ambiente organizacional.

\subsection{CONTRIBUIÇÕES DA SOCIALIZAÇÃO PARA A PROMOÇÃO DA CULTURA DE SEGURANÇA}

Por fim, verificou se o processo de socialização promove uma cultura de segurança, contribuindo para a redução no número de acidentes. Neste sentido, constatou-se que várias ações são realizadas na empresa visando a conscientização dos funcionários e a redução do número de acidentes. "A gente faz DDS, conscientizando-os, a gente faz as rotas e as campanhas, além das palestras, dos jogos, além da CIPA [...]" (TÉCNICO DE SEGURANÇA DO TRABALHO I, 2018).

[...] treinamentos, campanhas, fiscalizações em ambiente de trabalho, enfim quando ocorre um acidente numa, numa outra unidade da empresa é feito uma reunião geral para mostrar aquele acidente para outra unidade. Então, assim, enfim poderia te dizer 24 horas se falando de segurança (ENGENHEIRO DE SEGURANÇA DO TRABALHO, 2018).

E em casos que não foram possíveis de evitar os acidentes, mesmo assim a empresa possui uma rotina, com a finalidade de investigar e trabalhar para que os acidentes deste tipo não ocorram mais.

A gente faz a investigação do acidente quando tem perda. Tanto perda material ou perda da pessoa mesmo. Acidentes com corte, lesão. A gente chama a pessoa $e$ o supervisor e é feita a investigação. A gente vai no local de trabalho, faz a verificação e a gente vê qual é a causa a gente vê os porquês para chegar nas causas. Depois que a gente chega nas causas a gente faz um plano de ação pra eliminar esse risco e a gente faz o acompanhamento: se precisa ser treinado, a gente faz o treinamento, se precisa ser mudado o layout, a gente muda, a gente faz um planejamento para que seja evitado esses acidentes (TÉCNICO DE SEGURANÇA DO TRABALHO II, 2018).

No entanto, observa-se que, mesmo com este conjunto de ações e um processo de socialização ocorrendo conforme as estratégias de Van Maanen (1996), os acidentes ainda ocorrem todo o mês na empresa. "[...] acidente com afastamento que é o foco da empresa em trabalhar e evitar ele é uma média de dois por mês mais ou menos nos últimos três anos" (ENGENHEIRO DE SEGURANÇA DO TRABALHO, 2018). 
Os motivos pelos quais os entrevistados atribuem este número de acidentes são: alta rotatividade na empresa; novatos que se acidentam na ansiedade por mostrarem trabalho; falta de comprometimento da supervisão e dos próprios funcionários; não atendimento aos procedimentos; falta de atenção; não utilização do EPI - Equipamento de Proteção Individual; falta de atendimento as regras de segurança; baixa escolaridade dos funcionários o que dificulta o entendimento e o grande potencial de risco neste tipo de indústria.

\section{CONCLUSÕES}

Esta pesquisa analisou como ocorre o processo de socialização em segurança do trabalho em uma indústria alimentícia. Foi a partir de uma pesquisa descritiva e de abordagem qualitativa, que se verificou como o processo de socialização é realizado na empresa. Com relação a forma que o processo ocorre podese dizer que o mesmo possui ferramentas, programas e ações robustos e com boas intenções no sentido de realmente socializar os novos funcionários e buscar estabelecer uma cultura de segurança. No entanto, podemos constatar que o fato de uma empresa possuir diversos programas e ações focados em segurança, não garantem que a mesma possua um eficaz processo de socialização, nem mesmo uma cultura forte em termos de segurança, pois conforme foi nos colocado o número de acidentes com afastamento na empresa é significativo. Logo destaca-se as colocações de Van Maanen (1996) que dependendo da forma como o novo funcionário é socializado, o controle do comportamento pode não ser eficaz.

Pode-se afirmar com base nos diferentes conceitos de cultura de segurança, revisados na literatura que o mesmo está intimamente relacionado às questões comportamentais dos indivíduos ou grupos nas organizações, assim como as questões de crenças e valores. Frente a isto pode se dizer que a socialização deve ser vista como um processo que deve iniciar no momento da seleção, no sentido de buscar novos funcionários mais aderentes os valores, crenças da organização, mas que esta olhe também para a questão da cultura de segurança.

Como recomendações sugere-se um estudo de avaliação da cultura de maturidade em segurança no trabalho nesta indústria, verificando separadamente os níveis de gestão e de operação e os novos funcionários, para que a partir deste conhecimento possa se focar um trabalho de cultura de segurança nos grupos mais prioritários. Este estudo contribui para o maior conhecimento da socialização secundária voltadas a outras áreas, neste caso Segurança do Trabalho e não somente à área de Recursos Humanos, como comumente é visto.

\section{REFERÊNCIAS}

[1] BARDIN, L. Análise de conteúdo. Lisboa: edições,70, 1977.

[2] BERGER, P. L., \& LUCKMANN, T. A construção social da realidade: tratado de sociologia do conhecimento. Petrópolis: Vozes, 2007.

[3] COOPER, D. Improving safety culture: A practical guide. Wiley, 1998.

[4] COOPER, D. Towards a model of safety culture. Safety science, v. 36 n. 2, p. 111-136, 2000. Disponível em < https://www.sciencedirect.com/science/article/pii/S0925753500000357>. Acesso em 06 set. 2018.

[5] DENZIN, N. K., \& LINCOLN, Y. S. O planejamento da pesquisa qualitativa: teorias e abordagens. In 0 planejamento da pesquisa qualitativa: teorias e abordagens, 432-432, 2006.

[6] DIAS, G. M. R. S. Socialização Organizacional: A Integração de novos funcionários nas Organizações. Dissertação de Mestrado ULHT, Lisboa, 2014.

[7] DORMAN P. The economics of safety, health, and wellbeing at work: an overview. Geneva: ILO, 2000.

[8] GLENDON, A. I., \& STANTON, N. A. Perspectives on safety culture. Safety Science, v. 34. N. 1-3, p. 193-214, 2000. Disponível em < https://www.sciencedirect.com/science/article/pii/S0925753500000138>. Acesso em 10 set. 2018.

[9] GONÇALVES FILHO, A. P. Cultura e gestão da segurança no trabalho em organizações industriais: uma proposta de modelo. Tese (Doutorado em Engenharia Industrial) - Universidade Federal da Bahia, Faculdade Politécnica. Salvador, 2010.

[10] GONÇALVES FILHO, A. P., ANDRADE, J. C. S. \& MARINHO, M. M. de O. Cultura e gestão da segurança no trabalho: uma proposta de modelo. Gestão \& Produção, São Carlos, v. 18, n.1, p. 205-220, 2011. Disponível em < https://www.scielo.br/scielo.php?pid=S0104-530X2011000100015\&script=sci_arttext> Acesso 02 set. 2018. 
[11] GOULART, I. B., ITUASSU, C. T. \& MATTOS, A. F. O Processo de Socialização Organizacional em uma Instituição Policial. XV Colóquio Internacional de Gestão Universitária - CIGU, Mar del Plata, Argentina, 2015. Disponível em < https://repositorio.ufsc.br/bitstream/handle/123456789/136116/101_00223.pdf?sequence=1\&isAllowed=y> Acesso em 28 out. 2018.

[12] GRIFFIN, A. E., COLELlA, A., \& GOPARAJU, S. Newcomer and organizational socialization tactics: An interactionist perspective.Human resource management review, v. 10, n. 4, p. 453-474, 2000. Disponível em < https://www.sciencedirect.com/science/article/abs/pii/S105348220000036X>. Acesso em 08 set. 2018.

[13] LUZ, R. S. Gestão do clima organizacional. Qualitymark Editora Ltda, 2003.

[14] DO NASCIMENTO MANGAS, R. M., GÓMEZ, C. M., DA FONSECA THEDIM-COSTA, S. M. Acidentes de trabalho fatais e desproteção social na indústria da construção civil do Rio de Janeiro. Revista Brasileira de Saúde Ocupacional, v. 33, n. 118, p. 48-55, 2008. Disponível em < https://www.redalyc.org/pdf/1005/100512309006.pdf>. Acesso 08 set. 2018.

[15] MOTTA, F. C. P. Controle social nas organizações. Revista de Administração de Empresas, v. 19, n.3, p. 11-25, 1979. Disponível em < https://www.scielo.br/pdf/rae/v19n3/v19n3a02.pdf>. Acesso 08 set. 2018.

[16] NAEVESTAD, T. O. Mapping research on culture and safety in High-Risk organizations: Arguments for a sociotechnical understanding of safety culture. Journal of Contingencies and Crisis Management, v. 17, n. 2, p. 126-136, 2009. Disponível em < https://onlinelibrary.wiley.com/doi/abs/10.1111/j.1468-5973.2009.00573.x>. Acesso 08 set. 2018.

[17] PARKER, D., LAWRIE, M. \& HUDSON, P. A framework for understanding the development of organisational safety culture. Safety Science, v. 44, n. 6, p. 551-562, 2006. Disponível em < https://www.sciencedirect.com/science/article/pii/S0925753505001219>. Acesos 08 set. 2018.

[18] PINTO, V. C. \& MORTARI, E. C. M. A socialização do funcionário para a prevenção de acidentes. IX Congresso de Ciências da Comunicação na Região Sul - Guarapuava, Universidade Federal de Santa Maria, Santa Maria, RS, 2008.

[19] REASON, J. Managing the risks of organizational accidents. Routledge, 2016.

[20] RICHTER, A., \& KOCH, C. Integration, differentiation and ambiguity in safety cultures. Safety Science, v. 42, n. 8, p. 703-722, 2004. Disponível em < https://www.sciencedirect.com/science/article/pii/S0925753503001140>. Acesso 08 set. 2018.

[21] SANTANA, V. S., ARAÚJO-FILHO, J. B., ALBUQUERQUE-OLIVEIRA, P. R., \& BARBOSA-BRANCO, A. Acidentes de trabalho: custos previdenciários e dias de trabalho perdidos. Revista de Saúde Pública, v. 40, n. 6, p. 1004-1012, 2006. Disponível em < https://www.scielo.br/scielo.php?pid=S0034-89102006000700007\&script=sci_arttext >. Acesso 08 set. 2018.

[22] SCHEIN, E. H. Organizational Psychology, Prentice-Hall, Englewood Cliffs, NJ. 1965.

[23] SCHEIN, E. H. Organizational socialization and the profession of management. MIT Sloan management review, v. 30, n. 1, p. 53, 1988. Disponível em < https://search.proquest.com/openview/0b1b6c3d155a3003b5fbdf6f9b8ee375/1?pqorigsite $=$ gscholar \&cbl $=26142>$. Acesos 08 set. 2018.

[24] SILVA, S. C. A. Culturas de segurança e prevenção de acidentes de trabalho numa abordagem psicossocial: valores organizacionais declarados e em uso. Tese de Doutorado (Doutorado em Psicologia Social e Organizacional) Departamento de Psicologia Social e das Organizações-Instituto Superior de Ciências do Trabalho e da Empresa, Lisboa, 385 f., 2003.

[25] SOUSA-UVA, A. S., \& SERRANHEIRA, F. Saúde, doença e trabalho: ganhar ou perder a vida a trabalhar? Diário de Bordo Editores, 2013

[26] TRIVIÑOS, A. N. Introdução à pesquisa em ciências sociais: o positivismo, a fenomenologia, o marxismo. São Paulo: Atlas, 1987.

[27] VAN MAANEN, J. Processando as pessoas: estratégias de socialização organizacional. FLEURY, Maria Teresa Leme [et al]. Cultura e poder nas organizações. São Paulo: Atlas, 1996.

[28] VAN MAANEN, J. \& SCHEIN, E. Toward a theory of organizacional socialization, In: Research in Organizational Behavior. 1979.

[29] VASSEN, A. S., FORTUNATO, G., BASTOS, S. A. P. \& BALASSIANO, M. Fatores constituintes da cultura de segurança: olhar sobre a indústria de mineração. Revista Gestão \& Produção, v. 24, n. 4, p. 719-730, 2017. Disponível em < https://www.scielo.br/scielo.php?pid=S0104-530X2017005016103\&script=sci_arttext\&tlng=pt $>$. Acesso 08 set. 2018.

[30] YIN, R. K. Estudo de Caso: Planejamento e Métodos. Bookman editora, 2015. 


\section{Capítulo 9}

\section{A empreendedora \\ afro-brasileira: Desafios \\ $e$ perspectivas}

\section{Marcia Ferreira da Silva \\ Maria Crauviceia dos Santos Vieira \\ Francisco Carlos Ribeiro \\ Marcileide Muniz Cavalcante \\ Alexandre Santos}

Resumo: 0 objetivo desta pesquisa é discutir quais são as dificuldades e desafios enfrentados pela mulher afro-brasileira bem como analisar, baseado no auto relato, como essa mulher se sente no meio empreendedor. Optou-se por uma pesquisa qualitativa a fim de revelar como essas mulheres definem os seus eventos. Foram selecionadas quatro mulheres afro-brasileiras e empreendedoras. A técnica de amostragem utilizada foi não probabilística, por acessibilidade que, de acordo com Costa Neto (1988, citado por GIL, 2008), acontece quando se retira uma parte da população que seja prontamente acessível. 0 instrumento escolhido para a pesquisa foi a entrevista semiestruturada que foram realizadas, via vídeo conferência, sendo transcritas posteriormente, a partir da gravação. Diante dos resultados apresentados é possível afirmar que existe sim, muita discriminação e fatores que tornam o empreendedorismo muito mais difícil para as mulheres negras. Embora essa seja uma afirmação que pode ser feita com tranquilidade, a pesquisa revelou outros pontos que ainda ficam em aberto para futuros estudos como: Um aprofundamento no sentido geográfico do por que as empreendedoras do Nordeste têm maior facilidade em conseguir crédito, em relação as mulheres afros do Sudeste do Brasil.

Palavras Chave: mulher afro-brasileira, mulher empreendedora, empreendedorismo, representatividade. 


\section{INTRODUÇÃO}

Cerca de $60 \%$ da população feminina do Brasil, é formada de mulheres afro-brasileiras. De acordo com o Instituto Brasileiro de Geografia e Estatística (IBGE), a população afro-brasileira ganha menos em relação às pessoas brancas, mesmo que tenham qualificações e instruções acadêmicas superiores aos de cor clara.

Outros dados revelados pelo IBGE, indicam que cerca de $76 \%$ da população entre a parcela mais pobre do país é negra. Este é um dado muito significativo que aponta para uma desigualdade inegável existente a partir da segregação pela cor. (Curso Aprender a Empreender [Apostila e Vídeo], 2007).

Dito isso, esse trabalho acadêmico se propõe a investigar a inserção das mulheres afro-brasileira no mercado de trabalho na função de empreendedora, buscando descrever e discutir possíveis dificuldades originadas na diferença de raças existente no mundo corporativo.

Propõe-se, nesse artigo, novas formas de se olhar essa questão social. Pretende-se, a partir da perspectiva de mulheres afro-brasileiras e empreendedoras, conhecer as suas vivências, e propor um olhar futuro digno e contribuir para a sua inserção no mercado de trabalho, mapeando um pouco das dificuldades reais enfrentadas por essas mulheres.

Jhonatan e Silva (2007) observam que a questão da criação e condução de firmas por mulheres brasileiras possui grande relevância social e econômica no âmbito das micros, pequenas e médias empresas, pois $46 \%$ dos empreendedores brasileiros são mulheres, somando cerca de 6,4 milhões de empreendedoras (GLOBAL ENTREPRENEURSHIP MONITOR, 2003). Tal dado demonstra que pesquisas no sentido de compreender o universo feminino dentro do mercado de trabalho é fundamental não apenas para a evolução social, bem como para evolução econômica.

0 presente trabalho trata-se de uma pesquisa de campo exploratória e qualitativa, cuja tipologia usada será o levantamento de dados para avaliar a prática de mulheres negras que buscam empreender, fazendo uma intersecção entre empreendimento feminino e empreendimento negro, buscando investigar quais desafios dificultam o equilíbrio de gênero e raça na criação e manutenção de negócios?

Para cumprir este objetivo, serão avaliadas falas de mulheres brancas e negras, a partir de uma entrevista semiestruturada, de forma a buscar no discurso de cada mulher, dados que levem a compreensão do fenômeno estudado e depois comparar a vivência da mulher branca com a mulher negra para captar o ponto de intersecção entre gênero e raça.

\section{DEFININDO EMPREENDEDORISMO}

Empreendedorismo é tido como um motor do progresso econômico e surgimento de empregos, além de ter um papel decisivo para economias de países em desenvolvimento (GUROL; ATSAN, 2006). Souza (2001) ainda complementa dizendo que os empreendedores são vitais para a saúde econômica de um país, pois, além de gerar empregos, também estimulam o crescimento econômico e inserem inovações tecnológicas.

O mesmo autor ainda afirma que: tanto os grandes empreendedores como os pequenos são responsáveis pela geração de riquezas do País, já que eles influenciam a atual realidade dos negócios no Brasil e diz que, apesar dos relativos progressos, o empreendedorismo no Brasil está apenas começando e necessita de um olhar especial do Governo. Dessa forma, pode se dizer que todo empreendedor desenvolve papel fundamental na economia, não apenas as grandes corporações.

O SEBRAE (2007) conceitua empreendedorismo como o processo de criar algo novo com valor, dedicando o tempo e o esforço necessários, assumindo os riscos financeiros, psíquicos e sociais correspondentes e recebendo as consequentes recompensas da satisfação e independência econômica e pessoal. Dessa forma, a pessoa que opta por empreender deve ser possuidora de algumas características as quais sirvam de ferramenta na hora de criar esse algo novo com valor.

Dentro desse escopo de características ligadas ao empreendedor, Menezes (2003) propõe que o empreendedor, a partir de um comportamento criativo e inovador, sabe transformar contextos, estimular a colaboração, criar relacionamentos pessoais, gerar resultados, fazendo o que gosta de fazer, com entusiasmo, dedicação, autoconfiança, otimismo e necessidade de realização.

Ainda, no que diz respeito às características necessárias para empreender, Robbins (apud BRINGHENTI et al, 2000) declara que existe um perfil empreendedor caracterizado por três fatores: a motivação intrínseca determinada pela alta necessidade de realização, a disposição para correr riscos e uma autoconfiança 
elevada o suficiente para que o sujeito tenha a crença de que é o responsável por mudar a própria vida. Tais características, nem sempre vem da formação do indivíduo como pessoa, porém podem ser adquiridas ao longo de sua formação profissional, pois são possíveis de serem aprendidas.

No que se refere a formar indivíduos para se tornarem empreendedores, Lima (2000) aponta para a necessidade de criar ambientes favoráveis à criatividade e espaços para pensar no futuro, estimulando a busca por soluções de problemas presentes, de forma a incentivar que os alunos sejam visionários, focados no gerenciamento, execução de processos, com uma postura ousada.

\subsection{EMPREENDEDORISMO E GÊNERO}

Dados da Global Entrepreneurship Monitor (GEM, 2017) mostram que a maior parte dos países apresenta uma supremacia masculina no desenvolvimento de novos empreendimentos. Porém, no Brasil e no México, as taxas de homens e mulheres responsáveis por novos negócios são balanceadas. Em termos de porcentagem, no Brasil a TEA (Taxa de empreendimentos iniciais) é de 19,9\% para mulheres e 19,2\% para homens, demonstrando um equilíbrio na criação de novos negócios.

Contudo, os dados não demonstram o mesmo quando são analisadas as taxas específicas de empreendimentos estabelecidos (TEE), pois em todos os países listados, a participação em empreendimentos com mais de 42 meses de funcionamento é mais alta entre os homens do que entre as mulheres. No Brasil, as taxas de empreendedorismo estabelecido, segundo o gênero, alcançaram 19,6\% entre os homens e $14,3 \%$ entre as mulheres. Esses dados demonstram que, embora haja um equilíbrio na criação de novos negócios, os homens têm maior percentual de negócios que se mantém no mercado, gerando o questionamento sobre quais fatores estarão associados a essa disparidade.

Nesse contexto, Fernandes, Campos e Silva (1995) afirmam que o empreendedorismo feminino se evidenciou como consequência da "feminização" do mercado de trabalho. Dessa forma, gradualmente, vinha aumentando o número de empreendimentos cujas líderes e idealizadoras eram mulheres. Salientando que já nos anos 90, tal mudança gerava impactos na economia e relações de trabalho, conforme constatação dos autores mencionados.

Entretanto, ainda concluíram que entre as maiores dificuldades enfrentadas pelas mulheres está a culpa relacionada às cobranças, por essas mulheres estarem afastadas de seus papéis de esposa, cuidadora do lar e mães.

Tal dificuldade ainda existe porque, por muito tempo, mulheres foram vistas como incapazes de exercer atividades de liderança e tidas como únicas responsáveis pelo cuidado do lar, sendo alegado inclusive que, fisiologicamente, homens eram mais capacitados para o mundo dos negócios como afirma Amorim e Batista (2013).

Ao longo do tempo, também com a ajuda da evolução científica esses argumentos foram se tornando arcaicos e ultrapassados, porém, os efeitos que essas crenças, que perduraram séculos, exerceram sobre a sociedade, têm sido superados com muita luta pelas mulheres.

\subsection{EMPREENDEDORISMO E INTERSECCIONALIDADE ENTRE GÊNERO E RAÇA}

Dentro do panorama de empreendedorismo e mercado de trabalho surge o termo interseccionalidade entre gênero e raça proposto por Lima, Rios e França (2013) buscando compreender o fenômeno à luz dessas duas variáveis, nesse caso, a mulher negra.

Notou-se que, com o crescimento da escolaridade, aumentou o número de mulheres em ocupações com melhor renda, porém, as mulheres que se dirigem para ocupações de nível superior são predominantemente brancas, enquanto que as negras predominam no serviço doméstico, por exemplo.

Lima (1995) ainda aponta que quando as mulheres negras conseguem investir em educação numa tentativa de mobilidade social, elas se dirigem para empregos com menores rendimentos e menos reconhecidos no mercado de trabalho. A autora ainda acrescenta que há uma concentração de mulheres em cursos "tipicamente femininos" e de menor valorização no mercado de trabalho.

0 estudo realizado traz resultados impactantes sobre a participação da mulher negra no mercado e economia, demonstrando que embora elas superem homens negros em termos educacionais, ainda estão distantes das mulheres brancas. 
Estudos cujo enfoque é raça e mercado de trabalho, vem demonstrando o quanto ainda falta para os negros se igualarem aos brancos em posições de poder. Se for levado em consideração o já citado neste trabalho, onde a autoconfiança é vista como fator imprescindível na decisão e sucesso de empreender, é possível fazer uma correlação com o estudo de Gomes (2003), onde a autora discute estética negra, autoestima e sociedade.

No estudo, discute como acontece a formação da identidade negra do ponto de vista antropológico, trazendo à luz, questões relacionadas a visão que o negro tem de si mesmo e como isso é construído socialmente. Apontando para o fato de que, por muito tempo, a estética negra foi vista como contrária ao que é belo e sendo representada como símbolo de sujeira e aversão. Onde o cabelo crespo é o cabelo ruim, por exemplo.

Tal histórico fez com que muitos negros se vissem à mercê de um "embranquecimento" para serem aceitos socialmente. Muitas mulheres se submeteram a alisamento do cabelo e procedimentos estéticos para afinar rosto e nariz.

Dessa forma, a sociedade vive um momento onde o negro precisa reafirmar sua identidade e se apropriar de sua estética como fazendo parte do belo, do limpo, do capaz. Tal histórico prejudica a construção dessa identidade e autoestima, impactando, consequentemente, sua autoconfiança.

Campante, Crespo e Leite (2004) relatam em seu estudo que o trabalho do negro, por exemplo, é menor remunerado do que o trabalho de um branco na mesma função. Associado ao discurso de que o negro é preguiçoso e, portanto, produz menos do que o branco, fazendo com que o trabalho do branco tenha mais valor.

Todos esses fatores citados são importantes quando se fala em formação de um perfil empreendedor, de forma a favorecer que determinada classe tenha mais oportunidades e mais condições de obter sucesso na hora de criar um novo negócio.

\section{PROCEDIMENTOS METODOLÓGICOS}

Quando se trata do assunto "metodologia de pesquisa" as tipologias usadas variam conforme diversos fatores, tais como os descritos por Sigelmann (1984) e apresentado a seguir:

Dadas a"1. área aos quais se aplicam. Exemplo: educação, psicologia, biologia etc.; 2. o propósito. Exemplo: descrição, predição, causalidade, status etc.; 3. o lugar. Exemplo: campo ou laboratório; 4. a aplicação. Exemplo: pura (ou básica) e aplicada. 5. os recursos da coleta de dados. Exemplo: testes, questionários, entrevistas, bibliografias etc.; 6. os símbolos. Exemplo: matemáticos ou lingüísticos; 7. a forma do pensamento. Exemplo: dedutivo, indutivo, associativo etc.; 8. o controle dos fatores. Exemplo: experimentação controlada ou nãocontrolada, observação, participação etc.; 9. os métodos para estabelecimento das relações. Exemplo: concordância, diferença, resíduos, variação concomitante etc." (Sigelmann, 1984, p. 143).

Às especificidades de cada pesquisa fazem-se necessário esclarecer os recursos metodológicos utilizados, introduzindo, a priori, a característica qualitativa do atual estudo, tendo em consideração que a investigação qualitativa permite enxergar uma realidade com "densidade" (DUARTE, 2002). Dessa forma, optou-se por uma pesquisa qualitativa a fim de revelar como as pessoas definem os seus eventos, e também para a compreensão mais detalhada do fenômeno estudado, tal utilidade da pesquisa qualitativa foi descrita por Batista (2018).

Como o objetivo desse estudo é adquirir maior familiaridade com a problemática sugerida a fim de construir hipóteses mais adequadas e identificar os cursos relevantes de ação, classifica-se o estudo como exploratório já que, de acordo com Vieira (2002), o estudo exploratório é utilizado quando é necessário definir o problema com maior precisão e Malhotra (2018) ainda confirmar pontuando que o objetivo principal da pesquisa exploratória é possibilitar a compreensão do problema enfrentado pelo pesquisador. 


\subsection{AMOSTRAGEM}

A população da pesquisa foi delimitada à população de mulheres empreendedoras afro-brasileiras, fixando-se a quantidade de mulheres. Elas foram encontradas por indicação, sendo que uma entrevistada indicou outra até chegar ao número de quatro. A técnica de amostragem utilizada foi a não probabilística, por acessibilidade que, de acordo GIL (2008) "acontece quando se retira uma parte da população que seja prontamente acessível". Desta forma foram escolhidas mulheres localizadas na cidade de São Paulo, respeitando os fatores custo e tempo. Valendo pontuar que o uso desse tipo de amostragem, não permite quaisquer análises estatísticas ou generalizações (GIL, 2008).

\subsection{INSTRUMENTO}

O instrumento escolhido para realizar a pesquisa foi a entrevista semiestruturada que, de acordo com Batista (2018), está entre as principais abordagens qualitativas. E ainda menciona que este método de coleta de dados permite identificar e compreender os significados da vida cotidiana e revela o invisível e inobservável e continua afirmando que as entrevistas possibilitam ao pesquisador obter um material único e com profundidade.

Boni e Quaresma (2005) enfatizam que entrevistas são fundamentais quando se precisa ou deseja mapear práticas, crenças, valores e sistemas classificatórios de universos sociais específicos em que os conflitos e contradições não estejam claramente explicitados. Esta afirmação é muito pertinente, pois, embora haja hipóteses, o universo da mulher afro-brasileira empreendedora ainda não foi explicitado bem como seus conflitos e contradições.

Por fim, Duarte (2004) diz que entrevistas semiestruturadas bem realizadas, permitem ao pesquisador fazer uma espécie de mergulho em profundidade, coletando indícios dos modos como cada um daqueles sujeitos percebe e significa sua realidade.

Vale descrever que entrevista semiestruturadas são aquelas com um roteiro direcionado, porém que permite ao entrevistado e entrevistador fomentar novos pontos de destaque que surjam ao longo da entrevista e não estejam prescritos no roteiro.

As entrevistas foram realizadas via vídeo conferência, sendo transcrevidas posteriormente, a partir da gravação. Para preservar a identidade das voluntárias, elas receberam uma letra correspondente as quais serão utilizadas ao se referir a cada entrevistada.

\section{ANÁLISE DAS ENTREVISTAS}

\subsection{CARACTERIZAÇÃO DAS ENTREVISTADAS}

As mulheres afro-brasileiras empreendedoras que foram entrevistadas residem nas periferias da Cidade de São Paulo. Foram selecionadas para participarem das entrevistas semiestruradas com perfil proposto nos procedimentos metodológicos da pesquisa.

Todas as empreendedoras são afro-brasileiras e suas idades variam entre 24 a 43 anos, com suas respectivas empresas / negócios de pequeno e média porte baseando-se em seus faturamentos de renda anual, conforme segue, na tabela abaixo.

Tabela 1 - Caracterização das entrevistadas.

\begin{tabular}{|c|c|c|c|c|}
\hline Identificação & Idade & Porte da Empresa & Ramo da empresa & Cor \\
\hline A & 43 & Médio & Eventos & Negra \\
\hline B & 36 & Pequeno & Loja de turbantes & Negra \\
\hline C & 25 & Pequeno & Beleza & Negra \\
\hline D & 41 & Pequeno & Aceleradora de negócios & Branca \\
\hline \multicolumn{5}{|c}{ Fonte: Elaborada pelas autoras, 2020. }
\end{tabular}




\subsection{ANÁLISE DAS ENTREVISTAS}

A primeira pergunta dirigida às empreendedoras, foi concernente ao início de sua trajetória como empreendedora. Foi possível perceber que nenhuma delas vêm de um histórico de empreendedores, todas são a primeira geração familiar no empreendedorismo.

Empreendedora "A" ainda menciona que sua mãe era empregada doméstica. Quanto ao capital para o negócio, todas apresentaram alguma dificuldade ou insegurança na hora de conseguir o crédito. Desta forma, deixavam de procurar as instituições e acabavam recorrendo aos seus próprios recursos financeiros, bem como recorrer a ajuda de seus familiares para investirem em seus negócios.

Empreendedora "A" menciona:

"Não só com a questão da solicitação de crédito como também com atividades corriqueiras do dia a dia de uma rotina de banco, tais como pagar contas ou fazer operação de TED. Uma vez a atendente ficou 30 minutos tentando entender se de fato era eu a pessoa da foto do meu RG, em um processo simples de transferência bancária."

Tal relato demonstra que serviços bancários em geral geram tormentos, pois essas mulheres sentem que suas demandas são dificultadas desnecessariamente, fazendo com que elas evitem, ao máximo, lidar com o banco. Dizia empreendedora "C", que ainda não solicitou crédito, quando questionada sobre ter sofrido discriminação em situação de banco, respondeu: "não, porém já estou preparada para isso! ", demonstrando essa preocupação quanto a precisar de futuros serviços bancários. Esse, com certeza, é um fator impeditivo no que se refere a alavancar ou crescer em um negócio. Tal constatação é confirmada pelas falas seguintes:

"O racismo institucional e a minha insegurança em relação ao acesso à crédito impacta diretamente no crescimento e evolução da minha empresa. Se não tenho acesso a capital, não consigo expandir e inovar em meu negócio" empreendedora ("A").

"Todos esses empecilhos impedem a gente de crescer cada vez mais porque a gente não tem acesso a crédito, a gente não tem um programa especial de empreendedor no banco" empreendedora ("B"). [Texto original da entrevistada ] - (sic)

"A negação do crédito, não desestimula, a negação do crédito mata esse sonho dessa mulher porque ela não tem uma família filantrópica, ela não consegue ter uma família que vai conseguir subsidiar ela" empreendedora ("D"). [Texto original da entrevistada ] - (sic)

Ainda sobre o atendimento no banco, empreendeora "B" traz três relatos de suma importância para entender como a discriminação ocorre nesse meio:

"No banco que eu tenho conta, eu mesma com todos os documentos, tudo certinho eu não tive aceso ao crédito, devido às explicações que eles dão é que não tem score é ... comprovação de renda o suficiente". [Texto original da entrevistada ] (sic)

"Bem, no banco é aquela coisa, né? A gente chega, vai pra fila da pessoa jurídica, e quando chega lá as pessoas mandam a gente ir para a fila de pessoa física, você fala: não! Sou jurídica! "

"Eles mudaram o meu gerente pra gerente.... on-line. Ou seja, no banco eu não tenho acesso a gerente, só se eu mandar e-mail". [Texto original da entrevistada ] - (sic)

"B" também menciona a insegurança de começar um negócio na seguinte fala: "no começo é sempre difícil porque a gente não tem muitas informações, a gente acha que empreender não é pra gente". Sua fala demonstra que ela não considerava a atitude de empreender como algo que fosse para ela, como se ela não fizesse parte da classe para a qual o empreendedorismo foi feito.

Outro ponto observado é que, por terem dificuldade de acesso ao crédito, elas encontram novas formas de girar o capital como juntar dinheiro ou participar de projetos cujo objetivo é incentivar o empreendedorismo de minorias. Conforme relato das entrevistadas:

"Tudo que a gente ganhou assim foi trabalhando mesmo ou mesmo vendendo ou participando de alguns projetos que deram impulso financeiros pra gente como aceleradora" empreendedora ("B"). [Texto original da entrevistada ] - (sic) 
"Tava já na empresa, a gente começou a juntar dinheiro. Tinha a questão "tipo" da gente ter que conversar pra ser mandadas embora. Então a gente investiu tudo com os nossos direitos" empreendedora ("C"). [Texto original da entrevistada ] - (sic)

Quanto ao motivo pelos quais elas empreendem, "A" afirma: "O que me motivou a empreender no início com o brechó foi pela questão financeira, eu precisava ter dinheiro para comer, me deslocar, pagar as minhas despesas pessoais". Empreendedora "B", "em 2012 eu fui demitida e resolvi de lá pra cá eu resolvi empreender" [Texto original da entrevistada ] - (sic)

Porém, embora os relatos demonstrem que muitas mulheres negras só empreendem por necessidade, empreendedora " $\mathrm{D}$ " aponta para a importância de não generalizar dizendo:

"Porque parece que mulher preta, ela só empreende quando a água tá batendo no 'bumbum', ne? Quando ela tá passando necessidade. Não! Também em alguns casos são por escolhas, né? Óbvio que desde sempre a gente empreende demais. Porque a gente sempre teve um lugar de trabalho mais escasso, né? E mais difícil de ser encarado, mas isso não é totalidade. Então, tem muitas das mulheres que hoje empreende que saíram de postos de trabalho importantes e que voltaram para a suas periferias."

Na fala de empreendedora " $D$ " é possível observar um desejo pelo reconhecimento de que mulheres negras podem sim escolher serem empreendedoras. Em outras palavras, elas podem se sentir no direito de empreender, sentir que empreender também é atividade para uma mulher negra e, a partir daí, escolher essa atividade por um livre desejo e não somente por ser o único caminho possível em determinada realidade.

No que se refere aos preconceitos vivenciados na trajetória como empreendedoras, não somente para se tornarem empreendedoras, mas também em suas vivências diárias, vale ressaltar os seguintes relatos de empreendedora "B":

"Já cheguei em eventos de empreendedorismo e a pessoa chegou a falar pra mim: tira uma foto e mandar para o seu patrão para provar que você estava no evento"

"Quando chega no fórum de empreendedorismo que não seja afro a gente enfrenta a questão do tipo 'ah você vende turbante e então você não é uma empresa que vai captar muito dinheiro' ...a gente precisa estar sempre provando."

"As pessoas que falam: quando não der mais certo você vem vender os meus produtos".

"Nunca foi explícito por eu ser mulher e ser negra. Mas sempre fica aquela desconfiança de que: Ah, você tá num, num na periferia, você vende determinado tipo de produto. Será que isso vende mesmo? A gente sente essa desconfiança". [Texto original da entrevistada ] - (sic)

Empreendedora " $\mathrm{C}$ " aparenta ter uma vivência distinta quando diz "no meu negócio não porque no meu negócio eu acho que quem se aproxima da gente, são pessoa como a gente, sabe? ". Contudo, ela trabalha com Visagismo (É um conjunto de técnicas usadas para valorizar a beleza de um rosto entre a maquiagem e o penteado, ajudando as pessoas a encontrarem o seu estilo próprio). E quanto à consultoria de imagem, é um fato de que apenas pessoas da mesma cor, procurem os serviços dela. Já é um indicativo de segregação e discriminação.

Empreendedora " $\mathrm{D}$ ", também traz um relato importante quanto à representatividade no mundo corporativo: "A gente foi para um fórum que dentro de um fórum, de 500 pessoas participando a gente tinha cinco pessoas que eram de periferia. Dessas cinco pessoas que eram da periferia, só três eram negras. [...] O próprio fórum tinha pouquíssimas mulheres nas cadeiras de decisão, ou seja, tinha muita mulher participando, mas quase nenhuma mulher em mesas de destaque".

Outra questão importante se remete ao público alvo e clientes dessas empreendedoras. Três das quatro entrevistadas escolheram como empreendimento, produtos específicos para a população negra e quarta entrevistada, mesmo trabalhando com um serviço que abrange tanto negros quanto brancos afirma: empreendedora ( $C$ ") que busca maior são de pessoas negras, são pessoas que se identificam com a gente ou por conta do cabelo ou por conta da pele empreendedora ( $C \mathrm{C}$ "). Esses dados apontam para uma tendência de o mercado conduzido por pessoas negras giram entre eles.

A empreendedora " $D$ " que trabalha com aceleramento de empresas, por exemplo, ao notar a pouca representatividade de negros, mulheres e pessoas de periferia no empreendedorismo criou um fórum de empreendedorismo cujo objetivo era exatamente ser inclusivo conforme, o relato seguinte: "criamos em 
2017 o primeiro fórum de negócio de impacto de periferia, na periferia. A gente tinha em cada mesa dessa representatividade e gênero de raça e de local de cidade. [Texto original da entrevistada - (sic)

Das 60 inscrições que vieram nesse primeiro momento 90\% eram de mulheres, $70 \%$ eram de mulheres negras". A necessidade de criar novos modelos de negócios ou novos projetos para incluir os grupos citados se dá, possivelmente, pela dificuldade de moldar as práticas vigentes a fim de que todos tenham as mesmas oportunidades.

\section{CONSIDERAÇÕES FINAIS}

Diante dos resultados apresentados é possível afirmar que existe muita discriminação e fatores que tornam o empreendedorismo muito mais difícil para as mulheres negras. Embora essa seja uma afirmação que pode ser feita com tranquilidade, muitos pontos no que se refere ao empreendedorismo feminino e afro-brasileiro, ainda ficam em aberto para mais estudos, como, por exemplo, a relação entre empreendedoras afro-brasileiras e clientes e as motivações dessas mulheres quando buscam começar um negócio.

Os trechos apresentados confirmam o que se tem estudado até o presente nas relações de trabalho e dinheiro compostas socialmente. Os dados que demonstram a pouca durabilidade das empresas fundadas por mulheres em relação às fundadas por homens podem estar relacionados à dificuldade que essas mulheres têm de conseguir apoio ou crédito para alavancar, melhorar ou inovar em seu negócio.

Mesmo Souza (2001) tendo constatado que pequenas empresas também são importantes para girar a economia, a experiência dessas mulheres indica que o tamanho de seu negócio também impacta na hora de obter apoio. Como se elas fossem frequentemente subestimadas e é imposta a elas a necessidade de provar que seu negócio é capaz de crescer e trazer retorno.

Outro ponto observado foi a presente insegurança nessas mulheres, o que, conforme apresentado na fundamentação teórica, influência de forma significativa no progresso e maturação de qualquer um que se proponha a ser um líder, chefe ou dono de uma empresa.

Sugere-se também um estudo mais aprofundado no sentido geográfico. Do por que as empreendedoras do Nordeste têm maior facilidade em conseguir crédito, em relação as mulheres do Sudeste do Brasil.

Portanto, conclui-se que é de extrema importância buscar, conhecer ainda mais o universo da mulher empreendedora afro-brasileira, pois, sem práticas funcionais e diretivas no sentido de mudar o panorama corporativo atual no qual prevalece a valorização do masculino e branco, o caminho dessas mulheres continuará sendo árduo.

Uma realidade assim não apenas prejudica as mulheres, mas se qualifica em um atraso social e econômico, privando o mercado de trabalho de mais empregos, produtos e serviços, simplesmente por travar o caminho de milhares de pessoas com potencial e energia para agregar.

Por fim, vale salientar que o histórico de vida, bem como familiar, grande parte das vezes não capacita essas mulheres a se tornarem empreendedoras e adquirir as características citadas por alguns autores como fundamentais para quem deseja empreender. Elas precisam aprender na prática as habilidades necessárias e adquirir essas habilidades com um maior esforço para então, obter os resultados esperados.

\section{REFERÊNCIAS}

[1] AMORIM, Rosane Oliveira; BATISTA, Luiz Eduardo. Empreendedorismo feminino: razão do empreendimento. 2013. Monografia (Bacharel) - União das Instituições Educacionais de São Paulo, [S. l.], 2014. Disponível em: http://uniesp.edu.br/sites/_biblioteca/revistas/20170602115149.pdf. Acesso em: 11 nov. 2019.

[2] BATISTA, Marina Picazzio Perez et al. Reflexões sobre a realização de entrevistas com viúvas enlutadas em pesquisas qualitativas. Cad. Bras. Ter. Ocup, São Carlos, v. 26, ed. 4, p. 797-808, 2018.

[3] BONI, Valdete; QUARESMA, Sílvia Jurema. Aprendendo a entrevistar: como fazer entrevistas em Ciências Sociais. Revista Eletrônica dos Pós-Graduandos em Sociologia Política da UFSC, Santa Catarina, v. 2, ed. 1, p. 68-80, 2005.

[4] BRINGHENTI, C. et al. Técnicas de ensino do intraempreendedorismo. PPGEPS, 2000. 
[5] CAMPANTE, Filipe R.; CRESPO, Anna R. V.; LEITE, Phillippe G. P. G. Desigualdade Salarial entre Raças no Mercado de Trabalho Urbano Brasileiro: Aspectos Regionais. Revista Brasileira de Economia, Jun 2004, Volume 58, № 2, pág. $185-210$.

[6] DUARTE, Rosália. Entrevistas em pesquisas qualitativas. Educar, Curitiba, ed. 24, p. 213-225, 2004.

[7] DUARTE, Rosália. Pesquisa qualitativa: reflexões sobre o trabalho de campo. Cadernos de Pesquisa, São Paulo, n. 115, p. 139-154, 2002.

[8] GIL, A. C. Como elaborar projetos de pesquisa. 4. ed. São Paulo: Atlas, 2008.

[9] GLOBAL ENTREPRENEURSHIP MONITOR. Relatório Global de Empreendedorismo no Brasil. Curitiba, PR: Instituto Brasileiro de Qualidade e Produtividade no Paraná, 2003.

[10] GLOBAL ENTREPRENEURSHIP MONITOR. Empreendedorismo no Brasil: $2016 \backslash$ Coordenação de Simara Maria de Souza Silveira Greco; diversos autores -- Curitiba: IBQP, 2017. Pg. 208

[11] GOMES, Nilma Lino. Educação, identidade negra e formação de professores/as: um olhar sobre o corpo negro e o cabelo crespo. Educ. Pesqui. [online]. 2003, vol.29, n.1, pp.167-182.

[12] GUROL, Y.; ATSAN, N. Entrepreneurial characteristics amongst university students. Education and Training, [S.l.], v. 18, n. 1, p. 25-38, 2006.

[13] IBGE, (Curso Aprender a Empreender [Apostila e $\quad$ Vídeo], 2007):https://www.ibge.gov.br/estatisticas/sociais/populacao.html

[14] JONATHAN, Eva G.; SILVA, TAISSA M. R. da. Empreendedorismo Feminino: Tecendo A Trama De Demandas Conflitantes. Psicologia \& Sociedade, Rio de Janeiro, v. 19, ed. 1, p. 77-84, 2007.

[15] LIMA, I. A. O ambiente tecnológico e econômico as corporações e a formação dos intraempreendedores. PPGEPS, 2000

[16] LIMA, Márcia. Trajetória educacional e realização sócio-econômica das mulheres negras. Estudos Feministas. Ano 3. № $2 \backslash 95.1995$, p. 489-495

[17] MALHOTRA, N.K. Pesquisa de marketing: uma orientação aplicada. 3.ed. Porto Alegre: Bookman, p. 306-307, 2001.

[18] MARCONDES, Mariana Mazzini et al. (Orgs.). Dossiê mulheres negras: retrato das condições de vida das mulheres negras no Brasil. Brasília: Ipea, 2013. p. 53-80.

[19] MENEZES, L. C. M. Gestão de Projetos. 2. ed. São Paulo: Atlas, 2003.

[20] SEBRAE. Curso aprender a empreender. Apostilas e vídeos. [S.l.]: [s.n.], 2007: https://apostilasbr.blogspot.com/2007/10/aprender-empreender-sebrae.html

[21] SIGELMANN, Euda. Tipos de pesquisa: aspectos metodológicos específicos. Arq. bras. Psic., Rio de Janeiro, n. 3, ed. 36, p. 141-155, 1984.

[22] SILVA, Márcia Regina de Lima; RIOS, Flavia; FRANÇA, Danilo. Articulando gênero e raça: a participação das mulheres negras no mercado de trabalho (1995-2009). In: Dossiê mulheres negras: retrato das condições de vida das mulheres negras no Brasil[S.l: s.n.], 2013.

[23] SOUZA, E. C. L. de. A disseminação da cultura empreendedora e a mudança na relação universidade-empresa. Empreendedorismo: competência essencial para pequenas e médias empresas. Brasília, DF: ANPROTEC, 2001. p. 2841.

[24] FERNANDES, J., de CAMPOS, F. y Oliveira da SILVA, M.: "Mulheres empreendedoras: o desafio de empreender", en Contribuciones a las Ciencias Sociales, Junio 2013. Disponível em: www.eumed.net/rev/cccss/24/familia-trabalho.html. Acesso em 11/11/2019.

[25] VIEIRA, Valter Afonso. As tipologias, variações e características da pesquisa de marketing. Rev. FAE, Curitiba, n. 1, ed. 5, p. 61-70, 2002. 


\section{Capítulo 10}

\section{A audiência pública como ferramenta para a gestão municipal: A participação popular como fundamento para as decisões administrativas e sua vinculação}

\section{Diego Santos Rebelo}

Resumo: A evolução do modelo de democracia adotado pela constituição de 1988 no Brasil tem se aperfeiçoado e criado ferramentas para instrumentalizar o chamado principio da participação popular, principalmente na Administração Pública, no intuito de democratizar ainda mais o acesso ao poder decisório, bem como auxiliar o gestor público a ter uma melhor resposta das suas decisões para como as unidades administrativas. Neste trabalho destaca-se entre esses instrumentos a audiência pública, verificando notadamente na doutrina brasileira e estrangeira de que forma a audiência pública é auxiliar da gestão pública, e se ela pode ser utilizada, ainda que sem previsão legal, para atingir este objetivo na unidade administrativa do município. Além da busca desses resultados, verificar a possibilidade de vinculação da decisão administrativa ao debatido/decidido em audiência pública, e a existência de saídas para este descumprimento, preterindo a participação popular.

Palavras-Chave: Democracia - Participação popular - Audiência Pública - Gestão pública - Administração 


\section{INTRODUCĈ̃O}

A democracia brasileira é ainda jovem quando comparada às pretensões democráticas mais antigas do mundo, e vive uma fase em que o povo passa a ser o detentor de poder da formação do Estado democrático de Direito. Neste modelo de tratado político, a participação popular pode se dar de formas diversas, e por meio de instrumentos diversos de intervenção na Administração Pública, fiscalização, criação de leis entre outros.

Atualmente segundo Bobbio (p.66) a democracia busca espaços que superem a fase da extensão do sufrágio, e deem um passo adiante na sua evolução, assim define o autor:

“...em outros termos, quando se quer saber se houve um desenvolvimento da democracia num dado país o certo é procurar perceber se aumentou não o número dos que têm o direito de participar nas decisões que lhes dizem respeito, mas os espaços nos quais podem exercer este direito." (BOBBIO, p.23)

A democratização do Estado levará à democratização da própria sociedade resume Bobbio (p.23), e a Administração Pública é um dos espaços que indicam o crescimento de democracia dentro de um Estado, eis que é um dos grandes blocos de poder que pressionam os cidadãos, e onde a nossa Magna Carta permitiu por meio de ferramentas de participação popular a efetivação de processos democráticos.

Existe uma inquietação quanto às formas de efetivação da participação popular no processo democrático, e de que forma ela pode ser expressa diretamente. Essa participação existe como forma de buscar vincular a decisão administrativa, ao passo que imprime uma segurança a administração Pública, que estará segura no seu encalço de promover qualquer atitude pautada no interesse público.

No fundo o que se busca é melhorar o próprio modo como a administração caminha, auxiliá-la na gestão da coisa pública como pontua Gisele Cruz (2006) dizendo: "Ao contrário, o que se requer é justamente o aprofundamento da democracia por meio de instrumentos de poder que expressem o dinamismo da sociedade."

A audiência pública é assim uma das principais ferramentas de diálogo para realização da participação popular na Administração Pública, sendo em alguns casos obrigatória, por estar inserida na norma como essencial, e em outros casos podem ser levantadas pelo próprio poder público no intuito de ouvir populações atingidas, grupos de interesse ou qualquer cidadão.

Ainda que essa evolução da Democracia Participativa esteja em curso, há uma carência de participação popular e de democracia no acesso à administração pública, e é nesse ponto que a presente pesquisa será inicialmente direcionada. Segundo CRUZ (2006) A importância da participação da população na gestão pública tornou-se, atualmente, um discurso recorrente, não somente com relação a nova forma de estado que se emergia, mas principalmente devido à incapacidade do Estado de formular e implementar políticas públicas.

Os instrumentos de participação popular e representatividade na gestão pública do município, partindo das premissas de que aos governados é assegurado constitucionalmente o acesso a mecanismos de participação, ainda nos parece retraído, "acanhado", e em alguns casos inexistente, carecendo de uma determinação de efetividade e implementação prática destas ferramentas quando provocadas por populares.

A ideia é promover o estudo das ferramenta de participação popular que os munícipes tem se utilizado para auxiliar na gestão do município, bem como aquelas que a lei indica a obrigatoriedade, a exemplo da formação de conselhos de assistência entre outros, destacando as audiências públicas com o intuito de promover a participação da população na formulação de políticas públicas e administração nas diversas áreas que compõe o poder executivo das cidades, utilizando, o produto de outros estudos, doutrina e a participação efetiva em audiências públicas.

Buscou-se com a reflexão de como a pesquisa pode traçar uma nova forma de, no âmbito municipal, permitir que a audiência pública seja vista como uma ferramenta de gestão pública no município, verificando a possibilidade de efetiva participação popular e a atuação de grupos de interesse, a aplicação de instrumentos que legitimem a efetiva participação popular, bem como o cumprimento de regras que auxiliem essa participação.

A audiência pública é parte integrante das ferramentas constitucionais de participação popular na gestão pública e nas decisões sobre a cidade, e por esse contexto já podemos indicar que a tendência da 
Administração pública é utilizar a audiência pública como forma de indicar que abriu um tema determinado à oitiva do público, dando possibilidade de opinião sobre projetos e políticas públicas.

O que acontece é que há audiências em que a população, ou seus representantes, nos embates sobre determinado tema, entende por alterar o objeto ou um projeto, mas essa modificação que pode ser descrita, inserida na ata, e que é opinativa dos representantes do povo não é vinculatória, não há vinculação legal entre o que se decide em audiência pública e o que é aplicado pelo gestor público.

Inexiste a necessidade para o gestor de seguir as direções suscitadas na audiência, surge o questionamento: se há desacordo entre a sua decisão/solução, e as inclinações expressas em uma audiência pública não estaria o gestor descumprindo o Interesse Público e os interesses da gestão? Notadamente há casos em que isso acontecerá, e surge uma nova pergunta: Como os componentes, representantes e participantes de audiências públicas poderiam sustar que àquela decisão/solução vai de encontro ao debate público?

A pesquisa não pretende encerrar esse debate haja vista existirem muitos outros ramos atrelados à audiência pública, como ao exemplo da questão da representação, efetiva participação popular, legitimidade para propor audiência pública e discordâncias políticas entre tantos outros.

Acreditamos na existência de possibilidade do gestor, ou ente demandante da audiência pública estar vinculado às opiniões apresentadas pelos representantes das camadas populares, ou os atingidos por atos governamentais, ainda que exista a proteção constitucional de determinada discricionariedade decisória, desde quando obedecidos os princípios norteadores da atividade administrativa.

A pesquisa se ampara no modelo de análise bibliográfico e documental, apresentando a Democracia Participativa enquanto componente da atividade administrativa, estudo da evolução da participação popular na gestão, leis específicas que indicam a participação popular na gestão na atualidade, e estudo da audiência pública como parte integrante desse modelo de gestão participativa.

Para realizar esse trabalho, contamos como referencial teórico os autores Norberto Bobbio para iniciar o diálogo sobre Democracia na atualidade, Maria Silvia Zanella de Pietro com seus apontamentos sobre participação popular na administração pública e direito administrativo, José Afonso da Silva nas noções constitucionais da participação popular, o autor Paulo Modesto na explicitação dos instrumentos democráticos de participação, e mais especificamente para tratar de audiência pública duas importantes dissertações: "Os institutos de participação popular e suas delimitações" de Marina Centurion Dardani (PUC-SP), e "Participação popular na Administração Pública: A audiência Pública" de Alessandra Obara Soares da Silva (PUC-SP). Ademais, outros trabalhos ajudarão na condução do assunto abordado, bem como terão maior ou menor participação no debate.

A natureza da pesquisa se direciona a exploração do objeto de pesquisa e o confronto de estudos sobre a efetividade e a possibilidade de uma vinculação das decisões administrativas, aos meridianos apontados na audiência pública.

A coleta de dados se utilizará da doutrina, de artigos, documentos e decisões da nossa jurisprudência, bem como será amparado em revisão histórica, de literatura crítica, e contraposição de argumentos em Direito Administrativo, Gestão Participativa, Direito público, sistema político e democracia participativa.

A abordagem quando da apresentação dos dados será dada no sentido de qualificar os que mais estão ligados diretamente ao objeto, fazer o cruzamento das informações convergentes, encontrar os pontos de divergência para criar contraposição e argumentação, indicando de que forma isso deve ser utilizado para responder a hipótese.

A abordagem exploratória terá o condão de conduzir a pesquisa pelo caminho qualitativo, tratando os dados colhidos e as informações apresentadas, de forma a apresentar resoluções para os objetivos apresentados, e na condução de uma solução meridiana às hipóteses apresentadas. 


\section{REFERENCIAL TEÓRICO}

\subsection{DEMOCRACIA E PLURALIDADE}

A compreensão do contexto em que se inserem os mecanismos de participação popular no nosso Estado Democrático de Direito são carreados pelos conceitos iniciais de democracia e pluralismo político. A concussão de ideais e condições que geraram a preposição de normas capazes de criar harmonia entre modelos de representação diversos, devem ser estudados para se chegar ao entendimento sobre o que é a Democracia participativa.

Partindo da gênese da convivência social, podemos afirmar que a formação da consciência política do homem é ligada principalmente a sua convivência em sociedade, de tal forma que os filósofos antigos, ainda que demorassem a se aperceber ${ }^{1}$, notariam que a existência humana só se tornou possível na convivência social.

Hannah Arendt em sua obra "A condição Humana" (p. 31) analisando o nascimento do "homem como ser social" nos informa a prevalência da necessidade humana de convívio social, dizendo que "Nenhuma vida humana, nem mesmo a vida do eremita em meio a natureza selvagem, é possível sem um mundo que, direta ou indiretamente, testemunhe a presença de outros seres humanos."

A vida em sociedade é uma condição para a percepção racional do homem como ser social, sendo que a percepção de que os conflitos humanos deveriam se resolver no plano do diálogo, quando do surgimento e organização da "Polis", havendo uma alteração no modo de resolução de conflitos, nota-se uma prevalência do discurso em detrimento da violência na solução de conflitos:

A ênfase passou da ação para o discurso, e para o discurso como meio de persuasão não como forma especificamente humana de responder, replicar e enfrentar o que acontece ou o que é feito. 0 ser político, o viver numa polis, significava que tudo era decidido mediante palavras e persuasão, e não através de força e violência. (Hannah Arendt. A condição Humana. P. 35)

A propulsão do discurso fez do homem além de um ser social, um ser político atuante e que participava das decisões da cidade (polis), ainda que com as restrições características da organização dessas cidades, já que, segundo DARDANI (2014, p. 33) é de se destacar que a cidadania era "hereditária e conferida apenas aos filhos de atenienses e alguns estrangeiros, por decisão expressa de assembleia pública", e ainda que exemplos de democracia direta existiram historicamente ainda no século XIII, na Suíça, e no século XVIII na nova Inglaterra.

No ocidente, a democracia "ocorreu como forma alternativa aos sistemas absolutistas", sendo fortalecido pelos ideais de cunho teórico de pensamento de contratualistas como Rousseau e Locke, que apregoavam que "cada homem tem que ceder parte de seus direitos ao governo e deste receber as necessárias condições para o convívio em sociedade" (p.34), estava assim recomposta a concepção ideológica do estado, e da participação dos cidadãos na condução deste.

Para Norberto Bobbio (p.20) a democracia nasceu de uma concepção individualista da sociedade, contrapondo-se à concepção orgânica que era pensamento dominante na idade média, onde a regência do estado deveria ser exercida por grupos de interesse. Para o autor qualquer forma de sociedade, e em especial a sociedade política, é um produto artificial da vontade dos indivíduos.

E a virada para o moderno surgimento dessa concepção de sociedade segundo Bobbio (p.21) se caracterizou por meio de três eventos que foram preponderantes: 0 contratualismo, o nascimento da economia política e da filosofia que considera estados essencialmente individuais do homem. Bobbio (p.22) pontua ainda que mesmo tendo nascido dessa concepção individualista, os grupos, e não os indivíduos passaram a ter o protagonismo no sistema democrático de tal forma que indica que a sociedade real, preterida aos governos democráticos é pluralista. Nesse modelo de sociedade pluralista, a conjuntura de opiniões divergentes é que apontam a existência de interesses diversos dentro de uma democracia.

Na hodierna concepção Bobbio (p.17) acredita que para preencher uma definição mínima do que vem a ser democracia, em contraposição as formas de governo autocrático, esta deve ser caracterizada por um conjunto de regras (preliminares ou fundamentais) que estabelecem quem está autorizado a tomar as decisões coletivas e com quais procedimentos.

\footnotetext{
${ }^{1}$ Segundo Hannah Arendt: “Não que Aristóteles ou Platão ignorasse ou não desse importância ao fato de que o homem pode viver fora da companhia dos homens; simplesmente não incluíam tal condição entre as características especificamente humanas."
} 
O recorte histórico é preponderante para compreender de que forma a democracia foi surgindo no seio social, e se tornou parte do poder popular nas decisões do que vem a ser o estado. No Brasil, a democracia se amparou na pluralidade ideológica e na justaposição de instrumentos da chamada democracia indireta (representativa) e da democracia direta, sendo definida como semidireta.

A democracia direta se caracteriza segundo José Afonso da Silva (p. 138) por ser "aquela em que o povo exerce, por si, os poderes governamentais, fazendo leis, administrando e julgando". Já a democracia indireta para o autor é:

“[...] aquela na qual o povo, fonte primária do poder, não podendo dirigir os negócios do Estado diretamente, em face da extensão territorial, da densidade demográfica e da complexidade dos problemas sociais, outorga as funções de governo aos seus representantes, que elege periodicamente."

0 modelo brasileiro, que Silva (p.138) classifica como semidireta se caracteriza por ser "democracia representativa com alguns institutos de participação direta do povo nas funções de governo". A constituição Brasileira de 1988, combina assim os dois modelos democráticos de forma a fundamentar a democracia participativa, vejamos:

A Constituição combina representação e participação direta, tendendo, pois, para a democracia participativa. E o que, desde o parágrafo único do art. $1 \stackrel{\circ}{\text {, já }}$ está configurado, quando, aí, se diz que todo o poder emana do povo, que o exerce por meio de representantes eleitos (democracia representativa), ou diretamente (democracia participativa). ${ }^{2}$ (SILVA, p.138)

A escolha desde a parte preambular da constituição pela democracia participativa é de suma importância para compreender de que forma o estado brasileiro permite o exercício de poder popular direto em algumas funções de governo, por meio de instrumentos amparados no texto constitucional e infraconstitucional, também reconhecidos como instrumentos de participação popular na administração pública, os quais passamos a apresentar com vistas a destacar o instrumento desse estudo.

\subsubsection{A PARTICIPAÇÃO POPULAR E ADMINISTRAÇÃO PÚBLICA}

Introduzida a justificativa constitucional para a democracia participativa como viés político de administração do estado, resta necessário fundamentar seus pressupostos e apontar seu direcionamento legal e principiológico para compreender o ponto em que o Estado se abre a participação popular na administração pública.

A participação popular ainda guarda determinada divergência conceitual. Silva (2009, p.58 apud ENTERIA at al. 2004) informa que para estes autores da seara do Direito Administrativo espanhol, a participação popular se trata de todo e qualquer envolvimento no exercício da atividade com finalidade pública.

Essa definição, um tanto quanto alargada, dificulta a compreensão da instrumentalização de meios para a participação popular, eis que seguramente uma mera petição, ou participação em atividades do estado poderia ser confundida com a participação popular, e desvirtuaria o caminho procedimental que tentamos atingir. Tanto que Silva (2009, p. 58) indica as razões de divergir destes autores, dizendo:

“A participação popular que se pretende explorar é aquela decorrente do exercício direto de cidadania pelos particulares, ou seja, é a participação direta na formação das decisões públicas e não por meio de representantes eleitos democraticamente para compor o parlamento"

A participação popular descrita então reduz-se em certa parte, da retirada dos processos democráticos de delegação, ou de democracia indireta, aquele em que há a eleição de um representante, seja par o parlamento, câmara de deputados, senado, executivo federal, estadual ou municipal, não se tratando portando da participação no sufrágio, mas na participação no seio da administração pública. Em melhor grau a autora nos informa de que participação popular estamos tratando:

Neste sentido a participação popular será caracterizada quando ao particular for deferida a oportunidade de interferir na formação das decisões administrativas de gestão da coisa pública. Este Aliás é o entendimento que se

\footnotetext{
${ }^{2}$ SILVA. José Afonso. Curso de Direito Constitucional Positivo. 37o ed. - Editora Malheiros. São Paulo. p. 139
} 
coaduna com o devido processo legal substancial. A oportunidade de ter ciência da decisão administrativa, expor seu ponto de vista, a oportunidade de ter suas manifestações consideradas, analisada e acolhidas ou rechaçadas, motivadamente, é que dão correta ideia de participação popular na formação das decisões administrativas." (SILVA, 2009, p.60)

Essa é de forma sucinta o objetivo que pretendemos atingir sobre o conceito de participação popular necessária ao desenvolvimento do trabalho. São essas oportunidades de interferência, por meio dos instrumentos de participação que determinam como democracia participativa deve se aplicar à administração pública.

O professor Luiz Carlos Figueiredo de Melo, em seu artigo intitulado "O princípio da participação popular do processo administrativo" vai além, e em linhas gerais nos apresenta a participação popular como enraizada na constituição, que vem a lhe conferir características principiológicas indicando ser "uma verdadeira norma jurídica de status constitucional" (MELO, 2008, p. 227)

Estando contextualizada a participação popular, importante deixar claro quais são os instrumentos, ações e conceitos que priorizam essa inserção nas atividades da administração pública, motivo pelo qual passamos a tratar dos:

\subsubsection{INSTRUMENTOS DE PARTICIPAÇÃO POPULAR}

A participação popular, como vimos, é a possibilidade por meio de instrumentos democráticos de dar acesso ao povo à gestão na Administração Pública. Assim, a necessidade de criação de modelos de acesso se impende necessária, como bem introduz o tema Antônio Cabral:

A transposição do modelo tradicional da democracia representativa para o paradigma da democracia participativa e deliberativa impôs ao direito público a criação e o desenvolvimento de instrumentos que permitissem incrementar a participação do indivíduo nos processos de tomada de decisão estatal. (CABRAL, 2007, p.41)

Esses instrumentos informados são os responsáveis por organizar a participação do cidadão na atividade estatal. Suas subdivisões demandam da constituição seu processo de gênese e cabe ao ordenamento de forma completa criar mecanismos que possam permitir a participação do indivíduo neste ciclo de debates (CABRAL, p.42)

Esses instrumentos, criados pelo ordenamento jurídico, estão presentes nos três poderes: Executivo, Legislativo e Judiciário. Para Cabral (2007, p.42) os instrumentos podem ser identificados na conjuntura tripartite dos poderes da república da seguinte forma:

[...] Na esfera do Poder Legislativo, identificamos o plebiscito, o referendo e a iniciativa popular das leis como alguns desses mecanismos. No Judiciário, aponta a doutrina o exercício da ação popular constitucional e das ações coletivas em geral como vetor participativo de inserção cidadã e altruísta nas demandas que pretendem a proteção de bens caros a uma coletividade indeterminada.

A classificação trazida pelo autor identifica de forma específica alguns dos mecanismos de participação popular presentes no nosso ordenamento jurídico. Entretanto, nos auxilia em melhor grau Marina Centurion Dardani (2014, p.56) que se ampara na contextualização destes instrumentos de participação popular dentro da doutrina brasileira e estrangeira, com vistas a apresentar visões divergentes sobre sua classificação.

Segundo DARDANI (2014, apud SOARES 2007), uma outra classificação possível é quanto ao momento em que essa participação ocorre: formas de participação na fase preparatória, e fase de participação na fase decisória.

Já para Paulo Modesto (2007) nos seus estudos sobre operacionalização da participação popular, há uma maior pluralidade de participações populares inseridas no processo administrativo, devem ser verificadas nos termos da sua eficácia. Quanto a classificação para o autor, a participação popular pode ser:

(a) vinculante;

(a.1.) decisória (ex. co-gestão) 
(a.2.) condicionadora (ex. conselhos administrativos, que limitam discricionariedade da autoridade superior, exigindo motivação extensa em pronunciamentos divergentes);

(b) não vinculante (ex. conselhos meramente consultivos);

Temos assim, inicialmente, uma participação popular com um condão de vinculação ao processo ou ato administrativo seja de forma decisória, agindo no modelo de cogestão por exemplo, outro, de forma condicionante à exemplo dos conselhos administrativos que são levados em consideração na produção e formulação de respostas, sem as quais, não pode o gestor agir sem uma motivação devidamente fundamentada, e o caso deste decidir por divergência à um determinado conselho da administração.

As não vinculantes citadas por MODESTO (2007) estão classificadas sobre aquelas que não modificam, condicionam, ou são parte da decisão administrativa, tratam-se de formas meramente consultivas, que não vinculam a decisão administrativa, nesta classificação se insere a audiência pública conforme seus apontamentos.

Para MODESTO (2007) a participação popular, ainda pode ser classificada quanto à sua "matéria e a estrutura de sua intervenção", vejamos:

\section{(a) consultiva}

(a.1.) individual (ex. colaboração especializada)

(a.2.) colegial (ex. conselhos consultivos)

(a.3.) coletiva (ex. audiências públicas)

(b) executiva

(a.1.) co-gestão (ex. conselho de gestão)

(a.2.) autônoma (ex. organizações sociais, ongs, entidades de utilidade pública)

Certamente uma classificação mais complexa, ao passo que contempla a gama de possibilidades em que pode se subdividir, e de forma explicativa torna cada uma em ferramentas diversas que se encontram dispostas no nosso ordenamento pátrio, e que, nos parece ser, a que mais acompanha o curso deste trabalho. Nota-se que MODESTO (2007) já informa os instrumentos de participação popular que são considerados vinculantes

Mas de que forma esses instrumentos podem ser utilizados para que haja a aplicação na atividade administrativa?! Como tornar uma prática processual na administração pública a utilização desses instrumentos?

0 conhecimento acerca dos processos envolvidos em cada uma das espécies de instrumentos de participação popular deve ser levado em conta, bem como, a forma como estes se desenvolvem no seio da administração pública, assim passamos a apreensão dos conceitos de cada instrumento de forma individualizada.

\subsubsection{INSTRUMENTOS DE PARTICIPAÇÃO POPULAR EM ESPÉCIE}

Ações para aproximar o "povo" da administração popular acontecem em diversas frentes, tendo por condão comum uma movimentação no sentido de mostrar-se opinativo, avaliativo, colaborador com a gestão para melhor condução de suas ações.

MELO \& FERREIRA (2008, p. 234) entendem que o conjunto de ações de participação popular permeando a administração pública "é que possibilita todo o arcabouço de legitimidade de que o poder público necessita para desenvolver, da melhor forma possível, o exercício da função administrativa."

Seguindo o pensamento de MELO \& FERREIRA (2008, p. 235) é um patamar de eficiência da atividade administrativa a utilização destas ferramentas de participação popular, sendo apontadas pelos autores à título de exemplificação como formas ampliadas de participação, "o direito de petição do administrado", "criação de conselhos consultivos ou deliberativos", "audiências e consultas públicas", "delegação de competências para organizações não governamentais" e o "orçamento participativo".

Para MODESTO (2007) são diversos hoje os processos dentro da administração pública que dão poderes aos administrados para que exerçam a sua participação, mas delimita que existem entre eles maior e 
menor grau de autenticidade e integração social, e delimita de forma especial aqueles que lhe interessam ser estudados, sendo esses:

a) consulta pública (abertura de prazo para manifestação por escrito de terceiros, antes de decisão, em matéria de interesse geral);

b) audiência pública (sessão de discussão, aberta ao público, sobre tema ainda passível de decisão);

c) colegiados públicos (reconhecimento a cidadãos, ou a entidades representativas, do direito de integrar órgão de consulta ou de deliberação colegial no Poder Público);

d) assessoria externa (convocação da colaboração de especialistas para formulação de projetos, relatórios ou diagnósticos sobre questões a serem decididas);

e) denúncia pública (instrumento de formalização de denúncias quanto ao mau funcionamento ou responsabilidade especial de agente público; ex. representação administrativa);

f) reclamação relativa ao funcionamento dos serviços públicos (difere da representação administrativa, pois fundamenta-se em relação jurídica entre o Estado ou concessionário do Estado e o particular-usuário);

g) colaboração executiva (organizações que desenvolvam, sem intuito lucrativo, com alcance amplo ou comunitário, atividades de colaboração em áreas de atendimento social direto);

h) ombudsman (ouvidor);

i) participação ou "controle social" mediante ações judiciais (ação popular, ação civil pública, mandado de segurança coletivo, ação de inconstitucionalidade de lei ou ato normativo, entre outras);

j) fiscalização orgânica (obrigatoriedade, por exemplo, de participação de entidades representativas em bancas de concursos públicos, v.g, OAB).

Nota-se que a classificação de MODESTO (2007) nos parece mais completa para explicitar esses processos populares democráticos de cunho decisório e/ou consultivo, nas decisões administrativas. Assim, importante destacar dentre os referidos instrumentos processuais, o objeto do nosso estudo para maior aprofundamento em tópico específico, qual seja, a audiência pública, aqui descrita como "sessão de discussão, aberta ao público, sobre tema ainda passível de decisão".

Em que pese as preciosas contribuições dos autores citados, sobre as referidas ferramentas, é importante estudar de forma isolada a audiência pública, tema principal deste trabalho, permeando a discussão com diálogo e contraposições para que possamos entender como ela pode ser usada de forma mais eficaz na gestão pública no município.

\subsubsection{A AUDIÊNCIA PÚBLICA}

A audiência pública vai surgir da necessidade de escuta e opinião de populações atingidas por determinadas decisões administrativas. A necessidade de moderar o poder discricionário da administração para tomar decisões foi uma das principais razões para que houvesse o reconhecimento de que a participação popular auxilia na gestão da coisa pública e na defesa de interesses. Assim, segundo MELO E FERREIRA (2008, apud MOREIRA NETO 1992) o nível de aprovação, desaprovação e legitimidade de um dado governo dependem do diálogo deste com o público, vejamos:

A sociedade reage espontaneamente aos atos dos governantes, aprovando-os ou desaprovando-os: é um juízo de legitimidade, de como estão eles utilizando os poderes que lhe foram confiados. 0 governante originariamente legítimo para um grupo (presunção) poderá permanecer legítimo no exercício do poder (aprovação), aumentar sua legitimidade, vê-la reduzida ou, até, transformada em ilegitimidade (desaprovação). Ao contrário, um governante originariamente ilegítimo para um grupo (presunção) poderá permanecer ilegítimo ou ganhar 
legitimidade corrente (aprovação), se o exercício do poder coincidir com os desejos do grupo. (MOREIRA NETO, Diogo de Figueiredo. Direito da Participação Política: legislativa, administrativa, judicial. Op. cit., p. 26.)

A audiência pública, enquanto ferramenta de exercício do princípio da participação popular no seio da Administração pública, age de forma equânime a descrita na referência citada ditando de que forma a ação e a possível decisão pode afetar diretamente a sociedade e como este posicionamento é recebido pela população.

Em termos técnicos, para além do conteúdo subjetivo desta participação, define Agustín Gordillo (2013, p. XI-2) em sua obra "Tratado de Derecho Administrativo" que a audiência pública é "lá garantia de ouir al interesado antes de dictar una decisión que pueda afectar sus derechos", sendo um "un principio clásico del derecho constitucional y administrativo" ou seja uma forma de garantir voz aos interessados antes de tomar decisões de cunho administrativo. Tendo, segundo o autor, se iniciado no direito anglo-saxão, mas que hoje já é de natureza universal.

Já para Diogo de Figueiredo Moreira Neto (1997, apud SILVA 2009) a audiência pública é:

[...] audiência pública é um processo administrativo de participação aberto aos indivíduos e a grupos sociais determinados, visando ao aperfeiçoamento e a legitimidade das decisões da Administração Pública, criado por lei, que lhe preceitua a forma e a eficácia vinculatória, pela qual os administrados exercem o direito de expor tendências, preferências e opções que possam conduzir o poder público a decisões de maior aceitação consensual. (MOREIRA NETO, Diogo de Figueiredo. Mutações do Direito Administrativo. $3^{\circ}$ ed. Rio de Janeiro: 2007, p. 261-262)

$\mathrm{Na}$ conjugação dos conceitos apresentados, vemos uma complementariedade, tanto do quanto apresentado por GORDILLO (2013) quanto o apresentado por SILVA (2009) de que a audiência pública é ao mesmo tempo parte integrante de um princípio clássico do direito constitucional e administrativo universal, bem como se instrumentaliza como um processo de participação aberto aos indivíduos e a grupo sociais determinados visando a uma escola mais qualificada pela Administração Pública.

Em que pese a acertada posição de MOREIRA NETO (1997) há que se realizar algumas ressalvas tendo por base temas já levantados neste trabalho, haja vista, como informado por bandeira de Mello (2008) trata-se a participação popular na Administração Pública de verdadeira "Norma jurídica de status constitucional", e em se tratando destas normas principiológicas que visem assegurar direitos fundamentais a sua eficácia é imediata.

Já para Dardoni (2011) o conceito de audiência pública guarda maior proximidade e adequação ao que pretendemos trazer nesse trabalho. Assim conceitua a autora:

Caracteriza-se por ser um instituto em que a participação é aberta a todos os interessados - sejam eles simples cidadãos, associações da sociedade civil ou partidos políticos - e tem como principal vetor a busca pela legitimação das ações da Administração Pública, vez que a decisão tomada com base em uma participação democrática torna-se mais facilmente aceita e compreendida do que aquela imposta unilateralmente pela Administração Pública. (DARDONI, 2011, p. 93)

Notadamente as impressões sobre o instituto trazidas por DARDONI (2011) tem melhor correspondência com o caminho que queremos traçar para esse trabalho, não restringindo a atuação de pessoas ou grupos, de acordo com a constituição federal, bem como apresentando a audiência pública como ferramenta para instrumentalizar as decisões administrativas.

\subsubsection{A AUDIÊNCIA PÚBLICA E A GESTÃO DO MUNICÍPIO}

Apresentado o seu conceito, no que tange ao seu fundamento jurídico como parte integrante da participação popular na administração pública temos inserido no art. 5o XXXIII (Do direito à informação de interesse privado ou particular), XXXIV (Direito de petição e certidão para defesa de direitos e contra ilegalidade e abuso de poder público), LV (Direito ao contraditório e ampla defesa), Art. 37, "caput" (dos princípios da Administração Pública), Art. 194 (caráter democrático e descentralização administrativa da seguridade social) 198, III (Participação da comunidade na rede integrada do SUS), 204 II (Participação 
popular na formulação de políticas públicas e controle das ações em todos os níveis da assistência social), e 225 caput (Dever da coletividade em preservar o meio ambiente) todos da Constituição Federal.

Especificamente no art. 29 da Magna Carta, há a caracterização de possibilidade do município da utilização das ferramentas de iniciativa popular, e conjugado com os artigos acima, da possibilidade de abertura a participação popular no processo decisório da Administração Pública Municipal.

No plano infraconstitucional, a audiência pública já é considerada obrigatória no processo decisório do município, ou para apresentação de projetos, programas e resultados, bem como para prestação de contas. Assim, para exemplificar as audiências consideradas obrigatórias temos a audiência pública descrita na Lei de licitações (lei ${ }^{\circ}$ 8666/91) para a construção de grandes obras, no Estatuto das Cidades (lei 10.257/2001), Plano Plurianual, lei de diretrizes orçamentárias (base no 165 da CF).

Nas audiências públicas em que haja obrigatoriedade para a sua realização, já que "A legislação brasileira prevê casos em que a administração é obrigada a realizar a audiência pública, caso esta não seja realizada há a possibilidade de "anulação dos atos administrativos" que não observaram a referida obrigatoriedade (DARDONI, 2011 p. 96).

A promoção da audiência pública não está ligada apenas a sua vinculação legal, pois como dissemos anteriormente, a participação popular é princípio constitucional e parte preponderante na Defesa do Estado Democrático de direito, não estando adstrita às normas infraconstitucionais citadas, ou apenas a lei do município, podendo ser requerida sempre que houver interesse em debater temática que envolva a Administração pública Municipal. Para tanto nos informa DARDONI (2011, p.93) sobre a função desta:

Sua finalidade é a oitiva dos interessados, com vistas a apresentação de críticas e sugestões. A adoção dessas sugestões não é obrigatória, mas, em caso de recusa, a Administração Pública deverá motivas de forma clara o porquê da não adoção das medidas propostas.

A realização das audiências públicas propicia a concretização do direito do cidadão de ser ouvido naqueles assuntos que atingem diretamente a coletividade, estreitando os laços entre cidadãos e a Administração Pública.

Ainda que nos casos de adoção espontânea da audiência pública para fins decisórios dentro do patamar de discricionariedade da Administração Pública, a convocação não pode ser apenas expositiva neste modelo de instrumento de participação popular, há uma vinculação ainda que formal ao processo da audiência com a adesão de uma necessidade de respostas àquela reunião. Além disso, a audiência pública auxilia na tomada de decisões, de forma que, altera planejamentos, atualiza os dados da gestão, bem como verifica os interesses do público.

MELO E FERREIRA (2008, p. 239-241) indicam que por tratar-se de princípio da participação popular no cenário da Administração Pública, baseando-se em DI PIETRO (2006, p. 611) que o princípio se apresenta tanto na gestão, quanto no controle da Administração pública. Contemplam ainda a audiência pública como ferramenta preponderante da participação popular e na gestão pública dizendo:

[...] é interessante ter em mente que a participação dos administrados no cerne da Administração tem sido, em termos de gestão pública, uma importante alternativa para a efetivação dos direitos daqueles, bem como um eficiente instrumento de controle.

E complementam o pensamento informando que:

[...] Isto porque o correto manejo do Princípio da Participação Popular, bem como dos princípios e regras atinentes ao processo administrativo, dentro dos ditames do Estado Democrático de Direito, possui o condão, até mesmo, de reverter uma situação de conflito em um confortável quadro de cooperação entre Administração Pública e sociedade. Tal verificação se opera, pois, quando cada administrado, na qualidade de interessado em uma determinada decisão administrativa, se revela um verdadeiro agente colaborador com o poder público, na medida em que se faz ouvir, manifestando suas opções, anseios e preferências.

Enquanto princípio, já devidamente indicado neste trabalho, a participação popular, instrumentalizada por meio da audiência pública, tem como atividade precípua a abertura para que todos, de forma 
indiscriminada possam fazer parte das decisões sobre o dinheiro público, sobre obras e sobre a organização do município por exemplo.

GORDILLO (2013, p. 458) indica que a audiência pública deve ter inclusive um caráter prescritivo, de necessidade, e a Administração Pública não está limitada a realizar a audiência pública somente por imposição legal, mas obriga-se a realizar a audiência pública em todos os casos, em que os efeitos da decisão excedam a esfera do particular, e em que se demonstre necessário o direito de defesa dos usuários ou pessoas afetadas, levando assim a uma melhor eficácia e legitimidade jurídica e política das decisões.

DARDONI (2011, p. 97) tendo por base o referido autor diante do quando apresentado conclui que para ele "a Administração pública deve realizar tantas audiências públicas quanto possa, vez que a participação popular é o meio ideal para a busca do consenso, tendo a decisão tomada na audiência pública um melhor sustento fático e jurídico."

GORDILLO (2013, p. 458) ainda arremata dizendo que "mayor búsqueda y obtención de consenso en la opinión pública, respaldo ante la sociedad de la legitimidad y eficacia de sus decisiones y consolidación de su imagen ante la opinión pública en el cumplimiento de sus funciones."

A realização de audiências públicas, assim dentro do diálogo doutrinário aqui apresentado auxilia na realização da atividade administrativa, nas decisões em todas as esferas pública, e precipuamente a municipal, aqui estudada, bem como garante a gestão a busca do melhor caminho decisório acerca das possibilidades dentro da discricionariedade da Administração Pública Municipal, e ainda imprime uma imagem democrática de suas decisões evitando assim a sustação ou jurisdicialização da matéria administrativa.

Coadunando-se com a doutrina desses autores, e apresentando-se de forma propositiva, a cartilha do Instituto Polis ${ }^{3}$, importante ferramenta de direcionamento e auxílio nas decisões da Gestão municipal e no controle da administração pública, firma o entendimento de Mencio, Lotta e Paulics (2005), que ratificam a importância da audiência pública para a gestão pública municipal, informando que "as audiências públicas permitem à prefeitura conhecer necessidades e demandas da população, na medida em que são espaços de diálogo e negociação de interesses." É que para além da obrigação legal das prefeituras na realização de audiência por contar em legislação especial, conforme já apontamos, entendem que "a prefeitura pode aproveitar sua potencialidade, enquanto espaço de coleta de opinião e debate público, sempre que considerar oportuno para a comunidade."

Verificada a importância da audiência pública no seio da gestão pública municipal, passamos a exploração do segundo questionamento apresentado neste trabalho, que diz respeito a vinculação da decisão da gestão pública aos apontamentos colhidos durante a audiência pública e sua possibilidade de controle.

\subsubsection{A AUDIÊNCIA PÚBLICA E SUA VINCULAÇÃo}

Vincula-se o gestor público aos debates realizados numa audiência pública no seu processo decisório sobre o tema apresentado na referida audiência? Há assim uma consulta/apresentação/discussão na audiência, da qual tendo definido o melhor caminho decisório o gestor pode contrariar?

Conforme adiantamos em citações de autores anteriores há até agora a obrigatoriedade da realização quando a lei a torna obrigatória, nos dizeres de GORDILLO (2013) e DARDONI (2011) há a vinculação no caso desse tipo de audiência apenas da necessidade de sua realização, sendo inclusive passível de nulidade a decisão sem a observância legal da realização da audiência pública.

No tocante à vinculação do resultado MOREIRA NETO (2007, apud DARDONI p.99) acredita que a audiência pública tem caráter vinculante em relação ao seu resultado, mas promove uma ressalva dizendo que essa vinculação somente existiria quando a audiência for prevista em lei (Municipal, Estadual, Federal) que autorize a Administração pública a realiza-la, ademais o autor acredita que a audiência pública é em parte uma renúncia de poder por parte do estado em favor do povo.

Para SILVA (2008, p. 147) é de responsabilidade da autoridade administrativa decidir no caso de não ser satisfatória a audiência pública, observada a ata, para de forma fundamentada e sob juízo de ponderação sobre a realização de nova audiência pública determinando-o quando perceber que o resultado não

\footnotetext{
${ }^{3}$ MENCIO, Mariana; LOTTA, Gabriela; PAULICS, Veronika. DICAS - IDEIAS PARA AÇÃO MUNICIPAL: Realizar audiências públicas no município. 2005. Disponível em: <http://www.polis.org.br/uploads/671/671.pdf>. Acesso em: 24 jun. 2018.
} 
auxiliou na decisão. Nos casos em que a lei não impõe a realização da audiência, mas que a autoridade entendeu oportuna sua realização, caso haja alguma nulidade, ficará a critério da Administração uma nova audiência.

No tocante à Administração Pública e sua obrigatoriedade de vinculação ao resultado da audiência SILVA (2008, p.147) informa seu posicionamento sobre o tema dizendo:

0 resultado da audiência pública não vincula a Administração pública, por que sua finalidade é instruir o processo administrativo decisório e ampliar as balizas de controle do ato administrativo final. A audiência pública não serve para retirar do administrador o controle da decisão. Não serve para transferir a terceiros a responsabilidade pela avaliação de melhor decisão a ser adotada. Por estas razões, entendemos que eventual legislação que imponha tal efeito vinculante padecerá de vício de inconstitucionalidade, vez que implicará na retirada de poderes da administração pública, em afronta ao princípio da tripartição das funções estatais. Caso fosse válida tal legislação, o Poder Judiciário poderia subrogar-se em administrador e proclamar a decisão a ser adotada em substituição à avaliação de conveniência e oportunidade do administrado, por exemplo.

Acreditando que pode haver com a obrigatoriedade de um processo vinculatório um desvirtuamento da discricionariedade do administrador público, a autora acredita que isso pode jogar o processo decisório no "colo" dos juízes, que pela tripartição de poderes não poderiam ultrapassar a seara judicial e decidir pelo administrador. Em que pese a acertada preposição da autora, a tripartição de poderes é clausula pétrea da nossa Constituição Federal, ferir ela, certamente apresentaria o óbice de continuidade do processo, mas isso por si não seria capaz de afastar a possibilidade de vinculação ao decidido em audiência, principalmente quando se trata daquelas obrigatórias por lei, haja vista que, a título exemplificativo, na lei de licitações quando se trata de grandes obras, os excessos, e a decisão desfavorável ao município poderiam causar prejuízos de grande monta, bem como atingir grande contingente populacional.

Certamente há que caminhar a jurisprudência pátria, bem como os processos regulatórios acerca da audiência pública para tornar melhor definido que o resultado desta, tenha interferência direta na decisão administrativa, e principalmente no plano de gestão do município, eis que, com a subsunção dos modelos antigos de democracia representativa, o processo de instrumentalização da participação popular é uma realidade, e não pode ser visto como mera formalidade, mas como parte integrante do exercício do Estado democrático de Direito.

\section{METODOLOGIA}

A pesquisa se sustentou por meio da pesquisa de cunho bibliográfico que leva em consideração a reconstituição histórica da temática abordada, de forma a tornar-se didática para o leitor, nesse aspecto, Maxwell Ferreira de Oliveira em seu livro Metodologia Científica: Um manual para a realização da pesquisa em Administração informa que "toda pesquisa, deve ter o apoio e o embasamento na pesquisa bibliográfica, para que não se desperdice tempo com um problema que já foi solucionado e possa chegar a conclusões inovadoras" (2011, p. 40)

Tendo por base quando não presentes os documentos que realizem a progressão da pesquisa, criando um ambiente propicio para a produção do conhecimento sobre o tema, de forma a canalizar analisando os documentos históricos e sociais apresentados, o caminho para solucionar as questões trazidas, e delimitar o objeto.

Por base, também, fora apresentada a Democracia Participativa como parte preponderante do estado de direito, a ponto de ser considerada um princípio conjugado na Constituição e enquanto componente da atividade administrativa, estudo da evolução da participação popular na gestão, leis específicas que indicam a participação popular na gestão na atualidade, e estudo da audiência pública como parte integrante desse modelo de gestão participativa.

Chegado ao objeto que era a proposição de que a audiência pública é auxiliar na gestão municipal, bem como ratifica a validade das decisões da Administração Pública Municipal. Com o cumprimento do objeto o levantamento posterior foi acerca da vinculação da decisão administrativa ao quanto decidido em audiência, finalizando assim o trabalho com questões e proposições. 


\section{A COLETA DE DADOS}

A coleta de dados se utilizou da doutrina, de livros físicos e livros virtuais, bem como de artigos, apostilas e apontamentos indicativos para tomada de decisões pelas prefeituras municipais, outros documentos, bem como será amparado em revisão histórica, de literatura crítica, e contraposição de argumentos em Direito Administrativo, Gestão Participativa, Direito público, sistema político e democracia participativa além de delinear em alguns pontos reflexões de Filosofia do Direito.

O contato com dissertações de Mestrado sobre o tema forma de ajuda especial para conseguir entender as formas e os conceitos ligados a participação popular e a audiência pública, enquanto instrumento que auxiliam na gestão municipal.

Na classificação quanto a coleta de dados levou-se em conta o descrito por OLIVEIRA (2011, p. 59) tratando-se assim de pesquisa documental e bibliográfica, e já quanto a técnica e análise dos dados $t$ de análise tratou-se de uma pesquisa de conteúdo.

\section{RESULTADOS E DISCUSSÕES}

Como resultados aparentes da pesquisa temos inicialmente a compreensão de Democracia e de pluralidade no seio democrático, utilizamos conceitos diversos de autores auxiliares e contrapostos. A explanação acerca da participação popular reforçou a necessidade de integração desta na administração pública indicando trata-se de principio incluído no Estado Democrático de Direito, sendo além de defesa aos administrados, uma segurança para a Administração Pública.

Estudamos os instrumentos processuais e legais de participação popular, destacando a audiência pública, objeto deste estudo, e dialogando de forma a promover uma compreensão da necessidade de os entes realizarem audiências públicas, mesmo quando estas não estão descritas em lei, ou seja, que se tome a iniciativa para realização destas.

Por fim, decidimos por verificar se os resultados de uma audiência pública vinculam a decisão da autoridade administrativa, e se há possibilidade de não se levar em conta o quanto debatido nesta, apesar das opiniões diversas, a vinculação padece de uma melhor regulamentação, mas ressalvou-se que quando tratar-se de audiência legal obrigatória a vinculação poderia ser exigida, o contrário ocorre com àquela de interesse consultivo da gestão, que poderá ser revogada, ou não marcada, pelo interesse exclusivo da Administração.

\section{CONSIDERAÇÕES FINAIS}

A audiência pública é uma importante ferramenta de instrumentalização do princípio da participação popular, pulverizado na Constituição Federal em diversos artigos, e se tornou parte preponderante na condução do Estado democrático de direito. Ela está inserida no referido princípio podendo ser realizada sempre que a Administração Pública estiver obrigada pelo princípio da legalidade, bem como, pode ser realizada por qualquer dos poderes, com o intuito de sanar dúvidas, ouvir os tingidos por determinada decisão, ou mesmo para que haja a ratificação das suas proposições e possíveis decisões.

O preâmbulo constitucional informa que todo poder emana do povo, e por conseguinte, a nossa democracia representativa, ali também descrita, não dá conta sozinha de promover a devida representação, sendo portanto subsidiada por meio da democracia direta, formando o que se chama de democracia semidireta, em que o poder pode ser exercido das duas formas, e a audiência pública é ilustrativo dessa possibilidade.

No âmbito deste estudo, a intenção era promover um estudo que possibilitasse à administração pública municipal compreender que por meio da audiência pública, se faz uma gestão mais forte e mais próxima do povo, bem como garante que esta consiga ter suas decisões de certa forma ratificadas pela população. No espaço de um Município, seja qual for o seu porte, essa ratificação, dá ao gestor a aprovação popular para que mantenha uma política de gestão, ou uma política pública, serve-se como um avaliador do modelo de gestão que se está realizando. 
A vinculação do resultado da audiência pública, ainda guarda muita divergência doutrinária, em que pese a dificuldade de forçar o cumprimento da decisão tomada em audiência, o gestor tende a respeitar a decisão com o fito de evitar que mais ilações, indagações ou problemas surjam em outras searas, ainda pudemos verificar que institutos recomendam a realização da audiência ainda que não haja obrigatoriedade. Assim, a audiência pública pode ser um bom instrumento de gestão pública para o município no seu processo decisório de situações chave para o município.

\section{REFERÊNCIAS}

[1] BOBBIO, Norberto. O futuro da democracia. Uma defesa das regras do jogo. Tradução: Marco Aurélio Nogueira. Rio de Janeiro: Paz e Terra, 1986

[2] BORGES, Maria Alice Gonzalez. Supremacia do interesse público: desconstrução ou reconstrução? p.21, in Revista Eletrônica de Direito Administrativo Econômico, $\mathrm{n}^{\circ} \quad 26$, in http://www.direitopublico.com.br/pdf_seguro/Supremacia\%20do\%20Interesse $\% 20 \mathrm{P} \quad \%$ C3\%BAblico\%20\%20\%20Alice\%20Gonzalez\%20Borges.pdf, acesso em 30/10/2017.

[3] CABRAL, Antonio. Os efeitos processuais da audiência pública. Boletim Científico - Escola Superior do Ministério Público da União, Brasília, v. 24-25, n. -6, p.41-65, 2007. Disponível em: <http://boletimcientifico.escola.mpu.mp.br/boletins/boletim-cientifico-n.-24-e-n.-25-julho-dezembro-de-2007-1/osefeitos-processuais-da-audiencia-publica>. Acesso em: 10 maio 2018.]

[4] CAETANO, Marcelo. Princípios fundamentais do direito administrativo. Rio de Janeiro: Forense, 1989.

[5] COMPARATO, Fábio Konder. Direitos e deveres fundamentais em matéria de propriedade. In: Revista da Fundação Escola Superior do Ministério Público do Distrito Federal e Territórios. Ano 5- no 10 - jul/dez de 1997.

[6] CRUZ, Gisele dos Reis. Gestão Pública Participativa: o papel da reforma do estado e dos Movimentos sociais. 2006. Disponível em: <http://www.achegas.net/numero/38/gisele_38.pdf>. Acesso em: 27 jun. 2017.

[7] DARDANI, Marina Centurion. Os institutos de participação popular na administração pública e suas delimitações. 2014. 156 f. Dissertação (Mestrado) - Curso de Direito, Pontifica Univerisidade Católica de São Paulo, São Paulo, 2014.

[8] DAL BOSCO. Maria Gorete. Audiência Pública como Direito de Participação. Revista Jurídica UNIGRAM. v.4 n.8, jul-dez, 2002. pág 137-158.

[9] DI PIETRO, Maria Sylvia Zanella. Curso de Direito Administrativo. 29 ed. revista e ampl. Rio de Janeiro. Editora Forense. 2016. 1088 p.

[10] EDITORA SARAIVA. Vade Mecum Tradicional Saraiva. Obra coletiva de autoria da Editora Saraiva com a colaboração de Antônio Luiz de Toledo, Márcia Cristina Vaz dos Santos Windt e Lívia Céspedes. São Paulo: Editora Saraiva, $24^{\circ}$ ed., 2017.

[11] GORDILLO, Agustín. Tratado de derecho administrativo : parte general . - 10a ed. - Buenos Aires : Fund. de Derecho Administrativo, 2009. v. 1, 712 p.

[12] JUSTEN FILHO, Marçal. Curso de Direito Administrativo. São Paulo. Editora Revista dos Tribunais, 2016. $1017 \mathrm{p}$.

[13] Lubisco, NÌdia Maria Lienert. Manual de estilo acadêmico: monografias, dissertações e teses / Nidia M. L. Lubisco, Sônia Chagas Vieira, Isnaia Veiga Santana. 4. ed. rev. e ampl. ñ Salvador: EDUFBA, 2008 145 p.

[14] MELO, Luiz Carlos Figueira de; FERREIRA, Guilherme Ricardo de Assis. O PRINCÍPIO DA PARTICIPAÇÃO POPULAR NO PROCESSO ADMINISTRATIVO. Revista da Faculdade de Direito de Uberlândia, Uberlândia, v. 36, n. 0, p.225-252, jan. 2008. Disponível em: <http://www.seer.ufu.br/index.php/revistafadir/article/view/18453>. Acesso em: 28 maio 2018.

[15] MELLO. Celso Antônio Bandeira de. Curso de Direito Administrativo. 33 ed. São Paulo. Editora Malheiros. 2016. $1151 \mathrm{p}$.

[16] MENCIO, Mariana; LOTTA, Gabriela; PAULICS, Veronika. DICAS - IDEIAS PARA AÇÃO MUNICIPAL: Realizar audiências públicas no município. 2005. Disponível em: <http://www.polis.org.br/uploads/671/671.pdf>. Acesso em: 24 jun. 2018.

[17] MODESTO, Paulo. Participação popular na administração pública. Mecanismos de operacionalização. SADireito, 4 fev. 2002. Disponível em: <www.sadireito.com.br/index.asp?Ir=area.asp\&area=5\&texto=416>. Acesso em: 28 ago. 2007.

[18] Oliveira, Maxwell Ferreira de. Metodologia científica: um manual para a realização de pesquisas em Administração / Maxwell Ferreira de Oliveira. -- Catalão: UFG, 2011. 72 p.: il. 
[19] SANTOS, Fabio Gomes dos. Participação na administração como direito fundamental. Revista Digital de Direito Público, vol. 1, n. 1, 2012, p. 116 - 133. Disponível no URL: www.direitorp.usp.br/periodicos

[20] SILVA, Alessandra Obara Soares da. Participação Popular na Administração Pública: As audiências Públicas. 2009. 157 f. Dissertação (Mestrado) - Curso de Direito, Pontifica Univerisidade Católica de São Paulo, São Paulo, 2009.

[21] SOARES, Evanna., Rio de Janeiro, v. 229, p. 259-284, jul. 2002. Audiência pública no processo administrativo. Revista de Direito Administrativo ISSN 2238-5177. Disponível em:

<http://bibliotecadigital.fgv.br/ojs/index.php/rda/article/view/46444>. Acesso em: 29 Nov. 2017. doi:http://dx.doi.org/10.12660/rda.v229.2002.46444. 


\section{Capítulo 11}

Análise de riscos em não cumprimento de prazo de obras através da rede PERT/CPM - Um estudo de caso de uma obra pública no município de Belém

Alexandra Algélia da Silva França

Amanda Cremilda Lima Batista

André Augusto Azevedo Montenegro Duarte

Luíz Maurício Furtado Maués

Resumo: A análise de riscos de projetos visa subsidiar a tomada de decisão diante de eventos que possam criar restrições ou oportunidades para o empreendimento, apesar de serem dinâmicos e envoltos em incertezas, e se pautar nas principais esferas de um projeto, tais como: escopo, prazos, custos e qualidade. Diante disto, este trabalho que se tem como objeto de estudo uma obra pública estimada inicialmente para 240 dias, porém foi construído com 596 dias de atraso, o objetivo deste estudo de caso busca identificar o risco de não cumprimento do prazo inicial, através do planejamento da rede PERT/CPM.

Palavras chave: Análise de risco, incertezas, rede PERT/CPM e Obra pública.

O artigo compôs os Anais do Congresso Brasileiro de Engenharia de Produção, 2016, Ponta Grossa -PR.

Artigos Anais CONBREPRO 2016 - Engenharia de Desenvolvimento de Produto, Ponta Grossa - PR: APREPRO, 2016. v. 2016. 


\section{INTRODUÇÃO}

A falta de metodologias de análise de riscos nas obras públicas e até mesmo nas particulares, tem sido objeto de discursão de vários profissionais. E na tentativa de identificar os fatores de incertezas que configuram o sistema de gestão de projetos, diversos estudos estão sendo elaborados sobre os tipos de metodologias de análise, tratamento de respostas e tecnologias de controle, com o intuito de identificar, minimizar ou aproveitar oportunidades nos cenários de riscos de um projeto.

No estudo de caso objeto deste artigo, temos como objetivo avaliar o risco de uma obra já construída e comparar os resultados com os dados reais da obra, logo a avaliação do risco se deu no pós obra. A obra é composta de três pavimentos tipo, com uma área total de 1.908,28 $\mathrm{m}^{2}$, e o seu processo de construção se deu por concorrência pública de menor preço de acordo com a Lei 8.666 de 21 de junho de 1993, e a empresa vencedora ao longo da construção solicitou 5 (cinco) aditivos de tempos, pois a obra que inicialmente apresentava um tempo de execução de 240 dias, foi concluída com um atraso de 596 dias.

A metodologia de análise ocorreu em três fases, na qual a primeira será o levantamento quantitativo dos tempos unitários das subatividades e a segunda, será o planejamento através da rede PERT/CPM, e a última fase será a determinação dos riscos das subatividades e do projeto como um todo. Sendo que a variável de avaliação dos riscos será o tempo, logo esperamos obter como resultado o risco de não cumprimento da referida obra para o tempo que foi utilizado na licitação, 240 dias.

Solomon e Pringle (1981) coloca o risco como um grau de incerteza e por analogia onde existem incertezas, existem riscos, porém podemos avaliar sua análise não só de forma negativa como uma ameaça, mas sim como uma oportunidade de prever e evitar falhas no processo de execução. De acordo com Mendes, Valle e Fabra (2009), na gestão dos riscos de projetos ainda não há metodologias de análise eficientes em projetos de construção civil, pois o tema ainda não possui a importância que deveria na gestão de projetos, tornando-se um tema a ser explorado pela importância na tomada de decisão ao longo da cadeia de produção de qualquer empreendimento de construção.

\section{METODOLOGIA DE PESQUISA}

0 risco de um projeto é um evento ou condição incerta que provocará um efeito positivo ou negativo em um ou mais objetivos do projeto, tais como, escopo, prazos, custos e qualidade (GUIA PMBOK, 2014). Os riscos estão presentes em tudo o que fazemos, o que o tornar uma constante ao longo da implementação de qualquer empreendimento, podendo criar restrições negativas e/ou possibilidades de ganhos positivos (LIMMER, 1996).

O planejamento de um projeto toma por base parâmetros estimados sensíveis as variações ambientas em que o mesmo está inserido, sejam elas alterações endógenas e exógenas que proporcionam um comportamento mutável no cenário inicialmente imaginado (SLACK, 2009), gerando um meio incerto que necessita de um plano de gerenciamento dessas incertezas. De acordo com Lee Krajewski (2009), identificar essas incertezas, avaliar suas consequências dinâmicas, estabelecer estratégias de realinhamento e formular um sistema de controle, são etapas essenciais para elaborar um plano de gerenciamento dos riscos.

De acordo com o Guia PMBOK (2014), o plano de gerenciamento dos riscos é um processo de definição de como conduzir as atividades que geram riscos no projeto e o seu principal benefício é antecipar tomadas de decisões para corrigir desvios negativos ou aproveitar oportunidade ao longo do ciclo de vida do projeto. A figura 01, a seguir, abrange um esquema de um gerenciamento de risco.

Desta forma, o gerenciamento dos riscos se dá por entradas de informações geradas no gerenciamento do projeto, por técnicas analíticas dos ambientes endógenos e exógenos, e por saídas de informações que posteriormente serão entradas no processo de gerenciamento do projeto (GUIAPMBOK, 2014), caracterizando um laço cíclico de trocas de informações. 0 autor Nobert Wiener, advoga que o sistema de controle de processo que se realimentam se dá pelo controle de desempenho sucessivo do projeto e não pelo controle dos objetivos planejados (CAPRA, 2006), o que caracteriza um sistema de controle contínuo da incerteza. 
Figura 01: Planejamento do Gerenciamento dos riscos (Guia PMBOK, 2014)

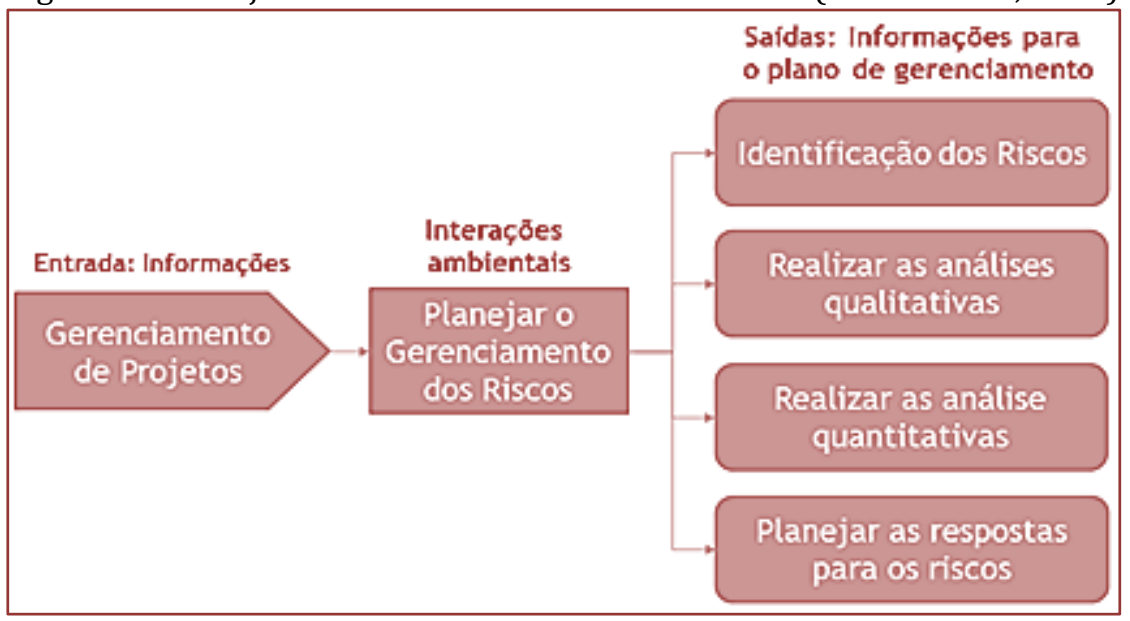

\subsection{IDENTIFICAÇÃO DOS RISCOS}

0 processo de identificação dos riscos visa identificar todos os riscos capazes de afetar o projeto e documentá-los, sendo necessário diversas respostas de feedback (PMP, 2009). À medida que o projeto avança, mais riscos podem surgir e os anteriormente observados podem apresentar impactos distintos ao longo do desempenho do projeto.

De acordo com Guimarães (2010), os riscos ocorrem em seis macro ambientes, ambientes externos (políticos, econômicos e naturais), financeiro, cadeia de suprimentos, planejamento dos custos e prazos, projetos (escopo), construção e comercialização, sendo este penúltimo subdividido em tecnologias, infraestrutura, equipamentos e recursos humanos.

A identificação das probabilidades e impactos nos macros ambientes citados por Guimarães (2010), se dá através de reuniões entre pessoas interessadas, experientes nas diversas etapas de projetos anteriores, usuários e equipe de gestão do projeto em discursão (PMP,2009). A saída do processo de identificação dos riscos são documentos com eventos potenciais que podem ocorrer e suas possíveis consequências, planos estratégicos de respostas e sinais de sensibilidade, ou seja, pontos que devem ser monitorados com maior cuidado, pois seu impacto e ocorrência possuem escalas maiores (ZAYED, 2007).

\subsection{ANÁLISE QUANTITATIVA E QUALITATIVA DOS RISCOS}

As ferramentas e técnicas de realizar a análise quantitativa e qualitativa dos riscos, de modo geral, têm por objetivo descobrir a probabilidade de um evento de risco e determinar seu impacto no projeto (KRAJEWSKI, 2009). As ferramentas mais usadas em projetos são as simulações computacionais, como: Monte Carlos (SMC), Séries Temporais (SST), Redes Neurais (SRN) e Fuzzy. Entre outras análises matemáticas complexas.

Há também as análises por estatística, denominadas de PERT/Risco, que será a ferramenta de análise neste trabalho, onde a variável sujeita a incertezas é o tempo, e a abordagem exige que os tempos de cada atividade do caminho crítico sejam declarados de acordo com três estimativas de tempo (LIMMER, 1996).

- $\quad$ Tempo otimista $(a)$ : é o tempo mais curto no qual a atividade pode ser concluída se tudo ocorrer excepcionalmente bem;

- Tempo mais provável $(m)$ : é o tempo provável necessário para a realização de uma atividade;

- Tempo pessimista $(b)$ : é o tempo mais longo estimado necessário para realizar uma atividade;

Com essas três estimativas de tempo, determinada a probabilidade de ocorrência de cada atividade, para isso é necessário calcular a variância de uma distribuição beta de probabilidade, permitindo que o tempo provável $m$ da atividade fique no intervalo de $a$ à $b$ (CUKIERMAN, 1982). Conforme a figura 02 . 
Figura 02: Distribuição beta de probabilidade da atividade concretagem do projeto em análise

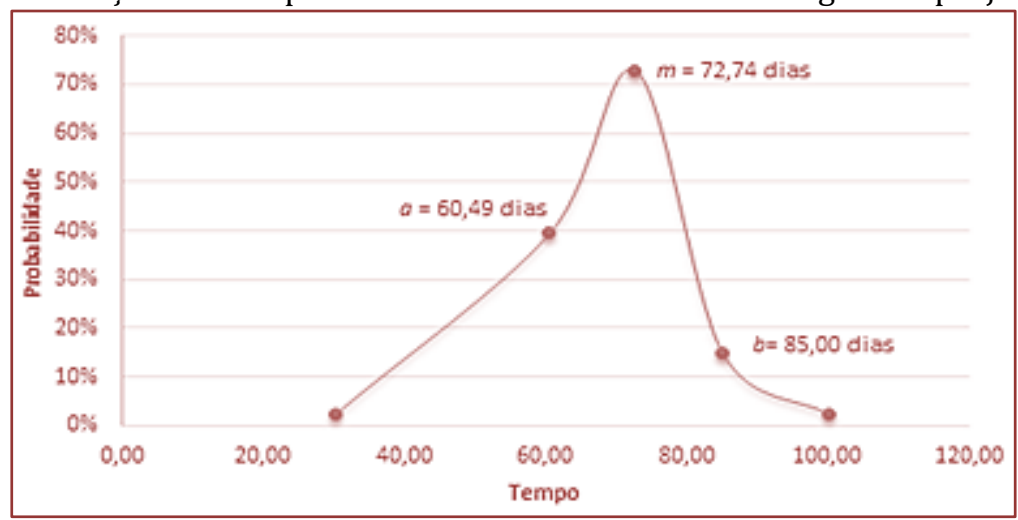

E para que tal avaliação, seja considerada como verdadeira, deve-se considerar duas condições de contorno (KRAJEWSKI, 2009). A primeira devemos supor que $a, m$ e $b$ podem ser calculados com exatidão, sendo que a será medido a partir do cálculo da duração unitária da atividade, tirada do banco de dados TCPO (PINI, 2012), $b$ será a partir da diferença da primeira data de início e da primeira data de término da atividade na rede PERT/CPM, e $m$ será a média aritmética, das datas $a$ e $b$. Conforme expresso na equação 01.

Equação 01: Formula da média aritmética das datas $a$ e $b$ de uma atividade

$$
m=\frac{a+b}{2}
$$

Diante desta condição, pode-se calcular a variância e o desvio-padrão da atividade o que permite calcular que na medida em que a diferença entre as datas $a$ e $b$ aumenta, os riscos de não concluir a atividade no prazo torna-se maior. As equações 02 e 03 expressam os cálculos.

Equação 02: Cálculo da variância da atividade

$$
v=\frac{(a-m)^{2}+(b-m)^{2}}{2}
$$

Equação 03: Cálculo do desvio-padrão da atividade de risco em não concluir a atividade no prazo

$$
\sigma=\sqrt{v}
$$

A segunda condição de contorno admite que nenhum outro caminho se tornará crítico durante o período de tempo de todo o projeto, o que permite avaliar qual o risco de não concluir o projeto no prazo planejado inicialmente, que é o fator $Z$, e este é o módulo da diferença da primeira data de termino do projeto $\left(P D T_{p}\right)$ e da última data de termino do projeto $\left(U D T_{P}\right)$ da rede PERT/CPM, dividido pela somatória das variâncias de todas as atividades que compõem o caminho crítico do projeto. Conforme equação 04.

Equação 04: Cálculo do risco de não cumprimento do prazo do projeto

$$
Z=\frac{U D T_{P}-P D T_{P}}{\sum_{n} v}
$$




\subsection{PLANEJAMENTO DAS RESPOSTAS PARA OS RISCOS}

Planejar as respostas aos riscos é o processo de desenvolvimento de opções e ações para aumentar as oportunidades e reduzir as ameaças aos objetivos do projeto (GUIA PMBOK, 2014). 0 principal benefício deste processo é a abordagem dos riscos por prioridades, injetando recursos e atividades no orçamento, no cronograma e no plano de gerenciamento do projeto, como num ciclo de estímulos, respostas e estratégias de realimentação ao longo de todo o período do empreendimento (SLACK, 2009).

As principais estratégias para os riscos negativos são, prevenir, transferir, mitigar e aceitar. Sendo que prevenir é realizar alterações antecipadas no plano gerencial do projeto que apresentam riscos futuros frequentes, por exemplo, compatibilizar os projetos de engenharia antes do início do empreendimento. Já a estratégia transferir riscos, é o ato de doar para terceiros problemas que geram riscos, como diminuição de produtividade devido as alterações climáticas, perda no cronograma de atividades com vários tipos de restrições, entre outros problemas. A quarta estratégia é o ato de mitigar o risco, que é fazer uma avaliação do seu impacto, pois pelo fato de não poder evitá-lo, elabora-se uma forma de minimizar seu impacto ao longo do projeto. E por fim, a estratégia de aceita o risco, que é estabelecer uma reserva de contingência ainda incluindo tempo (folgas) e recursos financeiros para evitar que o risco atinja escalas maiores (PMP, 2009).

E para analisar as possibilidades de ganho dos riscos, as estratégias de respostas são, explorar, melhorar, compartilhar e aceitar. Sendo que explorar o risco é avaliá-lo de forma positiva, e assim usar de métodos tecnológicos para "puxar" o cronograma para o mais próximo da sua primeira data de início, ou colocar na frente da gestão do projeto uma equipe experiente e qualificada (PORTER, 1991). A segunda estratégia é melhorar os riscos, por exemplo, qualificar a equipe através de treinamentos contínuos e usar de recursos financeiros para acelerar o cronograma. Já a penúltima estratégia, é o compartilhamento do risco que nada mais é do que fazer parcerias com fornecedores ou prestadores de serviços com qualificações maiores que sua equipe para resolver problemas emergências e/ou de gestão. E por fim, a estratégia aceitar, é reconhecer a existência do risco mais não se preocupar com ele, pois seu impacto não é tão importante ao longo do processo (GUIA PMBOK, 2014).

\subsection{CONTROLAR OS RISCOS}

Controlar os riscos é o processo de implementação de planos de respostas aos riscos, acompanhamento dos riscos identificados, monitoramento dos riscos residuais, identificação de novos riscos e avaliação da eficácia do processo de riscos durante todo o projeto (GUIA PMBOK, 2014). De acordo com Cox III (1997), o processo de controle do projeto é o que irá determinar as variações excedente do planejado e os limites permitidos para o bom desempenho do mesmo e assim, permite o desenvolvimento de respostas para correções corretivas ao longo de todo o empreendimento.

\section{ESTUDO DE CASO}

O objeto de estudo é uma obra pública, localizada no município de Belém, licitada na data 30 de novembro de 2010, com previsão de início na data 06 de junho de 2011, e previsão de conclusão dia 01 de fevereiro de 2012, totalizando um período de projeto de 240 dias contínuos. A área total do projeto é de 1.908,28 $\mathrm{m}^{2}$, uma média de $636,09 \mathrm{~m}^{2}$ por pavimento, sendo um total de três pavimentos, figuras 03,04 e 05 . 
Figura 03: Layout do $1^{\circ}$ pavimento do objeto de estudo

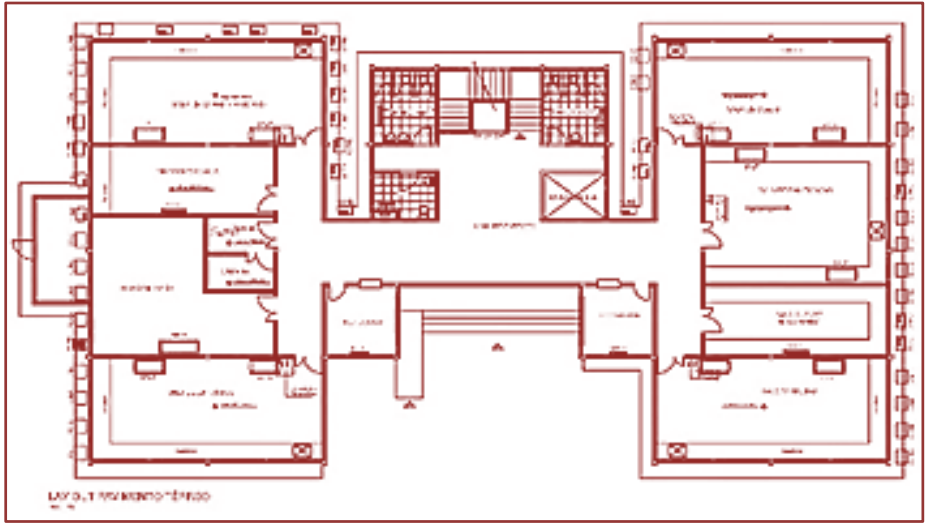

Figura 04: Layout do $2^{\circ}$ pavimento do objeto de estudo

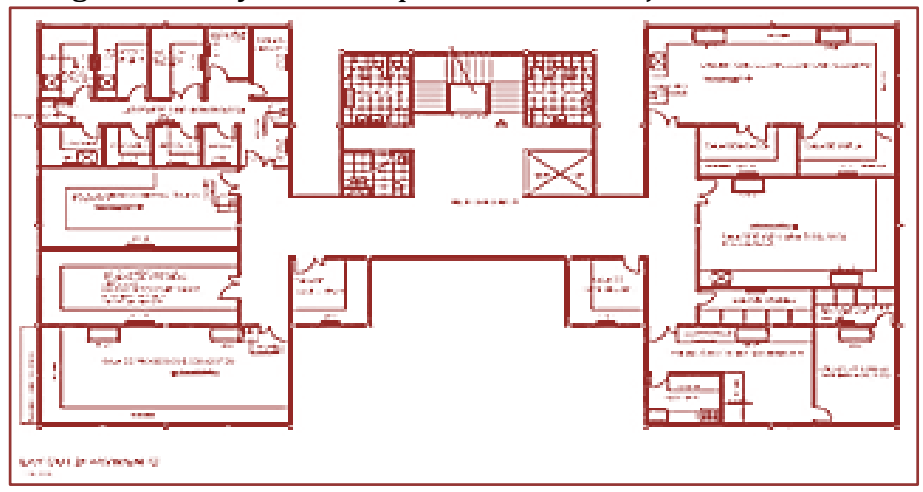

Figura 05: Layout do $3^{\circ}$ pavimento do objeto de estudo

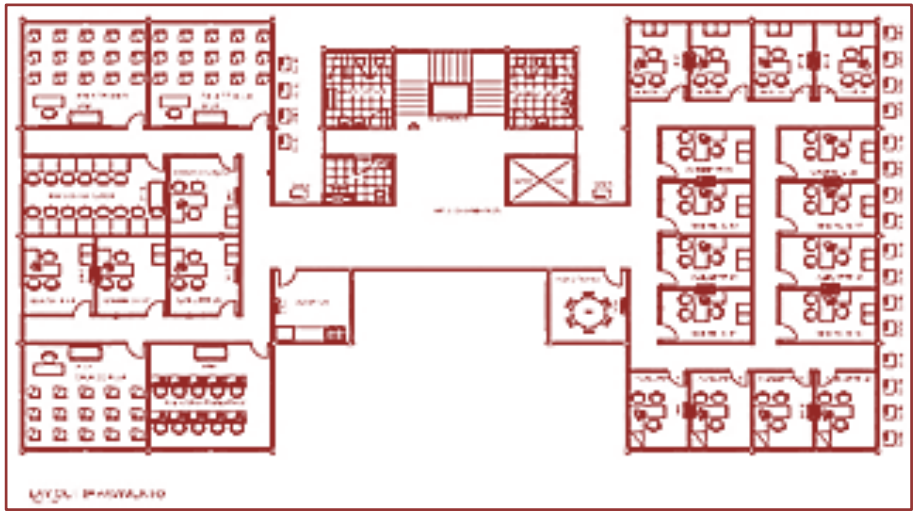

A análise do risco de não conclusão do projeto se deu pós obra, ou seja, quando o planejamento e a determinação dos riscos ocorreram a obra já estava entregue.

O que motivou a avaliação da referida obra foi seu atraso de 596 dias, pois a data real de entrega da obra foi 19 de setembro de 2013, um tempo de 148,33\% superior ao esperado. E de acordo com a avaliação dos processos da licitação, a construtora vencedora da concorrência solicitou 5 (cinco) reposições de prazo para o órgão licitante, alegando como justificativas dos aditivos os erros presentes nos projetos de fundação, instalações e cobertura, além das constantes faltas de luz e água na obra.

Desta forma, busca-se avaliar os riscos das subatividades que compõe as atividades fundação, instalações e cobertura e verificar se realmente o grande atraso da obra se justifica pelo elevado riscos destas e quais seus impactos no projeto como todo. Além de determinar as atividades que realmente merece um controle maior e que podem atrasar o projeto como um todo. 


\subsection{CÁLCULO DA PRIMEIRA DATA DE INÍCIO DAS ATIVIDADES (A)}

A estimativa da primeira data de início das subatividades (PDIs) que compões as macroatividades ocorreu através a elaboração de composições unitárias e estimativas dos tempos em horas presentes nos bancos de dados do TCPO (PINI,2012), e posterior transformações das horas em dias. Como mostra a Tabela 01.

Tabela 01: Estrutura analítica de projeto com suas macroatividades

\begin{tabular}{|c|c|c|c|c|c|}
\hline \multicolumn{6}{|c|}{ Estrutura Analítica de Projeto } \\
\hline Macro & Atividades & Macro & Atividades & Macro & Atividades \\
\hline 1 & $\begin{array}{c}\text { Serviços } \\
\text { Preliminares da obra }\end{array}$ & 10 & Rodapés, soleiras e peitoris & 19 & Iluminação e Tomadas \\
\hline 2 & $\begin{array}{l}\text { Movimentações de } \\
\text { Terra }\end{array}$ & 11 & Piso & 20 & Rede Estruturada \\
\hline 3 & Infra Estrutura & 12 & Forro & 21 & Ar Condicionado \\
\hline 4 & Super Estrutura & 13 & Pinturas & 22 & SPDA \\
\hline 5 & Vedações & 14 & Instalações Hidráulicas & 23 & Cabeamento Estruturado \\
\hline 6 & Cobertura & 15 & Instalações de Esgoto & 24 & Alimentadores \\
\hline 7 & Impermeabilizaçãoes & 16 & $\begin{array}{l}\text { Instalações de Combate de } \\
\text { Incêndio }\end{array}$ & 25 & $\begin{array}{c}\text { Subestação área de } \\
225 \mathrm{KVA}\end{array}$ \\
\hline 8 & Esquadrias & 17 & $\begin{array}{c}\text { Instalações de redes } \\
\text { frigorificas }\end{array}$ & 26 & Serviços Complementares \\
\hline 9 & Revestimentos & 18 & Aparelhos, Metais e Louças & 27 & Limpeza Final \\
\hline \multicolumn{5}{|c|}{ Primeira Data de Início de Projeto (PDI) } & $06 / 06 / 2011$ \\
\hline \multicolumn{5}{|c|}{ Primeira Data de Término de Projeto (PDT) } & $01 / 02 / 2012$ \\
\hline \multicolumn{5}{|c|}{ Tempo de Execção de Projeto em Dias Contínuos } & $27 / 08 / 1900$ \\
\hline
\end{tabular}

Posteriormente através de avaliações dos cronogramas presentes nos processos de solicitação de aditivos de tempo, tirou-se uma média de funcionários utilizados na execução das subatividades ao longo da obra, permitindo-se que se determinasse um tempo semelhante ao usando na gestão do projeto.

\subsection{ELABORAÇÃO DA REDE PERT/CPM}

Com o auxílio do software MSProject 2016 ${ }^{\circledR}$, determinou-se a rede PERT/CPM, permitindo-se que se retirasse a última data de término das subatividades ( $\mathrm{UDT}_{\mathrm{s}}$ ), e consequentemente se determina-se o caminho crítico do projeto. Como esquematizado na Figura 06.

Figura 06: Caminho crítico das subatividades do projeto, determinadas no MSProject $2016^{\circledR}$

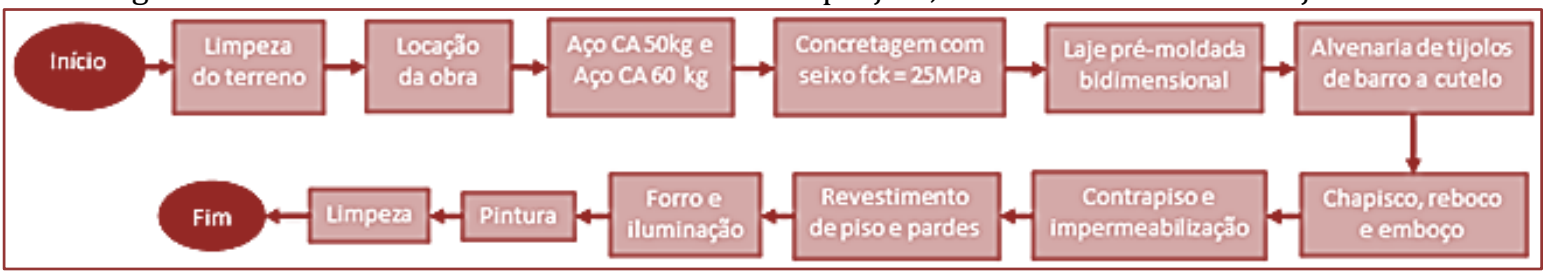

Com a determinação dos tempos $\mathrm{PDI}_{\mathrm{s}}(a)$ e $\mathrm{UDT}_{\mathrm{s}}(b)$ determina-se a média aritmética de cada atividade $(m)$, e posteriormente calcula-se a variância $(v)$ e o desvio-padrão $(\sigma)$ das mesmas. Assim pode se determinar o risco de não cumprimento do projeto, para o caminho crítico calculado. A Tabela 02 sintetiza os números. 
Tabela 02: Tabela com o cálculo dos tempos $a$ (primeira data de início), $b$ (última data de término), $m$ (média aritmética dos tempos), $v$ (variância) e $\sigma$ (desvio-padrão)

\begin{tabular}{|c|c|c|c|c|c|c|c|c|c|c|}
\hline \multirow[b]{3}{*}{ Item } & & & & \multicolumn{7}{|c|}{ GANTT TEMPO/RISCO } \\
\hline & \multicolumn{3}{|c|}{ Atividades } & \multirow{2}{*}{$\begin{array}{c}\text { Tempo } \\
\text { estima } \\
\text { do } \\
\text { (dias) }\end{array}$} & \multicolumn{2}{|c|}{ PERT } & \multicolumn{4}{|c|}{ Risco } \\
\hline & Descrição & Unidade & $\begin{array}{c}\text { Quantida } \\
\text { de }\end{array}$ & & PDI & PDT & b & $\mathrm{Tm}$ & $v$ & $\sigma$ \\
\hline 1.1 & $\begin{array}{l}\text { Limpeza do } \\
\text { Terreno }\end{array}$ & $\mathrm{m}^{2}$ & 807,86 & 5,74 & $06 / 06 / 11$ & $13 / 06 / 11$ & 7,00 & 6,37 & 0,40 & $\begin{array}{c}21,04 \\
\%\end{array}$ \\
\hline 1.2 & $\begin{array}{c}\text { Locação da } \\
\text { obra }\end{array}$ & $\mathrm{m}^{2}$ & 641,35 & 2,37 & $13 / 06 / 11$ & $16 / 06 / 11$ & 3,00 & 2,68 & 0,10 & $\begin{array}{c}31,57 \\
\%\end{array}$ \\
\hline 3.4 & $\begin{array}{c}\text { Aço CA } 50 \\
\mathrm{Kg}\end{array}$ & Kg & 958,00 & 1,63 & $16 / 06 / 11$ & $17 / 06 / 11$ & 1,00 & 1,32 & 0,10 & $\begin{array}{c}31,65 \\
\%\end{array}$ \\
\hline 4.1 & $\begin{array}{l}\text { Concreto } \\
\text { com seixo } \\
\text { Fck }=25 \\
\text { MPA }\end{array}$ & $\mathrm{m}^{3}$ & 354,87 & 60,49 & $04 / 08 / 11$ & $28 / 10 / 11$ & 85,00 & $\begin{array}{c}72,7 \\
4\end{array}$ & $\begin{array}{l}150,1 \\
9\end{array}$ & $\begin{array}{c}1225,5 \\
4 \%\end{array}$ \\
\hline 4.3 & $\begin{array}{c}\text { Aço CA } 50 \\
\text { Kg }\end{array}$ & $\mathrm{Kg}$ & $15.658,00$ & 26,69 & $17 / 06 / 11$ & $26 / 07 / 11$ & 39,00 & $\begin{array}{c}32,8 \\
4\end{array}$ & 37,89 & $\begin{array}{c}615,51 \\
\% \\
\end{array}$ \\
\hline 4.4 & $\begin{array}{c}\text { Aço CA } 60 \\
\mathrm{Kg}\end{array}$ & Kg & $3.802,00$ & 7,56 & $26 / 07 / 11$ & $04 / 08 / 11$ & 9,00 & 8,28 & 0,52 & $\begin{array}{c}71,96 \\
\% \\
\end{array}$ \\
\hline 4.7 & $\begin{array}{c}\text { Laje pré- } \\
\text { moldada } \\
\text { Bidireciona } \\
\text { l }\end{array}$ & $\mathrm{m}^{2}$ & $1.626,50$ & 33,73 & $28 / 10 / 11$ & $15 / 12 / 11$ & 48,00 & $\begin{array}{c}40,8 \\
7\end{array}$ & 50,90 & $\begin{array}{c}713,43 \\
\%\end{array}$ \\
\hline 5.1 & $\begin{array}{c}\text { Alvenaria } \\
\text { tijolo de } \\
\text { barro a } \\
\text { cutelo }\end{array}$ & $\mathrm{m}^{2}$ & $3.313,43$ & 84,72 & $15 / 12 / 11$ & $11 / 04 / 12$ & $\begin{array}{c}118,0 \\
0\end{array}$ & $\begin{array}{c}101 \\
36\end{array}$ & $\begin{array}{c}276,9 \\
2\end{array}$ & $\begin{array}{c}1664,0 \\
8 \%\end{array}$ \\
\hline 7.4 & $\begin{array}{l}\text { Impermeab } \\
\text { ilização } \\
\text { rebaixos de } \\
\text { banheiros, } \\
\text { cozinha } \\
\text { (Vedapren) }\end{array}$ & $\mathrm{m}^{2}$ & 128,31 & 1,57 & $07 / 09 / 12$ & $10 / 09 / 12$ & 3,00 & 2,28 & 0,51 & $\begin{array}{c}71,63 \\
\%\end{array}$ \\
\hline 9.1 & Chapisco & $\mathrm{m}^{2}$ & $7.011,18$ & 19,92 & $11 / 04 / 12$ & $09 / 05 / 12$ & 28,00 & $\begin{array}{c}23,9 \\
6\end{array}$ & 16,33 & $\begin{array}{c}404,09 \\
\%\end{array}$ \\
\hline 9.2 & Emboço & $\mathrm{m}^{2}$ & 295,14 & 4,78 & 09/05/12 & $16 / 05 / 12$ & 7,00 & 5,89 & 1,23 & $\begin{array}{c}111,04 \\
\%\end{array}$ \\
\hline 9.4 & $\begin{array}{l}\text { Reboco } \\
\text { interno }\end{array}$ & $\mathrm{m}^{2}$ & $4.839,76$ & 68,75 & $16 / 05 / 12$ & $21 / 08 / 12$ & 97,00 & $\begin{array}{c}82,8 \\
7 \\
\end{array}$ & $\begin{array}{c}199,5 \\
6\end{array}$ & $\begin{array}{c}1412,6 \\
7 \%\end{array}$ \\
\hline 10.1 & $\begin{array}{c}\text { Rodapé em } \\
\text { Korodur } \\
\text { (incluindo } \\
\text { polimento) }\end{array}$ & $\mathrm{Ml}$ & $1.322,94$ & 19,92 & $11 / 09 / 12$ & $09 / 10 / 12$ & 28,00 & $\begin{array}{c}23,9 \\
6\end{array}$ & 16,32 & $\begin{array}{c}404,04 \\
\%\end{array}$ \\
\hline 11.1 & $\begin{array}{c}\text { Camada } \\
\text { regularizad } \\
\text { ora }\end{array}$ & $\mathrm{m}^{2}$ & $1.814,97$ & 12,89 & $21 / 08 / 12$ & $07 / 09 / 12$ & 17,00 & $\begin{array}{c}14,9 \\
5\end{array}$ & 4,22 & $\begin{array}{c}205,48 \\
\%\end{array}$ \\
\hline
\end{tabular}




\section{(Continuação)}

Tabela 02: Tabela com o cálculo dos tempos $a$ (primeira data de início), $b$ (última data de término), $m$ (média aritmética dos tempos), $v$ (variância) e $\sigma$ (desvio-padrão)

\begin{tabular}{|c|c|c|c|c|c|c|c|c|c|c|}
\hline & & & & GANTT & TEMPO/RIS & & & & & \\
\hline & Ativ & lades & & Tempo & & & & & $\mathrm{co}$ & \\
\hline Item & Descrição & Unidade & $\begin{array}{c}\text { Quantida } \\
\text { de }\end{array}$ & $\begin{array}{c}\text { estima } \\
\text { do } \\
\text { (dias) }\end{array}$ & PDI & PDT & b & $\mathrm{Tm}$ & $v$ & $\sigma$ \\
\hline 11.3 & $\begin{array}{c}\text { Lajota } \\
\text { cerâmica } \\
41 \times 41 \mathrm{~cm} \\
\text { Cargo Plus } \\
\text { Boni Fab. } \\
\text { Eliane ou } \\
\text { similar } \\
\end{array}$ & $\mathrm{m}^{2}$ & 50,62 & 0,58 & $10 / 09 / 12$ & $11 / 09 / 12$ & 1,00 & 0,79 & 0,05 & $\begin{array}{c}21,24 \\
\%\end{array}$ \\
\hline 12.1 & $\begin{array}{c}\text { Forro em } \\
\text { Lambri de } \\
\text { PVC } \\
\text { L=10cm cor } \\
\text { Branca, } \\
\text { sobre } \\
\text { estrutura } \\
\text { em metalon }\end{array}$ & $\mathrm{m}^{2}$ & $1.793,45$ & 38,21 & $09 / 10 / 12$ & $30 / 11 / 12$ & 52,00 & $\begin{array}{c}45,1 \\
1\end{array}$ & 47,52 & $\begin{array}{c}689,36 \\
\%\end{array}$ \\
\hline 13.3 & $\begin{array}{c}\text { PVA } \\
\text { acrílica } \\
\text { interna, } \\
\text { padrão } \\
\text { metalatex } \\
\text { fab. } \\
\text { SHERWN } \\
\text { WILLIANS } \\
\text { ou similar - } \\
\text { cobertura } \\
\end{array}$ & $\mathrm{m}^{2}$ & $4.839,76$ & 68,75 & $15 / 05 / 13$ & $20 / 08 / 13$ & 97,00 & $\begin{array}{c}82,8 \\
7\end{array}$ & $\begin{array}{c}199,5 \\
6\end{array}$ & $\begin{array}{c}1412,6 \\
7 \%\end{array}$ \\
\hline 19.1 & Ilumin & ção e Tor & idas & $\begin{array}{c}117,8 \\
7\end{array}$ & $30 / 11 / 12$ & $15 / 05 / 13$ & $\begin{array}{c}166,0 \\
0\end{array}$ & $\begin{array}{c}141, \\
93\end{array}$ & $\begin{array}{c}579,2 \\
4\end{array}$ & $\begin{array}{c}2406,7 \\
3 \%\end{array}$ \\
\hline 27.1 & $\begin{array}{l}\text { Limpeza } \\
\text { permanent } \\
\text { e da obra } \\
\text { com bota } \\
\text { fora }\end{array}$ & $\mathrm{m}^{2}$ & $1.909,21$ & 10,85 & $20 / 08 / 13$ & $04 / 09 / 13$ & 15,00 & $\begin{array}{c}12,9 \\
2\end{array}$ & 4,31 & $\begin{array}{c}207,61 \\
\%\end{array}$ \\
\hline TEI & O CAMIN & RÍTIC & lculado & $\begin{array}{c}587,0 \\
0\end{array}$ & 06/06/11 & 04/09/13 & $\begin{array}{c}821,0 \\
0\end{array}$ & $\begin{array}{c}704, \\
00\end{array}$ & $\begin{array}{c}1585 \\
87\end{array}$ & $\begin{array}{c}14,76 \\
\%\end{array}$ \\
\hline
\end{tabular}

Como pode se observar, das 19 (dezenove) subatividades que fazem parte do caminho crítico do projeto, 5 (cinco) apresentam riscos elevadíssimos, itens 4.1, 5.1, 9.4, 13.3 e 19.1 da Tabela 02, e merecem um alto controle ao longo dos seus processos de produção, assim como elaborações de respostas eficientes caso contrário, poderá prejudicar o planejamento do projeto. Por exemplo, se essas 5 (cinco) atividades de altíssimo riscos sofrerem um atraso simultaneamente de $10 \%$, o projeto irá sofrer um atraso global de 56 dias e aumentará a sua variância em 72\%, confirmando o exposto por Krajewski (2009), com o aumento do afastamentos dos tempo $a$ e $b$ maior será o risco de não cumprimento dos prazos inicialmente projetados.

\section{ANÁLISE DOS RESULTADOS}

Fazendo o comparativo dos tempos planejado com os tempos reais, calculou-se o risco de projetos para a primeira data de término do projeto, 240 dias, em relação a última data de término planejada do empreendimento, 821 dias e assim, foi obtido um risco de $36,64 \%$ do projeto. Ou seja, se a obra estivesse sido planejada e se seus riscos estivessem sido avaliados previamente, poderia elaborar estratégias de redução de tempo das subatividades críticas e assim evitado um atraso tão significativo. Como é visto na Tabela 03. 
Figura 03: Tabela de comparativo dos riscos para o planejado e para o real do projeto

\begin{tabular}{|c|c|c|c|c|c|c|c|}
\hline \multicolumn{8}{|c|}{ AL - Avallaçao Global do Projeto } \\
\hline Descrição & a & PDI & UDT & b & $\mathrm{m}$ & $v$ & $\sigma$ \\
\hline $\begin{array}{l}\text { TEMPO DO CAMINHO CRITICO - } \\
\text { Planejado }\end{array}$ & 587,00 & 6/2011 & $9 / 2013$ & 821,00 & 704,00 & 1585,87 & $14,76 \%$ \\
\hline TEMPO REAL DA PROVA - Real & 240,00 & $06 / 06 / 2011$ & $19 / 09 / 2013$ & 836,00 & 538,00 & 1585,87 & $36,64 \%$ \\
\hline
\end{tabular}

Também podemos observar que a última data de término do planejado, 821 dias é bem próxima ao tempo real da obra, 836 dias o que podemos supor que não ocorreu negligência apenas pela empresa contratada mais também pelo órgão licitante, em negligenciar a fase de planejamento da obra, pois o tempo de execução proposto da obra, 240 dias não era compatível com tempo de projeto coerente com as condições necessárias para a obra ocorrer, que de acordo com o planejado seria de 587 dias.

Além disso, podemos analisar que as justificativas de atraso utilizadas pela empresa contratada não são compatíveis com as atividades críticas do planejado, que foram as subatividades: de concretagem, alvenaria, reboco interno, pintura e iluminação, que pelo seu volume foram restringidas por diversas subatividades logo, torna-se necessário um sistema de respostas e controle aos riscos eficiente não apenas sobre as subatividades que estão presentes no caminho crítico como também as outras subatividades restritivas já vista que apesar da condição de contorno em considerar o caminho crítico invariável, o mesmo apresenta um comportamento dinâmico e com diversas interações ao longo de todo o processo.

\section{CONCLUSÕES}

Um projeto, se inicia com o desejo e/ou a necessidade para de acordo com as informações fornecidas pelo cliente, como por exemplo: descrição, função, locação, clima, se inicia o estudo preliminar para a elaboração do anteprojeto, quando definidas, partir para a elaboração dos projetos de arquiteturas, constituídos de desenhos, textos, planilhas, cronogramas, fotografias, maquetes e quaisquer elementos de representação.

Após estas etapas, teremos o início dos dados topográficos e cadastral bem como uma compatibilidade dos projetos com o código de postura do órgão licitante, parte se para a elaboração dos projetos arquitetônicos (implantação, terraplanagem, pavimento(s), cobertura, cortes, elevações, detalhamentos e especificações técnicas), com estas definições e devidamente aprovados, passa-se para a etapa que necessita de prestação de serviços especializados, estruturas (fundação e superestrutura); instalações prediais (elétrica, telefone, logica, frigorigenas e hidrossanitária); comunicação visual; paisagismo, impermeabilização e outros elementos de acordo com a função e localização da construção. Conforme recomenda - ABNT NBR 13.531/1995 - Elaboração de projetos de edificações - Atividades Técnicas; NBR 12722/1992 - Discriminação de Serviços para construção de edifícios - Procedimento; e NBR 13.532/1995 - Elaboração de projetos de edificações - Arquitetura.

Como a maioria das obras públicas são financiadas pelo Governo Federal, após a fase de elaboração dos projetos deveria se efetuar a fase de gerenciamento de projetos com prazos mais compatíveis com a realidade e evitando assim atrasos e prejuízos sociais.

Como o gerenciamento de riscos faz parte do gerenciamento de projetos possibilitaria um maior controle sob os recursos de pessoal e financeiro, a definição de nível hierárquico das atividades e a verificação de cargas excessivas de trabalhos e dos recursos minimizariam os problemas e os prejuízos de tempo e financeiros observando também a linha de tempo de uma obra levando em consideração a posterior manutenção logo, buscar mais tempo na etapa referente ao planejamento e não somente utilizar o artificio de copiar e colar nas elaborações de escopo e cronograma físico traria um grande avanço na gestão de obras já que cada obra tem suas especificidades.

\section{REFERÊNCIAS}

[1] CUKIERMAN, ZIGMUNDO S. O modelo PERT/CPM aplicado a projetos. $4^{\circ}$ edição, Rio de Janeiro, 1982.

[2] CARL V. LIMMER. Planejamento, Orçamentação e Controle de Projetos e Obras. Editora LTC, Rio de Janeiro, 1997.

[3] CAPRA, FRITJOF. A teia da vida "The web of life". 10 edição, editora Pensamento-Cultrix Ltda, São Paulo, 2006. 
[4] GUIA PMBOK. Um Guia do Conhecimento de Projetos. 5 edição, editora Saraiva, São Paulo, 2014.

[5] GUIMARÃES, L. F. Análise de risco em projetos de construção naval e Offshore. UFRJ, Rio de Janeiro, 2010.

[6] JAMES, COX III; MICHAEL S. SPENCER. Manual da Teoria das Restrições. Editora Bookman, Porto Alegre, 2002.

[7] KRAJEWSKI, LEE; RITZMAN, LARRY; MALHOTRA, MANOJ. Administração de Produção e Operações. $10^{\circ}$ edição, editor Pearson, São Paulo, 2009.

[8] PORTER, MICHAEL E. Estratégia Competitiva. Técnicas para Análise de Indústrias e da Concorrência. $8^{\circ}$ edição, editora Campus, Rio de Janeiro, 1991.

[9] PMP, KIM HELDMAN. Gerência de Projetos. Guia para o exame oficial do PMI. Revista técnica, $5^{\circ}$ edição, editora Campus, Rio de Janeiro, 2009.

[10] SLACK, NIGEL; CHAMBERS, STUART; JOHNSTON, ROBERT. Administração da Produção. $3^{\circ}$ edição, editora Atlas, São Paulo, 2009.

[11] PINI. TCPO - Tabelas de Composições de Preços para Orçamento. $14^{\circ}$ edição, editora PINI Ltda, São Paulo, 2012.

[12] ZAYED, T.; AMER, M; PAN, J.; "Assessing risk and uncertainty inherent in Chinese highway projects using AHP", Science Direct International Journal of Project Management, 2007.

[13] NORMA TÉCNICA BRASILEIRA - ABNT NBR 12722/1992 - Discriminação de Serviços para construção de edifícios - Procedimento.

[14] NORMA TÉCNICA BRASILEIRA - ABNT NBR 13.531/1995 - Elaboração de projetos de edificações - Atividades Técnicas.

[15] NORMA TÉCNICA BRASILEIRA - ABNT NBR 13.532/1995 - Elaboração de projetos de edificações Arquitetura.

[16] SOLOMON, E.; PRINGLE, J.J. Introdução à Administração Financeira. Edição Atlas S/A, S.P. 1981.

[17] MENDES, J.R.B; VALLE, A.B; FABRA, MARCANTONIO. Gerenciamento de Projetos. Rio de Janeiro: FGV, 2009. 


\section{Capítulo 12}

\section{Gerenciamento de risco no transporte rodoviário de}

\section{cargas}

\section{Sergio Henrique Ribeiro Costa}

Daniel Martins da Silva

Eliene Rodrigues Sousa

Resumo: 0 transporte rodoviário de carga representa $60 \%$ dos bens e mercadorias transportadas no Brasil. Esse percentual exige que o modal rodoviário seja cada vez mais eficiente e seguro. E, para que isso aconteça, as empresas têm feito altos investimentos em gerenciamento de risco, ou seja, investem em seguros e tecnologias de rastreamento e monitoramento de veículo. Essas tecnologias são mecanismos do gerenciamento de risco, e é através destas que as gerenciadoras de risco (central de monitoramento) acompanham e controlam o veículo com a carga durante toda a viagem. Portanto, o objetivo desse trabalho é apresentar todo processo desse gerenciamento de risco no transporte rodoviário de carga, bem como os seguros, as tecnologias e os mecanismos utilizados pela gerenciadora de risco, visando principalmente assegurar que o veículo e sua carga chegarão ao destino final conforme o cumprimento do contrato anteriormente firmando entre o embarcador e o transportador.

Palavras-Chave: transporte rodoviário de carga; seguro e gerenciamento de risco. 


\section{INTRODUÇÃO}

As empresas, pensando em agir com eficiência e segurança, estão buscando constantemente alternativas para assegurar suas operações de transporte de cargas. Desse modo, estão investindo em tecnologias para rastrear e monitorar o veículo durante todo trajeto.

Nesse contexto, operações logísticas eficientes exercem papel fundamental na conquista de uma cadeia produtiva bem-sucedida. 0 transporte de produtos e matérias-primas representa uma importante ligação entre fornecedores, fabricantes e comerciantes (MARQUES, 2006).

o que torna essas operações ainda mais eficientes é o advento de tecnologias voltadas para o rastreamento, o monitoramento e a comunicação entre o condutor do veículo que transporta a carga e a central de monitoramento. Assim, é possível que todos envolvidos na operação de transporte obtenham informações em tempo real podendo prevenir e intervir em possíveis situações de risco.

O processo de Gerenciamento de Risco no Transporte Rodoviário de Carga inicia quando a transportadora recebe a mercadoria no embarcador e termina com a entrega do produto ao seu destinatário. Assim, a transportadora se responsabiliza pela segurança da carga enquanto esta estiver em seu poder durante a viagem. Por sua vez a gerenciadora de risco valendo-se dos instrumentos adequados para análise dos riscos e levantamento de adversidades no transporte rodoviário de carga, cria normas e regras para prevenir e diminuir os riscos de sinistro da carga transportada. Essa análise de risco é que vai indicar os pontos de maior ou menor risco e levar ao tratamento adequado a cada etapa do processo.

A implantação de tecnologias que influenciam diretamente nesse processo de gerenciamento de risco, consiste em melhorias ou mudanças dos equipamentos para gerar maior produtividade e qualidade no transporte rodoviário de carga. A logística é vista como uma atividade estratégica e as inovações tecnológicas visam contribuir significativamente para as empresas que atuam neste setor. É o caso dos sistemas de monitoramento que utilizam o rastreamento via satélite, tecnologia que vem sendo adotada progressivamente pelas transportadoras rodoviárias de cargas (ANEFALOS, 1999).

Observa-se que o transporte rodoviário de cargas é bastante significativo para economia. Esse tema se mostra relevante tendo em vista que no Brasil, este é o principal modal utilizado para transportar $60 \%$ de toda riqueza (FELIPPE, 2005). Ainda segundo o autor, discutir sobre o transporte rodoviário de carga é contribuir para que o assunto seja difundido e torne-se de interesse não só de empresas e governantes, mas também da sociedade em geral. Além disso, deve-se levar em conta aspectos como tributação sobre o setor de transporte e a infraestrutura precária que acarretam para o aumento significativo do preço final de cada produto transportado, tornando elevado o custo brasil.

Portanto, o objetivo desse trabalho é apresentar os mecanismos do gerenciamento de risco no transporte rodoviário de carga, bem como os tipos de seguro e as tecnologias utilizadas no processo de monitoramento e rastreamento de veículos.

Para melhor compreensão, o texto a seguir está organizado em sete seções incluindo esta introdução. Inicialmente, contextualizamos o transporte rodoviário de carga no Brasil, mostrando as condições e dimensões da malha rodoviária; a quantidade e tipos de transportadoras registradas na Agência Nacional de Transportes Terrestres - ANTT. Em seguida apresentamos a metodologia do trabalho e posteriormente, elencamos os tipos de seguro e os responsáveis pela contração deste no transporte rodoviário de carga. Logo após, apresentamos os mecanismos de gerenciamento de risco, bem como as tecnologias de rastreamento e monitoramento que são utilizadas para acompanhar e controlar o veiculo durante a viagem. Assim, mostramos todas as partes envolvidas nesse processo de gerenciamento de risco no transporte rodoviário de carga.

\section{O TRANSPORTE RODOVIÁRIO DE CARGAS NO BRASIL}

A economia brasileira é basicamente movimentada pelo Transporte Rodoviário de Cargas. A maioria dos produtos consumidos e recebidos em centros de distribuição, atacadistas, varejistas e domicílios chegam via transporte rodoviário.

Ter uma matriz de transporte eficiente é imprescindível para a manutenção e desenvolvimento econômico de um país com dimensões continentais como o Brasil. E para que isso aconteça é necessário que os grandes investimentos governamentais em infraestrutura, sejam efetivamente contemplados. Isto já pode ser percebido nas ações do governo em programas como: PAC (Programa de Aceleração do Crescimento); PIL (Programa de Investimento em Logística). Assim, percebe-se que há uma tentativa do governo em 
tornar essa matriz de transporte eficiente, no entanto há uma deficiência na conclusão e na entrega das obras - estas sempre inacabadas - impossibilitando o desenvolvimento do transporte rodoviário de cargas no país.

0 investimento em rodovias foi um fator importante no desenvolvimento econômico e social do país a partir da década de 50. Esse progresso é garantido principalmente pelo transporte rodoviário de cargas, pois somente este consegue integrar todos os modais de transporte. Além disso, visa o escoamento dos produtos de um determinado polo para outro. 0 modal rodoviário no Brasil é o maior responsável pelo transporte de cargas, representando cerca de $61,10 \%$ e de passageiros $95 \%$ - Confederação Nacional do Transporte - CNT 2015.

Com base nos dados apresentados no site da Agência Nacional de Transportes Terrestre - ANTT - órgão que regulamenta e fiscaliza o transporte terrestre - o número de veículos cadastros no Registro Nacional de Transportadores Rodoviário de Cargas - RNTRC aumentaram significativamente. O RNTRC é obrigatório para que o transportador possa exercer sua atividade, este registro contempla transportadores cadastrados em três categorias, sendo estas: Transportadores Autônomos de Cargas TAC, Empresas de Transporte Rodoviário de Cargas - ETC, e as Cooperativas de Transporte de Cargas CTC.

No quadro abaixo (figura 1) são apresentado dados dos anos de 2010 a 2014. Em 2010 o quadro trás números de transportadores registrados e o total de veículos considerando tanto recadastramentos, novos registro e transportadores não recadastrados. Vale ressaltar que a partir de 2011 são apresentados números de transportadores registrados e o total de veículos que estão em conformidade com os novos requisitos estabelecidos pela nova resolução ANTT $n^{\circ} 3056 / 2009$. Neste são considerados apenas registros recadastrados e novos registros efetivos, não sendo considerados os transportadores não recadastrados e/ou cancelados.

Figura 1: Transportadores e frota registrados nos anos de 2010 a 2014

\begin{tabular}{|c|c|c|c|}
\hline \multicolumn{4}{|c|}{ ANO 2010 - DADOS RELATIVOS A 31/12/2010 } \\
\hline Tipo de Transportador & Número de Registros & Número de veículos & Veículos/Transportado \\
\hline TAC & 1.079 .094 & 1.141 .952 & 1,1 \\
\hline ETC & 206.524 & 973.335 & 4,7 \\
\hline CTC & 736 & 11.839 & 16,1 \\
\hline Total & 1.286 .354 & 2.127 .126 & 1,7 \\
\hline \multicolumn{4}{|c|}{ ANO 2011 - DADOS RELATIVOS A 31/12/2011 } \\
\hline Tipo de Transportador & Número de Registros & Número de Veículos & Veiculos/Transportado \\
\hline TAC & 540.388 & 749.400 & 1,4 \\
\hline ETC & 100.934 & 854.315 & 8,5 \\
\hline CTC & 278 & 11.496 & 41,4 \\
\hline Total & 641.600 & 1.615 .211 & 2,5 \\
\hline \multicolumn{4}{|c|}{ ANO 2012 - DADOS RELATIVOS A 31/12/2012 } \\
\hline Tipo de Transportador & Número de Registros & Número de Veliculos & Veficulos/Transportador \\
\hline TAC & 650.450 & 838.600 & 1,3 \\
\hline ETC & 119.230 & 971.653 & 8,1 \\
\hline CTC & 320 & 13.000 & 40,6 \\
\hline Total & 770.000 & 1.823 .253 & 2,4 \\
\hline \multicolumn{4}{|c|}{ ANO 2013 - DADOS RELATIVOS A 31/12/2013 } \\
\hline Tipo de Transportador & Número de Reglstros & Número de Veficulos & Vefculos/Transportador \\
\hline TAC & 756.867 & 926.437 & 1,2 \\
\hline ETC & 145.621 & 1.116 .722 & 7,7 \\
\hline CTC & 368 & 15.707 & 42,7 \\
\hline Total & 902.856 & 2.058 .866 & 2,3 \\
\hline \multicolumn{4}{|c|}{ ANO 2014 - DADOS RELATIVOS A 31/12/2014 } \\
\hline Tipo de Transportador & Número de Registros & Número de Veículos & Veiculos/Transportador \\
\hline TAC & $\mathbf{8 4 8 . 7 7 2}$ & 1.009 .860 & 1,2 \\
\hline ETC & 168.450 & 1.211 .601 & 7,2 \\
\hline СтC & 405 & 17.697 & 43,7 \\
\hline Total & 1.017 .627 & 2.239 .158 & 2,2 \\
\hline
\end{tabular}

O Brasil conta com uma frota de 2.317.653 veículos de carga registrados no ano de 2015 (ANTT 2015), transportando 485.625 toneladas - quilômetro útil - TKU, segundo a Confederação Nacional do Transporte - CNT 2015. 
Além da grande frota de veículos de carga, o Brasil possui uma extensa malha rodoviária com $1.720 .607 \mathrm{~km}$ no total, divididos em rodovias pavimentadas $213.299 \mathrm{~km}$, não pavimentada $1.353 .186 \mathrm{~km}$ e planejada $154.192 \mathrm{~km}$. A malha rodoviária brasileira torna-se reduzida se comparada com toda a extensão territorial do país. Uma vez que o Brasil não se encontra numa posição satisfatória no ranking de competitividade global do Fórum Econômico Mundial.

Segundo o relatório divulgado pela CNT em setembro de 2015, a qualidade das rodovias brasileira encontra-se na $121^{a}$ a posição dos 140 países analisados, atrás de países como Chile (35ํㅜ), Uruguai (95aㅡ),

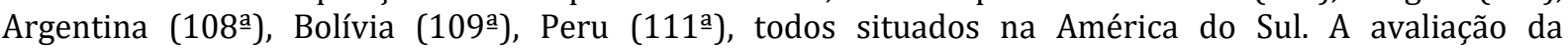
infraestrutura das rodovias utiliza notas que variam de 1 (extremamente subdesenvolvida - entre as piores do mundo) a 7 (extensa e eficiente - entre as melhores do mundo) e compreende o período de 2014 a 2015. Vale ressaltar que nesse índice de competitividade em questão, o Brasil recebeu a nota 2,7 (CNT 2015).

Ainda em 2015, foi feita uma pesquisa pela CNT (figura 2) onde foram avaliados $100.763 \mathrm{~km}$ de rodovias pavimentadas, incluindo toda a malha federal e as principais estaduais do país. Do total avaliado, 19,7\% (19.804km) são rodovias concedidas e 80,3\% (80.959) de gestão pública.

Figura 2: Classificação do Estado Geral - Gestões Concedida e Pública

\begin{tabular}{|l|r|r|r|r|}
\hline \multirow{2}{*}{ Estado Geral } & \multicolumn{3}{|c|}{ Gestä́ Concedida } & \multicolumn{3}{c|}{ Gestäo Pública } \\
\cline { 2 - 5 } & $\mathrm{km}$ & $\%$ & $\mathrm{~km}$ & $\%$ \\
\hline Ótimo & 7.415 & 37,4 & 5.225 & 6,5 \\
Bom & 8.084 & 40,9 & 22.380 & 27,6 \\
Regular & 3.808 & 19,2 & 31.297 & 38,7 \\
Ruim & 497 & 2,5 & 15.717 & 19,4 \\
Péssimo & - & - & 6.340 & 7,8 \\
\hline TOTAL & 19.804 & 100,0 & 80.959 & 100,0 \\
\hline
\end{tabular}

Percebe-se que as rodovias de gestão concedida apresentam resultados melhores, onde 78,3\% (15.499km) da extensão avaliada obtiveram avaliação positiva do estado geral, sendo classificadas como ótima ou boa. Em apenas 21,7\% há problemas, seja de pavimento, sinalização ou geometria e foram classificados em regular ou ruim.

Fazendo uma comparação desta com o estado geral das rodovias de gestão publica, geridas pelo governo, há uma situação inversa, em que a maioria da extensão 65,9\% (53.354km) apresenta algum tipo de deficiência e está classificada como regular ruim ou péssima. E somente 34,1\% (27.605km) da extensão pública foram classificadas como ótima ou boa.

Ao analisarmos os resultados por tipo de gestão, é possível compreender a importância do ente privado com relação à melhoria da qualidade das rodovias brasileiras. Assim, faz-se necessário que o governo crie cada vez mais projetos e mecanismos que possam captar recursos do setor privado para somar com recursos do governo e tornar o modal rodoviário efetivamente competitivo, sendo que este é o mais utilizado em nosso país.

Percebe-se que no Brasil, ainda existe uma grande diferença entre a quantidade de carga transportada pelo modal rodoviário em relação aos outros modais de transporte. Enquanto as rodovias levam 61,1\% da nossa carga, as ferrovias são responsáveis por $20,7 \%$, as hidrovias por $13,7 \%$, as dutovias por $4,2 \%$ e o modal aeroviário por $0,4 \%$ do transporte de cargas (CNT - 2015).

Diante do exposto, notamos que o modal rodoviário é o que transporta a maior parte do que é produzido, e não diferente dos demais modais, há riscos inerentes à atividade de transportes. Assim faz-se necessário que todas as cargas transportadas no modal rodoviário possuam seguro, pois, no país o mesmo é obrigatório tanto para o embarcador (quem manda a carga, na maioria das vezes o proprietário da carga) e o transportador (quem presta o serviço de transporte). 


\section{METODOLOGIA}

Essa pesquisa é de caráter bibliográfico, que incluiu livros, revistas especializadas, teses, artigos, reportagens, e consulta em sites de organizações envolvidas com o transporte rodoviário de cargas (portal do TRC, NTC \& Logística, ANTT, CNT, entre outros), gerenciamento de risco, órgãos governamentais, autarquias, companhias seguradoras e associações de classe, que disponibilizam, na Internet, informações atualizadas.

Optamos por uma por uma pesquisa descritiva, pois esta visa descrever todo o processo de gerenciamento de risco no transporte rodoviário de carga, identificando os mecanismos, as tecnologias utilizadas, os tipos de seguro, as características do modal rodoviário e posteriormente mostrar o funcionamento desse processo de acordo com os dados levantados.

\section{SEGURO NO TRANSPORTE RODOVIÁRIO DE CARGAS}

De acordo com a Superintendência de Seguros Privados - SUSEP4, a atividade seguradora no Brasil teve início com a abertura dos portos ao comércio internacional, em 1808. A primeira sociedade de seguros a funcionar no país foi a "Companhia de Seguros BOA-FÉ", em 24 de fevereiro daquele ano, que tinha por objetivo operar no seguro marítimo.

Neste período, a atividade seguradora era regulada pelas leis portuguesas. Somente em 1850, com a promulgação do "Código Comercial Brasileiro" (Lei $n^{\circ}$ 556, de 25 de junho de 1850) é que o seguro marítimo foi pela primeira vez estudado e regulamentado em todos os seus aspectos.

0 advento do "Código Comercial Brasileiro" foi de fundamental importância para o desenvolvimento do seguro no Brasil, incentivando o aparecimento de inúmeras seguradoras, que passaram a operar não só com o seguro marítimo, expressamente previsto na legislação, mas, também, com o seguro terrestre.

O mercado segurador brasileiro já havia alcançado desenvolvimento satisfatório no final do século XIX. Concorreram para isso, em primeiro lugar, o Código Comercial, estabelecendo as regras necessárias sobre seguros marítimos, aplicadas também para os seguros terrestres e, em segundo lugar, a instalação no Brasil de seguradoras estrangeiras, com vasta experiência em seguros terrestres.

O Decreto $\mathrm{n}^{\circ} 4.270$, de 10/12/1901, e seu regulamento anexo, conhecido como "Regulamento Murtinho", regulamentaram o funcionamento das companhias de seguros de vida, marítimos e terrestres, nacionais e estrangeiras, já existentes ou que viessem a se organizar no território nacional. Além de estender as normas de fiscalização a todas as seguradoras que operavam no País, o Regulamento Murtinho criou a "Superintendência Geral de Seguros", subordinada diretamente ao Ministério da Fazenda.

Com a promulgação da Constituição de 1937 (Estado Novo), foi estabelecido o "Princípio de Nacionalização do Seguro", já preconizado na Constituição de 1934. Em consequência, foi promulgado o Decreto ${ }^{\circ} 5.901$, de 20 de junho de 1940, criando os seguros obrigatórios para comerciantes, industriais e concessionários de serviços públicos, pessoas físicas ou jurídicas, contra os riscos de incêndios e transportes (ferroviário, rodoviário, aéreo, marítimo, fluvial ou lacustre), nas condições estabelecidas no mencionado regulamento.

Em 1966, através do Decreto-lei n 73, de 21 de 'novembro de 1966, foram reguladas todas as operações de seguros e resseguros e instituído o Sistema Nacional de Seguros Privados, constituído pelo Conselho Nacional de Seguros Privados (CNSP); Superintendência de Seguros Privados (SUSEP); Instituto de Resseguros do Brasil (IRB); sociedades autorizadas a operar em seguros privados; e corretores habilitados.

\subsection{TIPOS DE SEGUROS}

De acordo com o Guia do Transportador Rodoviário de Cargas - GTRC ${ }^{5}$ há três tipos de seguros no mercado de transporte de carga: um feito pelo embarcador e dois pelos transportadores. O Seguro Transporte Nacional é para o proprietário da carga. É obrigatório. O RCTR/C (Responsabilidade Civil do Transportador Rodoviário de Carga), também obrigatório, deve ser feito pela empresa de transporte, mas cobre apenas prejuízos pelos quais o próprio transportador seja responsável, como colisão, capotamento e

\footnotetext{
${ }^{4}$ http://www.susep.gov.br/menu/a-susep/historia-do-seguro

5 http://www.guiadotrc.com.br/lei/seguro.asp
} 
abalroamento. 0 terceiro, também feito pelas transportadoras, é opcional: RCF-DC (Responsabilidade Civil - Desaparecimento de Carga).

Ratificando, o Seguro Transporte Nacional contratado pelo embarcador é obrigatório e oferece cobertura completa, incluindo roubo e furto. Dependendo do caso a taxa pode chegar a $0,07 \%$ do valor da carga. 0 RCTR/C (Responsabilidade Civil do Transportador Rodoviário de Carga), contratado pelo transportador é obrigatório e cobre acidente cuja responsabilidade seja imputada ao transportador. Com taxa média de 0,013\% do valor da carga. O RCF-DC (Responsabilidade Civil - Desaparecimento de Carga), também contratado pelo transportador, porém é facultativo. Cobre o desaparecimento total ou parcial da carga por roubo ou furto. Com a taxa de $0,01 \%$ a $0,09 \%$ do valor das cargas, dependendo do risco.

Primeiramente, a seguradora e o embarcador (segurado) fazem um contrato de seguro que estabelece o pagamento do prêmió6para que a carga seja assegurada; a seguradora por sua vez, tem a obrigação de pagar ao embarcador determinada importância no caso de ocorrência de um sinistro. Este contrato é constituído de dois documentos principais, a saber: a proposta e a apólice. Na proposta, o embarcador fornece as informações necessárias para a avaliação do risco, e, caso a seguradora opte pela aceitação do mesmo, é emitida a apólice, formalizando o contrato. (Circular SUSEP 437/12). A apólice é o documento que formaliza o contrato de seguro, estabelecendo os direitos e as obrigações da sociedade seguradora e do segurado e discriminando as garantias contratadas. (Circular SUSEP no 308/05).

O seguro é importante por que garante o reembolso das reparações pecuniárias a que o segurado esteja obrigado, por força de lei, por perdas ou danos causados a bens e mercadorias pertencentes a terceiros e que lhe tenham sido entregues para transporte. Cobre os transportes por rodovia em território nacional, contra conhecimento de transporte rodoviário, nota de embarque ou ainda outro documento hábil, desde que aquelas perdas ou danos sejam decorrentes de acidentes ocorridos durante o transporte, tais como: colisão, capotagem, abalroamento, tombamento, incêndio ou explosão, exceto nos casos de dolo.

0 seguro se dá partir do momento em que os bens ou mercadorias são recebidos pelo transportador, no local de início da viagem contratada, e termina quando são entregues ao destinatário, no local de destino da mesma viagem.

\subsection{ALGUMAS MEDIDAS DE GERENCIAMENTO DE RISCO}

Vale ressaltar que as seguradoras, para as mercadorias específicas fixam, a seu critério, limites a partir dos quais só garantem a cobertura, se cumpridas pelo transportador uma série de medidas de gerenciamento de risco das quais as mais importantes são:

- $\quad$ Cadastro de Motoristas;

- $\quad$ Padronização de rotas com cercas eletrônicas;

- Padronização e controle de pontos de paradas dos veículos;

- Padronização e limite horário de tráfego permitido;

- Controle de velocidade dos veículos;

- $\quad$ Controle de pernoites;

- $\quad$ Controle de áreas de Riscos;

- $\quad$ Controle de abertura de portas do baú;

- Controle de desengates dos veículos;

- Controle do posicionamento dos veículos;

- Procedimentos de segurança quando ocorre acionamento do botão de emergência;

- Procedimentos/treinamentos de segurança para os motoristas;

- Serviço de apoio e atendimento aos transportadores e motoristas.

${ }^{6}$ Importância paga pelo segurado à seguradora para que esta assuma o risco a que o segurado está exposto. 
Tais medidas estão previstas no Plano de Gerenciamento de Risco. O PGR7 é o planejamento de todas as ações preventivas necessárias para o gerenciamento de riscos no transporte de cargas, de acordo com o grau de criticidade, o tipo de operação e a necessidade de cada cliente. Está baseado em detalhes do histórico de sinistralidade da mercadoria, do percurso, horários, opções do cliente, além de levar em consideração o Modus Operandi ${ }^{8}$ das quadrilhas envolvidas em roubos de carga.

\section{GERENCIAMENTO DE RISCO NO TRANSPORTE RODOVIÁRIO DE CARGAS - TRC}

De acordo com a NTC \& Logística (Associação Nacional do Transporte de Carga e Logística) ${ }^{9}$, Gerenciamento de Risco é a adoção de um conjunto de técnicas e medidas preventivas que visam identificar, avaliar e evitar ou minimizar os efeitos de perdas ou danos que possam ocorrer no transporte de mercadorias, desde a origem até o destino da carga, garantindo que o produto esteja no local desejado, dentro do prazo previsto e de acordo com sua conformidade.

Segundo Brasiliano (2006),

O Gerenciamento de riscos é o conjunto de ações que visa impedir ou minimizar as perdas que uma empresa pode sofrer tendo suas cargas roubadas, sem falar na possibilidade de perda de vidas. Através de prevenção de perdas são estudadas medidas para administrar e/ou reduzir a frequência e abrandar a severidade dos danos causados.

O gerenciamento de risco nos transporte rodoviário de carga faz-se importante, pois, como vimos acima, tem caráter preventivo e visa se antecipar a uma situação de risco em que o veiculo, motorista e carga possam se envolver durante toda a viagem. Essa importância do gerenciamento de risco fica comprovada diante dos dados apresentados com relação ao roubo de carga no Brasil (gráfico 1).

Gráfico 1: Dados estimados - rodovias e áreas urbanas entre 2009 e 2014

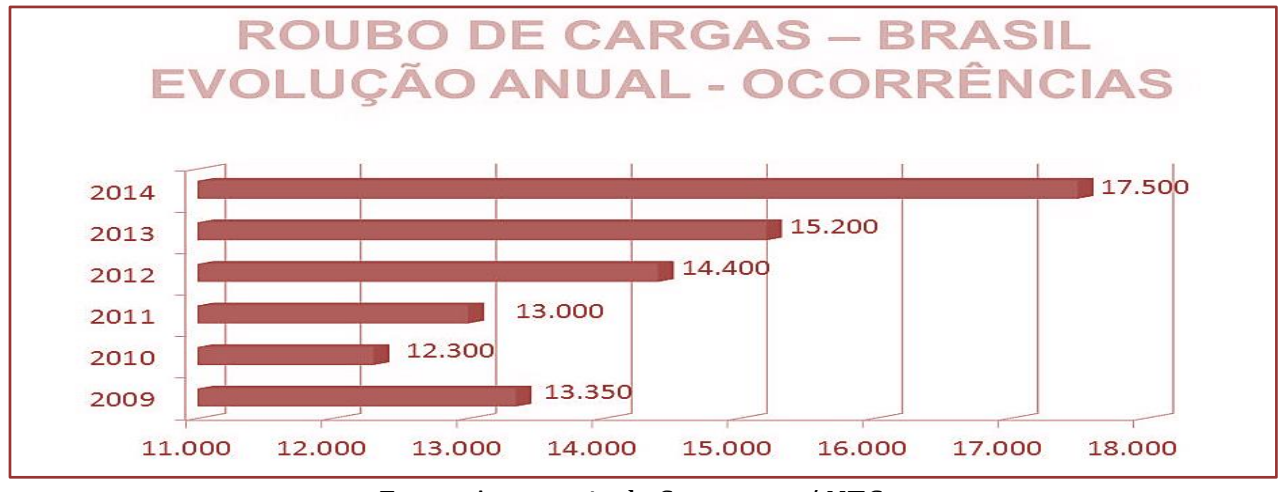

Fonte: Assessoria de Segurança / NTC

Percebe-se que, nos últimos anos, os índices de roubo de carga aumentaram significativamente (De acordo com gráfico 1). Esse cenário obriga as empresas a investir cada vez mais em tecnologias de rastreamento, monitoramento e seguro de carga. Visto que os valores subtraídos geram muitos prejuízos financeiros como vemos (gráfico 2) abaixo:

\footnotetext{
${ }^{7} \mathrm{http}: / /$ www.apisul.com.br/portal/apisul_download/linha_direta_ago_set_2011.pdf

8 É a forma de organização e de como agem as quadrilhas de roubo de carga em cada região.

${ }^{9}$ http://www.ntctec.org.br/media/files/paginas/o-gerenciamento-de-riscos-no-trc.pdf
} 
Gráfico 2: Dados estimados - rodovias e áreas urbanas entre 2009 e 2014

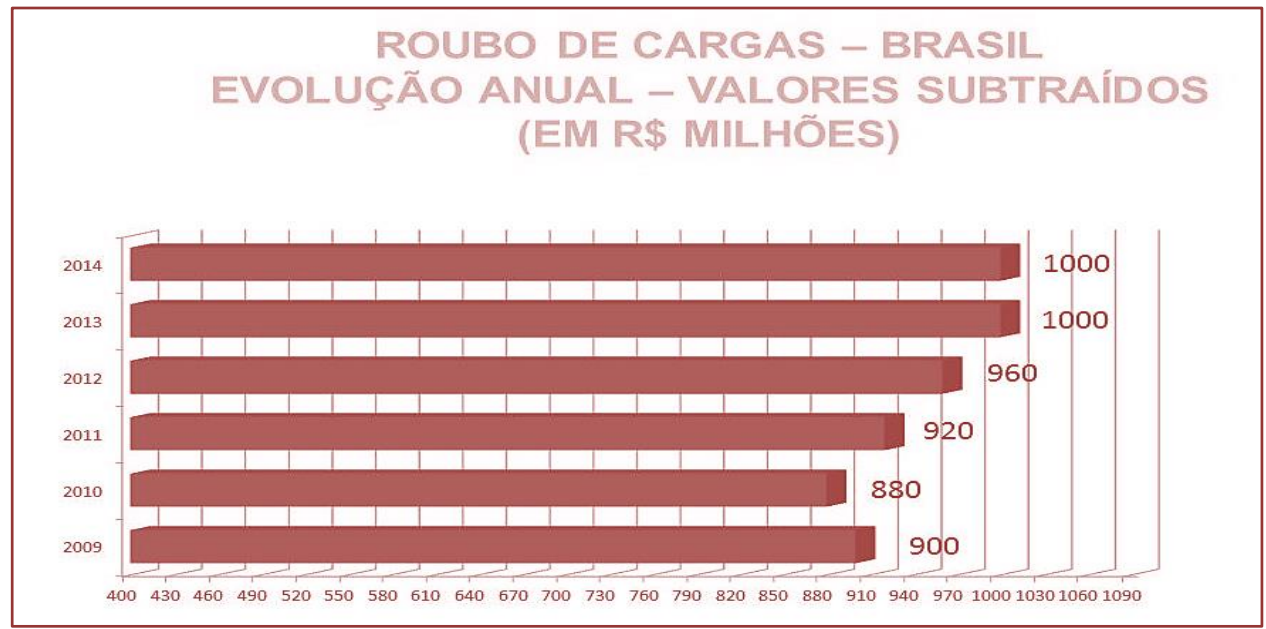

Fonte: Assessoria de Segurança / NTC

Diante desse quadro (gráfico 2) nota-se que as ocorrências de roubo de carga no Brasil diferem entre as regiões. Na região sudeste - com grande concentração de empresas - apresenta o maior índice de roubo de carga no Brasil como vemos no quadro (figura 3) a seguir:

Figura 3: Roubo de Carga no ano de 2014 em \% por região

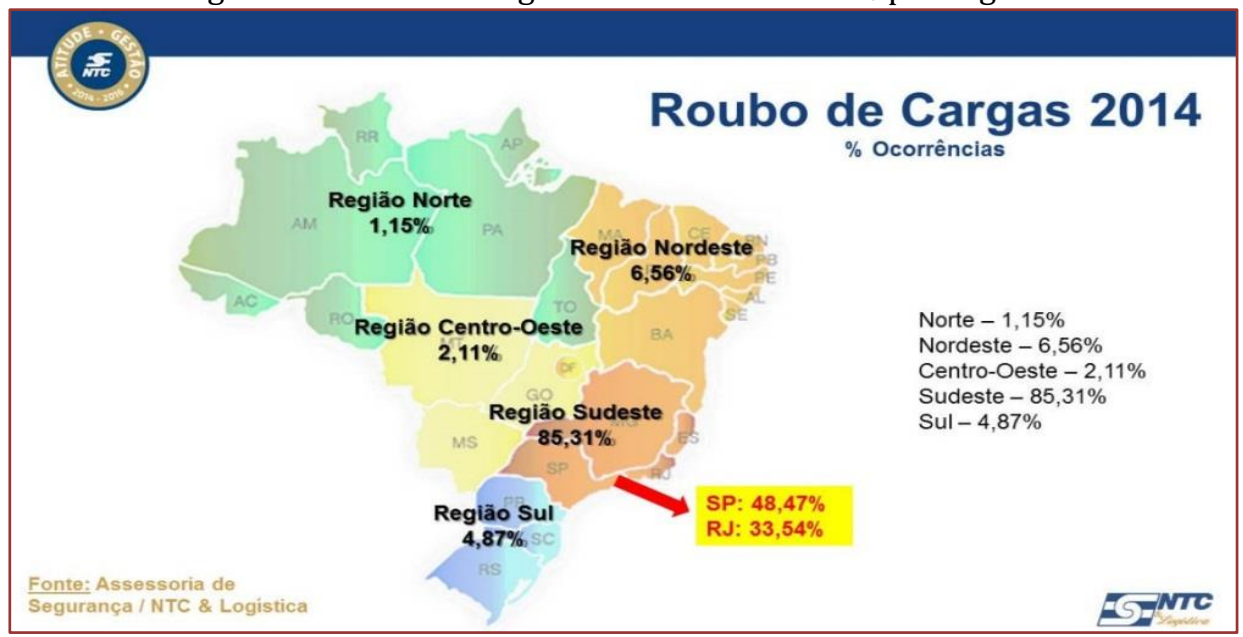

Fonte: Assessoria de Segurança / NTC \& Logística

\subsection{PROCESSOS DE GERENCIAMENTO DE RISCO NO TRANSPORTE RODOVIÁRIO DE CARGA - DO INICIO AO FIM DA VIAGEM}

0 processo de gerenciamento de risco inicia-se bem antes do veículo realizar o carregamento das mercadorias e seguir viagem. Primeiramente, há uma negociação entre o embarcador e o transportador para formalizar a negociação do serviço de transporte (frete). Nessa negociação, o embarcador apresenta o seu Plano de Gerenciamento de Risco - PGR para a transportadora e esta deve atender criteriosamente todas as normas e regras previstas no PGR.

O PGR apresenta as normas e regras que devem seguidas pela transportadora. Iniciando o processo o embarcador deve realizar o cadastro e consulta do motorista e do veículo (cavalo mecânico e carreta). A consulta é feita em um banco de dados da gerenciadora e em órgãos oficiais tais como: DETRAN, ANTT, SPC, PFR, TJ, e outros.

O objetivo dessa consulta é averiguar se o perfil do motorista está adequado ao risco. Logo depois desse cadastro e consulta é realizado o check-List de todos os equipamentos de rastreamento. Os veículos deverão estar equipados com sistemas de rastreamento reconhecidos e homologados pela Gerenciadora de Riscos, sensores e atuadores devem estar em perfeito funcionamento. 
Para que o monitoramento e rastreamento sejam plenamente executados são necessários, no veículo, os seguintes equipamentos, sensores e atuadores:

\section{Equipamentos:}

- $\quad$ OBC (Computador de Bordo);

- $\quad$ Antena de comunicação e de GPS;

- Teclado de Macros ou Alfanumérico;

- $\quad$ Equipamento Backup (recomendável);

Sensores:

- $\quad$ Ignição;
- $\quad$ Velocidade;
- $\quad$ Botão de Pânico;
- $\quad$ Proteção da Antena;
- $\quad$ Desengate (para veículos articulados);
- $\quad$ Portas de Cabine (Motorista e Carona);
- $\quad$ Porta do Baú Lateral e Traseira (aplicado ao perfil de carroceria);
- $\quad$ Temperatura (aplicado para cargas climatizadas, refrigeradas e/ou congeladas);

Atuadores:

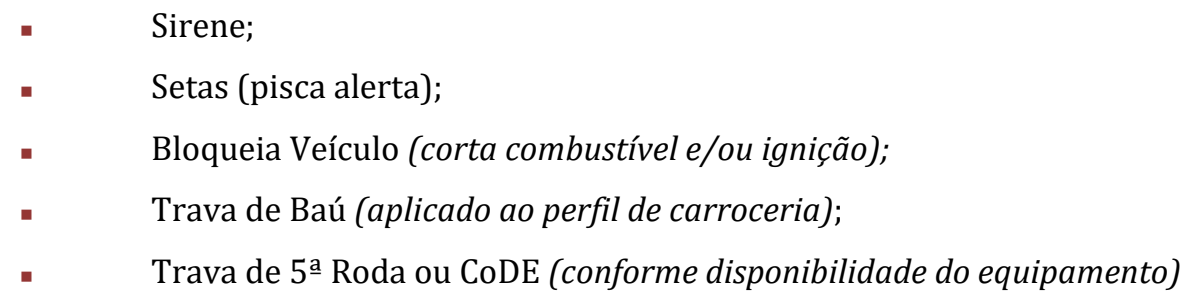

Durante o check list se for identificado algum problema no periférico ou antena do equipamento de rastreamento, o embarcador fica ciente que não é possível realizar os controles de risco sobre o mesmo até que este seja encaminhado para manutenção e posteriormente realizado todos os testes comprovando o funcionamento do periférico. Caso comprove algum defeito nesses equipamentos, o embarcador notifica a transportadora afim de que esta realize uma manutenção para liberação veiculo.

Após aprovação do veículo no check list, o embarcador faz a solicitação de monitoramento. Neste documento consta: dados do motorista e do veiculo; data e inicio de viagem; origem e destino; rota; locais, horários de paradas e pernoite. Além desses consta também dados referente à carga transportada: tipo do produto; valor; controle de temperatura (caso necessário); horário, data e endereço de entrega.

Com base nos dados da solicitação de monitoramento, a gerenciadora de risco cria o plano de viagem do veiculo. Porém, o motorista só poderá iniciar mediante o envio da macro inicio de viagem carregado para central de monitoramento. Ou seja, o motorista envia uma mensagem via terminal de comunicação (teclado) com sua senha, origem/destino e demais dados da carga/veículo. Assim, a central confronta os dados enviados pelo motorista com os da solicitação.

Com o veículo em trânsito, a gerenciadora é a responsável pelo monitoramento e rastreamento por todo o percurso da viagem; ela deve executar o PGR do cliente, além disso, assegurar que o motorista não irá descumprir as normas e regras estabelecidas no PGR. Por fim, cumprindo todas essas normas e regras, o motorista chega ao destino para a realização da descarga, solicitando, via teclado, a abertura da porta do baú. 


\section{TECNOLOGIA DE RASTREAMENTO E MONITORAMENTO}

As tecnologias de rastreamento e monitoramento de veículos são mecanismos do gerenciamento de risco. Ou seja, é através destas que as gerenciadoras de risco (central de monitoramento) acompanham e controlam a viagem do início ao fim. Durante todo o percurso o são controlados: locais de parada, pernoites, tempo em trânsito, aberturas de portas do veículo (cabine e baú). Também são mecanismos de gerenciamento de risco a consulta e cadastro de perfil do motorista, escolta armada e pronta resposta.

Os veículos de cargas devem possuir equipamentos rastreamento e monitoramento, pois através destes, as gerenciadoras acompanham e controlam o veículo (figura 4). Há no mercado muitas empresas especializadas em tecnologias de rastreamento e monitoramento que fornecem equipamentos de comunicação e segurança veicular. De forma geral, um sistema de rastreamento e monitoramento de um veículo é composto por: terminal de comunicação móvel (teclado); antena satelital, GPS, GSM/GPRS; bloqueador; sensores de porta da cabine, da porta do baú, do painel, de velocidade, de ignição e temperatura do baú.

Figura 4: Alguns sensores e atuadores instalados no veículo

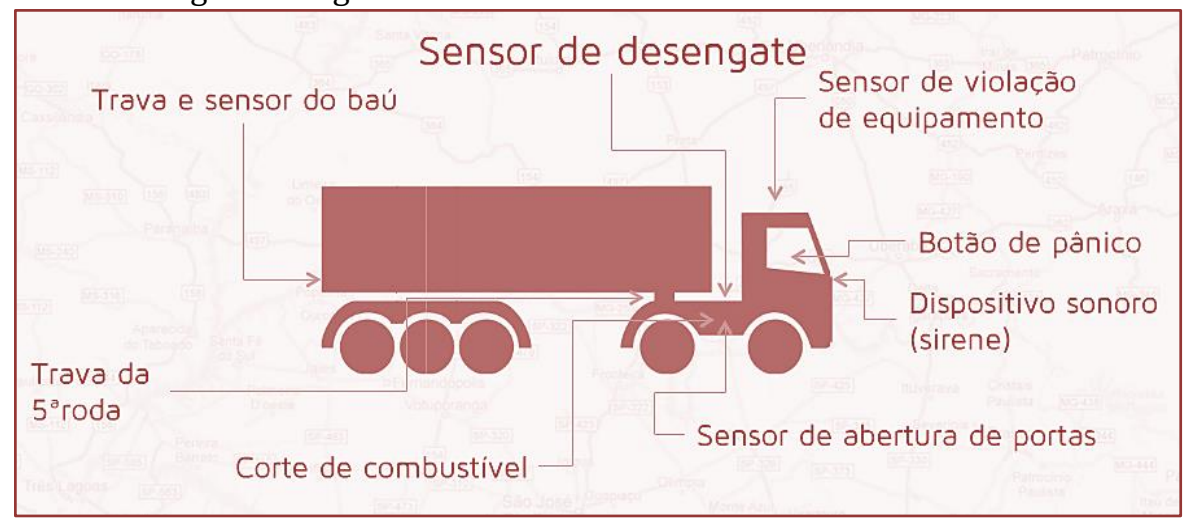

Fonte: Opentech

Estes equipamentos de rastreamento e monitoramento servem para comunicação e controle entre o terminal na base de operações da gerenciadora com o veículo e o motorista, como mostra a figura 5 abaixo:

Figura 5: Esquema de comunicação entre veiculo com a central utilizando satélite e GPS

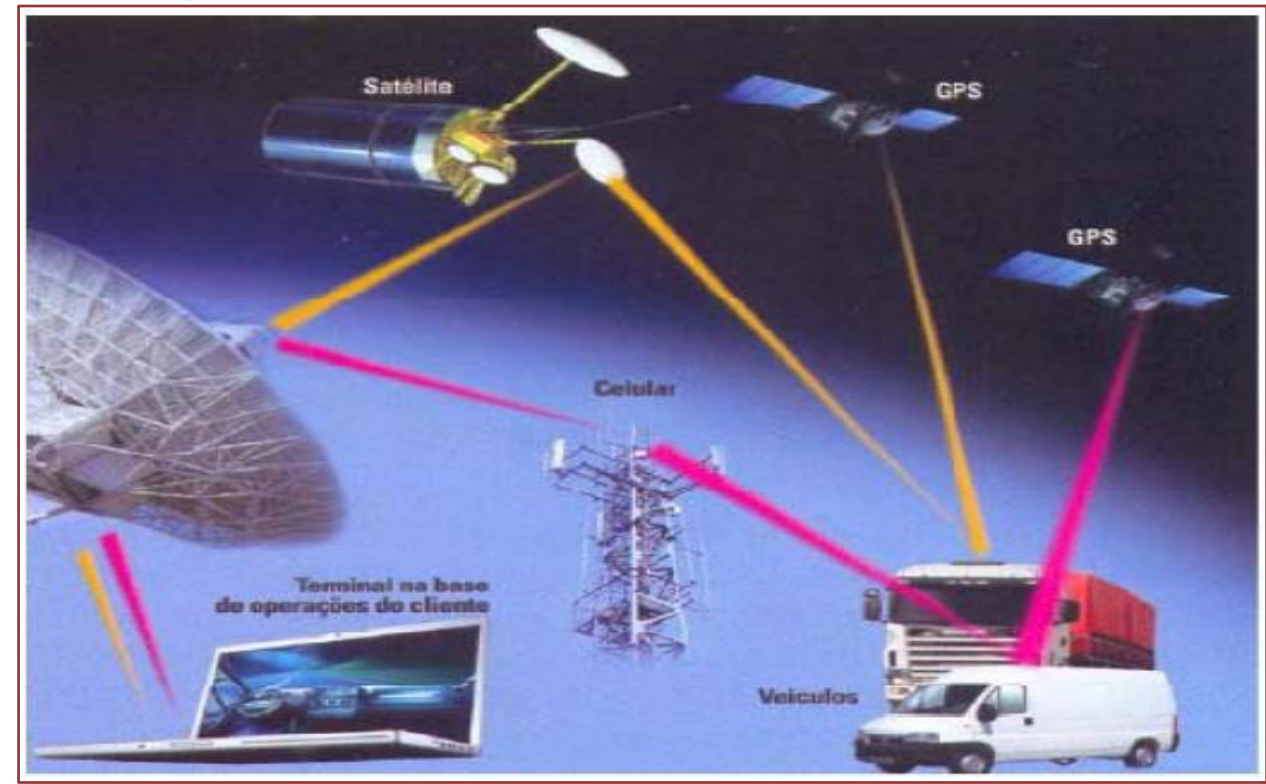

Fonte: anuário de gestão de frota 
De acordo com Anefalos (1999, apud REIS, 1997),

Os sistemas de rastreamento por satélites possuem três funções básicas: comunicação entre a estação de controle e os veículos; localização on-line dos veículos; controle da frota em relação aos elementos como nível de combustível, velocidade do veículo, temperatura do compartimento de cargas, fechamento das portas, entre outros.

A gestão logística apoiada pela tecnologia de rastreamento por satélite é uma área ainda pouco explorada pelos pesquisadores, é incomum a literatura científica a respeito do assunto e a maioria dos relatos advém de reportagens, revistas e sites especializados em logística e empresas em tecnologias de comunicação veicular.

Rodrigues (2006), afirma que o rastreamento vive um momento singular. A grande concorrência no mercado de rastreamento teve seu crescimento impulsionado pelo alto índice de roubos de veículos, isso pressiona a tecnologia envolvida nos rastreadores a oferecer mais que uma simples localização dos transportes, os benefícios oferecidos deverão ir além da segurança e serão as aplicações disponíveis pelos softwares os diferenciais competitivos dos rastreadores.

0 autor ainda ratifica que, segurança é apenas uma dimensão do rastreamento. Somado os custos do equipamento embarcado, há que extrair o máximo do investimento. É assim que se amplia o campo de aplicações, rumo à logística e à ampla gama de soluções corporativas.

Nesse contexto logístico, Alencar (2005), afirma que há duas razões principais para se acompanhar a execução das entregas das cargas: controle de produtividade e segurança. Para autor o controle é fundamental para a gestão logística e pode ser agilizado pela automação dos sistemas de monitoramento, é preciso acompanhar as informações, comparar o planejado com o executado a fim de melhorar o desempenho.

Mas para que isso aconteça, Drucker (2000) observa: "algumas fontes internas na empresa podem motivar a inovação: o sucesso ou fracasso inesperado, uma falha latente da organização e necessidade de aperfeiçoamento no processo". 0 evento externo inesperado e mudanças demográficas também podem ser um convite a inovar.

Assim, para que se tenha melhor êxito no gerenciamento risco é essencial que todos os envolvidos nesse processo tenham conhecimento das suas responsabilidades. Isto é, a transportadora deve oferecer veículos com equipamentos de rastreamento e monitoramento com tecnologias que permitam a comunicação entre a gerenciadora e o motorista. Este, por sua vez, deve manter essa comunicação com central através de mensagem enviadas pelo terminal e cumprir todas as normas e regras do PGR. A função da gerenciadora de risco é certificar de que esses equipamentos estão em condições funcionamento para seguir viagem; acompanhar todo o percurso da viagem; rastrear e monitorar todas as ações do veiculo/motorista e executar todas as normas e regras previstas no PGR do cliente. Este deve assegurar que a mercadoria entregue à transportadora está em plenas condições de seguir viagem.

\section{CONSIDERAÇÕES FINAIS}

Esse trabalho possibilita uma reflexão sobre todo o processo de gerenciamento de risco no transporte rodoviário de cargas. Apresentamos o mercado de transporte rodoviário de cargas no Brasil e todos os problemas de infraestrutura da malha rodoviária. Mostramos os tipos de seguros obrigatórios no transporte rodoviário de carga e apresentamos as tecnologias de rastreamento e monitoramento de veículos que funcionam como mecanismos do gerenciamento de risco.

0 trabalho mostrou como funciona o gerenciamento de risco no transporte rodoviário de cargas no Brasil. A operação inicia-se a partir do momento em que o embarcador contrata uma transportadora para levar uma carga de determinado um local a outro. Por sua vez, a transportadora deve atender a contratação com um veículo que possua equipamento de rastreamento e monitoramento e motorista com perfil adequado, ambos atendendo as normas e regras impostas pelo seguro, previsto no Plano de Gerenciamento Risco do embarcador.

Tudo isso é para que o consumidor final conheça todo esse processo e entenda que este pode acarretar aumentos no preço do produto final. Assim, percebe-se que quanto maior o risco para transportar determinada mercadoria, maior será os custos com segurança para que o produto seja entregue. Diante disso, vemos a importância do gerenciamento de risco no transporte rodoviário de carga no Brasil. Pois, as 
empresas estão cada vez mais preocupadas proteger suas mercadorias e se manter no mercado. Com isso, tem feito altos investimentos em tecnologias para rastrear e monitorar todo o percurso do veículo que transporta sua carga.

Como trabalhos futuros, pretendo desenvolver uma pesquisa mais aprofundada sobre os custos do gerenciamento de risco no transporte rodoviário de carga.

\section{REFERÊNCIAS}

[1] ALENCAR, Rui. Automação da Distribuição. Revista Logística Movimentação e Armazenagem de Materiais, São Paulo, 09 de Agosto de 2005.

[2] ANEFALOS, Lílian Cristina. Gerenciamento de Frotas do Transporte Rodoviário de Cargas Utilizando sistemas de Rastreamentos por Satélite. Dissertação de Mestrado em Economia Aplicada, Escola Superior de Agricultura Luiz Queiroz- Piracicaba, 134p.: il 1999.

[3] BRASILIANO, Antonio C.R. Gerenciamento de riscos no transporte rodoviário de cargas. Artigo disponível em <http://www.brasiliano.com.br/blog/?p=194>. Acesso em: outubro 2015.

[4] DRUCKER, P. F. Inovação e Espírito Empreendedor: Prática e Princípios. Editora Pioneira, $6^{\circ}$ Edição, Tradução de Carlos J. Malferrari, 2000.

[5] FILIPPE, Rômulo. A Força do Transporte, artigo da revista Caminhões. Ano I N 07- Novembro de 2005.

[6] MARQUES, Luis Ricardo Pedro. União Faz a Força, Artigo da Revista Logística no Brasil, 2006/7 Ano 2 N²2.

[7] REIS, N. G. dos. Estudos Técnicos do TRC: os rastreadores como ferramenta de logística e de segurança. São Paulo: NTC/ TM. 1997. 68 p.(mímeo).

[8] RODRIGUES, MARCOS. Professor da USP afirma que rastreamento vive momento singular, 28/08/2006. Disponível na Interne via <www.mundogeo.com.br/noticiasdiarias.php?id_noticia=6539>. Acesso em: 20 de nov. 2015.

[9] ANTT, Agência Nacional de Transportes Terrestres. RNTRC em Números. Disponível em<http://http://www.antt.gov.br/index.php/content/view/4969/RNTRC_em_Numeros.html>. Acesso em $15 / 12 / 2015$.

[10] APISUL, Linha Direta. Plano de Gerenciamento de Riscos. Plano de Gerenciamento de Riscos: integração tecnológica e excelência técnica a serviço da segurança. Disponível em < http://www.apisul.com.br/portal/apisul_download/linha_direta_ago_set_2011.pdf>. Acesso em 18/12/2015.

[11] ODALI, Bonfim. Seguros no transporte rodoviário de cargas. Disponível em <http://www.guiadotrc.com.br/lei/seguro.asp>. Acesso em 05/12/2015.

[12] SOUZA, Coronel Paulo Roberto. O Gerenciamento de Risco no TRC. Disponível em <http://www.ntctec.org.br/media/files/paginas/o-gerenciamento-de-riscos-no-trc.pdf>. Acesso em 05/12/2015.

[13] SUSEP, Superintendência de Seguros Privados. História do Seguro. Disponível em http://www.susep.gov.br/menu/a-susep/historia-do-seguro>. Acesso em 08/12/2015.

[14] CNT, Confederação Nacional do Transporte. Pesquisa CNT de Rodovias 2015. Disponível em <http://pesquisarodovias.cnt.org.br>. Acesso em 08/12/2015.

[15] OPENTECH, Gerenciamento de Risco. Alguns Itens do Sistema de Rastreamento e Monitoramento Instalados no Veículo. Disponível em <http://www.opentechgr.com.br>. Acesso em 20/12/2015. 


\section{Capítulo 13}

\section{O gerenciamento de riscos aplicado às organizações: integrando os silos do GRC}

Sérgio Luiz Hoeflich

Elenilson Oliveira Pinheiro

Marcelo D'Alessandro

Helios Malebranche

Resumo: 0 artigo apresenta um histórico da evolução da atividade de Gestão de Risco e o surgimento do Gerenciamento de Risco. Apresenta a estrutura organizacional da Governança, Risco e Conformidade (GRC), com a implantação nas empresas na abordagem tradicional, em áreas segregadas em forma de silos. Propõem uma abordagem orgânica do GRC integrando as dinâmicas do mapeamento, analise e tratamento dos riscos a partir de suas funções estratégicas, táticas ou operacionais. 0 uso deste método de abordagem no gerenciamento de risco conduz à prática sustentada do desempenho dos empreendimentos, promovendo mitigação dos custos da gestão e agregando valor ás atividades dos gestores de risco nas empresas.

Palavras-Chave: Gerenciamento de Riscos Orgânicos, Governança, Conformidade. 


\section{INTRODUÇÃO}

A Gestão de Risco teve o início de sua aplicação com base em técnicas específicas nos EUA e na Europa, a partir das décadas de 1950 e 1960. Nessa época, as empresas atuantes no setor de seguros assessoravam as empresas públicas e privadas na colocação do risco de seus ativos em apólices específicas de seguro [29]. Já nas décadas de 1960 e 1970, através da Risk Insurance Management Society (RIMS), entidade com mais de 80 anos de existência nos EUA, se difundiu a Gestão de Risco, cujo canal de informação e conhecimento técnico e de implantação eram as seguradoras e os corretores, ambos representando os maiores interessados em divulgar e promover as atividades conhecidas como Gestão de Risco e Gerenciamento de Risco [26,27]. No Brasil, no início dos anos 1980, um pequeno grupo de empresas vinculado à Federação das Indústrias do Estado de São Paulo (FIESP) foi o pioneiro em adotar no País essa cultura de Gestão de Risco, tendo formado em 1983 a Associação Brasileira de Gerência de Risco (ABGR). [29]

Para os fins deste artigo, consideramos o conceito Gestão como uma expressão mais ampla, mais abrangente e superior, sendo função direta dos executores, mesmo que não sejam gerentes ou administradores, cujo compromisso precípuo é obter os melhores resultados ou ampliar a qualidade dos processos e produtos. De outro modo, o termo Gerenciamento está associado à atividade de gerentes e diretores, sendo mais específica, setorizada e fortemente associada às atividades de controle executivo realizado por gerências e diretorias. É uma ação específica de setores executivos, dos administradores das organizações. [20]

VALERIANO (2005) define a Administração como a ciência que trata dos problemas típicos das empresas, tais como os recursos financeiros, recursos patrimoniais e recursos humanos, ou talentos. É a responsável pela criação de um ambiente favorável e é correspondente aos termos Administrar e Administrador. 0 Gerenciamento trata de níveis específicos da organização, tais como departamentos ou divisões, assim como também é usual no âmbito de projetos, correspondendo aos termos Gerenciar e Gerente. 0 Gerenciamento empenha aos processos de Gestão a característica de ação de continuado aperfeiçoamento, com vistas ao cumprimento da missão da empresa. Já o termo Gestão trata de níveis especializados, tanto no que diz respeito à administração, quanto ao gerenciamento. Como exemplo, a gestão em projetos, trata da gestão dos custos, da qualidade ou dos riscos, dentre outras, e tem como terminologias correspondentes a gerir e ao gestor. Assim, o termo Gestão empenha significado às ações diretas nos processos, para o cumprimento de metas previamente estabelecidas.

A associação das empresas à ABGR se ampliou, atingindo elevado número de interessados na Gestão de Risco nos anos 1990 e 2000. A figura do gerente de risco surgia de forma insipiente no cenário econômico, com poucos profissionais especializados em gerenciar riscos, identificando-os e tratando-os. Os profissionais que se especializaram fora do Brasil em empresas multinacionais realizavam treinamentos técnicos adequados à implantação da Gestão de Risco, considerando os parâmetros internacionais que deveriam ser adequados à realidade nacional.

A ABGR [29] foi a precursora da divulgação da Gerência de Risco no Brasil. Realizou a promoção da atividade através de seminários internacionais, nos mesmos moldes dos realizados nos EUA, utilizando a premissa de que as empresas, de forma geral e independentemente da atividade que desenvolvessem, necessitavam proteger seus patrimônios, transferindo os riscos físicos e catastróficos para as seguradoras. As seguradoras tinham interesse comercial para, através da rede de corretores de seguros, atender às demandas dos clientes no gerenciamento de seus riscos. Os corretores e seguradores apoiavam as empresas que sustentavam as boas práticas de Gestão de Risco.

Até o início do século XXI, a profissão de gerente de risco não era conhecida e, muito menos, reconhecida pelas autoridades ou organizações brasileiras. [29] 0 gerente de risco era um profissional que se apresentava como gerente de seguros ou responsável por seguros dentro das organizações e tinha diretrizes determinadas pelas matrizes localizadas no exterior, que mantinham essa prática corporativa em âmbito global. As empresas brasileiras não tinham essa prática, nem tão pouco interpretavam a atividade gerencial em seguros como sendo estratégica nos anos 1990 e 2000. A partir da ampliação das atividades da ABGR no País, bem como da promoção de seminários técnicos apoiados por seguradoras e corretoras com as mesmas características da RIMS dos EUA, foi despertado nas empresas brasileiras o interesse na área Gestão de Riscos, envolvendo tanto o tratamento quanto, principalmente, a transferência dos riscos para o mercado segurador, tornando-se este um parceiro das empresas contratantes. 
Em meados de 2002 a ABGR propõe ao então Ministério do Trabalho e Emprego (MTE) a formalização do cargo de Gerente de Risco. Esta iniciativa pioneira fez com que esse cargo, tivesse destaque no conjunto de funções e tarefas, desde o planejamento, a implantação, o desenvolvimento e a condução da gestão de riscos. Apoiada pela RIMS nos EUA a ABGR atuou na adequação da filosofia e forma de trabalho dos profissionais gerentes de risco. Ainda em 2002, nos EUA foi denunciado o maior evento de corrupção do mercado financeiro registrado até aquela data, fato que envolvia as empresas Enron, Worldcomp e Tyco. Esses fatos desencadearam nos EUA a preocupação de que gerenciamento de risco não poderia mais ser uma prática eventual, mas uma atividade de gestão a ser implantada de forma obrigatória e normatizada nas empresas. Em 30 de julho de 2002 foi aprovada nos EUA a lei conhecida por Sarbanes-Oxley ou apenas SOX, motivada por escândalos financeiros e visando melhor governança das empresas. LEOPOLDI (2009) identifica as repercussões dessa Lei que cria mecanismos de auditoria e comitês de supervisão de operações, mitigando fraudes e riscos aos negócios, além de promover a transparência na gestão das empresas. A SOX afeta o mercado brasileiro, pois atinge grandes empresas brasileiras com títulos negociados na bolsa de Nova Iorque (NYSE. Nessa Lei se destaca a gestão de risco operacional que, de forma simplificada, se traduz em boas práticas de finanças envolvendo fraude e especificamente ética contábil. Segundo sugere HOEFLICH et al. (2014), os riscos operacionais são aqueles relativos aos que impactam nos balançoes e são de natureza financeira, que determinam o valor de mercado de uma empresa e geração de caixa operacional (IBGC, 2007) e que podem ser formalizados nos demonstrativos contábeis e a avaliados nos balanços financeiros.

Quando a SOX foi implantada nas empresas norte americanas atuantes no Brasil, ainda era ainda ignorada por quase totalidade das empresas aqui sediadas, exceto por aquelas com títulos negociados na NYSE. Gradativamente essa lei foi sendo voluntariamente adotada por algumas das grandes empresas brasileiras. Entre 2002 e 2005 o mercado brasileiro ainda desconhecia ou questionava a função do Gerente de Risco e sua missão de implantar a gestão de riscos alinhada às estratégias das empresas. Desta forma, o trabalho era mais abrangente que a simples conformidade no cumprimento da SOX, que mencionava apenas práticas contábeis. Mais que isso, o gerente de risco deveria atender e apoiar os trabalhos de controles internos, implantando ferramentas de monitoração e controle de risco, além dos planos de mitigação de riscos e de gestão de crise.

Em meados de 2004, obrigadas pelo marco regulatório do mercado de ações, as empresas brasileiras listadas na NYSE deveriam ser fiscalizadas pelas empresas de auditoria e, assim, tiveram que criar áreas específicas para a gestão dos riscos, além de contratar técnicos com formação específica, para adequaremse à Lei SOX. Desta forma, entre 2004 e 2006, verificava-se a escassez de profissionais especializados no gerenciamento de risco operacional no mercado brasileiro, para o atendimento às solicitações dos auditores externos. Acrescente-se ainda que os profissionais de risco qualificados no exterior não conheciam em profundidade a complexidade das práticas contábeis brasileiras e detalhes da economia do País. Essa insuficiência de qualificação fez com que auditores nacionais enfrentassem o desafio de ocupar essa função, visando atendimento à conformidade operacional das normas americanas.

A pouca oferta de profissionais qualificados para o gerenciamento de riscos fez com que já em 2006 se verificasse no mercado que as empresas de auditoria eram contratadas por empresas públicas e privadas, para também atuar no mapeamento e na gestão de riscos, dada a dificuldade de constituírem gerências próprias que internalizassem essa função. De 2006 em diante a Gestão de Risco se apresenta de forma fragmentada e em sua maioria sendo aplicada apenas em departamentos específicos das empresas. Várias áreas dessas empresas necessitavam da aplicação de metodologias de Gestão de Risco de forma corporativa, mas a Gestão de Riscos continuava pulverizada nas áreas das organizações, devido à escassez de profissionais especializados.

\section{GERENCIAMENTO DO RISCO, GOVERNANÇA E CONFORMIDADE}

Tendo superado a definição dos conceitos e o histórico da terminologia relativa a Administração, Gestão e Gerenciamento, há que se pacificar a terminologia aplicada especificamente ao Gerenciamento de Riscos. Assim, segundo HEAD (2009), a "Gerência de Riscos é o processo de planejar, organizar, dirigir e controlar os recursos humanos e materiais de uma organização, no sentido de minimizar os efeitos dos riscos sobre essa organização, ao mínimo custo possível".

Para Fox (2013) existem várias ferramentas para redução do risco, os controles internos são mecanismos de controle que suportam tanto o processo de risco como de governança empresarial. Os controles auxiliam as organizações na luta contra a corrupção e, consequentemente, a mitigação de riscos da organização neste último aspecto, denominados de FCPA (Foreign Corrupt Practices Act). 
0 autor sugere em sua obra que manter um sistema de controles internos eficiente permite fornecer razoável garantia de que as operações são executadas em conformidade com a autorização, regras geral ou específica da gestão e, são registradas conforme necessário, a fim de permitir a preparação das demonstrações financeiras em conformidade com os princípios contábeis geralmente aceitos ou quaisquer outros critérios aplicáveis a tais declarações e manter a prestação de contas para ativos.Quanto ao acesso as informaç̧ões dos ativos, este é permitido apenas nos âmbitos da administração geral ou autorização específica; e a prestação de contas dos ativos é comparado com os ativos existentes nos registros periódicos e as diferenças comentadas. Tudo isso significa mais do que simplesmente ter um programa de conformidade, menciona Fox (2013). Menciona ainda que o Conselho deve ser exercida uma supervisão adequada do programa de conformidade e sua função e precisa fazer as perguntas difíceis e ser plenamente informado sobre a conformidade da estratégia global da empresa, daqui para frente.

Nos anos 1980 já havia sido criada nos EUA uma organização privada visando a prevenção de fraudes nos processos internos das empresas americanas: COSO - Committee of Sponsoring Organizations of the Treadway Commission. Em relação a controles, o modelo COSO frequentemente retrata controles internos, a fim de delimitar o ambiente de controle, a avaliação de riscos, as atividades de controle, a informação e a comunicação, e o monitoramento. Na atualização de 2013 do COSO, sua estrutura básica foi mantida enquanto acrescentaram-se três objetivos específicos, sendo o primeiro relativo à eficácia e à eficiência das operações, incluindo a salvaguarda de ativos contra perdas. 0 segundo objetivo é relativo às comunicações internas ou externas realizadas a partir de relatórios financeiros. E, finalmente, o terceiro objetivo é a conformidade, que significa a aderência às leis e regulamentos a que a organização está sujeita.

\subsection{A GESTÃO DO RISCO}

A função de gerente de risco vem se desenvolvendo a partir de uma visão inicial de prevenção de perdas e se amplia na condição de agregar valor aos negócios, premida pela necessidade de se ter um agente responsável pela administração dos processos críticos para o sucesso da empresa. Esta percepção, uma evolução da ideia anterior de apenas reagir aos efeitos dos riscos, tem sido o fator de demanda de uma nova abordagem dos riscos a partir de uma visão estratégica, não apenas numa ação tática ou mesmo operacional.

Assim, com as mudanças e evolução das exigências, em face de contínua ampliação da complexidade dos processos organizacionais, o perfil do gestor de risco vem evoluindo para o de um profissional com foco na gestão integral dos riscos, a partir de uma visão estratégica. A função de Gerente de Riscos Corporativos vem se desenvolvendo a partir da evolução da complexidade das atividades de planejamento dos controles dos riscos, premida pela necessidade de se ter um agente responsável pela administração dos processos críticos para o sucesso da empresa.

Ainda em fase de inserção no mercado de trabalho brasileiro, a profissão de Gerente de Risco ganha espaço cada vez mais nas empresas, independentemente de porte ou segmento de atuação. A principal atribuição confiada a esse profissional é mapear, mitigar, transferir e gerenciar todos os riscos que possam afetar diretamente a continuidade do negócio ou causar impacto importante nos resultados operacionais das empresas. Isso significa dizer que é parte principal da atividade do Gerente de Risco, ter conhecimento amplo de todas as atividades relacionadas à empresa. Essa característica exige do profissional uma interrelação com todos os departamentos da organização, possibilitando assim que esse profissional entenda os riscos de cada área e, dessa forma, possa iniciar o processo de tratamento dos riscos, viabilizando sua redução, mitigação e transferência, se utilizando de ferramentas disponíveis do mercado.

Em termos práticos, o profissional de Gestão de Risco já existe no Brasil desde os anos de 80, quando as empresas já faziam parte do "Grupo de Seguros 80 " e se dedicavam à Gestão de Riscos de forma pontualmente operacional e não adotavam ainda o moderno conceito de ERM (Enterprise Risk Managment), conhecido atualmente como gestão integral de riscos corporativos. Isso ocorria porque as empresas culturalmente não trabalhavam no formato corporativo e sim de resultado individual por área de atividade e custo.

A função do Gerente de Risco foi regulamentada em 2002 junto à CBO (Classificação Brasileira de Ocupação) com apoio e participação ativa da ABGR (Associação Brasileira de Gerencia de Risco) que, inclusive, se aproximou de entidades latino-americanas como a ALARYS (Associacion Latino Americana de Riesgos y Seguros) para apoiar na formação dos profissionais dedicados à Gestão de Risco, pois até aquela data não havia nenhuma entidade no mercado brasileiro para formar Gerentes de Risco. 
Com a internacionalização das empresas brasileiras e a necessidade de regulamentação junto ao mercado americano, nos anos 2000 aumentou a necessidade das empresas de manterem um profissional e uma área de risco dedicada à Gestão de Risco. Entre 2004 a 2006 a empresa de auditoria KPMG gerou dois importantes relatórios mencionando a falta de profissionais e a existência da área de risco em inúmeras empresas brasileiras, além do fato de que havia apenas uma promessa de que tal profissional seria contratado e a área seria estabelecida. Desde aquele momento, iniciou-se uma visão confusa entre funções e atribuições do Gerente de Risco, pois o próprio relatório mencionava que, na falta de profissionais específicos em Gestão de Risco, os próprios auditores estavam assumindo esse papel dentro das empresas conforme, consta no relatório da KPMG (2013).

Verificada a necessidade de profissionais de risco no mercado, as empresas começam a se organizar em meados de 2004 e a inserir em seu organograma uma gerência específica ou, até mesmo, uma diretoria de risco. Comitês de Risco foram formados para a tomada de decisão relativa aos principais riscos das empresas, em plena conformidade com a regulamentação exigida pela CVM (Comissão de Valores Mobiliários) e pela NYSE. Com a falta de um correto entendimento da função do Gerente de Risco, bem como com a escassez desse profissional no mercado, auditores começam a absorver essas funções dentro das empresas, face à imposição de regulamentações que pressionam os executivos e, mesmo sem entender bem a sobreposição de funções, aceitam os auditores como agentes que mapeiam os riscos e ao mesmo tempo fazem a auditoria dos mesmos, num ciclo completamente fragilizado de trabalho.

A ocorrência da fragilidade da sobreposição dessas funções foi verificada em 2001, quando as empresas ENRON E WORLD COMP geraram informações falsas em seus balanços, sob auditoria da empresa Arthur Andersen. 0 mundo passou a conhecer a partir de 2001 a maior regulamentação de empresas listadas em bolsa de valores nos EUA, a Lei SOX. Significava que naquele momento se estabelecia a necessidade das empresas estabelecerem uma Governança Corporativa para controle de fraudes financeiras e que os executivos respondessem civil e criminalmente pelos seus atos. Esse marco também acelerou a contratação de profissionais de Gestão de Risco, onde permaneciam indefinidos os responsáveis pela área de riscos.

\subsection{GOVERNANÇA E CONFORMIDADE}

Segundo o IBGC (2007), o objetivo da Governança Corporativa é criar um conjunto eficiente de mecanismos, tanto de incentivos quanto de monitoramento, a fim de assegurar que o comportamento dos administradores esteja sempre alinhado com o melhor interesse da empresa. Com um aumento no ativismo entre os acionistas e um maior controle das entidades reguladoras, os órgãos sociais e equipes de executivos estão mais focados do que nunca em questões relacionadas à governança. 0 processo de governança dentro da organização inclui elementos tais como a definição e comunicação de controle societário, as principais políticas, gerenciamento de riscos corporativos, gerenciamento de regulamentação e conformidade. e supervisão; Envolvendo desde questões éticas, até as opções de conformidade, assim como a supervisão geral de questões regulatórias e avaliação desempenho dos negócios, através de ferramentas específicas para análise avaliação dos riscos. Um processo de governança corporativa integra todos esses elementos de forma coerente.

Segundo a Associação Brasileira de Bancos Internacionais (ABBI, 2009) a função de Conformidade (Compliance) é a integração das boas práticas da função de Compliance, com as boas práticas de Governança Corporativa com as de Gestão de Riscos". 0 termo Compliance vem do verbo em inglês "to comply", que significa "cumprir, executar, satisfazer, realizar o que lhe foi imposto", desta forma, compliance é o dever de cumprir, estar em conformidade e fazer cumprir regulamentos internos e externos impostos às atividades da instituição. A aprovação da Lei 12.846/14, denominada de Lei Anticorrupção ou Lei da Empresa Limpa, instituiu a formalização da prática da conformidade nas empresas brasileiras e tem como principal consequência a possibilidade de responsabilização objetiva das empresas envolvidas em práticas nocivas ao patrimônio púbico. Essa lei abre a possibilidade de punição às empresas por atos de corrupção contra a administração pública, sem a necessidade de comprovação de dolo dos dirigentes ou proprietários. Considere-se que, conforme expressamente registrado na Lei, a responsabilidade individual de dirigentes, administradores ou de qualquer pessoa física envolvida em ato ilícito não é excluída pela responsabilização da empresa. 
Quando uma organização está lidando com várias fontes de regramentos ao mesmo tempo, um processo de racionalização do gerenciamento da conformidade com cada uma dessas iniciativas é fundamental, ou então, os custos podem assumir uma espiral fora de controle e o risco de descumprimento do regramento aumenta. 0 processo de conformidade permite que as organizações tornem o cumprimento repetível e, portanto, permite-lhes uma sustentação em base contínua e a um custo menor.

\section{GESTÃO DE RISCOS NO BRASIL}

A Gestão de Risco nas empresas brasileiras tem sido adotada de forma a dar cumprimento à regulamentação, buscando ser atendido ao silo referente ao Compliance. Esta visão ex post aos eventos permite pouca margem de manobra para se aproveitar as oportunidades que uma gestão integral dos riscos oferece como diferencial competitivo. A criação das estruturas de gestão de riscos tem sido organizada como consequência de um evento que causou impacto negativo no empreendimento e ativa uma postura prioritariamente reativa, que exige uma resposta às perdas que forma impostas ao negócio.

A percepção do mercado é ainda que, mesmo com diversos eventos de sinistros catastróficos, continua sendo de que a prevenção dos riscos é uma despesa dispensável, devido ao absoluto desconhecimento dos riscos a que o negócio está exposto. 0 mapeamento e análise dos riscos são substituídos pelo sentimento e pela intuição do gestor, que são notadamente supervalorizados, em comparação com as técnicas e ferramentas disponíveis de gestão dos riscos. A consciência dos gestores sobre a relevância da combinação entre metodologia (técnicas e ferramentas) e intuição (arte), costuma ser despertada somente após os prejuízos causados pelos sinistros.

0 apetite ao risco faz com que os riscos sejam percebidos primordialmente sob a forma do retorno positivo esperado, sendo considerados pouco relevantes os possíveis prejuízos. Essa cultura empresarial, que se pode chamar de "orientada aos resultados", costuma ofuscar as perdas, pela incorporação aos custos totais, e realçar os lucros, causando certa miopia nos administradores e empreendedores.

As demandas do mercado relativas à transparência e à sustentabilidade das empresas, juntamente com as regras exigindo processos de governança corporativa, têm impactado na mudança do comportamento dos gestores. Estas alterações no cenário empresarial estão resultando em alterações de percepções sobre o gerenciamento dos riscos, sendo relevante aproveitar a oportunidade para se oferecer ferramentas de gestão dos riscos que sejam ao mesmo tempo efetivas e de custo adequado para a sua implantação. Esta é motivação para a apresentação de um framework que integre os processos de gestão riscos que são tradicionalmente geridos em silos, cujos custos são ampliados pela estrutura difusa e pouco sinérgica entre as diferentes áreas das empresas.

\subsection{PROBLEMAS DA GESTÃO DE RISCOS EM SILOS}

0 risco dentro de uma empresa pode ter origem em várias fontes, incluindo fusões e aquisições (que exigem ampla integração em uma unidade de negócios), novos regulamentos (que podem estar sujeitos a diferentes interpretações) ou na entrada de uma empresa em um novo mercado. Com a implementação de uma estrutura de gerenciamento de risco empresarial (Enterprise Risk Management - ERM), as organizações podem reduzir a probabilidade de eventos de negócios disruptivos inesperados em seu ambiente. Como resultado, elas podem aumentar suas margens operacionais, reduzir a volatilidade dos resultados, aumentar a eficiência dos processos, melhorar a conformidade regulatória e otimizar as reservas de fluxo de caixa.

0 crescimento do ambiente regulatório, a superior complexidade dos negócios e um maior enfoque na responsabilização levaram as empresas a buscarem uma ampla gama de iniciativas de governança, risco e conformidade em toda a organização. No entanto, essas iniciativas não são coordenadas ou integradas, mesmo em uma era em que os riscos são interdependentes e os controles são compartilhados. Como resultado, essas iniciativas são planejadas e geridas em silos, o que aumenta potencialmente o risco global de negócios para a organização. Além disso, as iniciativas de conformidade e de risco quando conduzidas em paralelo, levam à duplicação de esforços e de custos, em uma espiral fora de controle. 0 gerenciamento de Governança, Risco e Conformidade (GRC) é o processo de identificação, controle, definição, execução e monitoramento, com a capacidade de coordenar e integrar essas atividades. 


\section{PROPOSTA DE FRAMEWORK DE GRC INTEGRADO}

O processo de integração de práticas de GRC deve ser um meio e não um fim. 0 valor real pode ser agregado quando e se todas as partes interessadas venham a trabalhar integradas uma à outra, e estabeleçam metas para dar passos práticos e criem medidas de desempenho referentes à integração. Desta forma, se propõe alinhar a gestão de risco com os aspectos definidos pela ação estratégia e na gestão de desempenho empresarial, sendo relativos à integração eficaz as atividades relativas à conformidade (compliance).

Com este propósito de integrar as atividades rompendo os silos das funções do GRC é que se propõem o framework a seguir.

Figura 1: GRC em Silos Integrado

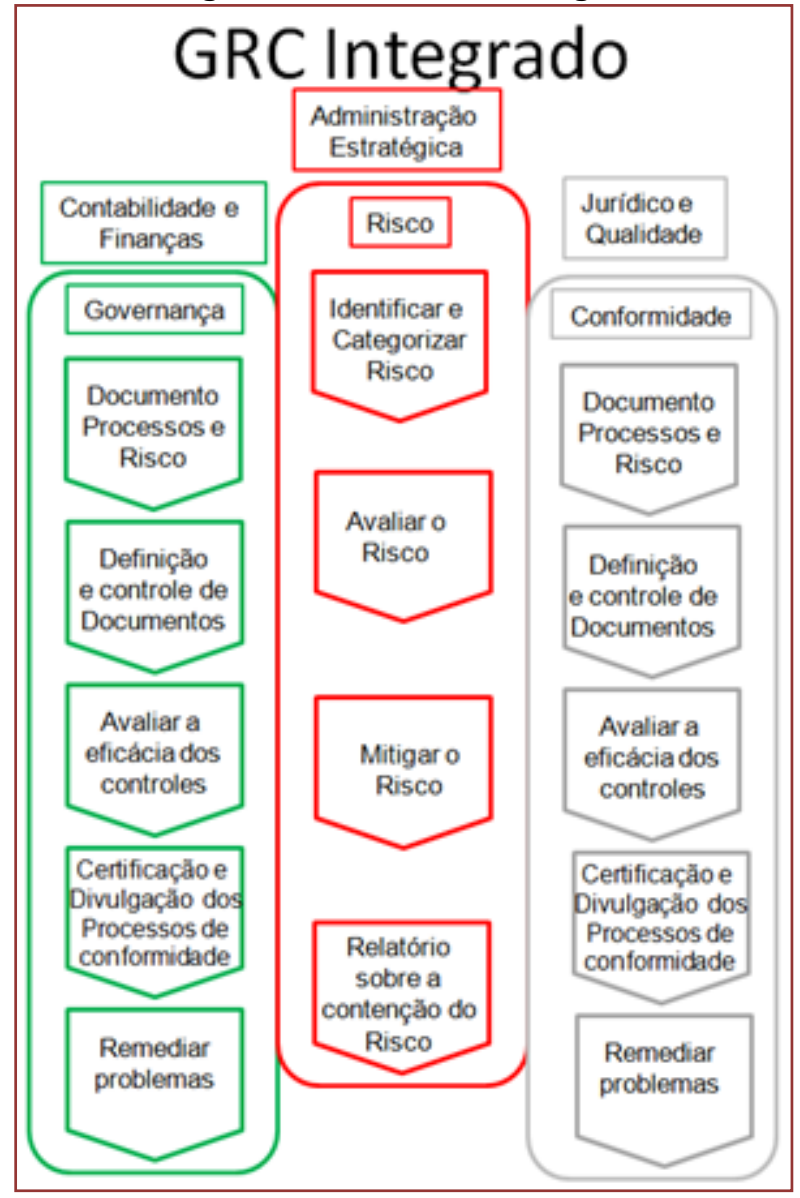

Os benefícios advindos da adoção de uma abordagem integrada GRC são relevantes, uma vez que diversas organizações estão gerindo as suas iniciativas de governança, risco e conformidade em silos, i.e., cada iniciativa é gerida separadamente, mesmo que as necessidades de relatórios se sobreponham. Como resultado dessa abordagem, as organizações possuem diversos sistemas, informatizados ou não, destinados a gerenciar separadamente iniciativas de governança, risco e conformidade, cada uma antes operando em seu próprio silo, sem integração.

A maioria das organizações encontra-se nesta situação hoje. No entanto, elas estão verificando rapidamente que, como as múltiplas iniciativas de risco e conformidade tornam-se mais interligadas a partir de perspectivas normativas e organizacionais, sistemas múltiplos podem causar muita confusão ou mesmo graves equívocos, devido a processos e documentação duplicadas e contraditórias. Além disso, a redundância de trabalho, bem como mera despesa de manutenção de várias soluções de software fazem com que o custo da conformidade aumente sem controle. 
Figura 2: GRC Orgânico Integrado

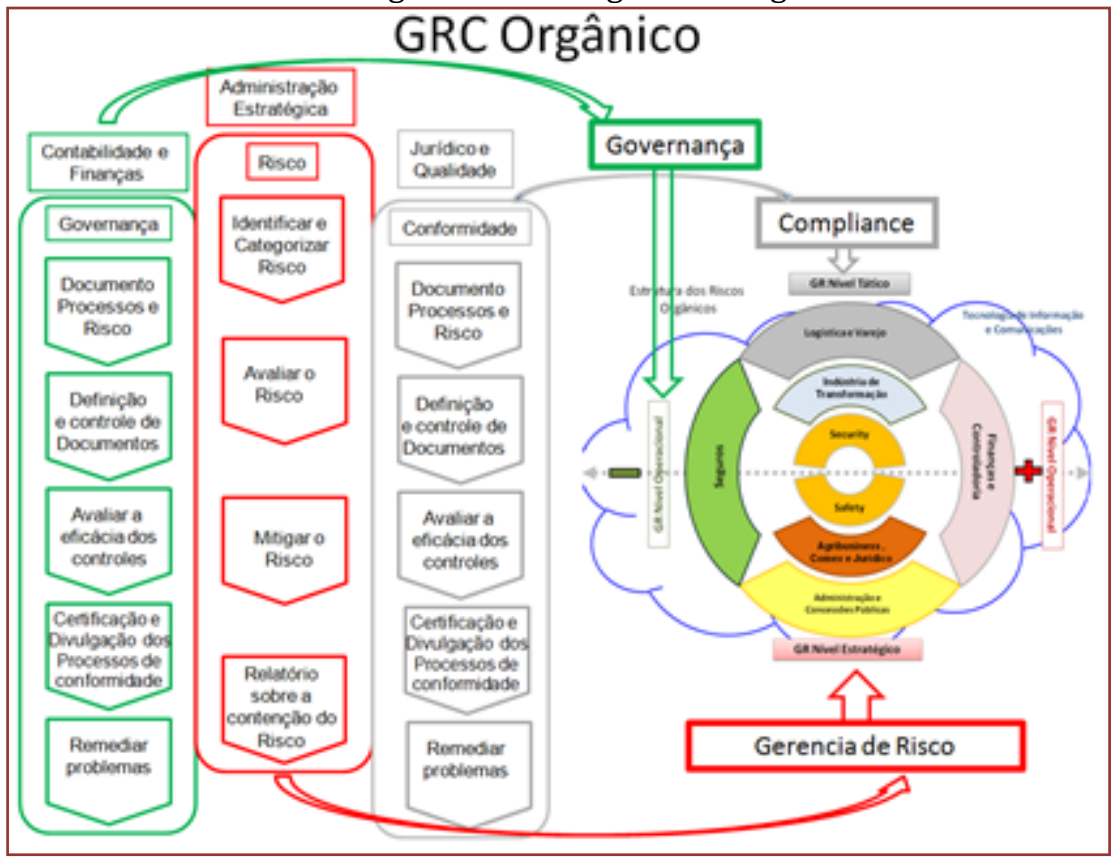

Como resposta à esta abordagem em silos, identifica-se a possibilidade de uma abordagem orgânica dos riscos a partir do conceito de que os riscos são elementos que exigem abordagem estratégica, a fim de cumprir seu fluxo de gerenciamento. Quanto à abordagem de Governança, esta é identificada como uma abordagem tática e que se ajusta dentro de protocolos de ação já definidos nas políticas da empresa. Por fim, os elementos de conformidade e qualidade definidos nas abordagens do setor jurídico das organizações são percebidos como ações de gestão de riscos operacionais.

A Figura 2 explicita a interação dos conceitos relativos à gestão integrada dos riscos orgânicos. Essa metodologia rompe os silos e permite a análise e avaliação dos riscos de forma integrada e transversal das áreas segmentas de gestão dos riscos. A integração dos processos exige a ação multidisciplinar para análise e avaliação dos riscos. Desta forma, o framework serve para posicionar tanto os gestores de risco em relação aos demais atores que atuam concomitantemente em processos correlatos na organização, como também a visão situacional das organizações em relação às competências dos seus colaboradores ou prestadores de serviços que realizem parte das ações de gerenciamento dos riscos na organização.

\section{CONCLUSÃO}

Esta metodologia de gestão integrada dos riscos orgânicos (GIROrg) exige estruturar um sistema de nomenclatura dos riscos para harmonização dos processos de avaliação e analise dos riscos. 0 GIROrg busca ser a base estruturante de um sistema informacional que permita a localização dos atores intervenientes e interessados no gerenciamento dos riscos das organizações. A partir a harmonização das nomenclaturas das diversas áreas de gestão dos riscos, pode-se viabilizar a estrutura de Planos de Gerenciamento de Riscos (PGR) e Planos de Continuidade de Negócios (PCN) que sejam inteligíveis pelos principais atores que irão atuar na gestão de riscos das organizações.

Este processo se inicia na visão da empresa e, passa pelas ações de gestão de riscos operacionais e é suportado por protocolos acionados a partir de toda a estrutura de gestão dos riscos, permitindo que os atores intervenientes e interessados na gestão dos riscos da organização se posicionem de forma harmônica e autônoma, propiciando ações coordenadas e complementares no gerenciamento dos riscos dessas organizações. 
Em futuros trabalhos relativos ao emprego desta metodologia deve-se identificar de que forma os auditores internos e externos podem contribuir para estruturar as matrizes de risco que possam ser compartilhadas, a fim de otimizar as ações de mitigação das ameaças ou de aproveitamento das oportunidades, além de viabilizar a estruturação de indicadores de desempenho que sejam compartilháveis pelas diversas áreas de gestão de riscos da organização.

\section{REFERÊNCIAS}

[1] ALARYS, A Gerência de Riscos como uma Função Organizacional, Revista Administración de Riesgos y Seguros, Revista Alarys, $N^{\circ}$ 2, 2004.

[2] ABNT, NBR 31.000: Gestão de riscos - princípios e diretrizes, 2009, 24p.

[3] BLOS, Maurício F. e HOEFLICH, Sérgio Luiz. Supply Chain Resilience Methodology - A General Framework. In: 4th Latin American Conference on Process Safety, 2012, Rio de Janeiro. Instituto de Petróleo, Gás e Biocombustíveis. Rio de Janeiro: CCPS, 2012.

[4] BERNSTEIN, Peter. L., Desafio aos Deuses: a fascinante história do risco, Rio de Janeiro, Elsevier, 1997 - 19 a reimpressão

[5] CAVALCANTI NETTO, M.A. e HOEFLICH, S. L. Identificação dos atributos de serviços: Etapa inicial para o planejamento da atuação dos Portos Secos na Logística Internacional. In: VIII Simpósio de Pesquisa Operacional e Logística da Marinha -CASNAV/RJ, 2005.

[6] DELOITTE and TOUCHE (2007): "Understanding Performance Drivers through the Use of Non-Financial Measurements", Audit Committee Conversations: A Deloitte Academy event, Melbourne, May 2007. Internet: www.deloitte.com (Data de acesso: Março de 2014).

[7] ELO GROUP “Handbook para gestão de Riscos positivos", 2007, Internet: www.elogroup.com.br (Data de acesso: Março de 2014).

[8] FERMA, "Norma de Gestão de riscos", 2003, Internet: www.www.ferma-asso.og (Data de acesso: Março de 2014).

[9] HOUAISS, A., Enciclopédia e Dicionário Ilustrado, Rio de Janeiro, Koogan, 1994.

[10] HEALTH \& SAFETY EXECUTIVE, Reducing risks, protecting people, HSE's decision-making process, HSE Books, England, 2001.

[11] IBGC, Guia de orientação para o gerenciamento de riscos corporativos, 2007. (Data de acesso: Março de 2014).

[12] IMO, "Amendments to the guidelines for formal safety assessment (FSA) for use in the IMO rule-making process - MSC-MEPC.2/Circ.5, 16 October 2006" Internet: www.imo.org.br (Data de acesso: Março de 2014).

[13] IMO, “Código Internacional para a Proteção de Navios e Instalações Portuárias(ISPS-CODE)” www.ccaimo.mar.mil.br/convencoes_e_codigos/codigos/isps (Data de acesso: Março de 2014).

[14] KATHERINE BAICKER, David Cutler and Zirui Song. 2010."Workplace Wellness Programs Can Generate Savings." Health Affairs 29 (2):304-311

[15] LEFF E. Pensamento sociológico, racionalidade ambiental e transformações do conhecimento, pp. 109-157. In E Leff. Epistemologia ambiental. Cortez Editora, São Paulo, 2000.

[16] MIRABAL, J., Em direção à Gerência Integral de Riscos (Enterpise Risk Mangement), Revista Administración de Riesgos y Seguros, Revista Alarys, N², 2004.

[17] PIEPER, J. . Virtudes fundamentais. Tradução de Narino e Silva e Beckert da Assumpção, Lisboa, Coleção Éfeso: Aster, 1960.

[18] PRICEWATERHOUSE COOPERS, COSO: Gerenciamento de Riscos na Empresa - Estrutura Integrada: Sumário Executivo e Estrutura - Integrated Framework: Application Techniques, 2 vol., 2007. . Internet: www.coso.org (Data de acesso: Março de 2014).

[19] LEOPOLDI, M. A.P., Regimes regulatórios e governança corporativa:a Lei Sarbanes-Oxley e suas repercuções. In: Transparência nos negócios e nas organizações: Os desafios de uma gestão para a sustentabilidade. São Paulo: Atlas, 2009. P. 80-84.

[20] VALERIANO, D., Moderno Gerenciamento de Projetos,São Paulo, Pearson, 2005.

[21] QUELHAS, O. LG., ET AL., A transparência através da gestão de riscos e dos controles internos. In: Transparência nos negócios e nas organizações: Os desafios de uma gestão para a sustentabilidade. São Paulo: Atlas, 2009. P. 97-111. 
[22] SAlles JUNIOR, Carlos A. C.; SOLER, A. M.; DO VALLE, J. A. S.; RABECHINI JUNIOR, R., Gerenciamento de Riscos em Projetos, Rio de Janeiro, FGV - Publicações FGV Management, 2006.

[23] ROSEMANN, M. e ELO GROUP "Gestão de riscos de processos de negócio, compliance e controles internos: uma Agenda de pesquisa”, 2009, Internet: www.elogroup.com.br (Data de acesso: Março de 2014).

[24] STEINER NETO, P. J. , A percepção dos resultados esperados pelos beneficiários como fator de influência no processo decisório" , Tese de Dr., Departamento de Administração da Faculdade de Economia, Administração e Contabilidade da USP, 1998.

[25] Internet: www.isaca.org, COBIT 5: A Business Framework for the Governance and Management of Enterprise IT, (Data de acesso: Março de 2014)

[26] SILVA, A.G., SANTANA, J.V.S, "O Perfil do Administrador de Empresas exigido pelo mercado de trabalho em tempo de crise" http://www.craes.org.br/arquivo/artigoTecnico/Perfil_Administrador_Mercado\%20de\%20Trabalho_Crise\%5B1\%5 D_37.pdf (Data de acesso: Abril de 2015)

[27] RIMS https://www.rims.org/Pages/Default.aspx. (Data de acesso: Abril de 2015) https://www.rims.org/aboutRIMS/Documents/RIMS_Bylaws.pdf

[28] ABGR http://www.abgr.com.br/(Data de acesso: Abril de 2015)

[29] HOEFLICH, S.L., BLOS, F.M., DIAS, E.M, "Proposta de um Framework Aplicado à Avaliação Qualitativa dos Riscos Orgânicos da Logística", X CNEG/RJ, 2014

[30] RIMS, Executive Report: Risk management and Internal Audit: Forging a Collaborative alliance.https://na.theiia.org/standards-

guidance/Public\%20Documents/RIMS\%20and\%20The\%20IIA\%20Executive\%20Report\%20Forging\%20a\%20Colla borative\%20Alliance.pdf /(Data de acesso: Abril de 2015)

[31] HEAD, G.L, Risk Management- Why and How: An illustrative introduction to risk management for business executive. IRMI, 2009. http://www.irmi.com/online/riskmgmt/risk-management-why-and-how.pdf /(Data de acesso: Abril de 2015)

[32] ABBI, Função de Compliance, 2009, http://www.abbi.com.br/download/funcaodecompliance_09.pdf /(Data de acesso: Abril de 2015)

[33] Lei 12.846/14, http://www.planalto.gov.br/ccivil_03/_ato2011-2014/2013/lei/l12846.htm Data de acesso: Abril de 2015)

[34] Governance, Risk and Compliance (GRC) Framework

http://www.metricstream.com/whitepapers/html/GRC_frame.htm Data de acesso: Abril de 2015)

[35] Proviti, Key Questions Regarding Integrated GRC,2009. http://www.protiviti.com/en-US/Documents/WhitePapers/Risk-Solutions/Integrated_GRC.pdf Data de acesso: Abril de 2015)

[36] IBRI, Guia rápido de Gestão de crise. http://www.ibri.org.br/Upload/Arquivos/guia_rapido_gestao_de_crise.pdf Data de acesso: Abril de 2015)

[37] FOX, T- Compliance Week, An e-Book publication sponsored by Workiva - 2013 - Acesso ao site www.complianceweek.com.

[38] Relatório de sustentabilidade, KPMG, 2013,

http://www.kpmg.com.br/relatoriodesustentabilidade2013/gestao-de-riscos-e-de-qualidade.html (Data de acesso: abril de 2015) 


\section{Capítulo 14}

Aplicações da filosofia lean manufacturing na recepção da cana-de-açúcar

\section{Manoel Gonçales Filho \\ Reinaldo Gomes da Silva \\ Clóvis Delboni \\ Sílvio Roberto Ignácio Pires}

Resumo: A água é um recurso finito e escasso que tem chamado a atenção de governantes e empresários com medidas para seu uso mais racional. A indústria sucroenergética está inclusa entre os que utilizam intensivamente a água para o desenvolvimento das suas atividades. Neste artigo, a atenção volta-se ao procedimento da limpeza da cana-de-açúcar no processo de recebimento na usina sucroalcooleira. Reutilizar água residuária ou substituí-la por outra opção de limpeza da cana-de-açúcar passa a ser uma exigência para o desenvolvimento de um negócio mais sustentável. Portanto, o objetivo é aplicar os princípios e algumas ferramentas lean para reduzir o uso da água no processo de recepção da cana-de-açúcar. 0 método de pesquisa utilizado foi, a partir de uma revisão bibliográfica, realizou-se um estudo de múltiplos casos. Os resultados mostram que a integração da Manufatura Enxuta (lean) com a Manufatura Verde (green) pode ser um caminho bem positivo e rentável para as empresas do setor.

Palavras-chave: Manufatura Enxuta, Processo Produtivo, Gestão da produção, Usina Sucroenergética. 


\section{INTRODUÇÃO}

A agroindústria sucroenergética brasileira é responsável por movimentar cerca de US\$ 14 bilhões em commodities (açúcar, etanol e derivados) anualmente (SINDIQUÍMICOS, 2014). 0 setor está incluso entre os setores de uso intensivo da água para o desenvolvimento das suas atividades, estima-se que o setor seja responsável por 23\% da demanda por água no Estado de São Paulo (ELIA NETO, SHINTAKU, 2009). Ainda segundo os mesmos autores, como essa matriz produtiva brasileira se apoia largamente no uso dos recursos hídricos, é necessário que a gestão deste recurso esteja inserida dentre as prioridades do país.

A procura por alternativas que eliminem o uso de água nas usinas é grande e reutilizar águas residuárias ou substituir por outra opção resolve dois problemas: (i) reduz o consumo de água fresca e (ii) o descarte de efluentes que estão impróprios ao meio ambiente, seja nos mananciais ou na irrigação das lavouras (PAQUES, 2014).

Assim, as usinas podem e devem investir na implantação de sistemas de gerenciamento e equipamentos. Conforme Piacente (2005), esses sistemas tem a finalidade de aumentar a eficiência das usinas, melhorar sua competitividade, produtividade e fazer com que seus processos se adequem às exigências e padrões de qualidade, ambiental, segurança, entre outros.

Nesse sentido, Verrier, Rose, Caillaud, Remita (2014) relatam que o sistema de Manufatura Enxuta (ME Lean Manufacturing) pode incidir sobre as formas de melhorar as operações, racionalizar o uso dos recursos utilizados na produção e reduzir o desperdício de forma a minimizar ou eliminar os resíduos do ponto de vista ambiental. Ainda segundo os mesmos autores, olhando para as operações a partir de uma perspectiva green pode-se beneficiar não só o ambiente, mas os stakeholders, proporcionando vantagem competitiva, lucratividade (que muitos fabricantes estão procurando) e sustentabilidade ambiental.

Então, visa-se relacionar aspectos da filosofia e de algumas ferramentas utilizadas na ME para contribuir na melhoria do processo de recepção de cana-de-açúcar nas usinas sucroalcooleira.

\section{FUNDAMENTAÇÃO TEÓRICA}

\subsection{MANUFATURA ENXUTA (LEAN MANUFACTURING)}

Segundo, Womack e Jones (1998), a Manufatura Enxuta (ME), do inglês Lean Manufacturing, é considerada enxuta porque é uma metodologia aplicada ao processo de produção que busca fazer cada vez mais utilizando cada vez menos recursos. Isso significa menos esforço humano, menos tempo, menos movimentação e menos espaço, eliminando, assim, desperdícios, diminuindo a geração de resíduos e aumentando os benefícios para a corporação por meio de atividades que apenas agreguem valor ao produto final, com foco nos clientes, para ofertar exatamente o que eles desejam.

Conforme Brunilde, Bertrand, Caillaud, Remita (2013), para tornar-se e manter-se competitivo, as organizações devem adotar estratégias de evolução e a ME é uma estratégia utilizada em várias empresas industriais que se baseia na identificação e eliminação de resíduos (desperdícios) em várias etapas dos processos de produção.

\subsubsection{MELHORIA CONTÍNUA}

O conceito Kaizen está fundamentado na cultura do Japão como um modo de vida, principalmente no pósguerra quando o país estava destruído e não apenas nas empresas as melhorias eram necessárias, mas nas suas próprias vidas. Nesse sentido, o melhoramento contínuo passou a ser uma "filosofia de vida" com a qual o povo japonês aprendeu a conviver no seu dia a dia.

Conforme Mano, Akoten, Yoshino, Sonobe 2014, o conceito de Kaizen é sempre estar em busca da melhoria contínua e isso pode refletir diretamente junto à produtividade e à qualidade sem gasto ou com o mínimo de dispêndio possível.

\subsubsection{MAPA DE FLUXO DE VALOR (MFV)}

O Mapa de Fluxo de Valor (MFV) consiste em duas fases principais: primeiro e inicialmente analisa-se o estado atual do fluxo de valor, por meio da análise do layout do fluxo verifica-se onde existem fontes de 
desperdícios, após descobertos são reduzidos, criando-se, na segunda fase, um novo fluxo de Valor (estado futuro), atacando-se também prazos de entrega e redução dos inventários (ROTHER, SHOOK, 2003).

O MFV permite "enxergar" o fluxo, tornando possível uma análise e otimização de fluxos melhorando o fluxo global com redução de tempo, custo ou de recursos naturais e sociais o que permite melhorias na produtividade e qualidade, ou seja, é o ponto de partida para melhorar o desempenho global (BERTHOLEY; BOURNIQUEL; RIVERY; COUDURIER; FOLLEA, 2009).

Portanto, para se manter a vantagem competitiva, as empresas buscam otimizar sua produção em termos de eficiência de custos, prazo de entrega e qualidade, ou por pressões necessárias à proteção ao meio ambiente. Diante deste cenário tem-se o Mapeamento do Fluxo de Valor (MFV) como sendo precursor de todo o processo de melhoria do sistema de manufatura.

\subsubsection{LEAN GREEN (LGN)}

A aplicação da Manufatura Enxuta (ME) pode trazer diversos resultados para a empresa em termos de produtividade e busca de racionalização na utilização dos recursos disponíveis. Dentre esses fatores, pode haver uma relação estreita da ME com o meio ambiente na busca de um menor impacto ambiental.

Assim, do ponto de vista da ME (Lean), ineficiências de recursos devem ser minimizadas, pois não contribuem para o valor agregado ao produto ou serviço. Dües, Tan e Lim (2013) afirmam que a aplicação da ME funciona como um catalisador para a Manufatura Verde (MV), pois facilita o processo de transformação da empresa em prol do seu desenvolvimento de forma sustentável.

Bergmiller e McCright (2009) identificaram a correlação entre as operações verdes e os resultados da ME (Lean). Os autores descobriram que as empresas que buscam as operações Lean alcançam melhores resultados quando incluem práticas verdes em relação às empresas que não o fazem.

Assim, tem-se que as práticas verdes estão diretas ou indiretamente ligadas às práticas Lean em um ambiente de melhoria contínua, sendo que o desenvolvimento da ME vai direcionar a empresa para a adoção dessas práticas em um contexto organizacional. Desse modo, a garantia de qualidade ambiental das organizações representa um desafio contínuo aos gestores das empresas de processo.

\subsection{RECEPÇ̃̃O DA CANA-DE-AÇÚCAR}

Uma das primeiras etapas do processo produtivo em uma usina sucroalcooleira é a atividade de recepção e limpeza, ilustrada na Figura 1. Nessa etapa busca-se minimizar as impurezas minerais e vegetais que foram impregnadas na matéria prima durante o seu cultivo. Tradicionalmente, executa-se essa limpeza com jatos de água antecedendo os ternos de moenda.

Figura 1: Ilustração da limpeza da cana-de-açúcar com água na recepção

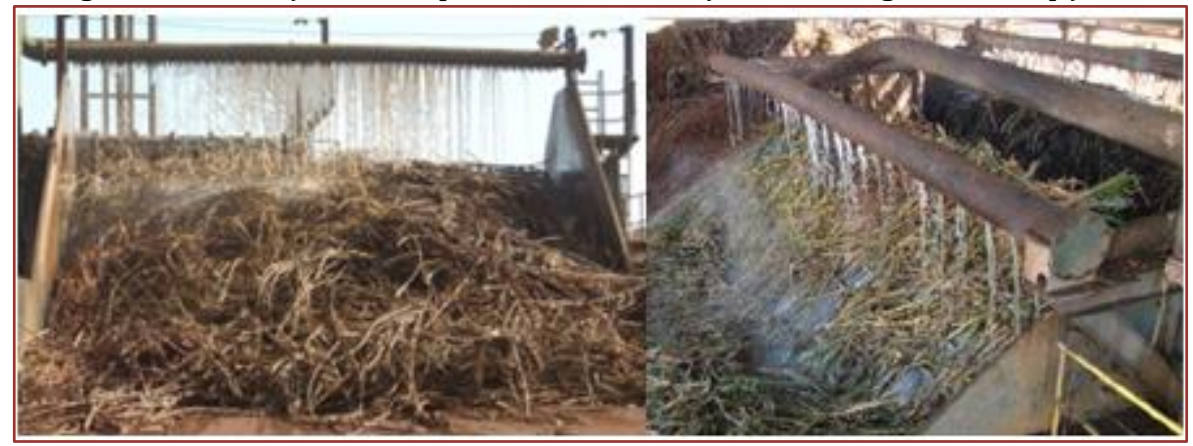

(Fonte: Embrapa, 2014; SBA; STAB; CTC; 2012).

A Figura 2 representa o início do processo produtivo que começa quando a cana-de-açúcar é descarregada diretamente nas mesas alimentadoras, as quais realizam a limpeza dessa matéria prima por meio da água retirada dos mananciais, represas e nascentes. Os picadores, desfibradores, difusores e ternos de moenda, na sequência, complementam o processo de moagem. 
Figura 2: Início do processo produtivo da usina sucroalcooleira

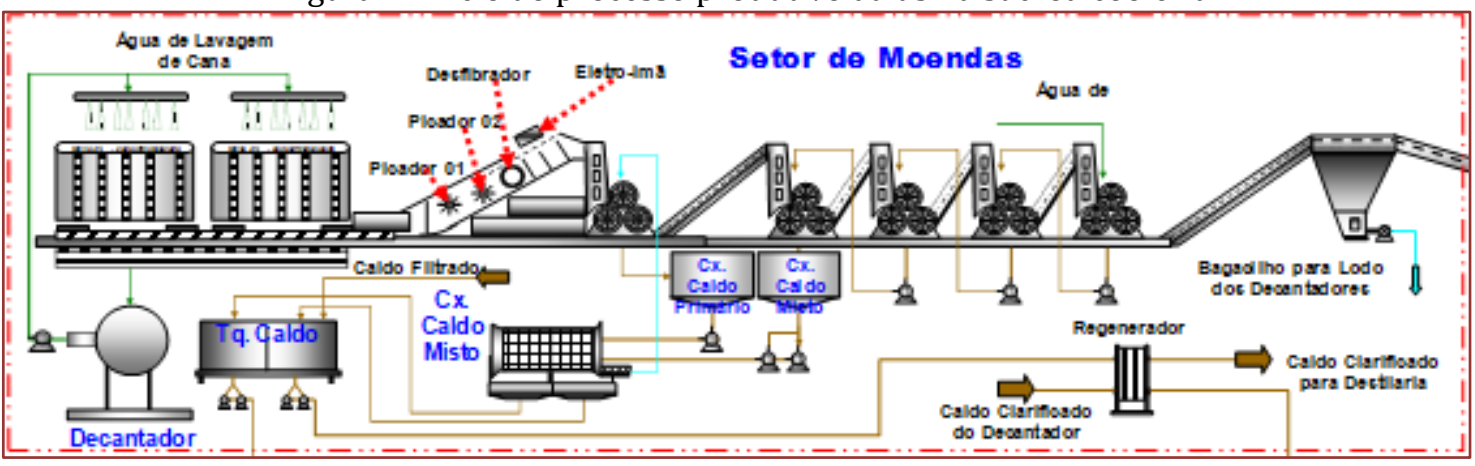

(Fonte: UDOP, 2014).

A pesquisa realizada por Omena, Callado, Pedrosa, Pimentel, Menezes, Torquato Jr, Lopes, Silva, (2004) apontou que as usinas misturam $50 \%$ de água de boa qualidade com $50 \%$ de água de baixa qualidade (a que retorna do decantador), isso porque sua qualidade físico-química e bacteriológica tende a diminuir ao longo da safra. 0 trabalho de pesquisa também identificou a adição de leite de cal para fazer a correção do pH da água na tentativa de manter sua qualidade, pois a água de reuso na limpeza da cana-de-açúcar possui grande potencial poluidor. Além do cal, estão constituídas de terra, nutrientes, açúcares, microrganismos e outras impurezas.

Payne (1990) afirmava, há 25 anos, que a não realização da limpeza da cana-de-açúcar acarretaria a presença de microrganismos que acabariam por diminuir a eficiência da etapa de fermentação. Referente ao meio ambiente, Stupiello (2014) relata que as medidas ambientais, especialmente ligadas ao consumo de água e às perdas de açúcares na limpeza da cana-de-açúcar obrigaram as unidades produtoras a deixarem de lavar ou a de buscarem um sistema de limpeza a seco.

\subsubsection{LIMPEZA A SECO}

Os principais motivos para a limpeza de cana-de-açúcar a seco são: (i) Aumento da colheita mecanizada, esse tipo de colheita tem a opção apenas da cana-de-açúcar picada que também traz a palha agregada e que a limpeza com água não separa; (ii) Aproveitamento de parte da palha para fins energéticos; (iii) Aproveitamento de parte da palha como adubo no próprio solo da atual colheita; (iv) Evitar o aumento do desgaste dos equipamentos (moagem); (v) Remoção das impurezas minerais e vegetais; (vi) Teor reduzido de impurezas minerais na palha separada e; (vii) Redução no nível de perdas (SBA; STAB; CTC, 2012).

A Figura 3 ilustra os equipamentos necessários para o procedimento de limpeza a seco. São eles: (i) Mesa alimentadora 45; (ii) Esteira metálica; (iii) Transportadores de cana-de-açúcar (correia); (iv) Ventiladores (sopradores); (v) Peneiras de separação de palha, terra e pedra; (vi) Transportadores de palha; (vii) Transportadores de terra e pedra; (viii) Picador de palha e; (ix) Transportadores de palha picada para a caldeira (DEDINI, 2015).

Figura 3: Ilustração dos equipamentos para limpeza a seco

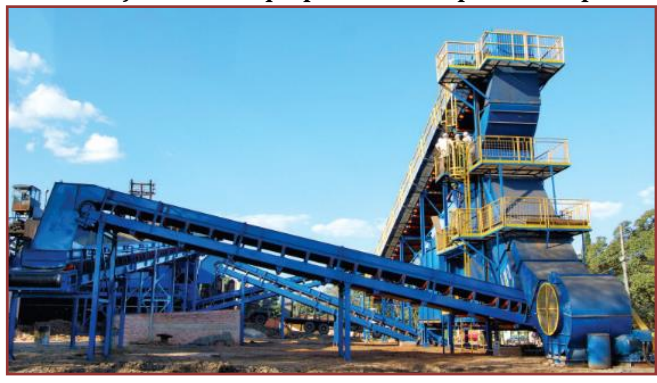

(Fonte: DEDINI, 2015).

Posteriormente à limpeza a seco, a cana-de-açúcar vai para um sistema de separação que consiste de uma mesa com discos que são acionados quando os eixos são movimentados por motos redutores. Nesse 
processo a cana-de-açúcar utilizada pode ser tanto inteira quanto picada, queimada ou não. Esta matéria prima é descarregada sobre esses discos e sofre a separação de matéria estranha ao passar entre os discos, ou seja, palha, pedra e terra são separadas da cana-de-açúcar. Depois da palha separada pelo sistema de limpeza a seco, passa pelo picador para que seja mais bem aproveitada quando queimada na caldeira, ou seja, a palha picada se torna mais inflamável e gera mais energia.

\subsection{DMAIC}

Conforme Kasahara e Carvalho (2003), as fases de aperfeiçoamento do processo e do treinamento das pessoas para que possam obter melhores resultados costumam ser denominadas de DMAIC: (i) definir (define), (ii) medição (measure), (iii) análise (analyse), (iv) aperfeiçoamento (improve) e (v) controle (control).

Assim, tais fases deverão ser seguidas na aplicação da ME (lean) na busca da melhoria da etapa de recepção da cana-de-açúcar pela usina sucroalcooleira. Por isso utilizou-se aqui do DMAIC por ser uma metodologia sistematizada e estruturada que possibilita a organização das atividades a serem desenvolvidas, ações a serem implementadas e melhorias a serem monitoradas.

\section{ABORDAGEM METODOLÓGICA}

O método de pesquisa utilizado foi o Estudo de Casos, que segundo Miguel (2007), é composto pelas etapas apresentadas na Figura 4.

Figura 4: Etapas para elaboração de Estudo de Casos

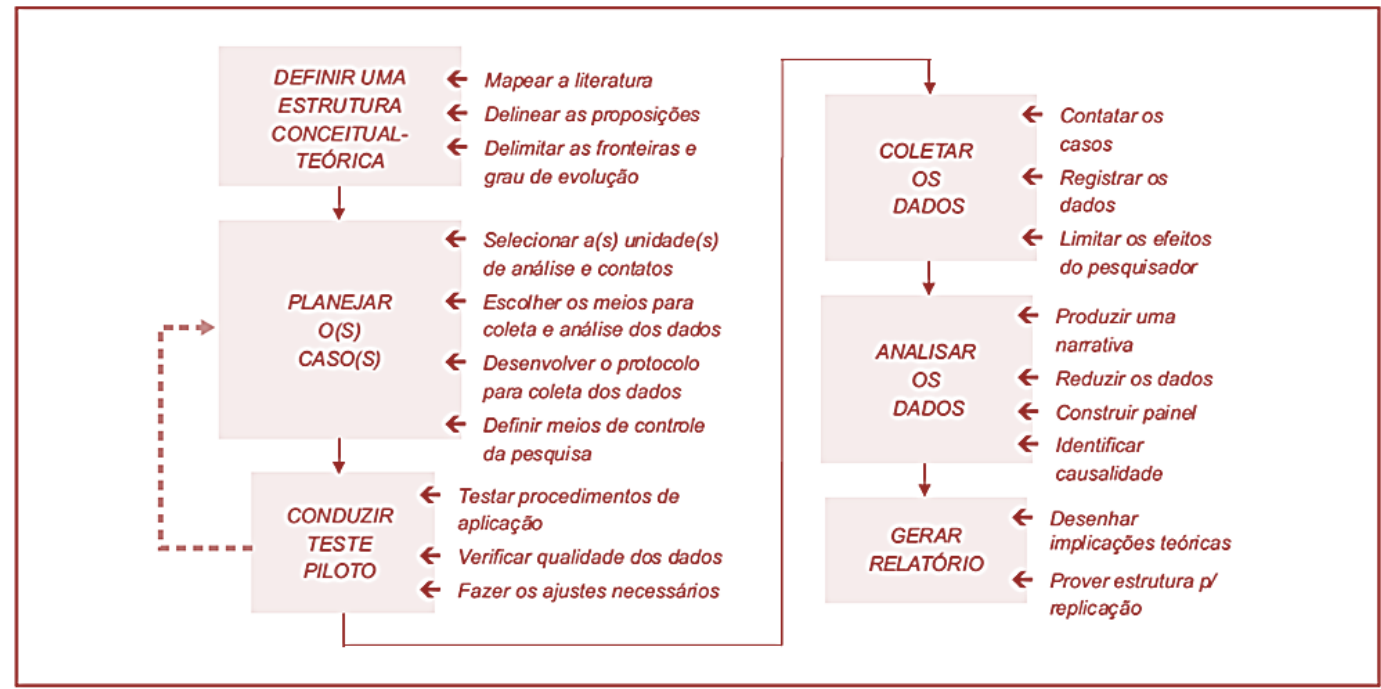

(Fonte: Miguel, 2007)

Foi realizada uma revisão bibliográfica, no período de 2004 a 2014, via o Portal de Periódicos da CAPES e de outras fontes para determinar a área de conhecimento por meio das palavras chaves: lean manufacturing, lean green, DMAIC, usina de açúcar e etanol e cana-de-açúcar, análise de viabilidade econômica.

O planejamento dos casos teve como critério de escolha das usinas, suas iniciativas de inovação organizacional e tecnológica para o desenvolvimento da gestão dos sistemas produtivos. Do total de oito usinas sucroalcooleiras contatadas, são seis as que participaram como unidades de análise, sendo que: duas delas serviram de teste piloto de conhecimento do processo produtivo de açúcar e álcool por meio de visitas técnicas previamente agendadas, bem como do aprimoramento do questionário de pesquisa. As outras quatro usinas restantes participaram como respondentes do questionário da pesquisa já aprimorado durante o teste piloto.

Foi elaborado um instrumento de coleta de dados (questionário) para que o estudo de casos fosse desenvolvido. Miguel (2007) recomenda que se utilize de teste-piloto (pré-teste) de forma a facilitar ao pesquisador a determinação de unidades de análise, verificar a qualidade dos dados e realizar os ajustes 
necessários para o aprimoramento do questionário. Sob essa orientação, realizaram-se duas visitas técnicas, sendo: a primeira em uma usina localizada na cidade de Jaú (SP) e a segunda na cidade de Iracemápolis (SP). Assim se pode-se aplicar, realizar ajustes e desenvolver esse instrumento de coleta de dados (questionário) da pesquisa.

A coleta dos dados foi de forma direta e concisa, acerca da gestão do processo produtivo pertinente ao problema ambiental proposto inicialmente. Nessa etapa, quatro usinas sucroalcooleiras participaram, que por motivos de sigilo das informações coletadas serão denominadas Usina A, B, C e D. A coleta e registro dos dados aconteceu por meio do JotForm (site de pesquisa) como repositório de informação. Geraram-se, automaticamente, informações que foram registradas em planilhas eletrônicas.

Dessa forma, construiu-se o relatório final com as implicações teóricas a partir da identificação dos principais resultados do estudo de múltiplos casos.

\section{ANÁLISE E RELATO DO ESTUDO DE CASOS}

Inicialmente, buscou-se investigar se essas usinas têm em sua cultura traços ou experiências da "filosofia" da ME. Constatou-se que, as usinas A e D, praticam e tem em sua cultura organizacional a ME como estratégia de produção.

Constatou-se nas usinas A, B, C e D que as impurezas (tais como terra, palha e pedras) entram no processo produtivo após a recepção da cana-de-açúcar, e foi unânime o reconhecimento de que essas impurezas se constituem em um problema que afeta o rendimento dos ternos de moenda, bem como acelera o desgaste dos equipamentos. Essas usinas reconhecem a possibilidade de separação da palha da cana-de-açúcar e de alguma forma transportá-la até a caldeira. Apenas uma delas, a usina B, não limpa a cana-de-açúcar antes de iniciar a moagem, ou seja, a matéria prima entra com todas as impurezas no seu processo produtivo. Porém, há o reconhecimento, por parte da empresa, que a quantidade de palha que entra no processo é grande.

O consumo de água para a limpeza da cana-de-açúcar na recepção das usinas existe para as usinas A e D. Sendo que a usina $\mathrm{D}$, tem os dois tipos de limpeza: com água e a seco. A usina $\mathrm{C}$, não utiliza água e realiza limpeza a seco. A usina B não faz limpeza. Entretanto, há o reconhecimento de que esse recurso natural precisa ser tratado (e é tratado) antes de ser devolvido à natureza pelas usinas A e D.

Com foco na utilização da palha, que possivelmente possa ser separada da cana-de-açúcar na recepção, buscou-se conhecer as práticas das usinas. Nas usinas C e D a palha é separada da cana-de-açúcar e está sendo aproveitada para fins energéticos e não faz falta para o campo, pois no momento do corte a colheita mecanizada deixa quantidade suficiente de palha no campo que é utilizada como adubo. Porém, as usinas A e B não separam a palha na recepção.

As usinas A e B relataram que há subtração de sacarose causada pela presença de palha e, também destacaram que, há diminuição perceptível da produtividade do processo de moagem. As usinas C e D opinaram que não percebem a perda de sacarose pela presença de palha e que, igualmente, não detectam perda de produtividade. É importante destacar que, os respondentes das usinas A e B, relataram que a palha não separada da cana-de-açúcar na recepção significa que, a cada tonelada de palha que entra no processo de moagem, tem-se uma tonelada a menos de cana-de-açúcar moída.

Na sequência, pesquisou-se sobre o destino da água utilizada pelas usinas após a limpeza da recepção da cana-de-açúcar. As usinas A e D destinam a água utilizada para o lago de decantação. Lembrando que a usina B não faz limpeza com água. A água, depois de decantada, volta para a limpeza da cana-de-açúcar na recepção do processo. A usina A reutiliza a água na limpeza da cana-de-açúcar mais de cinco vezes, e a usina D, no máximo, duas vezes; a usina $C$ não identificou o número de vezes que reutiliza a água. Logo, notou-se que a água é tratada durante todo o tempo do seu uso e reuso, ou seja, durante todo o período de safra ela recebe entre 42 a 54 toneladas de cal virgem para uma usina que processa 7.000 toneladas de cana-de-açúcar por dia (24h de trabalho). Para aumentar a sua oxigenação, é decantada no lago, e reutilizada na limpeza da cana-de-açúcar. Ao final de cada safra, é descartada na lavoura de cana-deaçúcar pelas usinas A e D.

As usinas A e B não possuem limpeza a seco, enquanto as usinas C e D possuem essa opção. Essas respostas estão adequadas com os resultados anteriores, pois se identificou que a usina $\mathrm{B}$ não limpa a cana-de-açúcar na recepção, e a usina D limpa a cana-de-açúcar por meio das duas opções, ou seja, limpeza com água e a seco (duas mesas alimentadoras 45ํ). A usina A respondeu que existe a possibilidade de 
instalação dos equipamentos para limpeza a seco, e pensa em analisar sua viabilidade econômico financeira, sendo que a usina B não vê a possibilidade dessa aplicação.

\subsection{PAINEL DE CAUSALIDADE}

A partir desses dados relatados anteriormente é possível sintetizar em um painel a causalidade apresentado na Tabela 1 entre as variáveis pesquisadas: água e palha na recepção da cana-de-açúcar.

Tabela 1: Implicações e causalidades.

\begin{tabular}{|c|c|c|c|}
\hline Recurso & Implicaçōes da revisão bibliográfica & Implicaçōes da pesquisa & Relação causal \\
\hline \multirow{8}{*}{ Água } & *A plicações da ME buscam a eliminação de desperdícios. & $\begin{array}{l}\text { "Existe o consumo de água na recepção para a limpeza da } \\
\text { cana. }\end{array}$ & $\begin{array}{l}{ }^{*} \text { Fazer intervenção no sistema de limpeza da cana, na } \\
\text { busca de melhorias, por meio da filos ofia da ME e na } \\
\text { direção da sustentabilidade do negócio. }\end{array}$ \\
\hline & $\begin{array}{l}\text { * Res íduos industriais são considerados desperdícios. A } \\
\text { água de limpeza ou reuso gera um efluente carregado de } \\
\text { cal. }\end{array}$ & $\begin{array}{l}\text { *A eliminação do uso da água no processo de limpeza da } \\
\text { cana na recepção ainda não é consenso nas usinas. }\end{array}$ & $\begin{array}{l}\text { *A ME pode trazer contribuição para o racionamento do } \\
\text { uso da água criando sinergia im pulsionada pela melhoria } \\
\text { ambiental. }\end{array}$ \\
\hline & $\begin{array}{l}\text { *A água de limpeza ou reuso não agrega valor e é } \\
\text { considerado desperdício evidente. A integração da } \\
\text { Manufatura Enxuta com a Manufatura Verde agrega valor } \\
\text { ao produto e reduz desperdícios de resíduos. }\end{array}$ & $\begin{array}{l}\text { *A eliminação do uso da água no processo de limpeza da } \\
\text { cana na recepção ainda não é consenso nas usinas. }\end{array}$ & $\begin{array}{l}\text { * O desperdício evidente de água na limpeza da cana deve } \\
\text { ser atac ado. }\end{array}$ \\
\hline & $\begin{array}{l}\text { *Na limpeza da cana as usinas podem operar por meio de } \\
\text { circuito aberto ou fechado. }\end{array}$ & $\begin{array}{l}\text { *Não há indicios de redução do uso de cal utilizado para } \\
\text { aumentar o } \mathrm{Ph} \text { na água de reuso. }\end{array}$ & $\begin{array}{l}\text { * O circ uito aberto piora a relação am biental, sendo o } \\
\text { circuito fec hado mais adequado nessa relação. }\end{array}$ \\
\hline & $\begin{array}{l}\text { *A eliminação do uso da água pode minimizar os impactos } \\
\text { prejudiciais à natureza. }\end{array}$ & " A usina reutillza a água a partir de circulto fechado. & $\begin{array}{l}\text { *A água de reuso não pode ser descartada nos mananciais } \\
\text { por estar carregada de cal, mas é desc artada na lavoura. }\end{array}$ \\
\hline & $\begin{array}{l}\text { *A sustentabilidade deve ser considerada como a } \\
\text { combinação de fatores ambientais, ec onömic os e sociais. }\end{array}$ & $\begin{array}{l}\text { "Necessidade de análise da viabilidade econômica } \\
\text { financeira para novos invetimentos. }\end{array}$ & $\begin{array}{l}\text { *A análise financeira pode vabilizar investimentos e assim } \\
\text { proporcionar melhorias no processo de recebimento da } \\
\text { cana. }\end{array}$ \\
\hline & $\begin{array}{l}\text { *Ao limpar a cana picada com água perde-se mais } \\
\text { sacarose do que com a cana inteira. }\end{array}$ & $\begin{array}{l}\text { *A cana entra no processo produtivo inteira pela colheita } \\
\text { manual e picada pela colleitadeira mec anizada. }\end{array}$ & $\begin{array}{l}\text { *A cana pic ada não deve ser limpa por meio de água para } \\
\text { não perder sac arose, mas a cana inteira poderia, visto que } \\
\text { a perda è menor. }\end{array}$ \\
\hline & * $O$ consumo de água na limpeza da cana é de 2,19 l/ton. & $\begin{array}{l}\text { " Durante a saffa, em média, se consomem } 3.762 .710 \text { litros } \\
\text { de água. }\end{array}$ & $\begin{array}{l}\text { * Há um consumo alto de água. O Ideal é buscar a } \\
\text { racionalização ou até a eliminação de seu uso. }\end{array}$ \\
\hline \multirow{3}{*}{ Palha } & $\begin{array}{l}\text { * Se não separada da cana na recepção diminui o } \\
\text { rendimento do processo produtivo, pois, cada tonelada de } \\
\text { palha que entra na moagem e menos uma tonelada de cana } \\
\text { processada. }\end{array}$ & $\begin{array}{l}\text { "A palha, pedra, terra, entre outras impurezas, entram no } \\
\text { processo produtivo (moagem). }\end{array}$ & *A limpeza com água não separa a palha da cana. \\
\hline & $\begin{array}{l}\text { * Se entrar no processo de moagem contribui para danificar } \\
\text { os equipamentos, aumentando a manutençẫo. }\end{array}$ & $\begin{array}{l}\text { *A cana limpa por meio de água, sem terra e pedras, } \\
\text { continua com a palha entrando no processo de moagem. }\end{array}$ & $\begin{array}{l}\text { * A palha está ac elerando e aumentando o desgaste dos } \\
\text { equipamentos e afetando o rendimento do processo } \\
\text { produtivo. }\end{array}$ \\
\hline & $\begin{array}{l}\text { *Existe oportunidade de melhoria de seu uso eficiente } \\
\text { como fonte energetica. }\end{array}$ & $\begin{array}{l}\text { *É possivel separar a palha da cana na recepçãoe } \\
\text { transportá-la até a caldeira por meio de esteiras ou qualquer } \\
\text { outro tipo de transportador. }\end{array}$ & \\
\hline
\end{tabular}

A partir da Tabela 1, conclui-se que: (i) Se a cana-de-açúcar não for lavada com água na recepção, todas as impurezas entram no processo de moagem, danificam os equipamentos, trazem problemas operacionais na caldeira e prejudicam as etapas de fermentação. Então é preciso livrar a cana-de-açúcar de impurezas antes do processo de moagem; (ii) As usinas que utilizam a água para a limpeza da cana-de-açúcar coletam-nas nos rios e tanques da região e, após o tratamento dessa água, reusa-se na própria limpeza dessa matéria prima. Notou-se que durante a limpeza a água evapora fazendo-se necessário a coleta constante para repor a quantidade evaporada. Em média, evaporam-se 15.358 litros que são captados dos rios ou tanques diariamente. Isso significa 2,194 litros por tonelada de cana-de-açúcar diariamente, para uma usina que processa 7.000 toneladas diárias (24h diárias de trabalho). Sabendo-se que uma safra anual, em média, tem a duração de 245 dias e que, multiplicado esse período por 7.000 toneladas diárias de processamento, resulta em 1.715 .000 toneladas produzidas no ano. Isso significa uma evaporação média de 3.762.710 litros de água por safra. Então é preciso reduzir a quantidade de água utilizada, principalmente porque ela é coletada de rios e tanques; (iii) Quando do término da safra, período de entressafra, toda a água que está parada no sistema (processo de limpeza), e o lodo que está no fundo do lago, são descartados na agricultura como adubo orgânico, isso porque não poderia ser direcionado aos rios, por estarem carregados de cal. Entretanto, essa prática pode atingir lençóis freáticos e dessa forma alcançar os rios. Então se for reduzida a quantidade de água no processo de limpeza na recepção da canade-açúcar, será reduzido o descarte na agricultura e seus riscos de contaminação dos lençóis freáticos e mananciais; (iv) Como a limpeza com água não separa a palha da cana-de-açúcar. Então é preciso buscar uma alternativa que separe esta palha da cana-de-açúcar na recepção; (v) Como a presença de palha no processo produtivo favorece o desgaste dos equipamentos e baixa o rendimento geral da moenda, além de diminuir a sacarose da cana-de-açúcar. Então é preciso buscar uma alternativa que elimine o máximo possível essa palha entrando no processo de moagem.

Portanto, dessas conclusões causais percebe-se a possibilidade de se aplicar os conceitos e algumas das ferramentas do ME, nos quais se identificam e qualificam os desperdícios, o que está agregando valor, o 
mapa de fluxo de valor, projetos de melhoria contínua, aspectos do meio ambiente a ser atacado e preservado (lean green). Para tanto, é necessária uma análise de viabilidade econômico-financeira dos ajustes, melhorias, implantações, projetos, que envolverão essa temática.

\section{APLICAÇÃO DE PRINCÍPIOS E FERRAMENTAS DA ME (LEAN) NA RECEPÇÃO DA CANA-DE-AÇÚCAR}

Para a aplicação de princípios e ferramentas da ME (Lean) na recepção da cana-de-açúcar de um modo estruturado e sistematizado, utilizou-se do DMAIC, para orientação das fases apresentadas pela Tabela 2.

Tabela 2: Aplicação do DMAIC na recepção da cana-de-açúcar.

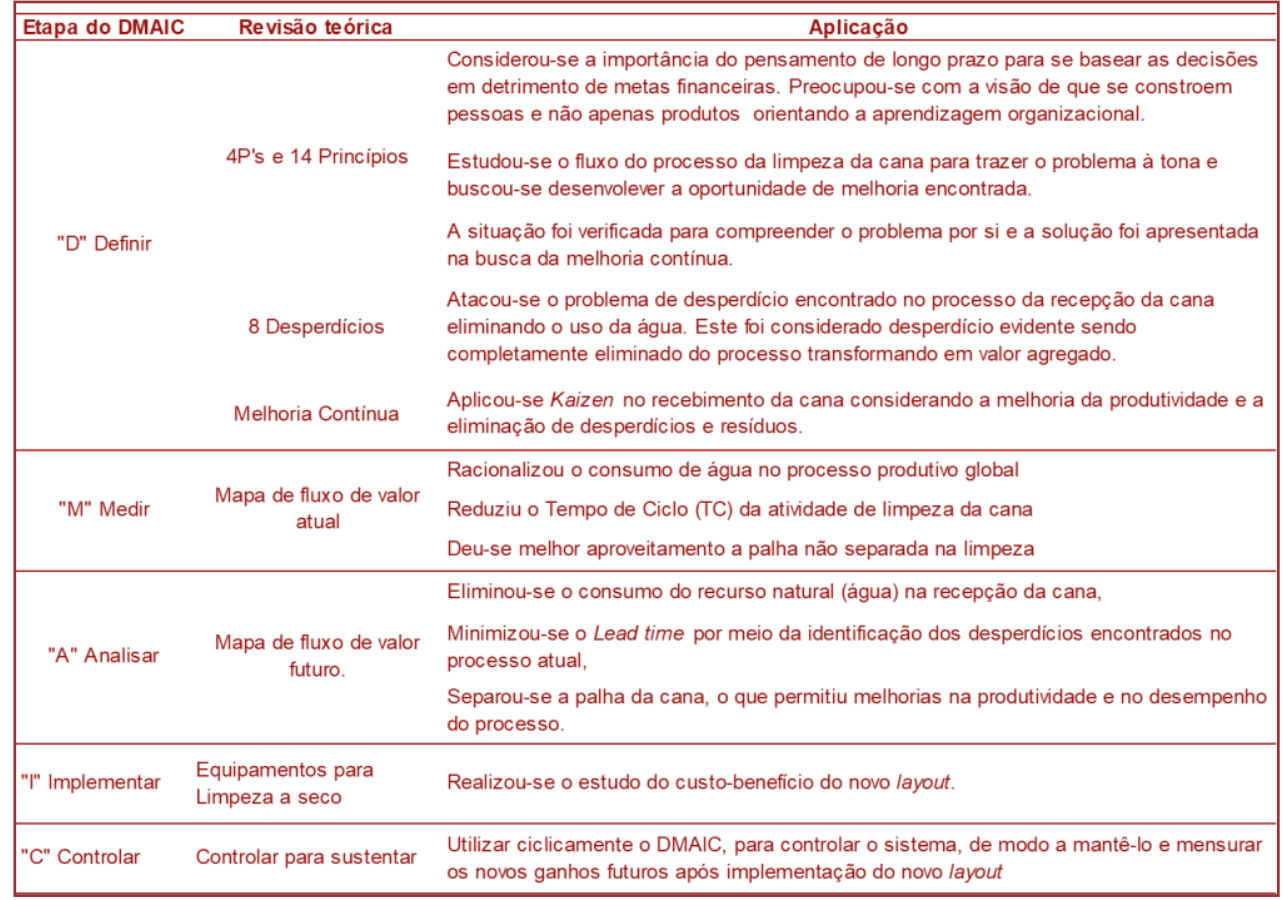

Definiram-se os requisitos dos stakeholders por meio do desenho dos processos da produção procurando identificar aqueles que têm relação com a qualidade, e que estão gerando resultados ruins, no que se refere às exigências ambientais, rendimento do processo, oportunidades de melhorias no processo, dentre outros. A característica crítica encontrada contribuiu com o objetivo do trabalho, ou seja, aplicar os princípios e algumas ferramentas da ME (Lean) para reduzir e/ou eliminar o uso da água no processo de recepção da cana-de-açúcar, bem como prover melhor tratamento à palha.

Do ponto de vista da ME essa redução do uso da água, deve ser considerada, pois não contribui em nada para o valor agregado ao produto. A redução ou eliminação desse recurso também é positiva sob a perspectiva da sustentabilidade do sistema produtivo, pois levam ao aumento do passivo ambiental gerado na usina. E a palha que entra no processo de moagem, por não ter sido separada da cana-de-açúcar na recepção foi, também, considerada desperdício evidente. Como está sendo utilizada, a palha reduz a eficiência de moagem e a produtividade geral do sistema. Tem também o problema de seu tempo de espera de secagem para que possa ser aproveitado na caldeira para geração de energia, o que causa uma ineficiência energética momentânea.

Para analisar o sistema observou-se e comparou-se o fluxo do valor atual e futuro, identificando-se lacunas entre o desempenho atual e o pretendido. A análise constatou que a busca pela solução de racionalizar o uso da água e dar melhor aproveitamento à palha passa a ser fundamental para proteção ambiental e o desenvolvimento sustentável. O MFV futuro está apresentado na Figura 5. 
Figura 5: MFV futuro

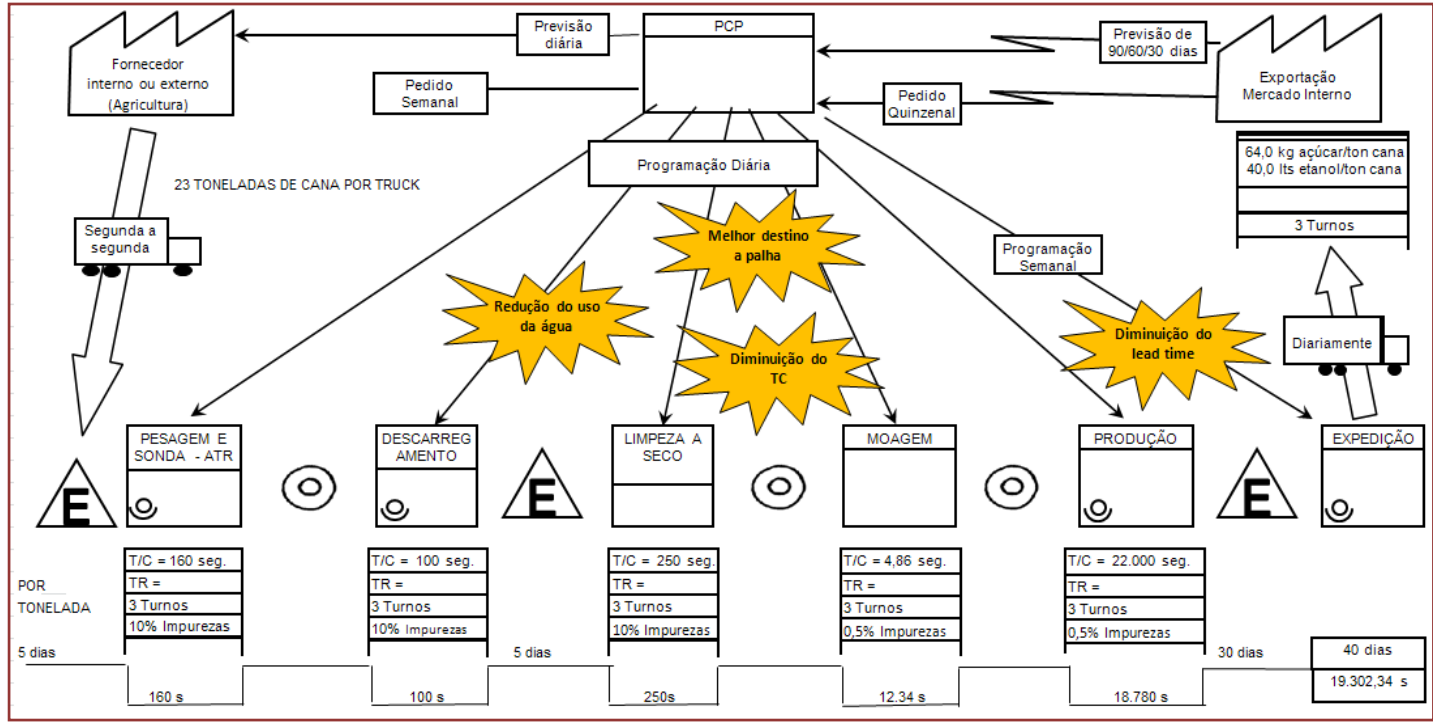

A cana-de-açúcar, uma vez limpa a seco, reduz as impurezas provenientes do campo de 10\% para 0,5\%, separando, com eficiência, a palha da cana-de-açúcar que segue fluxo produtivo normal.

Observa-se com a análise comparativa do estado atual e futuro, que é possível reduzir o Tempo de Ciclo (TC) na limpeza da cana-de-açúcar de $626 \mathrm{~s}$ para $250 \mathrm{~s}$ por tonelada, pelo sistema de limpeza a seco. Essa redução do TC poderá alimentar com maior velocidade as moendas, que tem o TC de 12,34 segundos por tonelada, e resultar em redução do lead time do processo produtivo em geral. Nesse caso, o ganho é de $2 \%$ (de 19.678 segundos para 19.302 segundos).

Constatou-se que, reduzindo o desperdício industrial por meio da economia de água e eliminando as contaminações ao meio ambiente, por não se ter mais a necessidade de depositar na agricultura os resíduos gerados na limpeza da cana-de-açúcar que estão impregnados de cal, encontra-se a relação estreita da ME com o meio ambiente na busca de um menor impacto ambiental. E a palha, por ser separada da cana-de-açúcar no processo de limpeza, poderá aumentar a produtividade e fomentar ganhos financeiros.

Portanto, a melhor sustentabilidade desses processos pode englobar os princípios da ME e da gestão ambiental. Além disso, essa sinergia promove a busca e o melhoramento contínuo por meio da reflexão junto à maior produtividade, no caso por: (i) melhorar o lead time do processo produtivo em geral; (ii) não se ter mais a palha entrando na etapa de moagem; (iii) melhorar a qualidade do açúcar por conter menos impurezas e exigir menos clarificação; (iv) pelo fomento e possível promoção de uma cultura de melhoria contínua.

Para a etapa de implementação encontrou-se um conjunto de equipamentos disponível no mercado de tecnologia canavieira que podem contribuir para a solução dos problemas identificados. Esse conjunto de equipamentos é composto de soprador, esteiras de separação das impurezas e picador. 0 soprador pode ser instalado após o descarregamento da cana-de-açúcar (embaixo ou acima) das mesas alimentadoras de 45‥ As impurezas (palha, terra, pedra, insetos) por gravidade caem nas esteiras de separação e a palha é transportada até o picador. Após ser picada ela é destinada para queima na caldeira. Assim, executa-se a limpeza a seco e substitui-se o uso da água no sistema tradicional da limpeza da cana-de-açúcar na recepção.

Na sequência, realizou-se o estudo do custo-benefício do projeto para a implementação da melhoria no sistema de recepção da cana-de-açúcar. Consolidaram-se os resultados para uma projeção de quatro anos e apuraram-se os retornos do capital investido com base no Fluxo de Caixa Operacional (FCO). A usina situada na cidade de Jaú/SP informou que os investimentos necessários para a implantação da limpeza a seco (equipamentos e instalação) estão na ordem de 10 milhões de reais e que sua Taxa Mínima de Atratividade (TMA) é de 1,2\% ao mês. Sabendo-se que a Demonstração do Resultado do Exercício (DRE) apresenta resultados no final do exercício fiscal (anual), foi necessário transformar a TMA mensal em taxa equivalente composta anual. 
A rentabilidade desse investimento equivale a 4,128\% ao ano. Se a Taxa interna de retorno (TIR) for maior do que a Taxa mínima de atratividade (TMA), se aceita o investimento. No exemplo a TIR é de 19,517\% e a TMA de 15,389\%, portanto, TIR maior que a TMA se aceita investir no novo empreendimento. 0 ganho será de 4,128\% a.a., que é a diferença da TIR com a TMA. Isso se comprova quando se observa um Valor presente líquido (VPL) positivo de $\mathrm{R} \$ 944.450,75$.

Logo, a implementação da limpeza a seco é um projeto viável economicamente. Dessa forma, sob a visão da sustentabilidade há um atendimento das suas três perspectivas, a saber: (i) meio ambiente: essa implementação da limpeza a seco causa menor dano pela redução do uso da água e pelo incremento de geração de energia limpa pela queima de mais palha (picada e seca); (ii) econômico: essa implementação da limpeza a seco demanda um investimento financeiro que, pela análise de viabilidade econômica verificou-se ser viável; (iii) social: essa implementação da limpeza a seco gera alguns benefícios à sociedade, dentre eles podem ser destacados: preservação dos mananciais e nascentes, preservação dos lençóis freáticos, menor poluição do ar por queimar palha em detrimento de outras fontes mais poluidoras (por exemplo, diesel em geradores).

Finalmente, para controlar o sistema após a implementação da melhoria, poderiam novamente aplicar o ciclo DMAIC, com o apoio de ferramentas da ME. Então é primordial um programa robusto de treinamento e capacitação nos princípios e ferramentas da ME, dentre outros que possam vir a surgir a partir do estilo gerencial dos gestores e das especificidades das equipes de trabalho envolvidas nessas questões.

\section{CONCLUSÃO}

As usinas de açúcar e etanol utilizam um montante alto de água em seu processo produtivo. A partir do objetivo traçado de aplicar os princípios e algumas ferramentas da ME (Lean) para reduzir e/ou eliminar o uso da água e melhor tratamento da palha (na recepção da cana-de-açúcar), pode-se afirmar que é possível obter melhorias em relação à produtividade, eficiência energética e benefícios relativos à sustentabilidade (perspectivas do meio ambiente, econômico e social).

A realização de uma revisão bibliográfica cruzada com visitas técnicas a duas usinas e estudo multicasos em quatro usinas, proveu condições de sistematizar, via a estrutura do DMAIC, uma aplicação dos princípios da ME (lean) com algumas de suas ferramentas. Essa aplicação apresenta detalhes, passo a passo, propondo a eliminação do uso da água na recepção do processo produtivo (limpeza a seco) e dando melhor aproveitamento à palha (picada e seca) proporcionando meios de gerar/manter vantagem competitiva, lucratividade e sustentabilidade.

Por esse levantamento feito e pela proposta de aplicação ilustrada, as questões relativas à sustentabilidade foram trabalhadas porque há potencial de ganho ambiental pela substituição da limpeza tradicional (com água, sem separação da palha) pela limpeza a seco (sem água, com separação da palha); de ganho econômico, em razão do VPL positivo; de ganho social, pela redução da utilização de captação de rios e mananciais, pelo aumento do uso geração de energia limpa pela queima eficiente da palha separada, trazendo resultados relevantes numa época de escassez de recursos hídricos e combate a todas as formas de poluição.

Este trabalho tratou de temas atuais, no que tange ao consumo de recursos naturais, a partir da aplicação de conhecimento sistematizado e tecnológico, pois muitas organizações encontram-se diante do aumento da pressão dos stakeholders para fazer negócios de uma maneira sustentável e, além disso, por uma série de circunstâncias, a sociedade civil, em geral, vem aprofundando o debate sobre essas questões ambientais.

Suporte financeiro: Este trabalho foi realizado com o apoio da Educação e Coordenação e Aperfeiçoamento de Pessoal de nível Superior - CAPES - Brasil.

\section{REFERÊNCIAS}

[1] BERGMILlER, G.G.; MCCRIGHT, P.R. Are lean and green programs synergistic? Industrial Engineering Research Conference. Disponível em: http://zworc.com/site/publications_assets/AreLeanAndGreenProgramsSynergistic.pdf, 2009.

[2] BERTHOLEY, F.; BOURNIQUEL, P.; RIVERY, E.; COUDURIER, N.; FOLLEA, G. Work organization improvement methods applied to Blood Transfusion Establishments (BTE): Lean Manufacturing, VSM, 5S. Transfusion Clinique et Biologique. Vol 16, N 2, PG 93-100, 2009. 
[3] BRUNILDE V.; BERTRAND R.; CAILLAUD E; REMITA, H. Combining organizational performance with sustainable development issues: the Lean and Green project benchmarking repository. Journal of Cleaner Production DOI: 10.1016/j.jclepro.2013.12.023, 2013.

[4] CAPES, Periódicos. Disponível em: http://periodicos.capes.gov.br.ez100.periodicos.capes.gov.br/index.php. Acesso em 27/05/2014.

[5] CTC - Centro de tecnologia canavieira. Disponível em: http://www.ctcanavieira.com.br. Acesso em: $02 / 10 / 2014$.

[6] DEDINI. Disponível em: file://C:/Documents\%20and\%20Settings/megoncales/Meus\%20documentos/Downloads/slc_pt\%20(1).pdf. Acesso em02/02/2015.

[7] DÜES, C. M.; TAN, K. H.; LIM, M. Green as the new Lean: how to use Lean practices as a catalyst to greening your supply chain. Journal of Cleaner Production, 40, 93 - 100 - DOI: 10.1016/j.jclepro.2011.12.023, 2013.

[8] ELIA NETO, A; SHINTAKU. Usos e reusos de água e geração de efluentes. Manual de Conservação e reuso de água na Agroindústria Sucroenergética. Agência Nacional de Águas; Federação das Indústrias do estado de São Paulo; União da Indústria da cana-de-açúcar; Centro de Tecnologia Canavieira.Cap. 5, p. 69 - 176. Brasília, 2009.

[9] EMBRAPA. Disponível em: http://www.agencia.cnptia.embrapa.br/gestor/cana-deaçúcar/arvore/CONTAG01_102_22122006154841.html. Acesso em 25/11/2014.

[10] Jotform. Software de pesquisa. Disponível em http://www.jotform.com/myforms. Acesso em 07/06/2014.

[11] KASAHARA, E. S.; CARVALHO, M. M; "Análise dos Modelos TQM e Seis Sigma: estudo de múltiplos casos". Anais: In XXIII ENEGEP - Encontro Nacional de Engenharia de Produção. Ouro Preto. Porto Alegre: V. 1, p. 1-8. UFRGS, 2003

[12] MANO, Y., AKOTEN, J., YOSHINO, Y., SONOBE, T. Teaching KAIZEN to small business owners: An experiment in a metalworking cluster in Nairobi. Journal of the Japanese and International Economies. Volume 33, páginas 25-42, setembro 2014

[13] MIGUEL, P. A. C., Estudo de caso na engenharia de produção: Estruturação e recomendações para sua condução. Produção, v. 17, n. 1, p. 216-229, Jan./Abr, 2007.

[14] OMENA, S. P. F.; CALlADO, N. H.; PEDROSA, V. A.; PIMENTEL, I. M. C.; MENEZES, A. C.; TORQUATO JR, H.; LOPES, J.C.; SILVA, J.B. Melhoria da qualidade ambiental, por meio da recirculação de água de limpeza da cana-deaçúcar na indústria sucro-alcooleira. VII Simpósio de Recursos Hídricos do Nordeste 30 de novembro a 3 de dezembro de 2004.

[15] PAQUES. Disponível em: http://br.paques.nl/aplicaces/other/reutilizaco-da-agua. Acesso em 04/11/2014.

[16] PAYNE J. H., Operações unitárias na produção de açúcar de cana-de-açúcar. Honolulu, Havaí. Empresa de consultoria e projetos para fábricas de açúcar. Nobel/STAB, 1990.

[17] PIACENTE F. J. Agroindústria canavieira e o sistema de gestão ambiental: o caso das usinas localizadas nas bacias hidrográficas dos rios Piracicaba, Capivari e Jundiaí. Universidade Estadual de Campinas - UNICAMP. Instituto de Economia. Programa de pós-graduação em desenvolvimento econômico. Dissertação de mestrado, 2005.

[18] ROTHER, M.; SHOOK, J. Learning to See: Value Stream Mapping to Add Value and Eliminate Muda.The Lean Enterprise Institute, Inc. One Cambridge Center, Cambridge, Ma 02142 USA, 102 pgs, 2003.

[19] SBA - 13o Seminário Brasileiro Agroindustrial; STAB - Açúcar, Álcool e Subprodutos; CTC - Centro de Tecnologia Canavieira, Ribeirão Preto, out 2012. Suleiman Hassuani, Disponível em: http://www.stab.org.br/13_sba_palestras/06_STAB_2012_Suleiman.pdf. Acesso em 30/12/2014.

[20] SINDIQUÍMICOS. Disponível em: http://sindiquimicos.com.br/2012/portal/index.php/noticias/115mediacao-mpv-647-2014, acesso em: 27/01/2015.

[21] STAB - Açúcar, Álcool e Subprodutos. Disponível em:

http://www.stab.org.br/index.php?option=com_content\&view=article\&id=32\&Itemid=44. Acesso em: 02/10/2014

[22] STUPIELLO, J. P. Conversando com a cana-de-açúcar. Stab açúcar, álcool e subprodutos, vol 32. № 3, 2014.

[23] UDOP. Disponível em: http://www.udop.com.br/index.php?item=noticias\&cod=29960. Acesso em $07 / 11 / 2014$.

[24] VERRIER, B.; ROSE, B.; CAILLAUD, E.; REMITA, H. Combining organizational performance with sustainable development issues: the Lean and Green project benchmarking repository. Journal of Cleaner Production. DOI:10.1016/j.jclepro.2013.12.023, Volume 85, Pages 83-93, 15. December 2014.

[25] WOMACK, J. P.; JONES, D. T. Lean Thinking: Banish Waste and Creat the Wealth in Your Corporation. New York: Simon and Schuster, p.165-208, 1998 


\section{Capítulo 15}

Utilização do Controle Estatístico do Processo (CEP) para o monitoramento do teor de umidade dos grãos de soja armazenada no Silo Agro Verde

\section{Claudilaine Caldas de Oliveira \\ Adriana de Souza Ferreira de Oliveira \\ Leandro Flora \\ Antônio Renato Pereira Moro}

Resumo: Este artigo trata da aplicação do Controle Estatístico do Processo (CEP) para a monitoração e controle dos grãos de soja armazenado no Silo Agro Verde na cidade de Boa Esperança - PR. A finalidade da pesquisa é identificar o momento adequado para intervir no controle da temperatura interna do silo, com o processo de resfriamento, denominado aeração. Tendo em vista, que o resfriamento do silo, sem a verificação do teor de umidade da soja, poderá desencadear vários danos e a perda da qualidade da soja. Como metodologia, objetivando realizar os cálculos para a elaboração do gráfico de controle e a análise do mesmo, esta pesquisa utilizou-se do método quantitativoqualitativo. Para a coleta de dados foram usadas as técnicas descritivas e exploratórias. Foi monitorado o teor de umidade dos grãos e elaborados gráficos de controle, podendo assim, identificar que a umidade dos grãos não apresenta um comportamento estável, sendo que a presente pesquisa demonstrou para a empresa que é possível fazer o controle da umidade e desencadear o processo de aeração somente quando for necessário. Assim, os resultados obtidos podem auxiliar na tomada de decisão, ou seja, no controle da temperatura interna do silo e que a adoção do monitoramento das variáveis de qualidade utilizando o CEP como rotina de trabalho são medidas imprescindíveis para a permanência da qualidade dos grãos.

Palavras-chave: Controle da Temperatura, Umidade dos Grãos, Cartas de Controle. 


\section{INTRODUÇÃO}

A armazenagem da produção de soja em silos corresponde a um dos mais importantes papéis a serem observados pelo agente responsável pela Gestão de Qualidade da produção de grãos. 0 principal mecanismo utilizado por este gestor é o do controle das variáveis referentes à qualidade dos grãos, ou seja, conservar o grão sem que haja danificação. Cada oscilação requer atenção e cuidados para que a qualidade dos grãos se mantenha.

Conforme Athié et al. (1998), os grãos com aspecto sadio podem ser prejudicados devido a forma como foi armazenado, existem fenômenos que são irreversíveis como por exemplo a deterioração. Boas técnicas de armazenamento podem permitir que isso não se propague rapidamente.

De acordo com Ferrasa (2008), alguns fatores interferem diretamente na qualidade dos grãos armazenados, como: a temperatura da massa de grãos, teor de umidade dos grãos, umidade relativa do ar, composição química, danos mecânicos, impurezas, insetos e fungos.

Um controle adequado se faz pelo monitoramento das variáveis dos grãos, com o intuito de evitar perdas na produção e conseqüentemente manter a qualidade e maximizar os lucros.

A estocagem dos grãos tem por finalidade o poder de barganha, no sentido que as vendas serão realizadas com o objetivo de especulação dos preços, além de manter abastecido o mercado consumidor. Todavia, nem sempre é realizado da forma adequada, sendo necessário utilizar de técnicas ou ferramentas da qualidade para o monitoramento dos grãos.

o Controle Estatístico do Processo (CEP) tem aplicações em vários segmentos de processo, com o intuito de monitorar e melhorar o desempenho operacional.

Para Corrêa e Corrêa (2004), o fundamento essencial do CEP é acompanhar os processos por meio do comportamento das estatísticas de suas saídas, separando as causas naturais das especiais de variações e tomar ações de correção quando uma causa especial é detectada.

Diante do exposto, este estudo tem por objetivo geral monitorar por meio do CEP o teor de umidade dos grãos armazenados nos Silos Agro Verde associando-os com as temperaturas internas do silo, para proporcionar melhorias na qualidade dos mesmos, evitando as perdas provenientes de grãos avariados, uma vez que controlado o processo de armazenamento.

\section{REVISÃO DE LITERATURA}

A busca incessante pela qualidade de produtos deve nortear os objetivos centrais de uma organização. 0 gestor de qualidade responsável por este controle, responsável pela garantia de satisfação dos clientes de uma corporação detêm em seu alcance algumas ferramentas, que utilizadas adequadamente, poderão garantir a qualidade do produto.

A gestão da qualidade é dividida em ferramentas estatísticas e metodologia da qualidade, dos programas e sistemas relativos à qualidade, dentre os quais, para o presente estudo denominado como Controle da Qualidade (CQ).

Para Souza (2008) o CQ consiste no desenvolvimento de sistemas que monitoram o projeto, o processo de fabricação e a assistência técnica de um produto ou de um serviço. Para o trabalho em questão o CQ incide na conservação de suas características enquanto armazenadas.

Para que o programa de controle da qualidade funcione, se faz necessária à utilização das ferramentas estatísticas que são indispensáveis para o gerenciamento de processos produtivos, especialmente no monitoramento e implantação de rotinas (OLIVEIRA; MEDEIROS; KOVALESKI, 2009).

Este CQ utilizará a ferramenta da qualidade, o Controle Estatístico de Processo (CEP) que é uma metodologia estatística muito útil no gerenciamento de processos, pois sua utilização proporciona um melhor controle e consequentemente uma maior eficiência produtiva para empresa.

Souza e Rigão (2005) descrevem que o CEP é uma metodologia que atua preventivamente sobre o processo produtivo com a utilização da estatística como instrumento básico para avaliar alterações e buscar do aperfeiçoamento contínuo da qualidade.

Dentro deste contexto, os gráficos ou cartas de controle são considerados no CEP uma das suas ferramentas mais importantes, que monitora e verifica os resultados de diversas amostras colhidas ao longo de um período de tempo. Esses gráficos podem ser por atributos, ou por variáveis. 
Os gráficos de controle por atributos se referem às características de qualidade que classificam itens em conformes e não conformes, enquanto que os gráficos de controle por variáveis baseiam-se na medida das características de qualidade do produto em uma escala contínua.

Todo processo de armazenagem dos grãos apresenta variações, sendo que estas podem causar a instabilidade do processo e assim prejudicar a qualidade dos grãos. Nesse sentido, o presente trabalho utilizará do gráfico de controle por variáveis com a função de monitorar e manter o processo de armazenagem sob controle, monitorando as variáveis de umidade nos grãos estejam conforme a especificação estabelecida.

Assim, com a utilização do CEP permite a verificação do controle da qualidade, fazendo uso dos processos estatísticos, que se exteriorizará pelo monitoramento dos grãos enquanto estocado nos silos.

\section{PROCEDIMENTO METODOLÓGICO}

0 método de abordagem adotado foi o quantitativo-qualitativo. 0 método foi quantitativo devido à realização de cálculos matemáticos baseados em Siqueira (1997), utilizando pela aplicação do Controle Estatístico de Processo (CEP), tendo por objetivo estabelecer relações entre variáveis que possam interferir na qualidade final dos grãos armazenados.

Por sua vez o objeto de análise foi qualitativo para as observações durante a coleta dos dados precisamente as notas de campo extraídas pela observância do comportamento da temperatura dos grãos enquanto armazenados nos silos e também na análise dos resultados com a aplicação do CEP.

De acordo com Vergara (2007) as pesquisas são classificadas quanto aos fins e quanto aos meios. A pesquisa aqui relatada classifica-se, quanto aos fins, como descritiva e exploratória, quanto aos meios, como bibliográfica, de campo e estudo de caso.

Para a coleta de informações foram realizadas observações não participativas do processo de armazenagem, conversas informais com os colaboradores responsáveis pelos setores, de classificação, de armazenagem e estocagem, com o agrônomo responsável pelo silo, entrevistas não estruturadas com um dos sócios da empresa, todos os responsáveis pelos departamentos, totalizando sete entrevistas, tudo para se identificar qual seria variável a ser pesquisada. De posse de todos estes dados optou-se pela concentração do estudo na identificação dos fatores que influenciavam as variações da umidade da soja estocada.

Os dados pertinentes ao presente trabalho foram coletados do interior do silo pelo classificador com a utilização do aparelho denominado calador. Cujo objetivo era o aferimento da umidade da soja. Para a verificação da temperatura, foi utilizado o aparelho de termometria. Assim, os dados anotados referentes à temperatura foram confrontados com o teor da umidade dos grãos a fim de verificar possíveis relações entre eles.

Após classificar os parâmetros a serem analisados estatisticamente e a coleta destes, manipulou-se e tabularam-se os dados por meio dos gráficos de Controle $\bar{X}-\mathrm{R}$, gerados por planilhas eletrônicas, sendo estes analisados e interpretados.

\section{RESULTADOS E DISCUSSÕES}

O acompanhamento da temperatura no interior do silo é uma variável que influencia o estado de conservação dos grãos, pois com o aumento da temperatura, aumenta a umidade, quanto mais elevada, mais úmido será o grão. E a alta umidade influi na qualidade da soja. De modo que qualquer aumento ou variação brusca de temperatura deve dar início à investigação das causas e possíveis medidas para solucionar o problema. Uma das medidas adotadas pela empresa é a realização do processo de aeração ${ }^{10}$.

Todavia, o processo de aeração deve ser realizado somente se a umidade do grão estiver alta, caso contrário o grão perde peso, e por conseqüência há diminuição do volume armazenado, o que acarreta prejuízos para empresa.

\footnotetext{
${ }^{10}$ A aeração consiste no resfriamento dos grãos, e de acordo com Weber (2005), é necessária para "a manutenção dos grãos armazenados, sem prejuízo da qualidade e da quantidade da massa armazenada, por meio de um sistema de ventilação mecânico".
} 
Assim, além de aumento da temperatura no interior do silo, para dar início ao processo de aeração, é necessário que haja aumento de umidade. Tal fato não é verificado pela empresa. De modo que, no intuito de provar que muitas vezes a aeração é desnecessária e prejudicial para o grão armazenado é necessário além de controlar a temperatura, mensurar o teor de umidade dos grãos.

Para acompanhar o teor de umidade dos grãos de soja e a temperatura interna do SILo X, foram coletadas as amostras no mês de Agosto de 2011 durante 10 dias e em horários diferentes, conforme a tabela 1.

Tabela 1 - Dados das Amostras

\begin{tabular}{|c|c|c|c|c|c|}
\hline \multicolumn{6}{|c|}{ Valores das Amostras por Teor de Umidade (\%) } \\
\hline Amostras & $\begin{array}{c}\text { Manhã } \\
\text { X1 }\end{array}$ & $\begin{array}{c}\text { Meio-dia } \\
\text { X2 }\end{array}$ & $\begin{array}{c}\text { Tarde } \\
\text { X3 }\end{array}$ & $\overline{\mathrm{X}}$ & $\overline{\mathrm{R}}$ \\
\hline 1 & 15,2 & 15,5 & 15,0 & 15,23 & 0,50 \\
\hline 2 & 14,2 & 15,6 & 15,3 & 15,03 & 1,40 \\
\hline 3 & 13,8 & 13,9 & 13,6 & 13,77 & 0,30 \\
\hline 4 & 13,5 & 13,6 & 13,4 & 13,50 & 0,20 \\
\hline 5 & 14,0 & 14,2 & 14,2 & 14,13 & 0,20 \\
\hline 6 & 15,0 & 16,1 & 16,0 & 15,70 & 1,10 \\
\hline 7 & 14,0 & 13,8 & 13,5 & 13,77 & 0,50 \\
\hline 8 & 13,5 & 13,6 & 13,3 & 13,47 & 0,30 \\
\hline 9 & 13,0 & 13,4 & 14,0 & 13,47 & 1,00 \\
\hline 10 & 14,6 & 14,9 & 14,6 & 14,70 & 0,30 \\
\hline & & & Média $=$ & 14,28 & 0,58 \\
\hline
\end{tabular}

Para verificar a umidade dos grãos, foram realizadas coletas dos mesmos, três vezes por dia, por volta de 8h00 a primeira, a segunda coleta próximo ao meio dia e a terceira no final da tarde, sendo que a amostra era de $60 \mathrm{~g}$ (sessenta gramas), retiradas de diversos pontos do silo.

Com a utilização do aparelho de umidade denominado megametro, a amostra selecionada sofre uma compressão de $575 \mathrm{~kg}$ (quinhentos e setenta e cinco quilos) de pressão. Ao término da compressão o aparelho revela o teor de umidade.

A tabela 1 representa a quantidade de dias e amostras realizadas. Onde $\overline{\mathrm{X}}$ representa as médias de cada amostra coletada, ao final encontra-se sua respectiva média $(\overline{\mathrm{X}})$. A coluna $\mathrm{R}$ (amplitude) é representa a diferença entre o maior e o menor valor que compõem a amostra, ao final desta coluna a média da somatória das amplitudes $(\overline{\mathrm{R}})$.

Por intermédio dos dados obtidos na Tabela 1, calculou-se os limites superior LCS e inferior LCIX de controle através das fórmulas matemáticas (1) e (2) conforme apresentadas abaixo:

$$
\begin{array}{r}
\operatorname{LCS}_{x}=\overline{\bar{X}}+A_{2} \times \bar{R} \\
\operatorname{LCS}_{X}=14,28+1,023 \times 0,58=14,87
\end{array}
$$

$$
\begin{aligned}
& \mathrm{LCI}_{x}=\overline{\overline{\mathrm{X}}}-\mathrm{A}_{2} \times \overline{\mathrm{R}} \\
& \mathrm{LCI}_{\mathrm{X}}=14,28-1,023 \times 0,58=13,68
\end{aligned}
$$

Para os cálculos, utilizou-se os valores dos coeficientes $A_{2}, D_{3}$ e $D_{4}$ retirados da tabela do Grant e Leavenworth (apud Kume, 1993, p. 225), pois estes dependem do tamanho da amostra. 0 tamanho da amostra conforme pode ser observado, o tamanho da amostra utilizado foi três de acordo com o número de elementos que compõem as amostras $\left(\mathrm{X}_{1}\right.$ a $\left.\mathrm{X}_{3}\right)$. Desta forma os valores correspondentes dos coeficientes são: $A_{2}: 1,023 ; D_{3}: 0$ e $D_{4}: 2,575$.

Após obter os limites de controle, elaborou-se a carta de controle $\overline{\mathrm{X}}$ conforme mostra a figura 1 . A carta $\overline{\mathrm{X}}$ é composta por uma a linha central $(\overline{\bar{X}}=14,28)$ representando a média do processo e as duas linhas nas extremidades que representam os limites superiores e inferiores de controle $\left(\mathrm{LCS}_{\mathrm{X}}=8,88\right.$ e $\left.\mathrm{LCI}_{\mathrm{X}}=7,69\right)$. 
A linha $\overline{\mathrm{R}}$ demonstra o quanto variou a umidade dos grãos no período analisado. A variação de umidade ocorreu em razão do aumento da temperatura externa que influenciou a temperatura interna do silo, como adiante será demonstrada pela tabela 3. Neste caso, em que a umidade superou a máxima tolerável a aeração é aconselhada como medida preventiva.

\section{Figura 1 - Carta de Controle $\overline{\mathrm{X}}$}

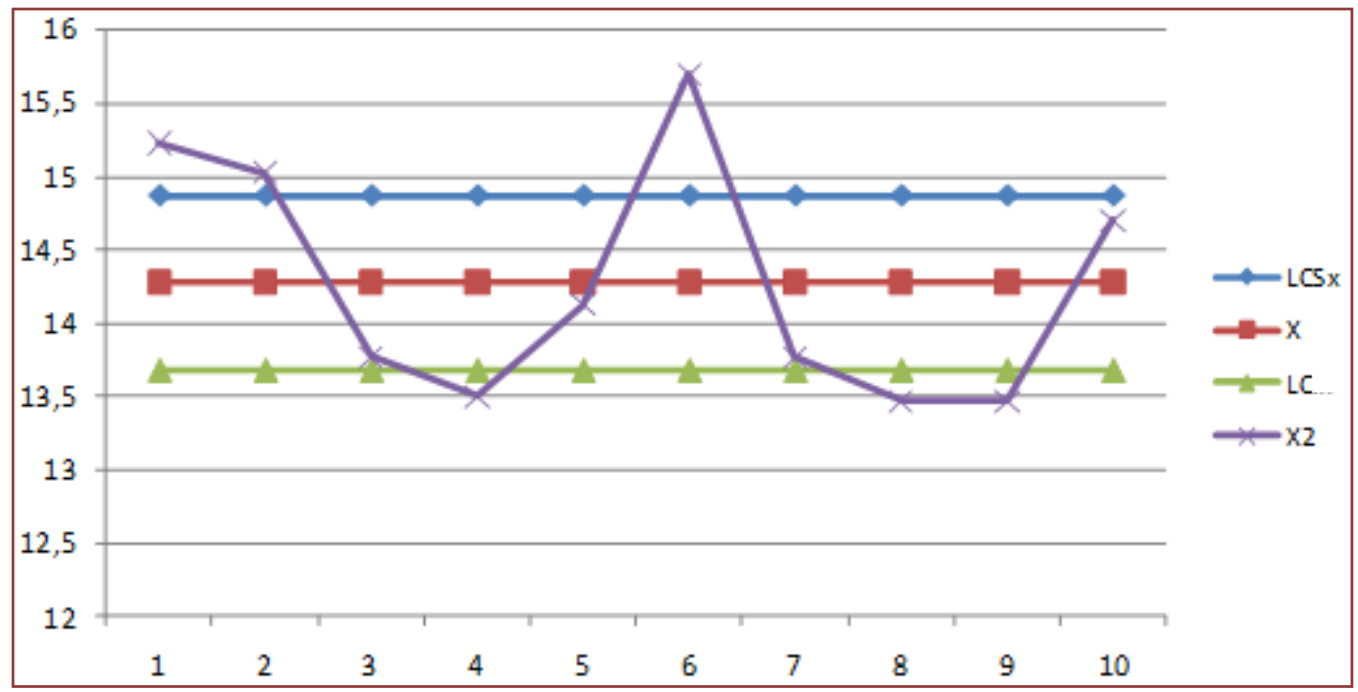

Observa-se que as amostras um e dois excedem a linha superior, o que demonstra o alto teor de umidade, ocasionado pelo aumento da temperatura. Tal fato levou a empresa a fazer o processo de aeração. Este processo resfriou o interior do silo e abaixou a umidade, ao ponto que a amostra quatro ficasse abaixo da linha de controle inferior.

A amostra seis demonstrou a mesma situação, o aumento da temperatura aumentou a umidade dos grãos e a aeração realizada pela empresa resultou na queda da umidade verificada nas amostras oito e nove.

A partir das amplitudes $(\overline{\mathrm{R}})$ das amostras obtidas na Tabela 2. Calcularam-se os limites de controle superior $\left(L C S_{R}\right)$ e inferior $\left(L_{C} I_{R}\right)$ de controle para carta de controle $\bar{R}$ por meio das fórmulas (3) e (4) conforme apresentado na seqüência.

$$
\begin{aligned}
& \mathrm{LCS}_{\mathrm{R}}=\mathrm{D}_{4} \overline{\mathrm{R}} \\
& \mathrm{LCS}_{\mathrm{R}}=2,575 \times 0,58=1,49 \\
& \mathrm{LCI}_{\mathrm{R}}=\mathrm{D}_{3} \overline{\mathrm{R}} \\
& \mathrm{LCI}_{\mathrm{R}}=0 \times 0,58=0
\end{aligned}
$$

Após obtenção dos limites de controle elaborou-se a carta de controle $\overline{\mathrm{R}}$, como pode ser visualizando na figura 2, na qual é composta por uma linha central que representa a média das amplitudes $(\bar{R}=0,58)$ e duas linhas que representam os limites superiores e inferiores de controle $\left(\mathrm{LCS}_{\mathrm{R}}=1,49\right.$ e $\mathrm{LCI}_{\mathrm{R}}=0$ ). 0 objetivo desta carta é facilitar a visualização da amplitude das amostras, além de auxiliar na identificação de causas especiais. 
Figura 2 - Carta de Controle $\overline{\mathrm{R}}$

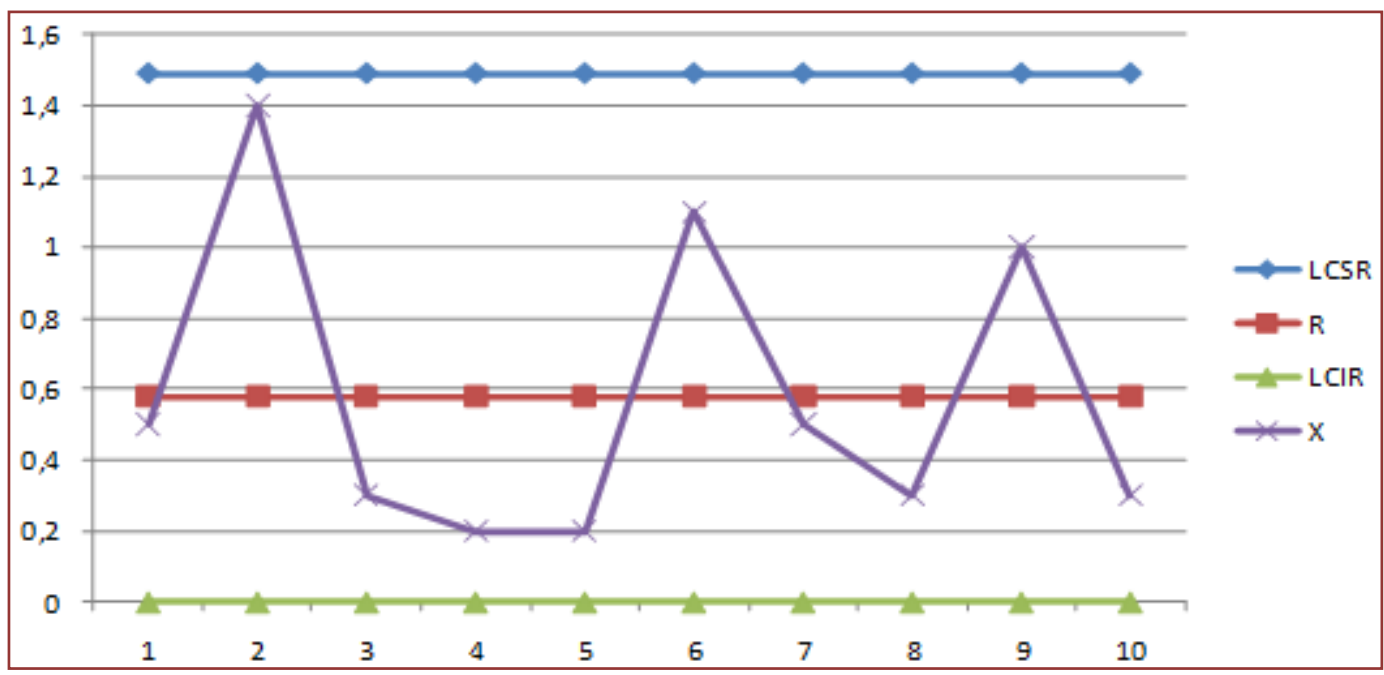

Esta carta de controle permite a visualização da amplitude das amostras, que como pode ser observado permaneceu de acordo com o esperado sem avanço dos limites tanto superiores quanto inferiores.

Durante os 10 dias que foram coletados as amostras, foi aferida a temperatura no interior do silo. Segundo Romagnolo (2011), sócio da empresa Agro Verde, a temperatura no interior do silo necessariamente deve ser de no máximo 30ำ para manter conservada a soja sem quaisquer riscos de deteriorização.

A coleta de dados foi realizada, após as instruções do classificador, com a utilização do aparelho destinado a termometria. Este aparelho é conectado em painel de controle fixado na parede externa do silo, por intermédio de um cabo. Dentro do silo ele se conecta com outros cinco cabos, equipados com seis sensores cada, distribuídos de forma vertical, em pontos distintos no interior, conforme figura 3.

Figura 3 - Silo com cabos de controle para mediçào da temperatura

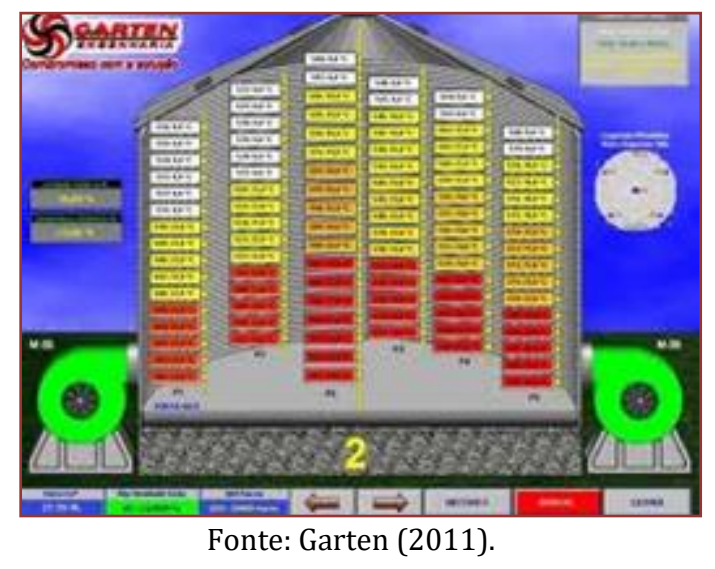

A figura 4, demonstra o painel de controle, o aparelho de termometria verifica as temperaturas de cada cabo individualmente. 
Figura 4 - Painel de Controle do aparelho de termometria

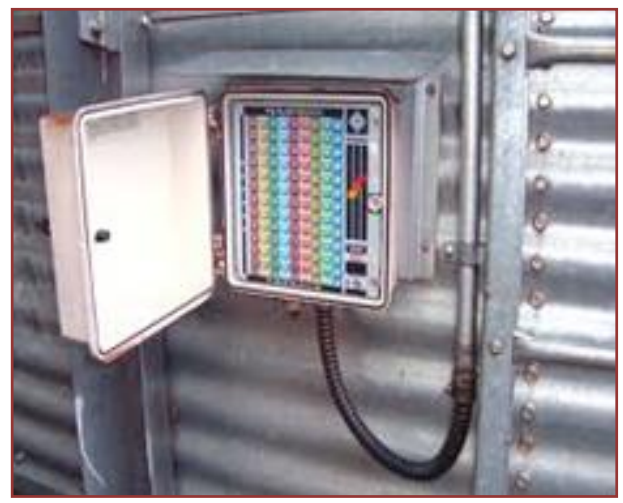

Fonte: Garten (2011).

O objetivo da coleta de temperatura foi verificar as variações de umidade enquanto armazenados, a fim de identificar se há relação entre a temperatura no interior do silo e a umidade dos grãos. A tabela a seguir, demonstra a temperatura no interior do silo.

A tabela 2 representa as datas e as distribuições das temperaturas de cada cabo no interior do silos. As linhas demonstram a data e a temperatura dos grãos estocados, distribuidos em cada cabo, bem como a média diária da temperatura obtida com a soma de cada cabo e a respectiva divisão.

Tabela 2 - Tabulação dos dados de Temperatura do Silo

\begin{tabular}{|c|c|c|c|c|c|c|}
\multicolumn{7}{|c|}{ Amostras de Temperatura (ํㅡ) Interna do Silo } \\
Amostra & CB1 & CB2 & CB3 & CB4 & CB5 & MÉDIA \\
\hline 1 & 30,33 & 29,83 & 32,67 & 30,50 & 32,00 & 31,06 \\
\hline 2 & 30,00 & 30,17 & 32,67 & 32,17 & 33,71 & 31,74 \\
\hline 3 & 25,10 & 24,50 & 24,75 & 25,15 & 26,50 & 25,20 \\
\hline 4 & 24,00 & 23,83 & 24,00 & 19,17 & 26,57 & 23,51 \\
\hline 5 & 23,83 & 23,33 & 23,50 & 19,17 & 27,43 & 23,45 \\
\hline 6 & 32,50 & 33,50 & 33,50 & 33,50 & 34,00 & 33,40 \\
\hline 7 & 26,50 & 25,00 & 24,75 & 25,67 & 26,50 & 25,68 \\
\hline 8 & 23,83 & 23,00 & 22,83 & 23,50 & 22,57 & 23,14 \\
\hline 9 & 23,50 & 23,55 & 23,00 & 23,20 & 22,71 & 23,19 \\
\hline 10 & 28,50 & 28,33 & 28,33 & 29,50 & 30,00 & 28,93 \\
\hline
\end{tabular}

Algumas variações de temperatura podem ser percebidas, isto em razão da variação da temperatura externa. Em dias mais quentes é possível perceber um aumento da temperatura interna do silo. Também é possível perceber variações de temperatura no mesmo dia e em pontos diferentes do interior do silo. İsto ocorre, segundo Romagnoli (2011), engenheiro agrônomo responsável pelo silos, pela presença de impurezas, ainda que pequenas e por grãos quebrados. Tal fênomeno ocorre pela falta de oxigenação naqueles pontos, pois as impurezas e grãos quebrados se ligam intensamente bloqueando a passagem de ar.

De acordo com a tabela 2 as amostras um, dois e seis demonstraram o aumento da temperatura com relação aos demais dias, observando a Carta de Controle $\overline{\mathrm{X}}$ nota-se que em igual período houve o aumento da umidade dos grãos. Nos demais dias, três, quatro, cinco, sete, oito, nove e dez, pôde ser observado a dimuição de temperatura, que por consequência reduziu a umidade da soja, de acordo com a carta de controle mencionada.

\section{CONSIDERAÇÕES FINAIS}

A partir da análise dos resultados encontrados foi possível constatar que a temperatura no interior dos silos é determinante para umidade dos grãos. Por sua vez a temperatura externa influencia a interna dos silos. 
O controle de umidade é fundamental para a conservação dos grãos. A umidade interfere diretamente no peso, na textura, em aspectos que interferem a qualidade, como mofos, queimados, chocos, ardidos e avariados. Como já mencionado não é realizada pela empresa um controle de umidade. A Empresa controla a temperatura no interior do silo, e se estiver elevada é realizado o processo de aeração. Este processo consiste em um sistema de ventilação mecânico que gera custos para empresa.

Além disto, fazer a aeração em grãos com padrões normais de umidade pode ser danoso. Isto porque o processo faz com que seque os grãos. E o grão seco perde peso e consistência. A perda de peso acarreta diminuição do volume do estoque. E a conseqüência é a perda de lucros.

Devido o auxílio das cartas de controle a Empresa Agro Verde pode monitorar com precisão a umidade dos grãos. E evitar processos de aerações desnecessários. Evitando custos e deterioração da soja estocada.

A aplicação do CEP, por intermédio de cartas de controle por variáveis, visou primeiramente monitorar o comportamento da temperatura dos grãos enquanto estocados. A utilização dessas cartas permitiu verificar quando os resultados obtidos são afetados por causas especiais de variação, ou seja, quando os mesmos ultrapassam os limites de controle inferior e superior da carta de controle.

Com a utilização do CEP, foi observado que os pontos que indicaram variação, aumento da umidade dos grãos, têm como justificativa o aumento da temperatura no interior do silo. Os resultados obtidos demonstraram eficiência no controle da umidade no processo de estocagem. Também que o uso dessa ferramenta de monitoramento é bastante prática e de fácil manuseio.

Todavia, para a sua aplicação na empresa Agro Verde é necessário a contratação ou treinamento de um funcionário para que este fique incumbido deste afazer. É preciso que a direção da empresa esteja consciente da importância de seu uso, pois as vantagens são inúmeras, basta perceber que com este controle poderá intervir auxiliar na tomada de decisões adequadas para o controle da umidade dos grãos estocados.

Assim, sugere-se que a empresa adote a implantação do CEP, utilizando as cartas de controle, para a continuidade no monitoramento da umidade dos grãos e outras variáveis que influenciam na qualidade do mesmo. Para que haja esta implantação, existe a necessidade da conscientização e treinamento dos funcionários da empresa sobre a importância do controle de qualidade, conceitos elementares de estatística devem ser abordados, de tal modo a Empresa obterá uma estabilidade nos grãos armazenados e consequentemente uma redução de perdas.

Em razão do enfoque do presente estudo, não se fez maiores explanações sobre como a empresa deve fazer a implementação do CEP. Isto porque o objetivo, com a ajuda desta ferramenta, era monitorar o processo de umidade e de temperatura dos grãos para identificar eventuais problemas.

Os problemas foram identificados e os erros apontados. Portanto, uma vez que a utilidade e a importância do CEP foram demonstradas o ideal seria que novas pesquisas fossem realizadas a fim de se identificar qual a melhor forma para implementar o CEP e as demais ferramentas do controle de qualidade. Cujo objetivo seria determinar a relação custo/benefício, a ponto de ser satisfatória para o Silo Agro Verde.

\section{REFERÊNCIAS}

[1] ATHIÉ, Ivania. et. al. Conservação de grãos. Campinas: Fundação Cargil. 1998.

[2] CORRÊA, Henrique Luiz; CORRÊA, Carlos Alberto. Administração de produção e operações: manufatura e serviços - uma abordagem estratégica. São Paulo: Atlas, 2004.

[3] FERRASA, Marcelo. Sistema de monitoramento de temperatura e umidade em silos graneleiros via rádio. 2008. 107 f. Tese (Doutorado em Energia na Agricultura). Faculdade de Ciências Agronômicas, Universidade Estadual Paulista, Botucatu, 2008. Disponível em: htpp:// http://www.fca.unesp.br/pos_graduacao/Teses/PDFs/Arq0352.pdf. Acesso em 15 out. 2011.

[4] GARTEN AUTOMAÇÃO. Gartem Engenharia: Compromisso com a Solução. Pelotas: 2011. Disponível em: www.garten.com.br. Acesso em: 22 out. 2011.

[5] KUME, H. Métodos Estatísticos para Melhoria da Qualidade. São Paulo: Editora Gente, 1993.

[6] OLIVEIRA, Claudilaine Caldas de; MEDEIROS, Jefferson Nascimento; KOVALESKI, João Luiz. O Controle Estatístico de Processo (CEP) aplicado ao pré-resfriamento do Abate de Aves; Congresso Internacional de Administração - ADM 2009; Ponta Grossa; BRASIL; Português. 
[7] ROMAGNOLO, Mauro. Informações de temperaturas internas no silo. Entrevista Concedida em Boa Esperança - PR. Agosto de 2011.

[8] SIQUEIRA, Luiz Gustavo Primo. Controle Estatístico de Processos. Equipe Grifo - Série Qualidade Brasil, Livro n. 9. São Paulo: Pioneira, 1997.

[9] SOUZA, Alexandre Amorim de. Principais ferramentas de gestão empresarial para a busca da qualidade. São Paulo, 10 fev 2008. Disponível em: http://www.administradores.com.br/informe-se/artigos/principais-ferramentasde-gestao-empresarial-para-a-busca-da-qualidade/21112/. Acesso em 08 dez 2011.

[10] SOUZA, Adriano Mendonça; RIGÃo, Maria Helena. Identificação de variáveis fora de controle em processos produtivos multivariados. Revista Produção on-line, v. 15, n. 1, p. 74-86, 2005.

[11] VERGARA, Sylvia Constante. Projetos e relatórios de Pesquisa em Administração. 8 ed. São Paulo: Atlas, 2007.

[12] WEBER, Érico Aquino. Excelência em beneficiamento e armazenagem de grãos. Vicoça: Universo Agricola. 2005. 


\section{Capítulo 16}

Utilização de abordagem sistêmica para proposta de solução de problemas construtivos em reservatório de água elevado em edifício residencial

\section{Carla Vitor Paim}

White José dos Santos

Antônio Cleber Gonçalves Tibiriçá

Resumo: 0 pensamento sistêmico é uma forma utilizada para descrever, analisar e compreender as forças e inter-relações das partes constituintes de um sistema como, por exemplo, uma obra de edificação. Mediante observação do comportamento do sistema e articulação dos seus subcomponentes, componentes e subsistemas com o sistema principal, facilita-se o planejamento e o controle de projetos, auxiliando na tomada de decisão de uma situação. Este capítulo tem como objetivo utilizar o pensamento sistêmico para definir a melhor proposta de solução do problema de infiltração da água de um reservatório elevado no teto da casa de máquinas de um edifício multifamiliar. A metodologia tem como base a abordagem sistêmica e pesquisa de campo e estudo da situação existente no reservatório, buscando identificar cada elemento e suas interações no sistema reservatório elevado e deste com o macrossistema -o próprio edifício-. Como resultado tem-se alternativas de solução para cada subsistema; interrelacionadas, obtiveram-se três propostas de solução. 0 caso estudado permite perceber e compreender a diversidade de possibilidades levantadas para a solução de um problema, e uma possível forma de escolher a mais adequada com vistas à organização e programação de uma atividade corretiva para o problema.

Palavras-chave: Abordagem Sistêmica; Problemas Construtivos; Reservatório de Água. 


\section{INTRODUÇÃO}

As tecnologias e o conjunto de informações disponíveis atualmente podem gerar uma grande diversidade de alternativas possíveis para resolver determinado problema na construção civil. Nessa área, o recurso do pensamento sistêmico pode auxiliar na tomada de decisão de uma situação problemática, observandose a sua articulação em termos de subcomponentes, componentes, subsistemas e sistema principal. Mandolesi (1981) e Ribeiro e Michalka (2003) descrevem a importância do pensamento sistêmico para o planejamento e o controle de empreendimentos, ressaltando a grande necessidade deste para a perfeita execução dos trabalhos. Afirmam que esse processo permite entender melhor, na Construção Civil, cada parte constituinte de uma obra de edificação e suas interações. 0 benefício fundamental da tecnologia do pensamento sistêmico é o aumento do entendimento do sistema e dos processos de construção, facilitando, assim, as atividades de planejamento, projeto, execução e manutenção e, consequentemente, permitindo resolver uma série de fatores conflitantes como: clientes $\mathrm{x}$ investidores; tempo vs custo; qualidade vs custo; funcionalidade vs produção vs montagem; normalização vs agilidade (SILVA, 2007; BRAGA, 2012).

Para as atividades de avaliação e diagnósticos de manifestações patológicas, o planejamento e o controle apoiado pelo pensamento sistêmico são importantes (SOUZA et al., 2016; LORDSLEEM Jr.; FARO, 2017; PEREIRA et al., 2020; PEREIRA; SILVA; HAMADYK, 2020). Estas ferramentas permitem melhor conduzir a execução dos trabalhos e a implantação de soluções em produtos e serviços de forma inovadora, que auxiliarão na melhoria da qualidade (LIMA, 2019; ROZENFELD et al., 2006). Na aplicação do pensamento sistêmico, as manifestações patológicas na Construção Civil associadas às várias técnicas permitem analisar e solucionar problemas causados tanto por projetos mal elaborados quanto pela má execução da obra. Tem-se como as principais técnicas: Matriz de Priorização - GUT; Análise SWOT; Plano de Ação, utilizando a ferramenta 5W2H; Fluxogramas; Matriz Morfológica; e Matriz de Responsabilidades (ROZENFELD et al., 2006; RIBEIRO; MICHALKA Jr., 2003).

Com essas considerações, neste capítulo recorre-se a ferramentas do pensamento sistêmico para estudar possíveis soluções para o problema de infiltração de água numa casa de máquinas de elevadores de um edifício multifamiliar devido a um reservatório elevado (RE), situação aqui denominada como Sistema Reservatório Elevado (SRE). Esse local do estudo apresenta um conjunto de manifestações patológicas decorrentes da falha no sistema de impermeabilização do SRE e situações conflitantes que condicionam possibilidades de solução.

Do exposto, destaca-se que, aplicando-se o pensamento sistêmico, o foco é identificar cada elemento e suas interações dentro do SRE e deste com o sistema principal, o Edifício A (macrossistema), gerando um conjunto de informações e possibilidades que auxiliem na melhor tomada de decisão para resolver o problema existente.

\section{METODOLOGIA}

A partir de uma visita exploratória ao SRE, e tendo como suporte a Teoria dos Sistemas, passou-se à investigação do caso da situação problematizada. Portanto, os procedimentos metodológicos tiveram início com a visita ao local para se ter clareza quanto ao objeto, a definição do escopo do estudo (caracterização do sistema) e a respectiva identificação de cada parte constituinte (subsistemas, componentes e subcomponentes) e suas interações com o Edifício A (macrossistema).

Para se caracterizar a situação problematizada e contextualizada sua localização, identificaram-se os problemas encontrados no objeto de estudo e foram analisados os aspectos econômico, social e ambiental de inserção do Edifício A. A fim de sistematizar o contexto da situação-problema, foram identificados também os pontos fortes e fracos, as ameaças e oportunidades do objeto de estudo. Seguiu-se a contextualização sistêmica do SRE do Edifício A, levando-se em conta o contexto e as circunstâncias de ocorrência da situação problematizada e das condições operacionais para se construir e apresentar alternativas de solução. Isso permitiu e facilitou desdobrar o SRE em suas partes constituintes (subsistema; componente; subcomponente), assim como descrevê-las e inter-relacioná-las.

Em seguida, foram pesquisados processos operacionais, métodos construtivos e alternativas tecnológicas que melhor se enquadravam na solução do problema e se compôs um conjunto de recursos possíveis de serem realizadas para cada subsistema, recorrendo-se a uma matriz morfológica e a uma matriz de responsabilidades. 
Diante das informações disponíveis sobre mão de obra, materiais e tecnologias adequadas, restrições orçamentárias e de bibliografia especializada, passou-se a investigar e analisar possibilidades de solução dos problemas associados a cada subsistema do SRE. Essas possibilidades foram interrelacionadas para a criação de propostas de solução que definiam processos operacionais, métodos construtivos e alternativas tecnológicas para a fase de intervenções no SRE, com repercussões na rotina do Edifício A.

Para escolher a melhor proposta de solução, foram realizadas análises qualitativas e quantitativas, suportadas por quadros e tabelas. Na análise qualitativa, foi feita a avaliação das vantagens e desvantagens de cada proposta. $\mathrm{Na}$ avaliação quantitativa, foram definidos pesos e notas para os critérios que se julgaram relevantes, segundo as condições mais aceitáveis para execução da obra e a posterior manutenção do reservatório elevado. Para o contexto do SRE, foram atribuídos pesos aos condicionantes de obra e manutenção do reservatório e foi definida uma escala de notas de 1 a 5, no qual 5 representa a melhor solução possível para cada condicionante. Fez-se uma ponderação dos pesos atribuídos e das notas estabelecidas.

Por fim, escolheu-se uma alternativa, optando-se pela proposta que apresentava o maior valor total ponderado, sendo desenvolvida uma solução para a situação-problema, levando-se em consideração os contextos econômico, social e ambiental para o SRE e o macrossistema.

\section{ESTUDO DE CASO: SISTEMA RESERVATÓRIO ELEVADO DO EDIFÍCIO A}

\subsection{CONSIDERAÇÕES GERAIS}

O edifício do caso de estudo (Edifício A) está localizado na área central da cidade de Viçosa-MG, na região da Zona da Mata. Esta cidade tem clima tropical de altitude, com verão chuvoso e temperaturas amenas.

A situação-problema decorre da infiltração da água do reservatório elevado (RE) na casa de máquinas, localizada logo abaixo do RE. As ocorrências são manifestações visualmente constatadas como consequência da situação identificada: microfissuras no reservatório elevado; perda de desempenho do sistema de impermeabilização do reservatório superior; umidade superficial e intersticial no teto e nas paredes da casa de máquinas; gotejamento na caixa de luz no teto da casa de máquinas; complexidade da manutenção / limpeza do RE, pelo difícil acesso; deficiências no subsistema de drenagem de água pluvial e de limpeza.

São restrições relacionadas ao contexto do RE: o abastecimento de água não pode parar durante o tempo de obra; prazo máximo de seis semanas para resolver o problema, com os menores transtornos possíveis para os moradores; orçamento de $\$ 30$ mil, podendo-se admitir acréscimo durante a obra, limitado a $25 \%$, se autorizado por assembleia de proprietários; a solução deve possuir facilidade de execução e de manutenção.

\subsection{PONTOS FORTES E FRACOS, AMEAÇAS E OPORTUNIDADES}

A fim de sistematizar o contexto da situação-problema do Edifício A, foram identificados os pontos fortes e fracos, as ameaças e oportunidades do objeto de estudo (ver Quadro 1).

Quadro 1 - Análise do cenário do SRE no contexto do Edifício A.

\begin{tabular}{|l|l|}
\hline \multicolumn{2}{|c|}{ Pontos fortes } \\
\hline $\begin{array}{l}\text { Reservatório de água atual possui dimensões que } \\
\text { possibilitam várias alternativas de solução. }\end{array}$ & $\begin{array}{l}\text { Casa de máquinas localizada logo abaixo do Sistema } \\
\text { Reservatório Elevado (SRE) }\end{array}$ \\
\hline $\begin{array}{l}\text { Espaço suficiente na cobertura do Edifício A para } \\
\text { instalação de reservatório temporário. }\end{array}$ & Reservatório elevado com impermeabilização comprometida \\
\hline $\begin{array}{l}\text { A existência do reservatório inferior possibilita o } \\
\text { abastecimento temporário do edifício. }\end{array}$ & $\begin{array}{l}\text { Dificuldade de acesso de equipamentos, materiais e mão de } \\
\text { obra ao SRE. }\end{array}$ \\
\hline & Existência de apenas uma célula o reservatório elevado. \\
\hline & $\begin{array}{l}\text { Dificuldade e pouca segurança no acesso à laje de cobertura e } \\
\text { ao interior do reservatório elevado. }\end{array}$ \\
\hline
\end{tabular}


continuação...

Quadro 1 - Análise do cenário do SRE no contexto do Edifício A.

\section{Oportunidades}

Aprendizado com a situação-problema.

Facilidade de acesso a profissionais de Engenharia da

Construção na Universidade Federal de Viçosa.

Facilidade de acesso a informações atualizadas de

soluções construtivas.

\section{Ameaças}

Carência de mão-de-obra especializada na região

Execução da obra fora do prazo e acima do limite orçamentário definido.

Possível paralisação do abastecimento de água durante a execução da obra.

Não encontrar recursos adequados para a solução do

problema na região.

\subsection{CONTEXTUALIZAÇÃO SISTÊMICA DO EDIFÍCIO A}

A Figura 1 apresenta a árvore relacional do desdobramento do SRE e as Figuras 2 a 8 as árvores relacionais dos subsistemas do SRE identificados no estudo de caso. Ao se perceber as interligações entre cada parte do sistema, foi possível analisar de forma mais detalhada e precisa as partes que podem sofrer alterações conforme as escolhas a serem tomadas para solucionar o problema. Os subsistemas desdobram-se em componentes e subcomponentes, para melhor entender a articulação de cada parte e suas possíveis soluções.

Figura 1 - Árvore relacional do sistema reservatório elevado.

\begin{tabular}{|c|c|}
\hline $\begin{array}{c}\text { Reservatório superior e casa } \\
\text { de máquinas }\end{array}$ \\
\hline
\end{tabular}

Conforme a Figura 1, foi considerado como sistema o reservatório de água elevado e a casa de máquinas. Como subsistemas, definiram-se as instalações elétricas, instalações hidráulicas, circulações, cobertura, vedações, sustentação e impermeabilização. A seguir são apresentados os subsistemas e seus respectivos componentes e subcomponentes:

a) instalações elétricas: na Figura 2, têm-se os componentes: descargas atmosféricas, que corresponde ao conjunto de partes que tem por função descarregar sobrecargas oriundas de raios, sendo que o existente não atende à norma; equipamentos de controle de enchimento do reservatório elevado, que correspondem a sensores capazes de identificar quando o RE está vazio ou cheio; controle dos elevadores; iluminação, compreendendo o conjunto de partes capazes de prover a iluminação necessária nos ambientes do SRE.

b) instalações hidráulicas: conforme esquema na Figura 3, corresponde ao conjunto de tubulações e equipamentos aparentes ou embutidos nas paredes, destinados ao transporte, disposição e/ou controle de fluxo de fluidos (fluidos com sólidos em suspensão, água ou gases) em uma edificação. Decompõem-se em: prevenção de incêndio (partes capazes de promover o abastecimento da rede de hidrantes para o combate a incêndio); abastecimento (partes capazes de distribuir a água potável do RE para os apartamentos e áreas sociais do edifício - problemas devido à não existência de duas câmaras no RE); recalque (partes que permitem a elevação da água do reservatório inferior até o RE com o auxílio de eletrobomba); e drenagem (partes capazes de retirar águas não potáveis e convergi-las para o sistema de captação pluvial e daí para a rede urbana: drenagem pluvial, limpeza do reservatório e extravasor de reservatório). 
Figura 2 - Árvore relacional do subsistema instalação elétrica.

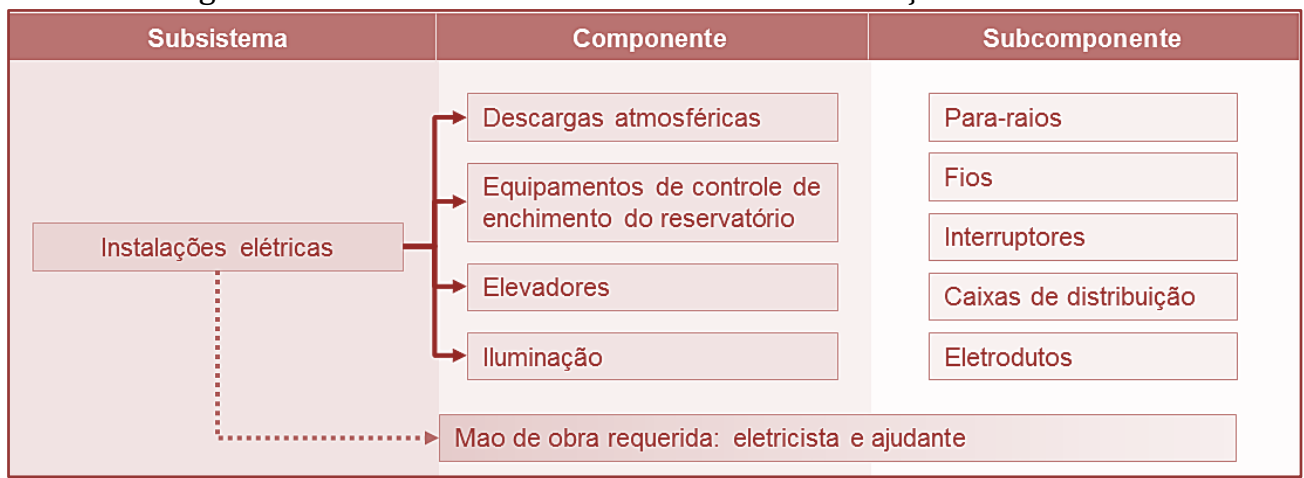

Figura 3 - Árvore relacional do subsistema instalação hidráulica.

\begin{tabular}{|c|c|c|}
\hline Subsistema & Componente & Subcomponente \\
\hline & Prevenção de incêndio & Bomba \\
\hline & Abastecimento & Tubos \\
\hline Instalações hidráulicas & Recalque & Conexões \\
\hline$\vdots$ & Drenagem: pluvial, de & Calha \\
\hline$\vdots$ & ladrão & Automático \\
\hline & ao de obra requerida: bc & inte \\
\hline
\end{tabular}

c) circulação: compreende-se as partes que permitam o acesso tanto à cobertura como ao reservatório elevado, para visitas e/ou manutenção destes. Constatou-se a precariedade do acesso existente, sendo composto por: escadas de acesso à cobertura, escada de marinheiro de acesso ao reservatório elevado e corredores técnicos de manutenção, que permitem a manutenção da cobertura do Edifício A. A Figura 4 mostra a subdivisão desse subsistema.

Figura 4 - Árvore relacional do subsistema circulação.

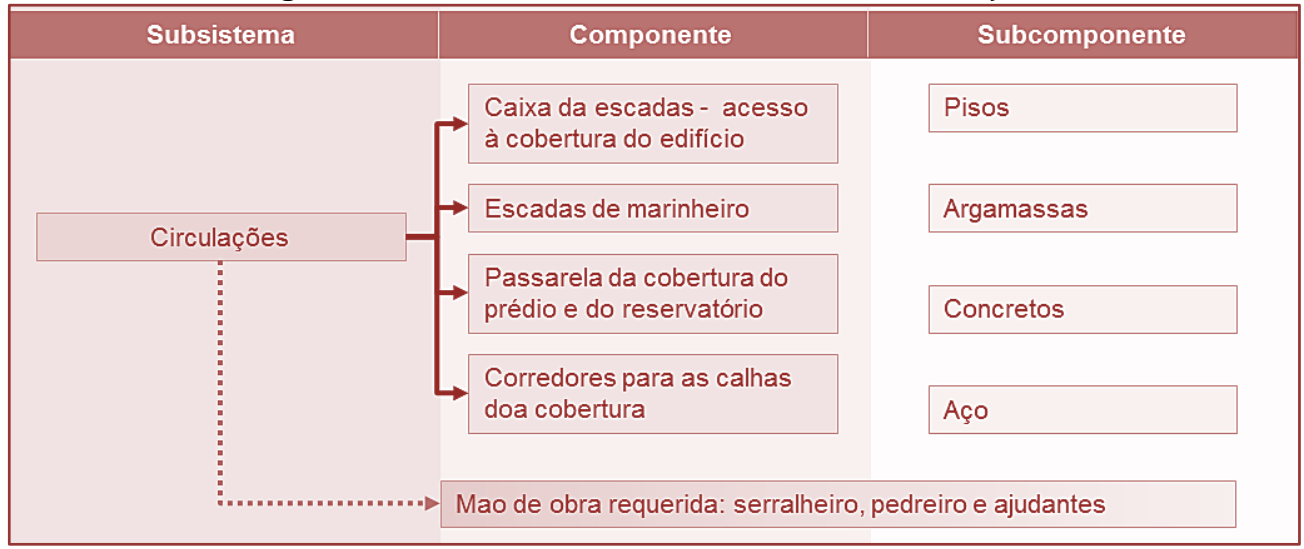

d) cobertura: a Figura 5 detalha a divisão desse subsistema e sua interação. Compreende: o telhado na cobertura dos apartamentos, bastante danificado devido ao uso; a laje do teto da casa de máquinas, que está com deterioração do revestimento e da armadura devido à presença de umidade; a laje da tampa do reservatório elevado também se apresenta com acentuada deterioração e exposição de armadura, causada por cobrimento insuficiente da armadura e pela ação de produtos químicos presentes na água tratada do reservatório. 
Figura 5 - Árvore relacional do subsistema cobertura.

\begin{tabular}{|c|l|l|l|}
\hline Subsistema & \multicolumn{1}{c|}{ Componente } & \multicolumn{1}{c|}{ Subcomponente } \\
\hline Cobertura & Telhado do prédio & Perfis metálicos \\
\hline & & Telha \\
\hline & Laje de cobertura do RS & Sarafusos \\
\hline
\end{tabular}

e) vedação: o subsistema vedação compreende os componentes: paredes da casa de máquinas e do reservatório, grades, portas e janelas, que se destina a separar os ambientes (Figura 6).

Figura 6 - Árvore relacional do subsistema vedações.

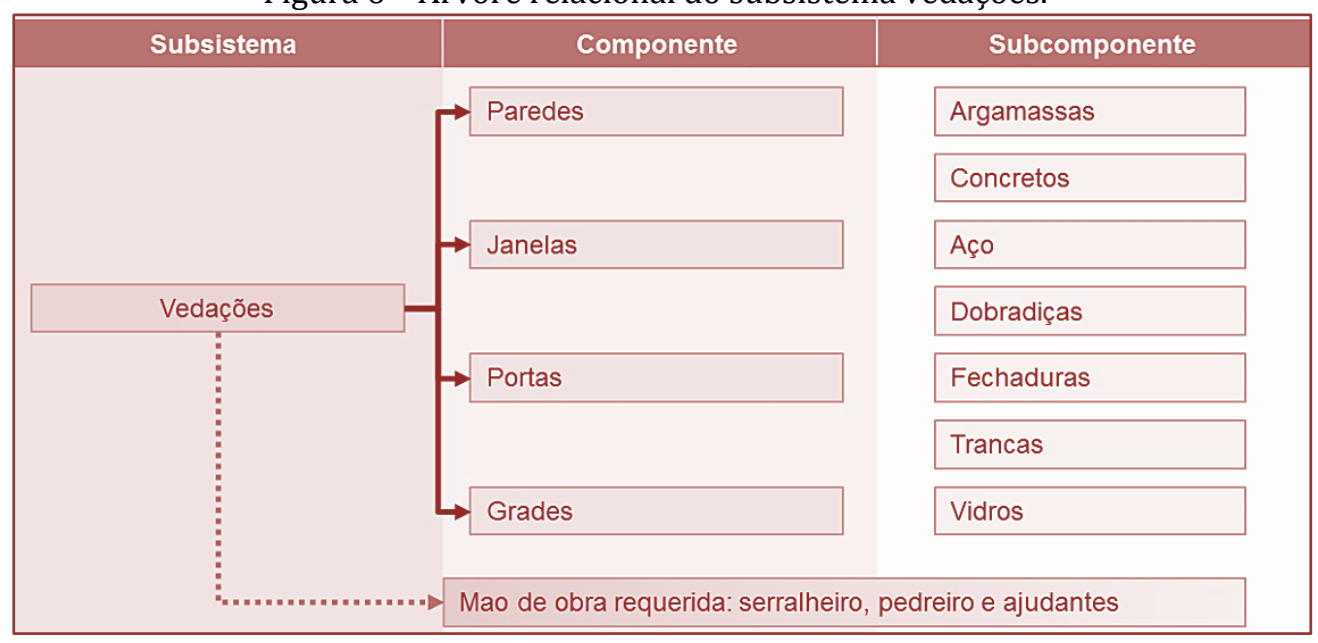

f) Sustentação: corresponde as partes capazes de suportar as cargas oriundas do peso próprio e de sobrecargas atuantes nas estruturas do Edifício A. Pode ser decomposta em: vigas paredes (paredes laterais do RE que têm a função de suportar as ações decorrentes do empuxo de água no interior do reservatório); laje de sustentação da casa de máquinas (destina-se a suportar as ações oriundas do peso da coluna de água dentro do reservatório), pilares, vigas e laje da caixa de escada (elementos que recebem todas as cargas decorrentes do peso da água do RE e da casa de máquinas). A Figura 7 retrata esse subsistema.

Figura 7 - Árvore relacional do subsistema sustentação.

\begin{tabular}{|c|c|c|}
\hline Subsistema & Componente & Subcomponente \\
\hline & $\begin{array}{l}\text { Vigas-paredes do } \\
\text { reservatório }\end{array}$ & Concretos \\
\hline \multirow[t]{3}{*}{ Sustentação } & Laje de sustentação & Aço \\
\hline & $\begin{array}{l}\text { Pilares e vigas da caixa de } \\
\text { escada }\end{array}$ & Madeira \\
\hline & o de obra requerid & dr \\
\hline
\end{tabular}


g) impermeabilização: consiste no problema central deste trabalho, no qual a falha na impermeabilização do reservatório (laje da casa de máquinas) está causando danos às instalações elétricas e aos quadros de comandos dos elevadores (Figura 8).

Figura 8 - Árvore relacional do subsistema impermeabilização.

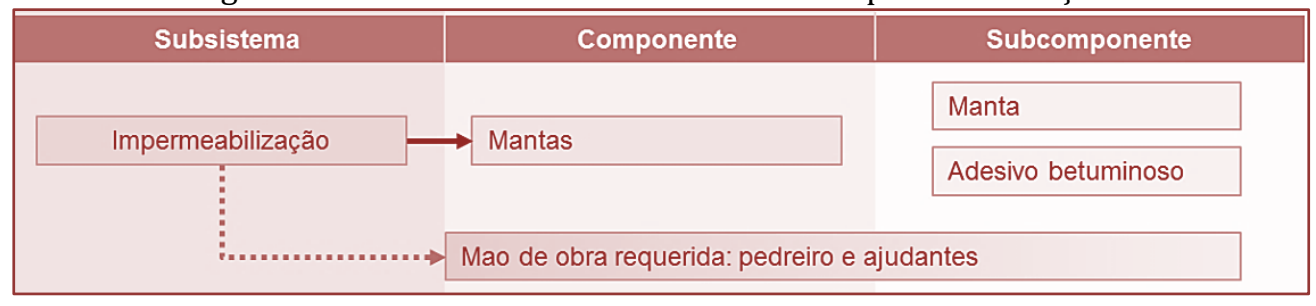

\subsection{ALTERNATIVAS DE SOLUÇÃO PARA A SITUAÇÃO PROBLEMA}

A fim de sistematizar o contexto e o entendimento dos fatores da situação-problema, foram detalhados e analisados os processos operacionais, métodos construtivos e alternativas tecnológicas para cada subsistema do objeto de estudo. Diante disso, identificou-se um elevado número de possibilidades e de interações admissíveis entre eles. Foram então, estruturados três esquemas que ilustram possibilidades de sequência de atividades (e suas interações) para a solução do problema de infiltração de água do SRE (Figuras 9, 10 e 11). Essas possibilidades podem ser compreendidas como:

a) primeira proposta: retratada na Figura 9, consiste na demolição manual da laje da tampa do RE, preservando as paredes do reservatório elevado, e instalação de dois reservatórios de polipropileno. 0 acesso ao RE seria por meio de nova escada de marinheiro e plataforma de serviço em estrutura metálica. Execução de impermeabilização somente na laje de fundo do RE. A parte elétrica de iluminação e sensores seria refeita de forma correta (sem improvisações). A parte hidráulica: de abastecimento, de incêndio e de drenagem da água pluvial, de limpeza do reservatório e de ladrão seriam novas, de forma a atender condições normativas e limitações espaciais do local de aplicação. Construção de um telhado em estrutura metálica sobre os dois reservatórios de polipropileno. Para essa proposta, seria construída uma estrutura de içamento e uma plataforma de serviço em estrutura metálica no topo do prédio para transporte e instalação dos reservatórios de polipropileno, das novas telhas metálicas, perfis metálicos e outros materiais que forem necessários. Instalação de reservatórios temporários de fibra de vidro (2 reservatórios de 2000 litros cada) para atender ao abastecimento e incêndio durante a obra.

b) segunda proposta: esquematizada na Figura 10, a solução propõe a manutenção das vigasparedes e do fundo do reservatório superior, a construção de uma parede de concreto armado dividindo-o em duas câmaras conjugadas para armazenamento de água, a demolição manual da laje de cobertura do RE (deterioração elevada) e reconstrução de outra com duas aberturas maiores (uma por câmara), de modo a facilitar o acesso e a manutenção do RE. Seria feita pequena parede em alvenaria de vedação sobre o reservatório, propiciando o uso da laje como plataforma de serviço. 0 acesso ao RE seria por meio de uma escada de marinheiro. Seria feita nova impermeabilização com manta em todo o reservatório (fundo, paredes, laje de fundo e topo do reservatório), mantendo-se o sistema existente (redução de entulho). Ao fim do processo, a realização de prova de carga é imprescindível para verificação da estanqueidade do subsistema. A parte elétrica de iluminação e sensores seria refeita de forma correta (sem improvisações). A parte hidráulica de abastecimento, incêndio, drenagem da água pluvial, limpeza do reservatório e do ladrão seriam refeitas de forma a atender condições normativas e limitações do local de aplicação. Ressalta-se que as ligações e registros seriam colocados externamente ao reservatório e próximo à escada de acesso, permitindo que as operações de manutenção sejam facilitadas. Estrutura de içamento: guinchos de coluna. Também seriam instalados reservatórios temporários de fibra de vidro (2 reservatórios de 2000 litros cada) para atender ao abastecimento e incêndio durante a obra. 
Figura 9 - Fluxograma esquemático para a primeira proposta de solução do problema de infiltração de água causado pelo SRE.

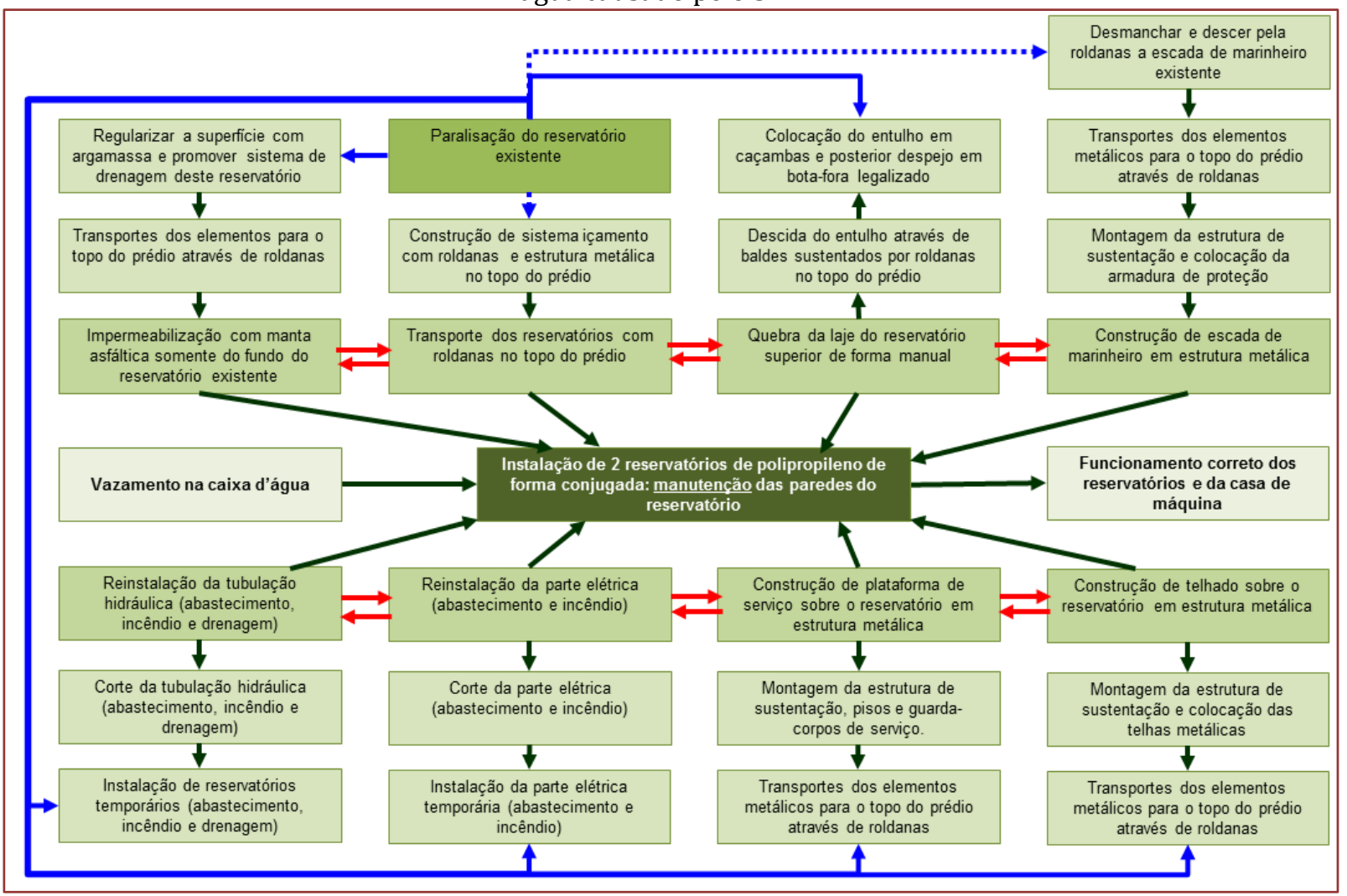

Figura 10- Fluxograma esquemático da segunda proposta de solução do problema de infiltração de água causado pelo SRE. As diferenças entre a primeira e a segunda propostas estão marcadas na cor lilás.

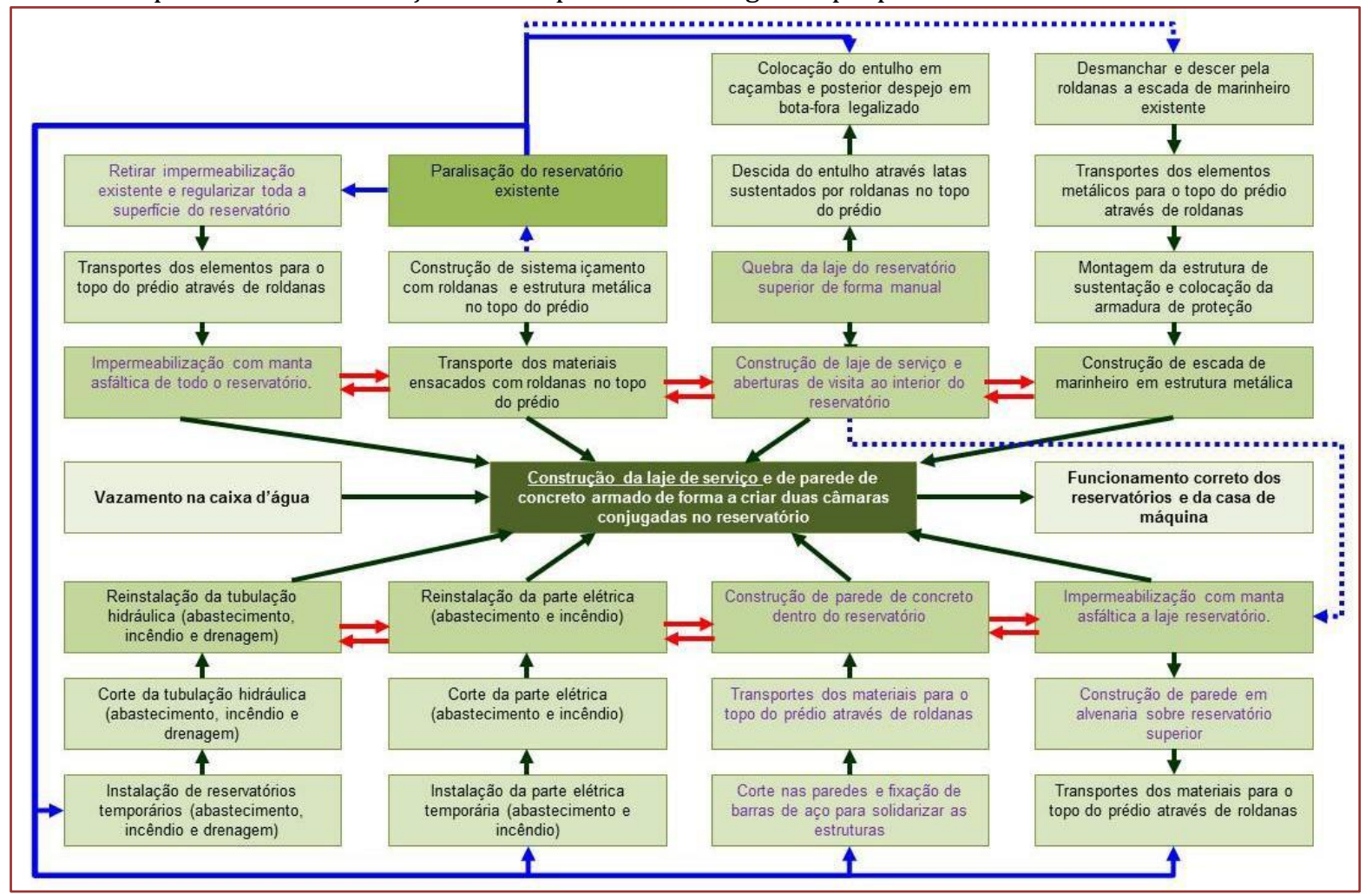


c) terceira proposta: o processo construtivo da terceira proposta é o mesmo da segunda (Figura 11), diferenciando-se apenas na alternativa tecnológica construtiva da parede que cria as duas câmaras conjugadas no interior do reservatório superior e recuperação da laje de forro existente no RE. Nesse caso, seria construída uma parede de tijolo maciço com armadura embutidas dentro das juntas argamassadas.

Figura 11 - Fluxograma esquemático para terceira proposta de solução do problema de infiltração de água causado pelo SRE. As diferenças entre a segunda e a terceira propostas estão marcadas na cor vermelha.

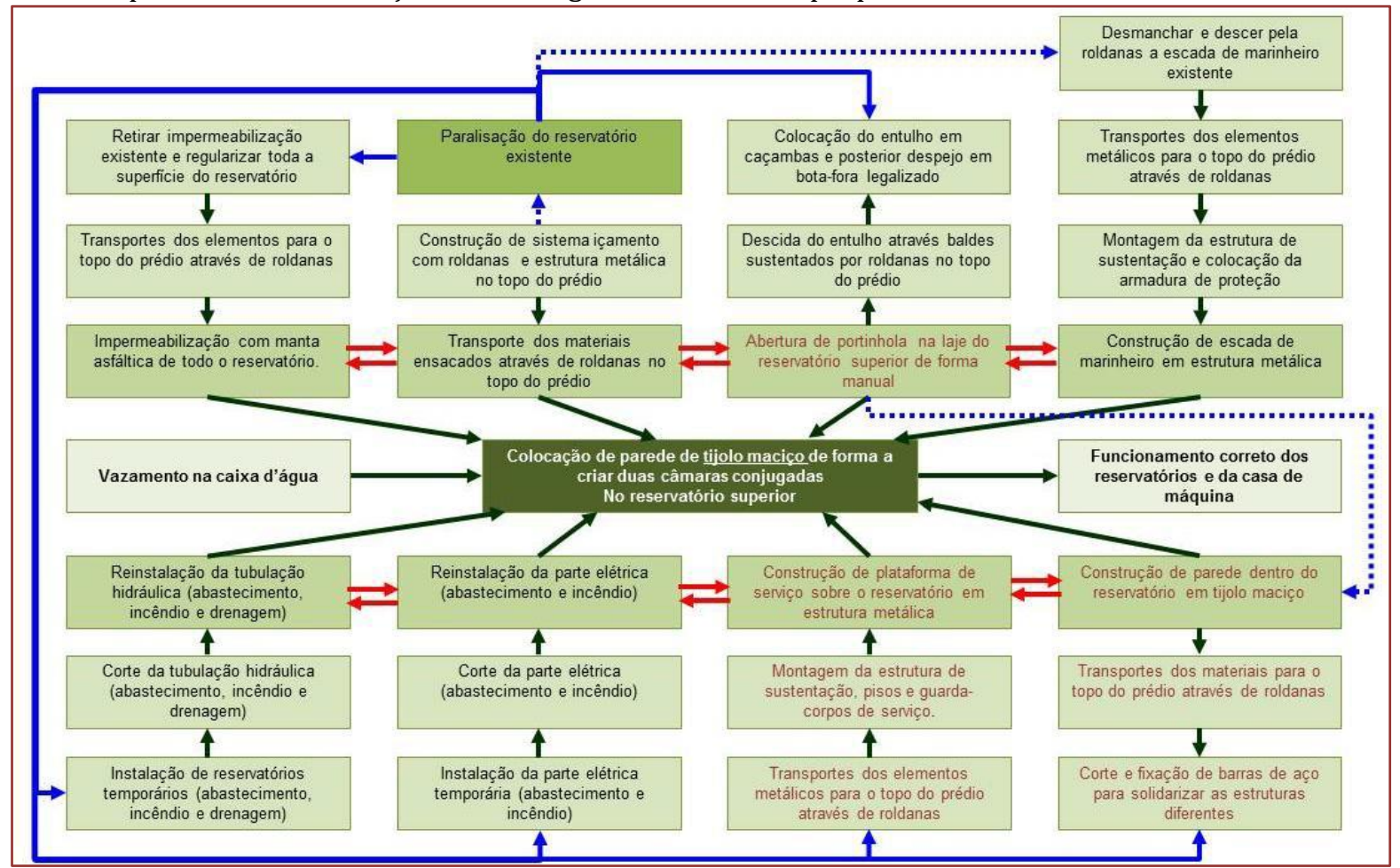

\subsection{AVALIAÇÃO E SELEÇÃO DAS PROPOSTAS}

A escolha da melhor proposta exigiu que se levantassem vantagens e desvantagens de cada alternativa. Para isso, primeiramente foram analisadas vantagens e desvantagens de cada uma, de maneira mais subjetiva/qualitativa. Depois se organizou uma avaliação quantitativa, conforme Quadro 2, buscando assim a proposta que permitisse resolver o problema do SRE e ficasse dentro do orçamento e dos prazos aceitáveis.

Quadro 2 - Procedimento para seleção das propostas.

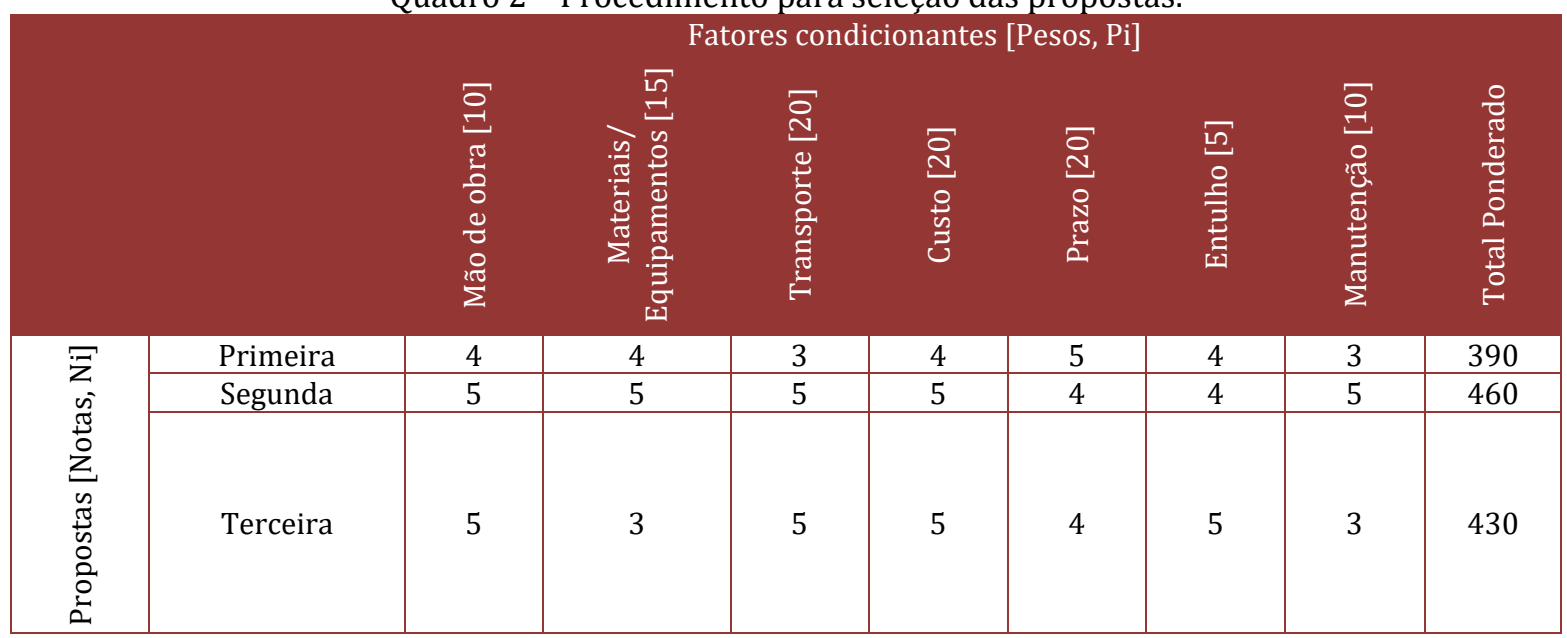


Atribuíram-se pesos para os condicionantes de obra e pós-obra mais importantes para a solução do problema no SRE. Quanto melhor a qualidade, facilidade ou disponibilidade de realização do condicionante, maior será a sua nota. Para isso foi estabelecida uma escala de notas de 1 a 5 (5 representa a melhor situação possível para o condicionante). Além disso, foram aplicados pesos para cada condicionante, avaliado por especialistas em função da relevância, importância para o desenvolvimento das atividades de execução da obra e para fins de manutenção do RE (Quadro 2).

Ponderando-se notas ( 1 a 5 ) com os pesos atribuídos, obteve-se um total para cada proposta, o que permitiu ranqueá-las. A ponderação foi obtida por meio da equação 1.

$$
\text { Total }=\Sigma \mathrm{Ni} . \mathrm{Pi}
$$

[Equação 1]

Analisadas de forma sistêmica e sistemática das propostas pelo Quadro 2, tem a segunda proposta como mais vantajosa (maiores valores) e, numa análise mais ampla e global, constatou-se também que esta permitirá maior conforto durante a manutenção, custos e prazos aceitáveis e facilidade de execução (materiais, mão de obra, equipamentos e transporte), sendo escolhida para detalhamento final e possível execução no Edifício A.

\subsection{PROPOSTA DE SOLUÇÃO PARA A SITUAÇÃO-PROBLEMA}

A reforma do reservatório elevado deverá ser composta pelas seguintes atividades e ordem de execução:

a) Instalar, antes de iniciar as obras, dois reservatórios temporários de fibra de vidro com $2000 \mathrm{~L}$ na cobertura de cada um dos dois blocos de apartamentos para o abastecimento do edifício até a finalização das obras. Salienta-se que as instalações elétricas e hidráulicas devem ser dispostas nos reservatórios temporários de forma a deixá-las em condição de realizar a reconexão com o sistema principal do prédio no menor tempo possível;

b) prever em cronograma as datas em que os reservatórios temporários deverão estar prontos para instalação, com dia e horário da troca devidamente comunicada aos moradores sobre a interrupção do fornecimento de água por até duas horas;

c) prosseguir com a instalação do sistema de içamento de guincho de coluna elétrico no topo do prédio, próximo ao corredor de serviço sobre a laje de cobertura dos apartamentos;

d) proceder à demolição manual da laje de cobertura do reservatório elevado e, no local onde ficará a parede de concreto, remover todo o revestimento interno do reservatório (parede e laje de fundo) numa faixa de $60 \mathrm{~cm}$ de largura;

e) tomar uma série de cuidados para a construção da parede de concreto armado no interior do RE como: limpeza da superfície de contato, fixação de barras que a sustentarão e a garantia da qualidade/características do concreto;

f) executar a construção da laje de forro do reservatório elevado segundo processos convencionais (formas, armaduras e concretagem), e junto a parede do RE.

g) aplicar uma inclinação de $1 \%$ a $2 \%$ no revestimento da laje de forro do reservatório elevado para as instalações de captação e escoamento pluvial das águas de chuva;

h) refazer as instalações hidráulicas e elétricas, conforme as especificações de projeto e normas pertinentes;

i) construir guarda-corpo em estrutura metálica com $90 \mathrm{~cm}$ de altura no contorno do RE;

j) executar uma escada de marinheiro com proteção contra quedas;

k) dispor as instalações elétricas (sensores, tomadas e pontos de iluminação) e hidráulicas (recalque, abastecimento, extravasor, drenagem da laje de forro e limpeza) no reservatório elevado de forma a deixálas em condição de realizar a reconexão com o sistema principal do prédio no menor tempo possível; 
1) aplicar, depois que a estrutura secar, adesivo de fixação a base de resina acrílica para permitir a perfeita aderência entre a estrutura antiga e a nova estrutura de impermeabilização;

m) regularizar, antes e depois da colocação da manta betuminosa, as paredes e a laje de piso interno e de forro do reservatório elevado com argamassa de cimento e areia, mantendo-se os cantos abaulados (arredondados);

n) iniciar, posteriormente a cura do concreto da parede e da laje de forro do reservatório elevado e da argamassa de regularização, o processo de impermeabilização do reservatório (piso e paredes internas e laje de cobertura na parte externa) com manta asfáltica;

o) realizar teste de carga d'água no reservatório elevado para testar a manta de impermeabilização;

p) promover a pintura de toda a parte interna do RE (piso, paredes e teto) com tinta a base de resina epóxi para deixar a superfície mais lisa e de fácil limpeza;

q) religar as novas instalações de água com o sistema principal, conforme item 'a' e realizar testes para verificar o correto funcionamento de todo o conjunto;

r) realizar as obras de reforma das paredes externas do reservatório superior;

s) instalar um novo componente para atender as possíveis descargas atmosféricas, atendendo ao item 5.1.1.3.3 da ABNT NBR 5419: 2001.

Conclui-se todo o processo com a desmontagem do canteiro de obras (andaimes, depósito de materiais, guincho de coluna etc.).

\section{CONSIDERAÇÕES FINAIS}

O estudo de caso do SRE no Edifício A permitiu refletir a grande diversidade de possibilidades que podem ser levantadas para a resolução de um problema: no caso, a infiltração de água do reservatório superior no teto da casa de máquinas dos elevadores. Ressalta-se que a geração das alternativas decorreu de ampla discussão para aclarar e compreender as multifaces que envolviam tomar a decisão da solução entendida como a melhor para todo o contexto apresentado. Neste sentido, estabelecer o sistema, seus desdobramentos e articulações (subsistemas, componentes, subcomponentes e as bases materiais) e suas interações com o macrossistema que se circunscreveu. Consequentemente, o uso da abordagem sistêmica foi essencial para compreender como alterações em uma parte geram a necessidade de alterações devidamente coordenadas com as demais. A estruturação e o tratamento dos subproblemas sistematizada e articuladamente ampliaram os cenários e horizontes para a análise das partes constituintes do problema e suas interações, permitindo objetividade na escolha/decisão pelos interessados e envolvidos com a situação.

A metodologia proposta para a resolução do trabalho permitiu qualificar e avaliar a importância dos vários aspectos existentes e, com o apoio de especialistas, atribuir fatores de ponderação de acordo com a relevância dos critérios de julgamento, seja durante a obra ou mesmo durante a manutenção/limpeza.

A proposta escolhida foi entendida como a que permitiria a reforma/adequação do sistema reservatório elevado de água do Edifício A causando menor incômodo aos condôminos e moradores num prazo ajustado entre as partes interessadas e envolvidas em todo o processo. Além disso, parâmetros como mão de obra facilitada (no sentido de que podem ser empregados profissionais sem grandes conhecimentos específicos para realização do serviço), custo dentro do orçamento, prazos aceitáveis (expectativa de 45 dias) e a maior facilidade de realizar a limpeza do reservatório, permitiram que tal opção fosse considerada a adequada, ou seja, a segunda proposta foi considerada como a melhor em termos de viabilidade técnica, econômica e ambiental para fins de intervenção física e procedimentos de manutenção. 


\section{REFERÊNCIAS}

[1] ASSOCIAÇÃO BRASILEIRA DE NORMAS TÉCNICAS - ABNT. NBR 5419. Proteção de estruturas contra descargas atmosféricas. Rio de Janeiro. 2010.

. NBR 9575. Impermeabilização - Seleção e projeto. Rio de Janeiro. 2012.

. NBR 9574. Execução de impermeabilização. Rio de Janeiro. 2008.

[2] BAÍA, L. L. M; SABBATINI, F. H. Projeto e execução de revestimentos de argamassa. 4ạa edição. Ed. O Nome da Rosa. 2008.

[3] BRAGA, R. T. Vaccare. Engenharia reversa e reengenharia. Disponível em: http://pt.scribd.com/ doc/38229403/Engenharia-Reversa-e-Reengenharia. Acesso em: 31.mar.2012.

[4] LORDSLEEM JR., A. C.; FARO, B. H. (2017). Facade cladding detachment: Case study. Revista de la Asociación Latinoamericana de Control de Calidad, Patología y Recuperación de la Construcción. 7: 148-159.

[5] LIMA, M. G. H. (2019). Diagnosis of incidences of pathological manifestations using the GUT matrix methodology - case study. Monograph (Federal Rural University of the Semi-Arid) of Civil Engineer.

[6] MANDOLESI, E. Edificación. Barcelona: CEAC, 1981.

[7] PEREIRA, C.; SILVA, E.; HAMADYK, A. (2020). Probabilistic analysis of the durability of architectural concrete surfaces. Applied Mathem. Mod. 77: 199-215.

[8] PEREIRA, C.; SILVA, A., BRITO J., SILVESTRE, J.D. (2020). Urgency of repair of building elements: Prediction and influencing factors in façade renders, Construction and Building Materials, 249: 1-16.

[9] PREFEITURA MUNICIPAL DE VIÇOSA. Localização. S.d. Disponível em: http://www.vicosa. mg.gov.br/index.php?option=com_content\&view=article\&id=46\&Itemid=57. Acesso em: 3.jun.2012.

[10] RIBEIRO, M. S.; MICHALKA Jr., C. A contribuição dos processos industriais de construção para adoção de novas tecnologias na construção civil no Brasil. Vértices. 5 (3) 2003.

[11] ROZENFELD, H.; FORCELlinI, F.; AMARAL, D.C.; TOLEDO, J.; ALLIPRANDINI, D.; SILVA, S.L. E SCALICE, R. Product Development Management: A Reference for Process Improvement. São Paulo: Saraiva. 2006.

[12] SOUZA, J.S. et al. Study of damage distribution and intensity in regions of the façade, Journal of Building Pathology and Rehabilitation, 3: 1-9. 2016.

[13] SILVA, M. E. Planejamento e controle de projetos. Apostila Técnica. FUMEP - Fundação Municipal de Ensino de Piracicaba, EEP - Escola de Engenharia de Piracicaba, COTIP - Colégio Técnico Industrial de Piracicaba. 2007. 


\section{Capítulo 17}

Plano de otimização da comunicação e estoque de um supermercado: Um estudo de caso

\section{Ana Angélica Batista Diniz Pereira \\ Raquel Ferreira de Souza \\ Paulo Marcelo Villani}

Resumo: A comunicação estratégica é uma área da Gestão Estratégica muito importante, porém pouco utilizada pelas empresas, de forma eficaz. Desta forma, esta pesquisa se trata de um estudo de caso, realizado no supermercado Rede Mania, localizado em Belo Horizonte - MG, cujo objetivo principal deste estudo é investigar os motivos da geração das falhas de comunicação existentes nos processos de fornecimento e falta de produtos para serem comercializados pela empresa e propor um plano de otimização estratégico para a empresa Rede Mania. A metodologia usada na pesquisa se baseia no método descritivo utilizando-se o estudo de campo, a amostra populacional é o sistema de comunicação da empresa. A pesquisa se baseou no questionário semiestruturado preparado pela própria autora da pesquisa. A pesquisa teve como resultado a identificação das falhas e possíveis soluções para melhoria.

Palavras-chave: Comunicação estratégica. Falhas. Estoque. Supermercado. 


\section{INTRODUÇÃO}

A presente pesquisa visa refletir sobre como as falhas de comunicação presentes nas empresas afetam o dia a dia das pessoas tendo em vista que, mesmo com a tecnologia aprimorada consideravelmente, ainda existem grandes falhas nos espaços organizacionais.

Entende-se por comunicação estratégica uma ferramenta principal para se alinhar planejamento, desenvolvimento e implantação de processos. É de grande utilidade na busca de soluções e no debate sobre os problemas que surgem a partir das demandas e expectativas da organização.

A pesquisa em questão mapeou as falhas de comunicação e estoque em um supermercado localizado na cidade de Belo Horizonte - MG - empresa de médio porte - e seus fornecedores, a fim de oferecer à empresa um plano de otimização da comunicação.

A mesma tem como objetivo principal mapear as falhas de comunicação e propor um plano de otimização da comunicação estratégica para a empresa Rede Mania, que foi alcançado por meio de questionário semiestruturado, pois a mesma foi feita com os funcionários da empresa de setores diferentes.

As falhas de comunicação existentes no supermercado Rede Mania nunca foram prioridade na lista de problemas a serem resolvidos. No entanto, uma comunicação falha e ineficaz gera atrasos na entrega de mercadorias, de modo que a empresa deixa de disponibilizá-los durante certo tempo dentro de cada mês, deixando de comercializá-los, o que implica diretamente nas vendas do supermercado.

0 efeito gerado pela indisponibilidade dos produtos implica não somente nos custos e lucros direto do supermercado, mas afetam também a concorrência, pois o cliente, ao ir ao estabelecimento e não encontrar o que procurava, fica insatisfeito e talvez não volte mais, acarretando assim a diminuição de vendas.

\section{REVISÃO DE LITERATURA}

\subsection{A IMPORTÂNCIA DA COMUNICAÇÃO}

Para Rosa e Landim (2009) foi necessário que a humanidade criasse inúmeras formas de comunicação para que pudesse viver, em sociedade, de forma mais harmônica. A comunicação mostra-se como fator indispensável para o convívio e comprovadamente o sucesso organizacional está intimamente relacionado com o modo como os indivíduos se comunicam.

Logo é possível definir comunicação como sendo extremamente necessária para que se desenvolvam vínculos entre os indivíduos. Impossível pensar na vida humana sem a existência de comunicação, já que nos comunicamos o tempo todo, seja em casa, na escola, no trabalho, no lazer ou em praticamente todos os momentos de nossa vida. Indivíduos de todas as faixas etárias buscam de alguma forma a comunicação e a transmissão dos acontecimentos. Comunicar é um fator determinante nos diversos tipos de relacionamentos (pessoal ou profissional), e torna-se determinante para a disseminação de conhecimento, difundir as diversas culturas existentes, criando conexões entre os seres humanos.

\subsection{COMUNICAÇÃO EFICAZ}

No meio empresarial é importante que a comunicação seja pensada de forma que dê resultados. Assim, para que o processo de comunicação em uma organização seja eficaz, deve-se preocupar com as características da mensagem, se esta possui destino, se foram pensadas todas as particularidades que possibilitam o entendimento da mesma, pois para que a eficácia seja caracterizada, é necessário que a mesma seja compreendida. Medeiros e Hernandes (2004) apresentam algumas condições para que o processo de comunicação seja eficaz, assim sendo: A comunicação é determinada pelo emissor, por sua posição, pelo status que ocupa na organização, pela credibilidade e reputação que desfruta, pelas experiências passadas de comunicação que proporcionou.

\subsection{COMUNICAÇÃO INTEGRADA}

Rosa e Landim (2009) explicam que a comunicação realizada de forma integrada deve ser compreendida como o diálogo entre o discurso que ocorrerá tanto no meio interno como no meio externo da empresa, de modo que a boa fluidez do meio interno beneficie o meio externo, devolvendo resultados positivos á 
organização. Rosa e Landim (2009) dizem ainda que uma comunicação integrada não é algo fácil de ser desenvolvido, tampouco de ser avaliado. Portanto é necessário que a organização disponibilize pessoas capazes de identificar os gargalos comunicativos e tratá-los, antes que os mesmos gerem resultados negativos à empresa, como perda de clientes, descumprimento de prazos entre outros.

\subsection{COMUNICAÇÃO ESTRATÉGICA}

A comunicação estratégica é uma ferramenta principal para se alinhar planejamento, desenvolvimento e implantação de processos em busca de um objetivo comum. Segundo Oliveira (2003) esta é uma ferramenta muito importante uma vez que possibilita alinhar as condutas da organização, permitindo associar todo o processo organizacional.

Com isso, a presente pesquisa abordará o tema de rotatividade de funcionários na empresa.

\subsection{ROTATIVIDADE DE FUNCIONÁRIOS}

A rotatividade de funcionários também conhecida como Turnover (termo em inglês), está relacionado à saída de funcionários de uma empresa. Chiavenato (1999) afirma que a rotatividade de funcionários é uma despesa que pode ser evitada. Afirma ainda que a alta rotatividade reflete na produção e no clima organizacional.

Com a alta rotatividade de funcionários, fica impossível constituir uma comunicação estratégica, pois para ter essa comunicação de forma efetiva é necessário tempo de treinamento e afinidade de comunicação entre os setores da empresa. Não é possível alcançar bons resultados sem as equipes estarem alinhadas, porque quando os setores não se comunicam, esses problemas irão impactar a produção, como por exemplo, a indisponibilidade de estoque, falta de produtos, o não cumprimento de prazos e falta de matéria prima. Ou seja, precisa de alinhamento na empresa para que a comunicação seja eficaz que possibilita chegar aos resultados.

\subsection{SISTEMAS INTEGRADOS}

Os sistemas integrados de gestão empresarial (ERP - Enterprise Resource Planning) são importantes para o desenvolvimento do negócio nas empresas. 0 mercado se desenvolveu rapidamente e as organizações precisam adaptar-se ás novas exigências, principalmente pela quantidade de informações geradas em todas as áreas da estrutura da empresa.

Toda organização precisa de sistemas informatizados e adaptados constantemente, para gerar informações rápidas e integradas. Os sistemas ERP podem trazer benefícios para a gestão dos negócios, facilitando e otimizando o fluxo de informações na empresa.

É possível observar que, ERP é um software que permite a empresa automatizar e integrar a maioria de seus processos, disponibilizando a informação em tempo real.

Em conformidade com o que foi exposto acima, Souza e Saccol (2003, p.19), dizem que "Os ERPs são sistemas de informação adquiridos na forma de pacotes comerciais de software que permitem a integração de dados dos sistemas de informação transacionais e dos processos de negócios ao longo de uma organização".

SAP (Systeme, Anwendungen und Produkte in der Datenverarbeitung) é um tipo de ERP que integra todos os departamentos da empresa. 0 sistema oferece soluções que podem ser utilizadas para qualquer tipo de segmento. De acordo com Santos (2000), o sistema SAP oferece algumas vantagens, como:

- Nível de Integração;

- Dados produzidos em qualquer ponto da cadeia são centralizados, o que elimina redundâncias e favorece a integridade da informação;

- Modularidade e Flexibilidade;

O ContaAzul, é um sistema de ERP simplificado que integra suas vendas com faturamento, cobrança e estoque. 0 sistema opera online com informações seguras e disponíveis a qualquer momento e qualquer 
lugar, há também integração com a contabilidade para evitar erros e garantir velocidade no fechamento mensal da empresa.

\subsection{GESTÃO DE ESTOQUE}

A Gestão de estoque tem como objetivo o gerenciamento do estoque para manter nível adequado para o funcionamento da empresa, definindo quando, quanto e o que comprar de cada produto para manter o estoque seguro suficiente para a empresa, não faltando e nem sobrando, pois pode ocorrer a perda de produtos por conta da sua validade. Com a constante falta de produtos acarreta na perda de vendas e consequentemente até a perda de cliente para a concorrência. Viana (2009) conceitua o estoque como amontoado de materiais e produtos para utilização em um espaço de tempo pré-determinado, de forma a atender à necessidade dos clientes e ao atendimento da empresa, diante da dificuldade de mensurar a demanda exata que a empresa terá.

\subsection{RUPTURA DE ESTOQUE}

Outro ponto a ser abordado na gestão de estoque seria a ruptura de estoque que segundo Brandalise (2017), a ruptura de estoque ocorre quando o estoque de segurança é totalmente consumido e como consequência causa prejuízos de diversas naturezas, no comercio, vendas perdidas e na produção parada. Já Accioly, Ayres \& Sucupira (2014), descreve que a ruptura de estoque ocorre quando um pedido deixa de ser atendido pelo estoque normal e causa consequências econômicas para a organização

\section{METODOLOGIA}

A pesquisa se baseia quanto aos fins, no método descritivo pois foi como objetivo descrever as características do problema de pesquisa, proporcionando uma nova visão sobre esta realidade já existente. A presente pesquisa se baseia quanto aos meios ao estudo de caso, pois o estudo foi feito de temas pré-selecionados através de coletas de dados.

Para esta pesquisa o universo escolhido foi a empresa Rede Mania localizada em BH-MG e a amostra populacional é o sistema de comunicação e estoque da empresa.

A pesquisa se baseou no questionário semiestruturado, pois a mesma foi feita com todos os funcionários da empresa de setores diferentes e nesse caso, a entrevista semiestruturada foi de grande valia, já que conseguiu fazer perguntas abertas sem precisar seguir exatamente somente as opções dada pela autora da pesquisa, proporcionando assim que os funcionários coloquem sua opinião descritiva.

Com base no questionário aplicado aos funcionários, os dados coletados foram tratados a partir de gráficos para melhor visualização dos resultados.

\section{APRESENTAÇÃO E ANÁLISE DOS RESULTADOS}

A comunicação é parte importante para que os processos sejam bem desenvolvidos nas empresas. Em face disso, foram realizadas perguntas aos funcionários, a fim de saber se existem falhas comunicativas e, em caso positivo, onde tais ocorrem e se impactam os processos do supermercado, sendo o foco a análise da gestão de estoque.

\subsection{ATRASOS NO FORNECIMENTO DE MERCADORIAS}

O fornecimento de mercadorias da empresa em estudo ocorre de forma que, não existe parâmetro ao qual os funcionários consigam repassar de forma sucinta as mercadorias que precisam ser repostas, com isso há sempre falta de produtos no supermercado, conforme constatado em questionário aplicado na empresa e demonstrado no gráfico 1 que segue: 


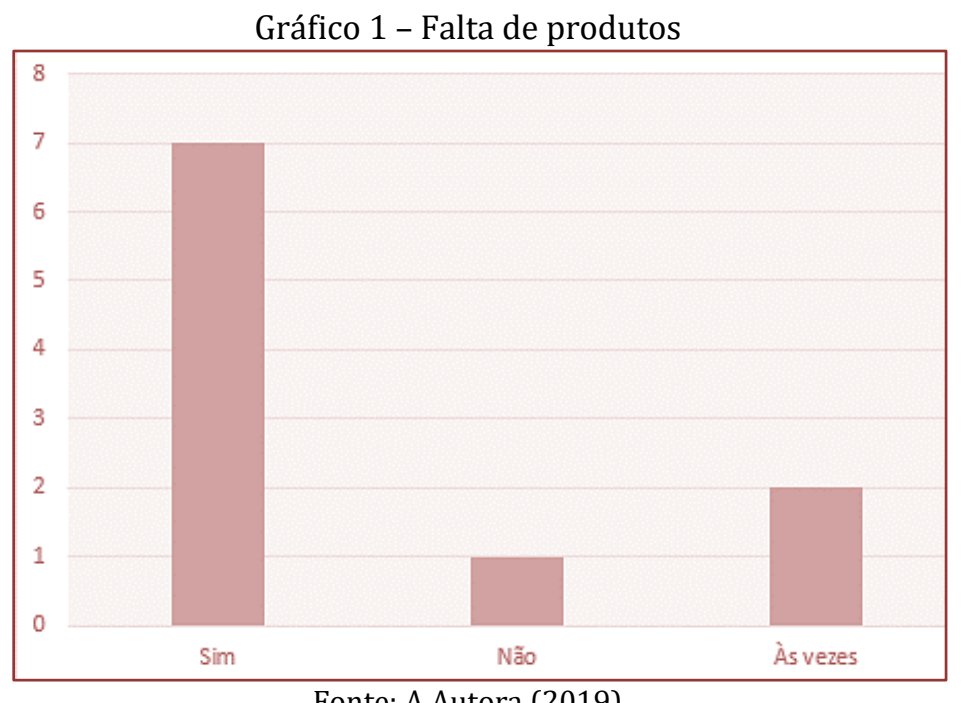

Fonte: A Autora (2019)

Conforme mostrado no gráfico 1, segundo as entrevistas $70 \%$ dos entrevistados afirmam que existe a falta de produtos ou ruptura com frequência, $20 \%$ afirmam que falta, às vezes, e somente $10 \%$ afirmam que não faltam produtos.

Como se pode observar, há uma discrepância em relação às respostas pois, mesmo ficando clara a frequência na falta de produtos, há colaboradores que aparentemente não a percebem.

Em conformidade com Brandalise (2017), é perceptível que há uma ruptura de estoque na empresa de acordo com os $70 \%$ entrevistados, acarretando a não venda de produtos além de o cliente ir até a concorrência e com isso a empresa deixa de lucrar. Já o gráfico 2 demonstra como ocorre o processo de reposição no caso da falta de algum produto.

Gráfico 2 - Reposição de produtos

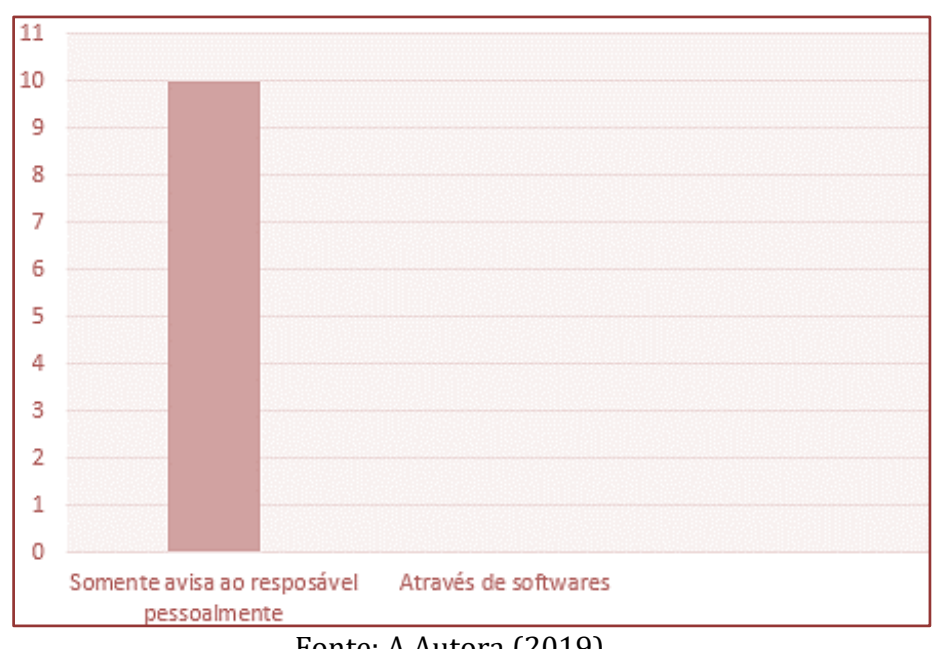

Fonte: A Autora (2019)

0 gráfico 2 demonstra que não se tem um processo formalizado ao qual os funcionários possam avisar sobre a falta de produtos, ou seja, é passado de pessoa para pessoa até chegar no responsável para que este faça os pedidos necessários. Segundo a entrevista, $100 \%$ relatam que somente avisam pessoalmente essa falta e que não existe um software específico para gestão de estoque e prateleiras, sendo que os pedidos são feitos somente de próprio punho.

As facilidades em que a empresa poderia ter ao utilizar um ERP seriam várias, como: ter um controle financeiro da empresa, controlar estoque, qualidade, vendas e outras. O ERP permite à empresa visualizar por completo as transações da empresa, tendo uma visão ampla dos processos e fluxo de informações claras e específicas para cada área da empresa. 


\subsection{ATRASOS E FALHAS}

$\mathrm{Na}$ entrevista feita aos colaboradores, forem mostrados também os motivos que levam aos atrasos pela não realização de pedidos, e de onde surgem as falhas de comunicação, conforme mostra o gráfico 3 que segue:

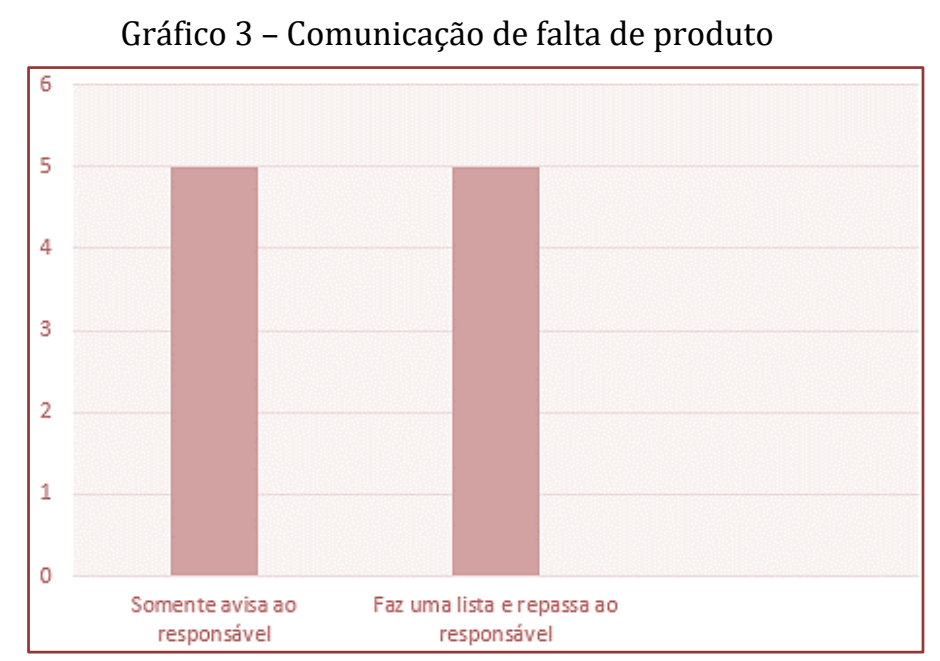

Fonte: A Autora (2019)

O gráfico 4 mostra que $50 \%$ dos entrevistados somente avisam ao responsável a falta de produtos pessoalmente, já os outros $50 \%$ afirmam que fazem uma lista de próprio punho colocando os produtos que estão faltando e entregam ao responsável. É possível notar que os funcionários não estão alinhados, de forma que metade deles faz de uma forma e a outra metade diferente, não tendo um padrão a ser seguido.

É necessário que haja um procedimento formal de pedido de reposição de produtos, já que os funcionários não estão alinhados para que a comunicação seja eficaz. Ao se ter um procedimento formal, como: algum formato de formulário que indique as mercadorias a serem repostas ou até mesmo que tal seja feito por email, tal problema poderia ser minimizado.

0 gráfico 5 mostra como os funcionários percebem a necessidade de refazer os pedidos, conforme demonstrado no gráfico que segue:

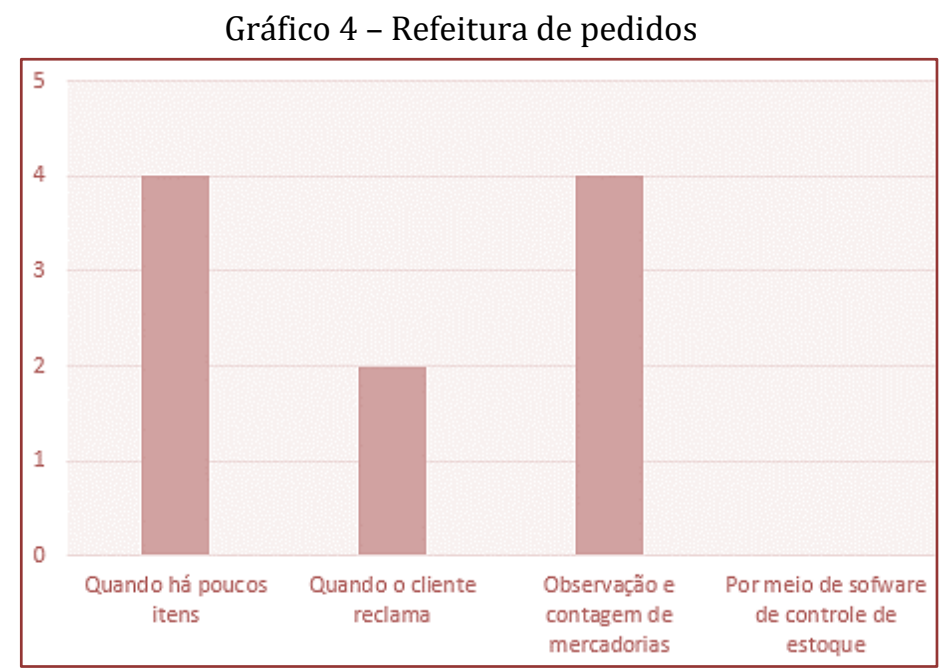

Fonte: A Autora (2019)

0 gráfico demonstra que, $40 \%$ dos entrevistados afirmam que fazem pedidos quando há poucos itens nas prateleiras, $20 \%$ afirmam que fazem quando o cliente faz alguma reclamação e os outros $40 \%$ afirmam 
que fazem os pedidos somente através de observação e contagem de mercadorias. Como já havia sido mostrado no gráfico 2, não existe software para contagem de mercadorias e para refeitura de pedidos, de forma eletrônica, de modo que, da forma como se tem feito, a chance de ocorrência de falhas no estoque é grande, pois a comunicação da necessidade de reposição é informal e não possui um procedimento próprio da empresa.

\subsection{PERFIL COMUNICACIONAL DA EMPRESA ESTUDADA}

A falta de comunicação entre setores de uma empresa pode gerar graves consequências, uma vez que a comunicação torna-se necessária em vários tipos de processos. Em um supermercado, tal falha pode acarretar atrasos no fornecimento de mercadorias, nesse contexto, é possível identificar falha na comunicação da empresa voltada à reposição e ao fornecimento de produtos.

No gráfico 5 que segue, é possível observar como os setores se comunicam:

\section{Gráfico 5 - Comunicação entre setores}

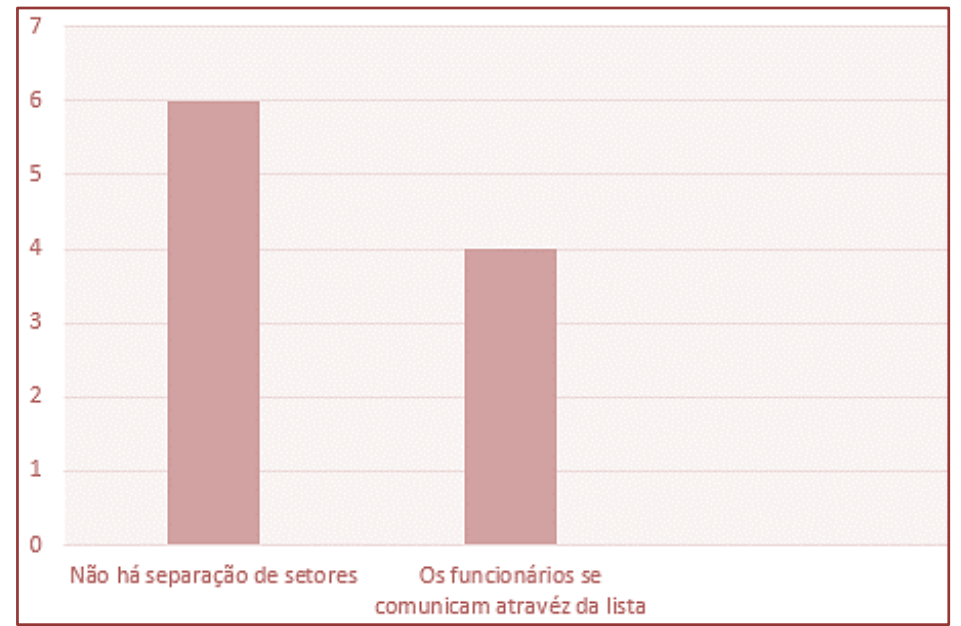

Fonte: A Autora (2019)

Na empresa em estudo não há separação de setores, o que dificulta a comunicação entres os funcionários. $40 \%$ dos entrevistados afirmam que se comunicam através de uma lista que o funcionário, faz ao passar nos corredores do supermercado e perceber a falta de produtos. Depois, essa lista é entregue ao responsável, ou seja, trata-se de comunicação informal, já que, não possui um responsável ou setor específico para fazê-la.

A empresa não adota a comunicação integrada, com isso não há fluidez no ambiente interno, logo não beneficia o meio externo, tal constatação esta de acordo com Rosa e Landim (2009). Além disso, na empresa não existe uma comunicação eficaz, pois a mesma precisa ser efetiva e assertiva, de forma a atingir o propósito de comunicar internamente. 
0 gráfico 6 aborda a rotatividade de funcionários na empresa:

Gráfico 6 - Rotatividade de funcionários na empresa

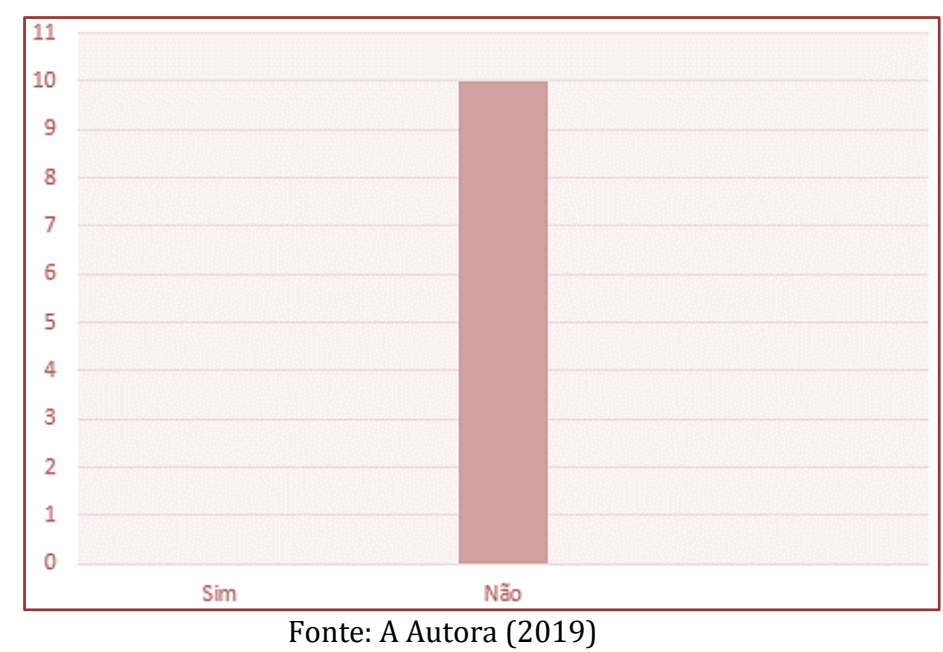

No gráfico, $100 \%$ dos entrevistados afirmam que não possui rotatividade da empresa, o que é um ponto importante e positivo para a empresa, a rotatividade dentro da empresa significa investimentos perdidos, além de afetar o nível de produtividade e o custo elevado do processo de desligamento da empresa. Embora seja um ponto positivo, também pode ser considerado um ponto negativo, se observado pelo viés de que a empresa ter funcionários antigos e praticar uma comunicação informal acarreta que, o funcionário deixa de adotar uma comunicação padronizada, para apenas avisar sobre a falta, pelos corredores da empresa, adotando além de uma comunicação informal, certa grau de intimidade, que deve ser evitado em uma organização.

\subsection{PLANO DE OTIMIZAÇÃO DA COMUNICAÇÃO PARA MELHOR GESTÃO DE ESTOQUE DA EMPRESA EM ESTUDO}

De acordo com a pesquisa elaborada, pode se identificar algumas falhas como:

- Atrasos no fornecimento de mercadorias;

- Falhas na comunicação interna;

- $\quad$ Falta de padronização da comunicação e de gestão do estoque.

Ainda conforme os resultados da pesquisa, os atrasos no fornecimento de mercadorias se devem ao fato de não existir um parâmetro para que os funcionários repassem, de forma eficaz, a informação sobre a falta de produtos, para que seja feito o pedido. Além de atrasos no fornecimento, foi possível constatar que há ruptura de estoque, acarretando na não venda de produtos, deixando a empresa de lucrar.

Para a melhoria no processo de fornecimento e pedidos de produtos, a proposta é de se implantar um software de gestão, não somente de estoque, compras e pedidos, mas de todo processo da empresa. Com relação aos softwares citados na pesquisa, SAP e ContaAzul, para a empresa em estudo seria viável financeiramente adquirir o ContaAzul, pois é mais específico para empresas de pequeno porte, além de a empresa poder fazer o teste de adaptação.

Outras formas de melhoria da gestão do estoque da empresa em estudo e da comunicação implicada em todo o processo que compreende a dinâmica de estoque seriam a adoção de aplicativos de celular que oferecem tal serviço, com baixo custo - sendo a maioria gratuita, com ônus apenas de manutenção - ou a criação de um formulário específico para conferência e realização de pedidos e o direcionamento de uma pessoa ou a criação de setor específico para se responsabilizar por essa demanda, com dias e horários específicos para tal, de preferência menos movimentados. 
Enfim, a pesquisa apontou três caminhos possíveis para otimizar a comunicação interna garantindo uma gestão de estoque sem rupturas, a saber: a aquisição de software de gestão de estoque - que se mostra mais onerosa para a empresa -; a adoção de um aplicativo de celular de gestão de estoque - que a empresa pagará apenas pela manutenção -; e a formalização de seus processos de gestão de estoque, estabelecendo regras para tal.

\section{CONCLUSÕES E CONSIDERAÇÕES FINAIS}

Inicialmente o objetivo geral desse pesquisa foi mapear possíveis falhas de comunicação e propor um plano de otimização da comunicação estratégica para a empresa Rede Mania. Para atingir esse objetivo, os seguintes itens foram executados:

- Mapeamento do processo de comunicação e fornecimento de mercadorias;

- Identificação de possíveis falhas na comunicação e no fornecimento de mercadorias;

- Delineamento do perfil comunicacional da empresa estudada;

- Propor elaboração do plano estratégico de comunicação e para gestão de estoque.

Com a realização do mapeamento do processo de comunicação, foi possível fazer a identificação das principais causas de não padronização na comunicação e rupturas de estoque. A pesquisadora apontou três caminhos possíveis para otimizar a comunicação interna garantindo uma gestão de estoque sem rupturas. É imprescindível que a integração das informações em uma empresa, pois a mesma evita problemas como a ruptura no estoque, o que foi apontado na pesquisa.

Nesse contexto se pode dizer que os objetivos dessa pesquisa foram atingidos, pois identificou as possíveis falhas, as causas e propôs um plano estratégico de comunicação interna e para gestão de estoque.

\section{REFERÊNCIAS}

[1] ACCIOLY, Felipe; AYRES, P. A. Salmeron; SUCUPIRA, Cezar. Gestão de estoques. Rio de Janeiro: Editora FGV, 2008

[2] BRANDALISE, Loreni. Administração de materiais e logística. Editora: SIMPLISSIMO, 2017. 460p

[3] CHIAVENATO, Idalberto. Planejamento, recrutamento e seleção de pessoal. Como agregar talentos à Empresa. São Paulo: Atlas, 1999.

[4] LAUDON, Kenneth C.; LAUDON, Jane P. Gerenciamento de Sistemas de Informação. 3. ed. Alexandre Oliveira. (Trad.) Rio de Janeiro: LTC, 2001.62 p.

[5] MEDEIROS, J. B.; HERNANDES, S. Manual da secretária: técnicas de trabalho.9. ed. São Paulo: Atlas, 2004.

[6] OLIVEIRA, José P. M.; MOTTA, Carlos A. P. Como escrever melhor. São Paulo: Publifolha, 2003

[7] ROSA, A. Silvério. LANDIM, D. C. Castro. Comunicação: a ferramenta do profissional, Minas Gerais, v. 6, n. 20, p. 141- 15, out. 2009. Disponível em: <http://www2.assis.unesp.br/egalhard/Internet1.htm> Acessado em: 23 Set. 2018.

[8] SOUZA, Cesar A. de; SACCOL, Amarolinda Z. (Org.). Sistemas ERP no Brasil: (Enterprise Resource Planning): teoria e casos. São Paulo: Atlas, 2003. 19 p.

[9] SANTOS, A. A. Um enfoque sobre a utilização do SAP R/3 em contabilidade e Custos. Ouro Preto, Brasil,2000.

[10] VIANA, João José. Administração de materiais: um enfoque prático. São Paulo: Atlas, 2009. 


\section{Capítulo 18}

Planejamento de logística e transportes: Um estudo dos planos de infraestrutura brasileiros

\section{Camila Avosani Zago}

Helios Malebranche

Resumo: 0 Brasil possui uma vasta extensão territorial, com características e diversidades em cada região, fazendo com que os programas de enfrentamento às desigualdades regionais sejam elaborados a partir de uma perspectiva de desenvolvimento socioeconômico compatível com os mapas logísticos de cada região. Tal realidade faz com que com que haja necessidade de investimentos e planejamento da infraestrutura de transportes e logística que levem em consideração as especificidades de cada região, respeitando as divisões territoriais em prol de uma dinâmica socioeconômica mais homogênea no que diz respeito à produção, deslocamento e acesso a mercados. Face a isso, este estudo objetiva verificar os diferentes planos de investimentos em infraestrutura de transportes e logística nacionais e enfocar no vetor Leste, definido pelo Plano Nacional de Logística e Transportes (PNLT/2007-2023), o qual é formado pelos estados do Espírito Santo, Rio de Janeiro, parcelas de Minas Gerais e leste de Goiás, incluindo Brasília. Para atingir o objetivo proposto, foram utilizadas pesquisas bibliográficas e documentais, sendo que a análise possui cunho descritivo e qualitativo. Foi possível verificar, entre outros aspectos, a preocupação dos planos, tanto estaduais quanto nacional averiguados, em alinhar os mapas logísticos e os mapas produtivos, visando redução de custos, geração de emprego e renda, bem como escoamento da produção e desenvolvimento.

Palavras-chave: Desenvolvimento socioeconômico, planos de logística e transportes, infraestrutura de logística e transportes. 


\section{INTRODUÇÃO}

0 progreesso e desenvolvimento de um país está intimamente relacionado à infraestrutura de logística e transpostes, já que essa possibilita o escoamento da produção e o fluxo de pessoas. 0 Brasil possui uma infraestrutura de transportes precária, que tem reflexo direto no chamado "Custo Brasil", que diz respeito ao somatório de dificuldades econômicas, estruturais e burocráticas, que impedem o desenvolvimento sustentável, implicando em perdas pela falta e/ou redução de investimentos, aumento do índice de desemprego e trabalho informal, entre outros.

O atual cenário econômico brasileiro, que conta com baixa participação no comércio internacional, elevada taxa de desemprego e inflação, associadas ao cenário político, implicam em uma acentuada desaceleração da economia. Essa realidade somada à vasta extensão territorial e às disparidades regionais que o País possui fazem com que a logística e os transportes sejam repensados e planejados, a fim de reduzir as desigualdades por meio de um desenvolvimento compatível com os mapas produtivos e logísticos de cada região.

Com o fito retomar o planejamento e desenvolvimento do setor de logística e transportes, o governo federal tem investido em planos de ação que preveem investimentos que possibilitam o crescimento econômico e a redução das disparidades regionais. Para tanto, em 2007 e com revisão em 2011, foi lançado o Programa de Aceleração do Crescimento (PAC), que visa reduzir as deficiências do país nas áreas de saneamento, logística, energia e habitação. Nesse mesmo período, em consonância com o PAC, o Ministério dos Transportes juntamente com o Ministério da Defesa, elaboraram o Plano Nacional de Logística e Transporte (PNLT), cujo caráter é indicativo, de médio e longo prazo, com o propósito de formalizar e perenizar o planejamento e análise, sob a perspectiva da logística, das intervenções públicas e privadas na infraestrutura e organização de transportes.

A partir de então, outras iniciativas não só do poder público surgiram, fez a Confederação Nacional dos Transportes (CNT) propor um plano de ações denominado Plano de Logística para o Brasil (PLB). Em 2015, foi lançada a segunda etapa do Plano/Programa de Investimento em Logística (PIL), o qual visa maior dinamismo na exonomia por meio de uma infraestrutura em logística e transportes moderna e integrada nos diferentes modais.

Além desses planos, foi lançado, mais recentemente, o Plano Nacional de Logística Integrada (PNLI), com o propósito de mapear oportunidades de investimento em parceria com o setor privado. Visando não só a integração entre o setor público e privado, para atingir os objetivos propostos foram traçados os Planos Estaduais de Logística (PELT), que se propõe a identificar os problemas e as demandas de cada estado, para em conjunto traçar estratégias globais e que integrem os estados.

Neste estudo serão averiguados, além dos planos nacionais, os planos dos Estados do Espírito Santo (PLETES) e Rio de Janeiro (PELC/Rio 2045), que fazem parte do chamado Vetor Leste definido pelo PNLT. Esses planos permitiram identificar os problemas/deficiências dos estados no âmbito da logística e transportes, direcionando investimentos prioritários nesse setor.

Logo, este estudo descreve resultados obtidos por meio de uma pesquisa descritiva e de cunho qualitativo, na qual se assume uma perspectiva de análise acerca do assunto. Estruturado em seis sessões: (i) introdução, onde é apresentado o problema de pesquisa; (ii) sistemas logísticos e de transportes; (iii) planos de logística e transportes, que abrange a estruturação dos planos, assim como a apreciação dos planos nacionais; (iv) Plano Estratégico de Logística e de Transportes (PELTS), contemplando apresentação e análise dos planos dos estados do Espírito Santo e Rio de Janeiro, em consonância com os planos nacionais; (v) por fim as considerações finais a respeito deste estudo seguidas das referências bibliográficas utilizadas.

\section{SISTEMA LOGÍSTICO E DE TRANSPORTES}

0 transporte consiste em uma das principais funções logísticas, uma vez que a logística visa melhorar o nível de rentabilidade da distribuição, por meio de planejamento, organização e controle das atividades de transporte e armazenagem, facilitando o fluxo de materiais (CHING, 2010). Além disso, o transporte contempla, na maioria das organizações, a maior parcela dos custos logísticos, já que representa, em média, " cerca de $60 \%$ das despesas logísticas, o que em alguns casos pode significar duas ou três vezes o lucro de uma companhia, como é o caso, por exemplo, do setor de distribuição de combustíveis" (WANKE, 2000). 
O sistema de transporte contempla as diferentes formas de movimentação dos materiais, produtos e pessoas, interna ou externamente, tendo correlação direta com a qualidade da entrega e dos serviços prestados ao consumidor. 0 transporte pode ser considerado uma vantagem competitiva no momento em que é efetuado dentro do prazo, com a qualidade desejada pelos consumidores e por organizações especializadas e com know-how para desenvolver tal atividade.

No que diz respeito aos produtos e materiais, o transporte é realizado através dos seguintes modais (BERKOWITZ et al, 2003; DIAS, 2012; FLEURY, WANKE; FIGUEIREDO, 2000; NOVAES, 2007):

- rodoviário - é o único modal que possibilita entregas door-to-door, sendo o mais utilizado no Brasil. Esse modal possui como vantagens a infraestrutura e acessibilidade, uma vez que as rotas são extensas, além do elevado nível de adaptação, rapidez e eficácia, custos baixos com embalagem e investimento para o transportador. No entanto, tem uma ampliação dos custos com a distância percorrida, não sendo vantajoso, apesar de muito utilizado, para longas distâncias. Além disso, está sujeito à circulação e trânsito, bem como possui limitação de espaço e peso, estando, ainda, sujeito à regulamentação (horários e mobilidade urbana);

- ferroviário - possui graves problemas estruturais provenientes ainda da época prédesestatização, associados ao desequilíbrio entre oferta e demanda no segmento de transportes e à deficiente regulamentação no setor. Esse modal apresenta como vantagens o baixo custo para longas distâncias, pouco afetado pelo tráfego, indicado para produtos de baixo valor agregado e alta densidade. Entretanto, também apresenta desvantagens, baixa flexibilidade de serviços e horários, pouca competitividade para distâncias curtas e cargas pequenas, depende de outros modais de transporte, elevados custos de movimentação dos materiais;

- aéreo - ideal para mercadorias de alto valor agregado e para longas distâncias, tendo em vista que possui como vantagem a rapidez e agilidade, bem como a flexibilidade e frequência entre as localidades. No entanto, é pouco flexivel no que tange à necessidade de terminais, acaba sendo lento quando utilizado para pequenas/curtas distâncias, além do elevado custo e baixa capacidade de carga;

- dutoviário - modal restrito a poucos produtos, apesar da longa vida útil, rapidez e pouca necessidade de mão-de-obra e manutenção. Porém, o investimento inicial desse tipo de modal é elevado;

- aquaviário - esse modal se subdivide em (i) marítimo - amplamente utilizado para transporte de cargas internacionais; (ii) fluvial - transporte por rios e no Brasil muito utilizado na região Amazônica, dada suas especificidades geográficas; (iii) ou cabotagem - transporte ao longo da costa. 0 modal aquaviário apresenta como vantagem a competitividade para produtos de baixo custo e valor agregado, sendo ideal para longas distâncias e grandes volumes pois possui baixo custo. Porém, sua flexibilidade é baixa, além da necessidade de infraestrutura no que tange a orla marítima, portos, rios e lagoas navegáveis.

A escolha pelo modal mais indicado para cada organização e operação a ser realizada depende do custo, produto a ser transportado, velocidade/tempo/prazo de entrega e a possibilidade de incorrer em perdas e danos. Assim, os modais de transporte podem ser avaliados com base nos seguintes critérios de serviços (BERKOWITZ et al, 2003): (i) custos; (ii) tempo/velocidade de deslocamento; (iii) capacidade da carga; (iv) confiabilidade na entrega e nos serviços prestados; (v) acessibilidade e infraestrutura disponível; e (vi) frequência nas entregas.

No Brasil, o modal rodoviário detém a maior parcela de utilização da malha de transportes, com $61,1 \%$, por conta da extensão das rodovias cobrindo todo o território nacional, proporcionando entrega ágil e precisa a um custo acessível. Essa parcela é seguida do modal ferroviário, que detém 20,7\%, posteriormente, pelo modal aquaviário com $13,6 \%$, do modal dutoviário com 4,2\% e, por último, está o modal aéreo com 0,4\%, considerando o total de 794.903 milhões de TKU's transportados (BERKOWITZ et al, 2003; BERTAGLIA, 2009; CNT, 2013; FLEURY, WANKE; FIGUEIREDO, 2000).

0 aumento considerável de circulação de pessoas e materiais proveniente do processo de globalização passa a exigir melhorias e expansão de capacidade e infraestrutura para escoamento da produção e circulação de pessoas. Apesar da infraestrutura de transportes ser fundamental para o desenvolvimento de uma região e do país, o The World Bank (2010) afirma que a infraestrutura ainda é o principal entrave na otimização do desempenho logístico dos países em desenvolvimento, dificultando suas trocas comerciais. 


\section{PLANOS DE LOGÍSTICA E TRANSPORTES}

\subsection{ESTRUTURA PARA ELABORAÇÃO}

O desempenho da logística e transportes de uma região ou país está intimamente relacionado a fatores como (BANCO MUNDIAL, 2006; BARBERO, 2010; MENDES LUNA et al, 2011): (i) infraestrutura e disponibilidade de serviços de transporte; (ii) a logística empresarial e a forma como a cadeia de suprimentos está estruturada, considerando as capacidades globais e individuais dos envolvidos; e (iii) a facilitação comercial, ou seja, aspectos documentais, burocráticos e de segurança nas trocas e movimentação de carga nacional e internacionalmente. Tal infraestrutura se reflete diretamente na qualidade dos serviços logísticos prestados e na agilidade no escoamento da produção, sendo que a tríade dos eixos temáticos a ser contemplada nos planos de logística e transportes é ilustrada na Figura 1 e discutida a seguir.

Figura 1 - Principais eixos temáticos de um plano de logística e transportes

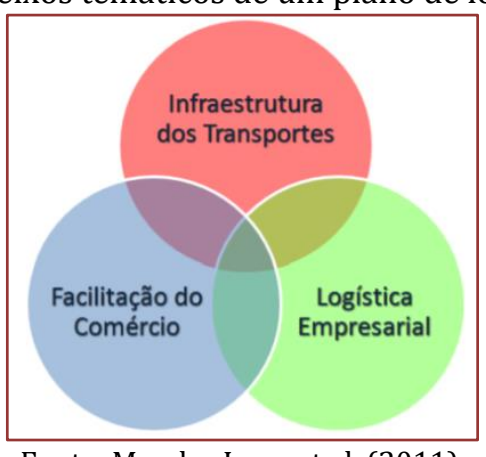

Fonte: Mendes Luna et al. (2011).

- Infraestrutura dos transportes - parte-se do mapeamento da oferta e demanda, a fim de identificar os gargalos atuais e futuros, bem como as perspectivas a longo prazo e a disponibilidade de infraestrutura disponível nos modais. A partir do levantamento da demanda futura, tem-se a perspectiva dos volumes a serem transportados e os investimentos necessários, que são a base para os planos de investimentos em logística e transportes. Os planos e os estudos realizados na área salientam a necessidade de serem realizados investimentos a fim de reduzir os gargalos inerentes a defasada infraestrutura que o Brasil possui;

- Logística empresarial - relaciona-se a forma como as organizações estão inseridas e estruturadas na sua cadeia de suprimentos, bem como a sua relação com os operadores e intermediários de mercado e suas capacidades produtivas. Trata-se de uma perspectiva microeconômica que influencia diretamente a competitividade da região, cabendo ao poder público a promoção e disponibilidade dos recursos de infraestrutura de forma eficiente a fim de facilitar a atuação das empresas;

- Facilitação do comércio - aspecto sobre o qual a atuação do Estado tem influência direta na melhoria do desempenho da logística e transportes. 0 Brasil possui uma burocracia muito grande em relação aos documentos necessários para o transporte, em especial, no âmbito do comércio internacional, fazendo com que a quantidade de documentos e o tempo para exportar e importar sejam muito maior que em outros países (THE WORLD BANK, 2007; 2010). Isso faz com que os custos logísticos se elevem significativamente e o nível de serviço caia, piorando a competitividade das empresas nacionais no mercado internacional. Para minimizar e sanar tais problemas diversos organismos públicos tem atuado em conjunto visando maior integração, a fim de agilizar os processos logísticos, reduzindo a burocracia por meio da implementação de sistemas de tecnologia da informação.

Assim, a sincronia nas informações e ações conjuntas tanto na esfera pública quanto privada possibilitam a identificação de possíveis gargalos atuais e futuros, a fim de elaborar planos de investimento em logística e transportes capazes de alavancar o crescimento e desenvolvimento das regiões e, consequentemente, do país. 


\subsection{PLANOS NACIONAIS}

\subsubsection{PLANO NACIONAL DE LOGÍSTICA E TRANSPORTES (PNLT/2007-2023)}

O Plano Nacional de Logística e Transportes (PNLT/2007-2023) foi desenvolvido em 2007 e revisado em 2011, por meio de uma parceria entre o Ministério dos Transportes (MT) e o Ministério da Defesa (MD). Esse plano possui cunho indicativo de médio e longo prazo, visando o desenvolvimento socioeconômico do país, com propósito de

formalizar e perenizar instrumentos de análise, sob a ótica da logística, para dar suporte ao planejamento de intervenções públicas e privadas na infraestrutura e na organização dos transportes, de modo que o setor possa contribuir efetivamente para a consecução das metas econômicas, sociais e ecológicas do país, em horizontes de médio a longo prazo, objetivando o desenvolvimento sustentado (MINISTÉRIO DOS TRANSPORTES, PORTOS E AVIAÇÃO CIVIL, 2014).

Trata-se de um plano multimodal que interliga a cadeia logística como um todo, incluindo a rede de transportes e as estratégias traçadas pelos diferentes elos da cadeia de suprimentos (CENTRAN, 2007). 0 PNLT foi elaborado de forma participativa, buscando orientar as ações do Estado juntamente com os setores produtivos, a fim de que o plano fosse orientado às reais necessidades dos usuários (MINISTÉRIO DOS TRANSPORTES E MINISTÉRIO DA DEFESA, 2014). Para isso foram necessárias duas etapas, primeiramente o dimensionamento da oferta e demanda no segmento de transportes e, posteriormente, a análise das alternativas de investimento em cada modal e malha de transportes (MINISTÉRIO DOS TRANSPORTES; MINISTÉRIO DA DEFESA, 2007). As projeções de oferta e demanda de produtos agregados contemplaram 80 tipos de produtos em 558 microregiões, as quais foram agrupadas em 7, denominadas vetores logísticos, conforme sintetiza o Quadro 1.

Com isso foi possível elaborar relatórios com projeções econômicas a nível macro, setorial e regional, fornecendo informações que embasaram o planejamento estratégico governamental, para três períodos básicos, 2008-2011, 2012-2015 e 2015-2023.

Quadro 1 - Divisão das regiões brasileiras de acordo com o PNLT

\begin{tabular}{|l|l|}
\multicolumn{1}{c|}{ VETORES } & \multicolumn{1}{c|}{ ABRANGÊNCIA } \\
\hline Amazônico & Amapá, Maranhão, parcelas do leste do Pará e do Mato Grosso e nordeste de Goiás; \\
\hline Centro-Norte & $\begin{array}{l}\text { Ceará, Rio Grande do Norte, Paraíba, Pernambuco, Sergipe e parcelas do norte de Alagoas } \\
\text { e Piaú; }\end{array}$ \\
\hline Nordeste Setentrional & Bahia e sudeste do Piauí, de Goiás, de Minas Gerais e Alagoas; \\
\hline Nordeste Meridional & $\begin{array}{l}\text { Espírito Santo, Rio de Janeiro, parcelas de Minas Gerais e leste de Goiás, incluindo } \\
\text { Brasília; }\end{array}$ \\
\hline Leste & $\begin{array}{l}\text { São Paulo, Mato Grosso do Sul, parcelas do sudeste de Minas Gerais, sul de Goiás e norte } \\
\text { do Paraná; }\end{array}$ \\
\hline Vetor Centro-Sudeste \\
\hline Sul & Rio Grande do Sul, Santa Catarina e parcela do Paraná. \\
\hline
\end{tabular}

O direcionamento de recursos aos vetores, sistemas e modais variou de acordo com as necessidades e expertises de cada região, a fim de fomentar ainda mais a economia local, sendo que o Gráfico 1 ilustra a previsão de distribuição dos investimentos até 2023 por modal. Salienta-se que a maior previsão de investimento, em 2011, foi na malha ferroviária, apesar do elevado volume de recursos destinados à malha rodoviária, que possui maior predominância no País.

No que tange aos vetores logísticos, percebe-se maior investimento, conforme relatórios de 2011, exposto no Gráfico 2, destinado ao Vetor Centro Sudeste, uma vez que consiste em um grande centro econômico do País, seguido do Vetor Leste (foco deste estudo). Os investimentos nos demais vetores estão distribuídos de acordo com o potencial e necessidades de cada região. 
Gráfico 1 - Distribuição de recursos por modal

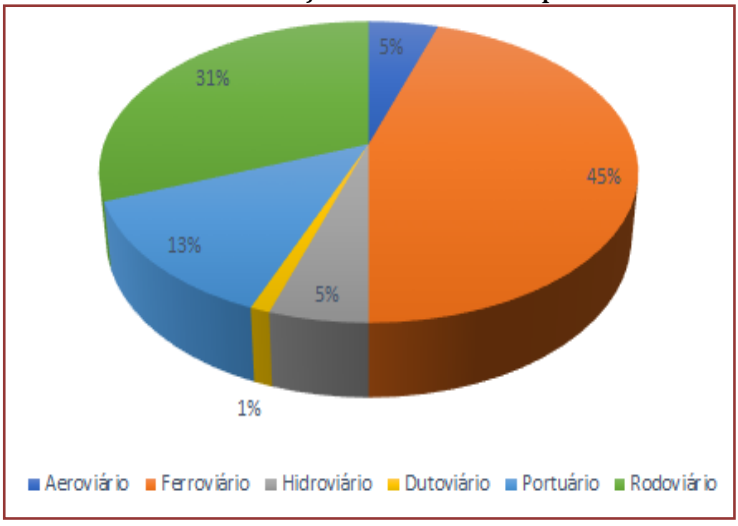

Fonte: Elaborado a partir do PNLT 2007/2023
Gráfico 2 - Distribuição de recursos por vetor

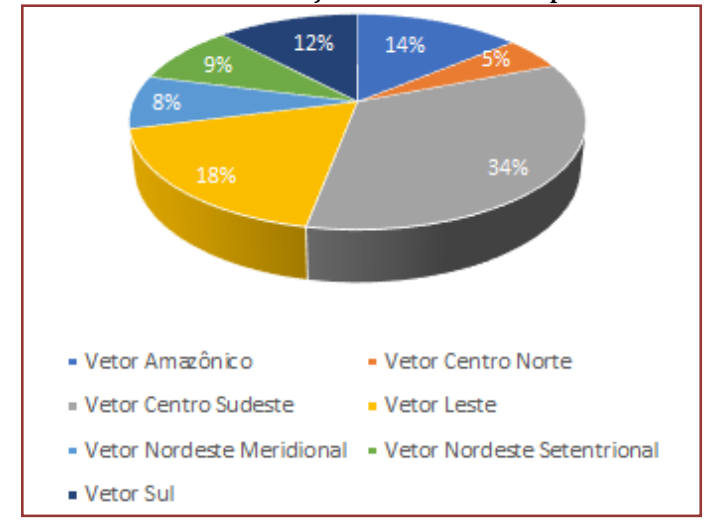

Fonte: Elaborado a partir do PNLT 2007/2023

O PNLT partiu dos indicadores socioeconômicos das diferentes regiões brasileiras para dividir o país em vetores e realizar o planejamento dos investimentos, a fim de minimizar as disparidades regionais e equilíbrar a atual matriz de transportes de cargas do País, bem como a formação de parcerias a fim de concretização do planejado.

\subsubsection{PLANO DE LOGÍSTICA PARA O BRASIL (PLB/CNT-2007)}

Elaborado em 2007 pela Confederação Nacional do Transporte (CNT), o Plano de Logística para o Brasil (PLB) abrange propostas de ampliação e integração da malha de transportes brasileira, com planos de adequação, construção e recuperação da infraestrutura dos modais e dos principais links da rede, terminais intermodais e portos marítimos. Para isso, o País foi dividido em eixos levando em consideração os fluxos macro e microrregionais, conforme sintetiza o Quadro 2. Tal Plano surgiu da preocupação em ampliar e integrar a matriz de transportes brasileira com aspectos quali e quantitativos de infraestrutura.

Quadro 2 - Divisão das regiões brasileiras de acordo com o PLB

\begin{tabular}{|l|l|}
\multicolumn{2}{|c|}{ EIXOS } \\
Nordeste-Sul & de Rio Grande (RS) a Fortaleza (CE); \\
\hline Litorâneo & liga a região Sul à região Norte do País; \\
\hline Norte-Sul & $\begin{array}{l}\text { liga a região Norte e a região Sul, cruzando a região Centro-Oeste e passando pelo interior } \\
\text { do país; }\end{array}$ \\
\hline Amazônico & $\begin{array}{l}\text { inicia em Tabatinga (AM) e segue ao longo das hidrovias até Macapá (AP), onde atinge o } \\
\text { Oceano Atlântico, por meio apenas do modal aquaviário; }\end{array}$ \\
\hline Centro-Norte & de Novo Mundo (MS) a Santarém (PA); \\
\hline Norte-Sudeste & liga as regiões Norte e Sudeste, passando pela região Centro-Oeste; \\
\hline Leste-Oeste & conecta o extremo oeste do Acre até a Bahia; \\
\hline Nordeste-Sudeste & de São Luis (MA) até o município do Rio de Janeiro; \\
\hline Cabotagem & $\begin{array}{l}\text { liga os principais portos marítimos brasileiros por meio das possíveis rotas operacionais de } \\
\text { cabotagem. }\end{array}$ \\
\hline
\end{tabular}

O PLB possui caráter indicativo, sendo formado por um conjunto de propostas voltadas aos Eixos logísticos supramencionados, os quais representam os fluxos macro e microrregionais do país. Os projetos elaborados tem o objetivo de oferecer maior nível de serviços aos operadores de transporte, aumentando a qualidade e reduzindo custos e poluição ambiental. Dessa forma, no que tange à infraestrutura de transportes, o PLB objetivou:

- Traçar um plano de infraestrutura de transporte ideal para o país, na visão dos operadores;

- Nortear os projetos principais direcionados à melhoria da malha de transporte do País;

- Promover maior integração física, econômica e social por meio de infraestrutura de transporte de qualidade;

- Otimizar a intermodalidade no País; 
Reduzir os impactos ambientais do transporte de cargas no País.

Com isso, focou-se na integração da infraestrutura logística por meio da intermodalidade, conectando o Brasil com os demais países da América Latina, a fim de fomentar a exportação e a integração das zonas de produção e consumo, tornando os produtos mais competitivos. Para a CNT, a eficiência e eficácia logística estão diretamente relacionadas à infraestrutura de transportes, a qual geralmente é planejada e financiada pelo poder público, enquanto, a maioria dos veículos de carga e passageiros é pertencente à iniciativa privada, logo, a qualidade no serviço prestado pelas empresas depende também da infraestrutura oferecida pelo Estado.

Além disso, conforme a CNT, a rede de infraestrutura brasileira opera de maneira diferenciada nas diferentes regiões brasileiras, havendo um desequilíbrio na matriz de transportes e no desenvolvimento das regiões. O PLB veio para suprir essas lacunas e priorizar investimentos de forma holística, visando reduzir as disparidas das diferentes regiões brasileiras por meio da identificação da oferta e demanda futura atrelada à melhoria operacional da matriz de transportes.

\subsubsection{PROGRAMA DE INVESTIMENTO EM LOGÍSTICA (PIL)}

Elaborado em 2012, juntamente com o programa de concessões de rodovias e ferrovias e, posteriormente, o PIL-Aeroportos e o PIL-Portos, o Programa de Investimentos em Logística (PIL) objetivou a ampliação dos investimentos em ingraestrutura de transportes, ampliando e modernizando a rede de transportes no País, reduzindo assim os custos aos usuários. Tais melhorias na infraestrutura visavam fomentar o agronegócio, turismo e escoamento da produção, bem como a redução de custos das importações e exportações, a integração da cadeia de valor, desenvolvimento sustentável, emprego e renda, reduzindo as disparidades regionais.

O PIL prevê a concessão de aeroportos, rodovias, ferrovias e portos na busca por melhorias e modernizações da infraestrutura da malha de transportes do País. Com essa proposta, a ideia é reduzir os investimentos do poder público, ampliando a participação da iniciativa privada no financiamento das melhorias propostas. Reforça-se a integração e articulação de parcerias público privaddas, assim como a intermodalidade ao longo da cadeia produtiva em prol do crescimento sustentável.

\subsubsection{PLANO NACIONAL DE LOGÍSTICA INTEGRADA (PNLI)}

Lançado em 2015, o Plano Nacional de Logística Integrada (PNLI) consiste no mais atual planejamento para o setor de transportes no Brasil. Tal plano objetiva "identificar as necessidades e oportunidades de investimentos a curto, médio e longo prazo, para prover o país de uma logística de transportes eficiente e competitiva, sempre com associação entre infraestrutura e serviços, numa visão Pública, Privada e Público-privada" (MINISTÉRIO DOS TRANSPORTES, 2015).

O PNLI perpassa a esfera governamental, comprometido com o desenvolvimento do País como um todo, a fim de garantir a integridade e segurança nacional e preservação do meio ambiente. Para tanto, outros planos foram considerados complementares, entre eles: (i) Planos Setoriais de Infraestrutura elaborados anteriormente pela esfera Federal; (ii) Planos Estaduais Estratégicos de Logística e Transporte (PELTS) (que neste estudo será enfocado nos PELTS dos Estados pertencentes ao Vetor Leste); (iii) Políticas de Integração e de Desenvolvimento Regional e; (iv) Política Nacional do Meio Ambiente.

O escopo temporal do Plano é de 20 anos (2015-2035), sendo que esse parte da identificação do panorama e dos padrões de serviço de transporte e infraestrutura atuais e simulações de implementações futuras, considerando o tráfego atual e as projeções futuras. Assim, o Plano se propõe a integração a partir da padronização, da identificação dos gargalos produtivos e de infraestrutura, priorizando os investimentos com vista a minimização das diferenças refionais e sociais nas diferentes regiões geográficas do País.

\section{PLANO ESTRATÉGiCo DE LOGístiCA E DE TRANSPORTES (PELTS) - APRESENTAÇÃo E ANÁLISE}

Os planos logísticos estaduais, articulados aos planos logísticos federais, orientaram os investimentos do Governo Federal por meio do PAC. Na esfera nacional os planos são organizados pelo Governo Federal em vetores logísticos, conforme exposto anteriormente no Quadro 1, que consiste em uma subdivisão logística do País em espaços territoriais considerando aspectos socioeconômicos, principalmente aqueles relativos à produção, deslocamentos e acesso aos mercados consumidores. Dessa forma, o PNLTsubdivide o País em 
sete regiões denominadas Vetores Logísticos, desconsiderando fronteiras estaduais. Salienta-se, neste estudo, será considerado o Vetor Leste do PNLT, que, embora contemple os Estados do Espírito Santo, Rio de Janeiro e partes de Minas Gerais, leste de Goiás e Brasília, o seu quadro situacional será ilustrado através apenas dos Estados do Espírito Santo e do Rio de Janeiro. 0 Quadro 3, expõe o propósito/objetivo dos PELTS apresentados e analisados na sequência.

\begin{tabular}{|c|c|}
\hline \multicolumn{2}{|c|}{ Quadro 3 - Objetivos dos PELTS ES e RJ } \\
PLANOS & PROPÓSITO \\
\hline $\begin{array}{c}\text { Plano Estratégico de Logística e de } \\
\text { Transportes do Espírito Santo } \\
\text { (PELTES) }\end{array}$ & objetiva um diagnóstico das demandas de infraestrutura e logística do \\
Espírito Santo;
\end{tabular}

No caso específico do Estado do Rio de Janeiro, seu Plano Estratégico de Logística e de Cargas mais recente, o PELC/RJ 2045 (RIO DE JANEIRO, 2016) se caracteria por reunir estudos de infraestrutura logística, atividades produtivas, empresas operadoras, governos, operações, demandas e outras possibilidades com indicações para investimentos no setor. Dentre outros elementos, o PELC/RJ 2045 apresenta: (i) diagnóstico completo do sistema logístico; (ii) planejamento amostral considerando contagem volumétrica e classificatória de veículos; (iii) análises de origem e destino; (iv) custos logísticos e das conexões RJ-MG e RJ-SP; (v) estudos sobre necessidade de investimentos em rodovias e níveis de serviço; (vi) avaliação de portfólio de projetos e medidas de gestão; (vii) planos de comunicações e de governança.

O Plano foi desenvolvido com base em 12 "Âncoras Logísticas", consideradas pontos-chave do Plano e em torno das quais são apontadas ações prioritárias, englobando portos, aeroportos, complexos multimodais e eixos logísticos. Naturalmente, foram levadas em conta as sustentabilidades econômica e socioambiental. As "Âncoras Logísticas do PELC/RJ 2045 são: (i) Porto do Rio de Janeiro; (ii) Eixo Multimodal do Açu; (iii) Aeroporto do Galeão; (iv) Porto de Itaguaí; (v) Eixos Multimodais RJ-ES; (vi) Eixos Multimodais RJ-SP; (vii) Eixo Multimodal Central Rio-MG; (viii) Arco Metropolitano; (ix) Eixos Rodoviários Metropolitanos; (x) Ligações Rodoviárias Transversais; (xi) Eixo Rodoviário Região Serrana-Noroeste Fluminense e; (xii) Instalações de Apoio Offshore.

No caso específico dos Portos do Rio e Itaguaí, algumas fontes de ineficiência merecem destaque: (i) os procedimentos do Ministério da Agricultura, Pecuária e Abastecimento (MAPA) e da Agência Nacional de Vigilância Sanitária (ANVISA) são lentos e poderiam ser agilizados se os processos ocorressem em conjunto; (ii) as equipes da ANVISA são reduzidas e com jornada irregular; (iii) a ANVISA não possui laboratórios para análises no RJ, sendo assim, as amostras são enviadas para outros estados; (iv) procedimentos de inspeção que demandem abertura de contêiner exigem presença de um funcionário habilitado para a retirada do lacre que, quando ausente, obriga reagendamentos; (v) falta de agilidade no posicionamento dos contêineres em locais em que atuam os diferentes anuentes; (vi) inexistência de postos bancários ou de arrecadação fazendária nos fins de semana, ampliando o tempo permanência da carga e os custos logísticos.

No caso do Estado do Espírito Santo, o Plano Estratégico de Logística e de Transportes do Espírito Santo PELTES (ESPÍRITO SANTO, 2009) contemplou análises dos setores industrial e agropecuário, além dos Arranjos Produtivos Locais (APLs), com o objetivo de identificar o potencial de cada microrregião e suas principais conexões econômicas internas e com o mercado externo. No desenvolvimento do PELTES se buscou a diversificação econômica, maior agregação de valor à produção e adensamento das cadeias produtivas, propiciando um desenvolvimento mais equilibrado entre a região metropolitana, o litoral e o interior. Alguns elementos básicos foram considerados no desenvolvimento do PELTES: (i) impacto e duração da crise mundial da época; (ii) desenvolvimento de plano como parte da preparação parra a retomada pós-crise; (iii) e foco no desenvolvimento das regiões, agregação de valor e integração competitiva nacional e internacional com a adoção dos eixos estratégicos do Projeto de Desenvolvimento do Espírito Santo - ES2025.

Os investimentos do Governo Federal em infraestrutura de transportes no Espírito Santo têm sido realtivamente baixos e aquém de suas necessidades. 0 quadro, no momento de desenvolvimento do Plano Logístico, era de obras de expansão do Aeroporto de Vitória paralisadas, privatização da BR-101 adiada, 
expansão do sistema ferroviário não contemplada, além da pequena ingerência das autoridades estaduais sobre sua infraestrutura logística sob controle do Governo Federal ou de empresas privadas. No PELTES a proposta para enfrentamento dos gargalos referentes setor portuário é de um novo porto com grande profundidade no acesso e nas áreas de atracação, que permita a operação de porta-contêineres e supergraneleiros, terrenos para complexos industriais, eficiente logística de terra, ampla retroárea, disponibilidade de água e energia, cais protegido e equipamentos eficientes para movimentação de cargas. No setor ferroviário as principais disfunções existentes no eixo Vitória-Rio-SP são: (i) diferença de bitolas; (ii) deficiência de manutenção das vias, instalações e equipamentos; (iii) inadequação de pátios e terminais; (iv) condições de traçado inadequadas e conflitos na travessia de áreas urbanas.

No PELTES foi apontada como de fundamental importância uma ligação ferroviária no eixo em bitola larga, interligando-se com os sistemas do corredor Rio-SP, para transporte dos fluxos potenciais identificados para a Ferrovia Litorânea Sul no mesmo trajeto pela possibilidade de captação de parte dos fluxos rodoviários de carga entre Vitória/Rio/SP. No setor rodoviário o quadro não é melhor, cerca de $10 \%$ das rodovias do Estado são pavimentados e todas são de pistas simples, gerando problemas de capacidade de transporte e segurança. As rodovias federais BR-101 e BR-262 possuem capacidade muito aquém das necessidades de escoamento dos portos, restringindo o desempenho econômico e operacional das empresas. Para o enfrentamento dos gargalos oriundos do setor rodoviário, identificou-se no PELTES a necessidade de: (i) adequação da capacidade da BR-101, com concessão à iniciativa privada; (ii) adequação da capacidade da BR-262; (iii) e implantação de eixos rodoviários interiores para aumentar a integração das regiões do Estado e com os estados vizinhos, sobretudo Rio de Janeiro e Minas Gerais. No setor aeroportuário o PELTES apontou a necessidade da retomada da expansão do Aeroporto de Vitória construção de um terminal de cargas e um novo terminal de passageiros para atender a mais de 2,1 milhões de passageiros/ano aumentando o fluxo turístico e a ampliação de negócios.

Os diagnósticos levantados pelo PELC/RJ 2045 e PELTES são convergentes e adotaram a metodologia dos planos nacionais, visando à definição de ações prioritárias no que tange à infraestrutura de transportes. Essa análise conjunta possibilita visualizar os investimentos em infraestrutura que recebem destaque a partir da análise da oferta e demanda, apesar das diferenciações quanto à subdivisão dos Vetores Logísticos no caso do PNLT e dos Eixos Estruturantes no caso do PLB. Ressalta-se que o denominado Vetor Leste do PNLT, foco desta análise, está correlacionado ao Eixo Litorâneo do PLB, que liga a região Sul à região Norte do País, entretanto, ambos os planos consideram os aspectos geo-socio-econômicos desconsiderando os limites fronteiriços.

Sumarizando os planos nacionais e estaduais apresentados e analisados, percebe-se que os mesmos, independente de se tratar de plano público (PNLT, PIL e PNLI) ou privado (PLB), levam em consideração a melhoria da malha viária, de transporte e de terminais, com fito da redução dos custos logísticos, por meio da maior competitividade dos produtos de cada região do País, a partir do diagnóstico da oferta e demanda. Além disso, todos os planos analisados possuem análise do impacto sócio-econômico das propostas efetuadas. Ressalta-se que, dos planos nacionais e estaduais averiguados, apenas o PLB e o PELC/RJ 2045 foram elaborados pela iniciativa privada, os demais (PNLT, PIL, PNLI e PELTES) foram elaborados pelo poder público, conforme exposto no Quadro 4.

Quadro 4 - Características dos planos de logística e transporte apreciados

\begin{tabular}{|c|c|c|c|c|c|c|}
\hline \multirow[b]{2}{*}{ PLANOS } & \multicolumn{2}{|c|}{ ELABORAÇÃO } & \multicolumn{4}{|c|}{ ASPECTOS DE INFRAESTRUTURA CONTEMPLADOS } \\
\hline & Setor Público & $\begin{array}{c}\text { Setor } \\
\text { Privado }\end{array}$ & $\begin{array}{c}\text { Diagnóstico de } \\
\text { Oferta e } \\
\text { Demanda }\end{array}$ & $\begin{array}{l}\text { Análise do } \\
\text { Impacto } \\
\text { Sócio- } \\
\text { econômico }\end{array}$ & $\begin{array}{c}\text { Impacto } \\
\text { Ambiental }\end{array}$ & $\begin{array}{c}\text { Arranjos } \\
\text { Institucionais }\end{array}$ \\
\hline PNLT & $\mathrm{X}$ & & $\mathrm{X}$ & $\mathrm{X}$ & $\mathrm{X}$ & \\
\hline PLB & & X & $X$ & X & X & \\
\hline PIL & $\mathrm{X}$ & & $\mathrm{X}$ & $\mathrm{X}$ & & \\
\hline PNLI & $\mathrm{X}$ & & $\mathrm{X}$ & $\mathrm{X}$ & $\mathrm{X}$ & $\mathrm{X}$ \\
\hline PELTES (ES) & $\mathrm{X}$ & & $\mathrm{X}$ & $\mathrm{X}$ & & $\mathrm{X}$ \\
\hline PELC/RJ 2045 (RJ) & & $\mathrm{X}$ & $\mathrm{X}$ & $\mathrm{X}$ & $\mathrm{X}$ & \\
\hline
\end{tabular}

No que tange aos aspectos ambientais, os Planos PNLT, PLB, PNLI e PELC/RJ 2045 abordam a questão, enquanto o PIL e o PELTES não contemplam essa análise em seu planejamento de infraestrutura. Por fim, 
apenas o PNLI e o PELTES contemplam arranjos institucionais para desenvolvimento e implementação de suas ações de melhoria em infraestrutura de logística e transportes.

Independente da elaboração do plano ter sido realizada pelo setor público ou privado, a participação de ambos é observada, uma vez que para a operacionalização e êxito dos planos é necessário cooperação e parcerias, visando o desenvolvimento sustentável das diferentes regiões do País. Além disso, as propostas convergem na utilização dos modais de transporte e no planejamento de investimentos em infraestrutura de logística e transportes, a fim de alavancar o crescimento econômico, o escoamento da produção e a circulação de pessoas.

\section{CONSIDERAÇÕES FINAIS}

A precariedade e a falta de investimentos na infraestrutura de logística e transportes inibe a competitividade, dificultando o escoamento da produção e a circulação de pessoas, diastanciando ainda mais as diferentes regiões brasileiras as quais já tem características díspares entre si e afetando negativamente o comércio internacional. Para minimizar os problemas de investimentos e infraestrutura em logística e transportes foram elaborados planos nacionais e estaduais que direcionam os investimentos de acordo com a análise da oferta e demanda no setor.

Nesse sentido, incialmente foi criado o PNLT, com o propósito da retomada dos planejamentos estratégicos em infraestrutura logística e de transportes, a partir de então foram elaborados outros planos a nível nacional (PLB, PIL e PNLI) e estadual (PELTS). Foi possível perceber a congruência entre os planos nacionais e estaduais, em prol da melhoria nas condições de infraestrutura e equidade entre as diferentes regiões brasileiras.

Aqui foram averiguados, além dos planos nacionais supramencionados, os planos dos estados do Espírito Santo (PELTES) e Rio de Janeiro (PELC/RJ 2045), sendo que ambos partiram da oferta e demanda atuais e projeções futuras no que tange aos transportes e infraestrutura logística. Ressalta-se que os planos dos estados do Espírito Santo e Rio de Janeiro apontam diversos problemas a serem sanados no quesito infraestrutura de logística e tranportes, bem como apontam várias possibilidades de sanar essas deficiências, prodendo fomentar a competitividade e integração entre as regiões. Tais melhorias terão impacto considerável no âmbito socioeconômico, ambiental e político, com vistas ao crescimento sustentável das regiões e entorno.

As propostas de investimentos preocupam-se com as áreas de produção econômica e sua integração, buscando minimizar as disparidades regionais do País. Isso se reflete no momento em que os planos nacionais efetuam divisões das regiões geográficas do País baseando-se na aproximação do mapa logístico e do mapa produtivo, levando em conta a expertise de cada região. Além disso, as propostas apresentadas visam também a aproximação dos setores público e privado em prol do desenvolvimento, por meio do escoamento da produção, da redução dos danos ambientais e dos custos.

\section{REFERÊNCIAS}

[1] BANCO MUNDIAL. Argentina: el desafío de reducir los costos logísticos ante el crecimiento del comercio. Departamento de Finazas, Sector Privado e Infraestructura. Región de América Latina y el Caribe. Informe No. 36606AR, 2006.

[2] BARBERO, J. A. A logística de cargas na América Latina e no Caribe: uma agenda para melhorar seu desempenho. Banco Interamericano de Desenvolvimento - Setor de Infraestrutura e Meio Ambiente - Notas Técnicas No. IDB-TN-103, Washington DC, USA., 2010.

[3] BERKOWITZ, E. N.; KERIN, R. A.; HARTLET, S. W.; RUDELIUS, W. Marketing. Vol. 2. 6. ed. Rio de Janeiro: LTC, 2003.

[4] BERTAGLIA, P. R. Logística e gerenciameno da cadeia de abastecimento. 2. ed. São Paulo: Saraiva, 2009.

[5] CHING, H. Y. Gestão de estoques na cadeia de logística integrada - supply chain. São Paulo: Atlas, 2010.

[6] CENTRAN. (2007). Plano Nacional de Logística e Transportes - PNLT. Disponível em: https://jornalggn.com.br/sites/default/files/documentos/Volume_1_-_Tomo_2_-_Parte_3.pdf. Acesso em: 3 jul. 2016.

[7] CNT - CONFEDERAÇÃO NACIONAL DO TRANSPORTE. Plano CNT de Transporte e Logística. 2013. Disponível em:http://www.cnt.org.br/. Acesso em: 23 set. 2015. 
[8] DIAS, M. A. P. Logística, transporte e infraestrutura: armazenagem, operador logístico, gestão via TI, multimodal. São Paulo: Atlas, 2012.

[9] ESPÍRITO SANTO. (2009). Secretaria de Estado de Transportes e Obras Públicas. Plano Estratégico de Logística e Transportes do Espírito Santo - PELTES. Disponível em: <http://www www.logistica-es.com.br/>. Acesso em: 02 set. 2017.

[10] FLEURY, P. F.; WANKE, P.; FIGUEIREDO, K. F. Logística empresarial: a perspectiva brasileira. São Paulo: Atlas, 2000 .

[11] MENDES LUNA, M.M.; MENDES LUNA, P.T.; FRIES, C. E.; MOTTA, K. S. Planejamento de logística e transporte no Brasil: uma análise dos planos nacional e estaduais. Anais do XXV ANPET- Congresso de Pesquisa e Ensino em Transportes; 2011; XXV ANPET- Congresso de Pesquisa e Ensino em Transportes, Belo Horizonte; BRASIL; Português.

[12] MINISTÉRIO DOS TRANSPORTES E MINISTÉRIO DA DEFESA (2007) Plano Nacional de Logística e Transporte: Sumário $\quad$ Executivo. Brasília. $\quad$ Disponível em: <http://www.transportes.gov.br/public/arquivo/arq1294950307.pdf>. Acesso em: 20 de abril de 2016.

[13] __. (2014) Plano Nacional de Logística e Transporte: Sumário Executivo. Brasília. Disponível em: < http://www.transportes.gov.br/public/arquivo/arq1294950307.pdf>. Acesso em: 06 abr. 2016.

[14] NOVAES, A. G. Logística e gerenciamento da cadeia de distribuição: estratégia, operação e avaliação. 3. ed. Rio de Janeiro: Elsevier, 2007.

[15] PLANO NACIONAL DE TRANSPORTE E LOGÍSTICA. (2011). Disponível em: http:< http://transportes.gov.br/conteudo/2818-pnlt-relatorio-executivo-2011.html >. Acesso em 02 set. 2017.

[16] PLANO DE LOGÍSTICA PARA 0 BRASIL. (2007). Disponível em: http:<www.cnt.org.br/informacoes/pesquisa/splb/2007>. Acesso em 26 de março de 2016.

[17] RIO DE JANEIRO. (2016). Secretaria de Estado de Transportes - SETRANS. Plano Estratégico de Logística e Cargas do Estado do Rio de Janeiro (PELC/RJ 2045). Disponível em: <http://www.pelcrj2045.rj.gov.br/>. Acesso em: 29 ago. 2017.

[18] THE WORLD BANK. Connecting to Compete 2007 - Trade Logistics in the Global Economy: The Logistics Performance Index and Its Indicators. Washington, World Bank, 2007.

[19] _. Connecting to Compete 2010 Trade Logistics in the Global Economy: The Logistics Performance Index and Its Indicators. Washington, World Bank, 2010.

[20] ZAGO, C. A.; MALEBRANCHE, H. Planejamento de logística e transportes: um estudo dos planos de infraestrutura brasileiros. In: Congresso Internacional de Administração - ADM 2016. Anais... Natal/RN, 2016.

[21] WANKE, P. (2000). O papel do transporte na estratégia logística. Disponível em: http://www.ilos.com.br/web/o-papel-do-transporte-na-estrategia-logistica/. Acesso em: 28 out. 2017. 


\section{Capítulo 19}

Relato técnico: O uso de biodigestor em pequenas propriedades da agricultura familiar no Município de Marechal Cândido Rondon - PR

\section{Elisiane Salzer}

\section{Elenice da Silva Carvalho}

\section{Djeimi Angela Leonhardt Neske}

Thayse Ana Ferreira

Resumo: A agricultura familiar vem apresentando grande relevância no desenvolvimento sustentável no país, considerando sua importância na produção de alimentos, seguridade alimentar e manutenção dos recursos naturais. Dessa forma, o uso de tecnologias sociais no campo se apresenta como alternativa para agregação de valor em pequenas propriedades de agricultura familiar. Este relato técnico descreve sobre $o$ Projeto "Construindo um biodigestor", desenvolvido com o objetivo de integrar a universidade e a comunidade, buscando a inclusão de práticas sustentáveis na agricultura, apresentando aos produtores familiares os benefícios econômicos, ambientais e sociais por meio do uso de um biodigestor de baixo custo para as propriedades de pequeno porte com produção orgânica. 0 projeto foi apresentado aos agricultores no município de Marechal Cândido Rondon - Paraná, por meio de um workshop. A demonstração evidenciou a troca de experiência e conhecimento entre os produtores e envolvidos no projeto. Os resultados frente aos objetivos propostos no estudo foram alcançados, visto que os agricultores perceberam os benefícios da interação proposta pelo projeto, como também do modelo de biodigestor apresentado.

Palavras-chave: biodigestor; benefícios; agricultura familiar; projeto. 


\section{INTRODUÇÃO}

A agricultura familiar apresenta grande relevância na produção de alimentos mundial, apesar de possuir características diferentes, como em relação ao tamanho das propriedades, acesso aos mercados e agregados familiares, entre outros. (FAO, 2014). No Brasil, a legislação caracteriza como agricultor familiar aquele que possui até 04 módulos fiscais, que utiliza mão de obra familiar nas atividades da propriedade e renda familiar proveniente das atividades econômicas da propriedade ou estabelecimento (Lei 11.326, 2006).

Apesar dos requisitos apresentados na legislação para concepção de agricultura familiar, as realidades dos agricultores familiares são diferentes em virtude da região ou estado do Brasil onde está localizada sua propriedade. Nesse sentido, é importante destacar que o valor do módulo fiscal pode ser diferente para cada município do país, variando de 05 a 110 hectares, pois leva em consideração fatores do município como tipo de exploração predominante e renda obtida dessa exploração (EMBRAPA, 2017).

A FAO (2014) ressalta que o desenvolvimento bem-sucedido da agricultura familiar tornar-se-á mais produtivo e sustentável por meio das políticas públicas de apoio, pelas inovações dentro de um sistema que reconheça sua diversidade e complexidade.

Dessa forma, as tecnologias sociais se apresentam como forma de agregação de valor para as pequenas propriedades. Elas são inovações criadas a partir de saberes populares ou desenvolvimento científico, propondo soluções simples e de baixo custo. (Carvalho, Silva, Vasconcelos \& Costa, 2016).

Diante disso, a tecnologia social biodigestor sertanejo, apresentado pelo Projeto Dom Helder Câmara e Diaconia no nordeste brasileiro, se apresenta como alternativa de baixo custo e simples manutenção para o pequeno agricultor (Mattos \& Farias, 2011).

Os estudos atuais demonstram modelos de biodigestores de grande porte e com alto custo de implantação, que não caracterizam a realidade da agricultura familiar de pequenas propriedades.

Nesse sentido, o objetivo deste estudo é apresentar o relato técnico do Projeto "Construindo um Biodigestor", que se caracteriza pela apresentação do modelo do biodigestor sertanejo aos agricultores familiares que fazem parte de uma associação de produtos orgânicos, localizada no município de Marechal Cândido Rondon, Paraná, e dos principais benefícios sociais, econômicos e ambientais gerados pela sua implantação.

\section{REFERENCIAL TEÓRICO}

\subsection{OS BIODIGESTORES E SEUS BENEFÍCIOS}

Biodigestores são de maneira simples, equipamentos que transforam a matéria orgânica em gás inflamável (biogás), podendo ser utilizados para diversas destinações, como em substituição ao gás de cozinha (GLP) (Mattos \& Farias, 2011).

A literatura que aborda a temática apresenta diversos benefícios para a implantação dos modelos de biodigestores. Esses enquadram-se nas três dimensões do desenvolvimento sustentável conforme proposto por Elkington (1997): econômica, social e ambiental.

A dimensão econômica aponta dentro dos aportes literários três benefícios com uso do biodigestor: a geração de energia, a produção de biofertilizante e a redução de custos.

Gomes e Raiher (2013), demonstram em seu estudo a relevância da geração de energia em diferentes situações de capacidade de um biodigestor, a geração de energia variou mais de $100 \%$ da capacidade por ano para uso da propriedade ou venda do excedente de energia. Barichello, Hoffmann, da Silva, Deimling e Casarotto Filho (2015) apontam a economia de energia em valores monetários gerados em pequenas propriedades por meio do comparativo de dois projetos, em que a energia gerada é utilizada exclusivamente nas propriedades, com a geração de $1700 \mathrm{KWh}$ e $5000 \mathrm{kWh}$ de energia por mês. Outros estudos demonstram propriedades rurais que diversificaram ou substituiram a energia das concessionárias pela energia gerada pelo biodigestor (Marin, Bley Junior, \& Gonzales, 2016; Montoro, Santos \& Lucas Junior, 2013; Silva \& Cirani, 2016; Sosa, Díaz, Cruz \& De la Fuente, 2014).

O biofertilizante como resultado de saída do uso de biodigetsores se apresenta como benéfico para as propriedades no que tange a geração de renda e diminuição dos custos da propriedade como alternativa para substituição do uso de adução química (Montoro et al., 2013, Silva \& Cirani, 2016). 
No tocante a dimensão social, os benefícios de utilização do biodigestor apontados pela literatura apontam a melhoria da qualidade de vida, principalmente para as mulheres e crianças, a redução do exôdo rural, promovendo a permanência na família no campo e ainda a uitlização do biogás como substituto para o gás de cozinha (gás GLP) (Barichello et al., 2015; Garfi, Marti-Herrero, Garwood \& Ferrer, 2016; Marin et al., 2016; Sosa et al., 2014).

Por último, mas não menos importante, o desdobramento dos benefícios gerados na dimensão ambiental: destinação de resíduos (biomassa de dejetos animais), (Andreazzi, dos Santos \& Lazaretti, 2015; Barichello et al., 2015; Gomes \& Raiher, 2013; Marin et al., 2016; Montoro et al., 2013); destinação de resíduos (biomassa e outros resíduos orgânicos), (Silva \& Cirani, 2016; Silva, Cirani \& Serra, 2016); Reduções de GEE/Crédito de Carbono e tecnologia limpa (Barichello et al., 2015, Garfi et al., 2016; Marin et al., 2016; Silva \& Cirani, 2016).

Destaca-se nesse sentido, a suinicultura no estado do Paraná, sendo objeto de estudos publicados, considerando o alto potencial de produção de material orgânico com as atividades de suinicultura na região (Andreazzi et al., 2015; Gomes \& Raiher, 2013; Marin et al., 2016). Desse modo, o uso dessa tecnologia também pode proporcionar a redução de gases de efeito estufa (GEE) e consequentemente a obtenção financeira pela venda de créditos de carbono (Barichello at al., 2015, Marin et al., 2016; Silva \& Cirani, 2016).

É imprescindível, verificar ainda, a viabilidade econômica da implantação de um biodigestor. Tal análise, contempla aspectos de valor financeiro e valor econômico. Os estudos dentre os diversos modelos apresentados, demonstram que há viabilidade econômica para implantação de biodigestores (Gomes \& Raiher, 2013; Silva \& Cirani, 2016; Montoro, Santos \& Lucas Junior, 2017). Entretanto, no modelo de biodigestor apresentado por Smith, Schroenn \& Blignaut (2014) para atender uma família em uma casa rural na África, em que as famílias não tiverem de desembolsar nenhum aporte financeiro, o estudo demonstrou que as famílias identificaram benefícios, porém, ficou claro que só fariam o investimento se o mesmo tivesse um retorno financeiro elevado, não considerando relevante o valor econômico. Levando em consideração a baixa renda dessas famílias e o impacto que o investimento causaria e ainda, o VPL negativo, visto que o modelo proposto tem custo elevado, o resultado é que no modelo apresentado, o estudo se apresentou inviável.

\subsection{BIODIGESTORES COMO TECNOLOGIA SOCIAL}

A literatura apresenta o biodigestor para uso em propriedades da agricultura familiar, principalmente em substituição ao gás GLP com a utilização do biogás para cozinhar. Em algumas pequenas propriedades, a lenha é utilizada no cozimento dos alimentos. Portanto, o biogás apresenta benefícios econômicos, ambientais e financeiros para as famílias, uma vez que economiza o tempo na coleta da lenha, preservando o meio ambiente, pois não há mais o corte de árvores para uso de lenha, e reduzindo gastos para cozinhar (Garfi et al., 2016; Smith et al., 2014).

Nesse sentido, as tecnologias sociais apresentam-se como alternativa de agregação de valor para a agricultura familiar, considerando seu contexto e diversidade frente a economia de grande escala. Elas são criações práticas e de baixo custo, devolvidas a partir de modelos de inovações advindas do setor industrial, entretanto apresentam como diferencial, serem projetos de baixo de custo, construídas a partir do potencial existente em cada localidade e voltadas principalmente para o uso sustentável (Carvalho et al., 2016).

A partir desse contexto, Mattos e Farias (2011), apresentam o modelo do biodigestor como tecnologia social, iniciativa do Projeto Dom Helder Câmara e Diaconia, como alternativa de baixo custo e construído a partir de materiais disponíveis em lojas de materiais para construção e de simples manutenção. 0 modelo de biodigestor sertanejo implementado inicialmente nos estados do nordeste brasileiro visava atender a população rural carente principalmente na produção de biogás para cozinhar, em substituição ao uso do fogão a lenha e ao gás GLP.

Considerando a diversidade da agricultura familiar e suas diferenças na ruralidade brasileira, o modelo do biodigestor sertanejo foi disseminado e adaptado para outras realidades de agricultores familiares e implementado nos estados de Santa Catarina e Rio Grande do Sul. Nestes estados, o modelo foi adaptado para além da geração de biogás para cozinhar e produção de biofertilizante, como fonte de energia complementar utilizada para aquecimento do chuveiro e outras necessidades de aquecimento de água das propriedades como: esterilização de equipamentos e aquecimento de currais (CRESOL, 2017). 
Para este estudo, o projeto apresenta o modelo do biodigestor sertanejo como tecnologia social e uma alternativa viável para os produtores orgânicos familiares também no estado do Paraná.

\section{METODOLOGIA}

0 projeto destacado neste relato técnico foi criado com base nas pesquisas e experiências desenvolvidas pelos alunos do Mestrado em Administração da Universidade Estadual do Oeste do Paraná, a partir da necessidade de aplicação prática junto à comunidade. Dessa forma, buscou-se verificar agricultores familiares que possuíssem as características para implementação do modelo proposto. A escolha de uma associação localizada no município de Marechal Candido Rondon - Paraná, para apresentar o modelo do biodigestor sertanejo e seus benefícios de implantação, culminou devido as características dos agricultores associados serem de pequeno porte e produtores orgânicos, que já utilizavam o biofertilizante com matéria-prima para a produção.

Para o levantamento dos benefícios, dificuldades e custos, buscou-se a experiência de um especialista que já realizou a instalação de biodigestores sertanejos nos estados de Santa Catarina e Rio Grande do Sul, visto que no estado do Paraná, não há registros de instalação de nenhum biodigestor do modelo proposto.

Com posse das informações, por meio de um breve workshop com os produtores, o projeto "construindo um biodigestor" foi apresentado, visando levar até eles, detalhes de instalação, com os devidos apontamentos prós e contra o projeto. 0 aspecto avaliado foi o de identificar a intenção de instalação do modelo proposto de biodigestor e também o conhecimento dos produtores familiares referente a outros modelos de biodigestores e suas respectivas características.

\section{RESULTADOS OBTIDOS E ANÁLISE}

\subsection{BIODIGESTOR SERTANEJO}

O biodigestor sertanejo é uma tecnologia social criada e disseminada pelo Projeto Dom Helder Câmara e Diaconia. Inicialmente foi desenvolvida no nordeste brasileiro como alternativa para substituição do fogão à lenha pelo fogão a gás com o uso do biogás gerado pelo biodigestor.

O biodigestor sertanejo é construído a partir de materiais de baixo custo e que podem ser comprados em lojas de materiais de construção. O projeto está descrito no manual apresentado pela Diaconia, em que consta todos os passos para construção e instalação do modelo. A Figura 1 demonstra o modelo construído a partir das experiências no nordeste brasileiro.

Figura 1. Biodigestor sertanejo construído no nordeste brasileiro. Fonte: Mattos, L. C., \& Farias, M. J. (2011). Manual do biodigestor sertanejo. Projeto Dom Helder Camara. 55p. Recuperado de http:// http://www.diaconia.org.br/novosite/biblioteca/int.php?id=53

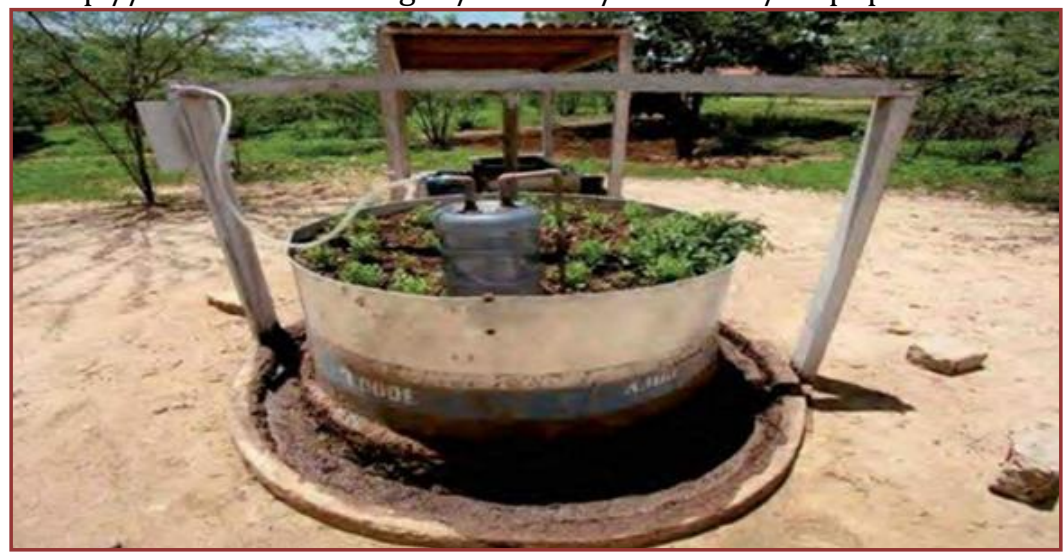

\subsection{PLANEJAMENTO E PROPOSTA DO PROJETO}

A proposta do projeto "Construindo um biodigestor" contemplou 04 fases:

I - Definição do público-alvo

A definição do público alvo culminou na busca de agricultores familiares que apresentassem características para implantação do modelo proposto. Dessa forma, definiu-se uma associação de 
produtores orgânicos localizada no município de Marechal Cândido Rondon - Paraná, por apresentarem características como, pequenas propriedades e pelo uso de biofertilizante na produção dos orgânicos, objeto da saída do biodigestor.

A parceria foi firmada com a associação no intuito de apresentar o modelo do biodigestor através de uma reunião com os mesmos.

\section{II - Relato de experiências anteriores}

A fim de identificar experiências anteriores com a implantação do modelo no sul do Brasil, contatou-se um especialista com experiências em outros projetos de instalação do modelo de biodigestor sertanejo nos estados de Santa Catarina e Rio Grande do Sul.

Como experiências positivas, a instalação do modelo nesses estados apresentou-se viável, considerando o baixo custo de instalação e o retorno do investimento sendo em média de 2 anos. Além da geração do gás para cozinhar, o modelo ainda foi adaptado em algumas propriedades para aquecimento da água do banho e para aquecimento de água para limpeza de ordenha e outras atividades acerca da produção. Outro fator apresentado pelo especialista foi em relação a qualidade do adubo resultante da fermentação do biodigestor para utilização na produção de orgânicos.

A experiência negativa apresentada pelo especialista foi em relação ao uso de dejetos de granja de suínos, em que gerou insucesso para este modelo de biodigestor, por deixar um odor ruim (gás sulfídrico) além da baixa produção de gás. A diminuição da produção com o excesso do frio na região, foi apontada como aprendizagem, pois em épocas de geada a produção torna-se baixa.

III - Levantamento de custos atualizados e viabilidade econômica

Os custos para instalação foram levantados com base no manual do biodigestor sertanejo e alicerçada no levantamento financeiro apurado com as experiências de instalação pelo especialista nos estados de Santa Catarina e Rio Grande do Sul.

Os custos foram atualizados com base em orçamentos em materiais de construção da região de Marechal Cândido Rondon. Com base no levantamento, o biodigestor apresentou como custo total no valor R\$ 3.297,60 incluindo o valor da mão-de-obra do pedreiro e especialista, podendo variar dependendo da região de instalação. Considerando o custo médio do botijão de gás entre $\mathrm{R} \$ 70,00$ a 74,00 e a produção e utilização da capacidade do biodigestor equivalente a 2 botijões mês por família, apresentou um retorno de investimento médio de 2 anos.

\section{IV - Convite}

A definição de data de aplicação do workshop foi verificada junto à associação de produtores orgânicos, responsável por realizar o convite junto aos agricultores. Dessa forma, como estratégia para que os agricultores participassem do encontro da data proposta culminou no mesmo dia da festa do município. Dessa forma, a apresentação seria realizada no sábado, no período da manhã e o período da tarde ficaria livre para que os agricultores pudessem participar da festa.

Além da associação, a divulgação foi realizada por meio dos meios de comunicação da cidade e de portal de rede social da universidade.

\subsection{APLICAÇÃO DO WORKSHOP}

O encontro foi realizado no dia 22 de julho de 2017 no salão de uma igreja localizada na região central da cidade de Marechal Cândido Rondon, a partir das 9:30 horas.

Os agricultores foram recepcionados pelos participantes do projeto com a entrega de um folder com os principais passos para instalação e informações relevantes sobre o biodigestor sertanejo. Participaram do encontro um total de 23 agricultores.

0 encontro foi iniciado com a apresentação de um vídeo que demonstra as experiências e o relato de agricultores que já fizeram a instalação do modelo do biodigestor sertanejo.

Na sequência foi apresentado por meio de fotos, o modelo do biodigestor e os 12 passos para construção do modelo, demonstrando de forma simples a possibilidade de instalação do modelo pelo agricultor, assim como os benefícios sociais, ambientais, econômicos e os custos e viabilidade de implantação do modelo. 
Durante o encontro foi verificado a presença de dois agricultores que já possuíam em suas propriedades dois modelos de fossas sépticas biodigestoras. Estes, puderam dar seus depoimentos para os outros agricultores acerca da funcionalidade e benefícios identificados. Os modelos de fossas sépticas dos agricultores foram construídas com a preocupação de não lançar os desejos humanos diretamente na natureza.

Após a apresentação foi aberto para questionamento, dúvidas e troca de experiências dos participantes. Destacou-se que os agricultores percebem a importância de utilização de tecnologias e inovações que contribuam para o desenvolvimento sustentável, principalmente quanto ao aspecto ambiental.

Durante a interação surgiram algumas dúvidas que não puderam ser respondidas devido ao aspecto técnico. 0 questionamento realizado por um dos agricultores em relação a utilização do biofertilizante para produtos orgânicos resultante de biomassa de resíduos de animais que utilizam medicamentos. 0 biodigestor através do seu processo de digestão elimina os resíduos dos medicamentos na transformação do produto de saída, o biofertilizante? Esse questionamento, não pode ser respondido, entretanto pode ser objeto de pesquisa por outras áreas do conhecimento.

Evidenciou-se com a apresentação do projeto, a troca de experiência entre os envolvidos, contribuindo para ampliar o conhecimento e verificar que os produtores mostraram a intenção de instalação do biodigestor.

Destaca-se que os agricultores reconhecem os benefícios sociais, econômicos e ambientais gerados pela implantação do modelo de biodigestor. Entretanto, a percepção do aspecto ambiental foi muito presente durante as discussões com o grupo. Nesse sentido, essa percepção contraria o resultado do estudo apresentado por Smith et al. (2014), em que as famílias na África apesar de reconhecerem o benefício gerado pela implantação do modelo, somente fariam o investimento se o mesmo tivesse um retorno financeiro elevado. Dessa forma, o modelo de biodigestor sertanejo, para este público, além de ser alternativa viável economicamente, é entendida como relevante também no aspecto ambiental.

\section{CONCLUSÕES}

As pequenas propriedades familiares são de suma importância na produção de alimentos de forma mundial, sendo que a produção de forma orgânica está preocupada com a saúde das pessoas e ainda com a preservação do meio ambiente enfatizando a sustentabilidade.

O relato técnico objetivou demonstrar a integração entre a universidade e comunidade, para troca de experiência e repasse de informações, buscando a inclusão de práticas sustentáveis na agricultura, visando demonstrar os benefícios sociais, ambientais e econômicos com o uso de um pequeno biodigestor sertanejo. 0 objetivo foi atendido integralmente, esse apontamento foi percebido pela conversa informal que ocorreu durante o almoço servido após o workshop e também pelo retorno oficial da associação.

Dessa forma, demonstra-se que os agricultores familiares, sócios de uma associação de produtos orgânicos no município de Marechal Cândido Rondon - Paraná, percebem os benefícios gerados pela implantação do modelo do biodigestor sertanejo, apresentando interesse na sua instalação.

A relevância do projeto não foi a aceitação da instalação do modelo pelos agricultores, mas a importância do reconhecimento de alternativas e tecnologias de baixo custo que possam agregar valor às propriedades de agricultura familiar. Sendo relevante o projeto para que a partir das necessidades identificadas e o reconhecimento dos agricultores, possam surgir alternativas para projetos de efetiva implantação do modelo proposto, a partir de parcerias firmadas entre associação, universidade e outros órgãos.

A partir deste estudo, outros órgãos em parceria com a universidade e a associação, possam desenvolver alternativas e novos projetos para a efetiva instalação do modelo de biodigestor proposto.

Este estudo limita-se ao apresentar o projeto e verificar a percepção apenas dos agricultores de orgânicos do Município de Marechal Cândido Rondon, entretanto, a aplicação do projeto para outras comunidades, associações e grupos de agricultores se apresenta como oportunidade de ampliação ou criação de um programa que contemple várias áreas de conhecimento com foco no desenvolvimento sustentável da agricultura familiar. 


\section{REFERÊNCIAS}

[1] Andreazzi, M. A., dos Santos, J. M. G., \& Lazaretti, R. M. J. (2015). Estudo sobre a destinação dos resíduos da suinocultura em granjas do estado do Paraná. Electronic Journal of Management, Education and Environmental Technology (REGET), 19(3), 744-751.

[2] Barichello, R., Hoffmann, R., Da Silva, S. O. C., Deimling, M. F., \& Casarotto Filho, N. (2015). O uso de biodigestores em pequenas e médias propriedades rurais com ênfase na agregação de valor: um estudo de caso na região Noroeste do Rio Grande do Sul. Revista em Agronegocio e Meio Ambiente, 8(2), 333-355. https://doi.org/10.17765/2176-9168.2015v8n2p333-355

[3] CRESOL. (2017). Recuperado em julho de 2017. Acesso em: <http:www.cresol.com.br>

[4] Carvalho, D. M., da Silva, J. L., de Oliveira Vasconcelos, R., \& da Costa, J. E. (2016). O Beneficiamento do amendoim em Ribeirópolis: do trabalho artesanal a aplicação de tecnologia social. Revista GeoNordeste, (1), 108-131.

[5] Elkington, J. (1997). Cannibals with forks. The triple bottom line of 21st century, 73

[6] Empresa Brasileira de Pesquisa Agropecuária (2017). Módulos Fiscais. Recuperado em: 30 de junho de 2017, de http:// https://www.embrapa.br/codigo-florestal/area-de-reserva-legal-arl/modulo-fiscal

[7] FAO (2014). Agricultura familiar en América Latina y el Caribe: Recomendaciones de Política. Santiago de Chile. FAO.

[8] Garfí, M., Martí-Herrero, J., Garwood, A., \& Ferrer, I. (2016). Household anaerobic digesters for biogas production in Latin America: A review. Renewable and Sustainable Energy Reviews, 60, 599-614. https://doi.org/10.1016/j.rser.2016.01.071

[9] Gomes, T., \& Raiher, A. (2013). Viabilidade econômica da produção de biogás de dejetos suínos: um estudo de caso. Revista Ciências Administrativas, 19(2), 776-815. https://doi.org/10.5020/2318-0722.2013.v19n2p776

[10] Lei 11326, de 24 de julho de 2006. (2006). Estabelece as diretrizes para formulação da Política Nacional da Agricultura Familiar e Empreendimentos Familiares Rurais. Recuperado em: junho de 2017, de http://www.planalto.gov.br/ccivil_03/_ato2004-2006/2006/lei/l11326.htm

[11] Marin, M.Z. , Bley Junior \& Gonzales, R.H.A.(2016). Espaços Rurais: além dos alimentos, a vocação energética. Boletim de Geografica, 34(3), 63-80. https://doi.org/10.4025/bolgeogr.v34i3.24079

[12] Mattos, L. C., \& Farias, M. J. (2011). Manual do biodigestor sertanejo. Projeto Dom Helder Camara. 55p. : il.

[13] Montoro, S. B., Santos, D. F. L., \& Lucas Junior, J. de. (2017). Economic and financial of digester use in cattle confinement for beef. Engenharia Agrícola, 37(2), 353-365. https://doi.org/10.1590/1809-4430eng.agric.v37n2p353-365/2017

[14] Montoro, S., Santos, D., \& Lucas Júnior, L. (2013). Análise Econômica de Investimentos que visam a produção de biogás e biofertilizante por meio de biodigestão anaeróbia na bovinocultura de corte. Revista Eletrônica Mestrado Em Administração, 5(2), 23-34. Retrieved from http://repositorio.unp.br/index.php/raunp/article/view/314

[15] Silva, A. R. da, \& Cirani, C. B. S. (2016). Viabilidade Econômica e Benefícios ambientais de tecnologia aplicada a bidigestores em empresas processadoras de mandioca no Paraná. Revista Eletrônica de Estratégia \& Negócios, 9, 2253. https://doi.org/10.19177/reen.v9e3201622-53

[16] Silva, A. R. da, Cirani, C. B. S., \& Serra, F. A. R. (2016). Desempenho Econômico e Ambiental: Práticas de Ecoinovação em Biodigestores em Empresas Processadoras de Mandioca. Revista de Gestão Ambiental E Sustentabilidade, 5(3), 72-86. https://doi.org/10.5585/geas.v5i3.584

[17] Smith, M. T., Schroenn Goebel, J., \& Blignaut, J. N. (2014). The financial and economic feasibility of rural household biodigesters for poor communities in South Africa. Waste Management, 34(2), 352-362. https://doi.org/10.1016/j.wasman.2013.10.042

[18] Sosa, R., Díaz, Y. M., Cruz, T., \& De La Fuente, J. L. (2014). Diversification and overviews of anaerobic digestion of Cuban pig breeding. Cuban Journal of Agricultural Science, 48(1), 67-72. Retrieved from https://www.scopus.com/inward/record.uri?eid=2-s2.0-

84902009379\&partnerID=40\&md5=ade3ec359e3cd2b50531d8409d29a94f 


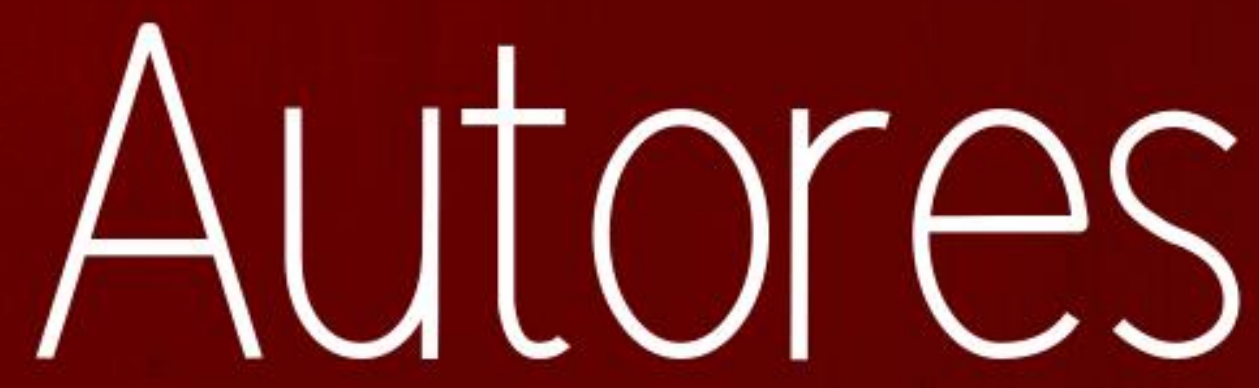




\section{ELIZANGELA DE JESUS OLIVEIRA (ORGANIZADORA)}

Professora Doutora da Universidade Federal do Amazonas. Doutorado em Administração pela UNIMEP - UNIVERSIDADE METODISTA DE PIRACICABA e Mestre em Administração pela FPL FUNDAÇÃO PEDRO LEOPOLDO DE MINAS GERAIS. Possui graduação em Administração pela UNIMONTES- Universidade Estadual de Montes Claros (2008). Especialista em Design Instrucional para Educação a Distância pela UNIFEI- Universidade Federal de Itajubál. Possui experiência como docente na Graduação Presencial dos cursos de Administração, Engenharias, e Cursos Superiores em Tecnologia de Logística, Comércio Exterior e Gestão Portuária e Gestão de Recursos Humanos. Estuda o tema felicidade no trabalho nas organizações e desenvolve consultoria na área de gestão de pessoas.

\section{SUELÂNIA CRISTINA GONZAGA DE FIGUEIREDO (ORGANIZADORA)}

Possui graduação em Economia pela Universidade Regional do Cariri URCA (1987), mestrado em Desenvolvimento Regional pela Universidade Federal do Amazonas UFAM (2008) e doutorado em Ciências da Educação pela Universidade Nihon Gakko Paraguai (2018). Atualmente é Coordenadora de Pesquisa e Extensão do Instituto Metropolitano de Ensino IME, atuando principalmente nos seguintes temas: Pesquisa e Extensão, Iniciação Científica, Sustentabilidade Ambiental, Articulação Pesquisa, Ensino, Extensão e Responsabilidade Social na formação acadêmica. Idealizadora e organizadora do Congresso Científico FAMETRO, realizando um trabalho de incentivo à produção e publicação acadêmica. Responsável pelo Programa de Intercâmbio e Mobilidade Acadêmicos do IME. Coordenadora de Pesquisa e extensão da Faculdade Santa Teresa-Manaus-Am.

\section{RAFAEL ALVES PEDROSA (ORGANIZADOR)}

Consultor de Gestão com enfoque em Logística Portuária e de Transportes, com graduação em Administração, Comércio Exterior, Logística e Transporte Multimodal e Gestão Portuária; Pós Graduação em Gestão de Comércio Exterior e Logística; Gestão Empresarial; Gestão, Docência e Tecnologias do Ensino Superior; MBA em Docência do Ensino Superior pela Fundação Getúlio Vargas - FGV; Mestre em Sustentabilidade de Sistemas Costeiros com dissertação voltada a Dragagem de Aprofundamento do Porto de Santos/SP; Doutorado em Planejamento e Gestão pela Universidade Federal do ABC (UFABC) com tese voltada ao impactos da expansão portuária do Porto de Santos na integração porto/cidade. Autor e organizador de livros e capítulos de livros relacionados a sua área de atuação. Coordenador de projetos de pesquisa e revisor de periódicos ligados as áreas de Logística e Comércio Exterior e planejamento territorial e urbano. Professor conteudista de cursos superiores em EaD. Possui cursos de atualização nas áreas de Administração, Logística e Comércio Exterior, fez intercâmbio na Argentina adquirindo fluência no idioma Espanhol, além de participar constantemente de fóruns destinados a estas áreas. Coordenador do curso de pós graduação em Gestão Portuária e Operações Internacionais. Com experiências na coordenação de Logística e transportes em empresas multinacionais sendo responsável pelo planejamento de distribuição e Logística das regiões Sul e Sudeste do país. Tendo sido contemplado com o prêmio de Melhor ideia inovadora 2010 . Atuou ainda no papel de Coordenador de Operações Portuárias. Já na docência foi contemplado com o prêmio Mérito Docente por atuação acadêmica destacada e foi contemplado com o prêmio Dr. Milton Teixeira pela orientação do melhor trabalho de iniciação cientifica.

\section{WANDERSON DA SILVA DAMIÃO (ORGANIZADOR)}

Doutor em Administração pela UNIMEP, possui mestrado acadêmico em Administração de Empresas pela UMESP, MBA em Gestão de Pessoas e especialização em Gestão Empresarial e Financeira pela Faculdades Anhanguera, Bacharelado em Teologia pela UMESP, Bacharelado em Teologia pelo Instituto FATEM e Tecnologia Mecânica pelo Centro Universitário de Santo André UNIA. Exerce atividades de Adminstração, Pesquisa, Docência e Coordenação de cursos EAD no Instituto FATEM, trabalhos técnicos em infraestrutura e equipamentos na Volkswagen do Brasil LTDA e é pesquisador em temáticas sobre Educação, Gestão e Inteligência Espiritual. 


\section{RUTE HOLANDA LOPES (ORGANIZADORA)}

Pesquisadora e Professora Adjunto da Universidade Federal do Amazonas - UFAM/ ICET (Economia Rural, Introdução à Economia e Gestão Ambiental). Coordenadora do Núcleo de Economia, Tecnologia, Gestão e Inovação; Coordenadora Administrativa da Incubadora do ICET - ICETech, Vice coordenadora do Curso de Engenharia de Produção, Coordenadora do COMEXI - Comitê de Extensão do ICET. Doutora em Ciências do Ambiente e Sustentabilidade da Amazônia pela UFAM (2015). Mestra em Desenvolvimento Regional pela UFAM (2008). Graduada em Ciências Econômicas pelo CIESA (2001), MBA em Empresas e Negócios pelo CIESA (2003). Pesquisas na área de: Economia Rural, Economia Regional, Engenharia de Produção, Produção Agrícola, Cadeias Produtivas Locais e Agricultura Familiar, Gestão Ambiental, Sustentabilidade. Possui experiência como consultora econômica e ambiental com trabalhos técnicos em Diagnósticos, Prognósticos, Caracterizações e Análises de Contexto dos municípios da Região Metropolitana de Manaus

\section{ADRIANA DE SOUZA FERREIRA DE OLIVEIRA}

Graduação em Administração pelo Centro Universitário Integrado. Gerente administrativo da Agro Verde - Grupo Romagnoli.

\section{ADRIELA DE MARCHI}

Doutoranda da Universidad de Ciencias Empresariales y Sociales - UCES, Buenos Aires/Argentina; Mestre em Administração pela Universidade do Vale do Itajaí - UNIVALI; Especialização em Gestão de Material e Patrimônio Público pela Faculdade Integrada da Grande Fortaleza - FGF; Bacharel em Administração pela Faculdade de Educação e Ciência Administrativa. Auditora da Universidade Federal do Amazonas - UFAM.

\section{ALEXANDRA ALGÉLIA DA SILVA FRANÇA}

Engenheira Civil graduada pela Universidade Federal do Pará - UFPA, especialista em Trânsito Urbano em 2012, Mestra em Construção Civil e Materiais 2019, ambos pela UFPA, doutoranda pelo Programa de Pós-Graduação em Educação na Amazônia - EDUCANORTE. Participante do grupo de pesquisa NUHAM. Além de cursos de pequena duração para constantemente aperfeiçoar meus conhecimentos. Em andamento MBA em Master BIM.

\section{ALEXANDRE SANTOS}

Graduado em Administração de Empresas com Habilidade em Comercio Exterior pela FECAP (CRA 90640), Técnico em Contabilidade (CRC SP-271988/0-8). Doutor em Tecnologias da Inteligência e Design Digital pela PUCSP. Mestre em Liderança pela UNISA. Mestre em Tecnologias da Inteligência e Design Digital pela PUCSP. Pós-Graduado em Gestão Empresarial pela FECAP. Pós-graduação em Design Instrucional pela Universidade Federal de Itajubá - UNIFEI - MG. Pós-graduando em Planejamento, Implementação e Gestão de EaD pela Universidade Federal Fluminense - UFF - RJ. Gestor Financeiro. Extensão em Gestão Empresarial pela Universidade de Mallorca na Espanha.

\section{AMANDA CREMILDA LIMA BATISTA}

Engenheira Civil, Mestre em Construção Civil e Doutoranda em Construção Civil pelo Programa de Pós-Graduação em Engenharia Civil pela Universidade Federal do Pará.

\section{ANA ANGÉLICA BATISTA}

Engenheira de Produção (FEAMIG); Pós-graduanda em Engenharia de Segurança do Trabalho (FEAMIG). 


\section{ANDRÉ MONTENEGRO DUARTE}

Engenheiro Civil, Mestre em Engenharia, Doutor em Geociências. Professor da Universidade Federal do Pará - UFPA. Instituto de Tecnologia - ITEC - Faculdade de Engenharia Civil

\section{ANDSON DE FREITAS VIANA}

Possui graduação em Administração de Empresas pela Faculdade Evolutivo (2005), especialização em Controladoria pela UFC ACEP (2009) e mestrado em Economia com foco em Finanças pela UFC CAEN (2012). Experiência na área de Administração, com ênfase em Administração Financeira, Orçamentária, Custos, Economia da Saúde e Controladoria em empresas financeiras e em operadoras de planos de saúde. Atualmente sou dono da FV Planner Consultoria e professor das faculdades Fametro e Fanor dos cursos de Administração de Empresas, Ciências Contábeis e Engenharia da Produção

\section{ANNA KARINE MONTEIRO DE SOUSA}

Graduada em Ciências Contábeis (UNIFOR) Especialista em Controladoria e Finanças (UNIGRANRIO) Mestre em Administração de Empresas (UNIFOR) Analista Contábil III da Companhia de Água e Esgoto do Ceará (CAGECE).

\section{ANTÔNIO CLEBER GONÇALVES TIBIRIÇÁ}

Professor Titular da Universidade Federal de Viçosa, atuante na área de Tecnologia e Ambiência das Construções.

\section{ANTÔNIO RENATO PEREIRA MORO}

Doutor e Mestre em Ciência do Movimento Humano pela Universidade Federal de Santa Maria (UFSM). Especialista em Pesquisa em Educação Física. Graduação em Licenciatura Plena em Educação Física. Professor Associado da Universidade Federal de Santa Catarina, vinculado ao Departamento de Educação Física. Desde o ano de 2000, coordena o Laboratório de Biomecânica (BIOMEC) e Lidera o Grupo de Estudo do Movimento Humano (GEMH). É Sócio Fundador da Sociedade Brasileira de Biomecânica (SBB) e Ergonomista Sênior pela Associação Brasileira de Ergonomia (ABERGO). Atua como Professor nos Programas de Pós-Graduação (M/D) em Engenharia de Produção (Área de Ergonomia) e em Educação Física (Área de Biodinâmica do Movimento Humano) da UFSC, Florianópolis/SC.

\section{ARETUZA BALARDIN SAINZ}

Possui graduação em Administração Com Habilitação em Administração de Empresas pelo Centro Universitário Metodista (2008) e Pós Graduação em Gestão do Capital Humano (RH). Atualmente é diretora - Fluxo Administração Inteligente, Professora colaboradora da Fatenp (2017 a 2020) e membro do NDE. Tem experiência na área de Administração e de Recursos Humanos.

\section{AURELIANO TAVARES}

Mestre em Engenharia Civil pela Universidade Federal Fluminense - UFF. MBA em Gestão Empresarial - Instituto Federal de Educação, Ciência e Tecnologia do Rio de Janeiro - IFRJ. Graduado em Administração de Empresas, pelo Instituto Superior de Estudos Sociais Clóvis Belilacqua. Reitor no IMES - Instituto de Ensino Superior da Bahia, Rede FTC, Unidade Vitória da Conquista, BA.

\section{CAMILA AVOSANI ZAGO}

Doutora em Engenharia de Produção - Logística e Transportes pela Universidade Federal de Santa Catarina - UFSC (2012), Mestre em Engenharia de Produção - Gerência de Produção pela Universidade Federal de Santa Maria - UFSM (2007), Especialista em Planejamento, Implementação 
e Gestão de EAD (PIGEAD) pela Universidade Federal Fluminense - UFF (2014 - 2017) e Bacharel em Administração de Empresas pelo Centro Universitário Franciscano - UNIFRA (2004).Foi Professora Adjunta na área de Operações na Universidade Federal Rural do Rio de Janeiro - UFRRJ, Instituto Três Rios - ITR (2010 - 2015), onde atuou também em cargos administrativos. Atualmente é Professora Adjunta área de Logística na Faculdade de Administração e Ciências Contábeis - FACC - Universidade Federal do Rio de Janeiro - UFRJ (2015 - atual). Atuou como professora visitante no Departamento de Organização de Empresas, Marketing e Sociologia na Universidad de Jaén (2017) e no Departamento Departamento de Contaduría Pública na Universidad Central de Bogotá (2019). Tem experiência na área de Administração, com ênfase em Logística, SCM e Gestão de Operações, Marketing e Administração Geral, atuando principalmente nos seguintes temas: competitividade, logística, gerenciamento da cadeia de suprimentos e gestão ambiental.

\section{CARLA VITOR PAIM}

Arquiteta e Urbanista. Mestre em Engenharia Civil pela Universidade Federal de Viçosa.

\section{CHRISTIAN TURATO BOLOGNEZI}

\section{CLARA AGUIAR REIS}

Graduação em Administração com atuação focada na área comercial.

\section{CLAUDILAINE CALDAS DE OLIVEIRA}

Doutora em Engenharia de Produção pela Universidade Federal de Santa Catarina (UFSC). Mestre em Engenharia de Produção pela Universidade Tecnológica Federal do Paraná (UTFPR). Especialista em Vigilância Sanitária em Alimentos pela Universidade Tecnológica Federal do Paraná (UTFPR). Graduada em Engenharia de Produção Agroindustrial pela Faculdade Estadual de Ciências e Letras de Campo Mourão (FECILCAM). Professora do Curso em Engenharia de Produção do Departamento em Engenharia Têxtil (DET) da Universidade Estadual de Maringá (UEM) - Campos Regional de Goioerê (CRG). Participante do grupo de pesquisas: Grupo de Estudo do Movimento Humano (GEMH) e Grupo de Estudos e Pesquisa em Processos e Gestão de Operações (GEPPGO).

\section{CLÓVIS DELBONI}

Possui Mestrado em Administração, também é Doutorando na mesma área pela Faculdade de Gestão e Negócios da Universidade Metodista de Piracicaba. É Especialista em Gestão Estratégica de Negócios e possui Graduação em Superior de Tecnologia em Gestão de Logística. É Professor Universitário em Graduação e Pós Graduação nas disciplinas de Gestão e Negócios. Atuou como Professor Coordenador de curso de Pós Graduação no SENAC São Paulo - Unidade Piracicaba. Profissionalmente já atuou como executivo na área comercial em empresas de médio porte do setor varejista. Atualmente é Gerente Executivo da Associação Comercial e Industrial de Rio Claro -SP. Entidade de Classe que promove ações de fomento ao comércio local, industria e prestadores de serviços através de Feiras, Rodadas de Negócios e Promoções Comerciais de incentivo ao consumo. É membro voluntário do Comitê Gestor da Incubadora de Empresas de Rio Claro, Conselheiro Fiscal voluntário na Associação Garantidora de Crédito Paulista. Também é voluntário no Observatório Social de Rio Claro como Diretor de Parcerias e Relações Institucionais. Membro voluntário do Conselho Municipal de Ciência Inovação Tecnológica e também do Conselho Municipal do Meio Ambiente, ambos da Prefeitura de Rio Claro - SP.

\section{DANIEL MARTINS DA SILVA}

Possui graduação em Ciência da Computação pela Universidade Federal do Tocantins (2010) e mestrado em Computação pela Universidade Federal Fluminense (2012). Atualmente é professor do magistério superior da Universidade Federal do Tocantins. , atuando principalmente nos seguintes temas: logística, sistema de informação, e-commerce, impactos socioeconômicos e transporte público. 


\section{DIEGO SANTOS REBELO}

Mestrando do Programa de Pós Graduação em Planejamento Territorial (UEFS). Possui graduação em Direito pela Universidade do Estado da Bahia (2013). Pós-Graduado em Direito Público (UNIFACS). Pós-Graduado em Gestão Pública Municipal pela Universidade Federal da Bahia (UFBA). Pós Graduado em Resolução de Conflitos: Praticas Restaurativas (FAVENI). É Mediador Judicial formado pelo observatório de pacificação social UFBA/TJBA, Assessor da Procuradoria do Município de Santa Bárbara-BA e Sócio do Escritório Rebelo \& Rolemberg Advocacia. Professor da Faculdade Regional de Riachão do Jacuipe - FARJ, onde ministra aulas nas área de Direito. É coordenador do Curso de Direito da Faculdade Regional do Jacuípe (FARJ) sendo responsável pela coordenação anterior do Núcleo Estruturante para implantação do referido curso na mesma instituição. Atua principalmente nos seguintes temas: acesso a informação, efetividade, Administração Pública, Gestão de políticas públicas e Direito do Estado.

\section{DIULNÉIA GRANJA PEREIRA}

Mestre em Administração pela Universidade do Vale do Itajaí - UNIVALI; MBA em Gestão Empresarial pela Unisinos; Bacharel em Administração com ênfase em Recursos Humanos pela Unisinos. Experiência de mais de dez anos na área de Recursos Humanos em empresas privadas; Experiência de dez anos na docência em universidades do RS e SC. Atualmente Consultora de Recursos Humanos para empresas de pequeno e médio porte.

\section{DJEIMI ANGELA LEONHARDT NESKE}

Mestre em administração (modalidade profissional) pela Unioeste (2018). Pós-graduada em docência do ensino superior - metodologias ativas (2019). Bacharel em Administração pela Unioeste (2017). Técnica em contabilidade (2007). Docente da FAG - Toledo (05/2018 - atual). Instrutora técnica no CIEE-PR (02/2020 - atual). Instrutora do Programa Bom Negócio Paraná (PBNP) UNIOESTE Campus de Marechal Cândido Rondon (Projeto de extensão) de 02/2017 a 04/2018. Gerente administrativo, de agosto de 2007 à fevereiro de 2017 (Loja de varejo, móveis e confecções). Experiência na áreas: financeira, gestão de pessoas, elaboração e análise de projetos, compras e vendas.

\section{EDUARDA BARBOSA VELLOSO}

Graduanda em Gestão de Recursos Humanos e em Administração com ênfase em Comércio Exterior. Atuação na área de Recursos Humanos.

\section{EDUARDO MARIO DIAS}

Doutor e Mestre em Engenharia Elétrica pela Escola Politécnica da USP. Desde 1994 é professor titular da Universidade de São Paulo (USP),onde ministra cursos na graduação e na pós-graduação na Escola Politécnica da USP. Professor do programa de pós-graduação do Instituto de Radiologia (INRAD) da Faculdade de Medicina da USP (FMUSP). Coordenador do GAESI - Gestão em Automação \& T.I., grupo de pesquisa da EPUSP. Atua principalmente nos seguintes temas: automação; cidades inteligentes; aplicação de Sistemas de Transportes Inteligentes (ITS), tendo participado da formação do Laboratório de Tecnologias e Protocolo Aberto para Mobilidade Urbana, junto com a Secretaria Municipal de Transportes (SMT) e suas empresas, a SPTrans e a CET; portos e logísticas, desenvolvendo diversas atividades com o Ministério dos Transportes e Empresa de Planejamento e Logística (EPL); motores de indução; desequilíbrio de tensão; iluminação elétrica e lógica fuzzy. Desenvolve projetos com a Petrobrás nas áreas de automação, rastreabilidade e ITS. Membro da Comissão de Inovação do Hospital das Clínicas da FMUSP e Conselheiro do CONIC (Conselho Superior de Inovação e Competitividade) da Federação da Indústria do Estado de São Paulo (FIESP) Faz parte do conselho Curador da Fundação Ilumina desde maio de 2019 a abril de 2023. Desde 2012 é Editor-in-Chief do WSEAS Transactions on Power Systems - Print ISSN:1790-9060 E-ISSN: 2224-350X. 


\section{EDY CARLOS SANTOS DE LIMA}

Doutor em Meio Ambiente e Desenvolvimento Regional pela Universidade Anhanguera - UNIDERP. Mestre em Produção e Gestão Agroindustrial, Anhanguera - UNIDERP (2010). Especialista: em Docência no Ensino à Distância - FAPAN (2019); em Gestão Empresarial Estratégica - MBA Executivo - Universidade de São Paulo - USP (2005) e em Gestão de Negócios e Controladoria - Faculdades Integradas de Jales - FAI (2002). Possui graduação em Pedagogia - Licenciatura - Faculdade de Paraíso do Norte - FAPAN (2018) e graduação em Administração - Faculdades Integradas de Jales (2000). Atualmente professor titular da Faculdade de Tecnologia - Prof. José Camargo - FATEC Jales/SP nos cursos de Tecnologia em Gestão Empresarial, Agronegócio e Análise e Desenvolvimento de Sistemas - ADS. Professor de programas de pós-graduação em diversas faculdades e universidades. Possui experiência desde 2008 em Consultoria Empresarial e Pública e na Docência em cursos de Administração, Agronegócio e Gestão Empresarial, com ênfase nas áreas relacionadas à Administração, atuando principalmente nos seguintes temas: Gestão de pessoas, planejamento estratégico, comportamento organizacional, sistemas de informação.

\section{ELEANDRA MARIA PRIGOL MENEGHINI}

Doutoranda pelo Programa de Pós-Graduação em Administração da Universidade do Vale do Itajaí. Mestre em Administração pelo Programa de Pós-Graduação em Administração da Universidade do Vale do Itajaí

\section{ELENICE DA SILVA CARVALHO}

Mestre em Administração pela Universidade Estadual do Oeste do Paraná (UNIOESTE) . Especialista em Gestão de Projetos pela UNOPAR e Especialista em Educação a Distância com Habilitação em Tecnologias Educacionais pelo Instituto Federal do Paraná (IFPR). Bacharel em Adminstração de Empresas pela FAESO de Ourinhos (2006). Servidora Pública no IFPR Campus Cascavel

\section{ELENILSON OLIVEIRA PINHEIRO}

Possui graduação em Bacharel em Administração de Empresas pela Fundação Técnico Educacional Souza Marques (1999), Mestrado em Sistema de Gestão pela UFF-RJ, Especialista em Gestão Estratégica de Negócios pelo INPG/Embraer;e em Marketing e Comércio Exterior INPG -Campinas com Extensão em: Custos-FGV, em Negócios Comerciais - UNICAMP-SP em 2007 finalizou a Especialização em Gerenciamento de Projetos pela SEGRAC/POLI - UFRJ. Desenvolveu sua carreira no setor aeronáutico, com mais de 15 anos de experiência no desenvolvimento de projetos, processos de fabricação, serviços de engenharia. Projetista aeronáutico na Embraer, Coordenador de projetos na Microleve, Gestor de Planejamento de Manutenção, Analista de Custos/Contratos.

\section{ELIENE RODRIGUES SOUSA}

Doutoranda em Ensino de Língua e Literatura pela UFT. Mestre em Ensino de Língua e Literatura pela Universidade Federal do Tocantins (UFT) - dissertação na área da literatura comparada e outras artes. Graduada em Letras português/inglês (2009) pela Universidade Federal do Tocantins (UFT). Professora de língua portuguesa, Inglesa e Arte do Ensino Fundamental e médio na rede pública de 2009 a 2014 e de 2016 a 2018. Atualmente é professora substituta de português e inglês no Instituto Federal do Tocantins - IFTO - campus de Araguaína.

\section{ELISIANE SALZER}

Coordenadora e Professora do Curso de Ciências Contábeis na Faculdade de Ensino Superior de Marechal Cândido Rondo - ISEPE Rondon. Mestre em Administração (Modalidade Profissional) pela Universidade Estadual do Oeste do Paraná - UNIOESTE - Área de concentração: Competitividade e Sustentabilidade - Linha de Pesquisa 2 - Sustentabilidade. Pós Graduada na Unioeste - Campus Cascavel em Práticas Contábeis (2016), Graduação em Ciências Contábeis (2013). 


\section{FRANCISCO CARLOS RIBEIRO}

Doutorando em História pela Pontifícia Universidade Católica de São Paulo (PUC-SP).

\section{FRANCISCO DE ASSIS COELHO}

Graduado em Ciências Contábeis pela Universidade de Taubaté, Mestre em Ciências Contábeis e Atuariais pela Pontifícia Universidade Católica de São Paulo (PUC-SP) Pós-graduando em Perícia Judicial e Práticas Atuariais com Docência em Ensino Superior no Instituto Tecnológico de Ciência e Pesquisa - ITCP. Professor Assistente na Universidade de Taubaté em regime integral desde 1992, Controlador Interno, Professor nos cursos de graduação - Ciências Contábeis e Sistema de Informação, Professor nos cursos de pós-graduação MBA - Gestão Financeira - Controladoria e Auditoria ,Gestão de Projetos, Diretor Financeiro da Fundação Artística e Cultura da Universidade de Taubaté, Membro do Conselho de Administração Fiscal do Instituto de Previdência do Município de Taubaté.

\section{GIOVANA TASSI DE PAULA}

Graduação em Administração, Especialização em Gestão Estratégica de Recursos Humanos, Gestão Empresarial e em Organização do Trabalho em Politécnica. Atuação de 22 anos em multinacional na área recursos humanos e docência a 12 anos nos cursos de Administração e Ciências Contábeis na Faculdade Machado Sobrinho.

\section{HELIOS MALEBRANCHE}

Prof Associado do Depto de Administração da UFRJ; Secretário Geral da Fundação Universitária da UFRJ; membro do Conselho Universitário e da Comissão de Legislação e Normas da UFRJ. Áreas de atuação: Gerenciamento de Projetos, Estratégia Empresarial, Mapeamento de Processos e Logística. Atividades anteriores: Coordenador da Comissão Própria de Avaliação da UFRJ; Coordenador de Planejamento do Centro de Ciências Jurídicas e Econômicas da UFRJ; Chefe do Depto de Administração da UFRJ; membro do Conselho de Graduação da UFRJ, Comissão de Legislação e Normas e Comissão de Corpo Docente; Superintendente de Educação Executiva da FGV; e Diretor Geral da Fundação de Apoio ao Desenvolvimento da Computação Científica (LNCC/MCTI).

\section{HELIOS MALEBRANCHE}

Prof Associado do Depto de Administração da UFRJ; Secretário Geral da Fundação Universitária; membro do Conselho Universitário da UFRJ e da Comissão de Legislação e Normas da UFRJ. Áreas de interesse: Gerenciamento de Projetos, Estratégia Empresarial, Mapeamento de Processos e Logística. Atividades anteriores: Coordenador de Planejamento do Centro de Ciências Jurídicas e Econômicas da UFRJ; Chefe do Depto de Administração da UFRJ; membro do Conselho de Graduação da UFRJ; Superintendente de Educação Executiva da FGV e Diretor Geral da Fundação de Apoio ao Desenvolvimento da Computação Científica (LNCC/MCTI).

\section{JOÃO VITOR FERRARI}

Possui Graduação em Agronomia pela Universidade Estadual Paulista Júlio de Mesquita Filho (2009), Especialidade em Agricultura Orgânica pela Universidade On-Line de Viçosa (2013), Licenciatura Plena em Agronomia (Programa Especial de Formação Pedagógica) pelo Centro Estadual de Educação Tecnológica Paula Souza (2013) e Mestrado e Doutorado em Agronomia (Sistemas de Produção) pela Universidade Estadual Paulista Júlio de Mesquita Filho (2010 a 2015). Atualmente exerce o cargo de Professor na Escola Técnica Estadual de Jales (ETEC) desde 2009, onde foi coordenador do curso de Agronegócio (2013) e ministrou aulas nos cursos de Agropecuária, Agronegócio, Produção de Cana-de-Açúcar, Agroindústria, Alimentos, Administração e Secretariado. Também é Professor Assistente da Faculdade de Tecnologia de Jales (FATEC) desde 2013, ministrando aulas no curso de Tecnologia em Agronegócio, onde atua também como Coordenador de Estágios. Possui experiência na área de Fitotecnia com ênfase nas culturas do milho, 
algodão, soja e sorgo. Participou de eventos técnicos e científicos no Brasil e Estados Unidos da América.

\section{JOYCE GONÇALVES ALTAF}

Doutoranda em Ciencias Empresariales y Sociales, mestrado em Administração e Desenvolvimento Empresarial, extensão em Marketing e Liderança pelo Marietta College, pós graduação em História Econômica, graduação em Administração de Empresas e em Serviço Social. Professora universitária e atua como responsável pela criação de novos negócios e pela gestão do setor de pós graduação e extensão da Rede Doctum que possui 23 unidades no país e atua em quatro segmentos: Ensino Superior, Educação Corporativa, Ensino Técnico e Educação Básica.

\section{LARISA HEMKEMEIER WEBBER DE MELLO}

Diretora de Vendas Independente Mary Kay. Atuou como Diretora Acadêmica e Operações do Grupo A, Diretora Executiva na Fatenp/Unigranrio, Diretora de Capacitação da ACIP - Associação Empresarial de Palhoça, Conselheira da Junior Achievement de Santa Catarina, sócia da empresa PFAD - Treinamento, Assessoria e Consultoria, Palestrante, Professora e Consultora de Projetos e Captação de Recursos. Formação em Gestão de Projetos, Captação de Recursos e Gestão da Qualidade.

\section{LEANDRO FLORA}

Graduação em Administração pelo Centro Universitário Integrado.

\section{LUIZ MAURÍCIO FURTADO MAUÉS}

Pesquisador com ênfase em Processos Construtivos nos seguintes temas: construção civil, racionalização, sistemas de gestão da qualidade, gerenciamento de obra, resíduos, risco, modelagem e planejamento e controle da produção. Professor Associado I da UFPA, membro do grupo de pesquisa NUHAM, Doutor pela UFPA, mestre em Engenharia de Produção pela Universidade Federal de Santa Catarina (1996), sendo graduado em engenharia civil pela UFPA.

\section{MANOEL GONÇALES FILHO}

Mestre em Engenharia de Produção e Doutorando em Administração pela UNIMEP. Administrador de Empresas pela EEP. Possui duas pós graduações LATU SENSU: Especialização em Gestão de Pessoas pela UNIMEP e MBA em Gestão Financeira FGV. É professor titular na FATEC e na UNISAL com as disciplinas de Administração, Contabilidade e Economia.

\section{MARCELO D’ALESSANDRO}

Diretor Administrativo Executivo da Associação Brasileira de Gerenciamento de Risco (ABGR) com experiência em gestão de riscos e de seguros, qualificação e quantificação, vivência internacional para desenvolvimento de gerenciamento de risco de projetos e programas corporativos de riscos e seguros, gestão e gerenciamento de crise, regulação e liquidação de sinistros, D\&O (Directors \& Officers), Riscos Operacionais, Lucros Cessantes, Riscos de Engenharia, Vida, Saúde e Acidentes Pessoais, Responsabilidade Civil, Transporte Nacional e Internacional, Crédito, Garantias Contratuais, Petróleo e Gás, "Off Shore", Energia (Hidroelétricas e Geradores), Linhas de Transmissão de Telecomunicações. Mestrado na Área de Energia (UFPR - Lactec).

\section{MARCELO LUIZ ALVES FERNANDEZ}

Marcelo Luiz Alves Fernandez é Agente Fiscal de Rendas da Secretaria da Fazenda do Estado de São Paulo, graduado em Engenharia Mecatrônica e em Direito, ambos pela Universidade de São Paulo, especialista em Direito Tributário pela Escola Superior da Procuradoria Geral do Estado de São Paulo, Mestre e Doutor pela Escola Politécnica da Universidade de São Paulo. 
Atua no Serviço Público desde 1998, tendo trabalhado no Banco Central do Brasil e como Auditor Fiscal Tributário na Secretaria de Finanças do Município de São Paulo. Foi professor em duas edições da Maestría Internacional Hacienda Pública Dirección y Admnistración Tributaria do Instituto de Estudos Fiscales do Ministerio de Hacienda y Administraciones Públicas del Goberno de España, cursos promovidos em parceria com os fiscos brasileiros.

Na Secretaria da Fazenda liderou os projetos da Nota Fiscal Eletrônica, Conhecimento de Transporte Eletrônico e Escrituração Fiscal Digital, atuou por 6 anos como Supervisor Fiscal de documentos digitais, foi juiz do TIT no biênio 2013/2014, exerceu por dois anos a função de Diretor Adjunto da Diretoria Executiva da Administração Tributária e por dois anos a função de Diretor de Informações junto à Coordenadoria da Administração Tributária. Atualmente trabalha na Fiscalização Direta de Tributos.

\section{MÁRCIA FERREIRA DA SILVA}

Profissional na área administrativa. Aluna do curso de Administração do Centro Universitário Adventista de São Paulo - UNASP

\section{MARCILEIDE MUNIZ CAVALCANTE}

Vivência mais de 15 anos em docência do ensino superior presenciais e ead, ministrando aulas para os cursos de Administração de Empresas, Ciências Contábeis, Tecnologia do Ensino Superior em Gestão em Recursos Humanos, Gestão Financeira, Marketing, Logística, COMEX, lecionando as disciplinas de: Administração de Recursos Humanos e/ou Gestão de Pessoas, Liderança, Comunicação, Motivação, Metodologia Científica, Teoria Geral da Administração - TGA, Empreendedorismo, Planejamento Estratégico, Qualidade de Vida no Trabalho e Sustentabilidade, Recrutamento e Seleção de Pessoal, Saúde e Segurança no Trabalho, Treinamento e Desenvolvimento, Tópicos Avançados em Gestão de Pessoas, Psicologia do Comportamento Organizacional, Planejamento de Carreira e Sucessão. Vivência em ministrar aulas nos cursos na metodologia da Educação à Distância (EaD) com aulas ao vivo via satélite e webconferência, nas disciplinas de Gestão de Pessoas e suas áreas afins, Teorias da Administração e suas áreas, Estratégico e Metodologia Científica. Vivência em ministrar aulas em cursos de pós-graduação, na disciplina de Gestão de Pessoas e Metodologia da Pesquisa. Experiência em ministrar cursos técnicos (in company) de qualificações ligadas à área de gestão de pessoas e/ou recursos humanos. Experiência em ministrar aulas PRONATEC SENAC 24 DE MAIO.

\section{MARCIO PEREIRA BASILIO}

Doutor em Engenharia de Produção - UFF Mestre em administração Pública - Ebape- FGV, Bacharel em Administração de Empresas.

\section{MARIA CRAUVICEIA DOS S. VIEIRA}

Profissional na área administrativa operacional, comercial e vendas. Acompanhamento de vendas, fluxo de caixa, contas a pagar e receber, classificação e lançamento de notas fiscais e caixinha no sistema integrado, e conciliação. Conhecimento em sistemas integrados: MEGA, COND21, DATASUL e UAU. Controle e emissão de planilhas, arquivos em geral. Recrutamento e seleção, documentação, controle de ponto e GFIP. Liderança em equipe, coordenação de atividades, atendimento ao cliente e fornecedores. Controle de materiais e patrimônios, cotação e compra de materiais e serviços, recepção e malotes. Informática - Word, Excel, Power Point, Outlook, internet. Comunicativa, organizada, pensamento crítico, liderança, atitude positiva, comprometimento e ética no trabalho, dinâmica, facilidade para aprender e trabalhar em equipe.

\section{MARICOELI GONÇALVES TAVARES}

Graduada em Ciências Contábeis (UNIFAMETRO) 


\section{NEURISANGELO CAVALCANTE DE FREITAS}

Possui graduação em Ciências Contábeis pela Universidade de Fortaleza (2000), MBA em Controladoria e Finanças pela Universidade do Grande Rio (2001), Mestrado em Controladoria pela Universidade Federal do Ceará (2008). Funcionário da Companhia de Água e Esgoto do Ceará Cagece e atualmente ocupando a função de Gerente de Controladoria. Tem experiência na área administrativa e financeira, com ênfase em Ciências Contábeis, atuando principalmente nos seguintes temas: controladoria, contabilidade, custos e sistema de informações gerenciais.

\section{ORLANDO LONGO}

Doutor em Engenharia de Transportes pela Universidade Federal do Rio de Janeiro - UFRJ. Mestre em Engenharia Civil pela Universidade Federal Fluminense - UFF. Professor Titular da UFF. Coordenador do Programa de Pós-graduação em Engenharia Civil da UFF (2005 - 2013).

\section{PAULO MARCELO VILLANI}

Graduado em História (UNI-BH); Pós-graduado em História (UNI-BH); Mestre em Administração (UNIHORIZONTES).

\section{RAQUEL FERREIRA DE SOUZA}

Graduada em Letras (PUCMINAS); Graduada em Direito (FAMIG); Pós graduada em Administração (UNOPAR); Pós graduada em EaD (Uniseb); Pós graduada em Linguística (Estácio); Mestre em Filosofia (FAJE).

\section{REINALDO GOMES DA SILVA}

Possui graduação em Ciências Econômicas pela Universidade Metodista de Piracicaba (1986), mestrado em Economia Politica pela Pontifícia Universidade Católica de São Paulo (1996) e doutorado em Ciências Sociais - Política pela Pontifícia Universidade Católica de São Paulo (2006). Atualmente é professor Escola de Engenharia de Piracicaba e professor do Centro Estadual de Educação Tecnológica Paula Souza - Fatec - Piracicaba. Tem experiência na área de Ciência Política, Economia e Administração. Atua como professor nessas áreas de conhecimento.

\section{RICARDO BORDEAUX REGO}

Doutor em Administração de Empresas.

\section{ROBSON SUETH}

Pós-Doutor e Doutor em Educação pela Universidade Federal Fluminense - UFF. Mestre em Educação pela Universidade Federal do Rio de Janeiro - UFRJ. Pesquisador do Núcleo de Estudos e Pesquisa em Educação Superior - NEPES da Universidade Federal Fluminense - UFF.

\section{SERGIO HENRIQUE RIBEIRO COSTA}

Atualmente cursa o MBA em Gestão da Engenharia de Produção e Operações Logísticas. Possuo graduação em Logística pela Universidade Federal do Tocantins (2016). Durante o curso, participou e organizou conjuntamente eventos acadêmicos. Foi o presidente fundador da empresa júnior de consultoria em logística. Ministrou a palestra sobre gerenciamento de risco no transporte rodoviário de cargas, durante a semana acadêmica do curso de logística. Trabalhou em empresa no setor de transportes rodoviários de cargas e de gerenciamento de risco. 


\section{SÉRGIO LUIZ HOEFLICH}

Doutor em Engenharia Elétrica no programa de Sistemas de Automação da Universidade de São Paulo (GAESI/USP), mestre em Ciências em Engenharia Oceânica pela Coppe/UFRJ (2005) , pós graduado (MBA) em Logística Empresarial pela FGV, com extensão na Manchester Business School (UK) (2001). Bacharel em Administração com Habilitação em Comércio Exterior pela FIAA (1993). É Catedrático da Academia Nacional de Seguros e Previdência (ANSP) eleito Coordenador da Cátedra de Inovação e Operações e Vice Coordenador da Cátedra de Educação em Seguros sendo membro das Cátedras de Gerencia de Riscos, de Contrato do Seguro e Riscos Financeiros atua como Coordenador do programa de Gestão de Riscos e Seguros da Escola de Negócio e Seguros (ENS Funenseg), Gestão Estratégica de Riscos Corporativos (GRISCOß) da FGV e de Gestão Estratégica de Compras Corporativas do Ibecorp. É pesquisador e professor em organizações e instituições de ensino (UFRJ, USP, Funenseg/ESNS, FGV In Company, Management e Cademp, ECEME, FEMAR, Ibmec, Fecap/SP, Uifebe/SC, ANSP, AIDA, Sindario, Unisescon, Aslog/Abralog) desenvolvendo pesquisa sobre analise de atributos de serviços e indicadores de desempenho aplicados à gestão de risco em cadeias logísticas seguras. A concentração de seu trabalho está na utilização de métodos quantitativos na certificação e monitaoramento da gestão dos riscos dos Operadores Econômicos Autorizados (OEA) na cadeia logística do comércio exterior. É palestrante, articulista sendo autor de artigos sobre gestão de riscos e logística. Sua experiência profissional inclui cargos executivos como gestor de logística e riscos em empresas como Penske Logistics, Tecninvest, Organización Clearing Argentino e Equifax. Atua como instrutor em programas de formação continuada e realiza treinamento de pessoas em cursos de Logística Empresarial, Gestão de Transportes e Distribuição de Materiais, Gestão de Riscos, Técnicas de Compras e Gestão das Operações de comércio Exterior no CADEMP. Na rede FGV Managem

\section{SHEILA RAQUEL DE MORAES LIMA}

Possui graduação em CIENCIAS ECONOMICAS pela Universidade Federal do Ceará (2005), especialização em Controladoria pela Universidade Federal do Ceará e mestrado profissionalizante em Administração e Controladoria da Universidade Federal do Ceará com foco em Controladoria. Atualmente é Técnico Bancário Novo - Caixa Econômica Federal, além de atuar na instrutoria desta institução. Tem experiência na área de Administração, com ênfase em Administração de Empresas e Financeira, além de Estudos Organizacionais, atuando principalmente nos seguintes temas: organizações, governança corporativa, finanças. Leciona na Fametro - Faculdade Metropolitana de Fortaleza nas áreas de Governança Corporativa e Sistemas de Informação Gerencial.

\section{SÍLVIO ROBERTO IGNÁCIO PIRES}

Graduado em Engenharia de Produção pela UFSCar(1983), mestrado em Engenharia (Engenharia de Produção) pela USP (1989) e doutorado em Engenharia (Engenharia de Produção) pela USP (1994). Antes de iniciar a vida acadêmica atuou cinco anos como engenheiro/supervisor de planejamento em um grande grupo industrial. É pós doutorado pelo IMD (Suiça) e Instituto de Empresa (Espanha). Foi professor do DEP-UFSCar e professor convidado do DEF-UNICAMP. Foi professor titular permanente e orientador do PPGA (mestrado e doutorado) da Universidade Metodista de Piracicaba (UNIMEP) desde 2007. Tem mais de 30 anos de experiência atuando na industria e na academia, principalmente em Gestão da Produção, Gestão da Cadeia de Suprimentos e Logistica. Orientou diversos mestrados e doutorados, participou de quase duas centenas de bancas avaliadoras de mestrado e/ou doutorado e publicou mais de uma centena de artigos científicos no Brasil e no exterior e quatro livros na área de atuação. Seu livro "Gestão da Cadeia de Suprimentos (Supply Chain Management): Conceitos, Estratégias, Práticas e Casos", lançado em 2004 é um livro pioneiro e o mais vendido no país em sua área, segundo dados da Editora Atlas/GEN. Teve uma terceira edição atualizada lançada no final de 2016. O livro "Operadores Logísticos: integrando processos em cadeias de suprimentos" (Editora Atlas/GEN) também é um livro pioneiro sobre o tema e o livro "Gestión de la Cadena de Suministros", publicado pela McGraw Hill de España em 2007/2009 é bem utilizado em muitos paises de língua espanhola. Tem ministrado cursos e palestras como professor convidado em instituiç̃os como FGV, CEL-UFRJ, ITA, UFSCar, CUNEFUniversidad Complutense de Madrid, Université Aix-Marseille e University of Bath. É bolsista produtividade do CNPq desde 1995. 


\section{THAYSE ANA FERREIRA}

Mestre pelo Programa de Mestrado Profissional em Administração pela Universidade Estadual do Oeste do Paraná (2019), linha de pesquisa: Sustentabilidade. Tem experiência em docência pelo Programa Bom Negócio Paraná. Atualmente é professora tutora EAD nos cursos de Administração e Recursos Humanos do Centro Universitário Univel.

\section{WHITE JOSÉ DOS SANTOS}

Professor Adjunto da Escola de Engenharia da Universidade Federal de Minas Gerais, atuante na área de Tecnologia e Materiais. 


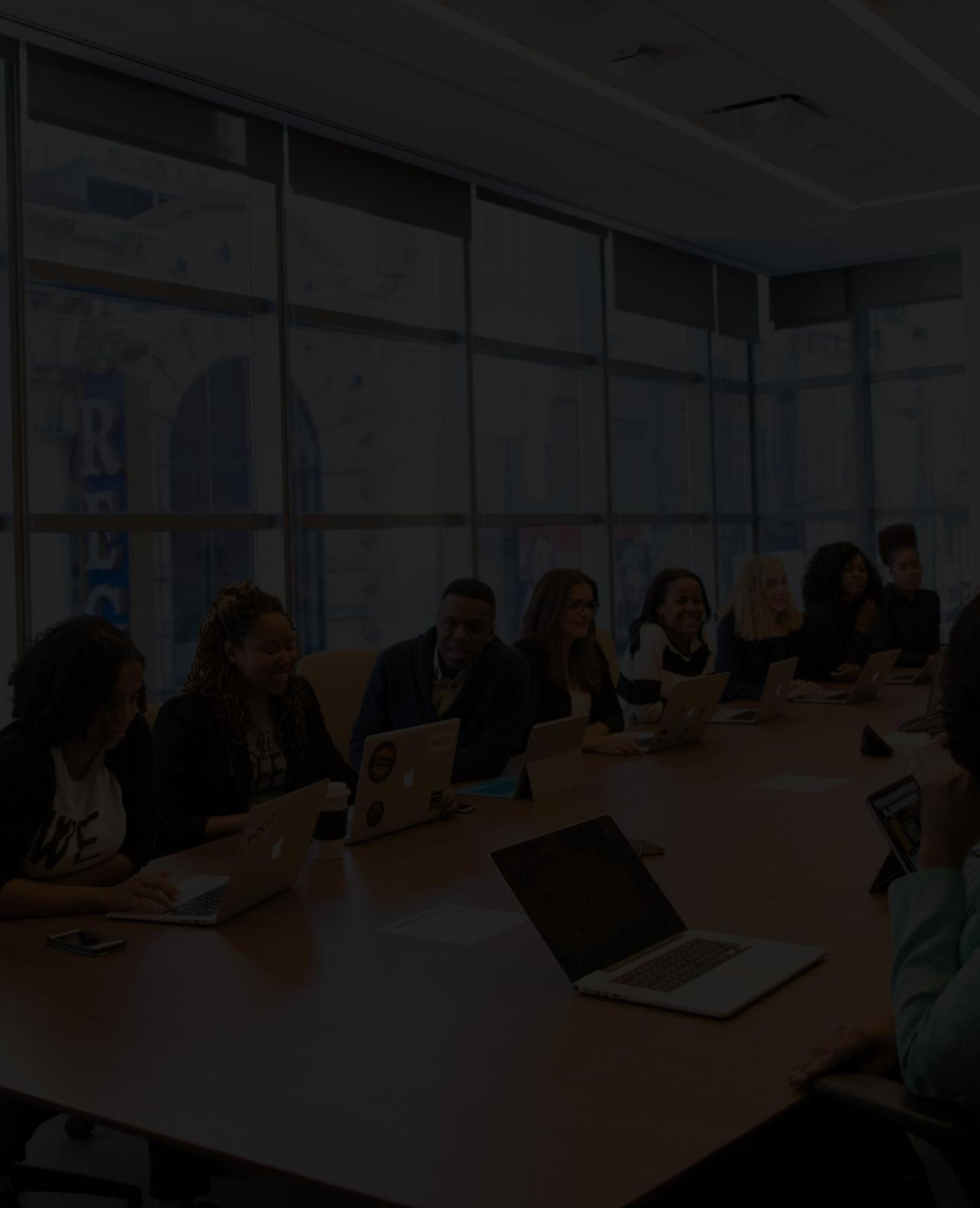

